\title{
ISLAMIC AREA STUDIES WITH GEOGRAPHICAL INFORMATION SYSTEMS
}

In this volume the contributors use geographical information systems (GIS) to reassess both historic and contemporary Asian countries and traditionally Islamic areas.

Subjects covered include:

- local society in eighteenth-century South India

- the use of GIS to locate abandoned villages

- water supplies and public fountains in Istanbul

- the characterization of Turkish urban street networks

- three-dimensional views in Bursa

- the spatial structure of commercial areas in Isfan

- how to construct spatial databases from historical documents and maps

- estimating land use and the structure of the administrative system in Ponneri, India.

This highly illustrated and comprehensive work highlights how GIS can be applied to the social sciences. With its description of how to process, construct, and manage geographical data the book is ideal for the non-specialist looking for a new and refreshing way to approach Islamic Area Studies.

Okabe Atsuyuki is Professor at the Center for Spatial Information Science at the University of Tokyo. 


\section{NEW HORIZONS IN ISLAMIC STUDIES Series Editor: SATO Tsugitaka}

The series "New Horizons in Islamic Studies" presents the fruitful results of the Islamic Area Studies Project conducted in Japan during the years 1997-2001. The project had planned to do multidisciplinary research on the dynamism of Muslim societies in both the Islamic and non-Islamic worlds, considering the fact that areas with close ties to Islam now encompass the whole world. This series provides the newest knowledge on the subjects of "symbiosis and conflict in Muslim societies," "ports, merchants and cross-cultural exchange," and "democratization and popular movement in Islam." The readers will find multifarious, useful achievements gained through international joint research with high technology of geographic information systems about Islamic religion and civilization, particularly emphasizing comparative and historical approaches.

PERSIAN DOCUMENTS

Social history of Iran and Turan in fifteenth-nineteenth centuries

Edited by KONDO Nobuaki

ISLAMIC AREA STUDIES WITH GEOGRAPHICAL INFORMATION SYSTEMS

Edited by OKABE Atsuyuki

MUSLIM SOCIETIES

Historical and comparative aspects

Edited by SATO Tsugitaka 


\title{
ISLAMIC AREA STUDIES WITH GEOGRAPHICAL INFORMATION SYSTEMS
}

\author{
Edited by Okabe Atsuyuki
}

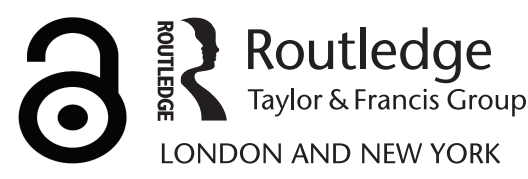


First published 2004

by RoutledgeCurzon

\section{Publised 2017 by Routledge \\ 2 Park Square, Milton Park, Abingdon, Oxon OX14 4RN \\ 711 Third Avenue, New York, NY 10017, USA}

Routledge is an imprint of the Taylor \& Francis Group, an informa business

Copyright (C) 2004 selection and editorial matter Okabe Atsuyuki: individual chapters, the contributors

Typeset in Times New Roman by

Newgen Imaging Systems (P) Ltd, Chennai, India

The Open Access version of this book, available at www.tandfebooks.com, has been made available under a Creative

Commons Attribution-Non Commercial-No Derivatives 4.0 license.

British Library Cataloguing in Publication Data

A catalogue record for this book is available from the British Library

Library of Congress Cataloging in Publication Data

Islamic area studies with geographical information systems/edited by Okabe Atsuyuki.

p. cm.- (New horizons in Islamic studies)

Includes bibliographical references and index.

1. Asia-Geography. 2. Islamic countries-Geography. 3. Geographic information systems - Asia. 4. Geographic information systems - Islamic countries.

I. Okabe Atsuyuki, 1945- II. New horizons in Islamic area studies.

DS5.92.I75 2004

$910^{\prime} .917^{\prime} 67-\mathrm{dc} 22$

2003015744

ISBN 978-0-415-33250-7 (hbk) 


\section{CONTENTS}

List of figures viii

List of tables xiii

List of contributors $\quad \mathrm{xV}$

Preface $\quad$ xx

Acknowledgments xxii

Book overview xxiii

1 Introducing geographical information systems in Islamic area studies

OKABE ATSUYUKI

\section{PART I}

Spatial data construction and a method for preliminary analysis

2 Constructing spatial databases from old paper documents

MIZUSHIMA TSUKASA

3 Constructing spatial databases from maps: a case in historical studies

SADAHIRO YUKIO

4 An exploratory method for discovering qualitatively changed areas using low resolution remotely sensed data:

a case in the Persian Gulf area during 1982-93

OKABE ATSUYUKI AND MASUYAMA ATSUSHI

5 Estimating land use using high resolution remotely sensed data (Landsat TM): a case study in Ponneri, India 


\section{PART II}

Regional analysis

6 Islamic rule and local society in eighteenth-century South India

MIZUSHIMA TSUKASA

7 Modeling the spatial structure of the administrative system in Ponneri, India, during the late eighteenth century

SADAHIRO YUKIO

8 The Ferghana project: Central Asian area studies with GIS KOMATSU HISAO AND GOTO YUTAKA

9 The use of GIS to locate abandoned villages listed in the Temettuat registers of Balıkesir district, Anatolia

EGAWA HIKARI

\section{PART III}

Urban analysis

10 The spatial structure of commercial areas in Turkey and other Islamic countries

TSURUTA YOSHIKO, ARAI YUII, JINNAI HIDENOBU,

SHISHIDO KATSUMI, AND SATO ATSUHIKO

11 The water supplies and public fountains of Ottoman

Istanbul

YAMASHITA KIMIYO

PART IV

Network analysis with space syntax

12 Application of GIS to network analysis: characterization of traditional Turkish urban street networks

ASAMI YASUSHI, KUBAT AYSE SEMA, AND ISTEK CIHANGIR

13 A three-dimensional analysis of the street network in Istanbul: an extension of space syntax using GIS ASAMI YASUSHI, KUBAT AYSE SEMA, KITAGAWA KENSUKE, AND IIDA SHINICHI 


\section{CONTENTS}

14 The space occupied by marketplaces and their societies in the Islamic world - with particular reference to Isfahan and Istanbul

ISTEK CIHANGIR

\section{PART V}

\section{Three-dimensional spatial analysis}

15 Three-dimensional view analysis using GIS: the locational tendency of mosques in Bursa, Turkey

KITAGAWA KENSUKE, ASAMI YASUSHI, AND DOSTOGLU NESLIHAN

16 An analysis on the visibility of Minarets in Sana'a Old City of Yemen

OIKAWA KIYOAKI 


\section{FIGURES}

1.1 The process of scanning a paper map using a scanner

1.2 Decomposition of a map into (a) a point set, (b) a line segment set, and (c) a polygon set

1.3 Digitizing using a cursor tablet

1.4 A remotely sensed raster map of (a) the Persian Gulf area, and (b) a magnified region of the map

1.5 Landsat 5 TM satellite images covering (a) Band 3:

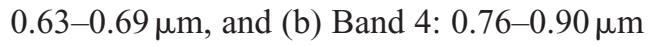

1.6 A remotely sensed raster map covered with clouds

1.7 Mobile GIS notebooks

1.8 A digital map installed in a mobile GIS notebook

1.9 An example of (a) points, (b) lines, and (c) polygons

1.10 An example representing the topology of the lines and polygons shown in Table 1.5

1.11 The area in which the Beyazit Mosque is within $400 \mathrm{~m}$

1.12 The area in which the coastline is within $500 \mathrm{~m}$

1.13 The area in which the Kapali Bazaar is within $200 \mathrm{~m}$

1.14 An AND operation, A1 AND A2

1.15 An OR operation, A1 OR A2

1.16 A NOT operation, A1 NOT A2

$\begin{array}{lll}1.17 & \text { An XOR operation, A1 XOR A2 } & 15\end{array}$

1.18 An intersection search operation 16

2.1 Settlement Register of one of the Ponneri villages in
1877—a sample

2.2 Villages held by the respective poligar castes

(Barnard Report, 1770s)

2.3 Villages held by the respective mirasidar castes

(Barnard Report, 1770s)

2.4 Villages held by the respective mirasidar castes (Place Report, 1799)

2.5 Caste composition in Ponneri villages (Barnard Report, 1770s) 
3.1 GIS data formats. (a) An original map; (b) vector data; and (c) raster data

3.2 Digitization of an aerial photograph. (a) The aerial photograph and (b) the spatial data

3.3 Digitization errors. (a) Original map and (b) data created by digitization

3.4 The data merging process 36

3.5 Identification numbers 37

4.1 The study area (E40-50, N27-37; almost $\left.800 \times 800 \mathrm{~km}^{2}\right)$

4.2 The NDVI values in the Persian Gulf area defined in Figure $4.1 \quad 43$

4.3 The monthly NDVI values of a cell located at N36.2, E49.8 over the year 1984

4.4 The NDVI trend curves obtained by two different sensors 45

4.5 A peak, a bottom, and a slope 46

4.6 An annual trend curve with (a) one distinctive peak and two smaller peaks, and (b) an annual trend curve with three distinct peaks

4.7 The global characteristics of an annual trend curve, $T$, with respect to level $z$, (a), (b), and (c)

4.8 Overall qualitative similarity between two trend curves 49

4.9 The distribution of peak heights 50

4.10 Three categories of NDVI annual trend curves 50

4.11 Qualitative change (level) in land cover in the Persian Gulf
area between 1983 and 1993

4.12 Overall qualitative change in land cover in the Persian Gulf area between years $t$ and $t+1$, where $t=1982, \ldots, 1983 \quad 52$

5.1 Spectral features of the data classes on February 14, $1997 \quad 56$

5.2 Spectral features of the data classes on May 18, $1996 \quad 57$

5.3 Spectral features of the data classes on August 25, $1997 \quad 58$

5.4 The types of land cover in Ponneri 59

$\begin{array}{lll}5.5 & \text { The overlay operation } & 60\end{array}$

5.6 Estimation of land use in Ponneri 61

$\begin{array}{lll}5.7 & \text { Estimation results with overlaid administration boundary map } & 62\end{array}$

5.8 Comparison between estimation results and local survey data 63

6.1 Location of Ponneri 68

6.2 Spatial distribution of the four types of village (Barnard Report, 1770s)

6.3 The four types of village and social classes (Barnard Report, 1770s)

6.4 Caste composition in Ponneri (Barnard Report, 1770s) 71

6.5 Spatial distribution of the caste composition in Ponneri
(Barnard Report, 1770s)

6.6 Caste composition in Ponneri (1871 Census) 72 
6.7 Location of villages held by mirasidars of different castes (Barnard Report, 1770s)

6.8 Mirasidar castes in Ponneri (Place Report, 1799) 75

6.9 Caste composition of mirasidars in Ponneri (Place Report, 1799)

6.10 Caste composition of mirasidars in Ponneri (Settlement Registers, 1870s)

6.11 Caste composition of landholding in Ponneri (Settlement Registers, 1870s)

6.12 A sample page from the Barnard Report

6.13 Annual change in new grants classified by grantors in Ponneri (Barnard Report, 1770s)

6.14 Location of new inam in Ponneri (Barnard Report, 1770s) 81

7.1 The area studied: Ponneri, India 86

7.2 (a) An example of the dependent tessellation $Y$ and (b) a set of independent tessellations $X=\left\{X_{1}, X_{2}, \ldots, X_{m}\right\}$

7.3 Modeling a dependent tessellation by a combination of regions as independent tessellations

7.4 Categorization of a numerical variable

7.5 Modeling a dependent tessellation by a combination of boundaries in independent tessellations

7.6 The two administrative systems in Ponneri in the late eighteenth century

7.7 Zamindari regions modeled by the region-based method 97

7.8 Zamindari boundaries modeled using the hybrid method 98

7.9 Magan boundaries modeled using the hybrid method 100

$\begin{array}{ll}7.10 & \text { The poligar system } \\ 8.100\end{array}$

8.1 Central Asia 104

8.2 The location of the Ferghana Valley 105

8.3 Ethnic composition in the rural area (the 1908 census) 108

$\begin{array}{lll}8.4 & \text { Minority groups } & 110\end{array}$

8.5 Major irrigation canals during the Soviet period 118

$\begin{array}{lll}9.1 & \text { The Balıkesir region } & 123\end{array}$

9.2 Villages belonging to the Balıkesir district 124

9.3 The Temettuat Register, No. 7228 (p. 199) 125

9.4 Estimated location of Köy-ili village 129

$\begin{array}{ll}9.5 & \text { Estimated location of Uluköy village } \\ 9 & 129\end{array}$

9.6 Estimated location of Al-i Temürcü village 130

9.7 Estimated location of Hacı Ömerler village 131

$\begin{array}{ll}9.8 & \text { Estimated location of Nişancı village } \\ 9.92\end{array}$

9.9 Estimated location of Hacıö̈y village 133

9.10 Estimated location of Çavlıköy village 134

9.11 Estimated location of Kesik (Kesek) village 134

9.12 Estimated location of Kadıöy village 135 


\section{FIGURES}

9.13 Estimated location of Zenciriye village 136

9.14 Estimated location of Kirca-uzun village 136

10.1 Plan of Commercial Area indicated with spatial form and functional categories

11.1 Water supplies from 1453 to $1512 \quad 164$

11.2 Water supplies from 1512 to $1603 \quad 166$

$\begin{array}{ll}11.3 & \text { Water supplies from } 1603 \text { to } 1703\end{array}$

11.4 Water supplies from 1703 to $1774 \quad 170$

$\begin{array}{ll}11.5 & \text { The lengths of the water supplies } \\ 172\end{array}$

11.6 Old map of Köprülü Water Supply 172

11.7 Example of a çeşme $\quad 175$

$\begin{array}{lll}11.8 & \text { Example of a sebil } & 175\end{array}$

11.9 Distribution map of the fountains: types 176

$\begin{array}{ll}11.10 & \text { Areas where the shortest distance is calculated } \\ 177\end{array}$

11.11 Area (1): the shortest distance between çeşmes
(Kurkçeșme Water Supply)

11.12 Area (2): the shortest distance between çeşmes (Kırkçeşme Water Supply) 178

11.13 Area (3): the shortest distance between çeşmes (Hekimoğlu, Koca Mustafa Pasha, Sarayçeşme Water Supplies)

11.14 Area (4): the shortest distance between çeşmes (Kırkçeşme Water Supply) 179

$\begin{array}{ll}11.15 \text { Distribution map of the fountains: sponsors } & 180\end{array}$

$\begin{array}{ll}12.1 & \text { Street networks in Turkey } \\ 12.20\end{array}$

$\begin{array}{ll}\text { 12.2 Street networks in the world } & 191\end{array}$

12.3 Black and white illustration of the open space structure of a sample street network

12.4 One- and two-dimensional space structures of a sample street network

12.5 Axial map of a sample street network 193

12.6 Study areas in Istanbul 201

13.1 Axial map and axial lines 208

13.2 Axial line and extended axial curve 208

13.3 Diamond-shaped graph 211

13.4 Average stories of buildings along extended axial lines 213

13.5 Experts' notion of local centers in Istanbul 214

13.6 Land-use map of Istanbul 215

14.1 (a) Convex map; (b) the observer point "p" seen convexly

14.2 Marketplaces and their axial map representations within the global urban context of Isfahan and Istanbul 225

14.3 (a) Distribution of global integration and segregation;
(b) locations of the markets and the GI-cores 
14.4 Distribution of the local integration cores in Isfahan and Istanbul

14.5 GI-core maps modeling the surrounding areas of the markets of Isfahan and Istanbul

14.6 (a) Distribution of GI-cores in Isfahan and Istanbul;

(b) distribution of most controlling streets shown with the locations of institutional buildings and major gateways;

(c) the distribution of GI-cores within the markets 231

14.7 Convex maps showing space-use 233

15.1 A model surface with a TIN 246

15.2 Representation of buildings as solid models 246

$\begin{array}{ll}15.3 & \text { Attachment of an old map } \\ & 247\end{array}$

15.4 Geography surrounding the Green Mosque 248

15.5 The distribution of the gradients of land and mosques 248

15.6 The visibility area of the minaret of the Green Mosque for $\begin{array}{ll}\text { the whole area } & 250\end{array}$

15.7 Visibility areas of the whole silhouette for the fifteenth-century area 250

15.8 View from the bazaar in the direction of the Green Mosque 251

15.9 Visibility line along the road from the bazaar in the direction
of the Green Mosque

16.1 View of Ghardia in M'zab Valley 254

16.2 View of Sana'a Old City 256

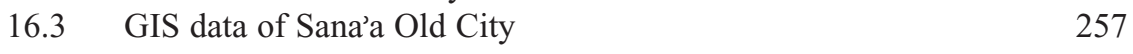

$\begin{array}{lll}16.4 & \text { Tower house } & 258\end{array}$

$\begin{array}{lll}16.5 & \text { Bustan } & 258\end{array}$

$\begin{array}{lll}16.6 & \text { Minaret } & 259\end{array}$

16.7 Display of three-dimensional spatial data 261

16.8 Locations of mosques, minarets, and viewpoints 262

16.9 Correlation between minaret height and visible volume 264

16.10 Visible quantities from viewpoints 265

16.11 Minaret-specific visible quantity 266

16.12 Visible sight lines $\quad 267$

16.13 Probability distribution of visible distance 267

16.14 GIS data of Damascus Old City in Syria 269

$\begin{array}{ll}16.15 & \text { Open spaces around buildings } \\ 16.16 & 270\end{array}$

16.16 Residential lot with envisioned courtyard house 271

$\begin{array}{ll}16.17 \text { Minaret-specific visible rate on grids } & 272\end{array}$

$\begin{array}{ll}16.18 & \text { Sample random distribution of minarets } \\ 16.19 & 273\end{array}$

16.19 Frequency distribution of visible quantity 274

$\begin{array}{ll}16.20 & \text { Minaret that serves as an eyestop } \\ & 275\end{array}$ 


\section{TABLES}

1.1 Earth observation satellites and their resolution 6

1.2 The table of points shown in Figure 1.9(a) 9

1.3 The table of lines shown in Figure 1.9(b) 9

1.4 The table of polygons shown in Figure 1.9(c) 10

1.5 A table representing the topological data of Figure 1.10 11

2.1 Poligar castes and the number of villages under their jurisdiction in Ponneri (Barnard Report, 1770s) 25

3.1 Locational and attribute data 30

3.2 Joining attribute data. (a) Spatial data; (b) attribute data; and (c) spatial data joined with the attribute data 38

5.1 The Landsat Thematic Mapper spectral bands 55

5.2 Land-use types in Ponneri 61

6.1 Titles of Poligars (Barnard Report, 1770s) 72

6.2 Religious recipients holding shares in the produce in
Chingleput (Barnard Report, 1770s)

6.3 Caste composition of the Mirasidars (Barnard Report, 1770s) 74

6.4 Grantors and grantees of new inam in Ponneri (Barnard
Report, 1770s)

7.1 Independent variables used in analysis 96

7.2 Modeling the zamindari system by the region-based method 97

7.3 Modeling the zamindari system using the hybrid method 98

7.4 Modeling the magan system using the hybrid method 99

8.1 Socio-economic change in Baliqchi 116

8.2 Agriculture in Aravan 116

8.3 Changes of ethnic composition (1897-1920) 117

8.4 The increase of population in the valley (Uzbekistan) 118

9.1 The households of villages belonging to the Balıkesir district 127

10.1 Superficial percentages of each spatial form and
functional categories

$\begin{array}{ll}10.2 & \text { The commercial area in Bursa } \\ 10.3\end{array}$

10.3 The commercial area in Safranbolu $\quad 150$ 


\section{TABLES}

10.4 The commercial area in Göynük 151

10.5 The commercial area in Aleppo 153

10.6 The commercial area in Qayrawan $\quad 155$

11.1 Halkalı Water Supplies 163

11.2 Total number of facilities to which the Halkalı Water Supplies and the Kırkçeşme Water Supply transported water

12.1 Values of all indices 197

12.2 Results of classification of cities by discriminant functions, $S S, I M$, and $A L$

12.3 Traditional character judged by the $S S$ discriminant function 202

13.1 Correlation coefficients for (conventional) axial lines 215

13.2 Correlation coefficients for extended axial lines 217

16.1 Land use in Sana'a Old City 260 


\section{CONTRIBUTORS}

Arai Yuji graduated from the Department of Architecture, Hosei University, in 1999. He was a research fellow of the Japan Society for the Promotion of Science in 1999-2002. He is currently a lecturer at the Department of Architecture, the Special Engineering College of Kogakuin University. He researches into the architectural and urban history of the Middle East. He has published many papers in books and journals. His principal publication is Cities and Urban Space in the Islamic World (he is an author and editor with Dr Hidenobu Jinnai).

Asami Yasushi received his $\mathrm{PhD}$ from the University of Pennsylvania in 1987. $\mathrm{He}$ is currently Professor of the Center for Spatial Information Science, University of Tokyo. His research interests include city planning, housing policy, real estate science, environmental psychology, and spatial information analysis. He has published many papers in journals, such as Journal of Regional Science, Geographical Analysis, Regional Science and Urban Economics, Journal of Urban Economics, Environment and Planning A, Environment and Planning B, and Urban Studies. He is now a board member of the several academic associations. Based on research in these areas, he is actively participating in various policy-oriented committees of the central government.

Dostoglu Neslihan studied architecture at Middle East Technical University in Ankara (B.Arch. 1978, M.Arch. 1981). She received her MS (1984) and PhD in Architecture (1986) from the University of Pennsylvania, Philadelphia. She is currently Professor and Vice Chair at the Department of Architecture in Uludag University, Bursa, and teaches architectural design studio, theory of design, and urban and architectural developments in Bursa throughout history. She has contributed articles to many national and international publications, and has received various awards in architectural design competitions. She serves on the editorial board of Mimarlik journal, and she is the Chair of the Board for the Preservation of Cultural and Natural Wealth in Bursa.

Duan Feng Jun received his PhD from Peking University in 1995. He is currently Lecturer (Faculty Researcher) at the Disaster Prevention Research Institute, Kyoto University. His research interests include geographical information 


\section{CONTRIBUTORS}

systems, remote sensing, geomorphology, and ocean environment assessment. He has published papers in journals, books, and conference proceedings on these topics. He is author (with Hajime Yamaguchi et al.) of GIS-aided Prediction for Sea-ice Distribution (JMST).

Egawa Hikari received her Masters Degree from Ochanomizu University in 1987. She is currently Associate Professor of the Faculty of Letters, Ritsumeikan University, Kyoto, Japan. She has been studying about the history of the Ottoman Empire, and her research interests include the social and economic transformations in the Ottoman Society, especially in the nineteenth century. She has published several papers in journals and books as follows; "The Tanzimat Reforms and Provincial Society: Analysis of the Temettü'ât Defteri in Balıkesir District (1840) from the view point of land possession" (in Japanese), The Toyo Gakuho (the journal of the Research Department of the Toyo Bunko), vol. 79 no. 2, 1997, "The Urban Society and Commerce-Industry of Balıkesir in the Middle of Nineteenth Century: especially from the point of aba industry" (in Japanese), Ochanomizushigaku, 1998, Ochanomizu University, no. 42.

Goto Yutaka received his $\mathrm{PhD}$ from the University of Tokyo in 1998. He is currently Associate Professor of the Department of Humanities, Hirosaki University. His research interests include geographical information systems, spatial analysis of cities, and commercial geography. At present, he is interested in the application of geographic information systems to the human science as in Oriental history.

Iida Shinichi received his MSc degree in Built Environment from University of London in 1997 and he is currently Research Fellow at Bartlett School of Graduate Studies, University College London, where he is working for his $\mathrm{PhD}$ His research interests include architectural and urban theory based on "space syntax" approach, spatial analysis, and transportation network.

Istek Cihangir is an architect and currently a lecturer at the Tama Art University. He studied at Istanbul Technical University and the Bartlett Graduate School, University College London. He completed his $\mathrm{PhD}$ at the University of Tokyo. He was granted a fellowship from the Japan Society for the Promotion of Science (2001-03). His research interests include Architecture and urban design, and theoretical and applied research on space and built environment. He has published a number of articles and papers in journals, books, and conference proceedings on these topics. In addition to his academic involvement, he practises as an architect and leads an interdisciplinary design practice on the premises of architecture, media, and body-movement.

Jinnai Hidenobu was born in Fukuoka in 1947. He studied in the Istituto Universitario di Architettura di Venezia on the scholarship of the Italian Government (1973-75) and received his doctoral degree in Engineering from the University of Tokyo in 1980. He is currently Professor of the Department of 


\section{CONTRIBUTORS}

Architecture at Hosei University. He was Visiting Professor of the University of Palermo (1986) and the University of Trento (1995). His research field is urban history and is author of Tokyo: A Spatial Anthropology (University of California Press, 1995).

Kitagawa Kensuke received his Masters in Engineering from the University of Tokyo in 2002. He is interested in analyzing Islamic cities using geographical information systems. He has analyzed Turkish cities and has written papers about them.

Komatsu Hisao graduated from the University of Tokyo, Graduate School of Humanities, Department of Oriental History in March 1980 (MA). He worked at Tokai University (1980-92) and Tokyo University of Foreign Studies (1992-95). He is currently Professor at the University of Tokyo, Graduate School of Humanities and Sociology. He studies modern history of Central Asia, and has published many works such as Revolutionary Central Asia: A Portrait of Abdurauf Fitrat (Tokyo, 1996), A History of Central Eurasia (Tokyo, 2000: editor), Islam in Politics in Russia and Central Asia: Early 18th to Late 20th Centuries (Kegan Paul, London-New York-Bahrain, 2001: co-editor).

Kubat Ayse Sema graduated as an architect from Istanbul Technical University and received the degree of Doctor of Urban Planning from Istanbul Technical University in 1985. She became Assistant Professor in 1986, Associate Professor in 1990, and Professor in 1996 in the field of City \& Regional Planning at the Faculty of Architecture of İTÜ (Istanbul Technical University). Her research interests include urban design, urban planning, urban morphology, urban preservation and renovation, geographical information systems, and spatial analysis. She has published many papers in journals, books, and conference proceedings on these topics, and has been involved in joint international research projects. Besides, she participated in preparing actual urban development plans and design guidelines.

Masuyama Atsushi received his doctoral degree in Engineering from the University of Tokyo in 2002. He is currently Assistant Professor of the Department of Urban Engineering, University of Tokyo. His present speciality is Geographical Information Science. In particular, he developed exploratory methods for detecting singular patterns from a huge amount of spatial data. In addition to this, he also developed methods for identifying the inconsistencies among supposedly identical spatial data and unifying them. He has published articles in journals and presented papers at conference proceedings on the above topics.

Mizushima Tsukasa, Professor, Department of Oriental History, University of Tokyo, is a historian working on South and Southeast Asia. Besides conducting a number of field studies on Indian communities in India and other countries he has explored various colonial records hitherto untouched in 


\section{CONTRIBUTORS}

archives and local offices. His papers have been published in books and in international journals. His current concern is to investigate into the spherical aspects of socio-economic changes that have occurred in the past two centuries in South India by analyzing village-level records with GIS tools.

Oikawa Kiyoaki received his doctoral degree in Engineering from the University of Tokyo in 1987. He is currently Professor of the Faculty of Science and Engineering, Ritsumeikan University. His research interests include development of mathematical techniques for the analysis of urban space, new architecture and urban design models, and characteristics of various dwelling cultures. To date, he has been conducting morphological field studies of more than 250 traditional villages throughout the world. He has published many papers in journals and books on these topics.

Okabe Atsuyuki received his $\mathrm{PhD}$ from the University of Pennsylvania in 1975 and his doctoral degree in Engineering from the University of Tokyo in 1977. He is currently Professor of the Department of Urban Engineering, University of Tokyo, and served as Director of the Center for Spatial Information Science (1998-2005). His research interests include geographical information systems, spatial analysis and spatial optimization. He has published many papers in journals, books, and conference proceedings on these topics. He is co-author (with Barry Boots, Kokichi Sugihara, and Sung Nok Chiu) of Spatial Tessellations: Concepts and Applications of Voronoi Diagrams (John Wiley). He serves on the editorial boards of nine international journals, like the International Journal of Geographical Information Science.

Sadahiro Yukio received his doctoral degree in Engineering from the University of Tokyo in 1995. He is currently Associate Professor of the Department of Urban Engineering, University of Tokyo. His research interests include geographical information science (GIS), spatial analysis, spatial representation, and visualization. He is currently a member of the editorial board of Geographical Analysis. He has published many papers in Geographical Analysis, International Journal of Geographical Information Science, Journal of Geographical Systems, Computers, Environment and Urban Systems, Cartography and Geographic Information Science, and in many other journals.

Sato Atsuhiko did his Masters in Architecture at the Graduate School of Hosei University in 2002. He is currently working at Saisan Misawa Co., Ltd.

Shishido Katsumi graduated from Kansai University in 1998 majoring in Architecture. He studied Turkish architectural culture at the graduate school of Hosei University from 1998 to 2002. While in the graduate school, he studied in Istanbul Technical University as a guest student for two years. He is currently working for shop the design control division of Doutor Coffee Co., Ltd. 


\section{CONTRIBUTORS}

Tsuruta Yoshiko received her PhD from Showa Women's University in 2002. She graduated in the doctoral course on Human Life Science and Culture, Graduate School of Human Life Sciences, Showa Women's University in 2002. She is currently a researcher at the Institute of International Culture, Showa Women's University. She worked as a research assistant at the Institute of Oriental Culture, University of Tokyo from 1999 to 2002. Her research interests include spatial analysis on the form of living space in Turkey and Europe.

Yamashita Kimiyo graduated from Istanbul Technical University, Turkey, in 1993. After she obtained her PhD from the University of Tsukuba in Japan in 1999, she was granted several postdoctoral fellowships such as the Fellowship of the Japan Society for Promotion of Science for her studies on Ottoman architecture. She is currently a postdoctoral research fellow of the Aga Khan Program for Islamic Architecture at Massachusetts Institute of Technology in the United States, as well as a visiting lecturer at the Tokyo University of Foreign Studies in Japan. Her research interests include Ottoman architecture and theories of conservation and restoration. 


\section{PREFACE}

This book presents part of the results obtained from the five-year project entitled Islamic Area Studies that began in April 1997 and ended in March 2002. The project was funded by a Grant-in-Aid for Creative Scientific Research for the Promotion of Sciences, provided under the aegis of the Japan Ministry of Education, Culture and Science. The project leader was Sato Tsugitaka (University of Tokyo).

The project had three main objectives:.

(1) to discover new approaches in Islamic area studies through the accumulation of primary data related to Islamic civilization and Muslim contemporary issues;

(2) to develop a computer system suitable for multilateral Islamic Area Studies; and

(3) to support and encourage the formation of a new generation of scholars to be entrusted with the future development of these studies.

Six research units carried out the project:

Unit 1: Thought and politics in the Islamic world (leader: Komatsu Hisao).

Unit 2: Society and communities in the Islamic world (leader: Kisaichi Masatoshi).

Unit 3: Nations, regions, and Islam (leader: Kato Hiroshi).

Unit 4: Geographic information systems for Islamic area studies (leader: Okabe Atsuyuki).

Unit 5: Islamic history and culture (leader: Haneda Masashi).

Unit 6: Source materials for the study of Islamic civilization (leader: Kitamura Hajime).

The members of Unit 4 are the contributors of this book.

The objective of Unit 4 was, in accordance with objectives (1) and (2) above, to introduce a new computer-aided approach - an approach with geographical information systems (GIS) - in Islamic area studies. GIS are computer systems for constructing, managing, analyzing, and visualizing geographical data. 
Literally, Islamic area studies are studies of the area occupied by Islamic societies and that area is characterized by various geographical factors. Traditionally, these factors were dealt with manually using paper maps. However, this manual method becomes laborious and inefficient as the geographical factors are multiplied. Recently, many more kinds of geographical data on Islamic areas have become available, owing to recent progress in information technologies. Fortunately, the difficulties of managing these data have been overcome by userfriendly GIS software packages that were developed in the 1990s.

In practice, however, employing GIS in Islamic area studies was not straightforward. Any computer-aided method is useless unless users can devote the time necessary to learn what it is, what it can do, and how to use it. In this case, where GIS technology had to be transferred to a non-computer-based discipline, human and social sciences, collaboration between researchers in GIS and those of the non-GIS researchers is indispensable. Fortunately, we had good collaboration in the Islamic Area Studies Project even though, at the outset of this project, few researchers in the field of Islamic Area Studies Project knew much about GIS and vice versa. A few years were required for this learning stage, during which we began collaborative work, and we were convinced that GIS methods were effective tools for Islamic area studies. They provided us with a new way of spatial thinking and this enabled us to detect new aspects of Islamic area studies that would not otherwise have been discovered. It is a pity that it was not until near the end of this project that we felt that we had developed sufficient understanding to use GIS to maximum advantage. However, we believe that we have taken a firm first step toward the use of GIS in Islamic area studies. We hope that this book encourages researchers not only in Islamic area studies but also those in other human and social sciences who are considering the use of GIS.

Okabe Atsuyuki

September 2002 


\section{ACKNOWLEDGMENTS}

So many people helped in so many ways during the preparation of this book that we are able to acknowledge only a few of them individually. First, we are deeply grateful to Professor Sato Tsugitaka, the leader of the project entitled Islamic Area Studies, for encouraging us to develop a new approach to Islamic area studies, that is, Islamic area studies with geographical information systems. We are also thankful to the members of the project management unit, in particular, Professor Hisao Komatsu (Director of general affairs) and Professor Toru Miura (Publication manager). The authors of each chapter thank several people, whose names are acknowledged at the end of each chapter. We should also acknowledge the Grant-in-Aid for Creative Scientific Research for the Promotion of Sciences,

provided under the aegis of the Japan Ministry of Education, Culture, and Science. We are indebted to the staff of the publisher, in particular, Ms. Stephanie Rogers, Ms. Zoe Botterill, and Mr. Vincent Antony. We must also express our debt to Ms. Yoko Hamaguchi for preparing our manuscripts. 


\section{BOOK OVERVIEW}

Following an introduction (Chapter 1), we have organized this book in five parts. Each part is a collection of two to four chapters that are subsumed under the same topic. The five parts deal with spatial data construction (Chapters 2-5), regional analysis (Chapters 6-9), urban analysis (Chapters 10 and 11), network analysis (Chapters 12-14), and three-dimensional spatial analysis (Chapters 15 and 16), respectively.

As implied by the title of our book, every chapter makes at least some use of geographic information systems (GIS). Thus, the book is readable if readers have some knowledge of GIS. However, we also welcome readers who are unfamiliar with GIS but are thinking of possible applications of GIS to Islamic area studies, or more broadly, human and social sciences. Chapter 1 provides such readers with an introduction to GIS. In short, GIS are computer-aided systems for processing geographical data. Chapter 1 illustrates elements of this processing, that is, constructing, managing, analyzing, and visualizing geographical data.

Part I is a collection of four chapters (Chapters 2-5) that deal with methods of acquiring and constructing geographical data (Chapters 2, 3, and 5), and a method for preliminary analysis (Chapter 4). By geographical data, we mean the data that consist of the attribute data of geographical objects (e.g. stores) and the location data (e.g. longitudes and latitudes) of these objects. Geographical data are alternatively called spatial data. The difference is subtle, but geographical data tend to refer to data on a two-dimensional surface, whereas spatial data tend to refer to data in three-dimensional space. Since some chapters deal with three-dimensional space (especially the chapters in Part V), the term "spatial data" is often used in this book. Geographical data include not only data given in the form of maps but also those in the form of tables, such as a table of the number of Muslims (attribute data) by districts (location data). In Islamic area studies, spatial data are often given in the form of tables included in paper documents, and so spatial data are constructed from the documents.

Chapter 2 describes the procedures and problems encountered in constructing databases from old paper documents. The study area is Ponneri in southern India, and the documents were written in the eighteenth and nineteenth centuries. In GIS, spatial data are supposed to be computer-readable data, called digital data. 


\section{BOOK OVERVIEW}

We can easily convert tables in paper documents into digital tables (digital data) simply by typing them into a computer.

However, when spatial data are given in the form of paper maps, conversion into digital maps (digital data) is not straightforward. In particular, this difficulty increases when paper maps are old and imprecise, as is often the case in Islamic Area Studies, especially in historical studies. Chapter 3 describes procedures and problems encountered in constructing a spatial database from paper maps in the case of Ponneri (the same region as in Chapter 2).

Chapter 4 demonstrates an exploratory method for finding a clue to a "gold vein." In Islamic regions, spatial data are often difficult to obtain. For example, maps and statistical documents of the regions are scarce and even if they do exist, their quality is not always good. Other problems are that bringing maps outside a country is sometimes not permitted and foreign researchers do not have easy access to the region. Under such difficult situations, it would be recommended to take the two-step approach. The first step is to conduct a preliminary investigation with easily available macroscopic data to find a potential district that would be worth investigating in depth. The second step is based on the first, and it involves a full investigation with detailed geographical data obtained from fieldwork in that district. Chapter 4 shows an illustrative example of how to conduct a first-step preliminary investigation in the Persian Gulf area using coarse but easily available remotely sensed data. Chapter 5 illustrates a typical second-step investigation: constructing a land-use map using fine-resolution remotely sensed data.

Part II is a collection of four chapters (Chapters 6-9) that deal with regional analysis using GIS. Chapter 6 discusses Islamic rules and local society in eighteenth-century South India. Nazim-ul-mulk, who was the highest official in the Mughal court, had steadily established an autonomous state that grew to be the most powerful in South India by the mid-eighteenth century. While engaged in military expeditions in different parts of the region, the Nizam gained control over the nawabs, who had been posted as provincial governors by the Mughal in several strategic places. One such nawab was the one posted in Arcot, who ruled the eastern part of the Tamil country. The main question in Chapter 6 is: how did the nawab assert his sovereignty when he belonged to the Muslim minority, and was newly posted to an area dominated by Hindus? Chapter 6 gives an answer to this question using GIS.

Chapter 7 proposes a method for modelling the spatial structure of the administrative system in Ponneri, India, during the late eighteenth century. Until the middle of the eighteenth century, South India had been under the rule of the Mughal Empire. There were administrative units called magans, which were almost equivalent to the national borders of today. In the late eighteenth century, the British introduced a colonial policy and the Mughal Empire gradually lost its power in Southern India. To govern the area and to collect taxes, the British appointed officers called zamindaris and sent them to some of the villages. Each zamindari governed 25 villages on average, and this formed a new administrative 
system, which we call the zamindari system. The spatial structure of the zamindari system does not completely agree with that of the magan system; they are partly similar but differ in some places. The major question raised in Chapter 6 is: why was the zamindari system spatially different from the magan system, even though they were both administrative systems for the same area? Chapter 6 gives an answer to this question.

Chapter 8 shows the results of the Ferghana project that studied the central Asia region using GIS. The Ferghana valley is located in the heart of Central Asia, at the meeting place of three newly independent states, Uzbekistan, Qyrghyzstan, and Tajikistan. After the final years of the Soviet period, a series of critical issues emerged in the valley, including ethnic conflict, serious tension between resurgent Islam and authoritarian powers, and penetration of "Islamic" militants and drugs from Afghanistan. Additionally, the area had to deal with socio-economic grievances due to the high unemployment rate, a strict border control that restricts mobility in the valley, and other negative legacies of the Soviet regime. These issues can potentially threaten the stability of Central Asia. In order to understand contemporary issues in the Ferghana Valley, the Ferghana project aims to gain a useful and reliable database by integrating historical sources, statistical data, imaging data, and research results of field surveys onto digitalized maps, using GIS. This chapter presents the research results of the past two years as its contribution to Central Asian area studies.

Chapter 9 shows a method, using GIS (DiMSIS), for extrapolating the locations of eleven villages ruined in the middle of the nineteenth century in the Balıkesir region. The data source is the Temettuat (Income) Registers, published in 1840 and now in the possession of the Ottoman Archive Department of the Prime Minister's Office (Başbakanlık Osmanlı Arşivi). This document does not indicate the exact locations of the eleven ruined villages, but it gives the distances from existing villages. With these distances and arterial roads in this region, Chapter 9 extrapolates their likely locations.

Part III is a collection of two chapters (Chapters 10 and 11) that deal with urban analysis. Chapter 10 surveys the spatial structure of commercial areas in Turkey and other Islamic countries. In most Islamic cities, there is a commercial space, called a bazaar (çarşı in Turkish, souq in Arabic, and bazar in Persian), which acts as a nucleus of the city. Chapter 10 compares bazaars in Aleppo (Syria), Qayrawab (Tunisia), Bursa (Turkey), Safranbolu (Turkey), and Göynük (Turkey) with respect to various elements, such as buildings, streets, plaza, voids, and so forth.

Chapter 11 investigates the impact of water supply systems on urban development in Ottoman Istanbul, particularly the area inside the city wall (Theodosian), from the mid-fifteenth century to the eighteenth century. The chapter first overviews the construction processes of the Halkalı Water Supply System and the Kırkçeşme Water Supply System. Second, the chapter examines the distribution of fountains in Ottoman Istanbul. The data sources are the documents of water facilities compiled by the Ministry of Vakuf in 1930, and two maps of the water supply systems drawn by Çeçen. Using GIS with these data, Chapter 11 
finds differences in water supply functions between the Halkalı System and the Kırkçeşme System.

Part V is a collection of three chapters (Chapters 12,13, and 14) that analyze street network patterns in Islamic cities with "space-syntax." The space syntax is a method for analyzing network patterns in terms of visibility on a network represented by a set of maximum straight-line segments that cover a street network. Chapter 12 examines the characteristics of traditional Turkish street networks using several space-syntax indices and graph-theoretical indices, and shows the major characteristics of the Turkish traditional networks.

Chapter 13 also analyzes street networks, but uses an extended method of space syntax. Originally, space syntax deals with visibility on a two-dimensional surface. However, in the real world, street networks are often on a hilly surface. To analyze such street networks, three-dimensional space should be considered and so Chapter 13 extends the space syntax to a three-dimensional space. Using this extended method, this chapter examines a street network in Istanbul.

Chapter 14 explores the possible connections between the locations of marketplaces and their societies. The theme of marketplaces has often been of particular interest to specific studies of Islamic urban forms, in which they are referred to as one of the most characteristic elements in the "Islamic city" concept. Within this historically constructed concept, the spatial forms and relations with cities and societies have been viewed primarily from a religious perspective, and Islam as an "urban religion" has been considered as their sole definer. Based on a comparative analysis using a methodology adopted from space syntax theory, the spatial forms and structures of two important classic cases, the cities of Isfahan and Istanbul and their underlying principles, this chapter argues that the religion of Islam is not the only definer of their forms.

Part VI is a collection of two chapters (Chapters 15 and 16) that deal with urban landscape in three-dimensional space. Chapter 15 models the landscape of Bursa with buildings represented by boxes and the ground surface represented by a triangulated irregular network (TIN) on which the boxes of buildings are placed. In Chapter 15, this model is used to discover the rationale behind the location of mosques in Bursa with respect to their visibility.

Chapter 16 focuses on religious towers, called minarets that characterize the landscape of Islamic cities. The major function of minarets is to inform people that it is time to worship but minarets also have a visual function, that of indicating the existence of mosques. Using GIS, Chapter 16 obtains the area in which at least one minaret is visible in Sana'a, capital of Yemen Arab Republic and discloses the intention behind the location of minarets in Sana'a.

Finally, an index for the above chapters is added at the end of this volume.

Okabe Atsuyuki 


\title{
INTRODUCING GEOGRAPHICAL INFORMATION SYSTEMS IN ISLAMIC AREA STUDIES
}

\author{
Okabe Atsuyuki
}

\section{A way to introduce GIS in Islamic area studies}

Islamic area studies deal with various phenomena that have occurred in regions influenced by Islam. Among these phenomena, we notice a class that is closely related to geographical factors. For example, desertification in relation to the selfsufficiency policy in the Persian Gulf (Chapter 4); income imbalance in relation to the geographical distribution of castes over the Ponneri region in India (Chapter 7); territorial conflicts in relation to the configuration of different racial settlements in the Ferghana valley in Russia (Chapter 8); and Islamic landscapes in relation to the arrangement of mosques in Istanbul (Chapter 15). We call this type of phenomenon a geographical phenomenon. Since Islamic area studies are area-specific (literally, Islamic area studies are Islamic AREA studies), we may say that almost all phenomena in Islamic area studies include geographical phenomena to some extent.

Traditionally, researchers in Islamic area studies treat geographical factors using manual methods and paper maps. These methods may be adequate when there are not many geographical factors involved, but when there are then these methods become very laborious and time-consuming. This difficulty is probably one of the reasons why little attention has been paid to geographical phenomena in Islamic area studies, and why the analysis of geographical phenomena remains fairly primitive.

Fortunately, this difficulty has been overcome in the 1990s by user-friendly computer-aided systems for processing geographical data, called geographical information systems (GIS). As mentioned in the preface of this book, we applied GIS to geographical phenomena that occurred in the Islamic area. We carried out a project called "GIS for Islamic area studies." This book presents the results of this project. To understand them in depth, readers are presumed to have some basic knowledge about GIS. Such knowledge may be obtained by reading standard GIS textbooks (e.g. Burrough 1986; Star and Estes 1990; Laurini and Thompson 1992; Bailey and Gatrell 1995). Some readers, however, may wish 


\section{OKABE ATSUYUKI}

to avoid this detour, and prefer a brief introduction to GIS. This introductory chapter has been written in response to this request. It provides a general outline of GIS, but it also remarks on special GIS issues inherent in Islamic area studies.

\section{What is GIS?}

One of the key terms in GIS is "geographical data." Geographical data are defined as the attribute data of geographical objects accompanied by their locations or geographical areas. Stated in another way, geographical data are paired data consisting of the attribute and location data of geographical objects. A location may be directly indicated by its coordinates in a geographical reference system (say, N35 42 39.6, E139 45 45.7), or it may be indirectly indicated by its address (say, 1-3-8 Hongo, Bunkyo-ku, Tokyo, Japan) or something similar. Geographical data are sometimes called spatial data. The difference between these terms is slight, but geographical data are concerned with data on the surface of the globe, that is, two-dimensional, but spatial data are concerned not only with data on the surface, but also with data below the ground and above the surface, that is, three-dimensional.

Obviously, data depicted on a map are geographical data, because maps show the attributes of geographical objects (e.g. the names of mosques) and their locations. Data shown by any kind of map (such as racial maps, land-use maps, geological maps, meteorological maps) are all geographical data. Geographical data, however, are not restricted to the data provided by maps. For example, data in tables showing the attribute values of areas, such as tables of the Muslim population by country, are also geographical data, because such tables show the number of Muslims (attribute data) in, for example, Japan (a geographical area). Thus, data shown by census tables with respect to census tracts are all geographical data. Data contained in a telephone directory are also geographical data, because they include the names of persons and stores (attribute data) with their addresses (locations). Even a picture taken at a point in a town may provide geographical data if the shooting location is explicitly recorded, because it shows the landscape (attribute data) at that location. As these examples demonstrate, geographical data are much broader in scope than readers may have thought.

In terms of geographical data, we may define GIS as computer-based systems for "processing" geographical data, where the processing consists of:

1 acquiring geographical data;

2 managing geographical data;

3 analyzing geographical data; and

4 visualizing geographical data.

In practice, these subprocesses occur in this order, although some re-ordering may take place among the subprocesses, while some others may be skipped. The contents of these subprocesses are explained in the subsequent sections. 
In a narrower sense, GIS can mean software for geographical data processing, such as Excel for statistical data processing. Well-known software packages are: ArcGIS, MapInfo, AtlasGIS, GeoMedia, and ERDAS. These packages are available at computer software shops at affordable prices. Some free shareware packages are also available through the Internet, such as GRASS at http:// www.baylor.edu/grass/index $2 . h t m l$, and TNTlite at http://www.microimages.com/ tntlite/ (data size is limited). Free resources related to GIS can also be found at http://freegis.org/index.en.html.

\section{Acquiring geographical data}

As mentioned before, the first process of a GIS is to acquire geographical data. Since GIS are computer-based systems, geographical data are supposed to be in computer readable form, called digital geographical data. In GIS, therefore, acquiring geographical data means acquiring digital geographical data.

Usually, we acquire geographical data by means of paper maps (such as a map of streets in Istanbul printed on a sheet of paper) and paper tables (such as the Muslim population by country in a census book), if these exist. However, these forms are not digital, and so they have to be transformed into digital data.

Transformation from a paper table to a table in digital form, called a digital table, is achieved simply by recording numbers, letters, and codes from the paper table in an electronic media format (such as a floppy disk) on a personal computer. However, transformation of a paper map into a digital map is not so simple. The methods for this transformation differ according to the types of digital maps required, namely a "raster-type" digital map or a "vector-type" digital map (to be defined below).

Transformation from a paper map into a "raster-type" digital map is performed through an electronic device called a scanner. One of the most familiar scanners in everyday life is the facsimile machine. A scanner shoots rays at (square) lattice points onto the sheet of a paper map (Figure 1.1). A sensor detects the magnitude of reflected light (the attribute of each point, that is, black or white in a

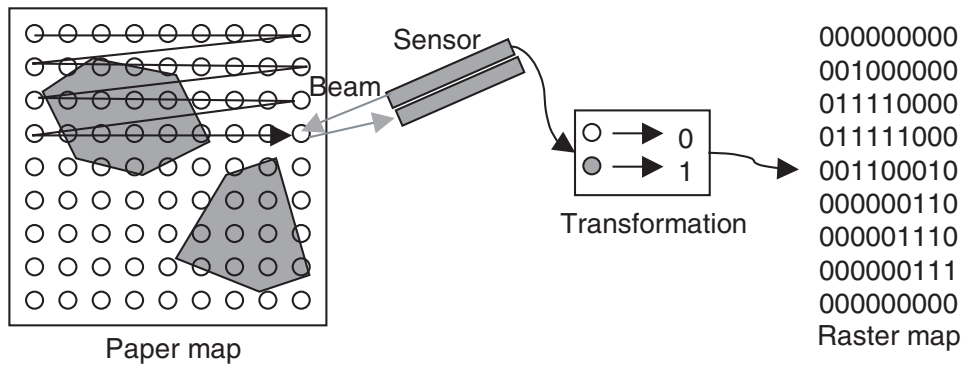

Figure 1.1 The process of scanning a paper map using a scanner. 


\section{OKABE ATSUYUKI}

black-white paper map, or color in a colored paper map, can be identified by the value of this magnitude), and the sensed magnitude is transformed into an electronic signal, which is recorded in an electronic medium as a number ( 1 or 0 for black-white paper, or a number representing a color for colored paper). This process is called scanning, and the resulting map is called a raster-type digital map or simply, a raster map. Stated a little more generally, a raster map is an array of numbers, letters and codes assigned to (square) lattice points or (square) cells that represent the attributes at those points or at those cells stored in an electronic medium.

The second type of digital maps is the "vector-type" digital map. Transformation from a paper map to this type of digital maps requires a few steps. First, every geographical object on the paper map is represented in terms of a point, a line segment, or a polygon (Figure 1.2). For example, a mosque, a river and a park may be represented in terms of a point, a line segment, and a polygon, respectively. (Note that, strictly speaking, no geographical object can be represented by points or lines, because geographical objects have areas, no matter how small they are, and representation by points and lines are for the sake of convenience.) Second, the location of a point is recorded in terms of the

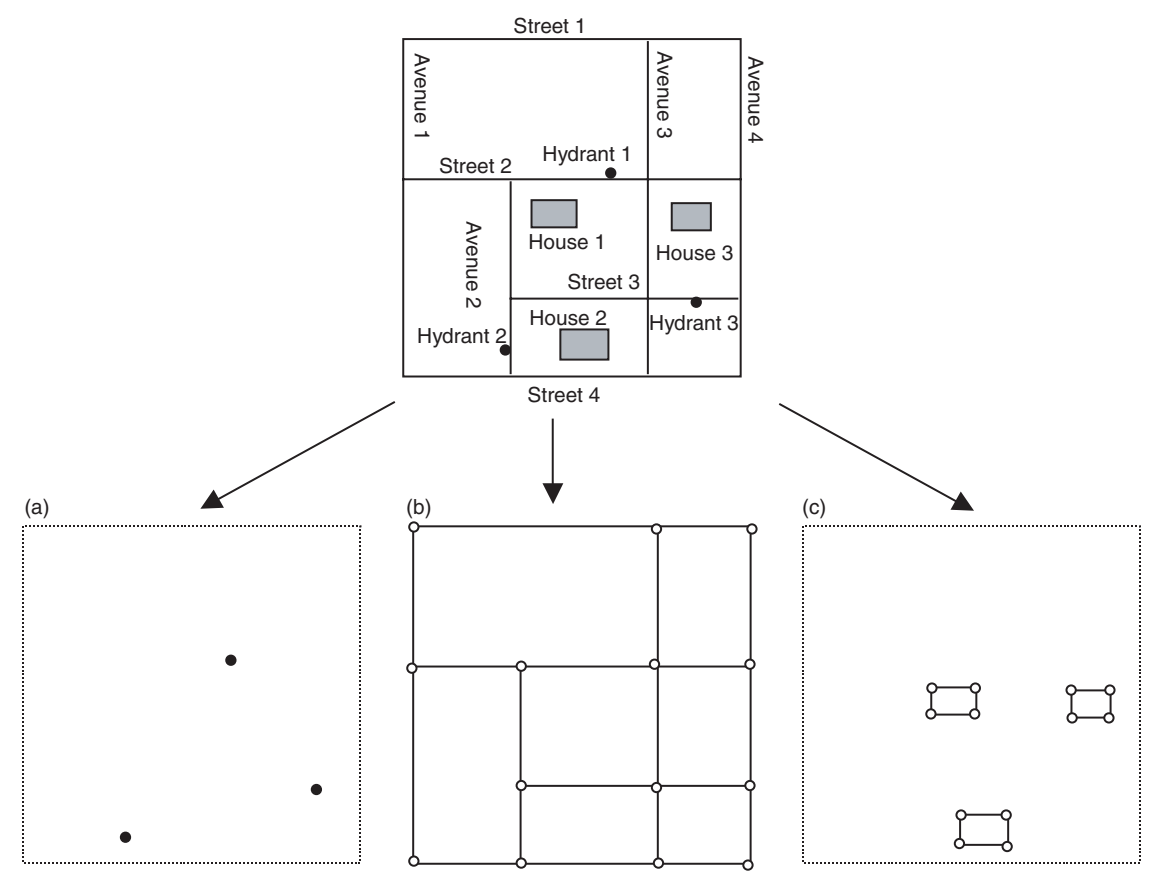

Figure 1.2 Decomposition of a map into (a) a point set, (b) a line segment set, and (c) a polygon set. 


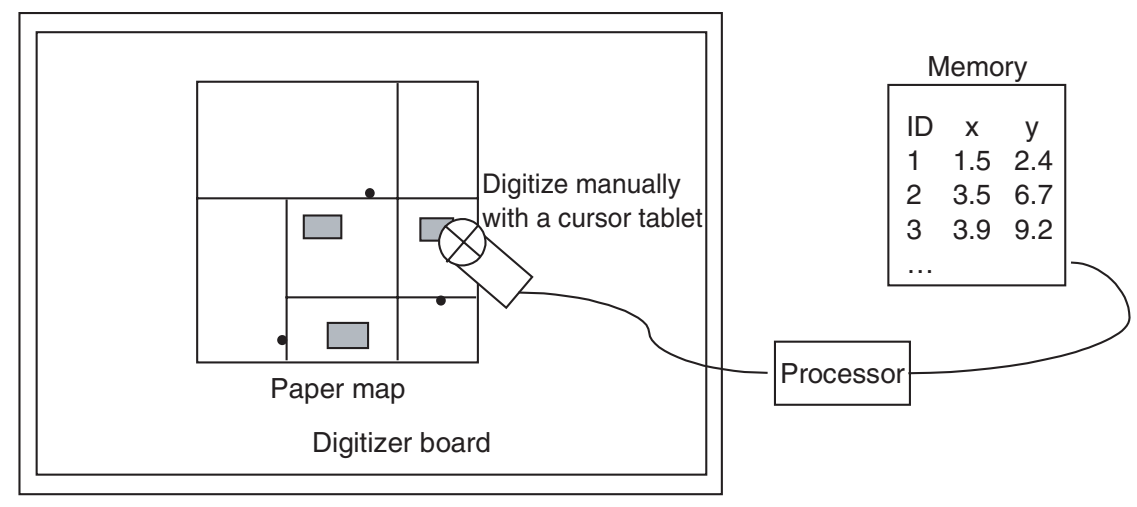

Figure 1.3 Digitizing using a cursor tablet.

coordinates of a certain system (latitudes-longitudes, or Cartesian $\mathrm{x}-\mathrm{y}$ coordinates). The location of a line segment is recorded in terms of a series of coordinates of the end points of the line segment, and the location of a polygon is recorded in terms of a series of coordinates of the vertex points of the polygon. This recording is achieved through an electric device called a digitizer (Figure 1.3). Finally, the coordinates obtained are stored in an electronic medium format. We call this process map digitizing, and the resulting map a vector-type digital map, or simply a vector map (see Chapter 3 for details).

Digital maps are readily available in developed countries, but in developing countries (which includes some Islamic countries), they are not always available. In particular, vector maps are hardly available. In cases where paper maps are available, we can transform these into digital maps by the methods mentioned above. The transformation into a raster map is easy; the transformation into a vector map is also easy when the number of geographical objects is small. When a paper map contains many geographical objects, however, the transformation into a vector map is laborious and costly. You should therefore consider whether such a costly proposition is worthwhile in your study, when a paper map would suffice.

In some Islamic countries, even paper maps are difficult to obtain. In such cases, there are a few other methods that one can employ. One alternative method is to use remotely sensed data from satellites (an example is shown in Figure 1.4). The names of notable Earth observation satellites are shown in the first column of Table 1.1 .

The data obtained by Earth observation satellites are of the raster data type, and the size of one cell determines the resolution (Figure 1.4b). Roughly speaking, the resolution is the minimum distance between two distinguishable geographical objects. The resolution of the satellites is shown in the second column of Table 1.1. The price of remotely sensed data varies according to the resolution. Some remotely sensed data by the NOAA AVHRR satellites are available without charge through the Internet (see Chapter 5). High-resolution data are expensive. 
(a)

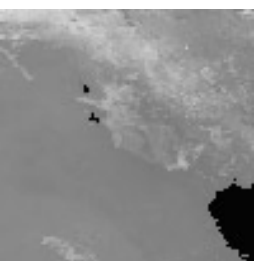

(b)

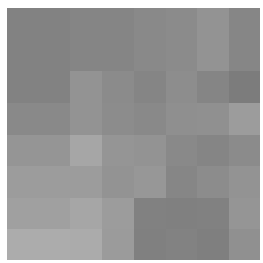

Figure 1.4 A remotely sensed raster map of (a) the Persian Gulf area, and (b) a magnified region of the map (Source: NOA).

Table 1.1 Earth observation satellites and their resolution

\begin{tabular}{lcc}
\hline Names & \multicolumn{2}{l}{ Resolution (in meters) } \\
\cline { 2 - 3 } & Panchromatic & Multispectral \\
\hline Landsat TM & & 30 \\
SPOT & 10 & 20 \\
IRS 1C & 5.8 & 36.5 \\
NOAA & & 1100 \\
IOSAT & 0.82 & 4 \\
QuickBird & 1.0 & 4 \\
\hline
\end{tabular}

One may think that remotely sensed images are the same as photographs taken by an ordinary camera. This is not quite true in two respects. First, remotely sensed images are digital data (raster data), while photographs are analog data (printed on paper). Second, remotely sensed data cover the visible wavelengths $(0.4-0.7 \mu \mathrm{m})$ and the invisible IR wavelengths (above $0.7 \mu \mathrm{m})$. Usually, a satellite mounts more than one sensor that covers the different wavelengths. For example, the AVHRR Landsat has five bands: 0.58-0.68, 0.725-1.10, 3.55-3.93, 10.30-11.30, and 11.50-12.50 $\mu \mathrm{m}$. We call such data multispectral data (data that cover the visible wavelengths are called panchromatic data). Figure 1.5 shows images taken by the Landsat 5 TM satellite using different sensors.

A problem with remotely sensed data from satellites is that an area is often covered with clouds, as shown in Figure 1.6. If the area is located in an arid region, this problem is unlikely to occur, but it does often in a monsoon region. We may overcome this problem, to a certain extent, if we have more than one remotely sensed map of the same area (see Chapters 4 and 5 for details).

In Islamic area studies, geographical data are often acquired by fieldwork. In traditional fieldwork, fieldworkers record geographical data in a field notebook. In recent developments, fieldworkers can use a computer-based field note (device) called a mobile GIS notebook, or mobile GIS (Okunuki et al. 2001). The mobile GIS notebook is a small computer or a personal digital assistant (PDA) in which GIS has been installed (Figure 1.7). The mobile GIS notebook has a global 
(a)

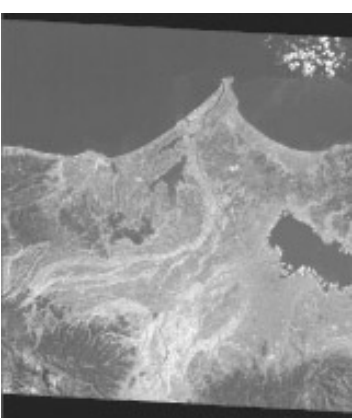

(b)

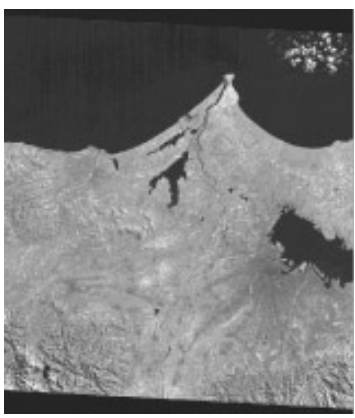

Figure 1.5 Landsat 5 TM satellite images covering (a) Band 3: 0.63-0.69 $\mu \mathrm{m}$, and (b) Band 4: 0.76-0.90 $\mu \mathrm{m}$ (Source: Space Imaging).

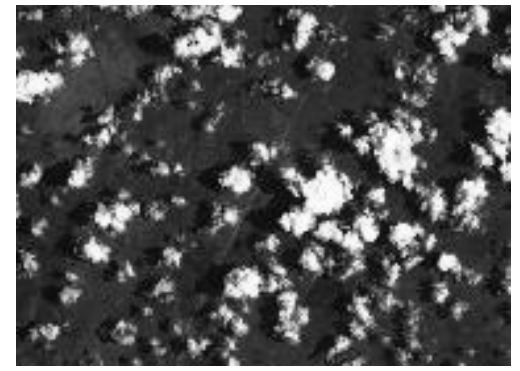

Figure 1.6 A remotely sensed raster map covered with clouds (Source: NOA).
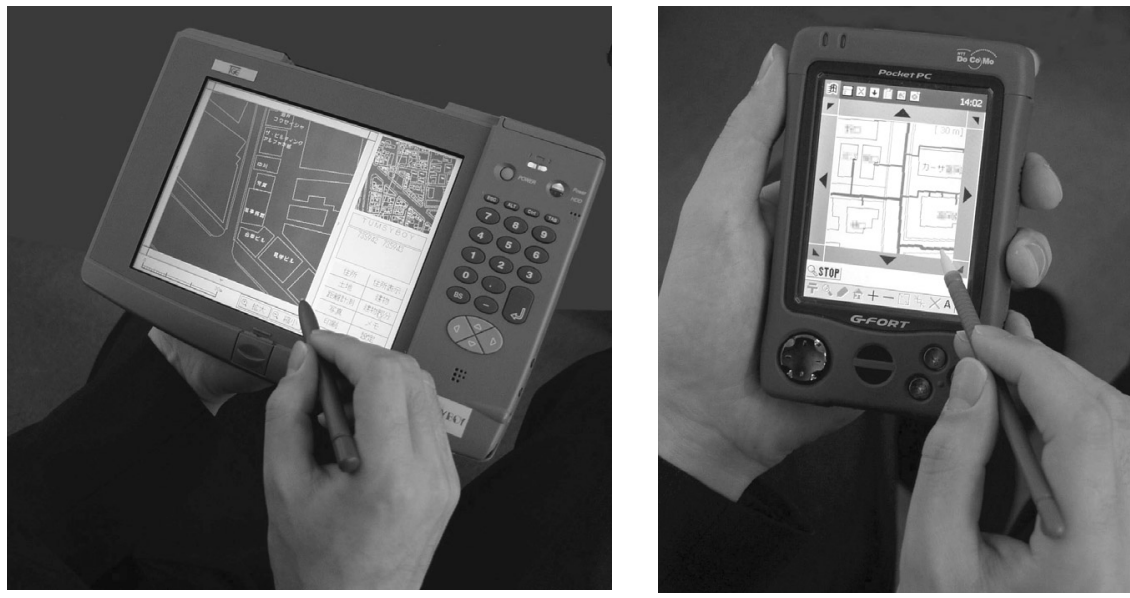

Figure 1.7 Mobile GIS notebooks. 


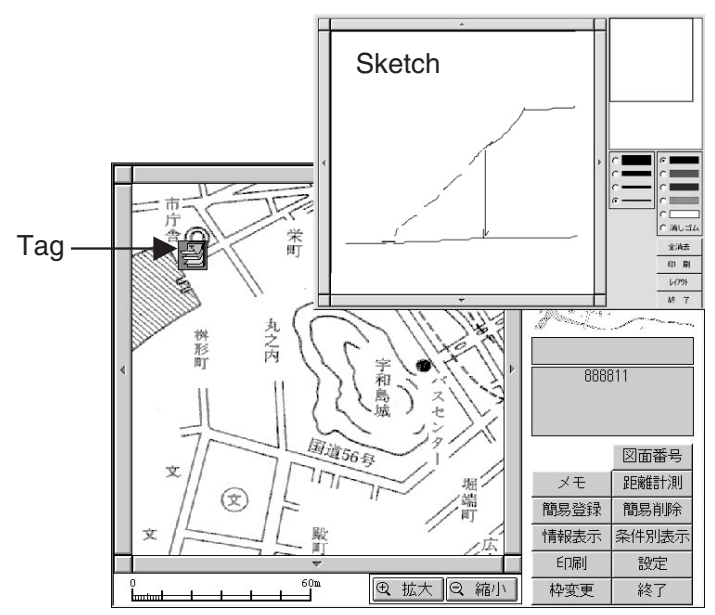

Figure 1.8 A digital map installed in a mobile GIS notebook, and a tag which pops up a window in which the user can draw a sketch by hand using an electronic pencil.

positioning system (GPS), by which fieldworkers can obtain the latitude, longitude, and altitude of their position. Thus, the fieldworker can make a note of geographical matters in the vicinity of the point with those coordinates. The note can include a sketch drawn by an electronic pencil on the screen of the mobile GIS notebook (see Figure 1.8). A mobile GIS notebook can be connected to a digital camera, and photographs taken at a point can be recorded along with the latitude, longitude, and altitude.

Fieldwork becomes more efficient when the digital map of the fieldwork area is available. It should be noted that the digital map is not necessarily a very precise map, as an outline map or a simplified map drawn by a fieldworker often is, in so far as the fieldworker can identify their location by that map. Figure 1.8 shows a mobile GIS notebook with an installed digital map. A fieldworker can attach a tag on this map, and the tag connects to a blank page in which the fieldworker can place a note, a hand-drawn sketch, or a photograph.

\section{Managing geographical data}

The second process in GIS is to manage the acquired geographical data; that is, to organize the acquired data and keep them for use. Software for this management is called a database. A GIS database consists of two parts: a database for attribute data, and a database for geometrical objects that represent geographical objects in the real world. The database for attribute data usually adopts a table-like data structure, called a relational database. Apart from GIS, probably the most commonly used table-like databases are Microsoft Excel and Access. GIS software is not well known in Islamic area studies (as well as many human and social sciences), but 
Excel is. Thus, a comfortable use of GIS in Islamic area studies hinges on having a good interface between the GIS software and Excel. As a matter of fact, the mobile GIS notebook referred to earlier adopts this interface.

Since the use of a table-like database is well known (many introductory books are now available), we will not discuss it here, but will focus on a database for geometrical objects; that is, the points, lines and polygons mentioned in the preceding section (an example is shown in Figure 1.9). Points are labeled (Figure 1.9a), and their coordinates are recorded in a table along with their labels (Table 1.2). Lines are labeled (Figure 1.9b), the direction of each line segment is given (the choice of direction is arbitrary), and the start point and the end point of each line segment are recorded (Table 1.3). Polygons are labeled (Figure 1.9c), and the labels forming the boundary-line segments of each polygon are sequentially recorded in a counterclockwise (or clockwise) direction (Table 1.4).

(a)

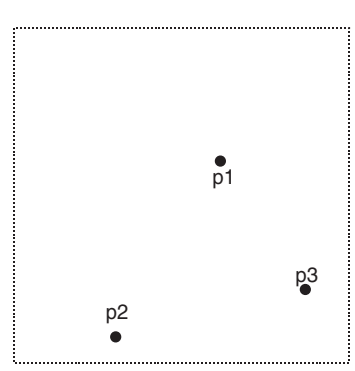

(b)

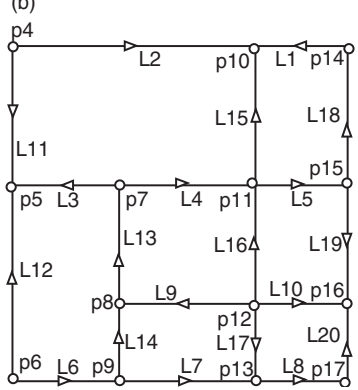

(c)

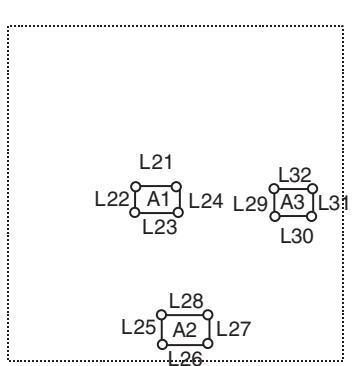

Figure 1.9 An example of (a) points, (b) lines, and (c) polygons.

Table 1.2 The table of points shown in Figure 1.9(a)

\begin{tabular}{lll}
\hline Label & $x$ & $y$ \\
\hline p1 & 1.5 & 2.3 \\
p2 & 3.4 & 5.1 \\
p3 & 6.3 & 9.7 \\
\hline
\end{tabular}

Table 1.3 The table of lines shown in Figure 1.9(b)

\begin{tabular}{lll}
\hline Label & Start & End \\
\hline L1 & $\mathrm{p} 14$ & $\mathrm{p} 10$ \\
L2 & $\mathrm{p} 4$ & $\mathrm{p} 10$ \\
L3 & $\mathrm{p} 7$ & $\mathrm{p} 5$ \\
\hline
\end{tabular}


OKABE ATSUYUKI

Table 1.4 The table of polygons shown in Figure 1.9(c)

\begin{tabular}{lllll}
\hline Label & Lines & & & \\
\hline A1 & L21 & L22 & L23 & L24 \\
A2 & L25 & L26 & L27 & L28 \\
A3 & L29 & L30 & L31 & L32 \\
\hline
\end{tabular}

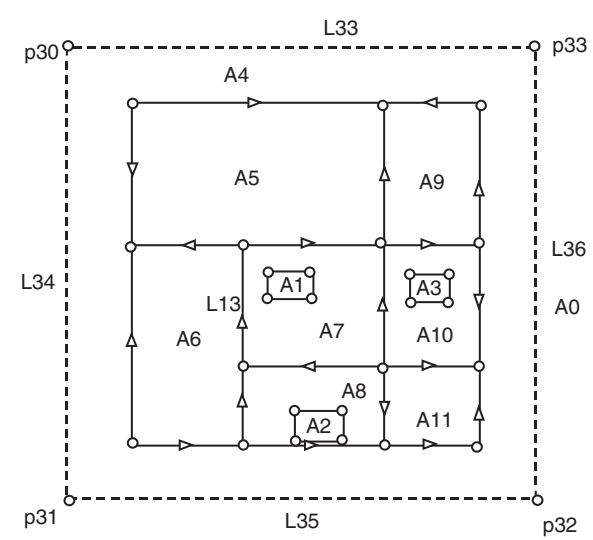

Figure 1.10 An example representing the topology of the lines and polygons shown in Table 1.5. (This figure is the integration of Figures 9(b) and 9(c), and the boundary lines.)

As a minimum, these three tables are necessary for managing geometrical objects. They are, however, not sufficient when we want to know the spatial relations among geographical objects, for example, in Istanbul we may want to know, "What street crosses the Bozdogan Kemeri (a water bridge)?", "What stations are next to the Yenikapi Station?", and "Does the Gulhane Park include the Eski Sark Eserleri Museum?"

To answer these questions, we have to manage the "topological" data of the geometrical objects (see Figure 1.10). These days, the GIS software automatically constructs the topological data (Table 1.5) from the data given in the tables of lines and polygons (Tables 1.3 and 1.4). Thus, users do not have to worry about the topological data of geometrical objects.

Islamic area studies often include historical studies (Chapters 6, 8, and 9). In such studies, we have to manage not only spatial data but also temporal data. At present, however, standard GIS software is fairly weak in the management of temporal data. Several theoretical methods have been proposed in the literature (e.g. Langran 1993), but we notice that those methods are not always appropriate for historical studies. In theory, a historical event starts at a point in time, $t_{\mathrm{s}}$, and ends at a point in time, $t_{\mathrm{e}}$. In practice, however, it is often difficult to determine the 
Table 1.5 A table representing the topological data of Figure 1.10

\begin{tabular}{lllll}
\hline Line & i.start & i.end & ii. right & ii. left \\
\hline L13 & p8 & p7 & A7 & A6 \\
L14 & p9 & p8 & A8 & A6 \\
L15 & p11 & p10 & A9 & A5 \\
\hline
\end{tabular}

exact start time $t_{\mathrm{s}}$, and the exact end time $t_{\mathrm{e}}$, because historical documents are often incomplete. To deal with this ambiguity, we may consider a start period $\left[t_{s 1}, t_{s 2}\right]$ where $t_{s 1}$ means that the historical event did not exist before time $t_{s 1}$, and did exist after time $t_{s 2}$, and in the same manner, we may consider an end period $\left[t_{e 1}, t_{e 2}\right]$. When historical documents are complete, $t_{s 1}=t_{s 2}$ and $t_{e 1}=t_{e 2}$. This idea was proposed by Ohsawa, and it has been implemented in GIS software that is publicly available.

\section{Analyzing geographical data}

Sometimes, beginners in GIS mistakenly regard GIS as a tool for managing geographical data (a database) or for visualizing geographical data (showing 'beautiful' colored maps). Although such functions of GIS are indeed useful in practice, the main process in GIS is to analyze geographical data. For this process GIS (software) provides many types of basic operation. Owing to constraints of space, we show only a few of the basic operations in this section.

One such operation, called the neighborhood operation, shows the neighborhood area of a geographical object (represented by geometrical elements). This operation is used when we want to know, for example, the area in which the Beyazit Mosque is within $400 \mathrm{~m}$ (denoted by A1 in Figure 1.11); the area in which the coastline is within $500 \mathrm{~m}$ (see Figure 1.12); and the area in which the Kapali Bazaar is within $200 \mathrm{~m}$ (denoted by A2 in Figure 1.13).

Geometrically, these neighborhoods are the neighborhoods of a point, a line segment, and a polygon, respectively.

A second operation, called the overlay operation, overlays a set of geographical objects on a set of other geographical objects. A geographical object may be a newly produced area from a neighborhood operation. The overlay operation is useful when we want to know, for example, the area in which a given mosque is within $400 \mathrm{~m}$, and the area where the Kapali Bazaar is within $500 \mathrm{~m}$ (Figure 1.14). Logically, this is expressed as A1 AND A2 (where the capitalized AND means a logical operation). The overlay operation may be extended to A1 OR A2 (Figure 1.15), A1 NOT A2 (i.e. the complement of A1 with respect to A2) (Figure 1.16), and A1 XOR A2 (i.e. [A1 OR A2] NOT [A1 AND A2]) (Figure 1.17).

A third operation, called the spatial search operation, searches for geographical objects that satisfy certain geographical conditions. This operation is useful when 


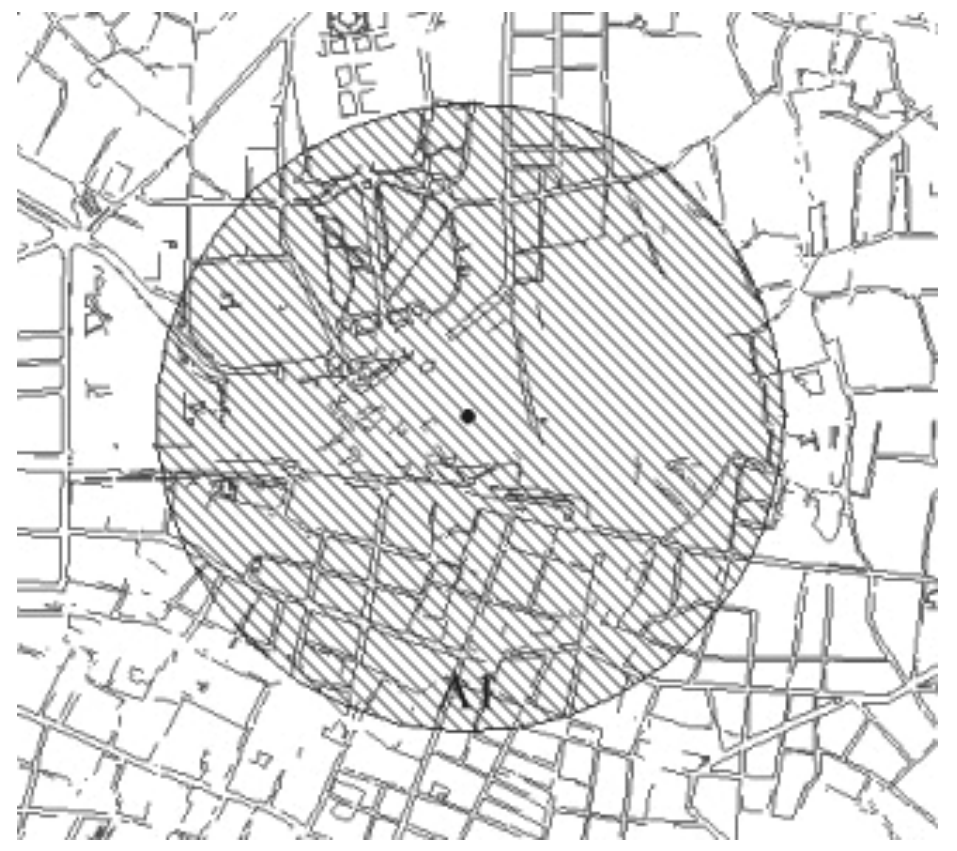

Figure 1.11 The area in which the Beyazit Mosque is within $400 \mathrm{~m}$ (denoted by A1).

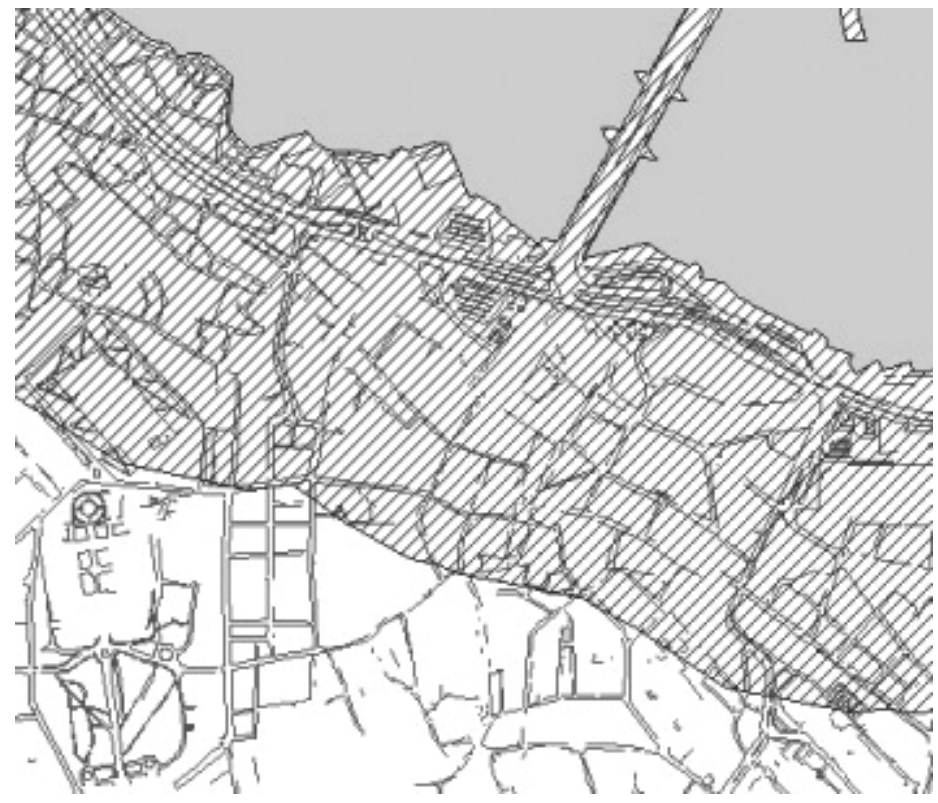

Figure 1.12 The area in which the coastline is within $500 \mathrm{~m}$. 


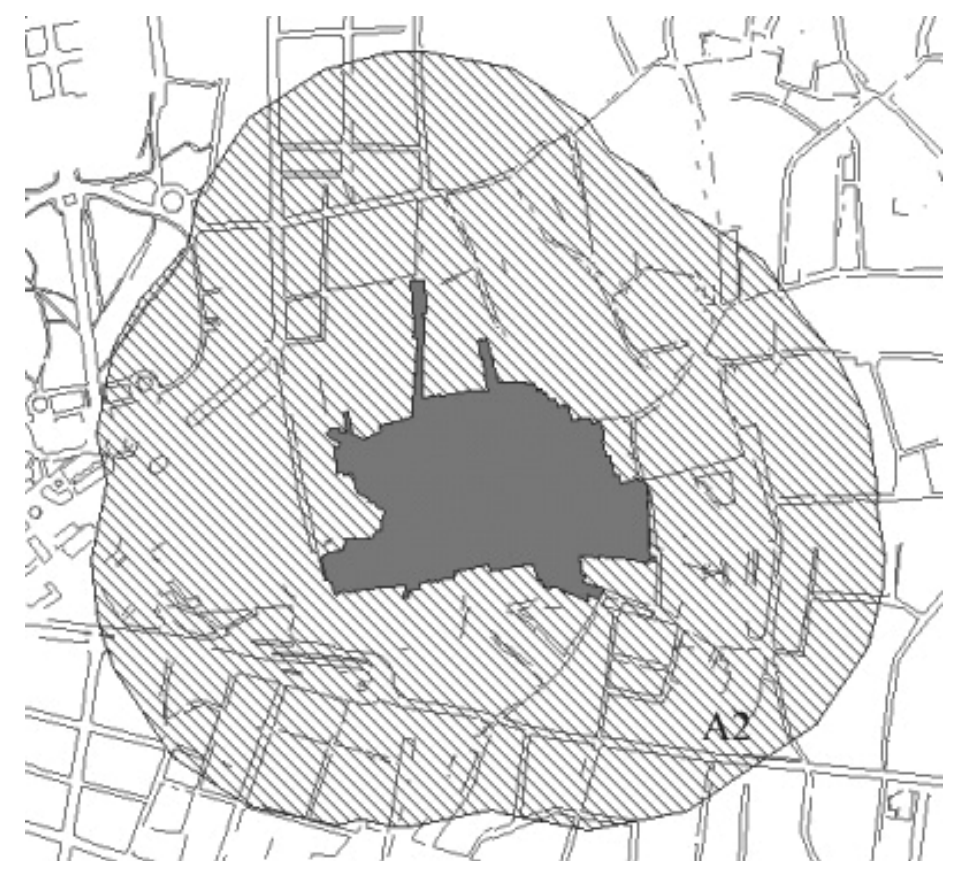

Figure 1.13 The area in which the Kapali Bazaar is within $200 \mathrm{~m}$ (denoted by A2).

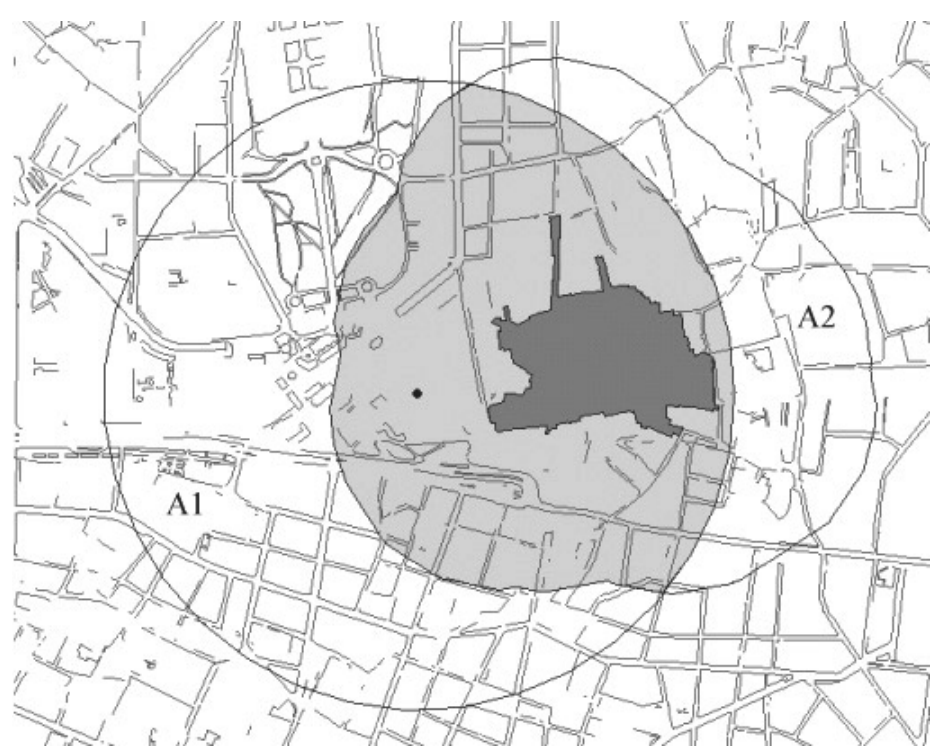

Figure 1.14 An AND operation, A1 AND A2. 


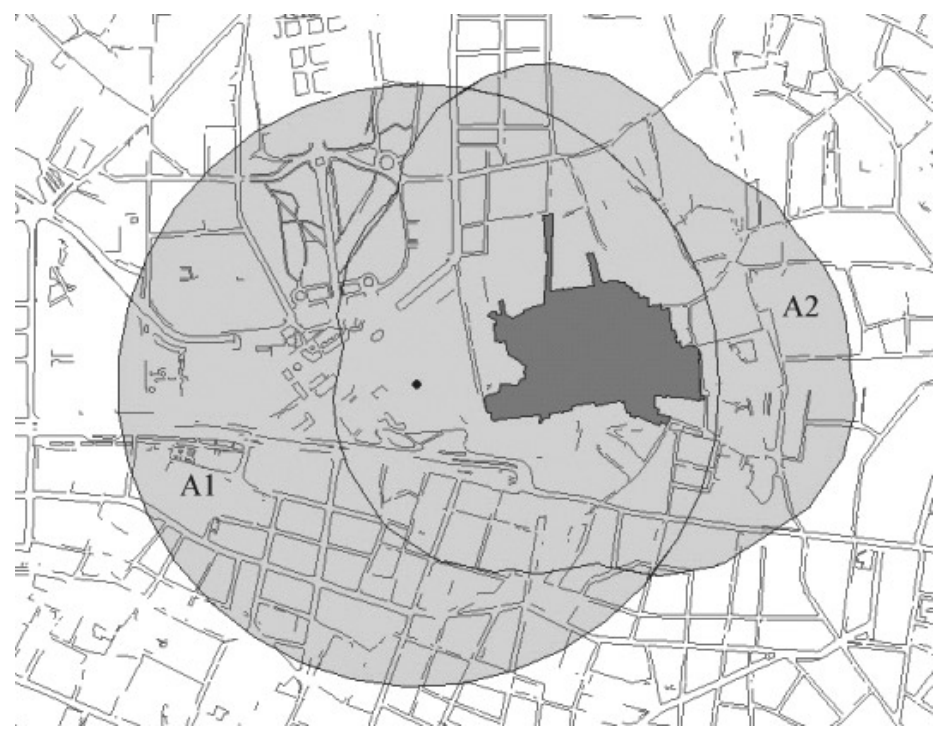

Figure 1.15 An OR operation, A1 OR A2.

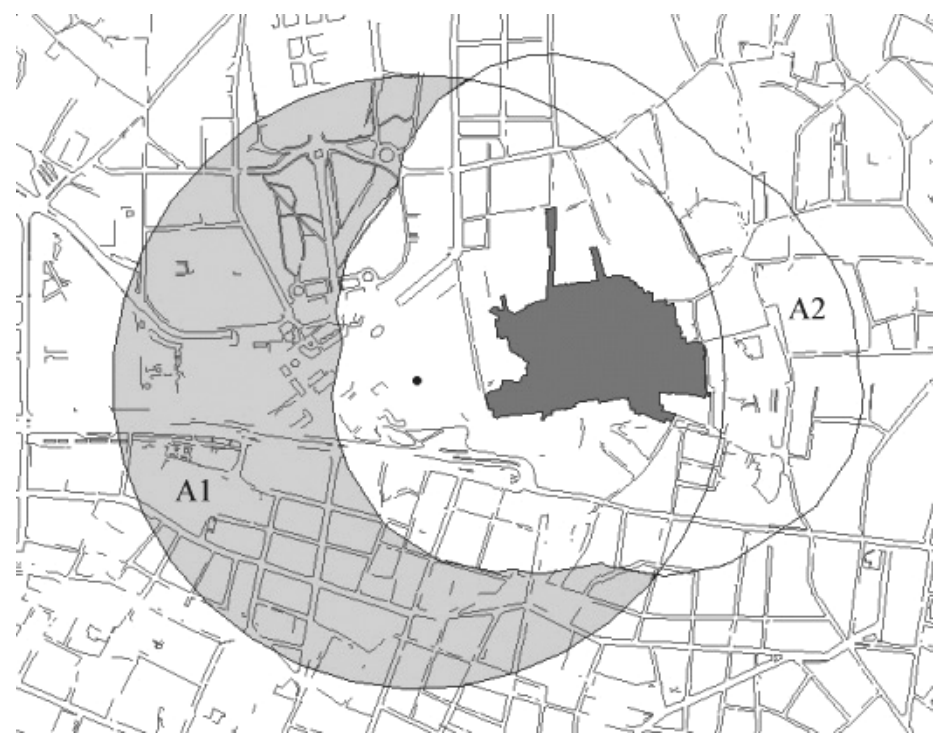

Figure 1.16 A NOT operation, A1 NOT A2. 


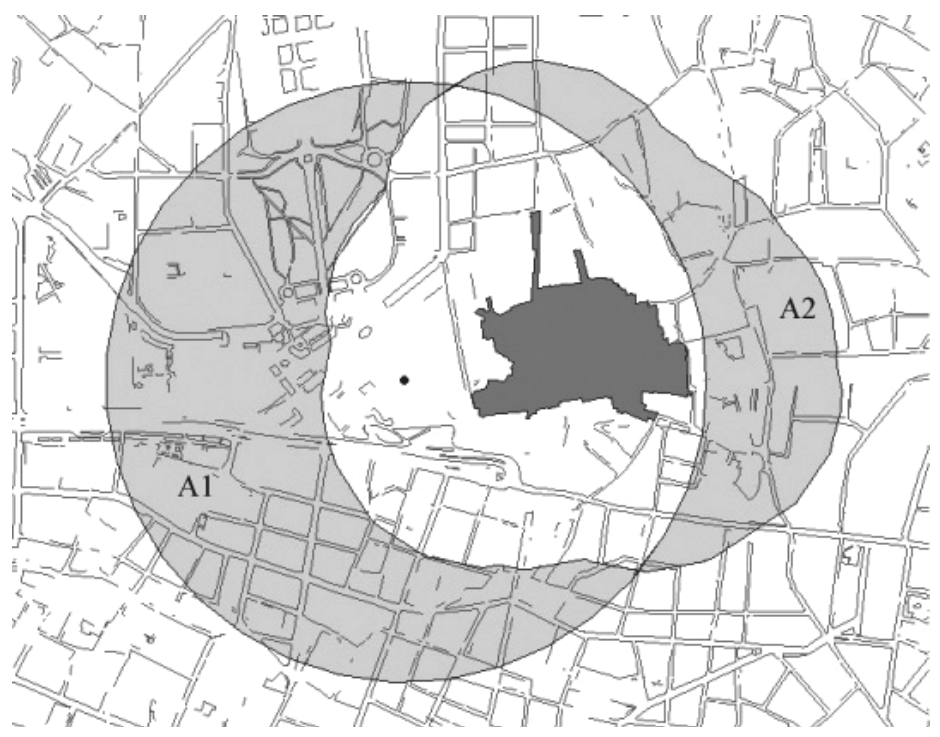

Figure 1.17 An XOR operation, A1 XOR A2.

we want to find, for example, mosques that are within $200 \mathrm{~m}$ from the Kapali Bazaar. Since this operation is conditioned by a distance, it is specifically called a distance search operation. Spatial search operations are not restricted to distance search operations. For example, spatial search operations include the operations: inclusion search operation, which searches geographical objects included in an area (e.g. to find a museum); and intersection search operation, which searches geographical objects that are intersected by another type of geographical object (e.g. to find streets intersected by a railway line) (see Figure 1.18).

Using these basic operations, we can carry out elementary analysis of geographical data. The analysis may be augmented by methods developed in spatial analysis (Bailey and Gatrell 1995) and spatial statistics (Ripley 1981; Upton and Fingleton 1985; Cressie 1991; Okabe et al. 2000). Examples of questions that can be solved by these methods are, "Are mosques randomly distributed in Istanbul?", "Do mosques tend to be located on the peaks of hills?", "Do mosques tend to be located along arterial streets?", "Do mosques tend to be located around large parks?", and "Is the distribution of mosques affected by topography?"

The methods that solve these questions are not built into an ordinary GIS, but are provided as add-on software-for example, the S+ SpaceStats packages, SAINF (http://okabe.t.u-tokyo.ac.jp/okabelab/atsu/sainf/sainf.html), and SANET (http://okabe.t.u-tokyo.ac.jp/okabelab/atsu/sanet/sanet-index.html).

Although many advanced methods for spatial analysis are available nowadays, these methods are not always sufficient for dealing with geographical data in Islamic area studies, and in particular historical geographical data. Unlike data 


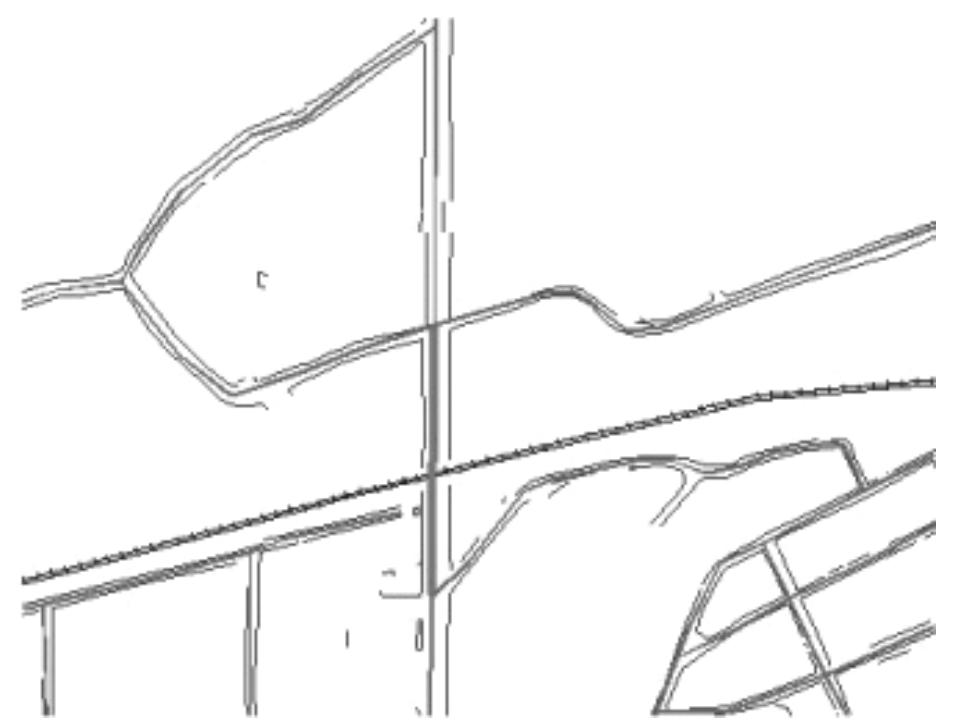

Figure 1.18 An intersection search operation.

used in natural sciences, data used in Islamic area studies are often ambiguous or inaccurate. For example, old maps and documents are often difficult to read. The application of advanced methods to these data sometimes leads to misleading conclusions, because almost all of the methods for spatial analysis assume accurate data. Through the studies in the ISA-GIS project, we learned that methods assuming inaccurate data were indispensable for spatial analysis in Islamic area studies. At present, such methods are under development. One example is shown in Chapter 5.

\section{Visualizing geographical data}

The last process in GIS is the visualization of geographical data. In practice, this is probably the most frequently used process of GIS. This is a reason why GIS is mistakenly regarded as a tool for visualizing "beautiful" colored maps. Although this is a misconception, it is not that visualizing geographical data is not important. Rather, the visualization often provides an insight into the understanding of geographical phenomena (good textbooks in this area include Cronley 1992, MacEachren and Taylor 1994, and Slocum 2003). In these books, the reader can find many kinds of visualizations, so they are not discussed in detail here, except for a few basic observations.

The manner in which geographical data is visualized depends on the nature of the geographical data. As mentioned before, geographical data are the combination of 
attribute data and location data of geographical objects. The attribute data of a geographical object may be univariate (single variable) or multivariate (many variables).

In the univariate case, visualization is fairly simple. The location of a geometrical object is shown by its geometrical element on a two-dimensional map. The attribute value may be shown by coloring the geometrical object on a two-dimensional map, or by the height of the geometrical object in a threedimensional map. When the geometrical objects are represented by points on a map, the map is referred to as a dot map (an example is shownn in Figure 6.2). When the geometrical objects are spatial units forming a tessellation, such as municipal districts, the map is referred to as a choropleth map. These figures become a little more imaginative if the plane is replaced with the topographical surface of a study region (such as in Figure 15.3).

In the multivariate case, in theory, we need more than a three-dimensional space. In some cases however, we may represent multivariates on a plane map using pi charts. An example is shown in Figure 2.4 where the ratios of castes in each region are shown by a pi chart placed in each region.

In historical analysis in Islamic area studies, we would often want to observe the change in attribute values of the same area over time. In such a case, animation may provide us with an insight into historical changes. An example is shown in Figure 4.12 that shows land cover change from 1982-93.

\section{Concluding remarks}

In this chapter, we have taken a brief look at GIS. We hope that this introduction helps readers understand the applications of GIS to Islamic area studies that will be described in the chapters that follow.

\section{Acknowledgments}

We express our thanks to Sadahiro Y. and an anonymous referee for valuable comments on an earlier draft. We also thank to Tokyo University Press for permitting the use of Figures 1-15 in Sato (2003).

\section{References}

Bailey, T.C. and Gatrell, A.C. (1995) Interactive Spatial Data Analysis, Burnt Mill: Longman.

Burrough, P.A. (1986) Principles of Geographical Information Systems for Earth Resources Assessment, Oxford: Clarendon Press.

Cressie, N. (1991) Statistics for Spatial Data, New York: John Wiley.

Cronley, R.G. (1992) Digital Cartography, Englewood Cliffs, NJ: Prentice-Hall.

Langran, G. (1993) Time in Geographic Information Systems, London: Taylor and Francis.

Laurini, R. and Thompson, D. (1992) Fundamentals of Spatial Information Systems, London: Academic Press.

MacEachren, A.M. and Taylor, D.R.F. (eds) (1994) Visualization in Modern Cartography, Amsterdam: Elsevier. 


\section{OKABE ATSUYUKI}

Okabe, A., Boots, B., Sugihara, K., and Chiu, S.N. (2000) Spatial Tessellations: Concepts and Applications of Voronoi Diagrams, Chichester: John Wiley.

Okunuki, K., Itoh, S., Okabe, A., Goto, Y., Kaneko, T., Shinoaki, S., Akita, Y., Kotsubo, H., Okita, Y., Tatematsu, T., and Shiozaki, G. (2001) A mobile GIS for fieldwork, Abstracts of Symposium on Asia GIS 2001, pp. 20-21.

Ripley, B.D. (1981) Spatial Statistics, New York: John Wiley.

Sato, T. (2003) Prospects in Islamic Area Studies, Tokyo: Tokyo University Press.

Slocum, T.A. (2003) Thematic Cartography and Visualization, Englewood Cliffs, NJ: Prentice-Hall.

Star, J. and Estes, J. (1990) Geographic Information Systems: An Introduction, Englewood Cliffs, NJ: Prentice-Hall.

Upton, G. and Fingleton, B. (1985) Spatial Data Analysis by Example, Chichester: John Wiley. 


\section{Part I}

\section{SPATIAL DATA CONSTRUCTION AND A METHOD FOR PRELIMINARY ANALYSIS}





\title{
CONSTRUCTING SPATIAL DATABASES FROM OLD PAPER DOCUMENTS
}

\author{
Mizushima Tsukasa
}

This chapter describes the procedures used and the problems encountered in constructing spatial databases from old paper documents. Geographical information systems (GIS) holds the promise of extending the horizon of historical studies in many respects. Possibly the most important contribution of GIS to historical studies is the generation of clear spatial images by integrating various facets of information, and it is useful to summarize some of the more notable features of historical GIS studies at this stage. The technical aspects relating to documentbased data using GIS will be discussed by Sadahiro in Chapter 3, and a historical analysis of southern India in the eighteenth and nineteenth centuries, based upon a constructed spatial database from old paper documents, will be attempted in Chapter 6.

\section{Sources}

By far the most important point in the application of GIS to historical studies is to find the proper historical sources. Sources suitable for GIS should have a considerable quantity of information that can be linked to a particular spatial point or area. Time-series sources having similar categories of information in more than two different periods and covering a wide area are ideal for tracing historical changes with the help of GIS-based tools.

One of the most important sources that more-or-less meets this requirement in Asian countries is the revenue administration records, and as these are for administration purposes, sets of standardized data have been regularly prepared in the past.

Southern India, which comes under investigation in Chapter 6, has a comparatively richer historical source than others. This is mainly due to the fact that the area was placed under the raiyatwari system by the English East India Company in the early nineteenth century. ${ }^{1}$ In contrast to other revenue systems, such as the village settlement or zamindari settlement systems, the primary revenue unit in the raiyatwari system was neither a village nor a zamindari, but a land lot. A person 

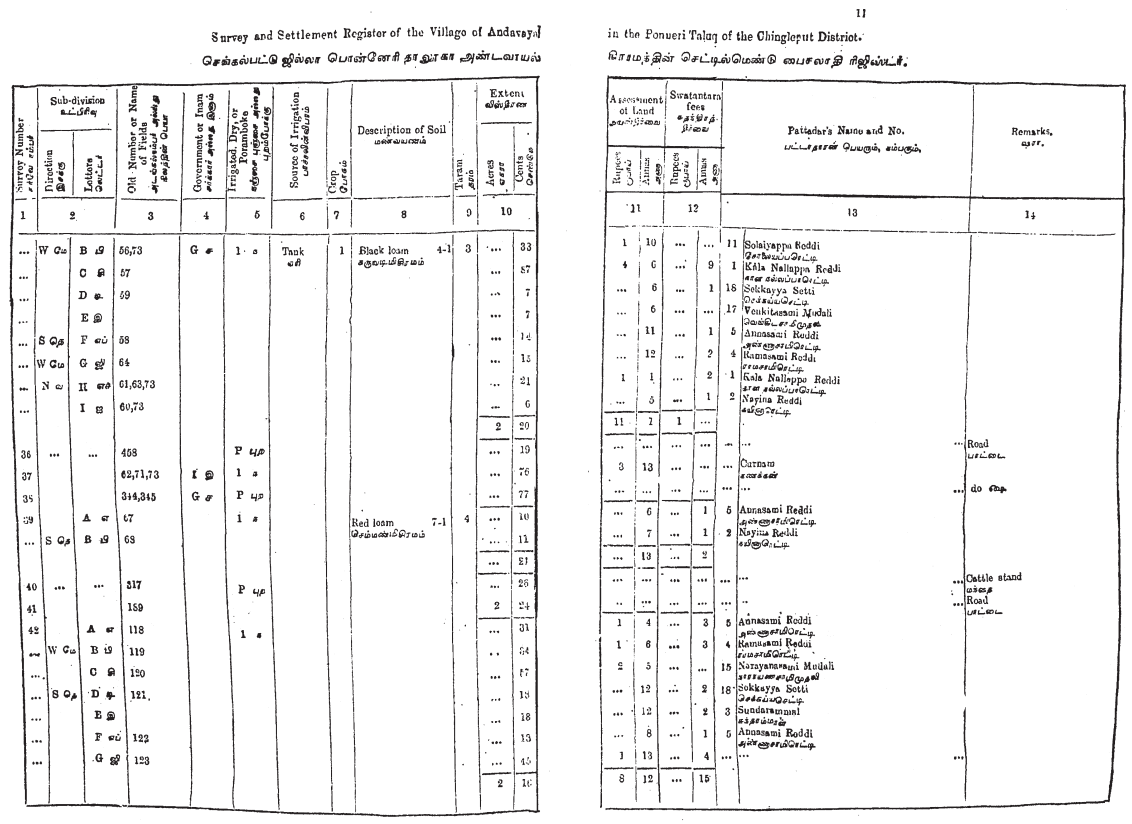

Figure 2.1 Settlement Register of one of the Ponneri villages in 1877—a sample.

who assumed responsibility for paying land tax for a certain number of lots was deemed to be a raiyat, or landholder. As shown in Figure 2.1, each village was demarcated into hundreds (and sometimes thousands) of land lots, and the details of the respective lots, such as the nature of the soil, acreage, assessment rate, irrigational condition, and landholder's name, were recorded every thirty years at the time of re-settlement. ${ }^{2}$

Before the raiyatwari system was enforced, older local records had also been collected by colonial officers in the late eighteenth century, when the records were either compiled from pre-colonial documents, or were freshly prepared by the colonial officers.

Three such records from the late eighteenth century are well known. The first is the report prepared by a British surveyor, Thomas Barnard, between 1767 and 1774. Barnard carried out a survey in the Jagir region (Chingleput currently spelled as Chengalpattu), and left a few dozen volumes of village accounts describing the details of village production in totally 2,200 villages in the area (see Chapter 6 for details). Its contents seem to be composed partly of a compilation of existing village documents, and partly of information directly obtained by him. We will call this report the Barnard Report.

The second important record is the Place Report, which was prepared by Lionel Place, a collector posted to the Jagir region in the 1790s. He traveled 
around the Jagir, introducing the village settlement (where the basic revenue unit was the village) in the area. Information on privileged holdings, and various fees and collections on village produce etc., was catalogued for each village.

The third record is the Permanent Settlement Record. Permanent settlement was introduced in the area at the beginning of the nineteenth century. Under this scheme, settlements in the Jagir area were divided into 60 zamindaris or basic revenue units, and the Permanent Settlement Record was prepared for assessing the amount of revenue from each zamindari. Information, as had similarly been collected by Place, was compiled for each village contained within the respective zamindaris, but in addition, this was also arranged by several important social elements, such as Poligars (military leaders), temples, and village accountants.

While these earlier sources offer standardized data for each village, the Settlement Registers of the 1870s offer additional information on each land lot. As the raiyatwari settlement was renewed every thirty years, changes that occurred during these periods can be analyzed in more detail.

Documents from later periods, especially those since the 1980s, unexpectedly provide little information at the village level. Most of the data are aggregated into wider administrative units, and to obtain data at the village level, we have to approach a village administration officer (VAO) who gathers statistics at the village level. ${ }^{3}$ However, under present circumstances obtaining full VAO records is a time-consuming task.

\section{Procedures and problems}

\section{Identifying the location code}

The first step in GIS work is the coding of place names found in historical sources. As historical maps are rarely available in most Asian countries, we have to go back to the past from contemporary maps.

So far as southern India is concerned, the most accurate maps identifying the location of place names are topographical sheets of 1:50000 scale. However, village boundaries are not demarcated on these maps, and sheets within 60 miles from the coast are restricted for security reasons. Alternative maps are the taluk (sub-district) maps prepared in the 1960s. These provide information on hamlets, village boundaries, village codes, roads and highways, watercourses, and tanks, and they also provide other data.

The case study in Chapter 6 adopts the village code used in the 1971 Census. Each hamlet in the taluk map was either given the village code used in the 1971 Census or was adjusted to it according to its location. For instance, if there exist three hamlets in village code 234 in the taluk map X, the three hamlets are given the codes X234A, X234B, and X234C, respectively.

There are three problems in allotting a location code to the place names recorded in historical sources. One problem arises from the time lag-for example, 
between the 1971 census and older records. Villages often appear and disappear, so that there always remain a considerable number of villages to be coded. The second problem is the discrepancy caused by the unstandardized transcript system of place names within the same source or among different sources. The same place can often be transcribed in several ways without following any fixed rules. The third problem arises from identical village names. For instance, there are a few dozen villages named Agaram, Kandigai, Kuppam, or Mettupalayam.

There are no easy solutions to these problems. One solution may be to sort the village lists (alphabetically or numerically in respective areas), and then utilize these lists to reduce the number of uncoded villages. The village area and other related statistics might also provide hints for identification.

\section{Tabulation}

Once the location codes have been assigned to place names, any information related to the place names should be tabulated, having the location code as a key index. All the information can be linked using the location code. Those place names without a location code cannot be utilized. Aggregated statistics for wider spatial units are recommended for creating more general views. Digitization and tabulation requires a great deal of time, and in practice, it consumes some $99 \%$ of the time spent in historical GIS studies.

In addition to the high probability of misreading the spelling or numerals in blurred manuscripts, there are three problems in constructing tables. The first problem is related to gathering statistics from the respective sources. Categories used for statistics very often differ from time to time or from source to source. For instance, land irrigated by private wells was often categorized as non-irrigated land in the colonial period. This is because the statistics were compiled for revenue assessment, and not for calculating the extent of irrigation. Thus, any statistics gathered can be deeply affected by the original objective of their collection, so that a meaningful analysis cannot be expected unless the original objective is traced through the study of contemporary sources. A simple statistical study can lead nowhere.

The second problem is caused by the lack of information or by the irregular nature of original statistics and their coverage, which is unavoidable in dealing with old documents. Time-series data having the same nature is hardly to be expected, so that a historian's own definition is often required. The technical point to be stressed is the necessity of differentiating the data whose information is missing from those whose information value is zero. The third problem is related to discrepancies contained within the original sources. In some cases, manipulation may be necessary, and if so, this should be followed by explanatory notes. 


\section{Tables, graphs, and maps}

When tabulation is complete, the preparatory work is almost over. The next step is to generate tables, graphs, and maps by using software appropriate for the purpose. To stress the merit of GIS against conventional table-based analysis, I have chosen a simple example by way of an explanation.

Table 2.1 is compiled from the Barnard Report, and indicates some information regarding the poligars ${ }^{4}$ or military leaders in Ponneri. The report provides information on the poligars' castes, ${ }^{5}$ their living places, and the number of villages under their jurisdiction. It is known from Table 2.1 that the majority had the title of either Raja or Naick, and that they belonged to military castes. What attracts more attention is the fact that several Vellalas were also included in the list. Usually, poligars were from military castes, and it was very rare for a Vellala, a member of an agricultural caste, to become a poligar. A possible interpretation of this data is that the phenomenon was new, and had recently arisen because of the incessant warfare in the pre-colonial period.

Figure 2.2 shows the location of the villages under the respective poligar castes, and provides another interesting feature that may have slipped our attention if we had not used GIS. As clearly indicated, those under the Vellala poligars were concentrated in the central part of the Ponneri area, near the town of Ponneri. This part of Ponneri was dominated by the Vellala landholders called as mirasidar, as indicated by Figure 2.3 prepared from the Barnard Report, and by Figure 2.4 prepared from the Place Report. Compared to other villages that had more of the Palli caste as residents, the central area had more Vellala in its population as shown in Figure 2.5. These features will form the basis of a future comparative study of village structures in the area.

Table 2.1 Poligar castes and the number of villages under their jurisdiction in Ponneri (Barnard Report, 1770s)

\begin{tabular}{lc}
\hline Poligar castes [ ]-living place & No. of villages \\
\hline Naick & 7 \\
Naick (Covray) & 3 \\
Naick (Palli) & 1 \\
Rajah & 111 \\
Rajah, Muttiriyan, Naick & 1 \\
Rajah, Naick (Muttiriyan) & 2 \\
Vellala [Madras] & 1 \\
Vellala [neighboring village] & 9 \\
Vellala [same village] & 10 \\
Not available & 5 \\
Total & 150 \\
\hline
\end{tabular}




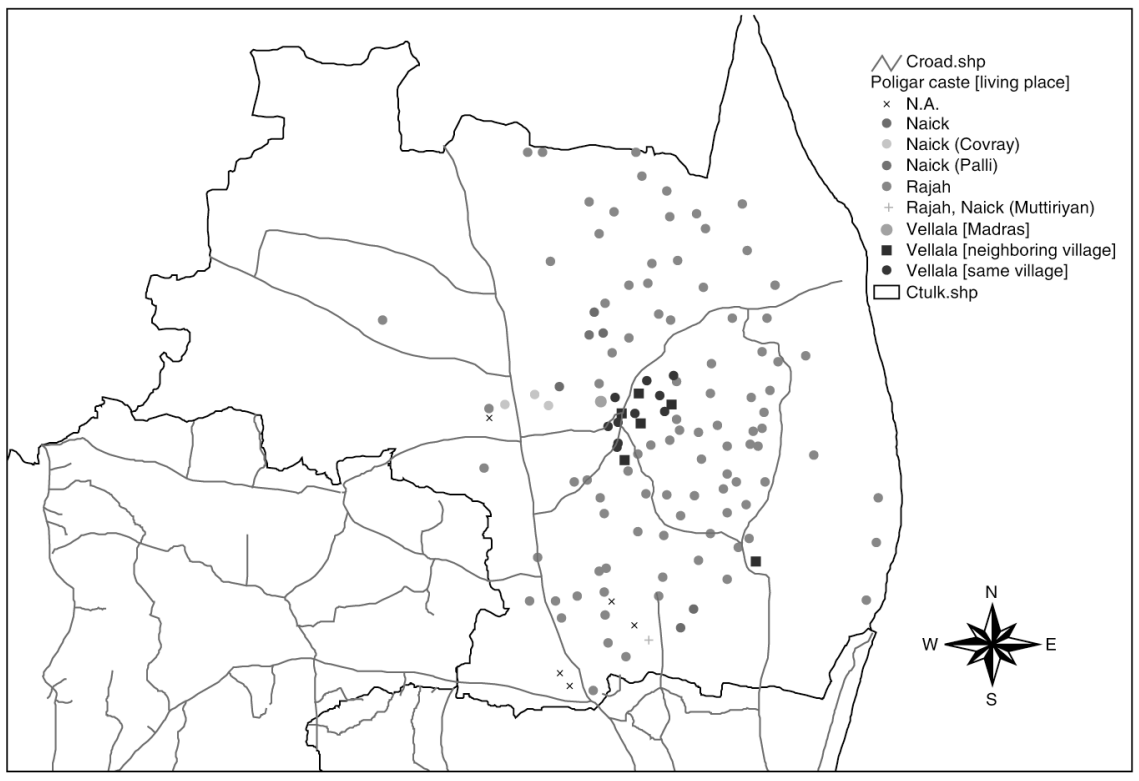

Figure 2.2 Villages held by the respective poligar castes (Barnard Report, 1770s).

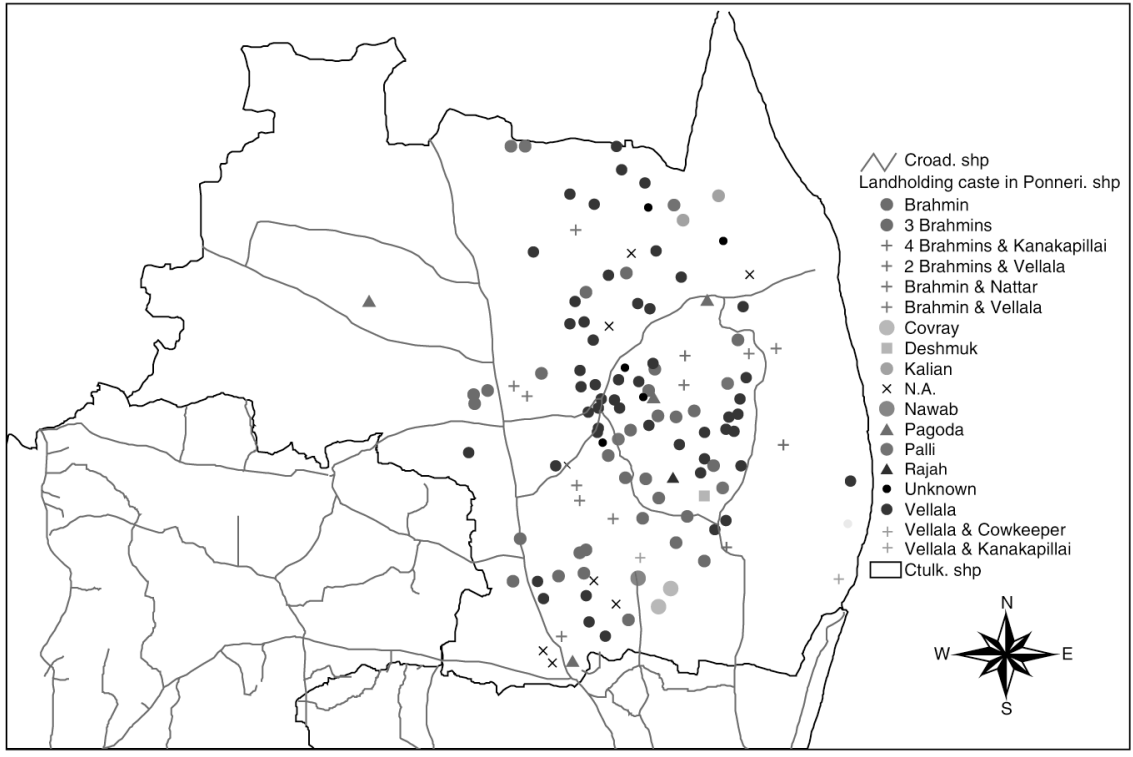

Figure 2.3 Villages held by the respective mirasidar castes (Barnard Report, 1770s). 


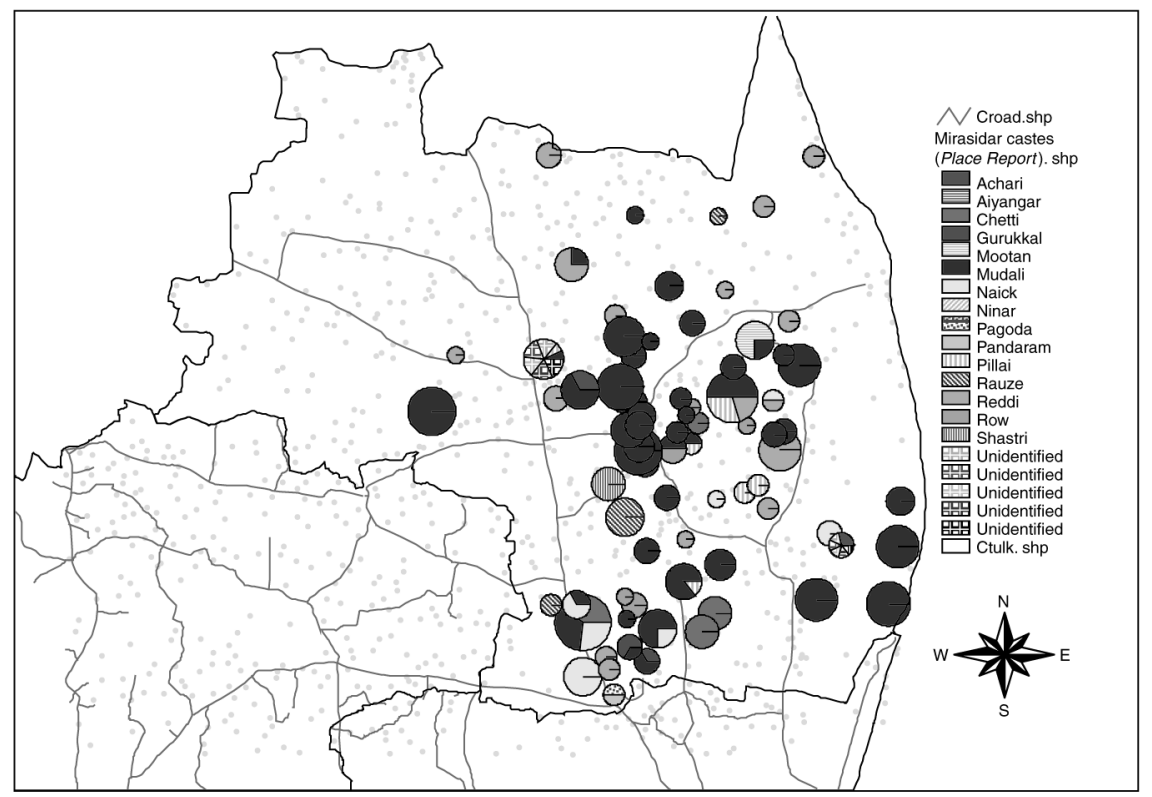

Figure 2.4 Villages held by the respective mirasidar castes (Place Report, 1799).

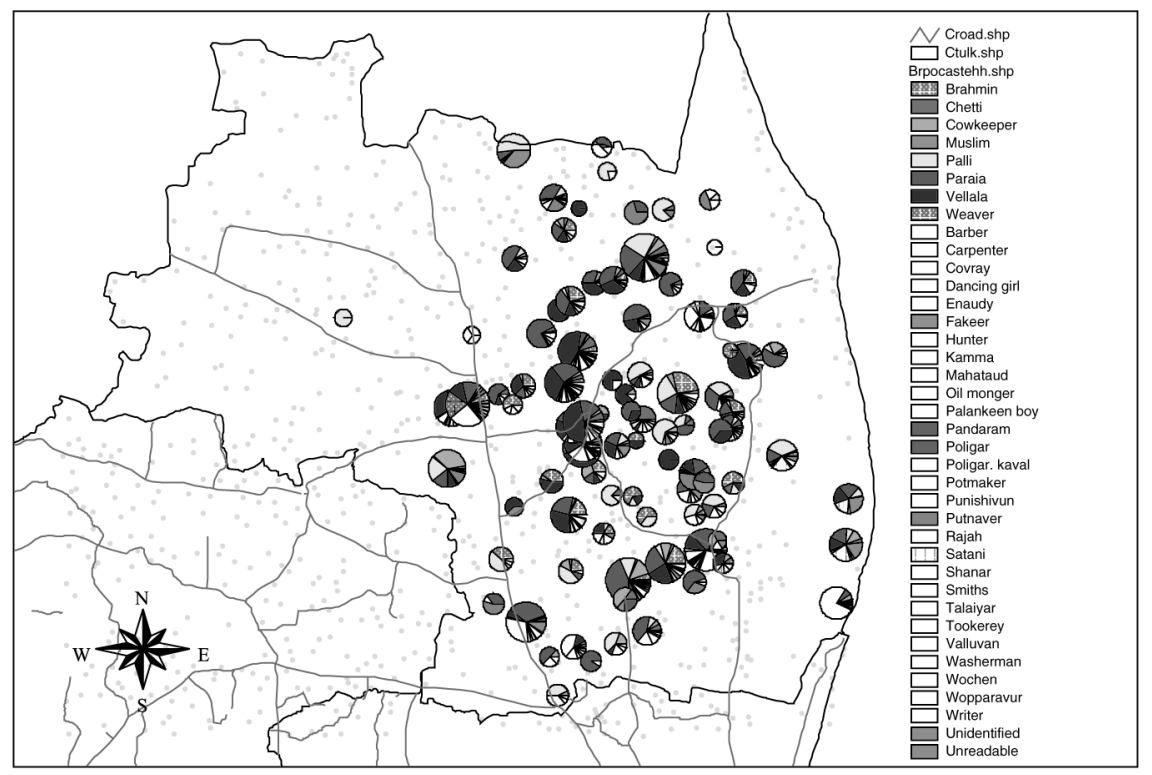

Figure 2.5 Caste composition in Ponneri villages (Barnard Report, 1770s). 


\section{Concluding remarks}

From the investigation attempted here, the following remarks can be made. GIS offers much more detailed spatial information on the study area than conventional "table-based" analysis. It provides us with direction in synthesizing multifaceted aspects, as it visualizes the heterogeneity and homogeneity of the study area and its historical changes. Topics such as the formation of locality, the relation between the political unit and the social unit, and many other aspects can be investigated further by accumulating appropriate databases.

\section{Notes}

1 A number of revenue documents were prepared for each village from the second raiyatwari settlement in the latter half of the nineteenth century. For details see Baden-Powell (1892), especially section III in chapter III.

2 As to the studies using settlement registers, see, for instance, Mizushima (1983).

3 Before VAOs were appointed in the mid-1980s, every village had a karnam (village writer) who had served in the same post for decades. They were (in a fashion) a walking dictionary of village administration, and their information was believed to be more accurate than that of the VAOs.

4 For the details of poligars in Chingleput, see Mizushima (1995).

5 An encyclopedic account of castes in south India is given by Thurston (1909).

\section{References}

Baden-Powell, B.H. (1892) The Land-Systems of British India, vol. III, The Raiyatwari and Allied Systems, Oxford: Clarendon Press.

Mizushima, T. (1983) "Changes, Chances and Choices-The Perspective of Indian Villagers," Socio-Cultural Change in Villages in Tiruchirapalli District, Tamil Nadu, India, Part 2, Modern Period-1, ILCAA, Tokyo University of Foreign Studies, pp. 27-221.

Mizushima, T. (1995) "A Study of Poligar in Chingleput in the Late Eighteenth Century" (in Japanese), Ajia-Africa Gengo Bunka Kenkyuu, ILCAA, Tokyo University of Foreign Studies, nos. 48 \& 49, pp. 681-718.

Thurston, E. (1909) Castes and Tribes of Southern India, Madras: Government Press. 


\title{
CONSTRUCTING SPATIAL DATABASES FROM MAPS
}

\author{
A case in historical studies
}

\author{
Sadahiro Yukio
}

\section{Introduction}

The first step in using geographical information systems (GIS), in any application, is to obtain spatial data that are suitable for the user's purpose (see Chapter 1). Until recently, however, data acquisition was not easy using GIS for the following reasons: (1) the necessary spatial data were often unavailable; (2) spatial data were usually expensive to obtain; and (3) the construction of a spatial database took quite a long time. Fortunately, these problems are now being solved by the development of socio-economic spatial databases and by the progress in spatial data acquisition tools (Longley et al. 1999). Socio-economic spatial data are now provided by both public organizations and private companies and are widely available to GIS users at low cost. Remotely sensed data, which will be discussed in the next chapter, provides us with high-resolution images of the Earth's surface every day. Global positioning systems (GPS) and mobile GIS enable us to trace the movement of spatial objects. The cost of data acquisition is far less expensive today, and is no longer an impediment to many GIS applications.

At least, the above description holds for GIS applications that need only recent spatial data, that is, spatial data from 10 years ago up to the present, with spatial data from the present being the most readily available. Many fields using GIS belong to this category: geography, epidemiology, urban planning, and transportation science, etc. On the other hand, historical studies examine very old spatial phenomena and human behavior, and historical studies using GIS still suffer from difficulties in spatial data acquisition. This is for the following reasons: (1) spatial data from the past are often unavailable; (2) even paper maps may be unavailable; (3) even if paper maps do exist, they are often inaccurate and incomplete, so that it is quite difficult to overlay them on a common base map; and (4) the manual production of digital data from paper maps is still a time-consuming task. Though these problems are now gradually being solved, the difficulty in data acquisition, at present, is not yet an insignificant problem in historical studies using GIS. 
It is still challenging to use GIS in historical studies, but GIS provides considerable benefits in the visualization, analysis, and modeling of spatial phenomena from the past. This chapter outlines the general process of spatial data acquisition for researchers in historical studies who are interested in using GIS in their studies, and is followed by a more detailed discussion in the next chapter, showing an example of our experience in the discipline of Islamic Studies.

\section{Data format}

Spatial data are divided into two parts: locational data and attribute data. The term "locational data" refers to an element of GIS data that indicates the location of spatial objects; for example, an address, latitude and longitude, $\mathrm{X}-\mathrm{Y}$ coordinates, and so forth. "Attribute data" indicates information about spatial objects apart from their location. "Spatial data" refers to a combination of locational and attribute data. Spatial data are different from other data in that they have locational information. Table 3.1 shows an example of locational and attribute data.

The above definitions of terminology are rather formal, and do not necessarily reflect the general use of the term "spatial data." We usually do not make a strict distinction between the terms "spatial data" and "locational data," and often use "spatial data" to mean both. We adopt this general use in the following.

Spatial data are stored in GIS in either a raster or vector format (see also Chapter 1). Suppose spatial objects shown in Figure 3.1a. Vector data represent spatial objects by a chain of vertices and edges representing the boundary of spatial objects (Figure 3.1b). Raster data represent spatial objects by overlaying a lattice (usually a square or rectangular lattice), and assign attribute values to individual cells (Figure 3.1c). Satellite images are usually in the raster format.

Both the raster and vector formats are widely used in GIS. Generally speaking, the vector format is preferred in human and social sciences while the raster format is frequently used in the natural sciences. However, the choice of data format depends on the circumstances. If the shape of spatial objects needs to be described precisely, then the vector format is appropriate because, as shown in Figure 3.1c, the raster format makes the shape of spatial objects discrete. On the other hand, vector data require more complicated computational algorithms for

Table 3.1 Locational and attribute data

\begin{tabular}{|c|c|c|c|c|}
\hline \multicolumn{2}{|c|}{ Locational data ( $X-Y$ coordinates $)$} & \multicolumn{3}{|l|}{ Attribute data } \\
\hline$X$ & $Y$ & Store type & Phone number & Area $\left(m^{2}\right)$ \\
\hline 206.9 & 204.0 & Barber & $5841-6225$ & 38.6 \\
\hline 275.7 & 167.2 & Bookshop & $5841-6273$ & 54.4 \\
\hline 337.8 & 142.1 & Supermarket & $5841-8521$ & 1094.5 \\
\hline 148.4 & 111.7 & Bakery & $5803-2540$ & 61.1 \\
\hline 121.3 & 156.6 & Hotel & 5804-3000 & 675.7 \\
\hline
\end{tabular}


(a)

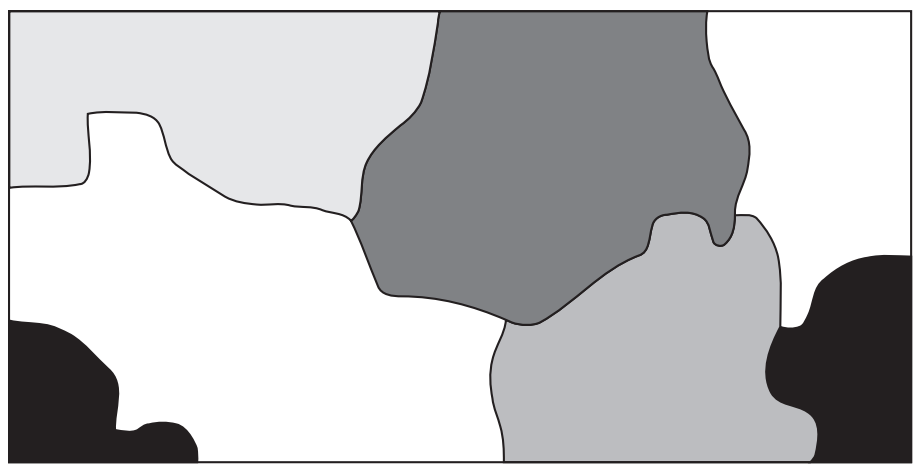

(b)

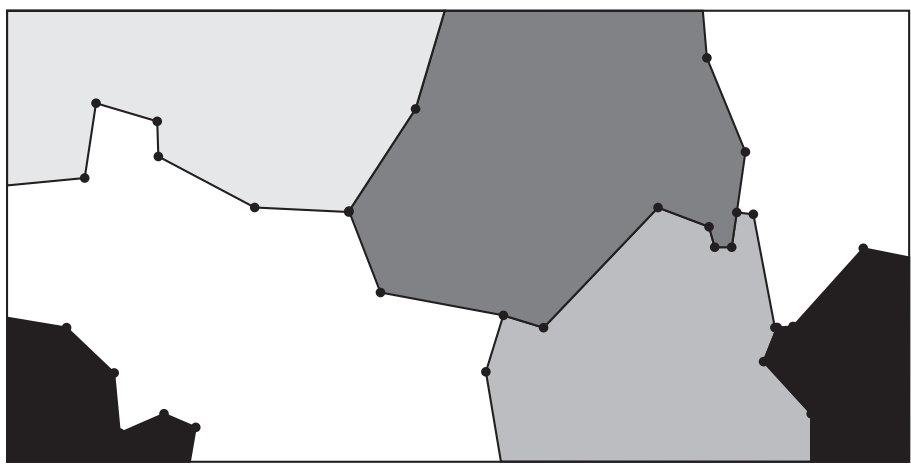

(c)

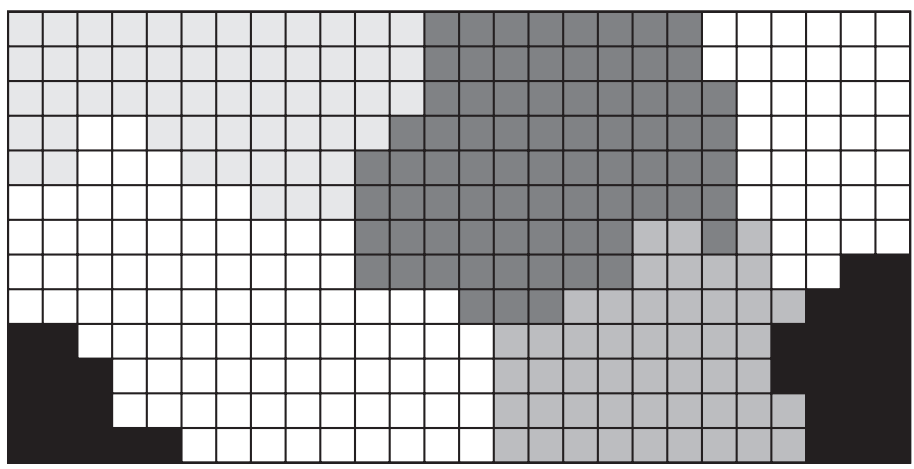

Figure 3.1 GIS data formats. (a) An original map; (b) vector data; and (c) raster data.

their construction, management, and analysis. Therefore, if the computer performance is not of a high level, then the raster format is the most desirable. Commercial GIS packages usually have their own specialties, whether in vector or raster format. 
We should also note that conversion from the vector to raster format is straightforward, while the reverse is very difficult, and practically impossible. Since there is no good computational algorithm of raster-to-vector conversion, the present method is to perform the conversion by hand rather than to use computational procedures, and this takes considerable time.

In our study, we used both raster and vector data. We created spatial data in vector format to represent villages, roads, and water systems etc., and the raster data were used to represent land use and land cover of the region studied. This chapter focuses on the acquisition and construction of vector data, as the acquisition of raster data will be discussed in Chapter 4 .

\section{Data acquisition}

There are two options available for obtaining spatial data: one is to buy or rent spatial data from public organizations or private companies, and the other is to construct one's own spatial database manually. The former is strongly recommended if the necessary spatial data are available and one can afford to buy them, because database construction is quite time-consuming as mentioned earlier. In the United States, one can search spatial data by consulting spatial data clearinghouses, which provide various information about available spatial data (http://www.fgdc.gov/clearinghouse/), and similar clearinghouses are located in Australia (http://www.csdc.gov.au/ icmisstrial.htm), and Japan (http://chouse.csis.u-tokyo.ac.jp/). Through these clearinghouses, we can search spatial data by content, keyword, data format, size, and time, etc. If we find the necessary data, then we can download them directly from the website, or send an e-mail asking whether they are open to the public, or whether they are sold on a commercial basis. Spatial data clearinghouses usually disclose information about the providers of their spatial data.

As mentioned in the introductory section, spatial data from the present that represent, for example, terrain elevation, water system, land use, land cover, and urban facilities are often the most readily available. They are all basic spatial components in either urban or rural area, and often included on one map. Such a map is called the base map, because we use it as the base on which we add the extra information necessary for our study. Though base maps represent the spatial phenomena of the present, they are also useful in historical studies because they can be used for estimating the spatial location of past objects, by comparing changes in their location, for example. Therefore, even in historical studies, it is desirable to obtain spatial data from the present as the base map, and these are often available at a reasonable cost.

In contrast, spatial data from the past are not readily available in digital format. They have to be created by the procedure shown in the next section.

If we obtain the necessary data, we may have to convert them into a different format because there are numerous formats for spatial data and a GIS package may not be able to read all spatial data formats. To convert the file format we can use other GIS or conversion packages. 


\section{Data creation}

If the necessary data were not available, then we would have to create them manually using GIS. This commonly happens in developing countries where even paper maps are often not available.

The process of creating spatial data in vector format usually consists of four steps: digitization, data correction, data merging, and joining attribute data. We outline these steps in the following sections. For details of each step, please consult a GIS textbook, for example, Star and Estes (1990), Laurini and Thompson (1992), Bonham-Carter (1994), Burrough and McDonnell (1998), or Longley et al. (1999).

\section{Digitization}

The first step of data creation is digitization. Paper maps or aerial photographs are digitized by a device called map digitizer, which is a large board with a mouse having four or sixteen buttons. We begin by placing a map on the board, and tracing its content using the mouse. The digitizer records the mouse location coordinates, and thus, the spatial objects on the map are represented in GIS digital format.

Recently, it has become possible to use image scanners and computer packages instead of a map digitizer. We read a map using an image scanner, and convert its image into digital format. The image on the computer display is then traced by a mouse. Figure 3.2 shows an example of an aerial photograph, and its spatial data created by digitization.

\section{Data correction}

Once a map is digitized, it is stored in a GIS digital format. The process of digitization, however, usually contains various errors, and so we usually have to correct for these in GIS (Figure 3.3).

1 Spatial objects that are not digitized: Even though a spatial object may exist on a map, we sometimes forget to digitize it for some reason or other. We can detect this type of error by comparing the data with the original map.

2 Extra spatial objects: In contrast, we may add an extra spatial object to the data. This often happens when we forget that we have digitized a spatial object, and then in error digitize the same object again.

3 Undershoots: Lines may not reach other lines as intended.

4 Overshoots: Lines may extend beyond the targeted location.

5 Polygons not closed: The presence of undershoots means that a polygon may not be closed and may therefore be recognized as a line rather than a polygon. (A polygon has to be bounded by a closed line.)

6 Sliver polygons (overlapping of polygons): If adjacent polygons are digitized separately, then they may overlap with each other. In this case, the small, elongated overlapping area is called a sliver polygon. 
(a)

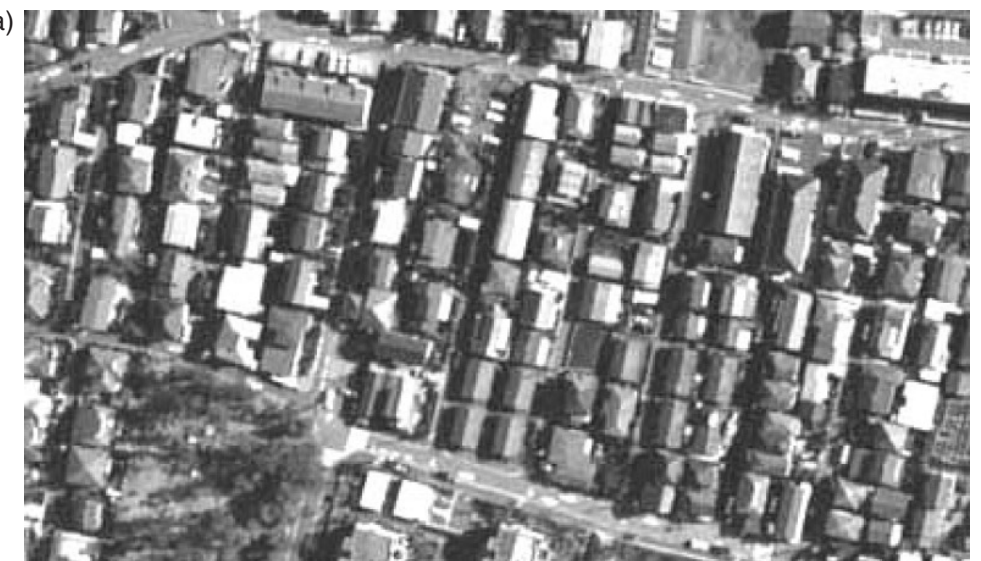

(b)

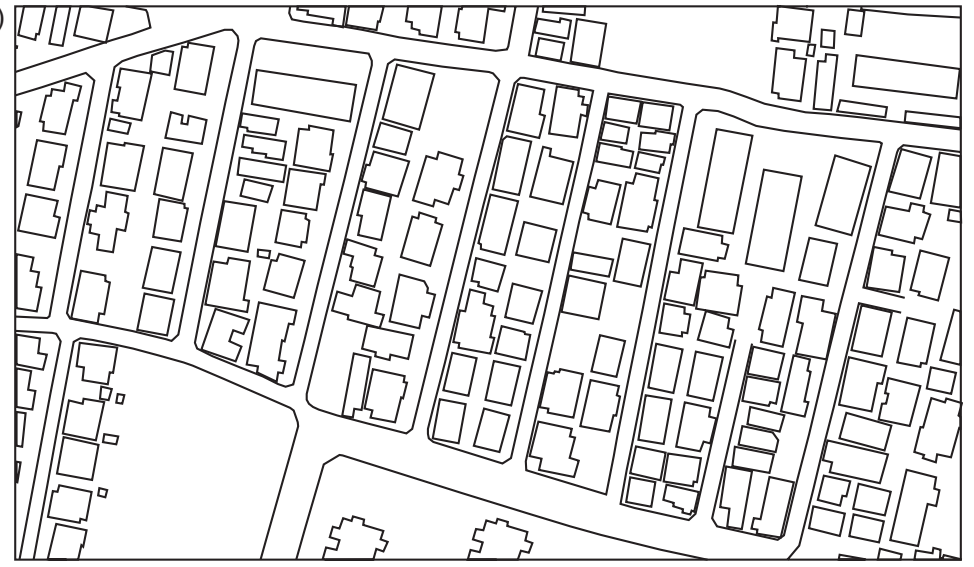

Figure 3.2 Digitization of an aerial photograph. (a) The aerial photograph and (b) the spatial data.

7 Gaps between polygons: If adjacent polygons are digitized separately, then a gap may appear between them.

We interactively correct for these errors in GIS, and recent GIS packages provide various functions that support interactive error correction.

\section{Data merging}

If the study area is small enough, we may obtain the whole spatial database by processing only one map. However, if the area spans more than one map, we have to digitize them separately and then merge the spatial data that are created. 
(a)

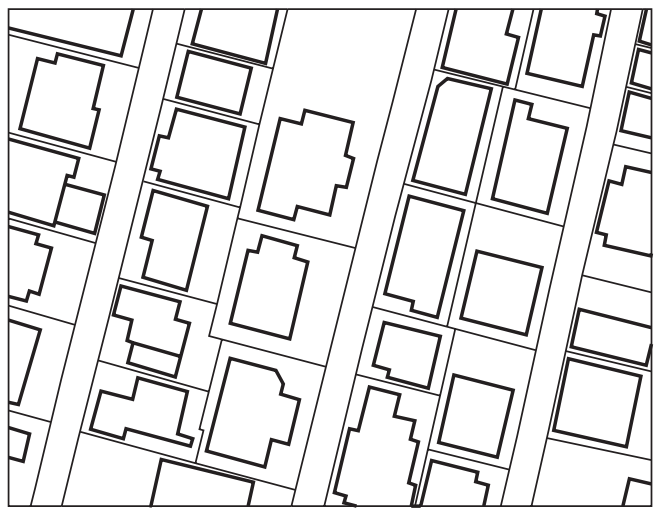

(b)

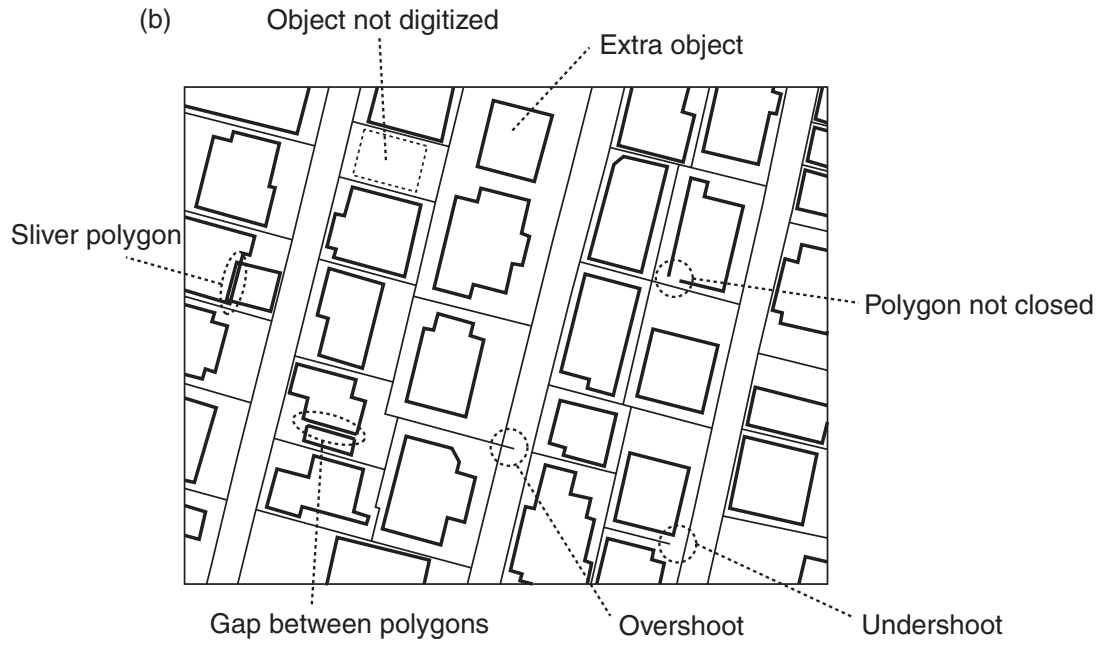

Figure 3.3 Digitization errors. (a) Original map and (b) data created by digitization.

GIS packages usually have functions that support data merging. For example, suppose that the two adjacent maps shown in Figure 3.4a are digitized separately, and that the errors inside individual maps have already been corrected. Joining the two maps, we obtain the result shown in Figure 3.4b, where several mismatches appear (indicated by the encircling broken lines). To correct these, we use a function called edgematching (Beard and Chrisman 1988; Sato et al. 2000), which transforms the maps so that they are consistent with each other at the map boundary. As shown in Figure 3.4c, lines cross the boundary smoothly after edgematching routines have been used.

Some GIS packages can automatically remove unwanted map boundaries by examining the attribute of spatial objects that cross the boundary. This function is sometimes called the fusion operation in GIS (Figure 3.4d). 
(a)
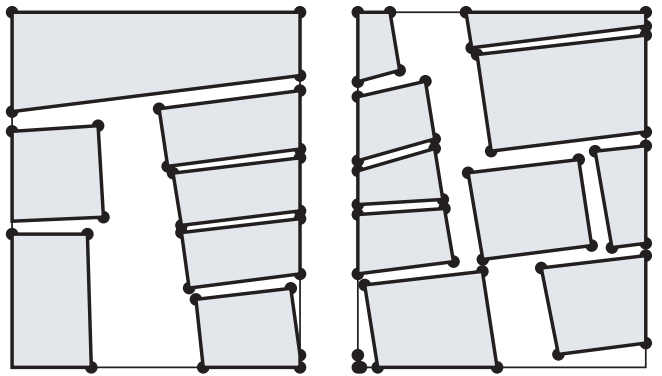

(b)

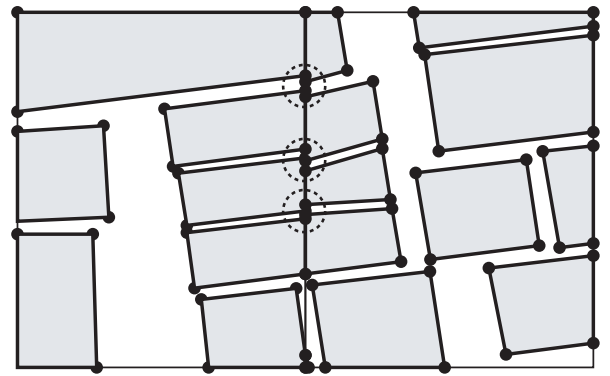

(c)

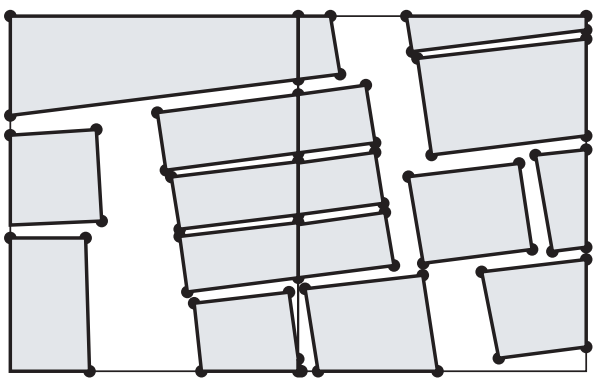

(d)

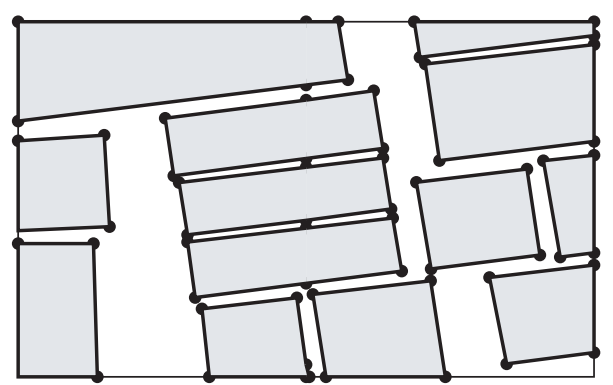

Figure 3.4 The data merging process. (a) Adjacent maps are digitized separately; (b) mismatches appear between the maps (encircled by broken lines); (c) the edgematching process; and (d) fusion of the maps. 


\section{Joining attribute data}

Having completed the data correction and merging operations, we finally join the spatial data with their corresponding attribute data.

Joining attribute data is begun by adding a common attribute shared by both spatial and attribute data. GIS packages use the attribute data to identify spatial objects using their attributes. In general, we use the identification number of spatial objects as their common attribute. A serial number serves this purpose, and this is automatically added by the GIS package for internal use (Figure 3.5a). If a different identification system is needed, we can define our own identification numbers and add them to the spatial objects (Figure 3.5b). These data are stored in a table-like format in the GIS package (Figure 3.5c).

(a)

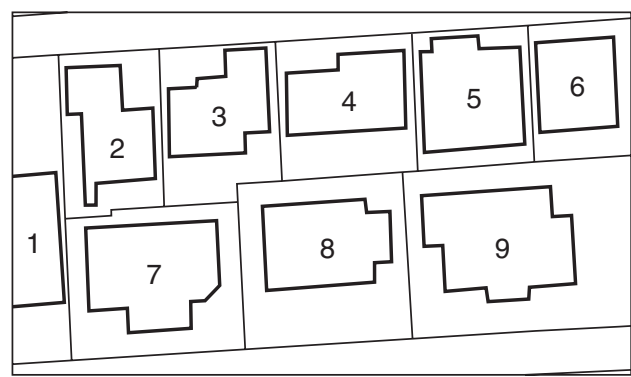

(b)

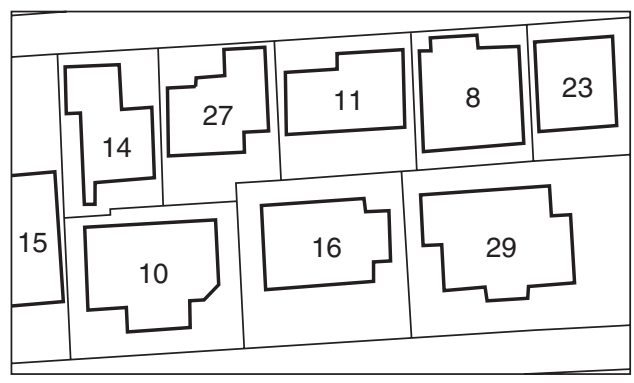

(c)

$\begin{array}{cc}\text { Internal ID } & \text { ID defined by user } \\ 1 & 15 \\ 2 & 14 \\ 3 & 27 \\ 4 & 11 \\ 5 & 8 \\ 6 & 23 \\ 7 & 10 \\ 8 & 16 \\ 9 & 29\end{array}$

Figure 3.5 Identification numbers. (a) Internal serial numbers; (b) identification numbers defined by the user; and (c) identification numbers stored in the GIS package. 
In addition to the identification number, other attributes, such as the address of houses and the name of house owners, can also be used as a common attribute. However, since character attributes are more likely to have typographical errors, numerical attributes are more desirable.

The common attribute is the key to joining spatial and attribute data. A GIS package reads the identification number of the first spatial object, looks up this number in the attribute data, and then joins the attributes to the spatial object (if the same identification number exists). Then, the GIS moves to the second spatial object and joins its attributes. This procedure is repeated for all the spatial objects in the generation of the complete spatial data (Table 3.2).

Table 3.2 Joining attribute data. (a) Spatial data; (b) attribute data; and (c) spatial data joined with the attribute data

\begin{tabular}{|c|c|c|c|}
\hline Internal ID & ID defined by user & Owner's name & Floor size \\
\hline \multicolumn{4}{|c|}{ (a) Spatial data } \\
\hline 1 & 15 & & \\
\hline 2 & 14 & & \\
\hline 3 & 27 & & \\
\hline 4 & 11 & & \\
\hline 5 & 8 & & \\
\hline 6 & 23 & & \\
\hline 7 & 10 & & \\
\hline 8 & 16 & & \\
\hline 9 & 29 & & \\
\hline \multicolumn{4}{|c|}{ (b) Attribute data } \\
\hline & 15 & Smith & 240.3 \\
\hline & 14 & Clark & 195.6 \\
\hline & 27 & Mayer & 212.4 \\
\hline & 11 & Hansen & 200.7 \\
\hline & 8 & MacDonald & 231.1 \\
\hline & 23 & Jones & 187.9 \\
\hline & 10 & Thompson & 242.4 \\
\hline & 16 & Fisher & 229.9 \\
\hline & 29 & Mark & 244.7 \\
\hline \multicolumn{4}{|c|}{ (c) Spatial data joined with attribute data } \\
\hline 1 & 15 & Smith & 240.3 \\
\hline 2 & 14 & Clark & 195.6 \\
\hline 3 & 27 & Mayer & 212.4 \\
\hline 4 & 11 & Hansen & 200.7 \\
\hline 5 & 8 & MacDonald & 231.1 \\
\hline 6 & 23 & Jones & 187.9 \\
\hline 7 & 10 & Thompson & 242.4 \\
\hline 8 & 16 & Fisher & 229.9 \\
\hline 9 & 29 & Mark & 244.7 \\
\hline
\end{tabular}


Attribute data should be prepared in either a table-like format, as used in spreadsheet packages such as Microsoft Excel and Lotus 1-2-3, or in a more database-friendly format such as CSV or dBASE. These are compatible with each other, and the conversion of data formats is straightforward.

Once the spatial data are completed, we can move on to the analysis and modeling of the spatial phenomena using GIS. Several examples are shown later on in this book. For details regarding general procedures of spatial analysis and modeling, see Bailey and Gatrell (1995), Openshaw and Openshaw (1997), and Lee and Wong (2001).

\section{Conclusion}

Database construction is always the first step in using GIS data. This step has prevented the widespread use of GIS, because of the limited availability of spatial data, and the lack of spatial data acquisition tools. Fortunately, these difficulties are now being resolved by the development of socio-economic spatial databases, and by progress in spatial data acquisition tools. This strongly promotes the use of GIS in various research fields, including historical studies.

The use of GIS improves the management of databases, helps in their interactive visualization, and enables quantitative analysis of spatial phenomena to be carried out. This applies not only to the natural sciences but also to human and social sciences. The use of GIS is strongly recommended for researchers who are concerned with spatial phenomena. GIS strongly supports visualization, analysis, and modeling of spatial phenomena.

\section{Acknowledgment}

The author is grateful to Okabe A., Mizushima T., Nagata J., Masuyama A., and Duan F.J. for fruitful discussions, and to an anonymous referee for valuable comments.

\section{References}

Aono, S. (2000) "Spatial structure of caste system in the late eighteenth century in Ponneri, India," unpublished graduation thesis, Department of Urban Engineering, University of Tokyo, Tokyo.

Bailey, T.C. and Gatrell, A.C. (1995) Interactive Spatial Data Analysis, London: Taylor \& Francis.

Beard, M.K. and Chrisman, N.R. (1988) “Zipper: a localized approach to edgematching," American Cartographer, 15, 163-172.

Bonham-Carter, G.F. (1994) Geographic Information Systems for Geoscientists, Tarrytown, New York: Pergamon.

Burrough, P.A. and McDonnell, R.A. (1998) Principles of Geographical Information Systems, New York: Oxford University Press. 


\section{SADAHIRO YUKIO}

Fuko, S. (2001) "Establishment of administrative system in the late eighteenth century in Ponneri, India," unpublished graduation thesis, Department of Urban Engineering, University of Tokyo, Tokyo.

Laurini, R. and Thompson, D. (1992) Fundamentals of Spatial Information Systems, London: Academic Press.

Lee, J. and Wong, D.W.S. (2001) Statistical Analysis with ArcView, New York: John Wiley. Longley, A., Goodchild, M.F., and Maguire, D.J. (1999) Geographic Information Systems: Principles, Techniques, Applications and Management, New York: John Wiley.

Mizushima, T. (2000) "Mirasi system as social grammar - state, local society, and Raiyat in the 18th-19th? South India," a report available on the website: http://www.1. u-tokyo.ac.jp/ zushima9/Archive/1-28.doc.

Openshaw, S. and Openshaw, C. (1997) Artificial Intelligence in Geography, Chichester: John Wiley.

Sato, T., Sadahiro, Y., and Okabe, A. (2000) "A computational procedure for joining separate map sheets," Geojournal, 52, 253-262.

Star, J. and Estes, J. (1990) Geographic Information Systems - An Introduction, Englewood Cliffs, NJ: Prentice Hall. 


\title{
AN EXPLORATORY METHOD FOR DISCOVERING QUALITATIVELY CHANGED AREAS USING LOW RESOLUTION REMOTELY SENSED DATA
}

\author{
A case in the Persian Gulf area during 1982-93
}

\author{
Okabe Atsuyuki and Masuyama Atsushi
}

\section{Introduction}

When carrying out geographical studies in the Islamic area, we often have difficulty in obtaining geographical data. For example, maps and statistical documents of the region are scarce, and even if they do exist, their quality is not always good. It is also sometimes forbidden to take maps out of a country; and foreign researchers cannot always gain easy access to the region. Under such difficult situations, a two-step approach is recommended. The first step is to conduct a preliminary investigation using easily available macroscopic data to find potential districts that are worth investigating in depth, and the second step, based on the first, is to carry out a full investigation using detailed geographical data obtained from fieldwork in that district. (The exploratory methods employed in the first step are proposed by Openshaw et al. 1987; Walker and Moore 1988; Monmonier 1989; Fotheringham and Zhan 1996; Unwin 1996; Openshaw et al. 1990; Fotheringham et al. 1998; Murray and Shyy 2000; and Okabe and Funamoto 2000). The objective of this chapter is to provide an example of how to conduct a first-step preliminary investigation in the Islamic area.

We wanted to analyze the land-cover change that had occurred in the area of the Persian Gulf (E40-50; N27-37; Figure 4.1) over a period of 10 years or so. However, we had difficulty in obtaining geographical data such as large-scale paper maps and local statistics. We also had difficulty in carrying out fieldwork owing to the international conflict that resulted in the Gulf War. Thus, as the first step, we decided to conduct a preliminary study to find potential districts where drastic land-cover changes may have occurred during the period 1982-93. 


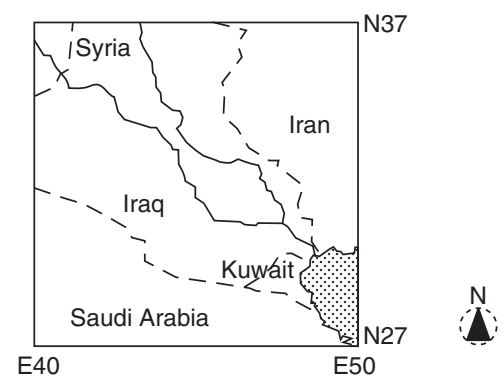

Figure 4.1 The study area (E40-50, N27-37; almost $\left.800 \times 800 \mathrm{~km}^{2}\right)$.

As mentioned in Chapter 1, when paper maps, tables, and documents are difficult to obtain, an alternative method is to use remotely sensed data. Remotely sensed data have several resolution (quality) levels, as shown in Table 1.1 in Chapter 1. We can use high-resolution data, but the cost of images covering an area as large as the Persian Gulf is very high. Since our study was a preliminary one, we used readily available low-resolution data.

However, low-resolution data contain ambiguities resulting from spatial aggregation. Ambiguity in geographical data is not restricted to low-resolution remotely sensed data, but may occur in many types of geographical data used in the humanities. For example, geographical data in historical maps and tables is often ambiguous, because legends and definitions of numerical values are often missing. When we analyze geographical phenomena with ambiguous data in the first, investigative step, qualitative methods assuming precise data are not always appropriate. Rather, qualitative methods that assume low-quality data are more appropriate. At present, these qualitative methods are less developed. In this chapter, we attempt to develop a qualitative method that is suitable for detecting land-cover change in the Persian Gulf when the data quality is low.

\section{Data sets}

We used the Pathfinder AVHRR Land data sets. These data sets are global land-surface data derived from the Advanced Very High Resolution Radiometers (AVHRR) located on the NOAA/TIROS operational meteorological satellites (Agbu and James 1994). These satellites provide a continuous daily and composite data set from July 1981 through to the present. The resolution of the images obtained from these satellites is $1100 \mathrm{~m}$ (Chapter 1), and the data were aggregated into square cells (pixels) with a $1^{\circ} \times 1^{\circ}$ size (approximately $8 \times 8 \mathrm{~km}^{2}$ ). This spatial aggregation increases the ambiguity.

The daily data set is likely to contain clouds that hide the land surface (see Figure 1.6 in Chapter 1). To remove clouds as much as possible from the data, the AVHRR data sets provide a composite data set derived from 10 daily data sets. Consequently, each month has three composites: the first composite is 
for days $1-10$, the second is for days $11-20$, and the final set is for the remaining days. This composite data set also increases the ambiguity.

To detect land-cover change, we use the Normalized Difference Vegetation Index (NDVI). This index is related to the proportion of photosynthetically absorbed radiation, and is defined by

$$
\frac{R_{2}-R_{1}}{R_{2}+R_{1}}
$$

where $R_{1}$ is the land-surface reflectance in the visible wavelength (Channel 1: $0.58-0.68$ micrometers), and $R_{2}$ is the land-surface reflectance in the reflective infrared wavelength (Channel 2: 0.725-1.1 micrometers) (see Chapter 1). The NDVI values in the study area are shown in Figure 4.2.

The principle behind this index is that Channel 1 is in a part of the spectrum where chlorophyll absorbs a considerable part of the incoming radiation, and Channel 2 is in a part where any spongy mesophyll leaf structure leads to considerable reflectance (Agbu and James 1994, pp. 2-3). Roughly speaking, this index shows a measure of the quantity of vegetation. In our analysis, we used monthly NDVI that were derived from the maximum NDVI among the three composites in one month. Consequently, our data sets consist of 144 images (12 months per year over 12 years) of the Persian Gulf area, and each image $\left(800 \times 800 \mathrm{~km}^{2}\right)$ contains 10000 cells (one cell is $\left.8 \times 8 \mathrm{~km}^{2}\right)$.

As mentioned above, the monthly NDVI data sets used in our study were of very coarse data; that is, the resolution was low, and the daily data sets were aggregated into monthly data sets. Moreover, the data quality was likely to vary over 12 years, because three satellites were used; that is, No. 7 launched in 1981, No. 9 launched in 1984, and No. 11 launched in 1988. Usually, remotely sensed data are confirmed by comparing the actual land cover (the ground truth data) at a number of points in the region. However, we did not do this, because it was difficult to obtain such data in the Persian Gulf. Although the monthly NDVI data have many limitations, we used them, because our study was preliminary, and the NDVI data sets were easy to obtain without charge via the Internet. The address is http://daac.gsfc.nasa.gov/CAMPAIGN_DOCS/FTP_SITE/readmes/pal.html.

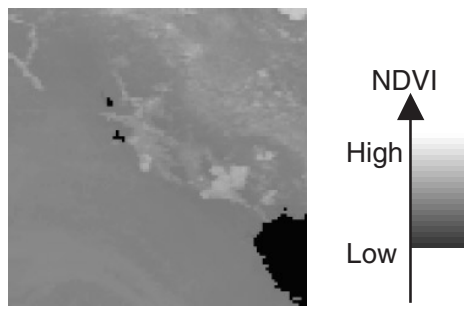

Figure 4.2 The NDVI values in the Persian Gulf area defined in Figure 4.1. 


\section{A method for finding qualitative land-cover changes}

Since the quality of our data was low, quantitative analysis was not always meaningful, as mentioned in the introduction. Hence, we developed a method to capture the qualitative characteristics of land-cover change during the period 1982-93.

Figure 4.3 shows an actual example of the monthly values of the NDVI of the cell located at N36.2, E49.8 during the year 1984. Owing to the nature of the data processing mentioned above, the actual day when the NDVI value was acquired is ambiguous. For example, the NDVI value in January may be the value on January 1, or it may be the value on January 31. For referential convenience, we call this variation the time-axis variation (horizontal axis variation). As our data has the time-axis variation, it is meaningless to distinguish the trend curve in panel (a) from that in panel (b).

Another ambiguity may result from deterioration in the sensors on the satellite. Hence, it is meaningless to distinguish the trend curve in panel (a) from that in panel (b) in Figure 4.4 where the sensitivity of the sensor used in panel (b)

(a) 0.576

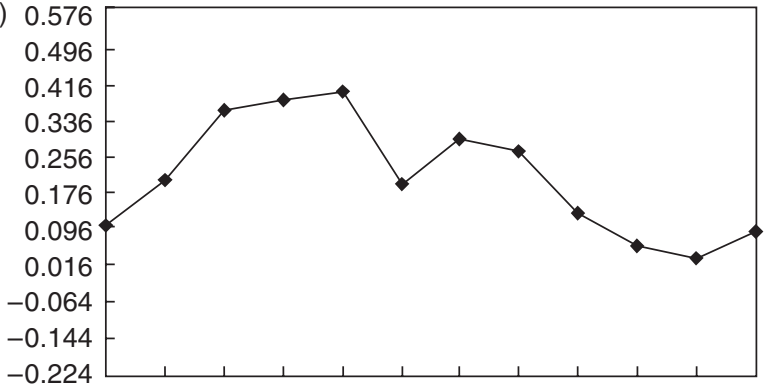

Jan Feb Mar Apr May Jun Jul Aug Sep Oct Nov Dec

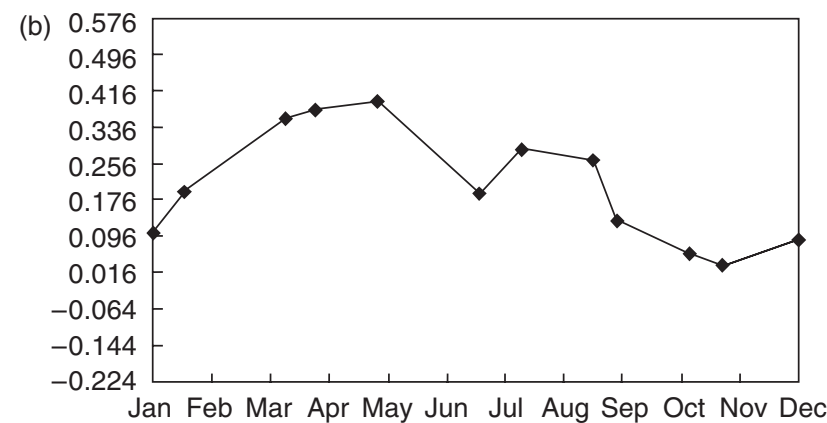

Figure 4.3 The monthly NDVI values of a cell located at N36.2, E49.8 over the year 1984. (Note that the day when the data were acquired in each month varies from month to month, and consequently, the curves in (a) and in (b) are indistinguishable.) 
(a)

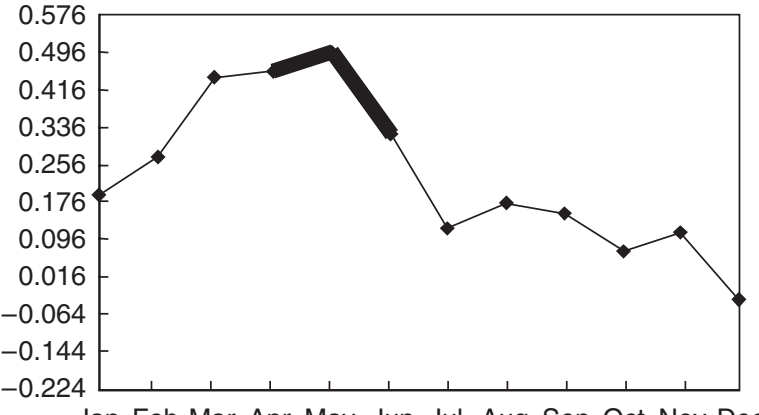

Jan Feb Mar Apr May Jun Jul Aug Sep Oct Nov Dec

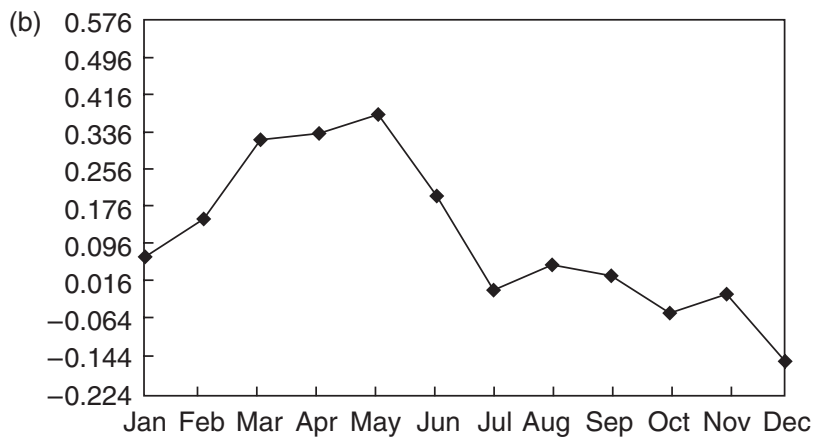

Figure 4.4 The NDVI trend curves obtained by two different sensors.

became lower than that of the sensor used in panel (a). We refer to this variation as the attribute-axis variation (vertical axis variation).

Since time-axis and attribute-axis variations exist in our data, we need to deal with characteristics that are independent of these variations. To define such qualitative characteristics, we first consider a local trend curve, $T_{i}$, defined by a curve formed by the values at month $i-1, i$, and $i+1$ (e.g. $T_{5}$ is indicated by the bold lines in Figure 4.4). We classify local trend curves into the three categories shown in Figure 4.5, and label them peaks, bottoms, and slopes, respectively. To state these terms mathematically, let $z_{i}$ be the NDVI value in month $i$, and let $C\left(T_{i}\right)=P, B, S$ be the local trend curve, $T_{i}$, being a peak, a bottom and a slope, respectively. Then, a peak, a bottom, and a slope are mathematically defined as:

$$
\begin{aligned}
& C\left(T_{i}\right)=P, \quad \text { if and only if, } \quad z_{i-1}<z_{i} \text { and } z_{i}>z_{i+1} \text { or } z_{1}>z_{2} \text { or } z_{n-1}<z_{12} ; \\
& C\left(T_{i}\right)=B, \quad \text { if and only if, } \quad z_{i-1}>z_{i} \text { and } z_{i}<z_{i+1} \text { or } z_{1}<z_{2} \text { or } \\
& C\left(T_{i}\right)=S, \quad \text { if and only if, } \quad z_{i-1}<z_{i 2}<z_{i+1} \text { or } z_{i-1}<z_{i}<z_{i+1} .
\end{aligned}
$$


(a)

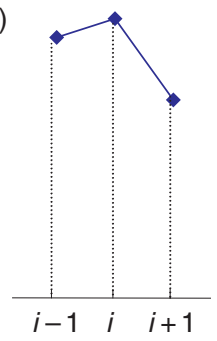

(b)

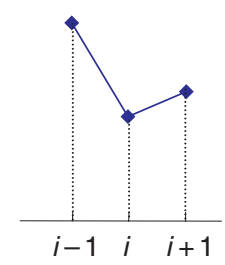

(c)

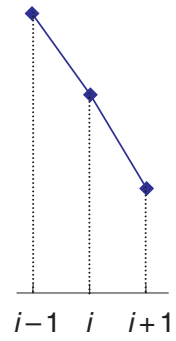

Figure 4.5 A peak, a bottom, and a slope.

In these terms, a sequence, $C(T)$, of the local characteristics of an annual trend curve

$$
T=\left(T_{1}, \ldots, T_{12}\right)
$$

is written as

$$
C(T)=\left(C\left(T_{1}\right), \ldots, C\left(T_{12}\right)\right) .
$$

For example, the sequence $C(T)$ of trend curve, $T$, in Figure 4.3 is given by

$$
C(T)=(B, S, S, S, P, B, S, S, S, B, P) \text {. }
$$

This sequence may represent a global characteristic of the annual trend curve, $T$. However, we notice that this representation contains redundant information, because slopes $(S, S)$ always exist between a peak $(P)$ and a bottom $(B)$. Moreover, the distinction between $(S)$ and $(S, S)$ is meaningless, because we are considering a property that does not change with a time-axis variation. Thus, $C(T)$ may be rewritten as $C^{*}(T)$, where slopes in $C(T)$ are eliminated. For example, $C(T)$ in Equation (7) can be written as

$$
C^{*}(T)=(B, P, B, P, B, P) .
$$

We call the property $C^{*}(T)$, the global characteristic of the annual trend curve $T$.

It should be noted that by definition, the global characteristic of an annual trend curve, $T$, is invariant against time-axis and attribute-axis variations. In this sense, the global characteristic $C^{*}(T)$, is qualitative. If the global characteristic $C^{*}\left(T^{a}\right)$ of an annual trend curve $T^{a}$ is the same as that of $C^{*}\left(T^{b}\right)$ of another annual trend curve, $T^{b}$, then

$$
C^{*}\left(T^{a}\right)=C^{*}\left(T^{b}\right),
$$

and we say that the annual trend curve $T^{a}$ is qualitatively similar to the annual trend curve, $T^{b}$. For example, the annual trend curves in panels (a) and (b) in Figures 4.3 and 4.4 are qualitatively similar. Trends $T^{a}$ and $T^{b}$ may be regarded as 
the annual trend curves, $T^{t}$ and $T^{t^{\prime}}$ in year $t$ and year $t^{\prime}\left(t<t^{\prime}\right)$, respectively. If $T^{t}$ and $T^{t^{\prime}}$ are not qualitatively similar, then we say that a qualitative change occurs during years $t$ and $t^{\prime}$.

We notice that the definitions of qualitative similarity and qualitative change in the above become arguable in the case of Figure 4.6. The annual trend curve, $T^{a}$, in panel (a) and that of $T^{b}$ in panel (b) are qualitatively similar by the above definition, but the two peaks in panel (a) look negligibly small. Small peaks may result from random variations, and these peaks may appear as a coincidence. To ignore such trifle peaks, we introduce the notion of peak "height." Suppose that a peak appears in month $i$, (e.g. June $(i=6)$ in Figure 4.6b), and consider the nearest bottom in months $1, \ldots, i-1$, and the nearest bottom in months $i+1, \ldots, 12$ from the peak (e.g. May and August in Figure 4.6b). Let $i^{*}$ and $i^{* *}$ be the months when these bottoms appear (e.g. $i^{*}=5$ and $i^{* *}=8$ in Figure 4.6b). We define the height, $h\left(T_{i}\right)$, of the peak in month $i$ (i.e. $C\left(T_{i}\right)=P$ ) by the minimum value among $z_{i^{*}}$ and $z_{i^{* *}}$ (Okabe and Masuda 1984); that is,

$h\left(T_{i}\right)=\min \left\{z_{i}-z_{i^{*}}, z_{i}-\mathrm{z}_{i^{*} *}\right\}$.
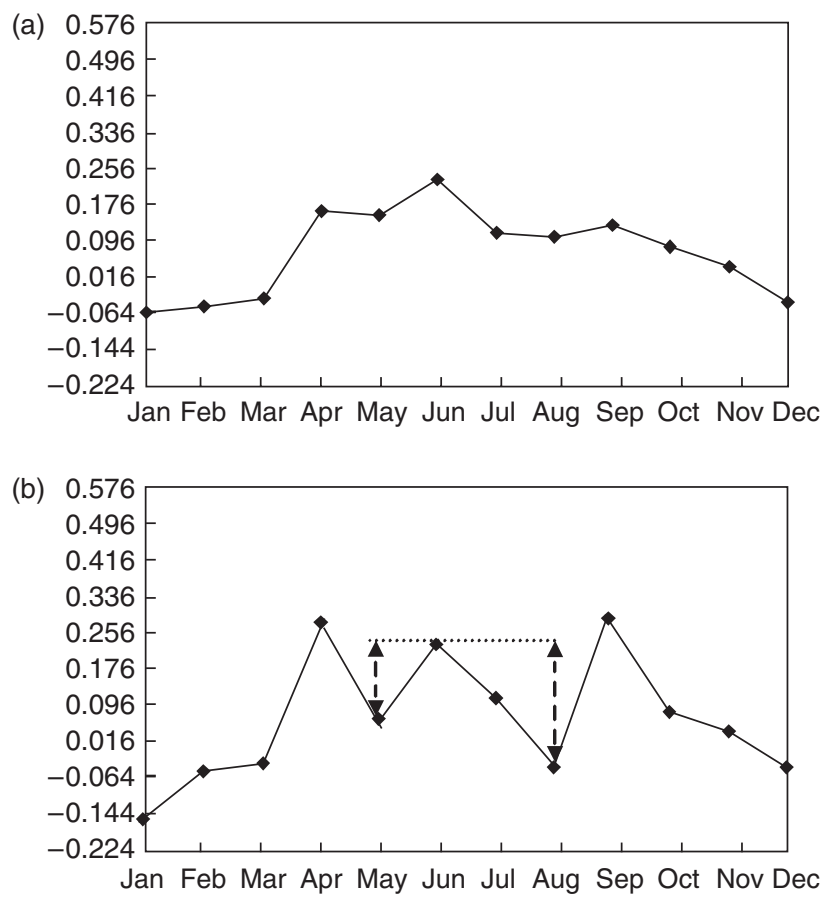

Figure 4.6 An annual trend curve with (a) one distinctive peak and two smaller peaks, and (b) an annual trend curve with three distinct peaks. 
Next, we order the peaks from the lowest to the highest values, and delete peaks from the lowest to the highest values one by one, as shown in Figure 4.7. Let $C^{*}(T \mid z)$ be the sequence in which peaks whose height is less than $z$ are deleted from $C^{*}(T)$ (note that $C^{*}(T)=C^{*}(T \mid 0)$ ). We call $C^{*}(T \mid z)$ the global characteristic of $T$ at level $z$. In the example shown in Figure 4.7, panel (a) shows $C^{*}(T \mid 0)$, panel (b) shows $C^{*}(T \mid 0.2)$ and panel (c) shows $C^{*}(T \mid 0.3)$. As can be observed in Figure 4.7, more distinctive peaks remain as the value of $z$ increases.
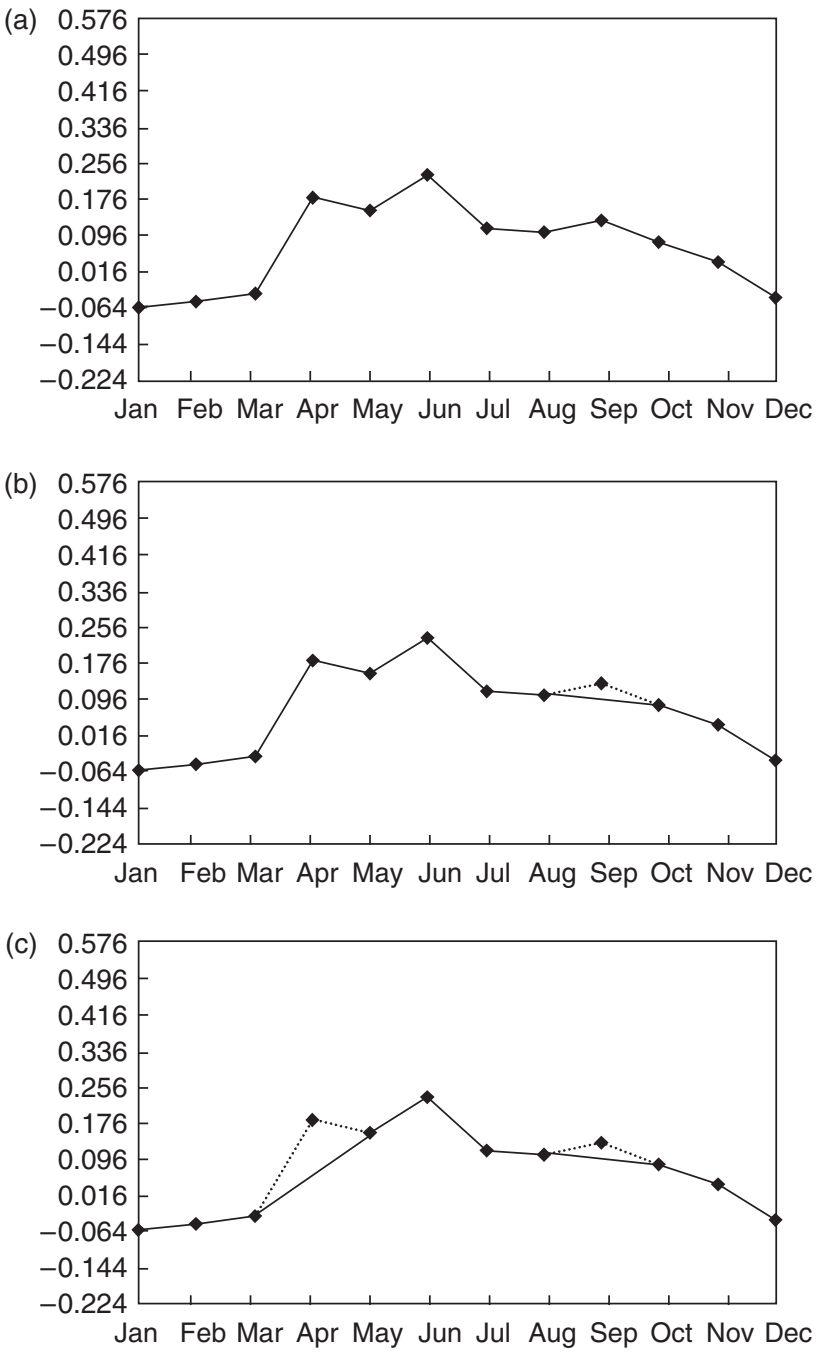

Figure 4.7 The global characteristics of an annual trend curve, $T$, with respect to level $z,(a),(b)$, and (c). 


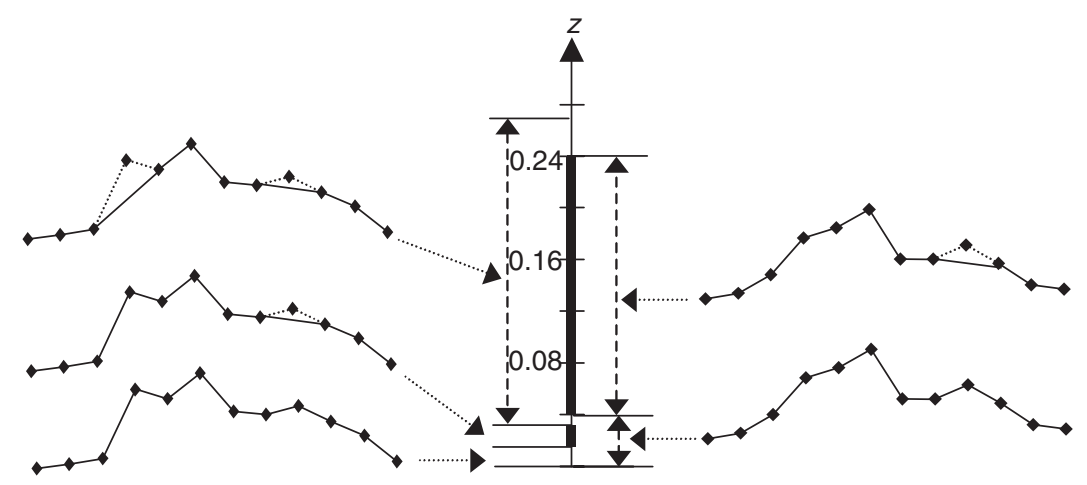

Figure 4.8 Overall qualitative similarity between two trend curves.

Having defined the height of a peak, our problem now is how to choose an appropriate value of $z$ for $C^{*}(T \mid z)$; that is, how high should a "distinct" (nontrivial) peak be. This choice is somewhat arbitrary, but we may choose a practical value, $z=a$, based on the distribution of peak heights for a given set of data. We shall show an actual example in the next section.

Although we may choose an appropriate value of $z=a$, we cannot completely exclude any arbitrariness. To avoid any arbitrariness, we propose a similarity index that is independent of the choice of $z$. An underlying idea of this index is that if the interval of $z$ in which two trend curves are similar is long, then the qualitative similarity is large. To formalize this idea, let $Z$ be the domain of a possible value of $z$; that is, $Z=\left\{z \mid 0 \leq z \leq z^{*}\right\}$ where $z^{*}$ is the maximum value, and let $Z\left(T^{a}, T^{b}\right)$ be the intervals in $\mathrm{Z}$ where two trend curves are qualitatively similar; that is, $C^{*}\left(T^{a} \mid z\right)=C^{*}\left(T^{b} \mid z\right)$ for $z$ in $Z\left(T^{a}, T^{b}\right)$. An example is shown in Figure 4.8, where $Z\left(T^{a}, T^{b}\right)$ is given by

$$
Z\left(T^{a}, T^{b}\right)=[0.016,0.032] \cup[0.048,0.24] .
$$

Let $\left|Z\left(T^{a}, T^{b}\right)\right|$ be the length of the intervals $Z\left(T^{a}, T^{b}\right)$, and $|Z|$ be the length of $Z$. We define the overall qualitative similarity index, $I$, by

$$
I=\frac{\left|Z\left(T^{a}, T^{b}\right)\right|}{|Z|} .
$$

In the example shown in Figure 4.8, $I=0.743$. Obviously, if two annual trend curves are completely the same for all $z$ in $Z$, then $I=1$. The value of $I$ will be in the range $0 \leq I \leq 1$.

\section{Analysis of qualitative change in land cover in the Persian Gulf area during 1982-93}

Having established the theoretical methods described in the preceding section, we now wish to apply those methods to the data shown in the Section "Data sets." 
First, to choose an appropriate value of $z$ in $C\left(T^{j} \mid z\right)$, we observe the distribution of the peak heights shown in Figure 4.9. The figure shows that the frequency of peaks whose height $=z$ rapidly decreases as $z$ increases. We consider that the curve bends steeply at $z=0.08$, and then fix $a=0.08$.

Given $a=0.08$, we classify the annual trend curves using the definition of qualitative similarity. To be explicit, every trend curve is classified into a category, such that:

(i) all annual trend curves in the same category are qualitatively similar;

(ii) any two trend curves in different categories are not qualitatively similar; and (iii) every category has at least two annual trend curves.

Using this classification method, we obtained three categories. The result is shown in Figure 4.10, where the three annual trend curves are typical curves in

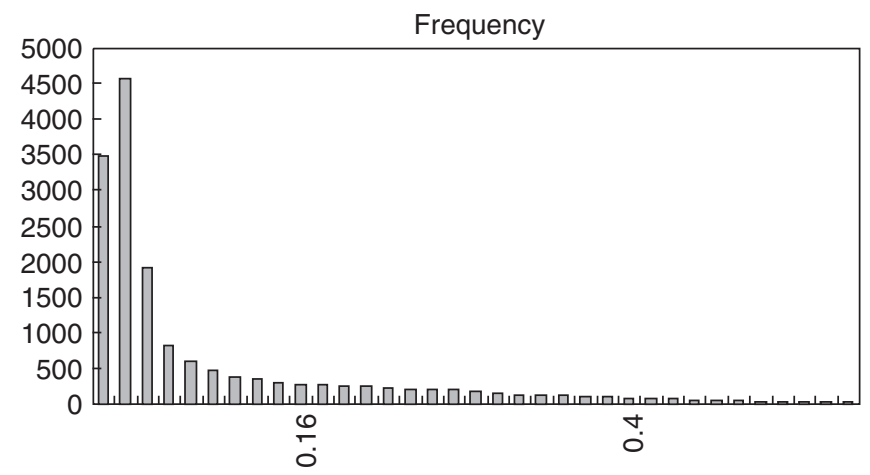

Figure 4.9 The distribution of peak heights.

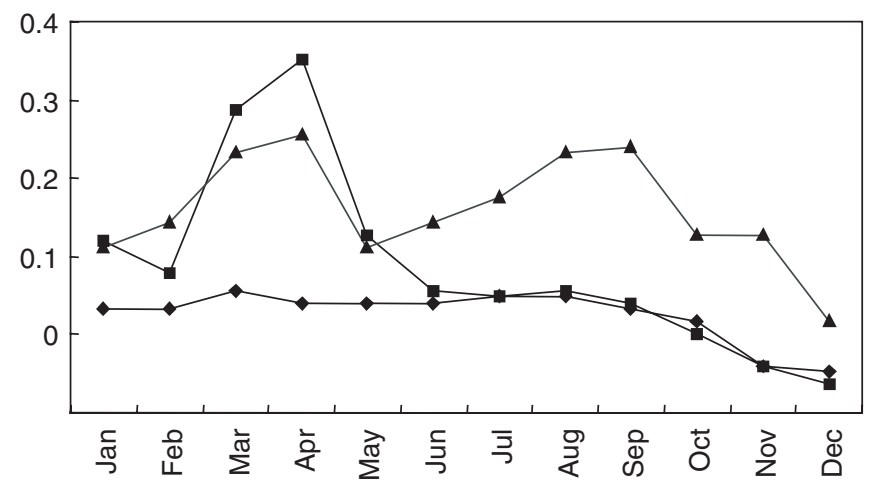

Figure 4.10 Three categories of NDVI annual trend curves. 


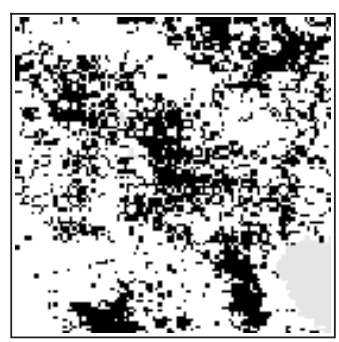

Figure 4.11 Qualitative change (level) in land cover in the Persian Gulf area between 1983 and 1993.

the three categories. The first category may correspond to single-cropping areas, the second category may correspond to double-cropping areas, and the third category may correspond to desert areas.

We may use these categories to see when and where qualitative change occurred in the Persian Gulf area between the two years $t$ and $t^{\prime}$ in 1982-93. If an annual trend curve at a cell in $t$, and that at the same cell in $t^{\prime}$ belong to the same category, then we may say that a qualitative change in land cover did not occur at the cell during years $t$ and $t^{\prime}$. Otherwise, a qualitative change occurred. As an example, we show the qualitative change in land cover between years 1982 and 1993 in Figure 4.11.

As mentioned before, since $z=0.08$ is a somewhat arbitrary choice, we can alternatively use the overall similarity index $I$, as defined by equation (12). Figure 4.12 shows the overall similarity index at every cell in the Persian Gulf area between years $t$ and $t+1$, where $t=1982, \ldots, 1993$. The brightness of the gray color indicates the magnitude of the overall qualitative similarity between years $t$ and $t+1$. As the brightness darkens, the overall qualitative similarity change becomes larger.

Having found the qualitative changes in Figure 4.12, we considered the possible factors that could have brought about these changes using any easily available information on this area. The primary factor is precipitation. The Monthly Climatic Data for the World (1982-93) shows that the Persian Gulf area had a distinctively high rainfall during 1987-88, and a distinctively low rainfall during 1988-89. These phenomena may correspond to the fact that the brightness of panels (f) and ( $g$ ) is relatively darker than that of the other panels. The agricultural census says that the production of barley increased characteristically during 1987-88, and decreased significantly during 1988-89. These phenomena may also correspond to the facts mentioned above regarding panels (f) and (g).

In addition to using easily available data, we also consulted a specialist in the Persian Gulf area, Ms Sakai (1998), to canvas her comments on the qualitative changes shown in Figure 4.10. She pointed out that the northwest area in panels (f) and (g) was an area where barely was cultivated without any irrigation 
(a)

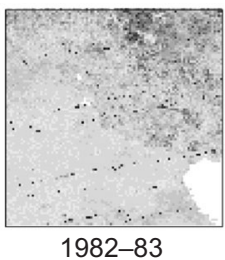

(e)

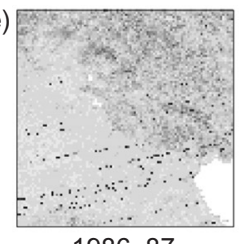

$1986-87$

(i)

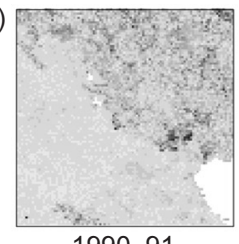

(b)
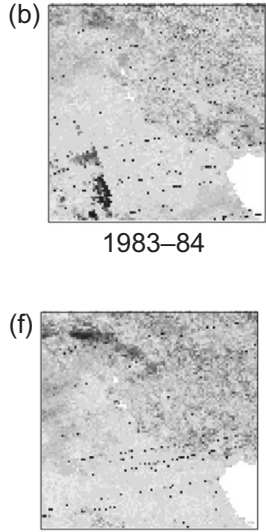

1987-88

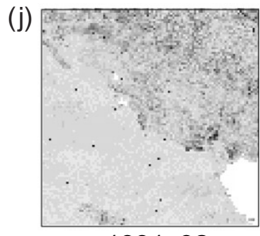

$1991-92$
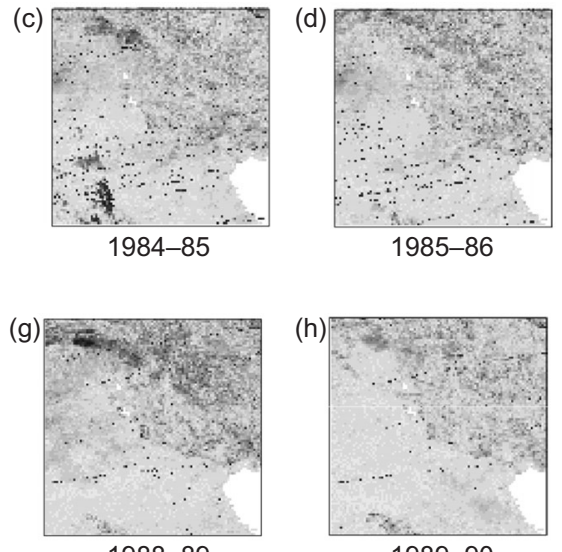

$1988-89$

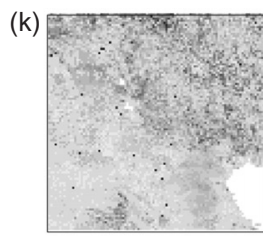

1992-93

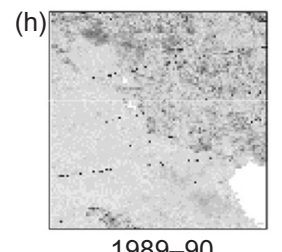

$1989-90$

Figure 4.12 Overall qualitative change in land cover in the Persian Gulf area between years $t$ and $t+1$, where $t=1982, \ldots, 1983$.

systems, but the south of that area had good irrigation systems. It is interesting to notice that the qualitative change in the southern area was small. She also commented that the dark gray pixels in the southwest corner of panels (b), (c), and (h) may correspond to the self-sufficiency policy of Saudi Arabia instigated in the 1980s. It has been reported that the barley yield increased by 20 times at the end of 1994.

\section{Concluding remarks}

This chapter describes a method of conducting a preliminary study on land-cover change using readily available coarse remotely sensed data. The proposed method detects qualitative changes in land cover, even when the quality of data is low. We applied this method to the Persian Gulf area, but the method is also applicable to any area in the world, because Pathfinder AVHRR Land data sets are available for almost every area of the world.

Although the proposed method is useful, we should note a limitation of this method. As mentioned in the introduction, the objective of the proposed method is to provide a tool for detecting potential areas that may be worth investigating in depth. For example, the objective of the study shown in the previous section is 
not to provide a complete study on the land-cover change in the Persian Gulf area, but to suggest that there seems to be drastic land-cover change in the dark-colored districts shown in Figure 4.10, and so a full investigation in those districts would reveal interesting phenomena.

We hope that the proposed method provides a means for finding interesting districts to study in the Islamic area.

\section{Acknowledgments}

We express our thanks to Sakai K., Shibasaki Y., Sadahiro Y., and an anonymous referee for their valuable comments on an earlier draft.

\section{References}

Agbu, P.A. and James, M.E. (1994) The NOAA/NASA Pathfinder AVHRR Land Data Set Users Manual, Goddard Distributed Active Archive Center, NASA, Goddard Space Flight Center, Greenbelt.

Fotheringham, A.S., Charlton, M.E., and Brunsdon, C. (1998) "Geographically weighted regression: a natural evolution of the expansion method for spatial data analysis," Environment and Planning A, 30, 1905-20.

Fotheringham, A.S. and Zhan, F.B. (1996) "A comparison of three exploratory methods for cluster detection in spatial point pattern," Geographical Analysis, 28(3), 200-218.

Murray, A.T. and Shyy, T.-K. (2000) "Integrating attribute and space characteristics in choropleth display and spatial data mining," International Journal of Geographical Information Science, 14(7), 649-667.

Monmonier, M. (1989) "Geographic brushing: enhancing exploratory analysis of the scatterplot matrix," Geographical Analysis, 21(1), 81-84.

Okabe, A. and Funamoto, S. (2000) "An exploratory method for detecting multi-level clumps in the distribution of points - a computational tool, VCM (Variable Clumping Method)," Journal of Geographical Systems, 2, 111-120.

Okabe, A. and Masuda, S. (1984) "Qualitative analysis of two-dimensional urban population distributions in Japan,” Geographical Analysis, 16(4), 301-312.

Openshaw, S., Charlton, M., Wymer, C., and Craft, A. (1987) "A Mark 1 geographical analysis machine for the automated analysis of point data sets," International Journal of Geographical Information Systems, 1(4), 335-358.

Openshaw, S., Cross, A., and Charlton, M. (1990) "Building a prototype geographical correlates exploration machine," International Journal of Geographical Information Systems, 4(3), 297-311.

Unwin, A. (1996) "Exploring spatio-temporal data," in Fisher, M., Scholten, H.J., and Unwin, D. (eds) Spatial Analytical Perspectives on GIS, London: Taylor and Francis, pp. 101-109.

Walker, P.A. and Moore, D.M. (1988), "SIMPLE: an inductive modelling and mapping tool for spatially-oriented data," International Journal of Geographical Information Systems, 2(4), 347-367. 


\title{
ESTIMATING LAND USE USING HIGH RESOLUTION REMOTELY SENSED DATA (LANDSAT TM)
}

\author{
A case study in Ponneri, India
}

\author{
Duan Feng Jun
}

\begin{abstract}
Introduction
Land-use maps are fundamental to Islamic Area Studies. In developed western countries, land-use maps are available in the form of paper maps as well as digital maps, but in many Islamic areas, even paper maps are unavailable. In such a case, as mentioned in Chapter 1, we can estimate land use using remotely sensed data. Actually, Chapter 4 demonstrates a method of how to estimate preliminary land use (cover) using coarse (low resolution) remotely sensed data, NDVI of NOAA-AVHRR (also see Takeishi 1995). However, land-use maps estimated by such coarse data are insufficient for local area studies. In this Chapter, we demonstrate a typical method for estimating land use using the Landsat Thematic Mapper (TM) data, which have a higher spatial resolution.
\end{abstract}

\section{Study area and raw data}

The study area, Ponneri, is located to the north of the city of Madras, on the eastern coastal plain of southern India, and west of the Bay of Bengal. Its latitude is between $13^{\circ} 10^{\prime}$ and $13^{\circ} 35^{\prime}$ north, and longitude between $79^{\circ} 55^{\prime}$ and $80^{\circ} 21^{\prime}$ east. It has a very low relief of no more than $100 \mathrm{~m}$ from the beach to the east to the hills in the west. The climate of the area is a tropical monsoon climate. According to earlier researches (e.g. Ramasamy 1991), the study area belongs to the proto-Cauvery delta. Therefore, there are plenty of natural tanks in the area, which consist of irrigation resources together with wells. Ponneri is an agricultural area and has no large city within its boundaries.

The raw data analyzed in this study were taken from Landsat TM data, which has a ground resolution of about $30 \mathrm{~m}$. One set of the data consisted of seven 
ESTIMATING LAND USE USING REMOTELY SENSED DATA

Table 5.1 The Landsat Thematic Mapper spectral bands

\begin{tabular}{lll}
\hline Band & Wavelength $(\mu \mathrm{m})$ & Nominal spectral location \\
\hline 1 & $0.45-0.52$ & Blue \\
2 & $0.52-0.60$ & Green \\
3 & $0.63-0.69$ & Red \\
4 & $0.76-0.90$ & Near infrared \\
5 & $1.55-1.75$ & Mid-infrared \\
6 & $10.4-12.5$ & Thermal infrared \\
7 & $2.08-2.35$ & Mid-infrared \\
\hline
\end{tabular}

bands from the visible to the thermal infrared region (Table 5.1). The raw data were geocoded and cut for further analysis.

\section{Analysis methods}

The main method used in this study was time-series analysis, which determined the land-use type according to the seasonal changes in land cover, aided by use of GIS. Based on the local climatic conditions and crop season features, we selected three sets of Landsat TM data for analysis, dated on February 14, 1997, May 18, 1996, and August 25, 1997, respectively. Careful attention was paid to choosing cloud-free data sets, because some radiation in parts of the spectrum used by the Landsat TM sensors cannot pass through cloud cover, and thus satellite images may be of cloud tops rather than of the Earth's surface.

\section{Unsupervised classification}

To estimate land use, the remotely sensed data were initially assigned to corresponding levels with respect to groups having homogeneous characteristics. This part of the remote sensing data processing method is called classification, and is performed as definition of classes, determination of decision rules, and classification using mathematical techniques (Burrough 1986; Japan Association on Remote Sensing 1996). There are two types of classification, depending on the method used to determine the decision rules. One is called supervised classification, in which the decision rules are determined through sampling of the training data from clearly identified training areas. Accurate and detailed survey data are necessary for this method. The other is called unsupervised classification, for which the decision rules are determined through analyzing the characteristics of the image. This latter method is appropriate for our study, because there was not much information about the study area.

The three sets of raw data were loaded into ERDAS IMAGINE, a classification software package. Each data set was classified into 40 classes using the unsupervised classification technique and using the maximum likelihood estimation function, as provided by the software. 


\section{DUAN FENG JUN}

\section{Signature analysis}

The Landsat TM data are records of the reflected solar radiation from the land surface. Thus, the value of each pixel shows the reflectance of the corresponding land area. However, different land surfaces reflect different proportions of the solar radiation falling upon them in different spectral bands (Townshend 1981). Therefore, from the analysis of the values of multi-bands for a pixel, the land surface type of the corresponding area can be distinguished. Depending on the regional conditions, the reflection features of three typical land surfaces were used as reference indexes in this study: water (absorbs almost all wavelengths), vegetation (has a weak reflection peak in the green, a strong reflection in the near infrared, and absorbs in the blue and red), and bare soil (shows a steadily increasing reflection with increasing wavelength).

On analysis, the signatures of the obtained 40 classes of each data set were divided into six groups according to the reflection features of seven satellite bands. Figures 5.1, 5.2, and 5.3 show the clustering results for February, May, and
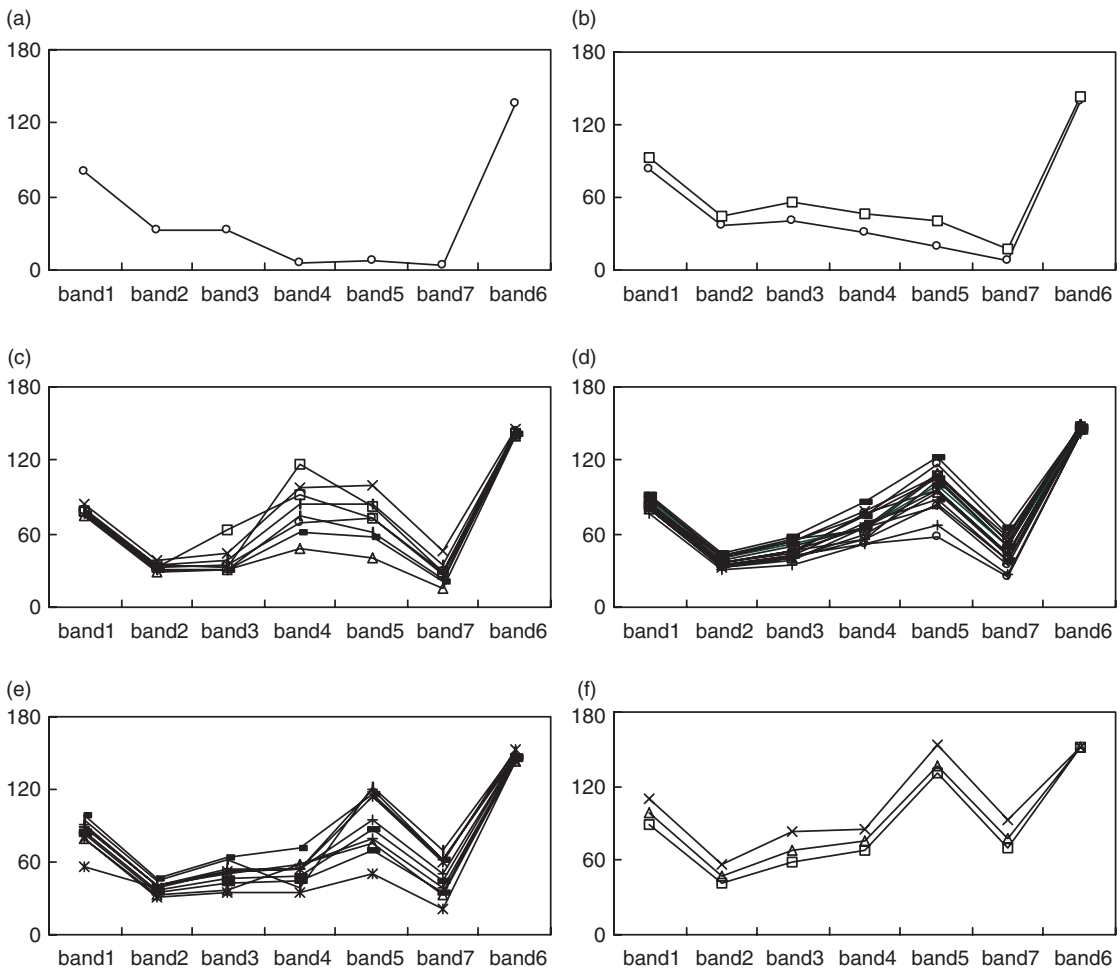

Figure 5.1 Spectral features of the data classes on February 14, 1997. (The X-and Y-axes indicate the bands of TM sensor and reflectance on each band, respectively. Each line represents an unsupervised classified class. The same specification applies for Figures 5.2 and 5.3.) 

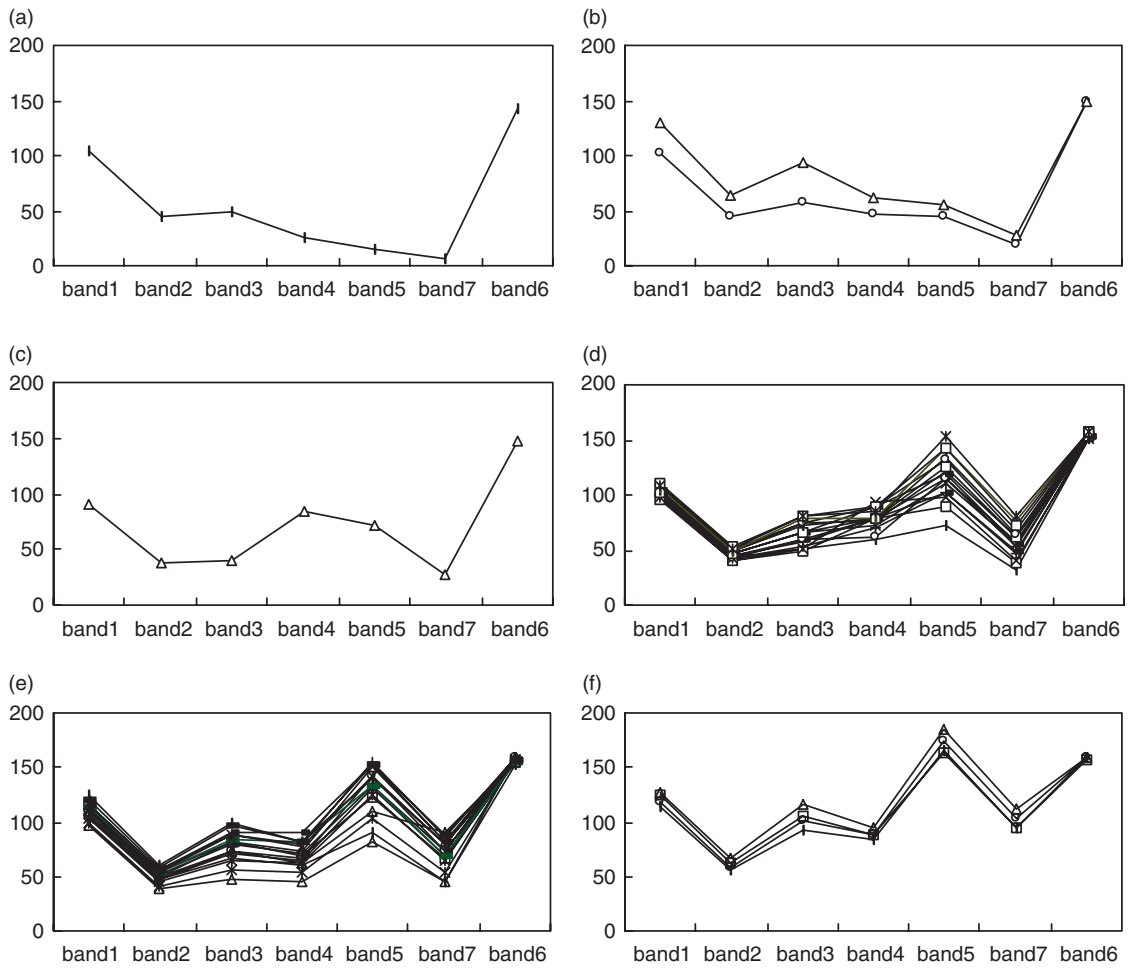

Figure 5.2 Spectral features of the data classes on May 18, 1996.

August, respectively. Group 1 (Figures 5.1a, 5.2a, and 5.3a) shows almost the same reflectance pattern as water, and so the land-cover type of the corresponding area is probably water. Group 2 (Figures $5.1 \mathrm{~b}, 5.2 \mathrm{~b}$, and $5.3 \mathrm{~b}$ ) shows a similar reflectance pattern as Group 1, but has a weak peak that can be seen in bands 3 and 4 . This is a feature of vegetation, and so the land cover in this area is probably wetland with vegetation. Group 3 (Figures 5.1c, 5.2c, and 5.3c) shows an obvious reflectance peak in band 4 . Referring to local information, we can deduce that the land cover of this group is probably wood and/or scrub. The high reflectance value in band 5 can be considered to be influenced by bare soil among the trees, because the forests in the study area are not dense natural forests. Group 4 (Figures 5.1d, 5.2d, and 5.3d), Group 5 (Figures 5.1e, 5.2e, and 5.3e), and Group 6 (Figures 5.1f, 5.2f, and 5.3f) show similar reflectance patterns, which have increasing reflectance values with increasing wavelength. That is a feature of bare soil. However, Group 4 has a relatively high reflectance value in band 4, which indicates the existence of weak vegetation. Therefore, the land-cover type of Group 4 is probably grassland. At the same time, Group 5 has relative low reflectance values in bands 4 and 7 , which means that the land-cover 

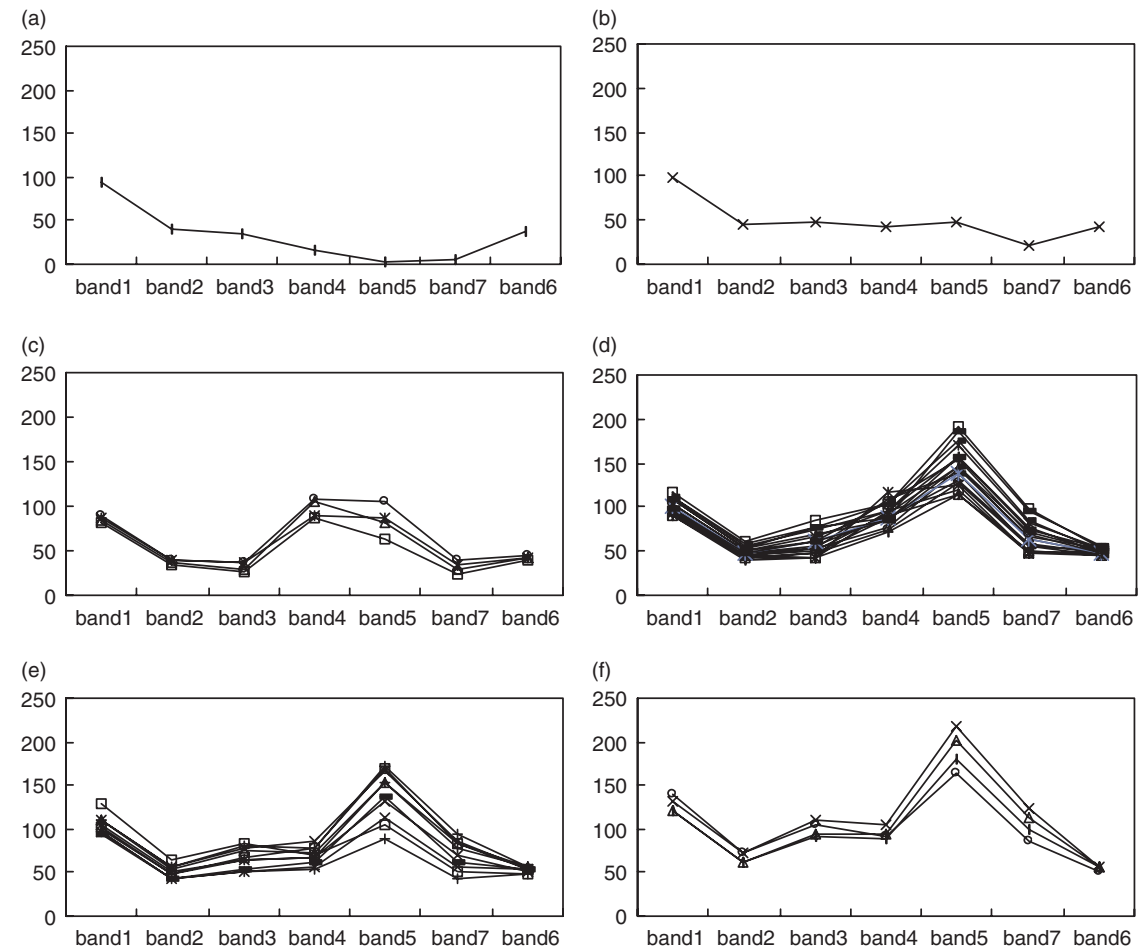

Figure 5.3 Spectral features of the data classes on August 25, 1997.

type is probably either wet soil or wetland without any vegetation. The land-cover type of Group 6 is probably dry soil or bare land.

Through the above analyses, we obtained three sets of land-cover data for the study area during different seasons (Figure 5.4). Each data set contained six types of land cover: water, wetland with vegetation, forests, grassland, wetland without vegetation, and bare land.

\section{Data combination}

In order to perform time-series analyses, we need to combine the three sets of land-cover data into one data set. We use a GIS method named overlay to carry out this combination. The method is illustrated in Figure 5.5. It is mainly used to benefit regional evaluation by combining various influence factors having various weights. Here, we use it to create a time-series code for each pixel. First, we code each pixel in each land-cover data set with a value from 1 to 6 , representing water, wetland with vegetation, wood and/or scrub, grassland, wetland without vegetation and bare land, respectively. Then, we assign a weighting of 100 to the 
(a)

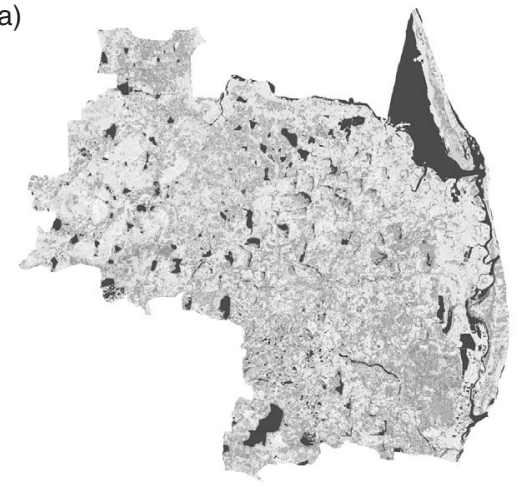

(c)

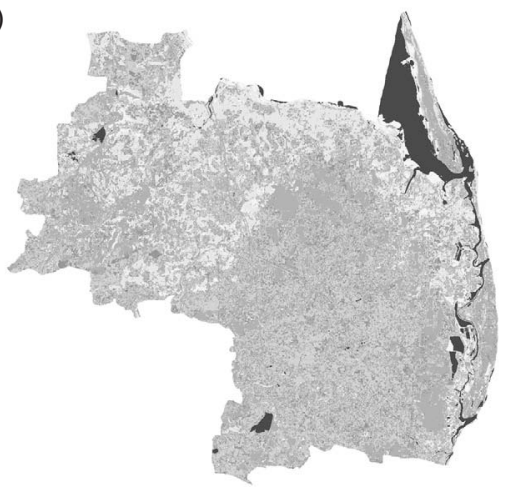

(b)

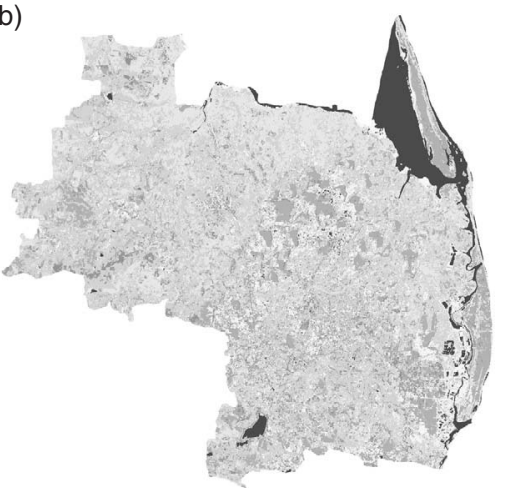

\begin{tabular}{l}
\hline \multicolumn{1}{c}{ Legend } \\
\hline Class_Name \\
Water \\
Wetland with vegetation \\
Wood/Scrub \\
Grass \\
Wetland without vegetation \\
Bare land
\end{tabular}

Figure 5.4 The types of land cover in Ponneri.

February data set, a weighting of 10 to the May data set, and a weighting of 1 to the August data set, and then we perform the following overlay.

$$
\text { Union layer }=\text { Layer_Feb } * 100+\text { Layer_May } * 10+\text { Layer_Aug } * 1 \text {. }
$$

After combination, we obtain a new layer in which each pixel contains a code consisting of three numbers. The first number indicates the land-cover type in February, the second indicates that of May, and the third indicates that of August. We call the code a time-series code, because it indicates the seasonal change of land cover for each pixel. The total number of time-series codes is 216 .

\section{Time-series analysis}

There are 98 codes that can be ignored, which has a negligible effect, as the number of pixels that contains these codes is less than $0.1 \%$ of the total pixel 
DUAN FENG JUN

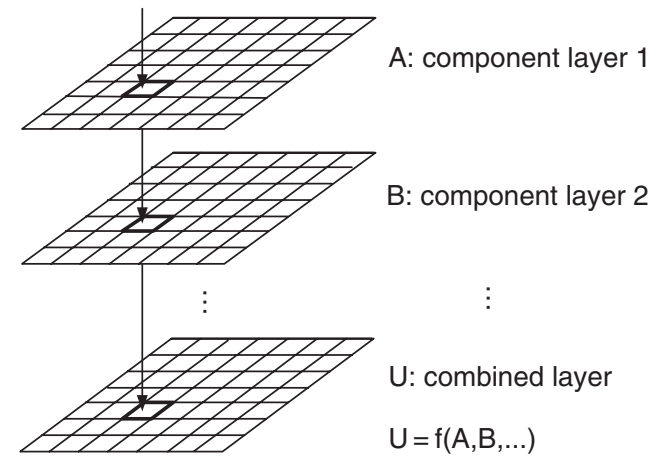

Figure 5.5 The overlay operation.

number. The remaining 118 codes are analyzed according to the local climate and crop season features.

As mentioned above, the climate condition of the study area is of the tropical monsoon type. The rainy season is from August to December, and the precipitation is concentrated in the months of October and November. The temperature is higher during March to September and lower during October to February. Based on the climate, there are three crop seasons in the area. During Sornavari (the dry season from April to July), the hot and dry conditions limit crops to areas with good irrigation facilities. During Samba (the hot wet season from August to November), the heat and water conditions allow all of the cultivated areas to be sown. The conditions in Navarai (the cold wet season from December to March) are somewhere between that of Sornavari and Samba, and thus, some of the cultivated areas can be sown, while others will be left as bare soil.

The three data sets used in this study belong to the late Navarai period (February 14), the early Sornavari period (May 18), and the beginning of Samba (August 25), respectively. Therefore, the regional land use can be estimated though the changing patterns of land cover. Here, another remote-sensing data set, IRS-1C panchromatic data dated on January 14, 1998, was used as reference data for performing the analysis. The IRS- $1 \mathrm{C}$ panchromatic data is single-band remote-sensing data with a ground resolution of about $5 \mathrm{~m}$. Therefore the landuse status can be determined by visual interpretation through texture analysis. We analyzed the samples for time-series codes that indicate the change patterns of land cover, and clustered them into eight land-use types (see Figure 5.6). The sample ratios are $1 / 10$ and $1 / 100$ for minority and majority respectively. At the meanwhile, we got the typical seasonal land-cover change patterns for every landuse types for the study area. These land-use types and typical seasonal land-cover change patterns are summarized in Table 5.2. 


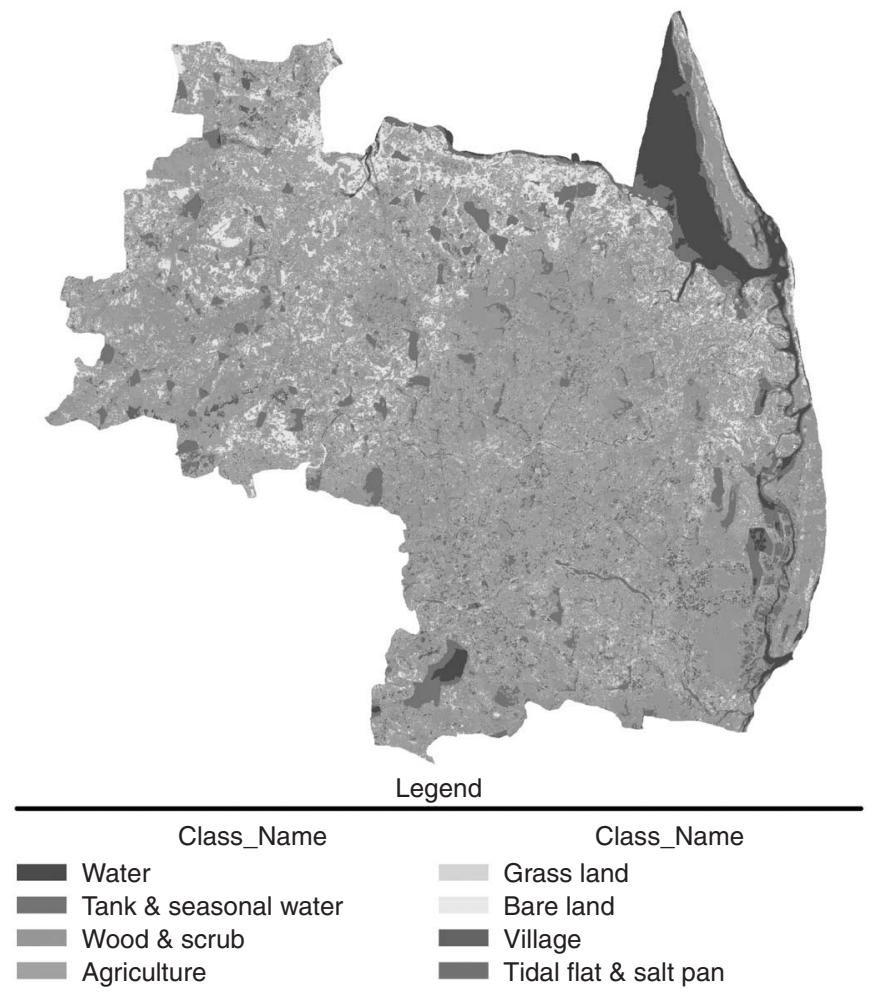

Figure 5.6 Estimation of land use in Ponneri.

Table 5.2 Land-use types in Ponneri

\begin{tabular}{ll}
\hline Land-use type & $\begin{array}{l}\text { Main land-cover change patterns } \\
\text { (Navarai-Sornavari-Samba) }\end{array}$ \\
\hline Water & AAA \\
Tank and seasonal water & ADD, AAE, ABB \\
Wood and scrub & FDB, DDB, DBB, BBB, FEB, CDB, FBB, CBB, EBB \\
Agriculture & DDD, FDD, CDD, FDF, FDC, DDC, FED, FDE, EDD \\
Grass land & CDC, FFD, DFD, EDF, DDE \\
Bare land & FFF, FEF \\
Village & CCD, CCC \\
Tidal flat and salt pan & EEE \\
\hline
\end{tabular}

Note

A: Water; B: Wetland with vegetation; C: Forests; D: Grassland; E: Wetland without vegetation; F: Bare land. 


\section{Evaluation of results}

In order to assess the time-series analysis method, the estimation results were evaluated with the actual ground data. Therefore, a field survey was carried out to collect data on the study area. The survey used two methods to collect data. The first was to obtain point data through video camera images while indicating the locations of the images using Global Positioning System (GPS). However, the collected data contained some location errors that were difficult to correct. The other method collected local survey data in the form of village administration officer (VAO) data, which were provided by each village leader. Based on this data set, a statistical evaluation of the estimation results was performed.

The VAO data contained the net crop area of each village. To obtain an estimated agricultural area of each village, an administration map was digitized and overlaid on the analysis result (see Figure 5.7). Then, the estimated agricultural area of each village was calculated and compared with the VAO data. Figure 5.8 shows the comparison result. Since it was limited by the local survey conditions, the comparison could be carried out for 252 villages, which occupied $90 \%$ of the total number of villages (280) in Ponneri. The estimation results show a high accuracy for most of the compared villages, except for the central western and eastern marine regions. According to the field survey, the central western region

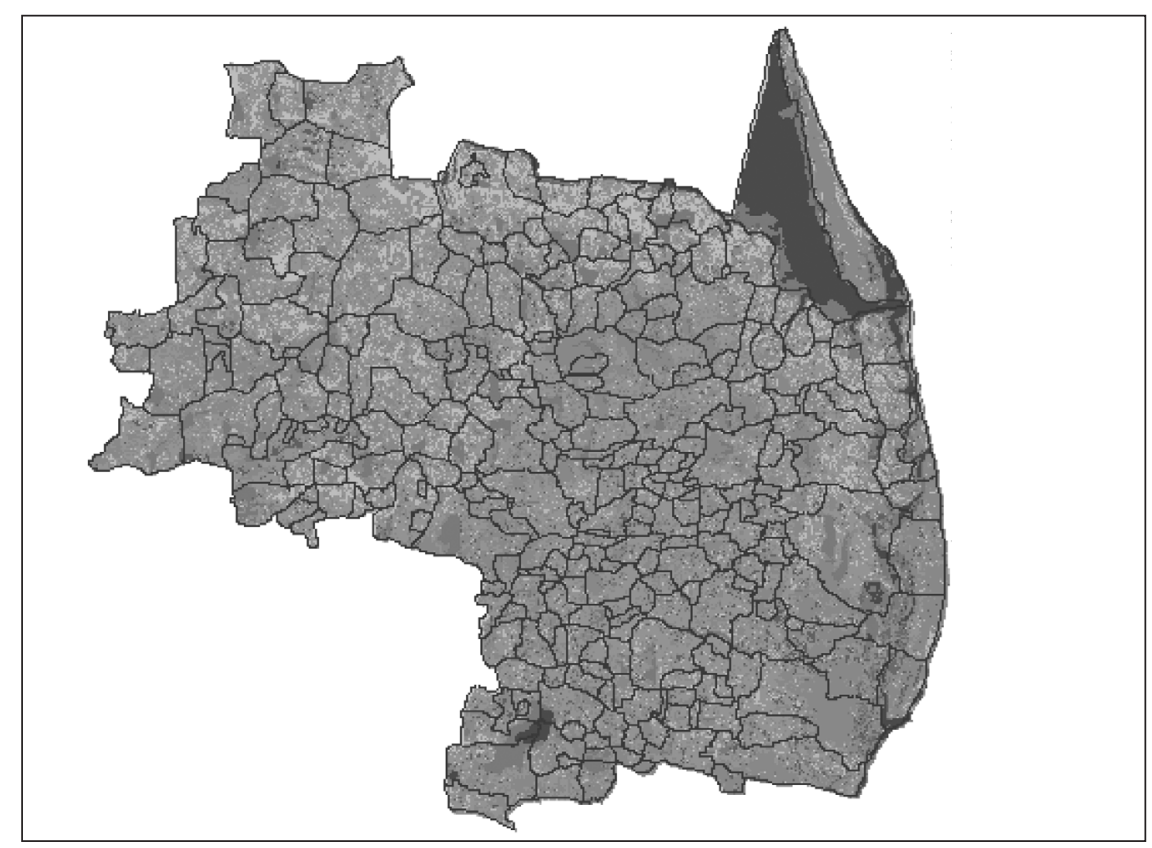

Figure 5.7 Estimation results with overlaid administration boundary map. (Lines indicate the village boundaries.) 


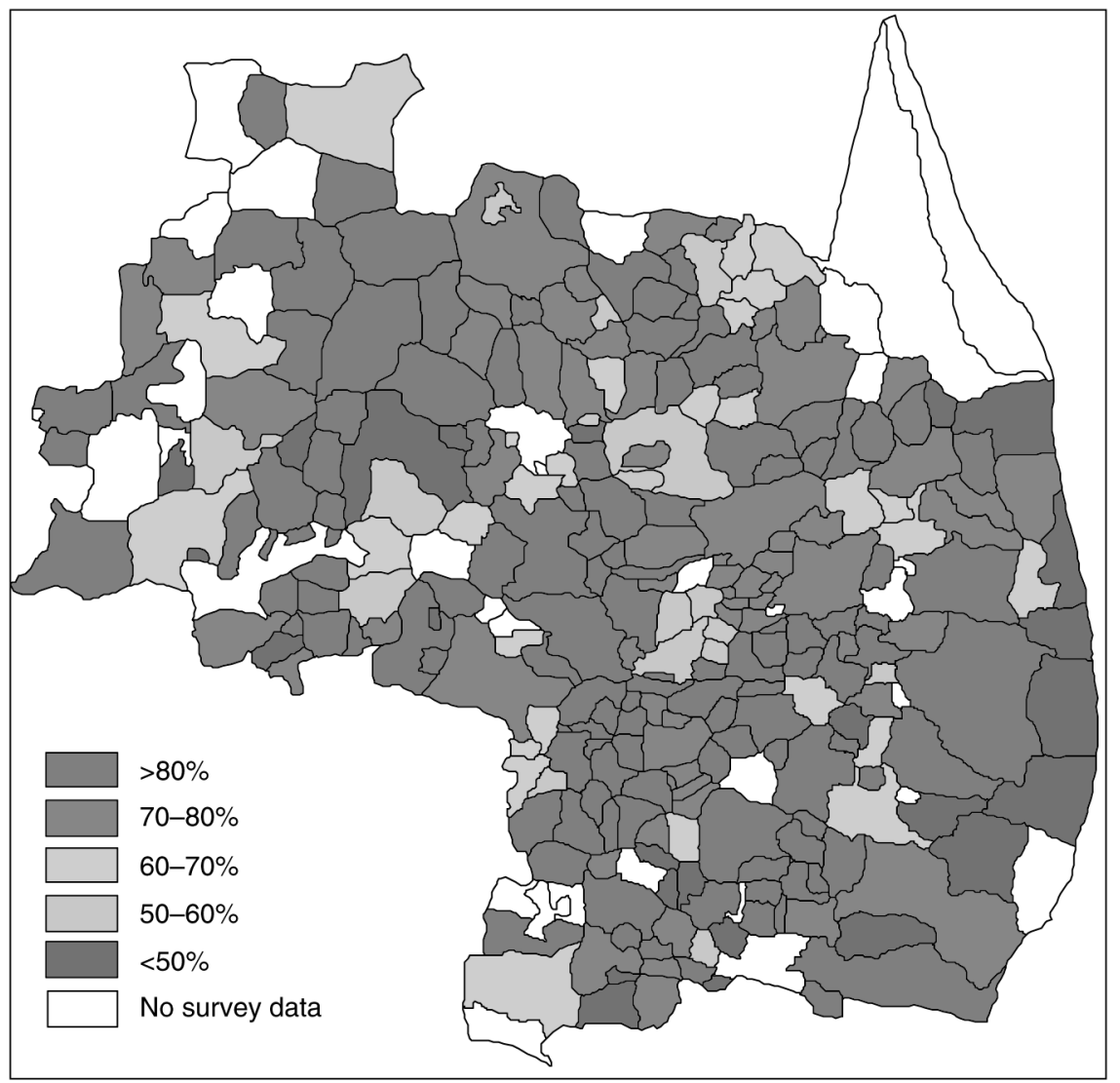

Figure 5.8 Comparison between estimation results and local survey data. (Percentages indicate the accuracy of estimation versus survey data.)

is a developing industrial area, in which a large area of land has been prepared for siting factories. Thus, there was an overestimation within the region. With regard to the eastern marine region, the estimation was less than the survey data. By referring to the estimated land use of this region (Figure 5.6), we can see that there are large areas estimated to be forest. According to the field survey, plantation areas (such as banana) are included in the net crop area. This can be considered as one of the reasons for the low accuracy of the results.

\section{Conclusion}

A method of estimating land use using Landsat TM data and time-series analysis with GIS software has been described, and as a case study, the land use during 1996-97 in Ponneri, South India has been estimated. A comparison with local 
survey data shows that the estimation was statistically satisfactory with regard to its accuracy. The above method can be used to estimate and evaluate land use at the local scale. Typical seasonal land-cover change patterns of main land-use types in the case study area are also derived in this study. They can be used to estimate and evaluate land use for similar regions.

However, there are still several problems that need to be solved. First, the estimation results were only evaluated using statistics, and the classification accuracy still needs to be verified by detailed field survey data. Second, in the case study, we only considered water, bare soil, and vegetation as indexes to convert the remote sensing data to land-cover data. To increase the estimation accuracy, it will be necessary to distinguish between the vegetation types, and this will need more data sets and more basic data on the local flora. Third, the selection of the timing of the data is also important to increase the estimation accuracy. For example, it is easier to distinguish an agricultural area by comparing the data at the beginning and the mid-term of the crop season.

\section{Acknowledgments}

I express my thanks to Okabe A., Masuyama A., Sadahiro Y., and Mizushima T. for valuable comments on an earlier version of the chapter.

\section{References}

Burrough, P.A. (1986) Principles of Geographical Information Systems for Land Resources Assessment, Oxford: Clarendon Press.

Japan association on remote sensing (1996) "Remote sensing note," Japan Association on Remote Sensing, IIS, University of Tokyo.

Ramasamy, S.M. (1991) “A remote sensing study of river deltas of Tamil Nadu,” Memoirs Geological Society of India, No. 22, 75-89, Bangalore, India.

Takeishi, R., Ahn, C.H., Wen, C.G., and Perera, L.K. (1995) "Development of global database," in Murai, S. (ed.) Toward Global Planning of Sustainable Use of the Earth, Elsevier Science B.V., The Netherlands, pp. 449-453.

Townshend, J.R.G. (ed.) (1981) Terrain Analysis and Remote Sensing, Great Britain: George Allen \& Unwin. 
Part II

\section{REGIONAL ANALYSIS}





\title{
ISLAMIC RULE AND LOCAL SOCIETY IN EIGHTEENTH-CENTURY SOUTH INDIA
}

\author{
Mizushima Tsukasa
}

\section{Introduction}

With the death of Aurangzeb at the beginning of the eighteenth century, a number of regional states emerged in the different parts of the Mughal Empire. These states are called "succession states," and the most influential among these was the Islamic state of Nizam, in Hyderabad, South India (Figure 6.1).

By the 1720s, Nizam-ul-mulk, who was the highest official in the Mughal court, had steadily established an autonomous state that grew to be the most powerful in South India by the mid-eighteenth century. While engaged in military expeditions in different parts of the region, the Nizam gained control over the nawabs who had been posted by the Mughals as provincial governors in several strategic places. One such nawab was the one posted in Arcot (Figure 6.1). The nawab of Arcot ruled the eastern part of the Tamil country including the Jagir (Chingleput, currently spelled as Chengalpattu) taken up in this study. ${ }^{1}$ The main question to be addressed here is, "How did the nawab assert his sovereignty when he belonged to the Muslim minority, and was newly posted to an area dominated by Hindus?"

In providing the answer to this problem, this chapter attempts to utilize geographical information systems (GIS) to test its possibilities in extending the horizon of historical investigation in South Asian studies. In doing so, we will show that the most important contribution of GIS is in its highly informative visual images that provide insights not available with conventional "table-style" analysis methods. The more the information accumulated in a sphere of interest, the more the promise GIS offers. In this chapter, several maps will be presented along with related tables to highlight the comparative merits of GIS.

The investigation will be carried out in the following order. First, the presence of Islamic elements will be assessed in the respective social levels in the period. Second, clues for the minority state to claim sovereignty will be explored in relation to the "Mirasi System."2 


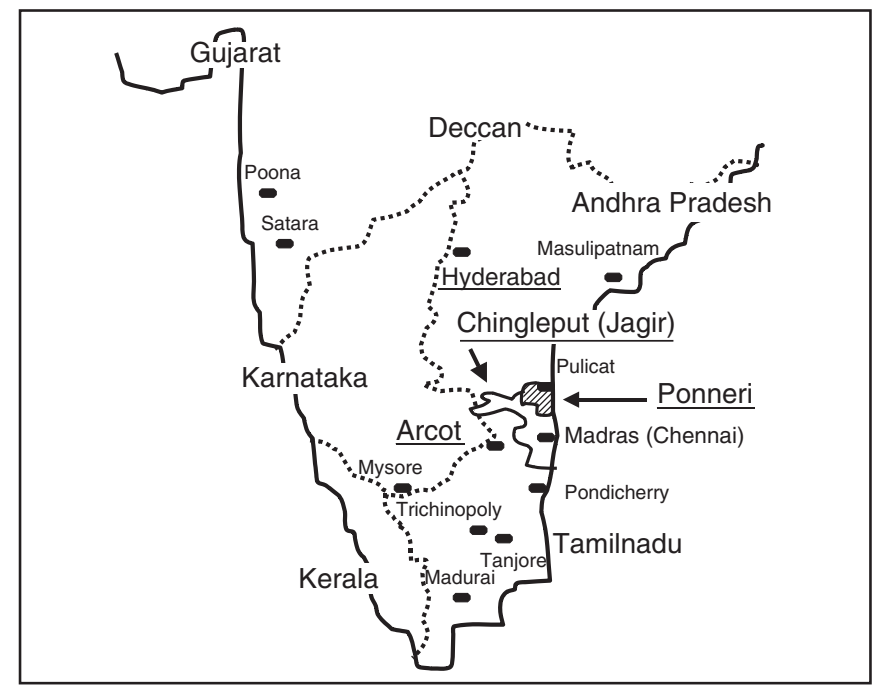

Figure 6.1 Location of Ponneri.

The study area is Ponneri area, located to the north of Madras (present-day Chennai) (see Figure 6.1). According to some late eighteenth-century records, Ponneri area had 150 villages and the Jagir (corresponding to the Chingleput district) contained 2,200 villages. Ponneri area was under the rule of the nawab of Arcot throughout most of the eighteenth century. Ponneri is now one of the taluks (sub-districts) included in the Chingleput district.

\section{The presence of Islamic elements in the different levels of society}

\section{Social classes}

Many of the eighteenth-century records of southern India categorized villages into four types: state, mokassah, shrotrium, and rented villages (see below for definitions). An important survey report on Chingleput villages in the 1760s-70s prepared by Thomas Barnard, a British surveyor, used the same four categories. ${ }^{3}$ The spatial distribution of the four village types deduced from the Barnard survey (hereafter referred to as the Barnard Report) is shown in Figures 6.2 and 6.3. Around two-thirds of the villages were of the state type, and were directly managed by the state. The rest were not under the state, but were under other social classes. For instance, the mokassah villages were under the direct control of the poligars (military leaders), who paid tribute to the state. The mokassah villages were concentrated in the northern part of Ponneri. 


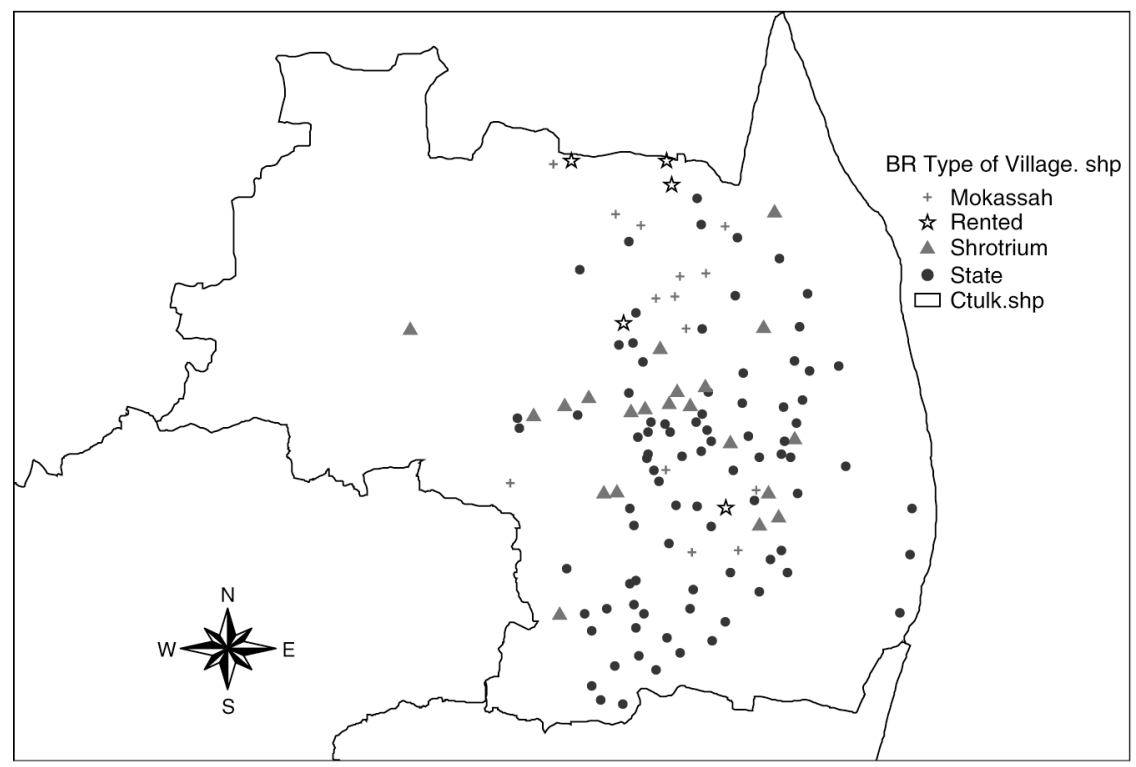

Figure 6.2 Spatial distribution of the four types of village (Barnard Report, 1770s).

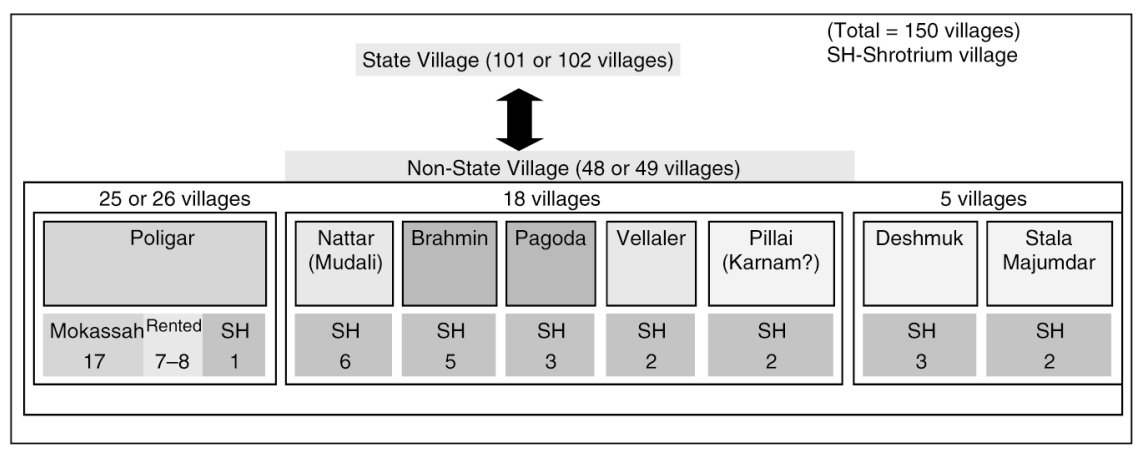

Figure 6.3 The four types of village and social classes (Barnard Report, 1770s).

The shrotrium (sometimes called inam) villages were totally (or partly) exempted from revenue, and they were allocated to individuals or institutions, very often religious ones, such as pagodas (Hindu temples), maths (monasteries), mosques, and gurus/fakirs (Hindu/Muslim religious teachers). These villages were mainly found in the central part of Ponneri. In addition, there were several villages rented by the poligars, mainly around Pulicat Lake located in the north of Ponneri. 
What is important is that these four village categories directly reflected the structure of the upper strata of the society in the period under investigation. The state, the poligars, and the religious institutions held more-or-less autonomous control over the villages. Each of these represented, in a way, the secular, military, and religious institutions of the day. The relative strength of the respective social classes may be partly judged by the number of villages held by each. The poligars, for instance, held 17 villages under mokassah, eight under rent, and one under shrotrium. A total of 23 other villages were held as shrotrium villages by other people. The Brahmin (the highest ranked caste ${ }^{4}$ ) and the pagodas held five and three villages respectively, some government high officials such as deshmuks or a stala majumdar posted in the locality held five, and those local magnates like nattars (representatives of the locality), Vellalers (the highest ranked agricultural caste), and Pillais (a writer or accountant caste) had ten in total.

At the village level, on the other hand, there was a landlord class called mirasidars. Many of the early colonial records indicate that almost every village possessed this class that claimed a controlling power over the entire village resources. ${ }^{5}$ The rest of the village population belonged to various castes, which were usually endogamous and maintained some specific customs and occupations.

\section{Islamic elements in the respective social classes}

Before going into the detail of the Islamic elements among the different social classes, we will briefly have a look at the caste composition in Ponneri in the 1770s. Figure 6.4 indicates the caste composition in the Ponneri area, as calculated from the Barnard Report. Out of 3,391 households, the Paraia (the lowest ranked caste, or the so-called "untouchables") constituted 24\%, the Vellaler constituted 16\%, the Palli (an agricultural caste) constituted 12\%, and the Brahmin constituted $9 \%$. In contrast, the Muslim community was quite negligible, constituting just $1 \%$ of the total. The spatial distribution was as indicated in Figure 6.5.

Unfortunately, information about the town of Pulicat and some other villages facing the Indian Ocean (and therefore with a larger Muslim population) is missing from the Barnard Report, so that the percentage of the Muslim population in the 1770 s could be an underestimate. One measure to revise this figure is to utilize more comprehensive statistics from later periods. As the statistics from the 1871 Census are available for the area, we will utilize them. The composition is indicated in Figure 6.6, and the result remains more-or-less the same. Although a higher Muslim population in Pulicat and some other villages is revealed, the overall size of the Muslim population remains negligible.

Next, we will examine the presence of Islamic elements in the different categories of social class. First, we will look at the poligars or military leaders. The names of the poligars recorded in the Barnard Report provide a hint of the poligars' communal identity. Table 6.1 is a list of titles used in their personal names. The most striking feature is the absence of Muslims among the poligars. 


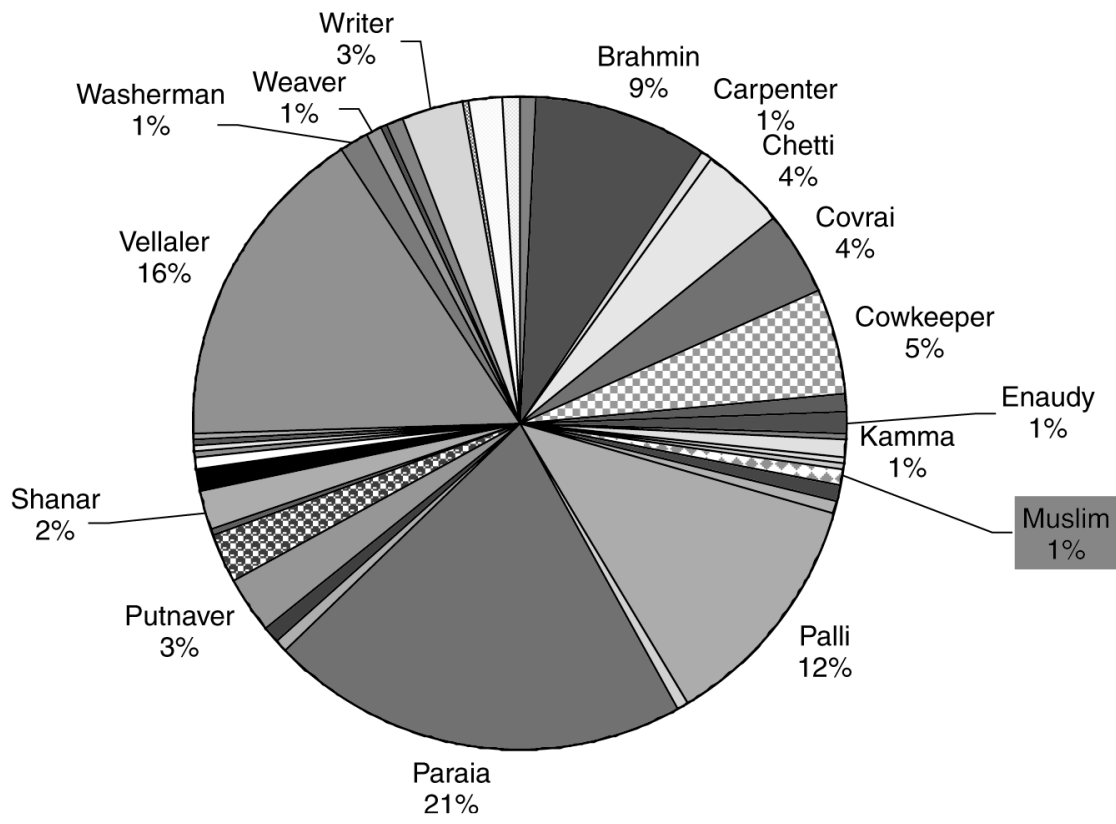

Figure 6.4 Caste composition in Ponneri (Barnard Report, 1770s).

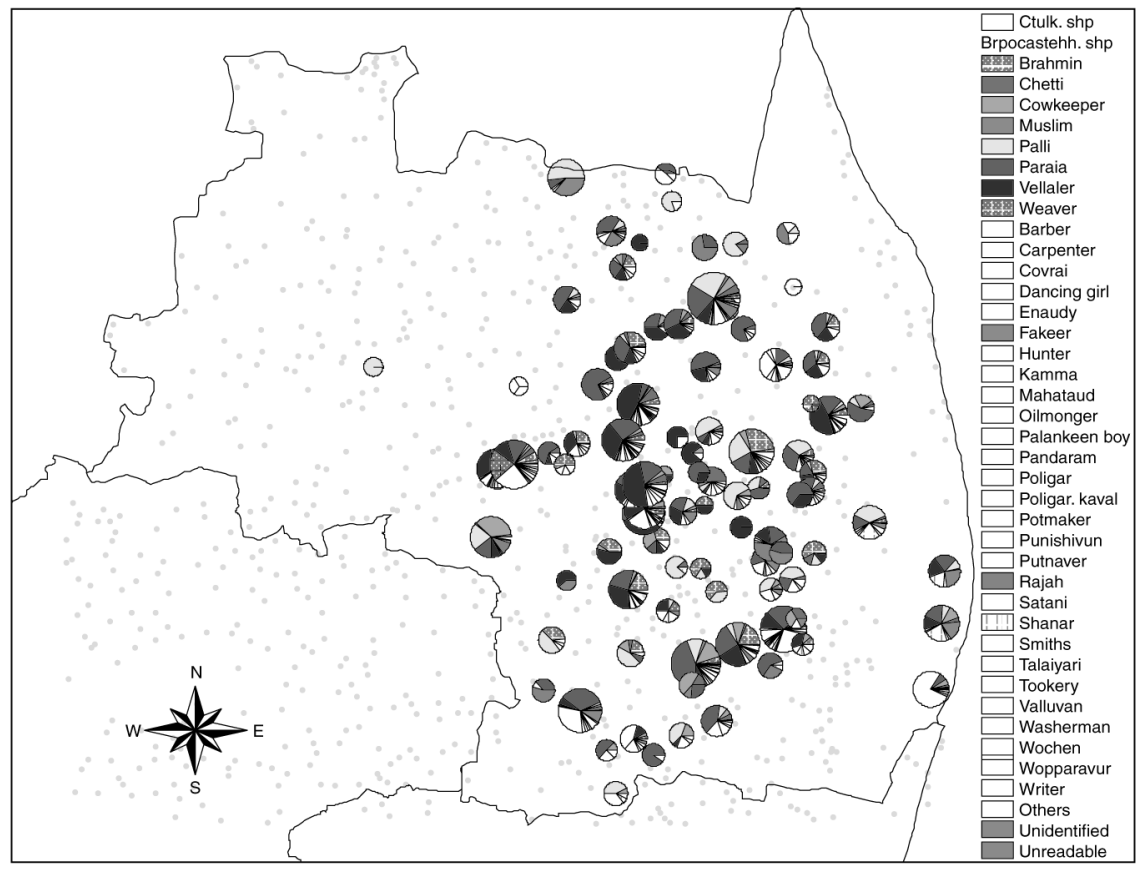

Figure 6.5 Spatial distribution of the caste composition in Ponneri (Barnard Report, 1770s). 


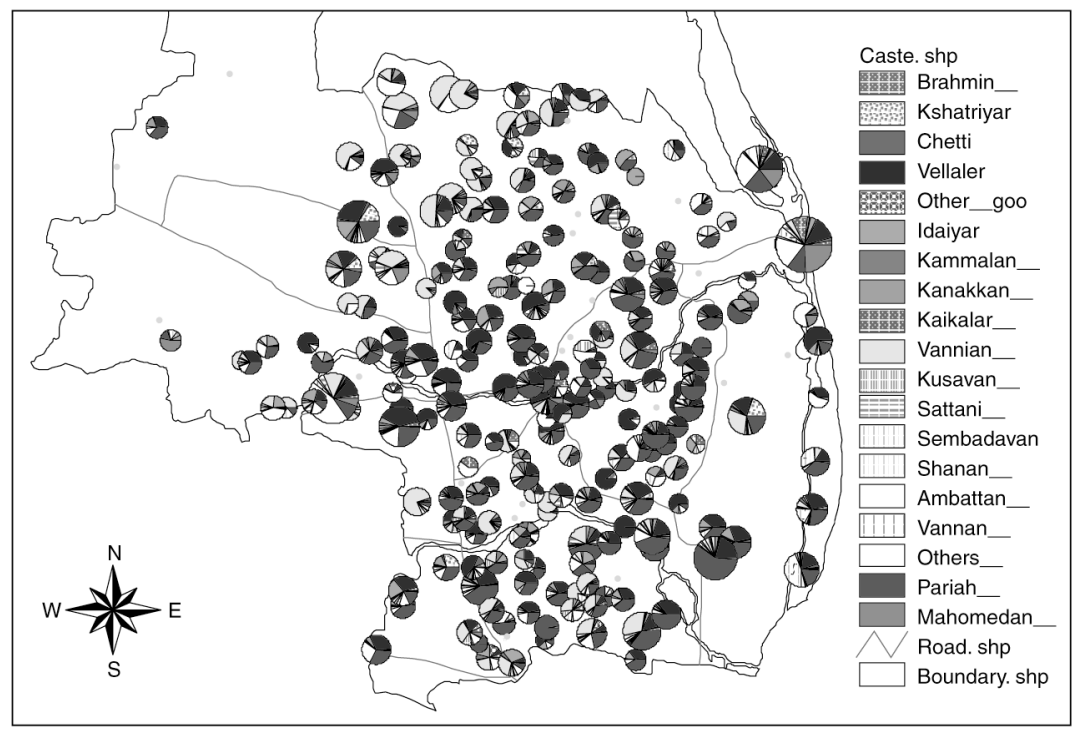

Figure 6.6 Caste composition in Ponneri (1871 Census).

Table 6.1 Titles of Poligars (Barnard Report, 1770s)

\begin{tabular}{lc}
\hline Poligar castes []-living place & No. of villages \\
\hline Naick & 7 \\
Naick (Covrai) & 3 \\
Naick (Palli) & 1 \\
Rajah & 111 \\
Rajah, Muttiriyan, Naick & 1 \\
Rajah, Naick (Muttiriyan) & 2 \\
Vellaler [Madras] & 1 \\
Vellaler [neighboring village] & 9 \\
Vellaler [same village] & 10 \\
Not available & 5 \\
Total & 150 \\
\hline
\end{tabular}

Note

Neighboring village — village located in close proximity.

What then, were the features of religious institutions or individuals? A study by Bajaj and Srinivas gives clues on this point. Table 6.2 is the list of religious recipients at the supra-local level holding some share in village produce. The number of villages where the allowances were made is also indicated. It is known from the table that Salapakkam Mullasaib, seemingly a Muslim religious teacher, was allocated shares in several dozen villages. 
ISLAMIC RULE AND LOCAL SOCIETY IN SOUTH INDIA

Table 6.2 Religious recipients holding shares in the produce in Chingleput (Barnard Report, 1770s)

\begin{tabular}{lc}
\hline Recipients & No. of Hamlets \\
\hline Kanchipuram Varadarajaswamy & 1,265 \\
Chingaperumol Kovil Pataladri Narasimhaswamy & 451 \\
Thirukkacchiyur Marundiswarar & 448 \\
Sriperumbudur Bhashyakkarar & 397 \\
Thirukkalukkunram Vedagiriswarar & 338 \\
Kumbhakonam Chikkodeyar (Kanchi Kamakoti Peetham) & 310 \\
Thiruvallikkeni Tholasingar & 259 \\
Thirupporoor Kandaswamy & 249 \\
Thiruvaliur Veeraraghavaswamy & 224 \\
Kanchipuram Kamakshiamman & 208 \\
Mylapur Kapaliswarar & 184 \\
Kanchipuram Paulia Pandaram & 174 \\
Thirumalisai Alwar & 172 \\
Thiruvayarpadi Karikrishnaswamy & 130 \\
Kanchipuram Pillailokachariar & 126 \\
Thiruppalavanam Thiruppaliswarar & 120 \\
Santhome Peerzada & 118 \\
Kanchipuram Gopalachariar & 84 \\
Kanchipuram Perundeviamman & 83 \\
Salappakkam Mullasaib (Muslim) & 69 \\
Thiruvidanthai Nityakalyanaswamy & 59 \\
Kanchipuram Ekambareswarar & 58 \\
Thiruvottiyur Choultry Fund & 47 \\
Kovalam Dargah (Islam) & 41 \\
Baburayanpettai Vijayavaradarajaswamy & 31 \\
\hline
\end{tabular}

Source: Bajaj, J.K. and Srinivas, M.D. Indian Economy and Polity in the Eighteenth Century: The Chengalpattu Survey 1767-74, Indian Economy and Polity, Centre for Policy Studies, Madras, Table VII, p. 80.

The same study shows that some Islamic institutions or individuals at the local level, such as a fakir, a mosque, and a dargah (a tomb of a Muslim religious teacher), received some allowance in more than five hundred villages in the region. ${ }^{6}$ This fact needs an interpretation, and I will come back to this point later.

What then was the significance of Islamic elements in the lower levels of society? Table 6.3 indicates the caste composition of the mirasidars, and Figure 6.7 shows the location of villages held by mirasidars of different castes. They are both prepared from the Barnard Report.

It may be noticed from Figure 6.7 that there seemed to be some specific concentration in their spatial distribution. The Palli, for instance, held several villages in the northern and central parts of Ponneri, whereas the Brahmin held villages in the central and southern parts. What is remarkable in relation to the subject of this chapter is that all the mirasidars except one were non-Muslim. The exceptional mirasidar was Nawab Mahfuz Khan himself who, according to the 
MIZUSHIMA TSUKASA

Table 6.3 Caste composition of the Mirasidars (Barnard Report, 1770s)

\begin{tabular}{lr}
\hline Brahmin & 51 \\
Vellaler & 79 \\
Palli & 7 \\
Pagoda & 3 \\
Covrai & 2 \\
Kalian & 2 \\
Cowkeeper & 2 \\
Deshmuk & 1 \\
Nawab & 1 \\
Raja & 1 \\
Kanakapillai & 1 \\
Nattar & 1 \\
Unknown & 11 \\
Total & 162 \\
\hline
\end{tabular}

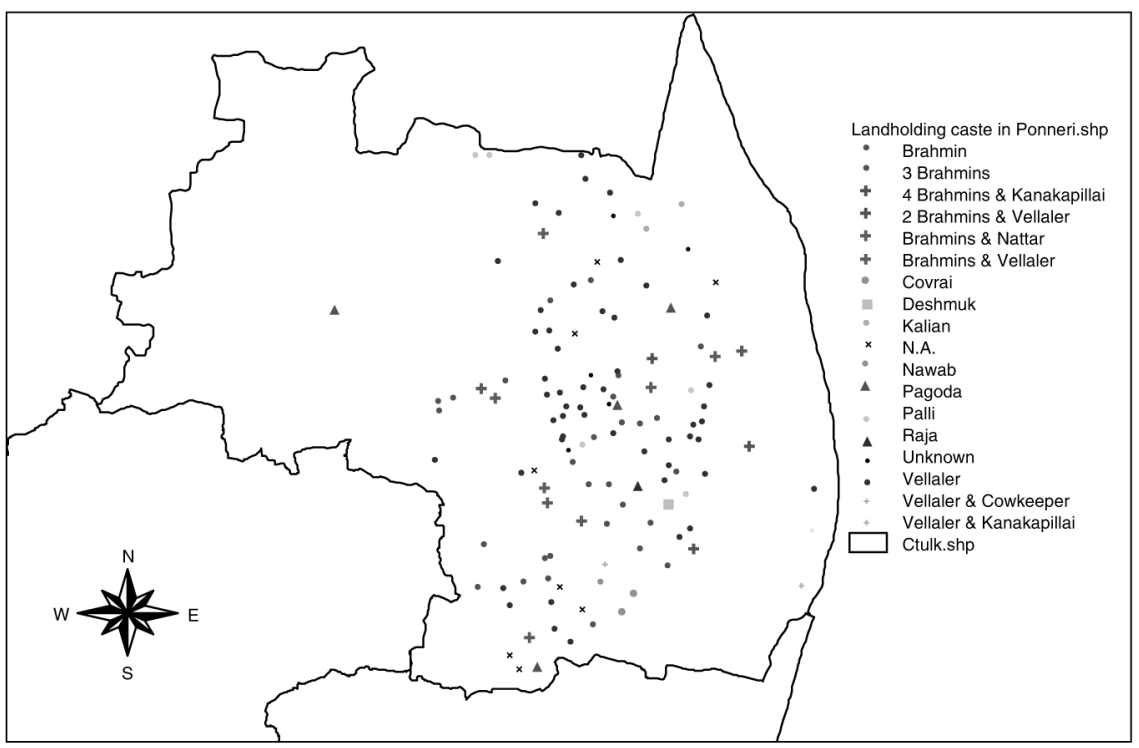

Figure 6.7 Location of villages held by mirasidars of different castes (Barnard Report, 1770s).

record, purchased the mirasidar's right of one village. The Nawab's case indicates the consistency of mirasi rights during the period, a matter to which I will come back later.

There was another important record prepared at the end of the eighteenth century by a British collector posted in Chingleput. His name was Lionel Place. ${ }^{7}$ 


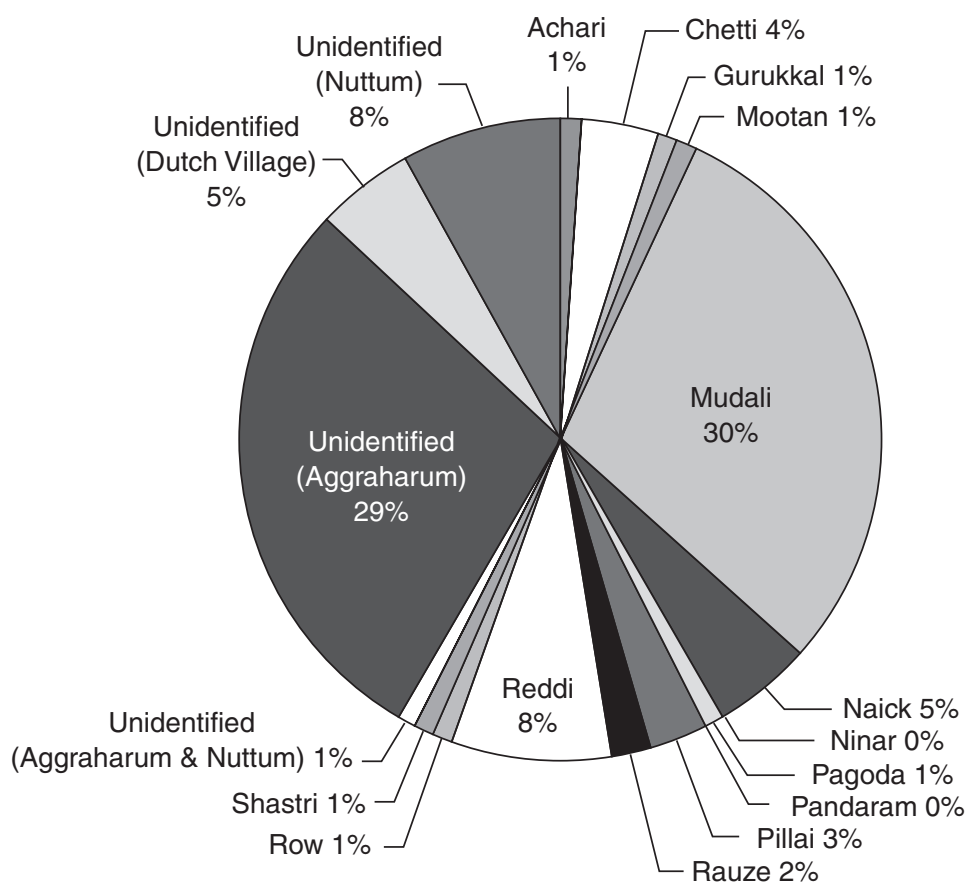

Figure 6.8 Mirasidar castes in Ponneri (Place Report, 1799).

Place recorded the personal names of all the mirasidars in each village in Chingleput. The result of the analysis of their caste identities is shown in Figure 6.8 , and the caste composition in the respective villages in the same year is indicated in Figure 6.9. The map shows that the Mudali (a caste title signifying "head," mostly of agricultural caste) heavily dominated the central and southeastern parts, while the Reddi (an agricultural caste originating from the Andhra region) held several villages in the northern and central parts. The Chetti (a merchant caste) held a few villages in the southern part of Ponneri near to Madras, but the Brahmin, on the other hand, seemed to have lost many of the villages that they controlled at the time of the Barnard Report. The reason for this is yet to be investigated. However, the total absence of Muslim mirasidars is the noticeable feature here.

The main colonial land system in South India was called the raiyatwari settlement, and it allocated a land lot to those having interests in landholding. In 1877 , when the second raiyatwari settlement was made, a land record called the Settlement Register was prepared for each village. From these registers, mirasidar names, as well as pattadar (landholder or holder of land-title) names can be obtained and analyzed. Figure 6.10 shows the composition of the mirasidars in Ponneri villages, as prepared from the Settlement Registers. 


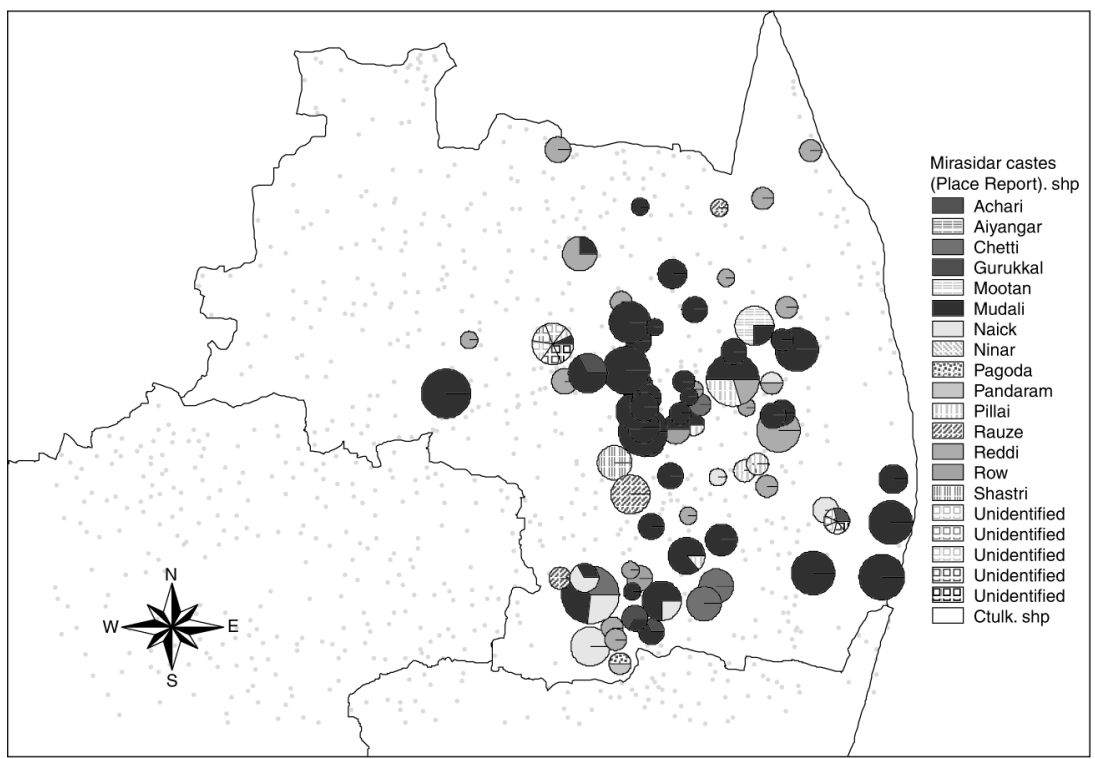

Figure 6.9 Caste composition of mirasidars in Ponneri (Place Report, 1799).

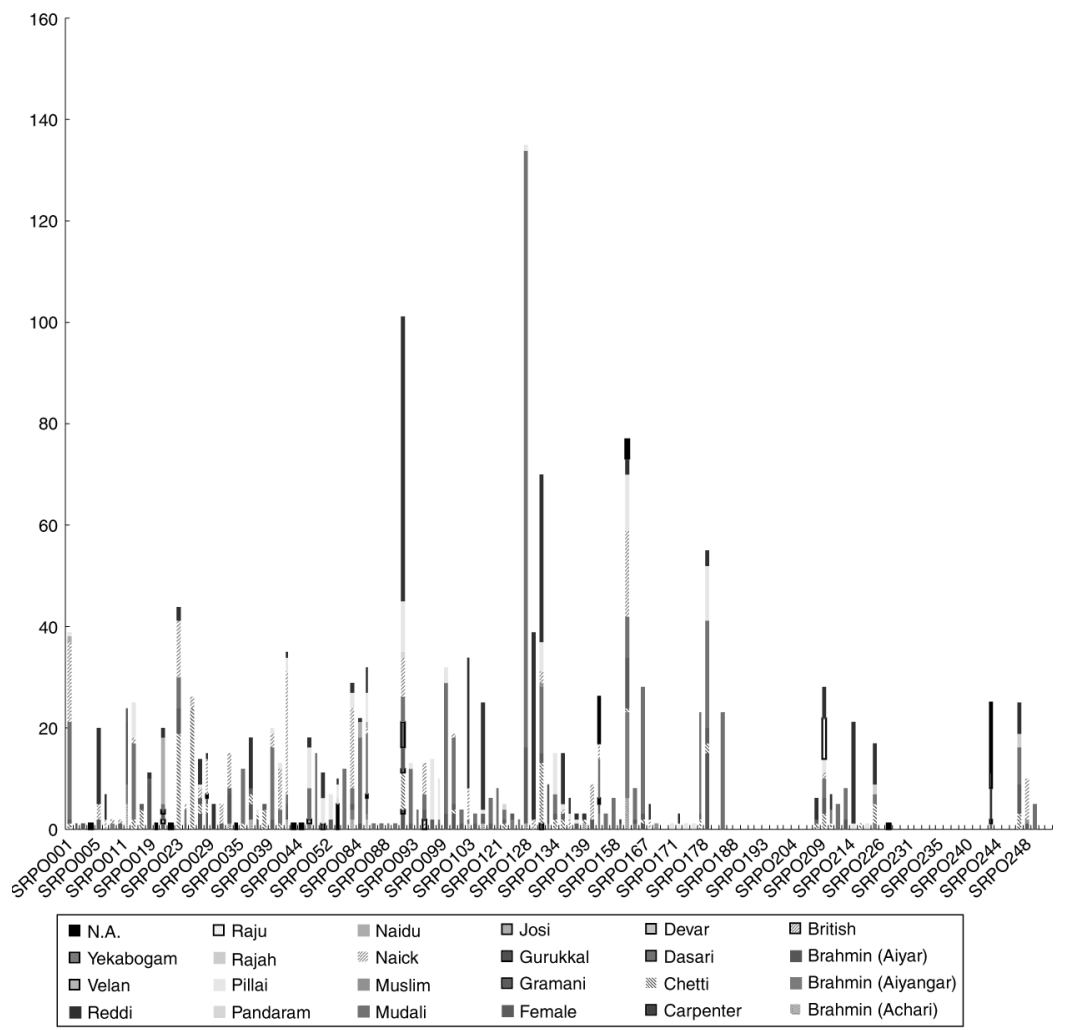

Figure 6.10 Caste composition of mirasidars in Ponneri (Settlement Registers, 1870s). 
The presence of Muslim mirasidars was nominal. Out of the 382 mirasidars recorded in 136 villages, there were only a total of three Muslims in three villages. In the first case, Mohamed Sayad Saheb held Andarmadam village as Yekabogam (a tax-exempted village held by one person). In the second case, Kadarmodin Saheb held one-eighth of Mangadu village with nine other mirasidars (mostly Naicks). In the last case, Syea[-d?] Mahomed Saheb held some share [unreadable] of Arani village with 71 others. There were no other Muslim mirasidars in the Ponneri area.

To find more about the presence of Islamic elements in society, the identities of the pattadars also need to be investigated. As discussed elsewhere, the mirasidars' right over the entire village area was reduced to a nominal one by the time of the second raiyatwari settlement in the 1870s, and the landed right was solely vested in the pattadars, into which almost all the mirasidars also entered. ${ }^{8}$ Figure 6.11 shows the caste composition of the landholdings in 54 villages in the Ponneri area. Out of a total of 21,455 acres of landholding, Muslims held just 2\% of the land. The number of Muslim pattadars in the 54 villages was 93 out of 4,776 pattadars, or around 2\%. Except those several large Muslim holdings found in and around Pulicat town, there were few villages where Muslim pattadars held land.

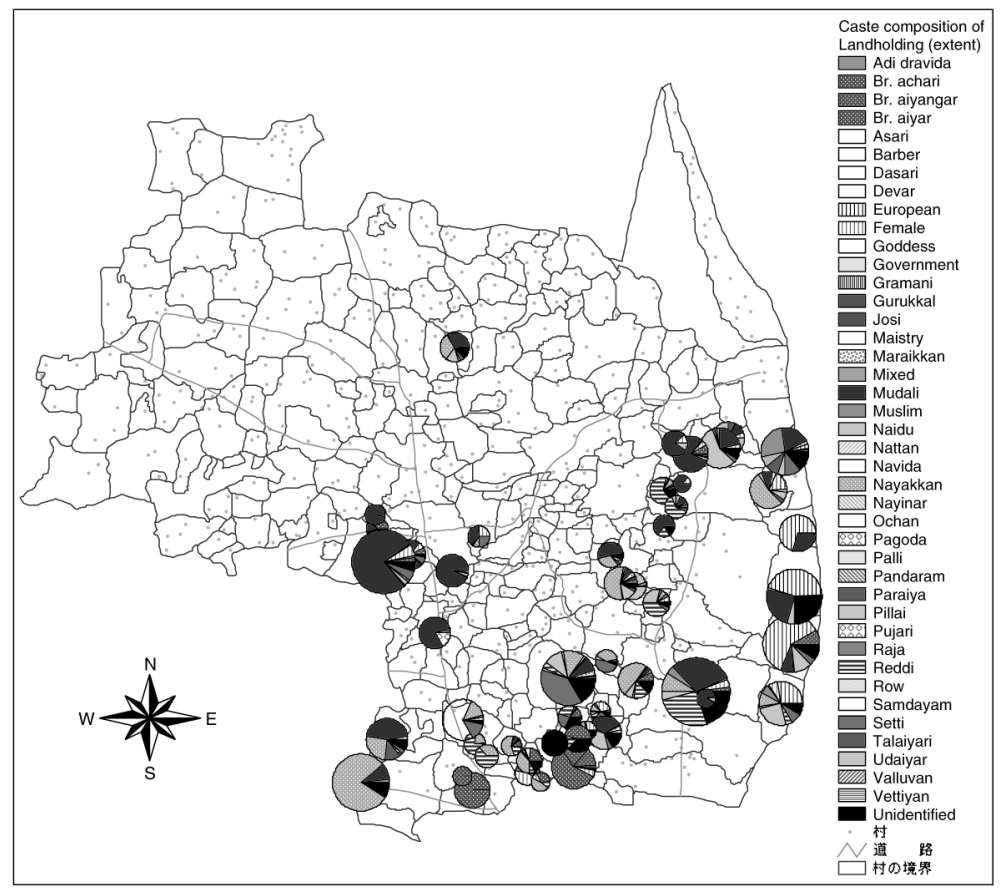

Figure 6.11 Caste composition of landholding in Ponneri (Settlement Registers, 1870s). 


\section{Summary of the findings}

The investigation so far attempted can be summarized as follows. Though the state was a Muslim state headed by the Nawab, the total Muslim population was just $1 \%$. None of the poligars were Muslims. A few Islamic religious institutions/individuals received shares in the area. The mirasidars were totally non-Muslim in the late eighteenth century, with one exceptional case where Nawab Mahfuz Khan himself purchased the mirasidar's right. The number of Muslims among the mirasidars in the late nineteenth century was three. The Muslim pattadars occupied only around $2 \%$ of the total landholding. In a word, Islamic elements were negligible among all the social classes in the Muslim state. Our next task is, therefore, to find clues as to how Muslim rule was possible without a base in any of the social classes.

\section{State and local society}

One of the possible power sources for the minority Muslim government was its military strength. It is true that the period had frequent military incursions, and the Nawab government often carried out military expeditions to various parts to collect revenue or for other purposes. It needs to be remembered, however, that the Nawab never failed to request military support from local leaders (mainly poligars) for any of his expeditions. A turning point of a battle was often the outcome of hostile movements of these followers who had been temporarily recruited by one of the parties. The military strength of the Nawab government was, therefore, not necessarily a decisive factor.

Pages of the Barnard Report give important clues in this regard. Figure 6.12 shows one of the pages contained in the report. The page is divided into several sections in which the details of allotments of inam (tax-exempted) land or of the share distribution of the total village produce are recorded.

One section, which calls for attention, contains a list of recipients of "new" inam with the names of grantors, and the year of granting. According to a note in the Barnard Report, the word "new" signifies that the grants were made either after 1710 or after the reign of Nawab Saudatulla Cawn (1710-32). An analysis of grantors in this category indicated in Table 6.4 clearly shows that several Muslims made many new land grants, though their identities are yet to be verified. The yearly change in new grants classified by grantors is indicated in Figure 6.13, which proves that some Muslims actively granted land during the period. The grants were spread around many parts of Ponneri, especially in the central parts, as indicated in Figure 6.14.

It is important to note that the recipients of the land grants were not necessarily Muslims, and often the grantees were Brahmin and other Hindus (cf. Table 6.4). This evidence strongly implies that these Muslim grantors, who were new to the area and were most probably associated with the Nawab government, tried to win favors from the Hindus by granting inam land. Though we do not have any 


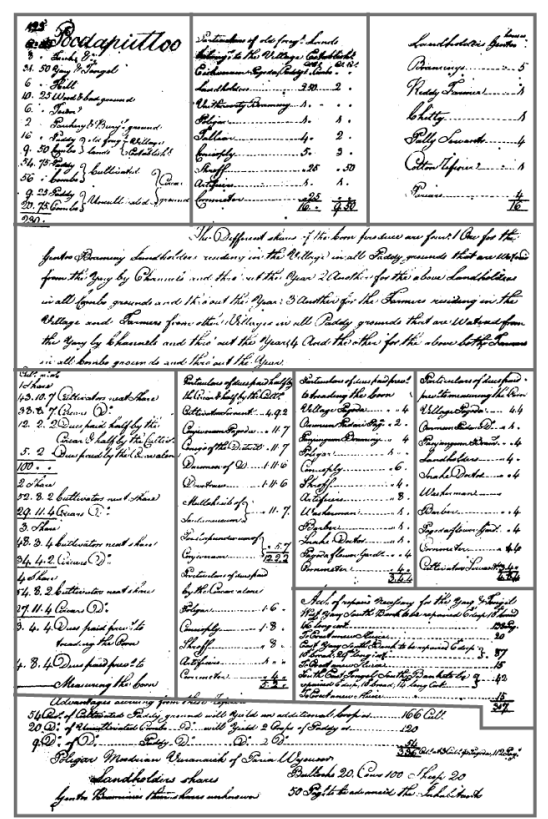

Figure 6.12 A sample page from the Barnard Report.

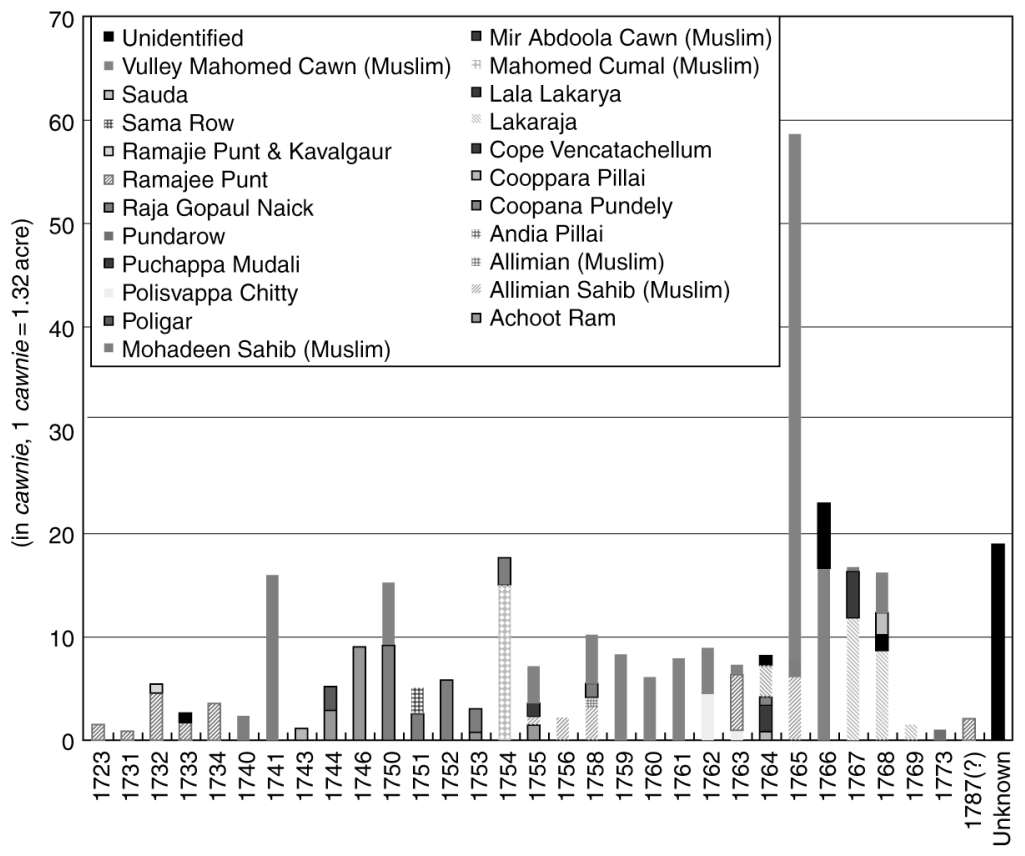

Figure 6.13 Annual change in new grants classified by grantors in Ponneri (Barnard Report, 1770s). 


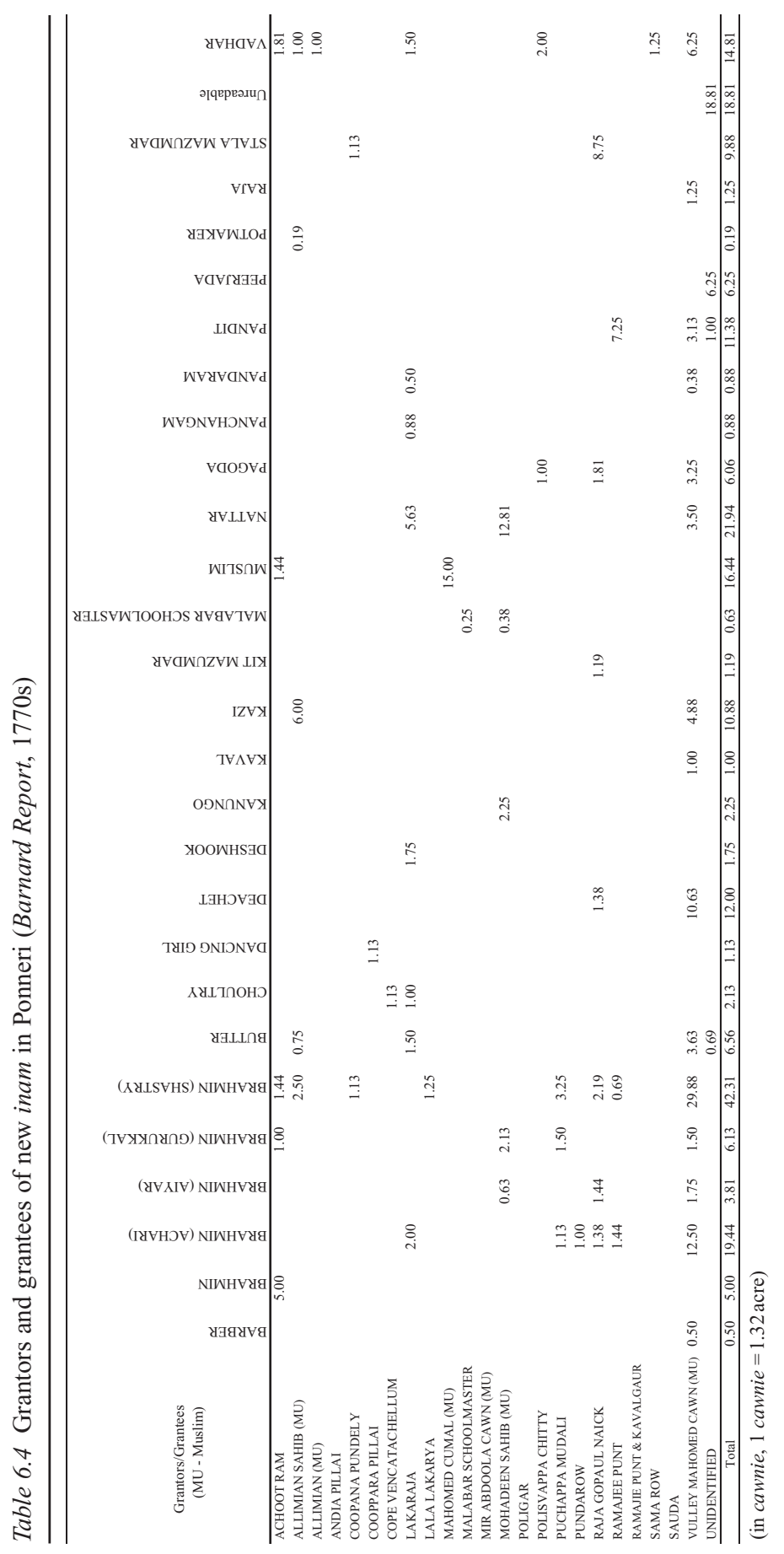




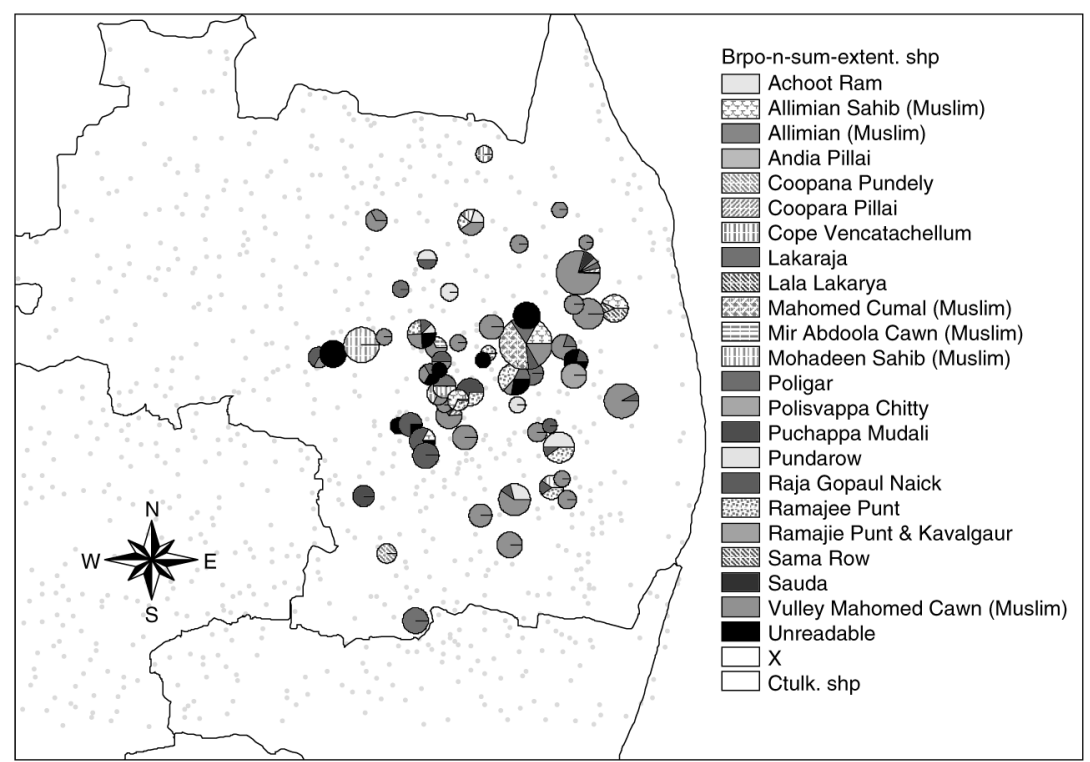

Figure 6.14 Location of new inam in Ponneri (Barnard Report, 1770s).

evidence, it is very likely that the same measures were taken for the shares in produce during this period.

Thus, the Muslim state, even though it belonged to a minority group in a new area, could gain legitimacy by making use of the existing system. This system, which allocated shares in village produce to various recipients, was called the mirasi system, and was acknowledged by many of the British officers posted to South India. As was exemplified in the Barnard Report, every village in the region had a similar share distribution system. An elaborate share distributing system of land and its produce in the shape of shrotrium villages, mokassah villages, rent villages, inam land, and dues, or fees was deeply enmeshed in South Indian society. The accumulation of wealth, social/class relations, and even personal hopes were all expressed in the mirasi system. The mirasi system thus functioned as a sort of social grammar. ${ }^{9}$ Moreover, we can also find similar systems in various parts of the Indian subcontinent such as Gujarat, Deccan, and elsewhere.

\section{Conclusion}

In the mirasi system both local and supra-local elements could expect to protect their own interests so long as they followed the "social grammar" called the mirasi system. This grammar had gradually formed from the relationship between 
the local and supra-local formations. Under this system, local society had relative autonomy in its relations with supra-local elements including states. This was also the case with the South Indian Muslim state in our study.

The system was consistent enough to allow such a minority state to claim sovereignty; that is, the right to collect the share allocated to the state by the system.

\section{Glossary}

Achari: a caste title given to Brahmin

Aggraharum: a village inhabited by Brahmin

Ambattan: a barber caste

Brahmin: the highest ranked caste

Chetti: a merchant caste

Corn-measurer: a man who measures the weight or amount of crop

Covrai: unidentified

Dargah: a tomb of a Muslim religious teacher

Deshmuk: a high official posted in a locality

Enaudy: a toddy-tapper or barber caste

Fakir: a Muslim religious teacher

Guru: a Hindu religious teacher

Gurukkal: the head priest, often a title for Brahmin

Idaiyar: a shepherding caste

Inam: tax-exempted land or village

Irrigation fund: a fund for repairing reservoirs

Kaik[k]alar: a weaving caste

Kalian: unidentified

Kamma[lan]: an agriculturalist or trader caste

Kanakapillai: a writer or accountant caste

Kanakkan: a writer or accountant caste

Kanungo: a high official (usually a writer or accountant) posted in a locality

Kaval: a watchman

Kovil: a Hindu temple

Kshatriya: a warrior caste or Varna

Kusavan: a potter caste

Mahataudy: a peon who collects revenue from a village

Maniyam: tax-exempted land

Math: a monastery

Mokassah: a village under the direct control of Poligars

Mootan: a trading caste in Malabar

Mudali: a caste title usually taken by Vellalers

Muttiriyan: a laborer caste, sometimes a watchman

Naick: a caste title, a captain or headman of soldiers

Nattar: a representative of a locality

Ninar: same as a Naick 
Nuttum: a village inhabited by non-Brahmin

Palankeen: A covered litter carried on poles on the shoulders

Palli: an agricultural laborer caste

Pandaram: a non-Brahman priest caste

Panisevar: a temple servant caste

Pariah/Paraia: the lowest ranked caste or the "untouchables"

Poligar: a military leader

Punishivun: a mendicant caste

Putnaver: unidentified

Raja: a military caste claiming to be of Kshatriya origin

Rauze: a military caste claiming to be of Kshatriya origin

Reddi: an agricultural caste of Telugu origin

Sat[t]ani: a temple servant caste

Sembadavan: a fisherman caste

Shanar: a toddy-tapping caste

Shastri: a man of learning, often a title for Brahmin

Shroff: a money changer

Shrotrium: a village totally or partly exempted from revenue

Stala Mazumdar: a high official posted in a locality

Talaiyari: a village policeman or watchman

Tookery: a head watchman

Totty: a village servant

Valluvan: a priest caste for the "untouchables"

Vannan: a washerman caste

Vannian: an agricultural laborer caste

Wochen: a temple priest caste

\section{Notes}

1 For a general description of colonial Chingleput, see Stewart (1879).

2 The details of the mirasi system were discussed by Mizushima (1996).

3 Jaghire-Barnard's Survey Accounts of Ponneri, vol. 68, Tamil Nadu Archives. Thomas Barnard was appointed to survey the area then called Jagir. Barnard commenced the work in February 1767 and completed it, after many interruptions, in November 1773. See Phillimore (1945), p. 88. There are 26 volumes in total of such accounts as prepared by Barnard. As to the general picture on the statistics obtained from the Barnard Report, see Bajaj and Srinivas (1994); Srinivas et al. (2001).

4 The classic account on castes can be found in Thurston (1909).

5 As for the mirasidars in South India, see for instance, Hudleston (1862). See also Mizushima (1996).

6 Bajaj and Srinivas (1994), Table VI, p. 79.

7 Place was appointed as the collector of the Jagir between 1794 and 1799. He prepared a number of revenue records at the village level. Among others, the most interesting are "Miscellaneous accounts, statistical tables etc. accompanying Lionel Place's report on the Company's Jaghire," vols. 1 and 2, Board's Collections, F/4/112, 2115-2116, OIOC. 8 Mizushima (2002).

9 Mizushima (2000), pp. 83-117. 


\section{MIZUSHIMA TSUKASA}

\section{References}

Bajaj, J.K. and Srinivas, M.D. (1994) "Indian economy and polity in the eighteenth century: the Chengalpattu survey: 1767-74," Indian Economy and Polity, Madras: Centre for Policy Studies.

Hudleston, W. (ed.) (1862) Papers on Mirasi Rights, Madras: Pharoah and Co. Athenaeum Press.

Mizushima, T. (1996) "The Mirasi system and local society in pre-colonial South India," in P. Robb et. al. (eds) Local Agrarian Societies in Colonial India-Japanese Perspectives, London: Curzon Press.

Mizushima, T. (2000) "Mirasi system as social grammar - state, local society, and raiyat in the 18th-19th centuries, South India," in Mizushima, T. (ed.) Minami-Indo Tamil Chiiki no Syakai Keizai Henka ni Kansuru Rekishiteki Kenkyu, Report of Research Project of Grant-in-aid for Scientific Research.

Mizushima, T. (2002) "From Mirasidar to Pattadar: South India in the Late Nineteenth Century," in Land, Politics and Trade in South Asia, 18th-20th Centuries: Essays in Memory of Dharma Kumar, Indian Economic and Social History Review, 39: 2 \& 3.

Phillimore, R.H. (1945) Historical Records of the Survey of India, vol. 1, 18th Century, published by order of the Surveyor General of India, India.

Srinivas, M.D. et al. (2001) Thirupporur and Vadakkuppattu—Eighteenth Century Locality Accounts, Chennai: Centre for Policy Studies.

Stewart, Charles (1879) The Chingleput, Late Madras District, A Manual compiled under the orders of the Madras Government, Madras: The Lawrence Asylum Press.

Thurston, E. (1909) Castes and Tribes of Southern India, Madras: Government Press. 


\title{
MODELING THE SPATIAL STRUCTURE OF THE ADMINISTRATIVE SYSTEM IN PONNERI, INDIA, DURING THE LATE EIGHTEENTH CENTURY
}

\author{
Sadahiro Yukio
}

\section{Introduction}

Until the middle of the eighteenth century, South India had been under the rule of the Mughal Empire. There were administrative units called magans, which were almost equivalent to the counties of today. In the late eighteenth century, a colonial policy was introduced by the British and the Mughal Empire gradually lost its power in South India. To govern the area and to collect taxes, the British appointed officers called zamindaris and sent them to some of the villages. Each zamindari governed 25 villages on average, and this formed a new administrative system, which we call the zamindari system.

The spatial structure of the zamindari system does not completely agree with that of the magan system, as we will see later. They are partly similar but differ in some places. Why was the zamindari system spatially different from the magan system, even though they were both administrative systems for the same area? This chapter aims to answer this question by modeling the zamindari system using various factors including the magan system.

\section{Data sources}

The data sources used in the analysis are the village accounts compiled by Thomas Barnard (Barnard Report, 1760s-70s), the Permanent Settlement Records on Zamindaris, Poligars, and Pagodas in 1801, and the census map of 1971 (for details, see Mizushima 2000). The Barnard Report contains reports on 144 villages, whose location was digitized into GIS by ArcInfo ver. 7.2.1 (Figure 7.1). The location of the villages was estimated by comparing the census map of 1971 and the Barnard Report, because village names had often changed 


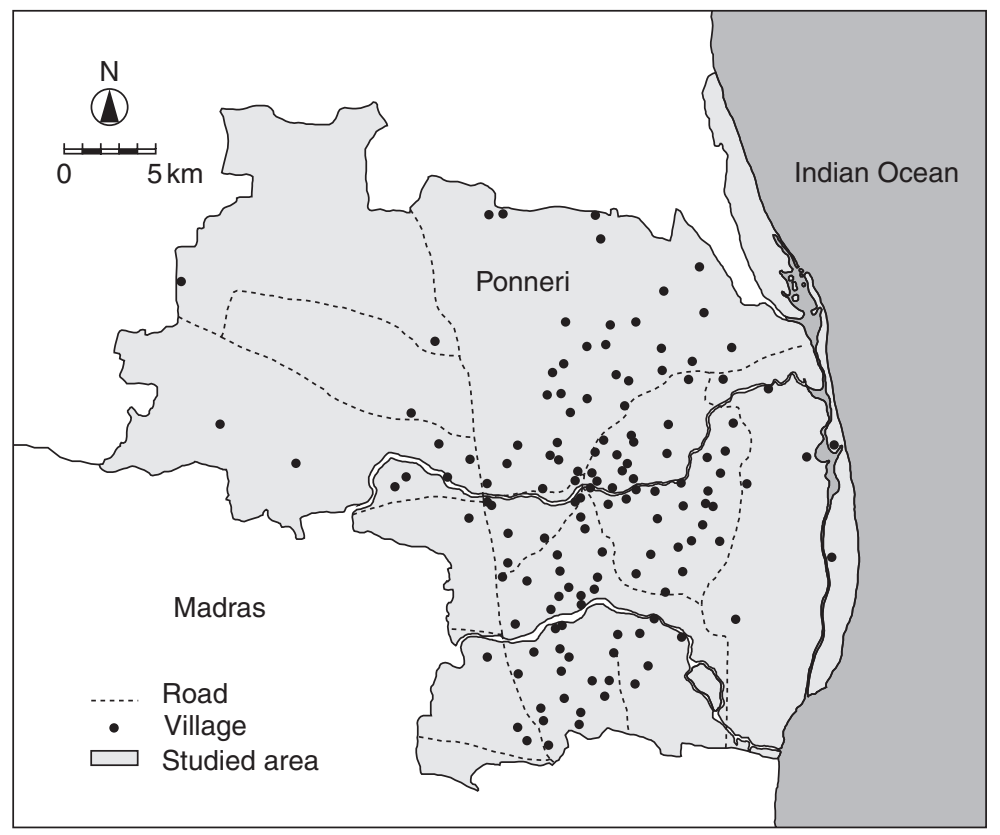

Figure 7.1 The area studied: Ponneri, India.

during the intervening 200 years. A huge amount of data about the villages is available, including socio-economic data such as population, caste composition, names of landholders, and agricultural products.

\section{Modeling a spatial tessellation by a set of other spatial tessellations}

The zamindari system is regarded as a spatial tessellation, that is, a set of non-overlapping space-filling regions (Okabe et al. 2000). Many of the variables that seem to have influenced the introduction and establishment of the zamindari system, including the magan system, also have tessellation structures. Therefore, to explain the zamindari system by other variables is, in a broad sense, to build a model representing a spatial tessellation by a set of other spatial tessellations. Such tessellation modeling often occurs in geography, urban analysis, sociology, and ecology. School districts can be modeled by administrative units, land uses, regions bounded by transportation facilities and those characterized by the socio-economic attributes of the residents, and electoral districts can be explained by administrative units, local communities, and census tracts, etc.

Formally, the problem we are facing is as follows. Suppose a region $S$, which is divided into a set of subregions by a categorical variable; for example, school districts or census tracts. The subregions form a spatial tessellation, which 
we want to explain by other tessellations. We call the categorical variable the dependent variable, as we do in regression analysis. Similarly, we call the tessellation given by the dependent variable the dependent tessellation, denoted as $Y=$ $\left\{y_{1}, y_{2}, \ldots, y_{n}\right\}$, where $y_{i}$ is the $i$ th region in $S$ (Figure 7.2a). To represent the spatial structure of the tessellations, we use a tessellation indicator function

$$
\rho\left(\mathbf{u} ; y_{i}\right)= \begin{cases}1 & \text { if } \mathbf{u} \in y_{i} \\ 0 & \text { otherwise. }\end{cases}
$$

From the indicator function, we can tell whether or not a point $\mathbf{u}$ is contained in $y_{i}$.

(a)

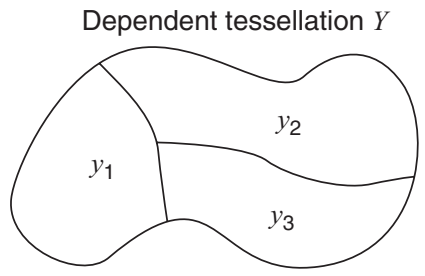

(b)
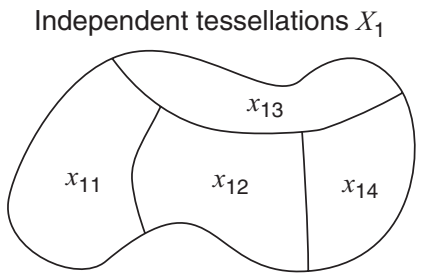

Independent tessellations $X_{2}$

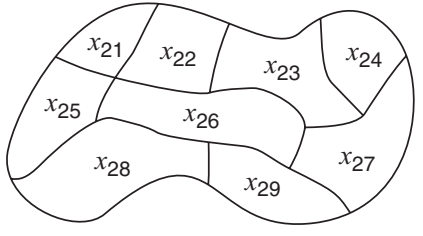

Independent tessellations $X_{3}$

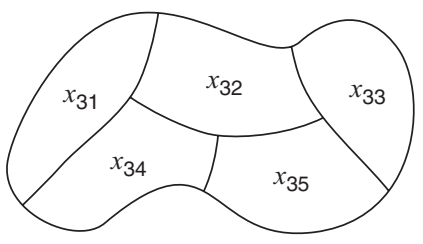

Figure 7.2 (a) An example of the dependent tessellation $Y$ and (b) a set of independent tessellations $X=\left\{X_{1}, X_{2}, \ldots, X_{m}\right\}$. 
To model the dependent tessellation $Y$, we have a set of tessellations given by independent variables. Let $X_{i}=\left\{x_{i 1}, x_{i 2}, \ldots, x_{i n_{i}}\right\}$ be the tessellation given by the $i$ th independent variable; for example, a set of administrative units (Figure 7.2b). The tessellation defined by an independent variable is called the independent tessellation. The set of independent tessellations is denoted by $X=\left\{X_{1}, X_{2}, \ldots, X_{m}\right\}$. The tessellation indicator function is also defined for independent tessellations.

Our objective is to explain the dependent tessellation $Y$ by a set of independent tessellations $X$. There are at least three existing approaches to this problem: (i) the contingency table, (ii) the multinomial logit model, and (iii) the decision tree (for details, see Sadahiro 2001a). These methods, however, lack the concept of space; that is, they do not explicitly consider the spatial structure of variables, so that in their original form, they are not appropriate for analysis of spatial tessellations. We thus adopt a new method for modeling a spatial tessellation by a set of other spatial tessellations that was originally developed by Sadahiro (2002).

This method is designed for exploratory spatial analysis rather than confirmatory analysis (Tukey 1977; Openshaw et al. 1987; Openshaw and Openshaw 1997; Anselin 1998; and Chapter 4 of this book). Exploratory spatial analysis searches for interesting patterns and plausible hypotheses in spatial phenomena, which help more sophisticated spatial analysis such as mathematical and statistical modeling. Exploratory spatial analysis is useful at an early stage of spatial analysis, especially when large volumes of spatial data are available.

In the following sections, we outline Sadahiro's three methods of tessellation modeling: (i) the region-based method, (ii) the boundary-based method, and (iii) the hybrid method. The region-based method focuses on regions that compose the dependent tessellation, while the boundary-based method emphasizes the boundaries dividing the whole region $S$. The hybrid method is a combination of the two methods.

\section{The region-based method}

The region-based method builds a model representing a dependent tessellation by a set of independent tessellations, focusing on regions that compose the dependent tessellation. Its basic idea is to decompose the region $S$ into subregions, and then to model them separately as small independent tessellations (Figure 7.3).

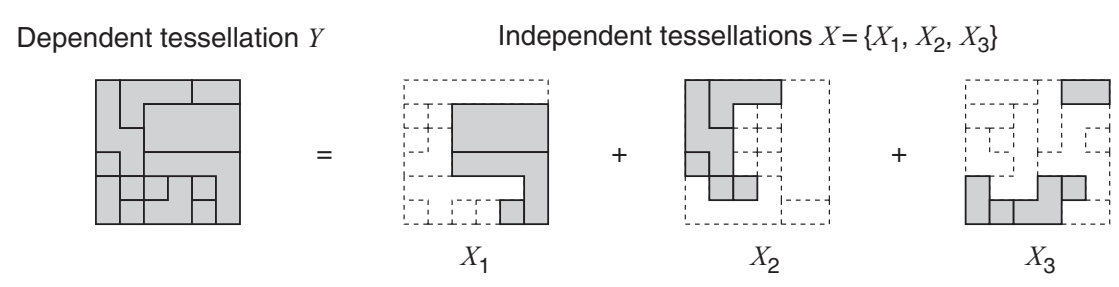

Figure 7.3 Modeling a dependent tessellation by a combination of regions as independent tessellations. 
To model $Y$ in this way, we have to find a set of independent tessellations whose combination agrees well with $Y$. The following algorithm detects such a set of independent tessellations $U$, and gives a set of regions $V$, as a model representing $Y$.

\section{Algorithm: region-based method}

Input: A dependent tessellation $Y$ and a set of independent tessellations $X=\left\{X_{1}\right.$, $\left.X_{2}, \ldots, X_{m}\right\}$

Output: A set of independent tessellations $U$ and a set of regions $V$ modeled by $U$.

Step 1: Set $U$ and $V$ empty.

Step 2: Do 2.1-2.5 while neither $X$ nor $Y$ is an empty set.

Step 2.1: Evaluate the agreement between $Y$ and $X_{i}$ for all $X_{i} \in X$.

Step 2.2: Choose the independent tessellation $X_{i}$ that gives the best agreement.

Step 2.3: Do 2.3.1 and 2.3.2 for all $y_{j} \in Y$.

2.3.1: Evaluate the fitness of $X_{i}$ for $y_{j}$.

2.3.2: If the fitness is significant, add $y_{j}$ to $V$ and remove $y_{j}$ from $Y$.

Step 2.4: If any $y_{j} \in Y$ was added to $V$, add $X_{i}$ to $U$.

Step 2.5: Remove $X_{i}$ from $X$.

Step 3: Report $U$ and $V$.

In Step 2.1, the region-based method evaluates the agreement between the dependent tessellation $Y$ and the independent tessellation $X_{i}$. To this end, we use a measure that we call the agreement index, which is defined as follows.

Consider a pairwise indicator function defined by

$$
\sigma(\mathbf{u}, \mathbf{v} ; Y)= \begin{cases}1 & \text { if } \exists i, \rho\left(\mathbf{u} ; y_{i}\right) \rho\left(\mathbf{v} ; y_{i}\right)=1 \\ 0 & \text { otherwise }\end{cases}
$$

where $\mathbf{u}$ and $\mathbf{v}$ are the locational vectors of points in the region $S$, and $Y$ is a spatial tessellation of $S$. If two locations belong to the same region in $Y$, then the function is equal to one. Otherwise, it becomes zero.

Using the pairwise indicator function, we can describe the spatial autocorrelation of the tessellation $T$ by a function of distance $d$ between two locations:

$$
\gamma(d ; Y)=\frac{\int_{\mathbf{u} \in S} \int_{\mathbf{v} \in S,|\mathbf{u}-\mathbf{v}|=d} \sigma(\mathbf{u}, \mathbf{v} ; Y) \mathrm{d} \mathbf{v} \mathrm{d} \mathbf{u}}{\int_{\mathbf{u} \in S} \int_{\mathbf{v} \in S,|\mathbf{u}-\mathbf{v}|=d} \mathrm{~d} \mathbf{v} \mathrm{d} \mathbf{u}} .
$$

The spatial autocorrelation function is similar to the covariogram used in geostatistics (Isaak and Srivastava 1989; Wackernagel 1995). The function $\gamma(d ; Y)$ 


\section{SADAHIRO YUKIO}

shows a large value if there exists a strong spatial autocorrelation in $Y$. If the tessellation $Y$ consists of small regions, then spatial autocorrelation is not strong, and $\gamma(d ; Y)$ thus shows a small value. The spatial autocorrelation function is also calculated for the independent tessellations.

The agreement index is then defined by

$$
A\left(X_{i} ; Y\right)=\int_{\mathbf{u} \in S} \int_{\mathbf{v} \in S} e\left(\mathbf{u}, \mathbf{v} ; X_{i}, Y\right) \mathrm{d} \mathbf{v} \mathrm{d} \mathbf{u},
$$

where

$$
e\left(\mathbf{u}, \mathbf{v} ; X_{i}, Y\right)= \begin{cases}1-\gamma(d ; Y) & \text { if } \sigma(\mathbf{u}, \mathbf{v} ; Y)=1 \text { and } \sigma\left(\mathbf{u}, \mathbf{v} ; X_{i}\right)=1 \\ -\gamma(d ; Y) & \text { if } \sigma(\mathbf{u}, \mathbf{v} ; Y)=1 \text { and } \sigma\left(\mathbf{u}, \mathbf{v} ; X_{i}\right)=0 \\ \gamma(d ; Y)-1 & \text { if } \sigma(\mathbf{u}, \mathbf{v} ; Y)=0 \text { and } \sigma\left(\mathbf{u}, \mathbf{v} ; X_{i}\right)=1 \\ \gamma(d ; Y) & \text { if } \sigma(\mathbf{u}, \mathbf{v} ; Y)=0 \text { and } \sigma\left(\mathbf{u}, \mathbf{v} ; X_{i}\right)=0 .\end{cases}
$$

In the following we use it in its standardized form

$\alpha\left(X_{i} ; Y\right)$

$$
\begin{aligned}
= & \left\{A\left(X_{i} ; Y\right)-\int_{\mathbf{u} \in S} \int_{\mathbf{v} \in S} \min \{-\gamma(|\mathbf{u}-\mathbf{v}| ; Y), \gamma(|\mathbf{u}-\mathbf{v}| ; Y)-1\} \mathrm{d} \mathbf{v} \mathrm{d} \mathbf{u}\right\} \\
& /\left\{\int_{\mathbf{u} \in S} \int_{\mathbf{v} \in S} \max \{1-\gamma(|\mathbf{u}-\mathbf{v}| ; Y), \gamma(|\mathbf{u}-\mathbf{v}| ; Y)\} \mathrm{d} \mathbf{v} \mathrm{d} \mathbf{u}\right. \\
& \left.-\int_{\mathbf{u} \in S} \int_{\mathbf{v} \in S} \min \{-\gamma(|\mathbf{u}-\mathbf{v}| ; Y), \gamma(|\mathbf{u}-\mathbf{v}| ; Y)-1\} \mathrm{d} \mathbf{v} \mathrm{d} \mathbf{u}\right\}
\end{aligned}
$$

which satisfies $0 \leq \alpha\left(X_{i} ; Y\right) \leq 1$. The agreement index $A\left(X_{i} ; Y\right)$ shows a large value if the tessellation $X_{i}$ agrees well with $Y$. Otherwise, if $X_{i}$ is quite different from $Y$, then $\alpha\left(X_{i} ; Y\right)$ becomes small.

Evaluation of the fitness of $X_{i}$ for $y_{j}$ (Step 2.3.1) is similar to that of the agreement between tessellations. The fitness index of $X_{i}$ with respect to $y_{j}$ is defined by

$$
\begin{aligned}
\beta\left(X_{i} ; y_{i}\right)= & \left\{\int_{\mathbf{u} \in y_{i}} \int_{\mathbf{v} \in S} e\left(\mathbf{u}, \mathbf{v} ; X_{i}, Y\right) \mathrm{d} \mathbf{v} \mathrm{d} \mathbf{u}\right. \\
& \left.\left.-\int_{\mathbf{u} \in y_{i}} \int_{\mathbf{v} \in S} \min \{-\gamma(|\mathbf{u}-\mathbf{v}|) ; Y), \gamma(|\mathbf{u}-\mathbf{v}| ; Y)-1\right\} \mathrm{~d} \mathbf{v} \mathrm{d} \mathbf{u}\right\} \\
& \left\langle\left\{\int_{\mathbf{u} \in y_{i}} \int_{\mathbf{v} \in S} \max \{1-\gamma(|\mathbf{u}-\mathbf{v}|) ; Y), \gamma(|\mathbf{u}-\mathbf{v}| ; Y)\right\} \mathrm{d} \mathbf{v} \mathrm{d} \mathbf{u}\right. \\
& \left.\left.-\int_{\mathbf{u} \in y_{i}} \int_{\mathbf{v} \in S} \min \{-\gamma(|\mathbf{u}-\mathbf{v}|) ; Y), \gamma(|\mathbf{u}-\mathbf{v}| ; Y)-1\right\} \mathrm{~d} \mathbf{v} \mathrm{d} \mathbf{u}\right\} .
\end{aligned}
$$


(a)

\begin{tabular}{|l|l|l|l|l|l|}
\hline 1 & 3 & 5 & 2 & 1 & 3 \\
\hline 4 & 1 & 9 & 7 & 4 & 3 \\
\hline 4 & 5 & 2 & 5 & 4 & 8 \\
\hline 3 & 4 & 3 & 1 & 8 & 9 \\
\hline 2 & 2 & 3 & 4 & 8 & 3 \\
\hline 4 & 3 & 6 & 3 & 7 & 6 \\
\hline
\end{tabular}

(b)

\begin{tabular}{|l|l|l|l|l|l|}
\hline$A$ & $A$ & $B$ & $A$ & $A$ & $A$ \\
\hline$B$ & $A$ & $C$ & $C$ & $B$ & $A$ \\
\hline$B$ & $B$ & $A$ & $B$ & $B$ & $C$ \\
\hline$A$ & $B$ & $A$ & $A$ & $C$ & $C$ \\
\hline$A$ & $A$ & $A$ & $B$ & $C$ & $A$ \\
\hline$B$ & $A$ & $C$ & $A$ & $C$ & $C$ \\
\hline
\end{tabular}

(c)

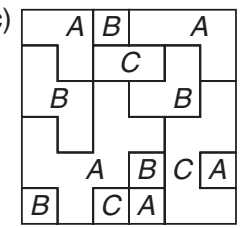

Figure 7.4 Categorization of a numerical variable. (a) The dependent tessellation $Y$; (b) a set of independent tessellations $X$; and (c) another set of independent tessellations $X^{\prime}$.

Its significance is determined by a threshold value $\beta_{T}$ provided by the analyst. The independent tessellation $X_{i}$ is said to fit $y_{j}$ significantly if

$$
\beta\left(X_{i} ; y_{i}\right) \geq \beta_{T} .
$$

The choice of the threshold $\beta_{T}$ depends on the circumstances. If analysis were at an early stage, then a small value would be appropriate because it permits a loose fit of the tessellations so that various independent variables can be discussed later. When the focus is on only important variables, then the threshold $\beta_{T}$ should be large so that independent tessellations closely fit the dependent tessellation.

In addition to categorical variables, numerical variables such as the area and population of each region can be taken into account in the region-based method. Suppose a numerical variable exists as shown in Figure 7.4a. We categorize the variable into several classes; for example, three classes [0-3.5], [3.5-5.5], [5.5-10], label them as A, B, and C (Figure 7.4b), and merge adjacent regions having the same labels (Figure 7.4c). The categorization is performed so that it maximizes the agreement between the numerical and the dependent variables with respect to their spatial tessellations (for details, see Sadahiro, 2002).

\section{The boundary-based method}

The region-based method focuses on regions that compose the dependent tessellation, and considers them as essential components of the tessellation. The boundarybased method, on the other hand, emphasizes the boundaries between regions rather than the regions themselves. The basis of the boundary-based method is that the tessellation is generated by dividing a region into subregions, and not combining subregions into a larger region, though the method does not explicitly take into account the process of tessellation development.

The scale of analysis is also somewhat different between the two methods. The region-based method takes a global view of tessellations. Its agreement index evaluates all the point pairs in $S$ whether or not they are equivalent with respect to the pairwise indicator function, even if they are located a great distance apart. The boundary-based method, by its nature, looks at tessellations locally because the division process is usually a local phenomenon. As will be seen later, it considers only pairs of adjacent regions in $Y$ in its agreement evaluation. 


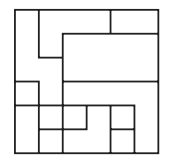

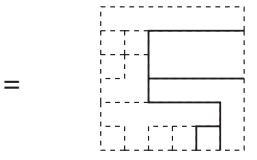

$X_{1}$

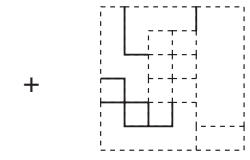

$X_{2}$

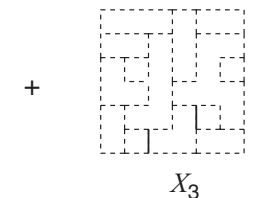

Figure 7.5 Modeling a dependent tessellation by a combination of boundaries in independent tessellations.

Consider the example shown in Figure 7.5. The independent tessellations $X_{1}$, $X_{2}$, and $X_{3}$ are all different from the dependent tessellation $Y$. However, all three tessellations partly agree with $Y$ for some of the boundaries, which are shown by the solid lines in the figure. Consequently, the dependent tessellation $Y$ can be modeled by a combination of some of the boundaries in $X_{1}, X_{2}$, and $X_{3}$. This is the basic idea of the boundary-based method.

Let $b(y)_{i j}$ be the boundary between the regions $y_{i}$ and $y_{j}$. The set of boundaries that composes the dependent tessellation $Y$ is $B(Y)=\left\{b(y)_{i j}, i, j \in N\right\}$, where $N=\{1,2, \ldots, n\}$. We define the boundary indicator function:

$$
s\left(y_{i}, y_{j}\right)= \begin{cases}1 & \text { if } b(Y)_{i j} \text { exists } \\ 0 & \text { otherwise. }\end{cases}
$$

The function returns a value of one if the regions $y_{i}$ and $y_{j}$ share the same boundary. The boundaries of the independent tessellation $X_{i}$ are similarly represented. The boundary between the regions $x_{i j}$ and $x_{i k}$ is denoted by $b\left(X_{i}\right)_{j k}$, and the set of boundaries of $X_{i}$ is given by $B\left(X_{i}\right)=\left\{b\left(X_{i}\right)_{j k}, j, k \in N_{i}\right\}$, where $N_{i}=\left\{1,2, \ldots, n_{i}\right\}$.

The boundary indicator function of $X_{k}$ is defined by

$$
\boldsymbol{s}\left(x_{k i}, x_{k j}\right)= \begin{cases}1 & \text { if } b\left(X_{k}\right)_{i j} \text { exists } \\ 0 & \text { otherwise. }\end{cases}
$$

Each tessellation is hereafter represented by either its composing regions or its boundaries; the dependent tessellation, for instance, is represented by either $Y$ or $B(Y)$. The algorithm of the boundary-based method is as follows.

\section{Algorithm: boundary-based method}

Input: A dependent tessellation $B(Y)$ and a set of independent tessellations $B(X)=\left\{B\left(X_{1}\right), B\left(X_{2}\right), \ldots, B\left(X_{k}\right)\right\}$

Output: A set of independent tessellations $B(U)$ and a set of boundaries $B(V)$ explained by $B(U)$.

Step 1: Set $B(U)$ and $B(V)$ empty.

Step 2: Do 2.1-2.5 while neither $B(X)$ nor $B(Y)$ is an empty set.

Step 2.1: Evaluate the agreement between $B(Y)$ and $B\left(X_{k}\right)$ for all $B\left(X_{k}\right) \in B(X)$.

Step 2.2: Choose the independent tessellation $B\left(X_{k}\right)$ that gives the best agreement. 
Step 2.3: Do 2.3.1 and 2.3.2 for all $b(Y)_{i j} \in B(Y)$.

2.3.1: Evaluate the fit of $B\left(X_{k}\right)$ for $b(Y)_{i j}$.

2.3.2: If the fit is acceptable, add $b(Y)_{i j}$ to $B(V)$ and remove $b(Y)_{i j}$ from $B(Y)$.

Step 2.4: If any $b(Y)_{i j} \in B(Y)$ was added to $B(V)$, add $B\left(X_{k}\right)$ to $B(U)$.

Step 2.5: Remove $B\left(X_{k}\right)$ from $B(X)$.

Step 3: Report $B(U)$ and $B(V)$.

The agreement between the independent tessellation $B\left(X_{i}\right)$ and the dependent tessellation $B(Y)$ is measured by

$$
A^{\prime}\left(B\left(X_{i}\right) ; B(Y)\right)=\sum_{j, k, s\left(y_{j}, y_{k}\right)=1} \int_{\mathbf{u} \in y_{j} \cup y_{y_{k}}} \int_{\mathbf{v} \in y_{j} \cup y_{k}} e\left(\mathbf{u}, \mathbf{v} ; X_{i}, Y\right) \mathrm{d} \mathbf{v} \mathrm{d} \mathbf{u}
$$

and in its standardized form

$$
\begin{aligned}
& \alpha^{\prime}\left(B\left(X_{i}\right) ; B(Y)\right) \\
& \left.=\left\{A^{\prime}\left(X_{i} ; Y\right)-\sum_{j, k, s\left(y_{j}, y_{k}\right)=1} \int_{\mathbf{u} \in y_{j}, y_{y_{k}}} \int_{\mathbf{v} \in y_{j} \cup y_{y_{k}}} \min \{-\gamma(|\mathbf{u}-\mathbf{v}|) ; Y), \gamma(|\mathbf{u}-\mathbf{v}| ; Y)-1\right\} \mathrm{d} \mathbf{v d u}\right\} \\
& /\left\{\sum _ { j , k , S , y _ { j } , y _ { k } ) = 1 } \left[\int_{\mathbf{u} \in y_{i} \cup y_{k}} \int_{\mathbf{v} \in y_{j}, y_{y_{k}}} \max \{1-\gamma(|\mathbf{u}-\mathbf{v}| ; Y), \gamma(|\mathbf{u}-\mathbf{v}| ; Y)\} \mathrm{d} \mathbf{v} \mathrm{d} \mathbf{u}\right.\right. \\
& \left.\left.-\int_{\mathbf{u} \in y_{j}, y_{k}} \int_{\mathbf{v} \in y_{j}, y_{y_{k}}} \min \{-\gamma(|\mathbf{u}-\mathbf{v}| ; Y), \gamma(|\mathbf{u}-\mathbf{v}| ; Y)-1\} \mathrm{d} \mathbf{v} \mathrm{d} \mathbf{u}\right]\right\} .
\end{aligned}
$$

The difference between equations (4) and (11) lies in the domain of integration. The former integrates the pairwise evaluation function for all $\mathbf{u}$ and $\mathbf{v}$ in $S$, while the latter considers only the point pairs in regions adjacent in $Y$. This reflects the different views of the methods mentioned earlier.

The fitness of $B\left(X_{i}\right)$ for $b(Y)_{j k}$ is evaluated by

$$
\begin{aligned}
\beta( & \left.B\left(X_{i}\right) ; b(Y)_{j k}\right) \\
= & \left\{\int_{\mathbf{u} \in y_{j} \cup y_{k} y_{k}} \int_{\mathbf{v} \in y_{j} \cup y_{y_{k}}} e\left(\mathbf{u}, \mathbf{v}, X_{i}, Y\right) \mathrm{d} \mathbf{v} \mathrm{d} \mathbf{u}\right. \\
& \left.-\int_{\mathbf{u} \in y_{j} \cup y_{k}} \int_{\mathbf{v} \in y_{j} \cup y_{y_{k}}} \min \{-\gamma(|\mathbf{u}-\mathbf{v}| ; Y), \gamma(|\mathbf{u}-\mathbf{v}| ; Y)-1\} \mathrm{d} \mathbf{v} \mathrm{d} \mathbf{u}\right\} \\
& /\left\{\int_{\mathbf{u} \in y_{j} \cup y_{k}} \int_{\mathbf{v} \in y_{j} \cup y_{y_{k}}} \max \{1-\gamma(|\mathbf{u}-\mathbf{v}| ; Y), \gamma(|\mathbf{u}-\mathbf{v}| ; Y)\} \mathrm{d} \mathbf{v} \mathrm{d} \mathbf{u}\right. \\
& \left.-\int_{\mathbf{u} \in y_{j} \cup y_{k}} \int_{\mathbf{v} \in y_{j} \cup y_{y_{k}}} \min \{-\gamma(|\mathbf{u}-\mathbf{v}| ; Y), \gamma(|\mathbf{u}-\mathbf{v}| ; Y)-1\} \mathrm{d} \mathbf{v} \mathrm{d} \mathbf{u}\right\} .
\end{aligned}
$$


Whether it is acceptable or not is again judged by the threshold value $\beta_{T}^{\prime}$ provided by the analyst. Numerical variables can also be included in the analysis as for the region-based method.

\section{The hybrid method}

The region-based and boundary-based methods are complementary in the sense that regions are defined by boundaries while boundaries are given by regions. However, they differ in their scales of analysis as mentioned earlier. The regionbased method treats tessellations globally, while the boundary-based method focuses on local heterogeneity in the variables.

This difference in scale naturally leads to the idea that they can complement each other. Since the region-based method is suitable for global analysis, it should be performed first, and then followed by the boundary-based method. The boundarybased method is applied to a part of the original dependent tessellation that is not explained by the region-based method. We call this the hybrid method.

The input of the hybrid method is a dependent tessellation and a set of independent tessellations represented by both regions and boundaries. Its output is a set of regions and boundaries explained by the two methods, and the set of independent tessellations used for the explanation.

\section{Modeling of the zamindari system}

Using the methods described in the previous section, this section analyzes the zamindari system using a set of available independent variables. Even before the zamindari system was introduced in the late eighteenth century, the magan system had existed, as mentioned earlier. Figure 7.6 shows the magan and zamindari systems as Voronoi diagrams. Since the village boundary was not known in map format, it was approximated by the Voronoi diagram in which villages were used as generators.

As could be expected, the zamindari system does not completely agree with the magan system. Their spatial structures are similar in some places but different in others. They agree well in the central Ponneri region, but have different structures in the surrounding areas. Why is the zamindari system different from the magan system?

To answer this question, we first visually compared the map of the zamindari system with maps containing other variables that might have affected its introduction and establishment (Aono 2000; Fuko 2001). However, this process was quite difficult and inefficient because of a huge amount of attribute data; it took a long time to compare maps visually. This experience led us to develop the exploratory method proposed in the previous sections. We have developed it to extract possible influential factors among numerous variables, to evaluate them in terms of the agreement with the zamindari system, and finally to explain the underlying structure of the zamindari system, in an effective and objective 
(a)

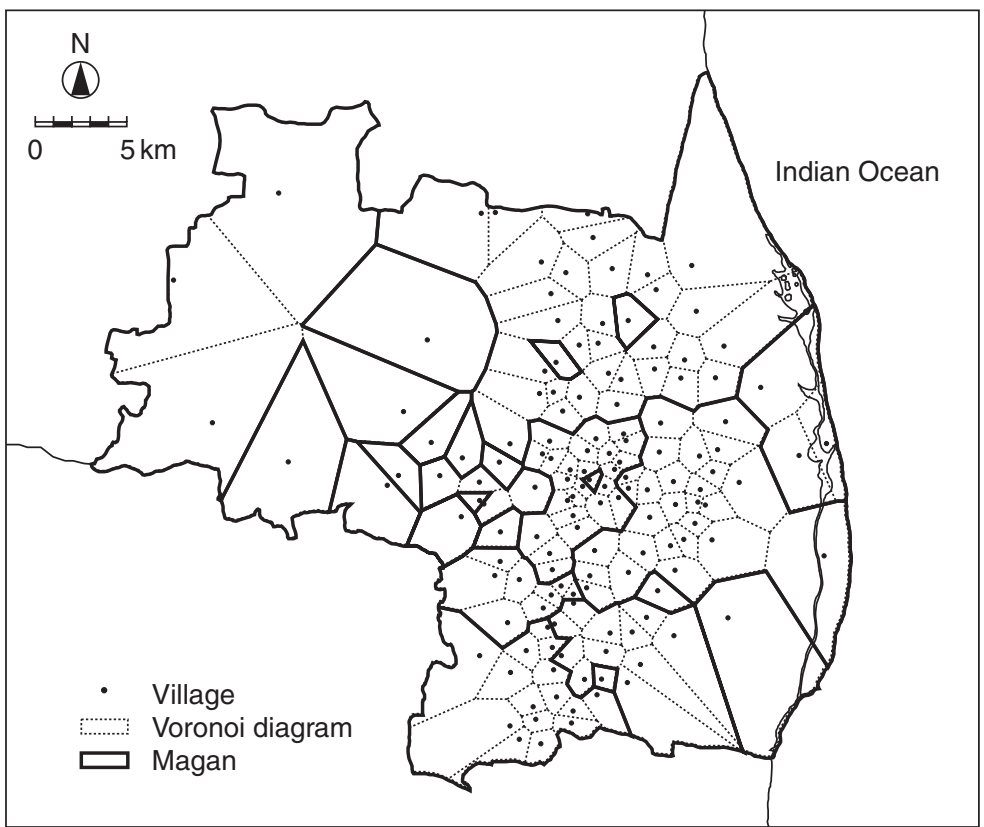

(b)

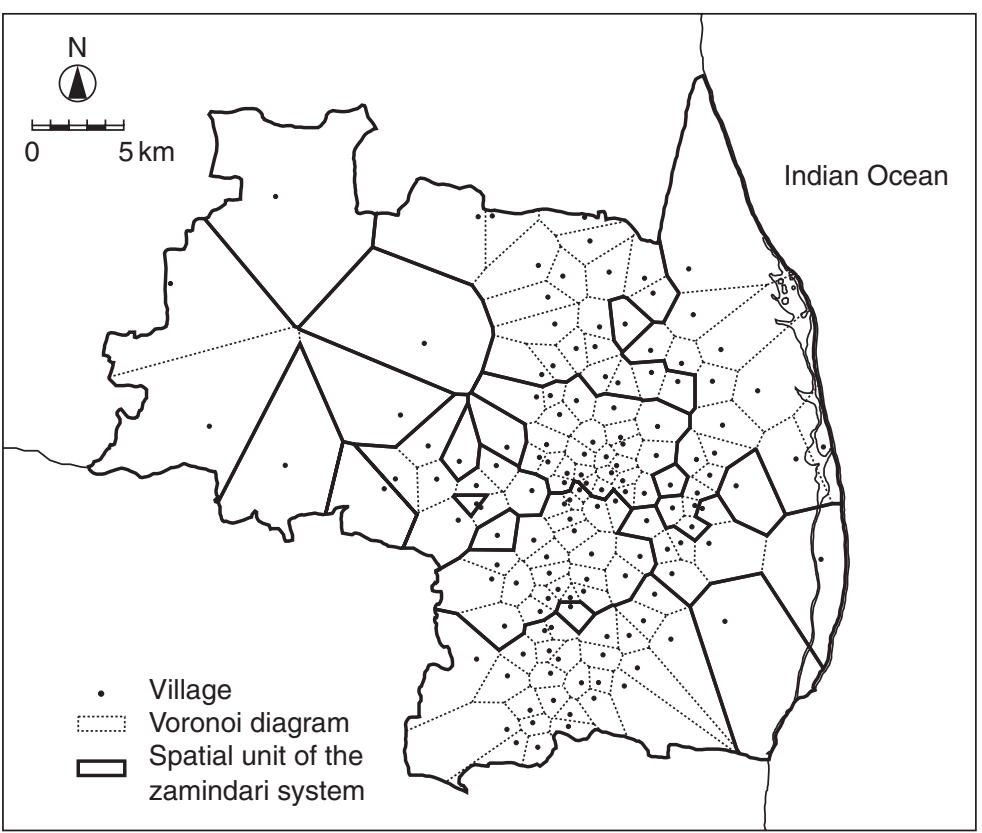

Figure 7.6 The two administrative systems in Ponneri in the late eighteenth century; (a) the magan system and (b) the zamindari system. 
way. We should also note that, through visual analysis, we noticed that the zamindari system might be composed of a spatial combination of the magan system and other factors: a part of the zamindari system not explained by the magan system seemed to agree with the tessellations given by other variables. That is why we chose the combination approach discussed in the previous section.

The dependent tessellation is, therefore, the zamindari system represented by a set of Voronoi regions as shown in Figure 7.6b. From the attribute data of the villages, we chose fifteen variables as the independent variables (Table 7.1). They were also transformed into Voronoi diagrams, being the independent tessellations.

We first applied the region-based method to model the zamindari system. The threshold value $\beta_{T}$ was set to 0.99 , a relatively large value, to detect only the influential factors. As shown in Table 7.2, the method reported after the first execution of Step 2.1 that the magan system was the most influential among all the variables. We therefore removed the regions explained by the magan system and investigated the other independent variables in turn. However, since none of the other variables showed significant fitness for the regions left in $Y$, the final result $U$ contains only the magan system. Figure 7.7 shows a set of regions $V$ explained by the magan system.

The result is quite reasonable because it is unlikely that the zamindari system was completely ignored by the existing magan system. However, the area of the zamindari regions as explained by the magan system accounts for only $22.43 \%$,

Table 7.1 Independent variables used in analysis

\begin{tabular}{ll}
\hline $\begin{array}{l}\text { Categorical variables } \\
\text { Magan }\end{array}$ & Administrative unit in the mid-eighteenth century \\
Poligar & Military assigned the role to keep law and order \\
Caste composition & Village category based on caste composition \\
$\begin{array}{l}\text { Dominant caste } \\
\text { Brahman }\end{array}$ & $\begin{array}{c}\text { Existence of a dominant caste (binary variable) } \\
\text { The highest priest of Hindu }\end{array}$ \\
Vrop type & Village category based on crops cultivated \\
Numerical variables & Number of residents \\
Population & Area of a village \\
Area & Homogeneity in caste composition measured by the extropy \\
Caste homogeneity & index \\
Irrigated farmland & Ratio of the area of irrigated farmland to that of the total \\
farmland & Ratio of the area of wasteland to that of the whole village \\
Wasteland & Ratio of the area of forest to that of the whole village \\
Forest & Ratio of the area of land owned by state to that of the \\
State-owned land & whole village \\
Noe & Number of hoes \\
Tree & Number of trees \\
\hline
\end{tabular}


Table 7.2 Modeling the zamindari system by the regionbased method

\begin{tabular}{lc}
\hline Agreement index $\alpha\left(X_{i} ; Y\right)$ at the first execution of Step 2.1 \\
Magan & 0.8249 \\
Poligar & 0.7682 \\
Caste composition & 0.4648 \\
Dominant caste & 0.6076 \\
Brahman & 0.3497 \\
Crop type & 0.4105 \\
Population & 0.7512 \\
Area & 0.7548 \\
Caste homogeneity & 0.7401 \\
Irrigated farmland & 0.7740 \\
Wasteland & 0.7669 \\
Forest & 0.7623 \\
State-owned land & 0.7495 \\
Hoe & 0.4681 \\
Tree & 0.4676 \\
The best agreement index $\alpha\left(X_{i} ; Y\right)$ after & the first \\
execution of Step 2.1 & \\
Irrigated farmland & 0.7591 \\
Wasteland & 0.7496 \\
Forest & 0.7245 \\
State-owned land & 0.7231 \\
Dominant caste & 0.7189 \\
Population & 0.7158 \\
\hline
\end{tabular}

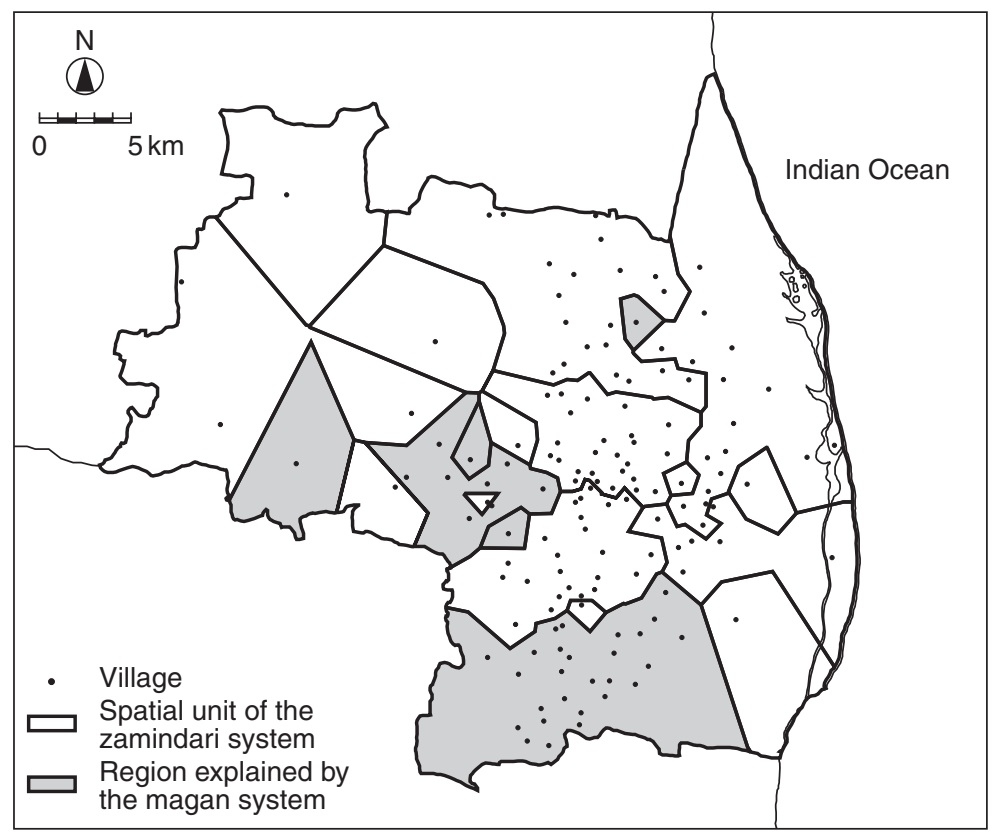

Figure 7.7 Zamindari regions modeled by the region-based method. 
which is not satisfactory. We then applied the boundary-based method to the same data, with the threshold value $\beta_{T}^{\prime}=0.99$. Unfortunately, it did not improve the results significantly, so we applied the hybrid method and obtained the results shown in Table 7.3 and Figure 7.8.

Table 7.3 Modeling the zamindari system using the hybrid method

\begin{tabular}{ll}
\hline $\begin{array}{l}\text { The best agreement index } \alpha\left(X_{i} ; Y\right) \text { reported } \\
\text { in the region-based method }\end{array}$ \\
Magan & 0.8249 \\
The best agreement index $\alpha\left(X_{i} ; Y\right)$ reported & \\
in the boundary-based method & \\
Dominant caste & 0.8974 \\
Poligar & 0.8952 \\
Population & 0.8911 \\
Wasteland & 0.8902 \\
Area & 0.8900 \\
State-owned land & 0.8892
\end{tabular}

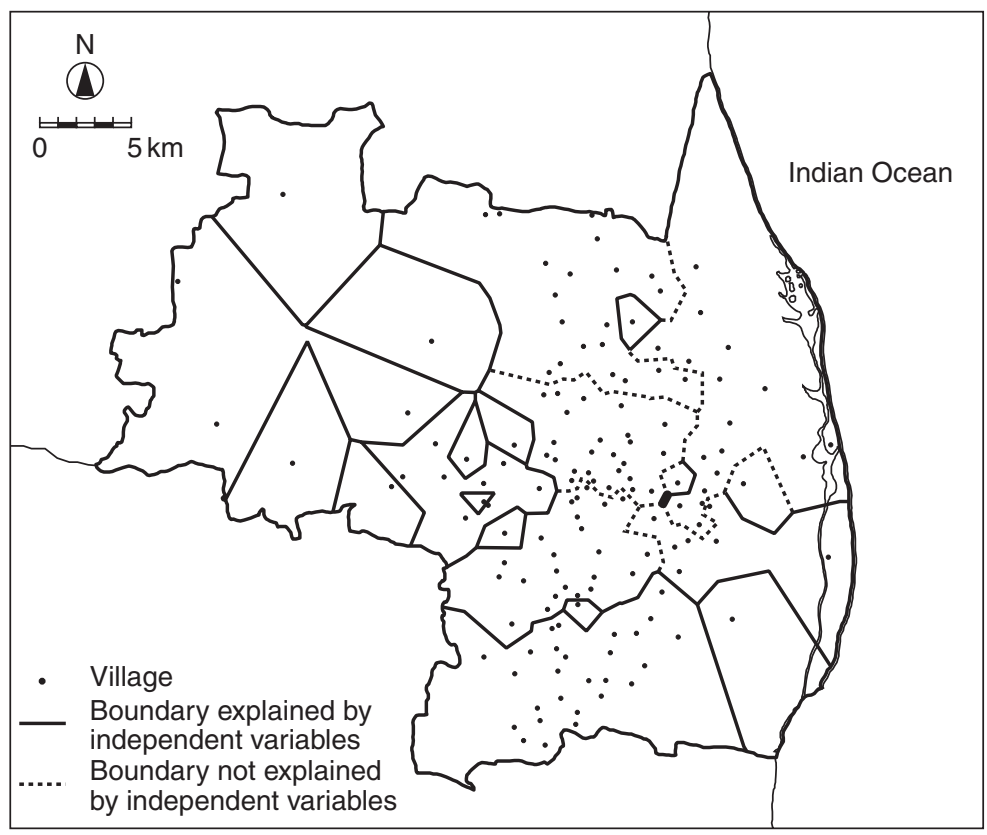

Figure 7.8 Zamindari boundaries modeled using the hybrid method. 
The combination of the two methods yielded better result than those from the individual methods. Among all the boundaries $76.77 \%$ are explained by four independent variables: the magan system, the dominant caste, the poligar system, and the population. Poligars were the military who were assigned to ensure security and maintain order, so the poligar system was, in a sense, another administrative system in those days. Consequently, it is understandable that the poligar system affected the spatial structure of the zamindari system. Analysis also detected the ratio of the dominant caste as an influential factor. There were a number of villages in which a certain caste accounted for a large proportion of the residents; for example, pariah (untouchable), vellalar (farmer), or idaiyar (cow keeper). Such villages were usually characterized by their dominant castes, and it is thus possible that the existence of a dominant caste affected the zamindari system.

From the above results, we can at least say that the magan system was the most influential among the various factors that affected the spatial structure of the zamindari system. This naturally leads to a question on the formation of the magan system: "How was it formed?" To answer this, we next analyzed the magan system using variables other than the zamindari system. From the three methods discussed before, we chose the hybrid method, because it yielded the best results in the previous analysis. The threshold values $\beta_{T}$ and $\beta_{T}^{\prime}$ were set to 0.99 . The results are shown in Table 7.4 and Figure 7.9.

The hybrid method explains $84.26 \%$ of the boundaries of the magan system by four independent variables: the poligar system, irrigated farmland, the dominant caste, and the population. The poligar system (Figure 7.10) was the most influential among the variables, which suggests that the magan system had its roots in the poligar system. This seems to reflect a chain of administrative systems: the poligar system, the magan system, and finally the zamindari system. Older administrative systems are always partly inherited by newer systems.

Table 7.4 Modeling the magan system using the hybrid method

The best agreement index $\alpha\left(X_{i} ; Y\right)$ reported in the region-based method

$\begin{array}{ll}\text { Poligar } & 0.7759\end{array}$

The best agreement index $\alpha\left(X_{i} ; Y\right)$ reported in the boundary-based method

Irrigated farmland $\quad 0.8523$

Poligar $\quad 0.8952$

Population $\quad 0.8911$

Wasteland $\quad 0.8902$

Area $\quad 0.8900$

State-owned land $\quad 0.8892$ 


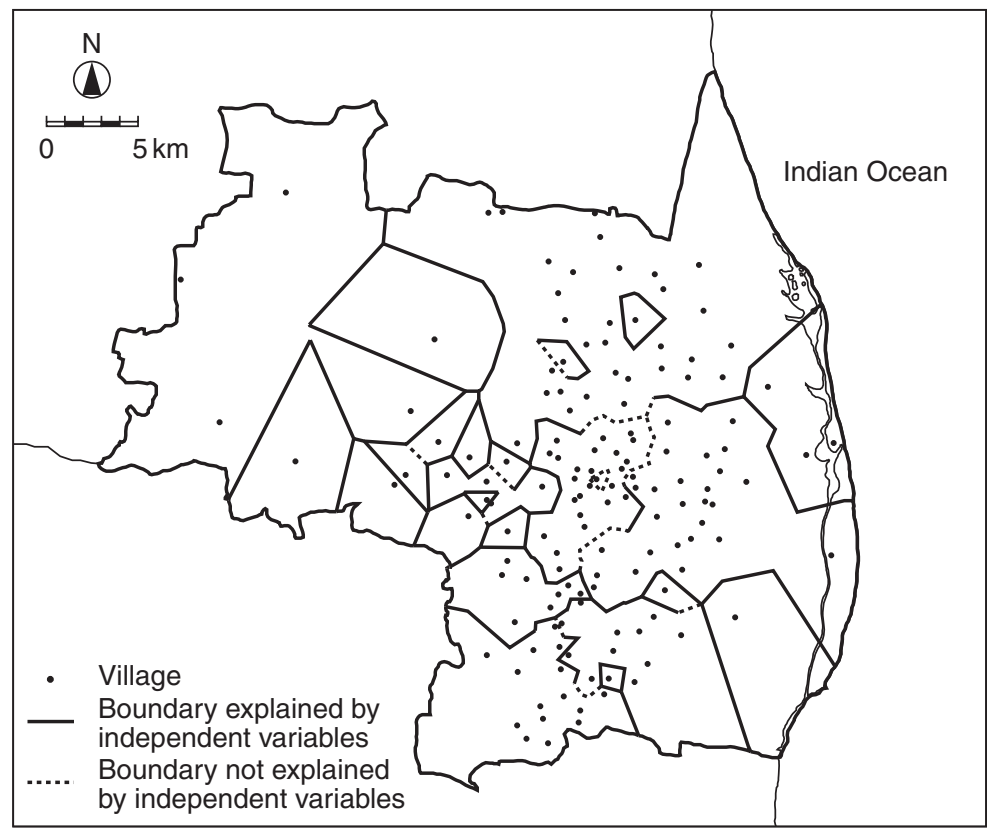

Figure 7.9 Magan boundaries modeled using the hybrid method.

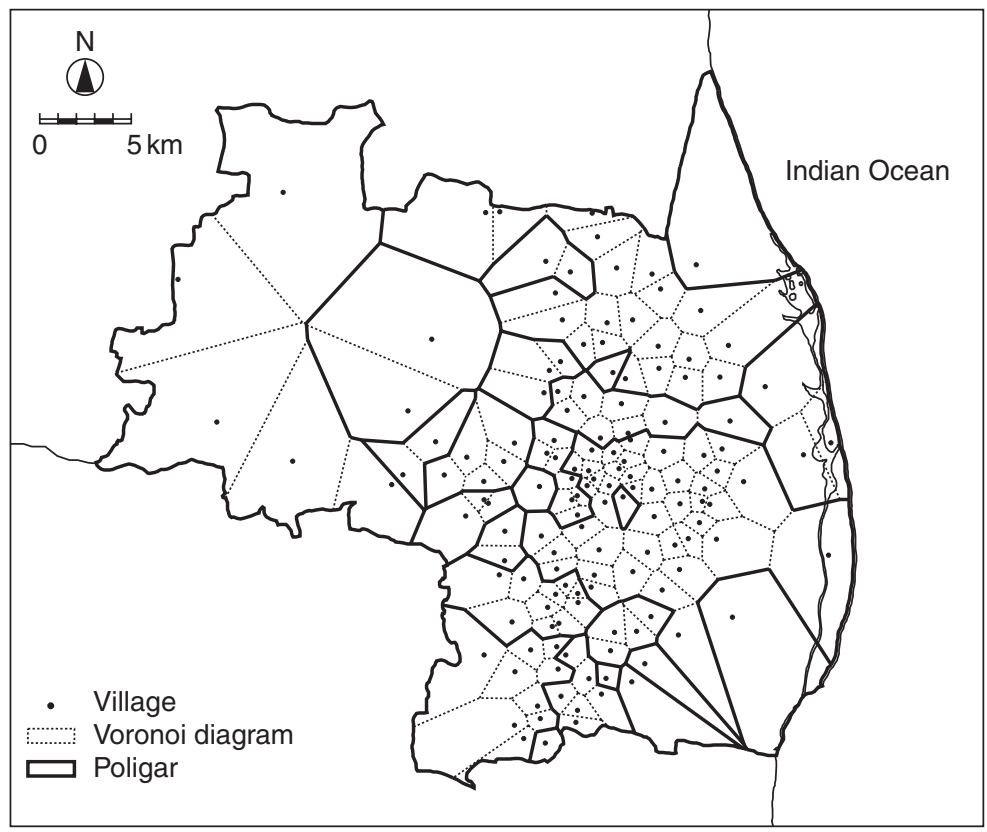

Figure 7.10 The poligar system. 


\section{Conclusions}

In this chapter, we have built a model representing the zamindari system in Ponneri, India, during the late eighteenth century. As reviewed in the section on modeling a spatial tessellation, there are at least three existing methods available for modeling spatial tessellations: the contingency table, the multinomial logit model, and the decision tree. These methods, however, lack the concept of space; that is, they do not explicitly consider the spatial structure of variables, so that in their original form they are not appropriate for modeling spatial tessellations. We thus used the exploratory modeling methods proposed by Sadahiro (2002). Among the three methods, the hybrid method gave the best results in terms of model fitting; $76.77 \%$ of the zamindari boundary was explained by four independent variables: the magan system, dominant caste, poligar system, and population. We then applied the hybrid method to the magan system to explain it using factors other than the zamindari system, then the results showed that the magan system is mainly described by the poligar system. These results reflect a chain of administrative systems: the poligar system, the magan system, and finally the zamindari system.

We finally discuss some limitations of our study for future research. First, spatial tessellations are not only formed by other spatial tessellations, but are also affected by other spatial objects such as points, lines, and scalar and vector fields. For instance, when school districts are determined, the location of transportation facilities is always taken into consideration. The zamindari and magan systems may have been affected by other types of spatial object; for example, road networks, water system, terrain elevation, and so forth. A more flexible model that treats a wide variety of spatial objects needs to be developed and applied. Second, benchmark values for the thresholds $\beta_{T}$ and $\beta_{T}^{\prime}$ used in fitness evaluation should be discussed further. In our study we found that values around 0.99 worked successfully in terms of the balance between the rigidity and looseness of model fit. However, this value may not be appropriate for other applications. Though the thresholds can be determined arbitrarily, it is convenient if some benchmark values can be presented through empirical studies. Third, we analyzed the zamindari and magan systems, which were administrative systems during the late eighteenth century. We found that the zamindari system was closely related to the magan system, and it seems that the magan system had its roots in the poligar system. Older administrative systems are always partly inherited by newer systems. Consequently, it is quite important to investigate these in the spatio-temporal domain; that is, the spatio-temporal analysis of administrative systems. Unfortunately, there are few methods applicable to the analysis of tessellation change (Langran 1992; Sadahiro 2001b,c). The methodology of spatio-temporal analysis of spatial tessellations needs to be further developed. In addition, the area and period covered in this study should be extended to make the results of the analysis more general and persuasive. 


\section{SADAHIRO YUKIO}

\section{Acknowledgments}

The author is grateful to Okabe A. and Mizushima T. for fruitful discussions, and wishes to thank Masuyama A., Shimizu E., Sato T., and an anonymous referee for their valuable comments.

\section{References}

Anselin, L. (1998) "Exploratory spatial data analysis in a geocomputational environment," in P.A. Longley, S.M. Brooks, R. McDonnell, and B. Macmillan (eds) Geocomputation: A Primer, Chichester: John Wiley, pp 77-94.

Aono, S. (2000) "Spatial structure of caste system in the late eighteenth century in Ponneri, India," unpublished graduation thesis, Department of Urban Engineering, University of Tokyo, Tokyo.

Fuko, S. (2001) "Establishment of administrative system in the late eighteenth century in Ponneri, India," unpublished graduation thesis, Department of Urban Engineering, University of Tokyo, Tokyo.

Isaak, E.H. and Srivastava, R.M. (1989) Applied Geostatistics, New York: Oxford University Press.

Langran, G. (1992) Time in Geographic Information Systems, London: Taylor \& Francis.

Mizushima, T. (2000) "Mirasi system as social grammar — state, local society, and Raiyat in the 18th-19th century South India," a report available on the website: http://www.l.utokyo.ac.jp/ zushima9/Archive/1-28.doc.

Okabe, A., Boots, B., Sugihara, K., and Chiu S.-N. (2000) Spatial Tessellations: Concepts and Applications of Voronoi Diagram, Chichester: John Wiley.

Openshaw, S. and Openshaw, C. (1997) Artificial Intelligence in Geography, Chichester: John Wiley.

Openshaw, S., Charlton, M., Wymer, C., and Craft, A. (1987) "A mark 1 geographical analysis machine for the automated analysis of point data sets," International Journal of Geographical Information Systems, 1: 335-358.

Sadahiro, Y. (2001a) "Exploratory modeling of a spatial tessellation by a set of other spatial tessellations," Discussion Paper Series, 88, Department of Urban Engineering, University of Tokyo, Tokyo.

Sadahiro, Y. (2001b) "Analysis of surface changes using primitive events," International Journal of Geographical Information Science, 15: 523-538.

Sadahiro, Y. (2001c) "Spatio-temporal analysis of surface changes by tessellations," Geographical Analysis, 33: 312-329.

Sadahiro, Y. (2002) "An exploratory method for analyzing a spatial tessellation in relation to a set of other spatial tessellations," Environment and Planning A, 34: 1037-1058.

Tukey, J.W. (1977) Exploratory Data Analysis, New York: Addison-Wesley.

Wackernagel, H. (1995) Multivariate Geostatistics, Berlin: Springer. 


\title{
THE FERGHANA PROJECT
}

\section{Central Asian area studies with GIS}

\author{
Komatsu Hisao and Goto Yutaka
}

\section{Introduction}

In 1999, seeking a comprehensive understanding of the present-day Ferghana Valley, we began the Ferghana Project within the Islamic Area Studies Project. This valley is in the heart of Central Asia, at the confluence of three newly independent states, Uzbekistan, Qyrghyzstan, and Tajikistan, and where the Syr Darya, one of the largest rivers in Central Asia, flows (Figures 8.1 and 8.2). This single river basin occupies only 5\% of all Central Asian land, yet $20 \%$ of Central Asia's population lives there (Calming the Ferghana Valley 1999: 34). The Ferghana Valley's fertility is one of its outstanding characteristics.

After the final years of the Soviet period, a series of critical issues emerged in the valley, including ethnic conflict, serious tension between resurgent Islam and authoritarian powers, and the penetration of "Islamic" militants and drugs from Afghanistan. In addition, people had socio-economic grievances due to the high unemployment rate, a strict border control that restricted mobility in the valley, and other negative legacies of the Soviet regime. The interests of the three republics clashed on security issues, ethnic conflicts, and natural resources, which has made international relations complicated and unstable not only in the valley itself but also in Central Asia as a whole.

Many researchers are interested in the contemporary political, social, and economic situation in the Ferghana Valley, yet important questions as to why Islamic resurgence is so important in the valley, and what the causes of this resurgence are, cannot be answered because of a lack of sufficient information. Also, despite various controversies on ethnic issues, we have not yet carried out sufficient analysis of fundamental questions, such as how the National Delimitation in the valley was conducted and how contemporary nations and current ethnic composition took shape during the long Soviet period. Overall, a method by which to consider contemporary issues from a historical perspective is missing.

Looking at more recent history, we find this area affected by many dynamic changes in Central Asia since the end of the nineteenth century. After the Russian 


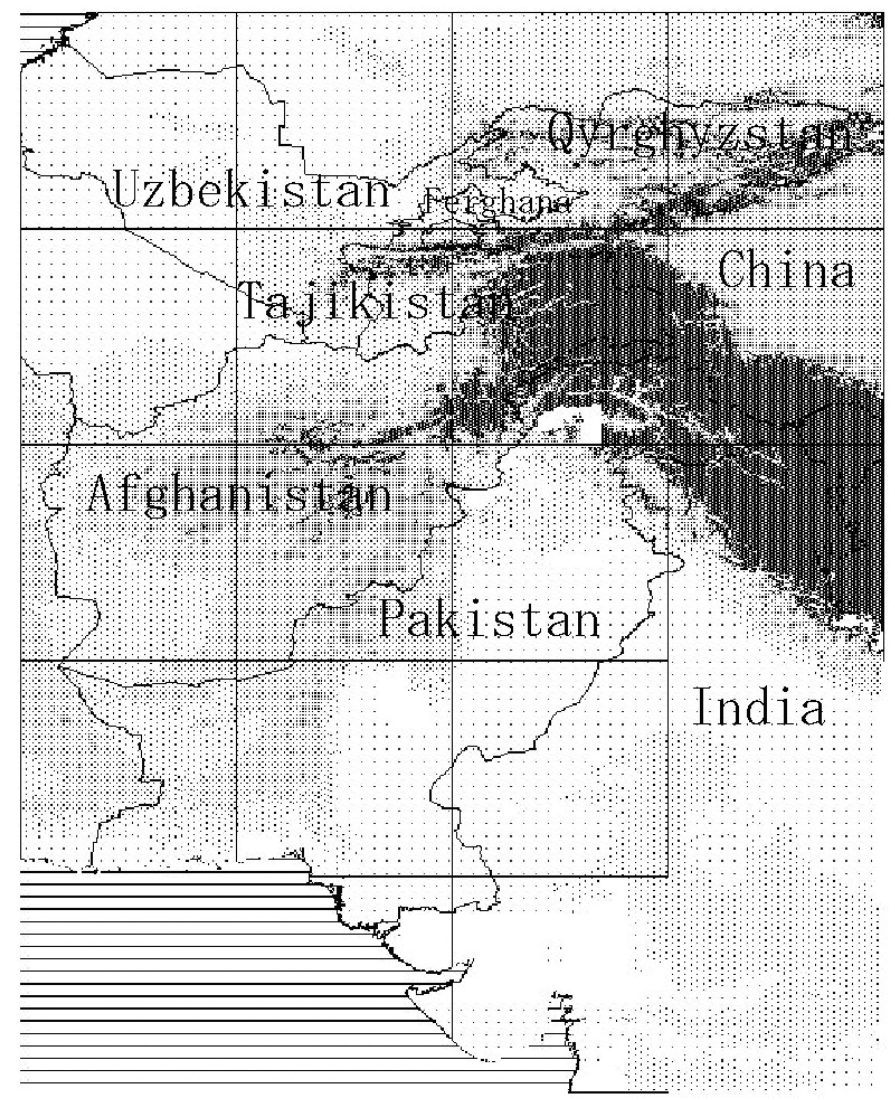

Figure 8.1 Central Asia.

conquest in 1876, the valley became that empire's most important cotton production region. Meanwhile, resisting Russian colonial rule, Muslims in the valley raised many popular revolts, the Andijan Uprising of 1898 being the most radical during this period. Later, in the post-revolution years after 1917, popular resistance against Soviet authority, the so-called Basmachi movements, spread in the valley; the subsequent brutal civil war devastated the social and economic life of the population.

The Soviets created three republics, dividing the valley by nationality for the first time in the history of Central Asia. Although this National Delimitation policy imposed in 1924 aimed to facilitate the process of national integration for the valley's multiethnic population, the changes also created complicated problems about national border issues, especially after the independence of the three republics in 1991 (Olimov 1998). The underlying problems in Soviet nationality policy became clear in ethnic conflicts at the end of the Soviet period, including 


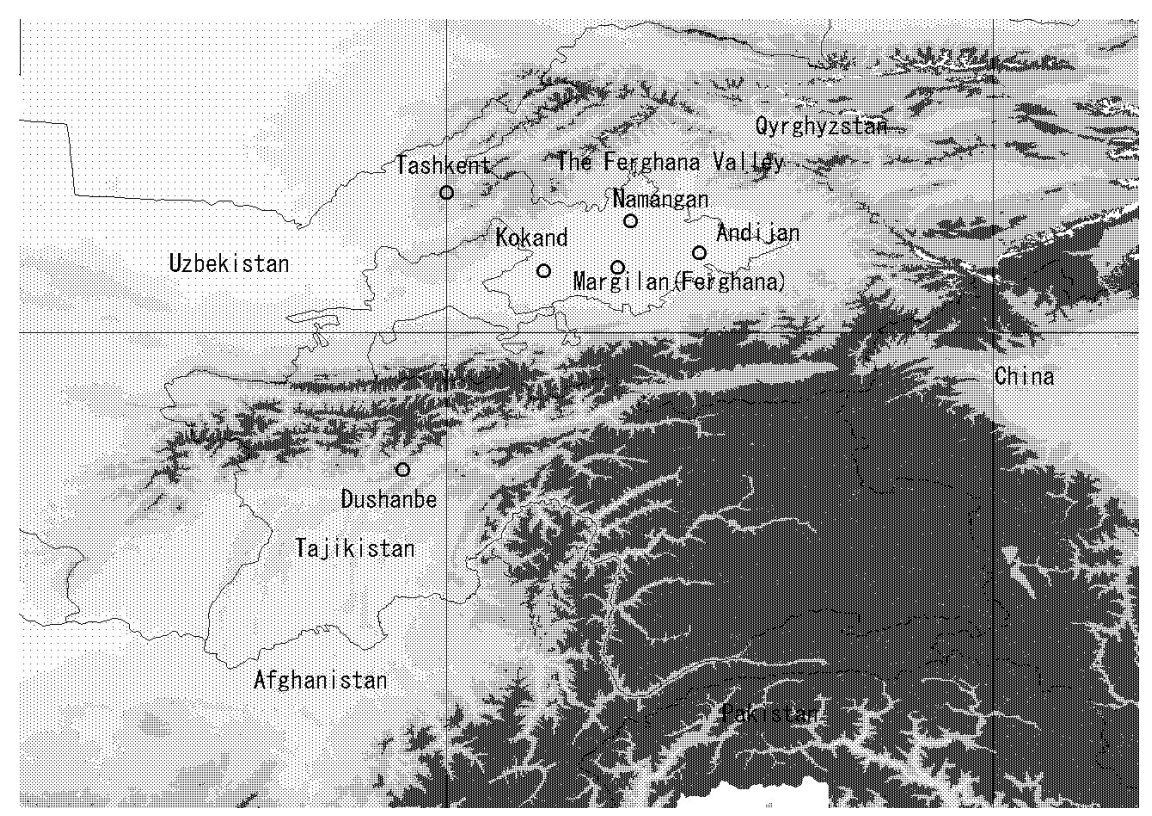

Figure 8.2 The location of the Ferghana Valley.

the Ferghana Incident in June 1989 and the Osh Incident in June 1990, the causes of which have not yet been fully identified.

To understand comprehensively the critical events in the Ferghana Valley, as well as the self-stabilizing functions of the society, a consideration of historical dynamism as it evolved in the valley, and its causes during the last century, is essential. This will be the Ferghana project's starting point. By integrating historical sources, statistical data, imaging data, and research results of field surveys onto digitalized maps, using geographic information systems (GIS), the project gains a useful and reliable database for analyzing contemporary issues in the Ferghana Valley, one that will embody the basic problems of Central Asia during a great transition. This chapter will present the research results of the past two years as its contribution to Central Asian area studies.

\section{Statistical data, maps, and GIS operation}

The project's first stage was to study population movements and ethnic composition in the Ferghana Valley from the end of the nineteenth century to the 1920s, because these data provide a basis for considering changes in the valley during the past century. 


\section{Statistical data}

In 1876, Czarist Russia incorporated the Kokand khanate to establish the Ferghana province under the administration of the Governorate-General of Turkistan, located in Tashkent. The Ferghana province (oblast') consisted of five prefectures (uyezd), Margilan, Andijan, Osh, Namangan, and Kokand, each of which had a central city with the same name. The provincial center was located in New Margilan (since 1907 named Skobelev, now Ferghana), newly constructed for Russians in 1877 to the south of old Margilan inhabited by the Muslim population. Although the Russians gathered much statistical material about the valley, the oldest statistical material in this project is from the 1897 census (Pervaya vseobshchaya perepis' 1904).

That census contains not only the population totals for both sexes and the number of houses for each prefecture but also various data such as urban and rural population and population by age, social stratum, occupation, literacy rate, religious faith, mother tongue, foreign residents, and so on. The investigators may or may not have had sufficient knowledge of the languages and ethnic consciousness of the Muslim population, but this census was certainly conducted under the same conditions for the whole population of the Ferghana Valley. Despite some defects, the 1897 census has valuable data for comparison with later statistical materials.

The next statistical material used in the project is the detailed data prepared by the Statistical Committee of the Ferghana Province in 1908 (Spisok naselennykh

mest' 1909). It contains the following items for each village:

1 Names of prefecture, county, district, and village

2 Number of households (total)

3 Households with agricultural land

4 Households without agricultural land

5 Male population

6 Female population

7 Total population

8 Major ethnic group in each village, such as Tajiks, Uzbeks, Qyrghyz, and others

9 Distance from the prefecture center

10 Name of the nearest railway or postal station

11 Distance from the nearest station

(In reference to the eighth item above, note that this census therefore does not necessarily provide correct population numbers for each ethnic group.)

This 1908 census, with fundamental data at the village level, enables us to trace population movements and changes of ethnic composition by comparing its data with later statistical materials. By using the distance data, we can locate each village on a map and both reconstruct the process of agricultural development during the last century and survey a mutual relationship between natural environment and ethnic distribution. 
The third group consists of various statistical data prepared during the Soviet period. To understand how political and socio-economic changes came to the Ferghana Valley after the Russian Revolution in 1917, we looked mainly at statistical data prepared in Uzbekistan in the 1920s, since by the National Delimitation in 1924 newly formed Uzbekistan gained most of the valley plains as territory. For example, in the mid-1920s the Soviet authority conducted a detailed rural survey to get a full picture of socio-economic conditions in Central Asian villages. These reports are nothing more than the result of fixed-point observation. Our project used the research reports for two districts, Baliqchi and Aravan (Sovremennyi kishlak 1927). These important historical sources enrich our database.

\section{Maps}

The project's base map was the digitalized map of the Ferghana Valley derived from the 1:200000-scale maps prepared by the General Staff Office of the Soviet Army between 1984 and 1991. These maps, as the most recent available, show the present situation in detail-for example, the irrigation canal networks spread through the valley. We combined 24 maps into a single map that covers the whole valley, including the surrounding mountains. This map has both vector data and Digital Elevation Model (DEM) data. In the course of our work, adding other geographical information obtained from historical sources and maps to this base map, we prepared various other maps necessary for our project.

\section{GIS operation}

The Ferghana project, combining statistical data with digitalized mapping by GIS, has produced new visual tools for historical studies. For example, after reconstructing the old administrative boundaries in the Ferghana province on the base map, we prepared a number of maps with charts that show ethnic composition and distribution in the valley before and after the Russian Revolution in 1917 (Figure 8.3). These maps are useful for historical interpretation about changes in the valley, and our research results are presented in this chapter.

\section{Research results}

\section{Minority groups}

GIS analysis provides important information about the distribution and population movements of minority groups in the valley. Especially after the Soviets divided the Ferghana region into separate national republics in 1924, most minority groups were integrated into the Uzbek nation and thus disappeared officially regardless of actual ethnic identity. However, no consideration of historical development and ethnic diversity in the valley should ignore their existence (Schoeberlein-Engel 1996: 12-20). 


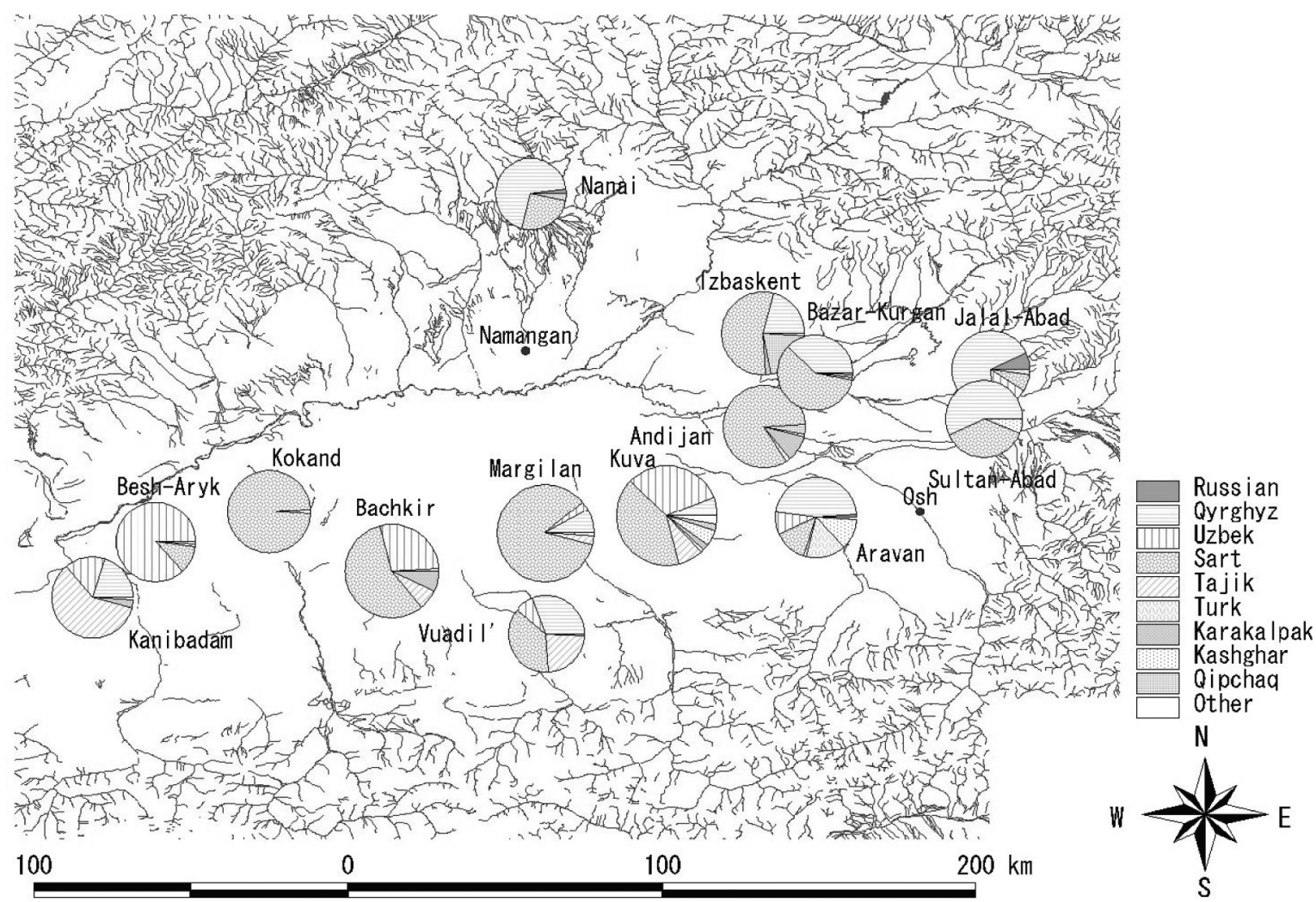

Figure 8.3 Ethnic composition in the rural area (the 1908 census). 


\section{The Kashgharis (Qashgharlik)}

Kashghar is an ancient city, east of the Ferghana valley and beyond the Pamirs, which has been the political, economic, and cultural center of Eastern Turkistan (Xinjiang). Muslims in the Ferghana valley called Turkic Muslims in Eastern Turkistan "Kashgharis" due to their commercial and cultural relations with Kashghar through the centuries. Conquered by the Qing dynasty in 1759, Turkic Muslims in Eastern Turkistan carried on holy wars (jihad) against the infidel Chinese rule throughout the nineteenth century. These jihad, headed by Naqshbandi ishans (Sufi shaykhs), were all repelled by the Qing army, and thus many Kashgharis emigrated to the Ferghana valley and formed their own small communities. Despite linguistic and cultural elements being in common with the Ferghani Muslims, the Kashgharis retained their group identity. Russian authority recognized the Kashgharis as an individual ethnic group, as the 1897 and 1908 census data show.

The Kashgharis had close ties with the Andijan Uprising in $1898 .{ }^{1}$ At dawn on May 18, 1898, 2000 Muslim partisans commanded by a Naqshbandi shaykh, Dukchi Ishan, suddenly attacked Russian troops stationed at Andijan. This attack was planned as the start of a full-blown revolt against Russian colonial rule in the eastern Ferghana Valley. Although the jihad ended in failure, it was the first strong impact on Russian rule in Turkistan since her conquest in the mid-1860s. After the uprising the Governor-General of Turkistan, Dukhovskoi, submitted to Czar Nicholas II a detailed report that advised the czar to draw up a state strategy against Islam, "which had been hostile to Russian civilization with no exception."

The Kashghar connection with the Andijan Uprising is further confirmed because they constituted an integral part of the followers of Dukchi Ishan. When he refers to his followers in his work, 'Ibrat al-Ghäfilìn [Lessons for Ignorant People], he never fails to mention the Kashgharis. For example, in its introduction he writes:

O dear ulama who read Arabic and Persian, and dear Sufi Mulla! Allow me to write these words of admonition in Turkic. Because our country [ilimiz] is the land of Turks, Kashgharis, and Qyrghyz, it is impossible to understand each other in the Arabic or Persian language. Therefore I wrote this 'Ibrat al-Ghäfilīn in Turkic. ${ }^{2}$

It is noteworthy that Dukchi Ishan includes the Kashgharis, despite their small numbers, with major groups such as the Qyrghyz, Tajiks, and the Uzbeks. According to a Russian source, his father was an émigré from Kashghar, evidence of close relations between Dukchi Ishan and the Kashgharis. GIS information clearly shows that the Kashgharis concentrated in Margilan, Andijan, and Osh prefectures, where Dukchi Ishan exerted a substantial influence on the Muslim population (Figure 8.4). Comparing the 1897 and 1908 census data, the Kashgharis' increasing population 


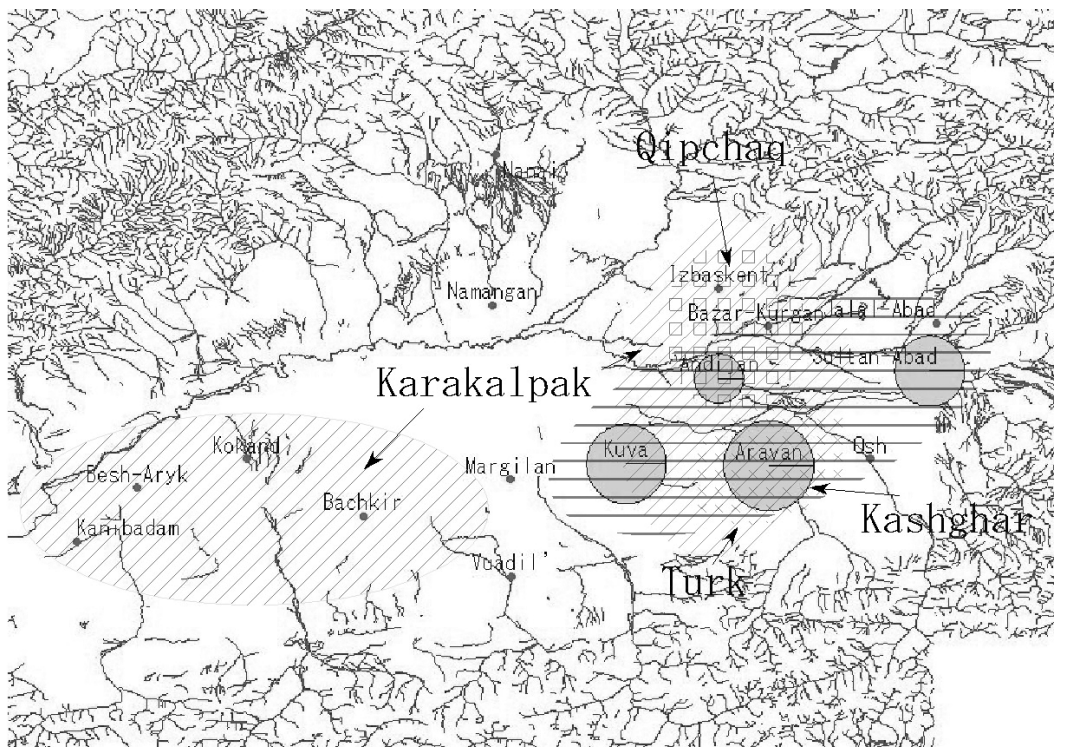

Figure 8.4 Minority groups.

is found much more in the Margilan than the Andijan prefecture. Whether this change was related to the Andijan Uprising or not is worth consideration.

It is generally accepted that after 1924 the ethnic classification of Kashghari disappeared as they merged with the Uzbeks. However, this does not mean that the identity of the Kashgharis has completely ceased to exist. When visiting the suburbs of Andijan in July 2001, in the courtyard of a mosque in a district inhabited by the descendants of the Kashgharis we found the place of arrival (qadamja) of Naqshbandi shaykh Makhdum-i A'zam (1461-1542), who enjoyed a great reputation among the Turkic Muslims in Eastern Turkistan for many centuries.

\section{The Qipchaqs, Turks, and Karakalpaks}

The Qipchaqs, Turks, and Karakalpaks (Figure 8.4), as distinguished from the settled population, Sarts and Uzbeks, were those who preserved their own tribal and nomadic traditions until recently. The nomadic Qipchaqs played an important role in political struggles during the last decades of the Kokand khanate and came to settle down since the end of the nineteenth century. The Turks were the descendants of Turkic tribes that migrated into the Ferghana Valley before the Uzbek invasion in the sixteenth century. The Karakalpaks migrated into the valley in waves from the lower and middle basin of the Syr Darya throughout the eighteenth century (Gubaeva 1983). 
When we estimate distribution of these minority groups by GIS, we find them concentrated in the southeastern parts of the valley and at the foot of the southern mountains. In future we would like to examine, from the viewpoint of regional history, whether historical factors or ecological conditions caused this. Although these groups were recognized individual ethnic groups until the 1920s, they were eventually integrated into the Uzbeks, as the Kashgharis were. GIS helps us demonstrate the integration process of a composite nation, Uzbeks, by showing the distribution and scale of these minority groups.

\section{Major ethnic groups}

Our statistical data list Qyrghyz, Tajiks, Sarts, Uzbeks, and Turk-Tatars as the five major ethnic groups in the Ferghana Valley. While Russian authorities had a proper understanding as to the Qyrghyz and Tajiks, sometimes they got misleading information of the remaining groups.

\section{The Qyrghyz (called "Kara Kirgiz” in Russian, before 1925)}

The Qyrghyz are a Turkic nomadic people that migrated into the mountains surrounding the Ferghana Valley from Eastern Turkistan around the seventeenth century. Their Islamization began in the latter half of the seventeenth century, by the efforts of Naqshbandi ishans. Keeping a distinct tribal and clan organization, they were often at odds with each other; however, they could unite in a common identity against such frequent opponents as the Kazakh nomads in the northern steppes and the settled population of the Ferghana Valley. Indeed, Qyrghyz superior military forces threatened the political power of the Kokand khanate in its last decades, and they constituted the main body of the partisans in the Andijan Uprising. Although most of them continued a nomadic or half-nomadic way of life under Russian rule, some began to settle and engage in agriculture at the foot of the mountains and small valleys surrounding the valley. By the end of the nineteenth century, however, Russian peasants had penetrated into the same area, because the densely populated plains in the Ferghana Valley left little room for Russian settlement. Russian immigration brought about the expropriation of lands by the Russian authorities, which increased tension between the Qyrghyz and the Russian peasants. We plan to analyze with the aid of GIS the population balance between the Qyrghyz and Russian immigrants as well as land ownership of Russians on the outskirts of the Ferghana Valley. ${ }^{3}$

Strangely, the 1897 census does not count Qyrghyz population in the Osh prefecture, where the Qyrghyz should have a majority, and instead lists most of the population as Turk-Tatars. Since Turk-Tatar was used as a general term for Turkic Muslims in the Russian Empire, this attribution has no meaning. Instead, as shown by later census data, most Turk-Tatars were most likely the Qyrghyz. This is one of many examples of how GIS reveals errors in statistical data. 


\section{The Tajiks}

In ancient times, the settled people in the oasis areas of Central Asia were Iranians. Since the sixth century, Turkic nomadic groups have penetrated in waves into the oasis areas including the Ferghana Valley to stimulate the Turkification of the Iranian people and to settle down in rural areas and cities by themselves. However, despite the historical process of Turkification, an Iranian population survived in many places up to the twentieth century. While mingling with Turkic peoples and often using Turkic languages, this population preserved their mother tongue, the Persian-Tajik language, as well as Iranian traditions. In modern Central Asia they are called the Tajiks. And during the period of the Kokand khanate a number of Tajiks migrated into the valley from the southern mountain area, where the present Tajikistan is located.

There is consistency between Russian and Soviet census statistical data regarding the Tajiks, indicating relatively good information on this subject. GIS shows that despite the considerable population of Tajiks, especially in the Namangan, Kokand, and Margilan prefectures, most Tajiks belonged not to Tajikistan but to Uzbekistan after the National Delimitation in 1924. In 1929, when the Tajik Autonomous Republic established in the framework of Uzbekistan in 1924 was raised to the status of Union republic, the Khujand region that inherited a part of the former Kokand prefecture was ceded from Uzbekistan to Tajikistan. However in the Ferghana Valley many "Diaspora" Tajik groups were left (see Figure 8.3).

According to some contemporary Tajik intellectuals, many Tajiks in the Ferghana Valley were left outside Tajikistan due to the lack of responsible Tajik communists and intellectuals who could speak for the Tajik cause in the discussions of the National Delimitation (Masov 1991; 1995). In the late 1980s, when the Perestroika permitted every nationalist to openly express ideas throughout the Soviet Union, a group of leading Tajik intellectuals made a claim of Tajik irredentism as to the Ferghana Valley as well as Bukhara and Samarkand in Uzbekistan. Demanding protection of the basic rights of the Tajik population, they protested an alleged assimilation policy conducted by Uzbek authorities since 1924 (Komatsu 1995: 250-274). It seems the Tajik civil war put aside Tajik irredentism as a critical issue for Tajikistan, but GIS analysis shows the potential claims for the Tajik nationalist cause. Certainly, we should take into account the symbiotic relationship historically cultivated between the Tajik and Uzbek populations in the Ferghana Valley. Nationalistic claims do not always reflect reality. In summary, GIS analysis regarding the Tajiks raises once again fundamental questions about the National Delimitation in 1924.

\section{The Sarts and Uzbeks}

Sart is a historical term used for the settled Turkic Muslim population in Central Asia (Turkistan) before the Russian Revolution. The Sarts included both descendants of the Turkified Iranian population and of settled Turkic-speaking people 
who were nomadic by origin. The Sarts constituted most of the urban and rural population in oasis areas and had what was almost a common way of life and culture. They did not call themselves Sart, however, preferring to be identified by the place of residence: Kokandi, Andijani, Namangani, and the like. Commenting on this, Russian Orientalist Baltol'd writes:

The settled peoples of Central Asia are in the first place Muslims and think of themselves only secondarily as living in a particular town or district; to them the idea of belonging to a particular stock is of no significance. It is only in modern times under the influence of European culture (through the intermediary of Russia) that a striving for national unity has arisen (Barthold).

Sart was not a self-denomination widely accepted by the settled people. Instead, nomadic peoples such as the Kazakhs used the term Sart for settled people. When nomadic peoples used the term Sart, however, it bore a pejorative meaning, reflecting nomadic peoples' negative idea of settled people as, for example, "cowardly, greedy and hypocritical." The Russians, probably learning the term Sart from the Kazakhs, used it officially for the settled Turkic Muslim population in the Turkistan colony.

The Uzbeks originally meant descendants of the nomadic Uzbek tribes that had invaded oasis areas from the northern Qipchaq steppes since the latter half of the fifteenth century to restore the rule of the Genghisid dynasty (the Shaybanids) in Central Asia. The Uzbek invasion was the last large scale wave of a Turkic nomad influx into the southern oasis areas, repeated in the history of Central Asia. Since the end of the eighteenth century, establishing independent political powers such as the Bukhara, Khiva, and Kokand khanates, the Uzbeks preserved their tribal identification until the Russian conquest. Although they differed from the Sarts that lacked any tribal identification, settled Uzbeks came to have a common way of life and dialects with the Sarts.

The 1897 and 1908 census data recognize the Sarts and Uzbeks as separate ethnic groups. GIS analysis shows that only in Kokand prefecture are the Uzbeks a relatively significant part of the Muslim population (Table 8.3). Possibly, the Uzbek tribes concentrated around the capital of the Kokand khanate to hold onto political power, ${ }^{4}$ or the Kokandis preferred to profess themselves as Uzbeks, as the name of ruling ethnic groups. The correct answer will require further study of contemporary historical sources.

In the statistical data of 1920, the Sarts have disappeared and former Sarts have been integrated into the Uzbeks. This change, as Baltol'd suggested, corresponded to the rise of national consciousness among the Turkic Muslims in Turkistan. Early in the twentieth century, Muslim intellectuals in Turkistan, influenced by reformist movements among the Tatars and the Ottomans rather than by the Russians, started a social and cultural reform movement. As their movement aimed to introduce New Method (usul-i jadid) Schools as the foundation of 
social, economic, and cultural development of their backward society, it is called the Jadid movement (Jadidism). After the First Russian Revolution in 1905, their arguments came to bear a nationalistic character, and Jadid intellectuals made efforts to create a national identity among the people who had only tribal or local identity apart from a Muslim consciousness. In the beginning of the 1910s they sparked off a controversy with the Russians and Tatars about the term Sart in journals and newspapers, arguing that the term was unrecognized among the people themselves. Protesting use of the pejorative term Sart, they proposed more appropriate names for themselves, such as Turks, Turkistanis, and Uzbeks.

After the Russian Revolution in 1917, as Muslim intellectuals participated in social and cultural activities in the former Russian colony and Muslim Communists began to play important roles in the Soviet organizations, the use of Sart came to be restricted and was eventually replaced by Uzbek. Indeed, for the census in 1917 investigators were instructed that "an independent nation named Sarts doesn't exist, and this term should be replaced by Uzbek." In those days, however, most investigators did not fully understand this issue (Zarubin 1925: 15-16). We therefore believe that only later, in the 1920 census, ${ }^{5}$ was the term Sarts totally replaced by the Uzbeks; that is, the Sarts were incorporated into the Uzbeks. GIS analysis shows the rational increase of the Uzbek population by incorporating the Sarts. The existence of the Sarts also demonstrates the complex process of making the Uzbek nation. ${ }^{6}$

\section{The damages of the civil war and the dynamism of restoration}

\section{The damages of the civil war}

The February Revolution that overthrew the Czar in 1917 encouraged the Jadid intellectuals to develop the Turkistan Autonomous Movement within the framework of a democratic Republic of Russia. The October Revolution, however, fell short of their expectations; the Bolsheviks of Tashkent, who proclaimed the new authority of the Soviets over Turkistan, preserved the former colonialist character. Claiming legitimate authority as soldiers and workers, Russian colonialists asserted the first Soviet power in Turkistan, and access to this power was withheld from the Muslims - $92 \%$ of the population - because a few of them were proletariat or soldiers. Against the Bolsheviks in Tashkent, the Jadid intellectuals held an extraordinary Muslim congress in Kokand in November 1917 and established the Turkistan Autonomous Government. Giving broad suffrage to Russians and Jews, this government proclaimed its political legitimacy against the Soviet power. However, the Soviets refused to recognize this "bourgeois nationalist" autonomous government and liquidated it by superior military force in February 1918. Attacked and plundered by Soviet forces, Kokand experienced a bloodbath.

This brutal Bolshevik operation, combined with the political and social disorder after the revolution, aroused the anti-Soviet Muslim resistance movement, the 
so-called Basmachi movement, throughout the Ferghana Valley. The Basmachi movement developed rapidly under worsening conditions such as a shortage of food, the oppressive policy adopted by the Soviet power toward the Muslim population, and the arbitrary activities of Muslim outlaw groups. The Basmachi armed forces had about 20000 troops in February 1919. Participants in this movement included not only Muslim social groups headed by tribal and religious leaders but also Russian peasants, a diversity of leadership that prevented the Basmachi groups from uniting their armed forces. We expect GIS to be a useful research tool to survey the development and structure of the Basmachi movement in the Ferghana Valley.

Facing the threat of the Basmachi movement, the Soviet power set up the Ferghana front to strengthen its military force, and at the same time endeavored to gain support from the Muslim masses by incorporating Muslims into the Communist Party and government posts, sweeping away the vestiges of colonialism, and easing anti-Islamic policies adopted in the first years. These measures enabled Soviet power to suppress the Basmachi movement almost until 1924 and restore public order in the Ferghana Valley, but this fierce civil war severely damaged socio-economic life in the valley.

Our study of the damage brought about by revolution and civil war used village survey reports for the Baliqchi district located in the western part of the Andijan prefecture in Uzbekistan and the Aravan district located in the Osh province of the Qyrghyz Autonomous Republic. These villages are situated in the fertile plains of the Ferghana Valley and before the revolution enjoyed rich agricultural production, especially cotton production on irrigated land. In the Baliqchi district the Uzbeks had the ethnic majority, and in the Aravan district the Qyrghyz and Uzbeks were mixed. Socio-economic trends in these districts show a drastic decline in population, especially the loss of male population, the increase of absent households, the radical decline of the cotton production, the devastation of irrigation canals, and a sharp drop in the number of cattle (horse and sheep) due to confiscation by Soviet and Basmachi sides alike (Tables 8.1 and 8.2). Table 8.3 shows the magnitude of the damages brought by the civil war. In Margilan and Namangan prefectures population declined between 1908 and 1920, and the total population of the Ferghana Valley hardly increased during the same period. It is likely the same devastation prevailed in the entire Ferghana Valley during the years of the civil war.

\section{The dynamism of restoration}

Socio-economic trends from 1923 to 1925 show some indication of restoration despite the ruinous conditions. When we recall that the Ferghana Valley did not have a great inflow of population in those years, the trend of population recovery suggests the return of refugees. The Soviet power urgently needed to restore and develop agricultural production in the fertile valley, for the survival of the Soviet Union itself. The Soviets thus drove forward the collectivization of agriculture and began a construction project of principal irrigation canals such as the Great 
Table 8.1 Socio-economic change in Baliqchi

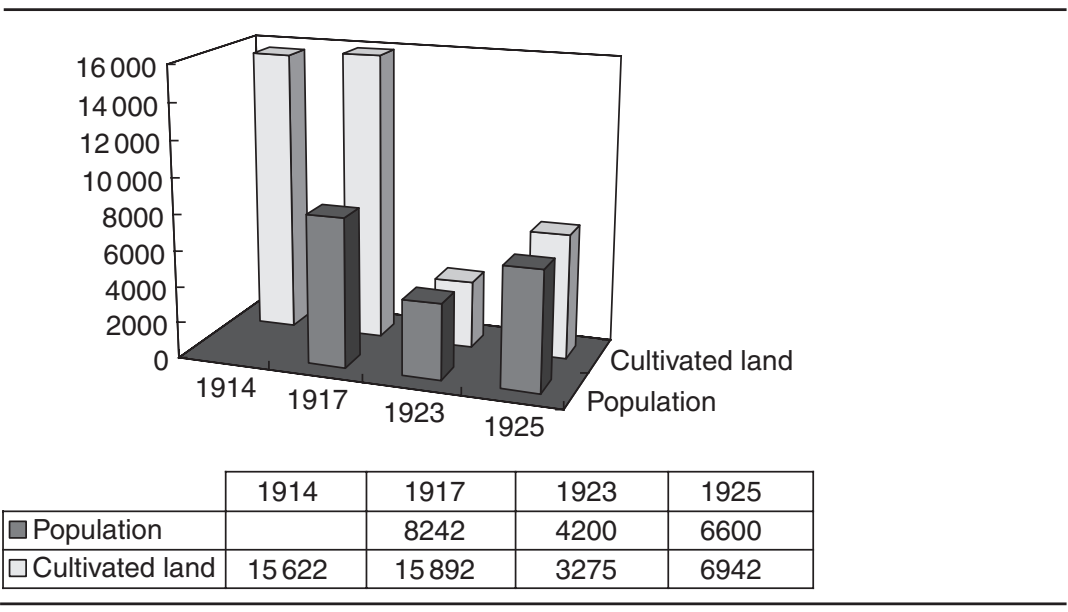

Table 8.2 Agriculture in Aravan

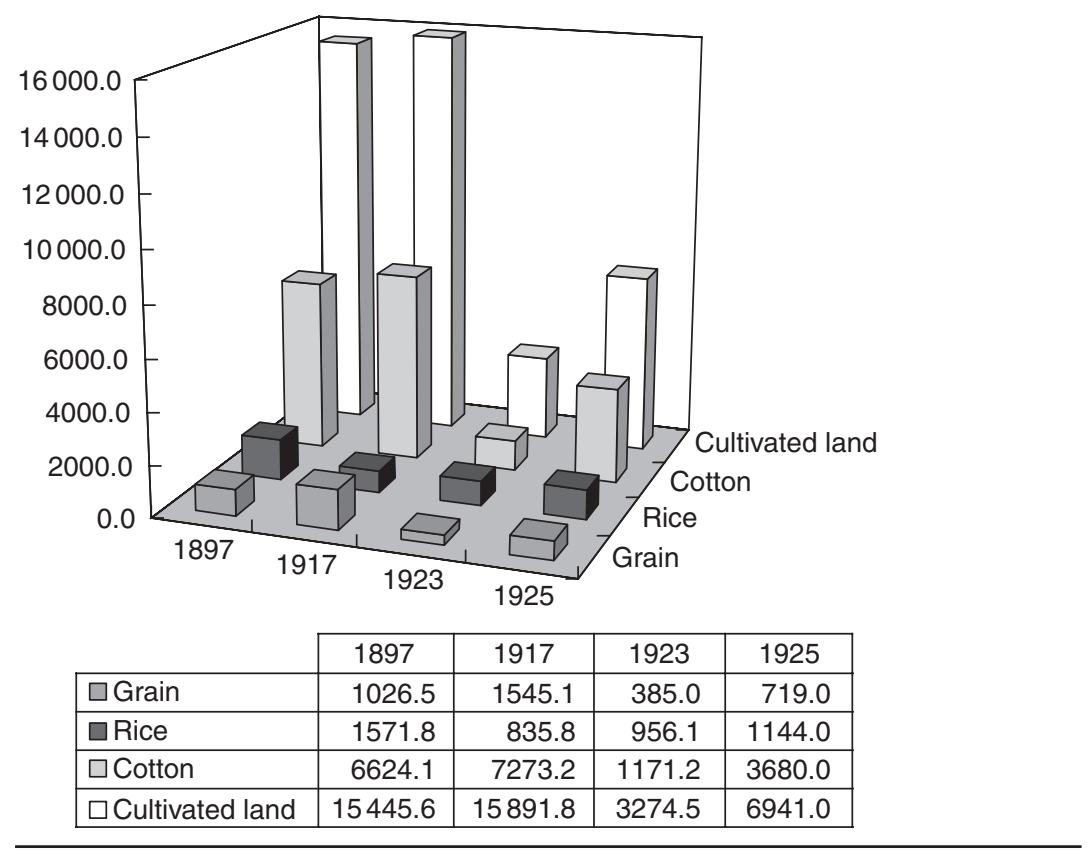


Table 8.3 Changes of ethnic composition (1897-1920)
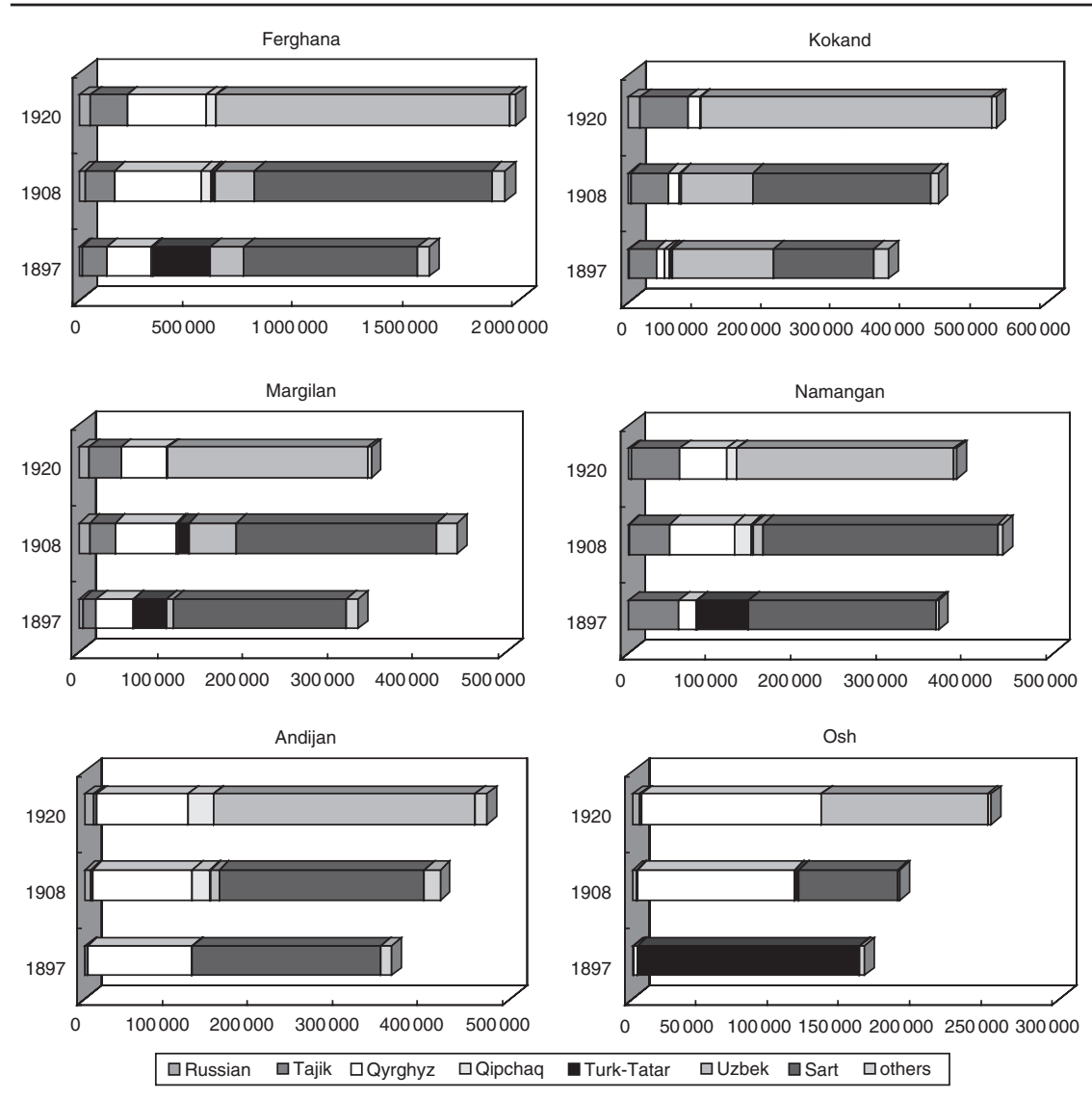

Ferghana Canal (1939), the South Ferghana Canal (1940), and the North Ferghana Canal (1940) (Figure 8.5). These principal canals are the basis of contemporary irrigation networks spread within the valley. Such gigantic state projects brought about the rapid growth of agricultural production and accelerated the already great increase of population in the valley (Table 8.4).

The socio-economic development during the Soviet period we will leave to future studies. Here, however, we would like to point out how that development has a close relevance to two contemporary issues.

The first issue is the resurgence of Islam since the Perestroika period in the Ferghana Valley. ${ }^{7}$ As is well known, since the end of the 1920s the Soviet power carried out an intensive anti-Islamic policy and endeavored to eliminate the Islamic tradition from any social and cultural spheres. Islamic tradition suffered great damage during the Soviet period but was never completely rooted out. Since the end of the 1970s, Islamic resurgence began and rapidly developed in the 


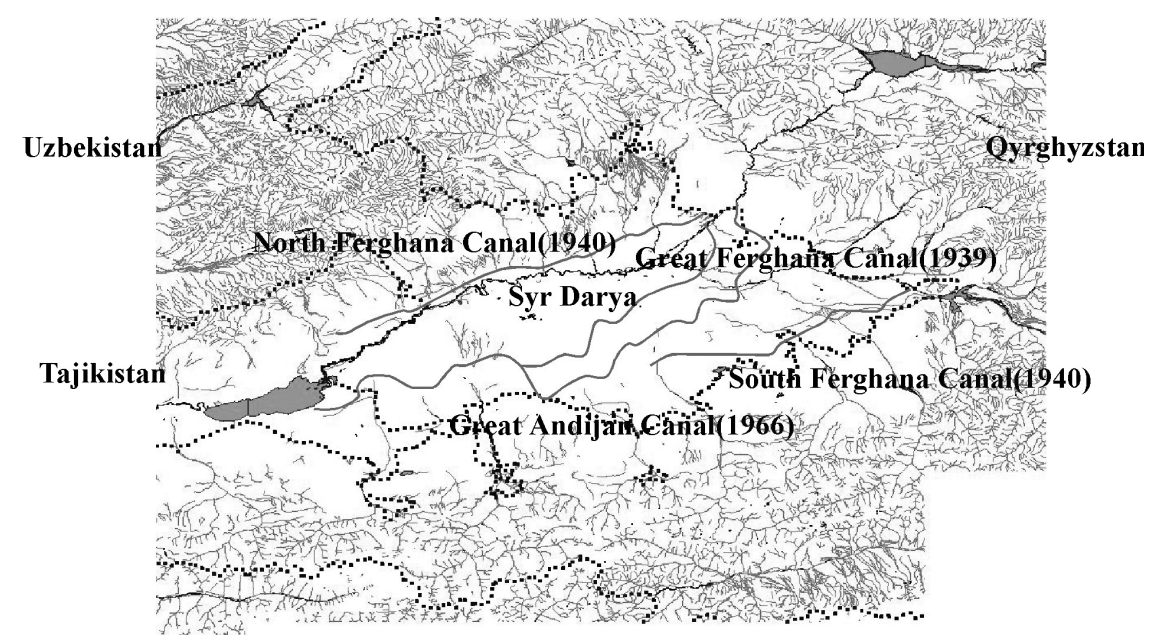

Figure 8.5 Major irrigation canals during the Soviet period.

Table 8.4 The increase of population in the valley (Uzbekistan)

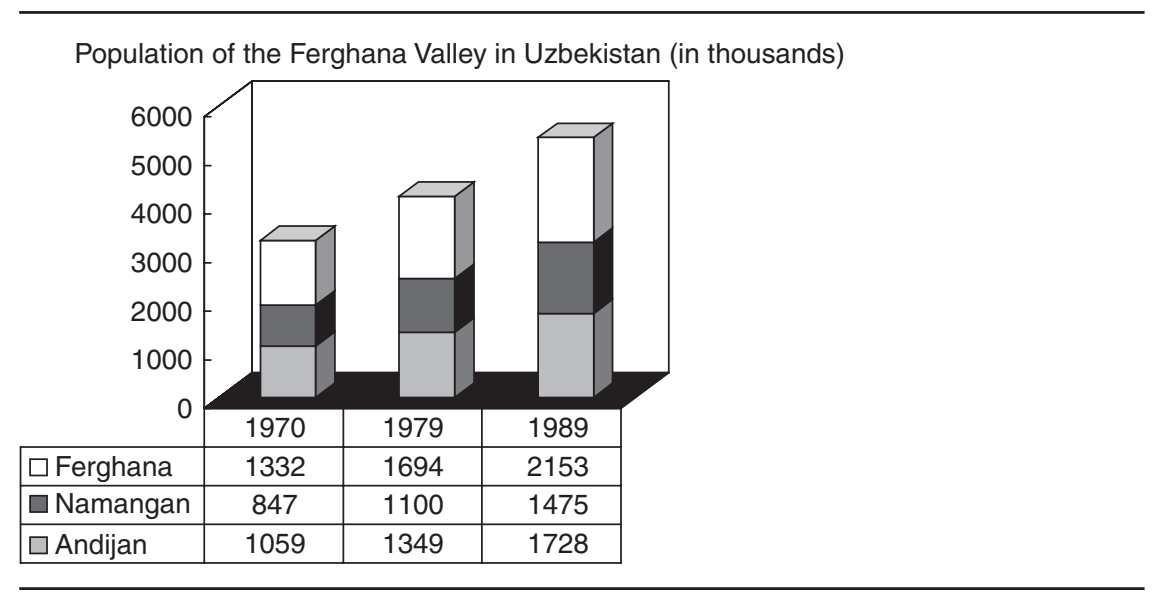

Ferghana Valley under the Soviet regime. One important reason for this was the existence of a vast and dense Muslim community formed during the Soviet period. To study the foundations of this Islamic resurgence, we should analyze the structure and features of this community. Certainly, external factors such as impacts from the Middle East and South Asia played an important role in Islamic resurgence in Soviet Central Asia, but internal factors also contributed to the revival of Islam in the Ferghana Valley. 
The second issue is a conflict over water resources among Central Asian countries; this was especially serious in the Ferghana Valley where the borders between Uzbekistan, Tajikistan, and Qyrghyzstan divide the ecological entity of the valley. During the Soviet period, when boundaries were only nominal, water resource management was under the control of Moscow. Since the collapse of the Soviet Union, however, the interests of three independent republics in this limited resource have come into conflict. From this point of view, research on irrigation networks constructed during the Soviet period is important for the analysis of contemporary conflicts over water resources. GIS will contribute to our research in this direction.

\section{Conclusion}

Our Ferghana project grew out of the belief that GIS can be an effective method that provides comprehensive understanding of the dynamism developed in the Ferghana Valley as it relates to significant changes in modern Central Asia. As is obvious from this chapter, our project has just begun. We have many problems to be solved and many source materials to be examined. But GIS clearly introduces a new method to area studies; integrating historical sources, statistical data, imaging data, and research results of field surveys onto detailed digitalized maps gives us a useful and reliable database for area studies. What is more, it gives us new ideas; it will enlarge our historical perspective and enrich our historical imagination. To sum up, GIS, by employing a new method of historical studies, combines historical studies with area studies.

In conclusion, we would like to list the studies to be taken up in our second stage:

- Mapping the villages shown in the 1908 census and tracing their development

- Elucidating any mutual relationships between the natural environment (altitude, slope, water supply, and so on) and the distribution of ethnic groups

- Analyzing the development of irrigation networks during the Soviet period

- Mapping religious buildings and sites (mosques, madrasas, shrines, etc.)

- Analyzing the urbanization process in the Ferghana Valley.

\section{Notes}

1 For the Andijan Uprising, see Babadžanov 1998: 167-191; Komatsu forthcoming. For the bibliographical information, see Bregel 1995: 620-621.

2 'Ibrat al-Ghäfilìn, Biruni Institute of Oriental Studies, Academy of Sciences of Uzbekistan, Manuscript No. 1725, 12a-b.

3 From this point of view a map attached to the following work is very interesting (Dzhamgerchinov 1959).

4 S.S. Gubaeva points out that the ruling tribe Ming migrated to the Kokand area. See Gubaeva 1983: 55. 


\section{KOMATSU HISAO AND GOTO YUTAKA}

5 As to the 1920 census we used the data cited in Vaidyanath, R. (1967) The Formation of the Soviet Central Asian Republics: A Study in Soviet Nationalities Policy 1917-1936, New Delhi: People's Publishing House.

6 As to the making of the Uzbek nation, see Baldauf 1991: 79-96.

7 As to the Islamic resurgence in the Ferghana valley, see Babadzhanov 1999: 125-131; 2001: 153-169; Abdullaev and Kolesnikov 1998: 249-282; Babadjanov and Kamilov 2001: 195-219; Schoeberlein 2001: 323-339.

\section{Bibliography}

Abdullaev, E.V. and Kolesnikov, L.F. (1998) "Islam i religioznyi faktor v sovremennom Uzbekistane," Uzbekistan: Obretenie novogo oblika, tom 1, Moskva, pp. 249-282.

Babadjanov, B. and Kamilov, M. (2001) "Muhammadjan Hindustani (1892-1989) and the Beginning of the 'Great Schism' among the Muslims of Uzbekistan," in Dudoignon, Stéphane A. and Komatsu Hisao (eds) Islam in Politics in Russia and Central Asia (Early Eighteenth to Late Twentieth Centuries), London-New York-Bahrain: Kegan Paul, pp. 195-219.

Babadžanov, B. (1998) "Dūkčĩ İšān und der Aufstand von Andižan 1898," in Anke von Kügelgen, Michael Kemper, and Allan J. Frank (eds) Muslim Culture in Russia and Central Asia from the 18th to the Early 20th Centuries, vol. 2, Inter-Regional and InterEthnic Relations, Berlin: Klaus Schwarz Verlag, pp. 167-191.

Babadzhanov, B. (1999) "Ferganskaya dolina; istochnik ili zhertva islamskogo fundamentalizma?," Tsentral'naya Aziya i Kavkaz, No. 4 (5), pp. 125-131.

Babadzhanov, B.(2001), "O deyatel'nosti 'Khizb at-takhrir al-islami' v Uzbekistane," Islam na postsovetskom prostranstve: vzglyad iznutri, pod red. A.Malashenko i M.B. Olkott, Moskva: Moskovskii Tsentr Karnegi, pp. 153-169.

Baldauf, I. (1991) "Some Thoughts on the Making of the Uzbek Nation," Cahiers $d u$ monde russe et soviétique, 32/1, pp. 79-96.

Barthold, W. "Sart," in The Encyclopaedia of Islam, First edition.

Bregel, Yu. (ed.) (1995) Bibliography of Islamic Central Asia, Part I, Bloomington, Indiana: Indiana University.

Calming the Ferghana Valley: Development and Dialogue in the Heart of Central Asia, Center for Preventing Action Reports, Vol. 4 (1999), New York: The Century Foundation Press.

Dzhamgerchinov, B. (1959) Prisoedinenie Kirgizii k Rossii, Moskva.

Gubaeva, S.S. (1983) Etnicheskii sostav naseleniya Fergany v kontse XIX-nachale XX v., Tashkent.

Irrigatsiya Uzbekistana, tom 1, Razvitie irrigatsii v komplekse proizvoditel'nykh sil Uzbekistana (1975) Tashkent.

Komatsu Hisao (1995) "Hutatsuno toshino tajikujin [Tajiks in Bukhara and Samarkand]," in Hara Teruyuki and Yamauchi Masayuki (eds) Surabuno Minzoku [Peoples in the Slavic World], Tokyo: Koubundou, pp. 250-274 (in Japanese).

Komatsu Hisao (forthcoming) "Andijan Uprising Reconsidered," in Sato Tsugitaka (ed.)

Muslim Societies: Historical and Comparative Aspects, London: RoutledgeCurzon.

Masal'skii, V. I. (1913) Turkestanskii krai, Sankt-Peterburg.

Masov, R. (1991) Istoriya topornovo razdeleniya, Dushanbe.

Masov, R. (1995) Tadzhiki: istoriya s grifom "sovershenno sekretno," Dushanbe.

Narodnoe khozyaistvo Uzbekskoi SSP v 1988 g. (1989) Tashkent. 
Olimov, Muzaffar/Saodat Olimova (1998) "Khudzhand: mezhdu Ferganoi i Tadzhikistanom," Vestnik Evrazii/Acta Eurasica, No. 1-2(4-5), pp. 203-220.

Ozbekistanni rayonlashtirish ishidagi materiyarlar, Birinchi bulak (1926) Samarakand.

Pervaya vseobshchaya perepis' naseleniya Rossiiskoi imperii 1897 g., LXXXIX, Ferganskaya oblast' (1904) Sankt-Peterburg.

Schoeberlein-Engel, J. (1996) "The Prospects for Uzbek National Identity," Central Asia Monitor, No. 2, pp. 12-20.

Schoeberlein, J. (2001) "Islam in the Ferghana Valley: Challenges for New States," in Dudoignon, Stéphane A., and Komatsu Hisao (eds) Islam in Politics in Russia and Central Asia (Early Eighteenth to Late Twentieth Centuries), London-New YorkBahrain: Kegan Paul, pp. 323-339.

Sovremennyi kishlak Srednei Azii (Sotsial'no-ekonomicheskii ocherk), vypusk 5, Balykchinskaya volost; vypusk 7, Aravanskaya volost' (1927) Tashkent.

Spisok naselennykh mest Ferganskoi oblasti, Izdanie Ferganskogo oblastnogo statisticheskogo komiteta (1909) Skobelev.

Spisok naselennykh punktov Uzbekskoi SSR 1928 goda, chst'VI, Okrug Khodzhent; chast' VII, Okrug Fergana; chast' VIII, Okrug Andijan (1929) Samarkand.

Zarubin, I.I. (1925) Spisok narodnostei Turkestanskogo kraya, Leningrad. 


\title{
THE USE OF GIS TO LOCATE ABANDONED VILLAGES LISTED IN THE TEMETTUAT REGISTERS OF BALIKESIR DISTRICT, ANATOLIA
}

\author{
Egawa Hikari
}

\section{Introduction}

Located in the northwest of Anatolia in the Republic of Turkey, the Balıkesir region is the nodal region of inland traffic linking the three large cities of Istanbul, Bursa, and Izmir (Figure 9.1). By the middle of the nineteenth century, 11 villages in this district (Kaza) were ruined and lost, and today there is little explicit evidence showing the locations of these villages. This study attempts to extrapolate the locations of these villages from only one sheet of a historical document with the aid of geographical information systems (GIS).

The Balıkesir region is well known as a center where many nomadic groups settled from the beginning of the Ottoman Empire, and also for the thriving industries manufacturing woollen and leather goods. In the first half of the nineteenth century, the Janissary Army, which was the traditional elite army unit of the Ottoman Empire, was abolished and replaced by a newly established westernstyle army. The fact that on this occasion, the Balıkesir region was responsible for producing a coarse woollen cloth, called $a b a$, for the new military uniform indicates that the woollen industry in this region was both stable and superior in quality (Kütükoğlu 1981; Egawa 1998).

Kütükoğlu (1995) had already noted that the Temettuat (Income) Registers in the possession of the Ottoman Archive Department of the Prime Minister's Office (Başbakanlık Osmanlı Arşivi) provided basic historical materials about the kinds of industry that had prospered, the kinds of occupation the inhabitants were employed, and the level of assets and incomes they had; in other words, the kind of socio-economic activities that had been conducted in the various regions of the Ottoman Empire in the mid-nineteenth century. Egawa (1997, 1998, forthcoming) has analyzed the Temettuat Registers (No. 7225-7228) and studied Balıkesir district. These studies reveal that, in the Balikesir district of the mid-nineteenth century, 


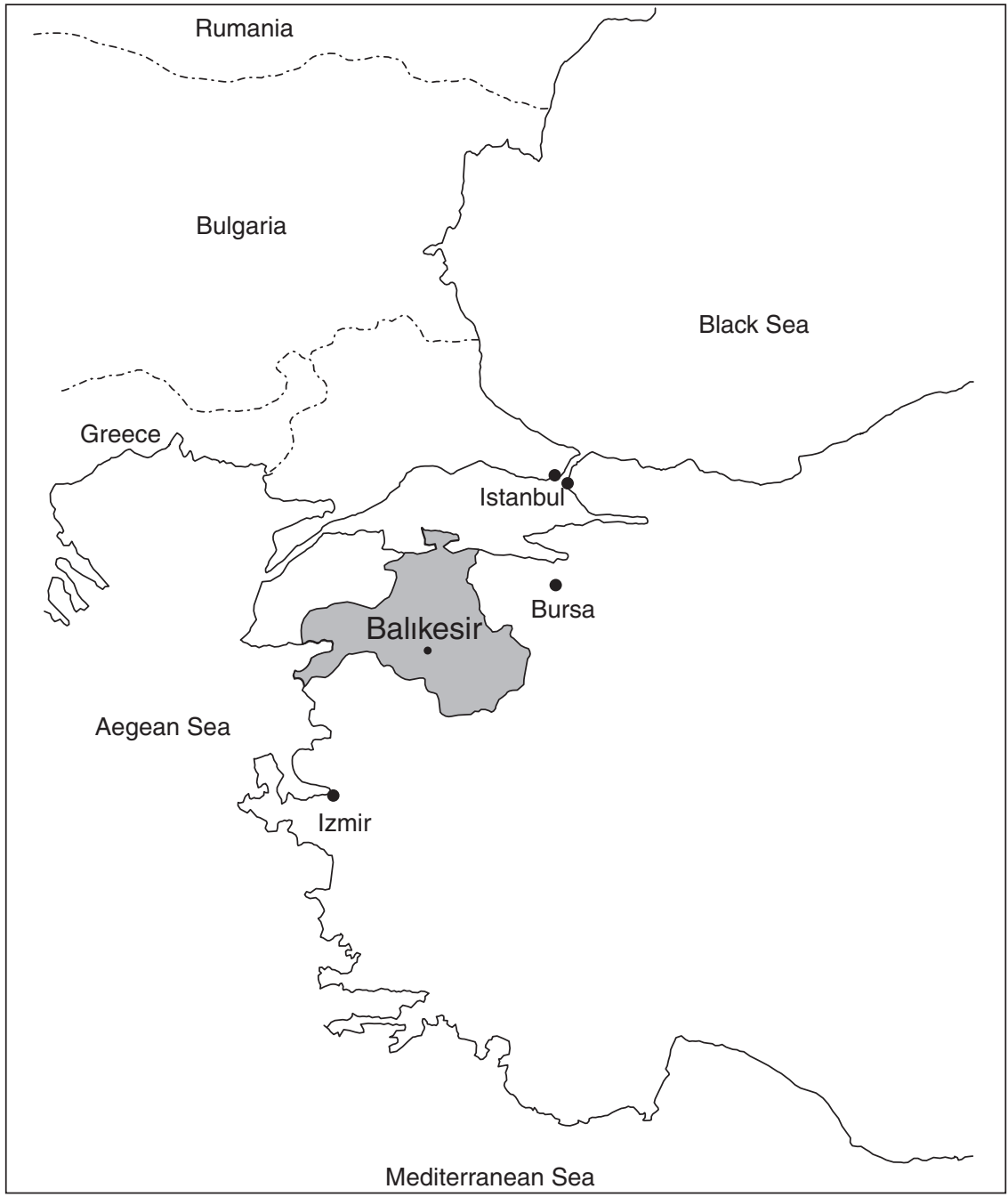

Figure 9.1 The Balıkesir region.

the population increase of the central city (Balıkesir) had led to structural changes in the city. The development of the $a b a$ woollen industry had been carried out not only by the residents of Balıkesir city but also by villagers in the surrounding areas and nomads.

In this chapter, based on studies referred to before, we attempt to extrapolate the locations of the 11 ruined villages from the last page (p. 199) of the Temettuat Register (No. 7228) that referred to the Balıkesir city area (Figure 9.2). We refer to this page as Document TR 199 (Figure 9.3). 


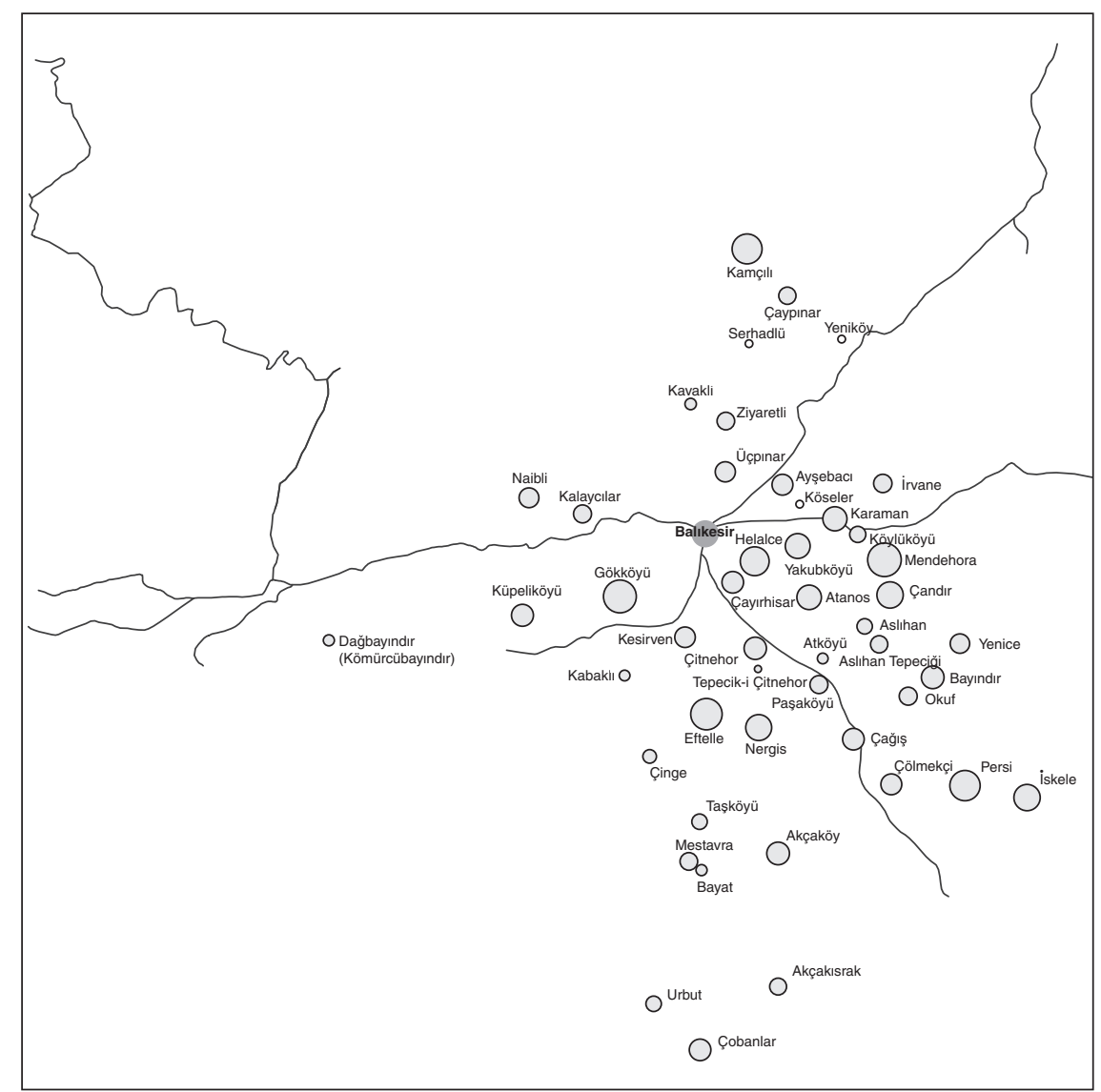

Figure 9.2 Villages belonging to the Balıkesir district.

Document TR199 is just a single page document but it names the villages that had existed around the Balıkesir city area but were later ruined. It contains extremely valuable information on the development and degeneration of villages, including movement of the population. Thus, it affords information that clarifies the changes in this region from a historical perspective. A series of such documents could be used effectively as socio-economic sources that are a part of the historical records to clarify changes and population movements in the villages and towns of each region.

\section{DiMSIS-Ex}

We used a GIS called DiMSIS (Disaster Management Spatial Information System)-Ex (Expansion) for our analysis. DiMSIS-Ex is the disaster prevention 


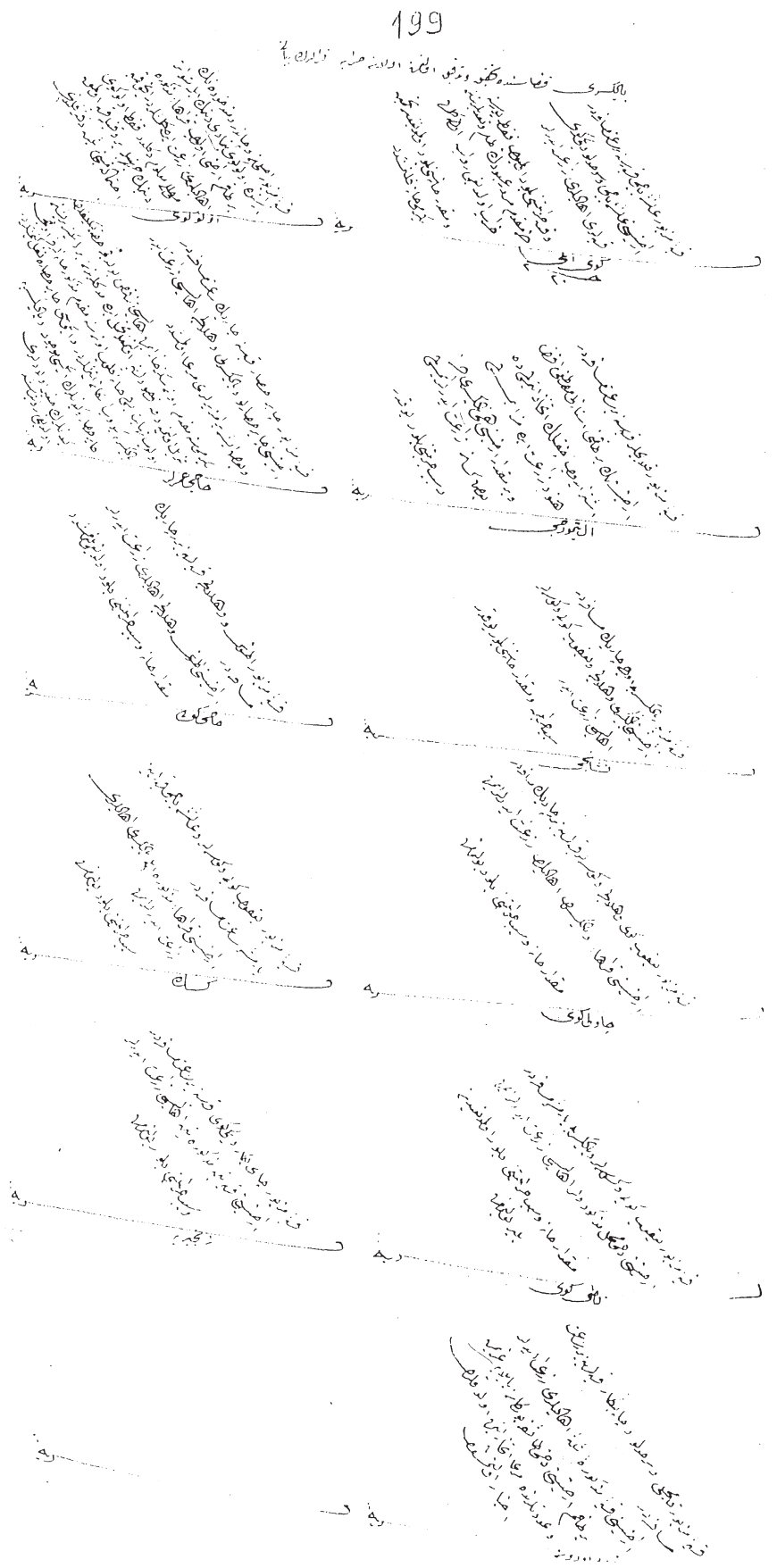

Figure 9.3 The Temettuat Register, No. 7228 (p. 199). 
system (Kameda et al. 1997; Hatayama et al. 1999a) that was developed as a result of the Hanshin/Awaji Great Earthquake in the dawn of January 17, 1995. DiMSIS-Ex is a spatio-temporal system that can be used for disaster management not only before but also directly after a disaster. A distinctive feature of DiMSIS-Ex is an easy treatment of time series events (Hatayama et al. 1999a,b), and this feature makes it appropriate for historical studies.

We note that DiMSIS-Ex was also used in volunteer activities at Düzce city (leader: S. Kakumoto) during the restoration activity after the Turkey earthquakes that occurred on August 17, 1999 (Kajitani et al. 2000). This use motivated us to use DiMSIS for our study of Ottoman historical material.

\section{Ruined villages in Balıkesir district}

In the 1840 Temettuat Register concerning Balıkesir district (No. 7225-7228), 46 villages with a total of 1957 households are recorded in the Register (No. 7227) that describes village residents.

The locations of these 46 villages (except for Kalya(?), the 26th village) have been confirmed by Ünlüyol (1995), whose investigations had been conducted on Balıkesir district of the eighteenth century. Based on the study of Ünlüyol, we indicated these 45 villages at the time of 1840 in the map along with the arterial roads of the present day (Figure 9.2). Note that the sizes of the circles on the maps are in ratio to the numbers of households (Table 9.1) registered in each village.

Köseler and Yeniköy were not indicated in Temettuat Register No. 7227, but they were indicated in No. 7228 where the names of ruined villages were listed. However, the locations of these villages have been confirmed in the Registers of Religious Court in Balıkesir district from the beginning of the eighteenth century, and Köseler is additionally confirmed as belonging to Balıkesir district in 1890 (Mutaf 1995: 63). Today, Köseler is a village and Yeniköy is a local administrative section of Balıkesir district and their locations have been confirmed (Ballkesri 1973).

Apart from these 45 villages, Document TR199 describes the 11 villages that were ruined in 1840 but had existed in Balıkesir district at the end of the Register on the city section (No. 7228), "the explanation concerning the ruined villages investigated and confirmed in Balıkesir district (Balıkesri kazâsında tahkîk ve tedkîk olunmuş olan harâbe kurâların beyani)."

To extrapolate to the locations of these villages, we adopted the following criteria. First, a travel time indicated in Document TR199 was converted into a distance with the conversion rate of $4 \mathrm{~km}$ per hour on foot. For example, " 45 minutes from $X$ village," was converted to " $3 \mathrm{~km}$ from the central point of $\mathrm{X}$ village." Thus, possible locations estimated from " 45 minutes from $\mathrm{X}$ village," are on the circle with a $3 \mathrm{~km}$ radius centered at the central point of $\mathrm{X}$ village. However, " $4 \mathrm{~km}$ per hour on foot" was achieved only along good roads. Therefore, we should consider that the circle indicates a fuzzy ringshaped zone. 
Table 9.1 The households of villages belonging to the Balıkesir district

\begin{tabular}{|c|c|}
\hline Names of villages & $\begin{array}{l}\text { Number of } \\
\text { households }\end{array}$ \\
\hline Aişebacı (Ayşebacı) & 42 \\
\hline Akçakısrak & 27 \\
\hline Akçaköy & 50 \\
\hline Aslihan & 23 \\
\hline Aslihan Tepeciği & 29 \\
\hline Atanos & 57 \\
\hline Atköyü & 11 \\
\hline Bayat & 12 \\
\hline Bayındır & 50 \\
\hline Çağış & 44 \\
\hline Çandır & 66 \\
\hline Çayırhisar & 45 \\
\hline Çaypınar & 29 \\
\hline Çinge & 18 \\
\hline Çitnehor & 47 \\
\hline Çobanlar & 44 \\
\hline Çölmekçi & 42 \\
\hline Dağbayındır (Kömürcübayındır) & 12 \\
\hline Eftelle & 93 \\
\hline Gökköyü & 103 \\
\hline Helalce & 80 \\
\hline İvane & 32 \\
\hline İskele & 67 \\
\hline Kabakl1 & 11 \\
\hline Kamçılı & 86 \\
\hline Kalaycilar & 31 \\
\hline Kalya(?) & 22 \\
\hline Karaman & 55 \\
\hline Kavaklı & 13 \\
\hline Kesirven & 40 \\
\hline Köylüköyü & 25 \\
\hline Küpeliköyü & 46 \\
\hline Mendehora & 108 \\
\hline Mestavra & 30 \\
\hline Naibli & 37 \\
\hline Nergis & 65 \\
\hline Okuf & 31 \\
\hline Paşaköyü & 31 \\
\hline Persi & 88 \\
\hline Taşköyü & 23 \\
\hline Tepecik-i Çitnehor & 5 \\
\hline Urbut & 23 \\
\hline Üçpınar & 39 \\
\hline Yakubköyü & 59 \\
\hline Yenice & 36 \\
\hline Ziyaretli & 30 \\
\hline Total number of households & 1957 \\
\hline
\end{tabular}


Second, when there are peoples, who belong to different villages, farming in a ruined village, we considered that the ruined village was almost at the same distance from their villages.

Last, when descriptions in Document TR199 gave a clue to the locations of ruined villages on a map, we considered them for our extrapolation. For example, as arterial roads radiated in all directions from Balıkesir city, we considered that the travel speed from Balıkesir city would be faster than " $4 \mathrm{~km}$ per hour on foot." In contrast, conditions are likely to be less favorable for moving from village to village because topographical features such as mountains, forests, marshes, and so forth prevented easy travel. In such a case, even when two villages are connected by a straight road, we considered that the travel time between them was longer.

In the following arguments, we first provide the translation of the description of each village in Document TR199, and then we extrapolate to the location of each village using the above criteria.

\section{Köy-ili village (Karye-i Köy-ili), 20 households (20 hane)}

The text referring to Köy-ili village in Document TR199 reads:

This village was at a distance of one hour to Aişebacı (Ayşebacı) village. The land was farmed by the inhabitants of the villages of Aişebac1 (Ayşebac1), Serhadlü, and Yeniköy. Nobody knows when this village was laid waste but it has been said that the village had degenerated from the oppression of passing traffic a hundred years ago. It has been estimated as 20 households, as nobody knows even the approximate number of households that existed.

The location of Serhadlü is ambiguous, but as it will be mentioned below with the analysis of Kirca-uzun village, Serhadlü is estimated to be on the other apex probably situated in the west of the triangle formed by the straight line from the middle point between Ayşebacı and Yeniköy to Yeniköy (see Figure 9.14). By the calculation of $4 \mathrm{~km}$ per hour, it will be on the circle in Figure 9.4, and when the village of the farming inhabitants is considered, Köy-ili village could be in the section of the dark disk. In fact, the west of the dark disk was mentioned as Köteylü in the 1530 Land Register (166 Numaralı Muhâsebe-i Vilayeti Anadolu Defteri (937/1530)) and a village called Köteyli had existed in the first half of the eighteenth century (Ünlüyol 1995: 110, 112), in 1891 (Mutaf 1995: 63), in 1945 (Balıkesir Map), and to this day. The present day Köteyli is situated $5 \mathrm{~km}$ from Ayşebac1 and $6 \mathrm{~km}$ from Yeniköy, northwest from the arterial road stretching from Balıkesir city to Bursa. The location of this Köteyli near the arterial road seems to substantiate the "oppression from passing traffic" mentioned in the document. 


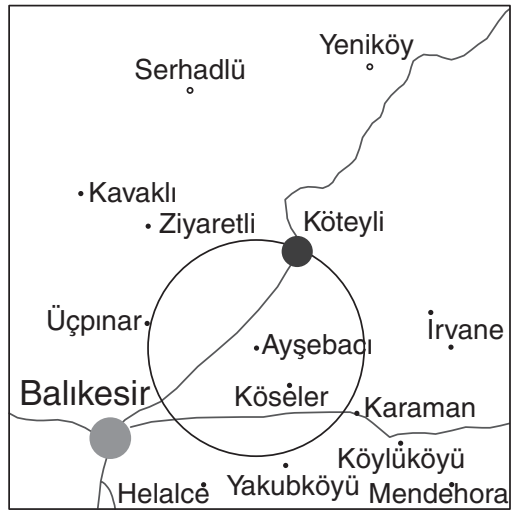

Figure 9.4 Estimated location of Köy-ili village.

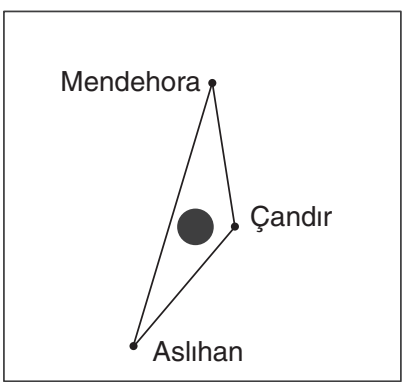

Figure 9.5 Estimated location of Uluköy village.

\section{Uluköy village (Karye-i Uluköy)}

The text referring to Uluköy village in Document TR199 reads:

This village is a lot of land known as "Uluköy timarı," situated between Aslihan, Çandır, and Mendehora, and the inhabitants of the above-mentioned three villages had farmed it. However, the location of Uluköy village is not known. Since it had the name of "Uluköy," this place had the potential, in time, to become a village and so came to be recorded in the Register.

Since Uluköy village is said to be located "between" the three villages mentioned earlier, it is estimated to be approximately around the triangle linking the central point of the three villages (see Figure 9.5). Additionally, it must have been on land suitable for farming as it was a "timar" (small military fief). 


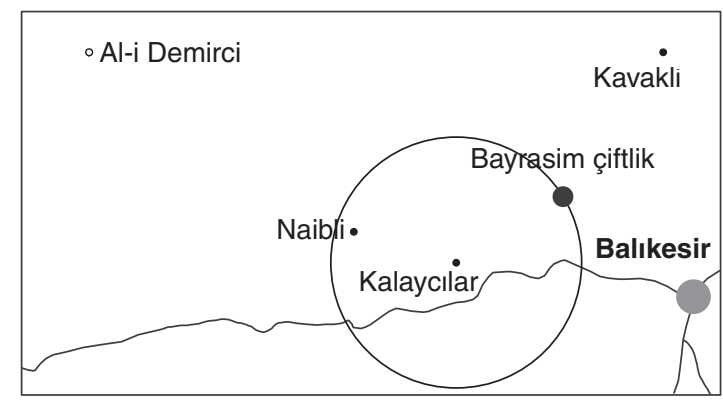

Figure 9.6 Estimated location of Al-i Temürcü village.

\section{Al-i Temürcü village (Karye-i Al-i Temürcü)}

The text referring to Al-i Temürcü village in Document TR199 reads:

This village is at a distance of one hour from Kalaycilar village. Mustafa efendi had purchased a part of the land in question and made it into a çiftlik [farm], but it had not been farmed yet. [Moreover, a part of this land] seems to have been farmed by some people from Balıkesir. Nobody knows the reason for the degeneration of this village.

A village named Al-i Demirci exists in the place indicated with a circle at the westernmost edge of Figure 9.6. This Al-i Demirci village has been confirmed in the Land Register of 1530 and in the maps at the beginning of the eighteenth century and in 1945. For example, there were 4.5 households that were levied the avariz tax in 1702/1703 (Ünlüyol 1995: 110). In 1890, Al-i Demirci was a village belonging to the Balya district (Mutaf 1995: 70) that adjoins the northwest border of Balıkesir district. However, as indicated with a circle in Figure 9.6, this Al-i Demirci was at a distance of approximately $11 \mathrm{~km}$ from Kalaycilar village, according to the 1945 map. For this reason, the Al-i Demirci based on the 1945 map and the Al-i Temürcü of 1840 do not coincide in location. If we ignore the rather far-fetched possibility that the distance of about $11 \mathrm{~km}$ could have been perceived roughly as "a long distance $=$ one hour" in 1840 , we are left with the probability that this is another village on a circle of radius $4 \mathrm{~km}$ (an hour) from Kalaycılar village. The name "Bayrasim çiftlik" exists on this circle on the 1945 map. When considering that a çiftlik could exist in such a place, it is also possible to think of the continuation of Al-i Temürcü as a çiftlik.

\section{Hacı Ömerler village (Karye-i Hacı Ömerler)}

The text referring to Hacı Ömerler village in Document TR199 reads:

This village is at a distance of a quarter-hour from Çayırhisar village. The inhabitants of Çayırhisar, Balıkesir, and Helalce had farmed this 
land, and some of them had turned a part of this land unsuitable for farming into a pasture (mer'a). Probably, 18 households had existed twenty years ago. Insufficient tax payment occurred when the tax amount imposed on the village did not reduce with the decrease of inhabitants. The villagers [who could not endure such tax burdens] began to leave the land in small groups and finally only five households were left. Ten years ago, three out of these five households seemed to have moved to Balıkesir and settled there. The remaining two households moved to Çayırhisar. Of those who had moved to Çayırhisar, two households still remain today [in Çayırhisar], and those who had moved to Balıkesir are said to be children.

Hacı Ömerler village could be assumed to be approximately on the dark disc shown on Figure 9.7 as it is between the point on the circle that is a quarter minutes to Çayırhisar village and the point which could be presumed to be 30 minutes equidistant from Çayırhisar, Balıkesir city, and Helalce, according to the information given above about the farmers' native villages. The circumstances leading to changes in the village of Hacı Ömerler can be easily understood from the above-mentioned explanations. Hac1 Ömerler is recorded as a village where households were levied the avartz tax (Ünlüyol 1995: 112), in the name of Hacı Ömer, as three households in 1702/1703 and 1.5 households in 1730/1731. Being on land adjoining Balıkesir city and the comparatively large Helalce village (with 80 households), Hacı Ömerler village had probably been absorbed into both areas. Refer to Egawa (2004) as to where many of those had existed who had moved and settled in Balıkesir city from surrounding villages.

\section{Nişanct village (Karye-i Nişancı)}

The text referring to Nişancı village in Document TR199 reads:

This village is at a distance of 45 minutes from Balıkesir. The dwellers of Balıkesir, Helalce, Yakubköy, and Köseler are farming this land.

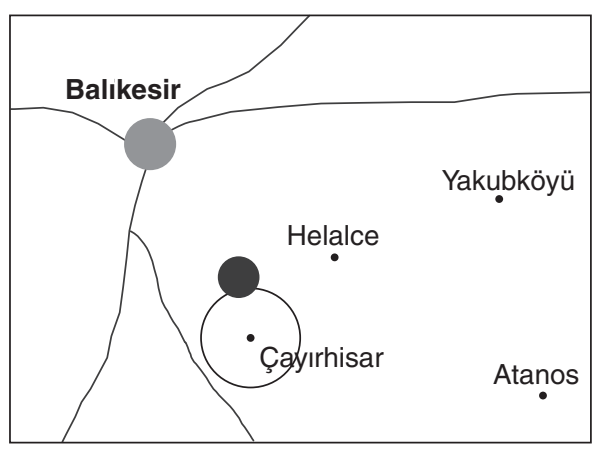

Figure 9.7 Estimated location of Hac1 Ömerler village. 
Nobody with the knowledge of the reason for the degeneration and number of dwellers' households was found.

From the fact that the farmers are the dwellers of Balıkesir city, Helalce, Yakubköy, and Köseler, it could be presumed that Nişanc1 village is situated on the circle that is 45 minutes from Balıkesir city, and also equidistant and easy to commute to from Helalce, Yakubköy, and Köseler (Figure 9.8). Therefore, it is approximately on the dark disk somewhere along the arterial road. In fact, the dark disk is shown outside the circle marking 45 minutes from Balıkesir. Determining the estimated location of the ruined village took into account the third criterion mentioned above. As mentioned earlier, the journey from Balıkesir city to Nişanc1 village was along an arterial road, and it may be supposed that movement from Balıkesir city to Nişancı would have been more efficient than for inhabitants of the three farming villages.

\section{Hacıköy village (Karye-i Hackköy)}

The text referring to Hacıköy village in Document TR199 reads:

This village is situated respectively a quarter-hour from both the villages of Atanos and Helalce. The dwellers of Atanos and Helalce are farming this land. It was unclear whether there were any persons who knew the number of dwellers' households and the reason for the degeneration.

Since the two circles do not converge when drawn according to the descriptions, Hacıköy village is presumed to be approximately on the dark disk that is equidistant from the two villages (Figure 9.9).

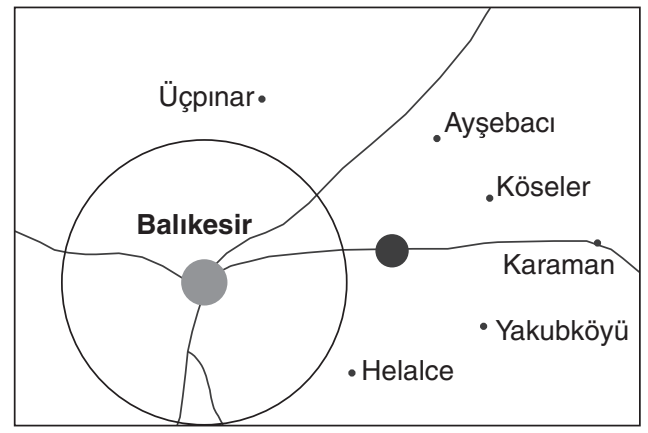

Figure 9.8 Estimated location of Nişancı village. 


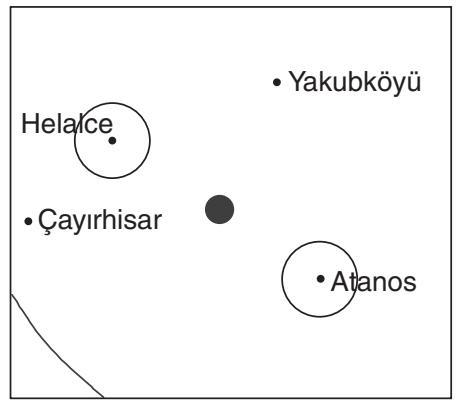

Figure 9.9 Estimated location of Hac1köy village.

\section{Çavlıköy village (Karye-i Çavlıköy)}

The text referring to Çavlıköy village in Document TR199 reads:

This village is at a distance of a quarter-hour from the villages of Yakubköy, Helalce, and Köseler. It seems that the inhabitants of these three villages and those of Balıkesir are farming this land. No persons with the knowledge of the number of dwellers' households and the reason for the degeneration were found.

Since the three circles do not converge when drawn according to the descriptions, Çavliköy village is presumed to be approximately on the dark disk at the intersecting point of the double diameters of the concentric circles from the three villages (Figure 9.10). The location of this black disk is roughly one hour distant from Balıkesir city. However, as noted for Figure 9.8, the inhabitants of Balıkesir city would have been traveling along the arterial road, and therefore under conditions more favorable than movement from the other three villages.

\section{Kesik (Kesek) village (Karye-i Kesik (Kesek))}

The text referring to Kesik (Kesek) village in Document TR199 reads:

This village is situated at a distance of 30 minutes respectively from the villages of Yakubköy, Köseler, and Aişebacı (Ayşebac1). It seems that the inhabitants of these three villages and those of Balıkesir are farming this land. No persons with the knowledge of the reason for the degeneration were found.

Since the three circles do not converge when drawn according to the descriptions, Kesik (Kesek) village is presumed to be approximately on the dark disk at the point where the extended diameters of the concentric circles from the three villages intersect (Figure 9.11). It is probable that the dwellers of 


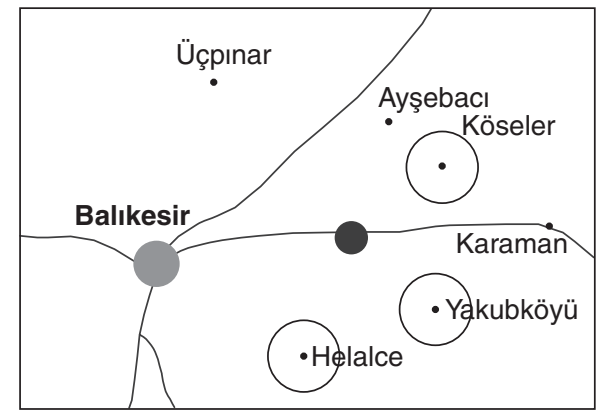

Figure 9.10 Estimated location of Çavlıköy village.

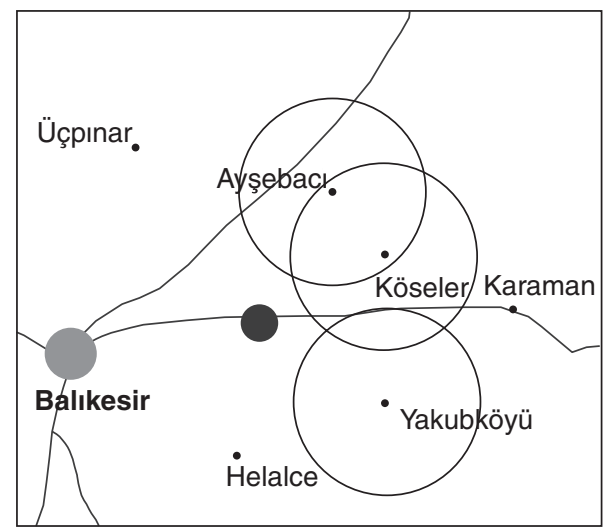

Figure 9.11 Estimated location of Kesik (Kesek) village.

Yakubköy, Köseler, and Ayşebacı as well as Balıkesir city farmed this land when this village was situated in this location, as for Çavlıköy (Figure 9.10). Kesik (Kesek) village is recorded as having the avarız tax (Ünlüyol 1995: 112) in the name of Kesik levied on 1.5 households in 1702/1703 and 0.25 households in $1730 / 1731$.

\section{Kadık̈̈y village (Karye-i Kadıköy)}

The text referring to Kadıköy village in Document TR199 reads:

This village is situated at a distance of 30 minutes respectively from Yakubköy, Köseler, and Balıkesir. It seems that the inhabitants of 
these three regions are farming this land. No persons with the knowledge of the number of dwellers' households and the reason for the degeneration were found.

As the three circles do not intersect when drawn according to the descriptions, Kadıköy village is presumed to be approximately on the dark disk at the point where the extended diameters of the concentric circles of Yakubköy and Köseler intersect (Figure 9.12). As for Figure 9.10 and 9.11, it seems likely that the inhabitants of Balıkesir city could reach this village more quickly than those of the other two villages. Kadıköy village is recorded as having the avarız tax (Ünlüyol 1995: 113) in the name of Kadı levied on 0.5 households in 1702/1703 and 1730/1731.

\section{Zenciriye village (Karye-i Zenciriye)}

The text referring to Zenciriye village in Document TR199 reads:

This village is situated at a distance of one hour respectively from the villages of Çaypınar and Yeniköy. The inhabitants of these villages are farming this land. No persons with the knowledge of the reason for the degeneration were found.

Zenciriye village is assumed to be in the neighborhood of one of the intersections of the two circles in Figure 9.13. Since Yeniköy village was not included in the villages belonging to Balıkesir county, it could be assumed that Zenciriye village was situated in the border region between Balıkesir county and Susurluk county. Zenciriye village is recorded as having four households levied with the avarlz tax (Ünlüyol 1995: 111) in 1702/1703 and one household in 1730/1731.

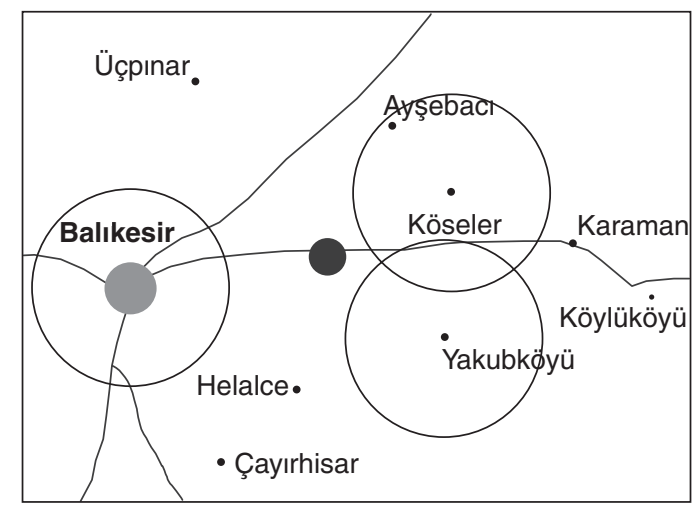

Figure 9.12 Estimated location of Kadıöy village. 


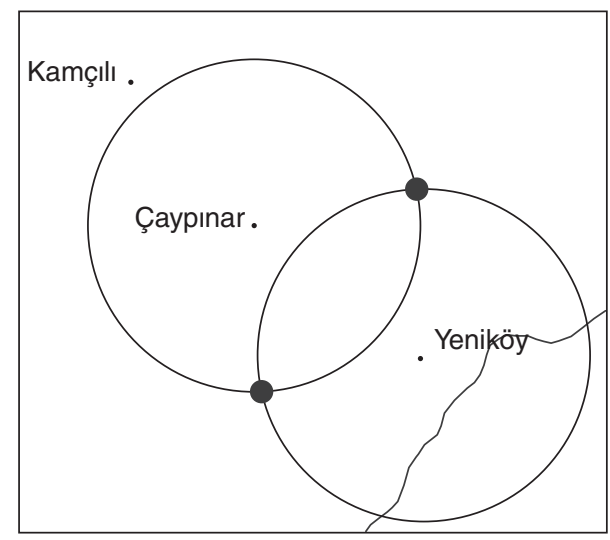

Figure 9.13 Estimated location of Zenciriye village.

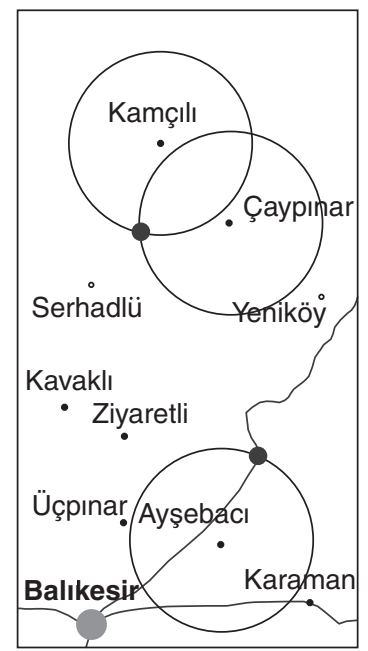

Figure 9.14 Estimated location of Kirca-uzun village.

\section{Krra-uzun village (Karye-i Krrca-uzun)}

The text referring to Kirca-uzun village in Document TR199 reads:

This village is situated at a distance of one hour respectively from the villages of Kamçı1ı, Serhadlü, and Çaypınar. It seems that the inhabitants of these three regions are farming this land. A part of the land seems to have been used as pasture for nomadic groups when staying in summer camp. 
In Figure 9.14 we combine the above information with that from Figure 9.4. Both the southern intersecting point of the two circles and the concentric circle that is one hour from Serhadlü, intersect on the same point. Therefore, Kirca-uzun village is in the neighborhood of the southern intersection of the two circles, and the location of Serhadlü presumed in Figure 9.4 could be confirmed again.

\section{Conclusions and future prospects}

From the observations mentioned above and using the DiMSIS-Ex GIS System, the approximate locations of the ruined villages (as of 1840) have become clear. However, there still remain problems such as those mentioned below.

First, there is a breadth in the "time" information described in the historical documents. It goes without saying that the concept or awareness of "time" in history varies according to the time, region, or the individual. In addition, the roads could be mountain paths or on level ground, and might be obstructed by features such as thickets or marshy ground. In other words, the track between villages would not, in general, follow a straight line. By using GIS, the latter issue, that is, a more precise analysis would become possible with the accumulation of geographic data including more accurate contour lines.

Second, the accumulation of historical information concerning the villages is still not enough. Nevertheless, by referring to the Land Registers and the studies by Ünlüyol and Mutaf, the rough outline of the rise and decline of the villages during the sixteenth to twentieth centuries could be indicated. By using other Ottoman historical materials, including court records that were unavailable at this time, it would be essential to accumulate the historical information of each village.

Third, it is understood that on-site survey is indispensable in information gathering rooted in the lives of ordinary people. Bearing in mind these qualifications, the future issues would be to restore the Balıkesir society in three-dimensions, as well as breaking into the spiritual world by accumulating more Ottoman material and information by using GIS(DiMSIS-Ex).

\section{Acknowledgments}

We express our appreciation to Sato Tsugitaka, Okabe Atsuyuki, Asami Yasushi, and Hayashi Kayoko. We acknowledge the guidance and advice given us by Kakumoto Shigeru, Hatayama Michinori, Kajitani Yoshio, Big Survey \& Design Co., Ltd., and Yoshida Printing Inc. Furthermore, to İlhan Şahin for the deciphering of Ottoman historical materials, and Aynur Ünlüyol for Balıkesir in the eighteenth century, Okabe Atsuyuki, Asami Yasushi and an anonymous referee for their valuable comments on completion of this manuscript, we acknowledge and express our gratitude. 


\section{EGAWA HIKARI}

\section{References}

Başbakanlık Osmanlı Arşivi, Temettuat Defterleri[ML.VRD.TMT] No. 7227, 7228.

Egawa, Hikari (1997) "The Tanzimat Reforms and Provincial Society: Analysis of the Temettü'ât Defteri in Balıkesir District (1840) from the Viewpoint of Land Possession" (written in Japanese), The Toyo Gakuho (The journal of the Research Department of the Toyo Bunko), vol. 79 no. 2, Tokyo: the Toyo Bunko: 01-029.

Egawa, Hikari (1998) "The Urban Society and Commerce-Industry of Balıkesir in the Middle of Nineteenth Century: Especially from the Point of the Aba Industry" (written in Japanese), Ochanomizushigaku, no. 42: 1-42 Tokyo: Ochanomizu University.

Egawa, Hikari (forthcoming) "A Study of Socio-Economic Change in Balıkesir in the Middle of the Nineteenth Century through the Temettuat Register," Hayashi, K. and Aydin, M. (eds), The Ottoman State and Local Societies in Change: A Joint-Study on the Temettuat Registers Studies (IAS series), London: Kegan Paul.

Hatayama, M., Matsuno, F., Kakumoto, S., and Kameda, H. (1999a) "Development of Spatial Temporal Information System DiMSIS" (written in Japanese), Theory and Applications of GIS, vol. 7, no. 2: 25-33.

Hatayama, M., Matsuno, F., Kakumoto, S., and Kameda, H. (1999b) "Development of Rescue Support System and its Application to Disaster Drill in Nagata Ward, Kobe City for Realizing Risk-Adaptive Regional Management Spatial Information System (2)," Thirteenth Annual Conference on Geographic Information Systems GIS 99, Vancouver: 175-178.

Kajitani, Y., Yoshikawa, K., Kakumoto, S., and Hatayama, M. (2000) "Spatial-Temporal GIS System Analysis of Houses in Duzce City Damaged by the 1999 Turkey Earthquakes" (written in Japanese), Proceedings of the Annual Conference of the Institute of Social Safety Science, no. 10: 121-124.

Kameda, H., Kakumoto, S., Ohno, S., Hatayama, M., Taniguchi, T., and Iwai, S. (1997) “A Critical Appraisal of a Disaster Information Processing at Nagata Ward Office, Kobe in the Great Hanshin-Awaji Earthquake Disaster-A Proposal for Development of RiskAdaptive Regional Management Information System," IMDR (Integrated Management for Disaster Risk) Research Report, no.1, Division of Integrated Management for Disaster Risk Disaster Prevention Research Institute, Kyoto: Kyoto University.

Kütükoğlu, M. S. (1981) "Asâkir-i Mansûre-i Muhammediyye Kıyâfeti ve Malzemesinin Temini Meselesi," Doğumunun 100. Yllında Atatürk'e Armă̆an(ayrı baskl), Istanbul: 519-605.

Kütükoğlu, M. S. (1995) “Osmanlı Sosyal ve İktisâdî Tarihi Kaynaklarından Temettü Defterleri," Belleten, vol. 59, no. 225: 395-412(+6).

Mutaf, A. (1995) Sâlnamelerde Karesi Sancă̆ı (1847-1922), Balıkesir: Taner Ofset.

Ünlüyol, Aynur (1995) Şeriyye Sicillerine Göre XVIII. Asrın Ilk Yarısında Balıkesir (1700-1730), unpublished thesis, Bursa: T.C. Uludağ Üniversitesi.

166 Numaralı Muhâsebe-i Vilayeti Anadolu Defteri (937/1530), Ankara, 1995.

Cumhuriyetin 50.yılında Balıkesir 1973 Il Yıllı̆̆ $l$, Istanbul, 1973.

1/100000 Balıkesir Map, Harita Genel Müdürlügü, Ankara, 1945. 


\section{Part III}

\section{URBAN ANALYSIS}





\title{
THE SPATIAL STRUCTURE OF COMMERCIAL AREAS IN TURKEY AND OTHER ISLAMIC COUNTRIES
}

\author{
Tsuruta Yoshiko, Arai Yuji, Jinnai Hidenobu, \\ Shishido Katsumi, and Sato Atsuhiko
}

\section{Objectives and methods}

In Islamic regions, the central part of a city has a lively commercial space, which is called çarşı in Turkish, souq in Arabic, and bazaar in Persian. This commercial space is filled with various functions including commercial ones, and acts as the nucleus of the city. The objective of this study is to analyze the structure of this commercial area using geographical information systems (GIS), and understand the urban characteristics of cities in Islamic regions, primarily in Turkey. To achieve this objective, we study three cities in Turkey, namely, Bursa, Safranbolu, and Göynük, which differ in both size and character. In addition, to clearly contrast the characteristics of these Turkish cities, we also study two cities in the Arab region, namely, Aleppo in Syria, and Qayrawan in Tunisia.

In Turkey, where climates and natural conditions vary from region to region, Bursa, Safranbolu, and Göynük belong to the region characterized by a greeneryfilled, wooden-built culture. Thus, many buildings are independent of one another and they do not share walls. These cities have much open space, and consequently their landscape gives an impression of spaciousness. The open spaces are of various kinds, including plazas, courtyards, and external gardens on the premises of mosques (or Külliye in Turkish). Such spaces are also commonly found in a commercial area located in the center of a city. As a city becomes bigger, so too does the central commercial area, and the percentage of the area occupied by buildings in the commercial area increases. With the expansion of the commercial area, the number of commercial facilities such as shops and Hans (i.e. lodging houses and offices for caravans) also increases (note that these are Han in Turkish, Fondok in Arabic, and Caravanserai in Persian). Urbanization has resulted in a high-density area and a large number of facilities. On the other hand, small cities have ample open spaces, and the spatial structure of a central commercial area is simple and clear. 
In contrast, Aleppo and Qayrawan are oasis cities in the arid zone and they are located close to the desert region. In these cities, there is little greenery; buildings are made of stone and rubble that are obtained near those cities; and the cities predominantly belong to the stone-built culture zone. Most of the buildings have courtyards and are built close to one another, sharing walls. Thus, the streets and plazas are very narrow and they have an air of oppression and of being closed-in. There are many tunnel-like streets. The courtyard is the only open space and it is used for various activities. Even in the central commercial area, streets are narrow, are arcaded, and open space mostly consists of courtyards of mosques and Hans. The differences between big cities and small cities are reflected in the size of the central commercial area and the number of commercial facilities. However, the spatial structure itself does not differ much.

To enhance the above comparative analysis, we adopted the following procedure. First, we tried to find the central commercial area by observing city maps and thus determined the research areas (Figure 10.1). Second, we classified subareas constituting the central commercial area into a number of categories according to spatial forms and functions. The categorized subareas are indicated on a map with colored patterns (Figure 10.1). This visualization was very helpful for achieving the task of categorical classification. Third, we calculated the area occupied by each subarea category. By comparing the resulting numerical values (Table 10.1), we identified the spatial structure and characteristics of the central commercial area. For this task, we used GIS to digitize maps and to measure the area of each subarea category. Digitizing was a rather tedious task, but once done, we could easily measure areas and examine spatial functions and forms from various viewpoints.

In the above procedure, categorization was the key task, and therefore we explain it in detail here. Using the database mentioned above, we classified spaces into two categories based on spatial forms: the area occupied by buildings; and the area not occupied by buildings, which includes streets, plazas, gardens, and other open spaces. We refer to the former as "buildings" and the latter as "voids." We further classified the voids into two categories: "covered voids" such as streets covered with arcades, and "uncovered voids" such as open-air plazas. Note that, in total, we have three categories of forms (see the categorical legend in Figure 10.1).

At the same time, we classified the voids into four categories based on function: "streets," "plazas," "plazas and streets with open-air markets," and "other voids," and we classified buildings into six categories based on function: "shops," "Hans," "Bedestens" (a Turkish term, implying buildings in a bazaar with fireproof vaults where valuable goods are kept), "religious facilities," "Hamams" (a Turkish term meaning a public bath, "Hammam" in Arabic), and "other types of buildings." The former three buildings have commercial functions and the latter three have non-commercial functions. Note that, in total, we have 10 categories of functions (see the categorical legend in Figure 10.1).

The product of 10 functional categories and 3 form categories defined above produces 30 categories (see the categorical legend in Figure 10.1). We calculated 


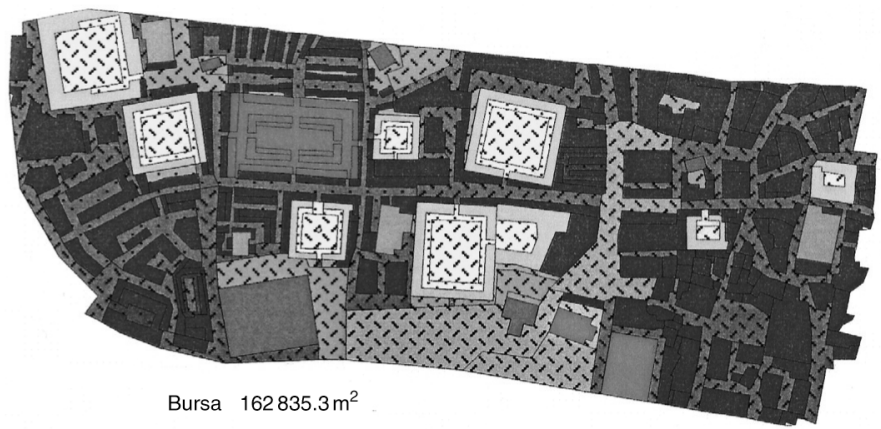

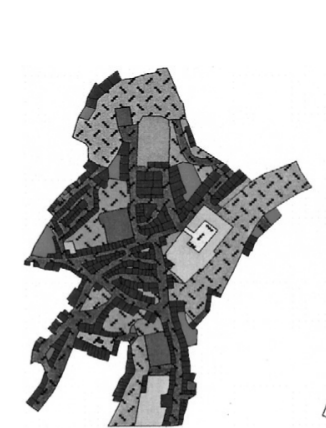

Safranbolu $31398.5 \mathrm{~m}^{2}$

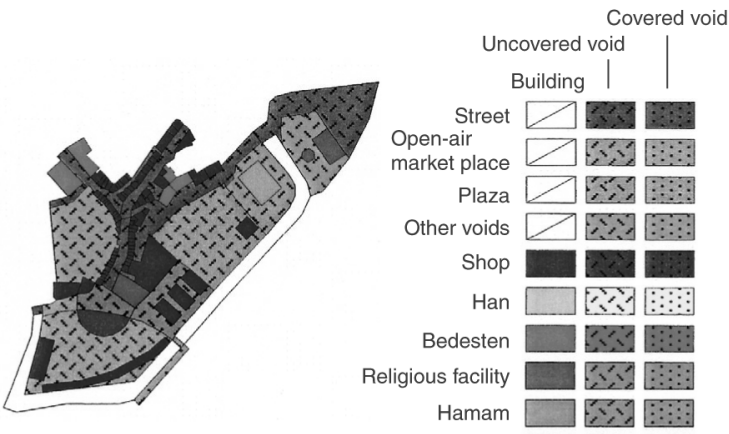

Göynük $30733.7 \mathrm{~m}^{2}$

Other types of building

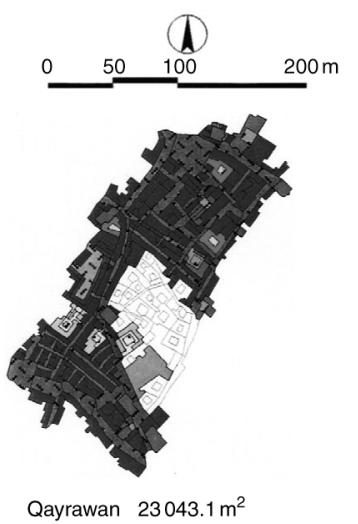

Figure 10.1 Plan of Commercial Area indicated with spatial form and functional categories.

the areas of each subarea category as well as their ratios, and examined the characteristics of the central commercial areas. In the following text, we describe these categories in detail.

The first four functional categories belong to the voids (Figure 10.1). First, the "streets" are linear public space for human and car travel. Second, the "plazas" 


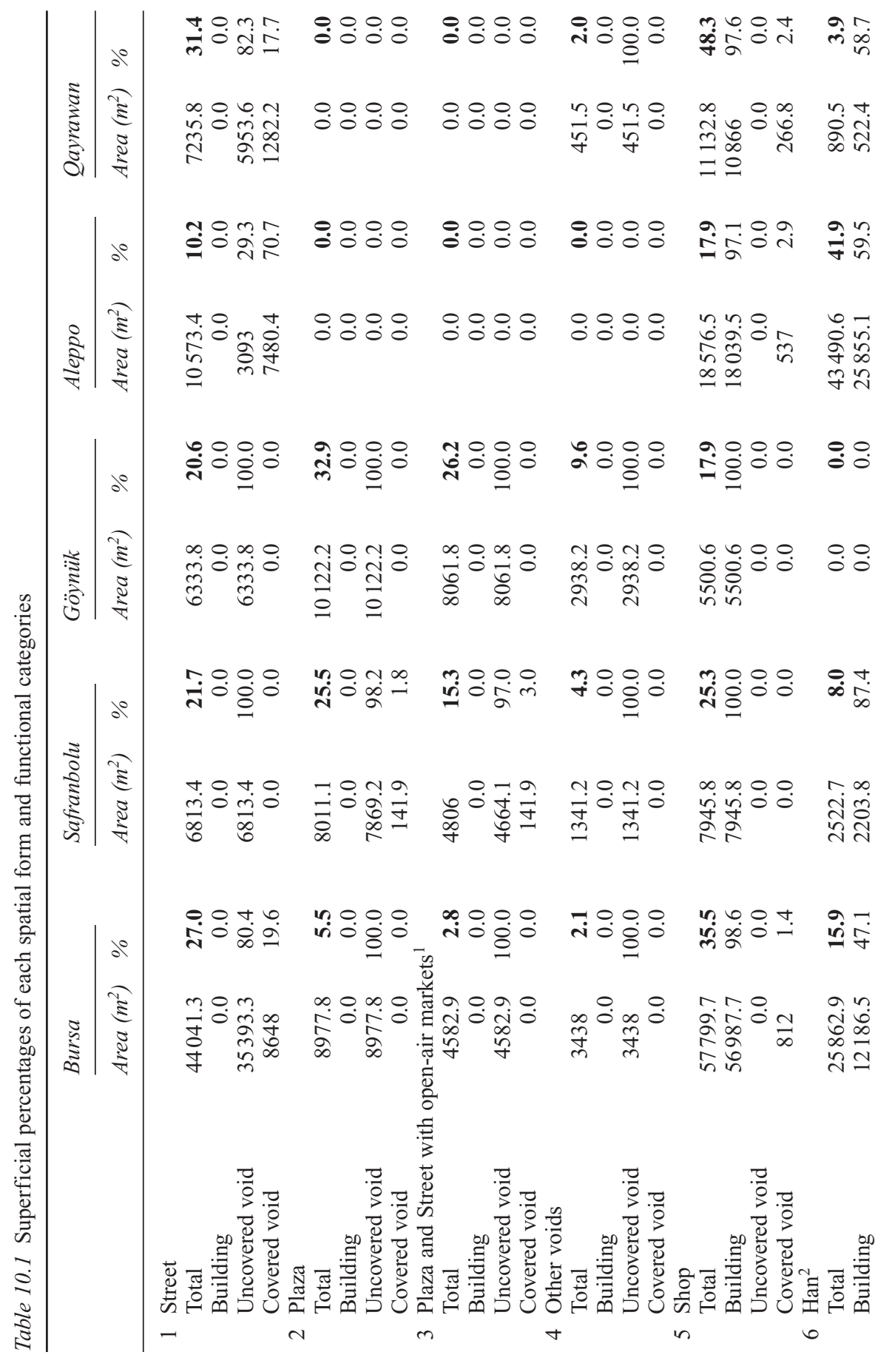




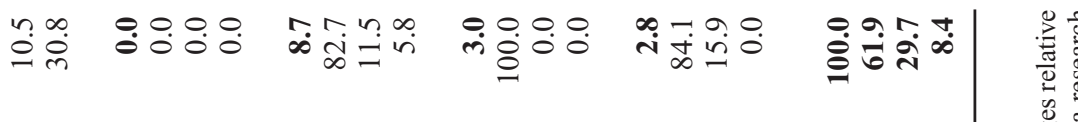

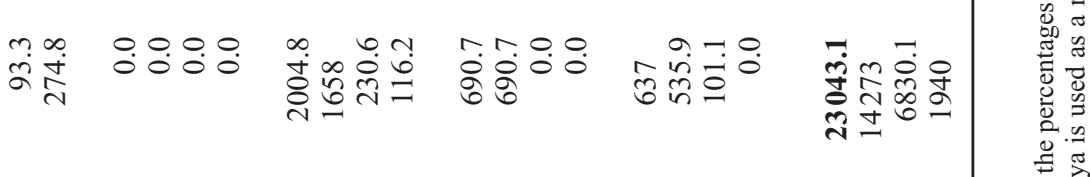

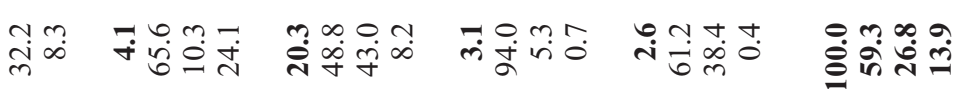

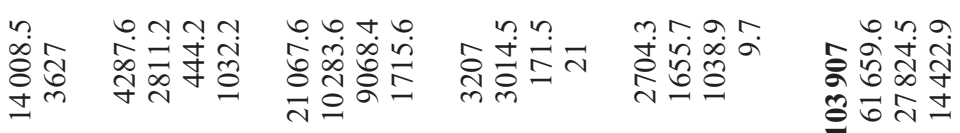

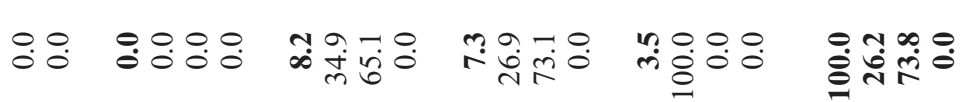

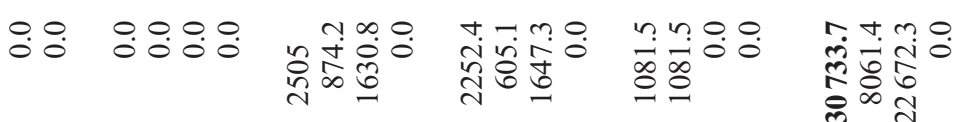

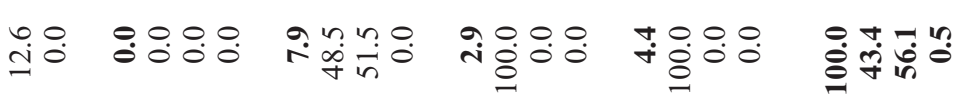

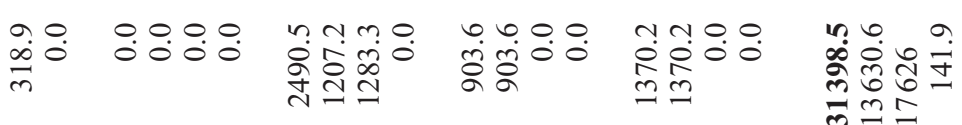

$$
\begin{aligned}
& \text { 率 }
\end{aligned}
$$

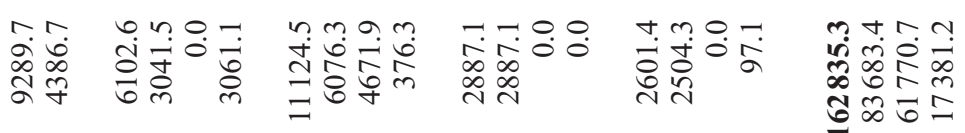

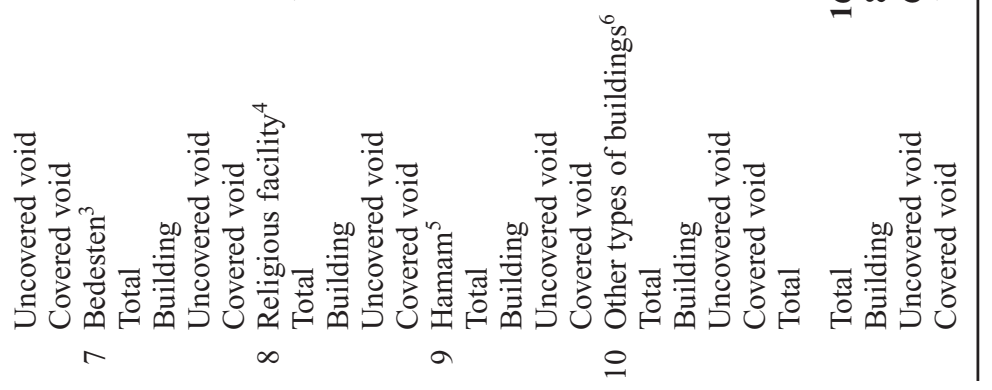


are surface-type public space that supports a large number of people. Third, "streets and plazas with open-air markets" are the places where a market opens once or twice a week and tents are pitched. We treat these places as a special case of the first and second categories. Fourth, "other voids" are voids between buildings. Such voids are likely to exist in Turkey because buildings often stand on sloped areas.

The next three categories have commercial functions, and the last three categories have non-commercial functions (the column in Figure 10.1). The "shops" are retail shops along streets and alongside other buildings. A "Han" functions as a lodging house for caravan people, but today it is a historical commercial facility that serves as an office, warehouse, workplace, and shop. Architecturally, many are two-storeyed and have a courtyard. "Bedestens" started out as trading sites for precious merchandise, particularly silk. They are of a more sturdy architecture than the other commercial facilities and are located in the center of commercial areas. Architecturally, they are rectangular-shaped and contain a well. In many, the roofs are shaped like mini domes. There are gates with locks on two sides or four sides of a squared block. Some are independent buildings and face a street, while others are located inside a grand bazaar. Many shops line the inside of a Bedesten, and there are passageways between one shop and another. This passageway-area is treated as a roofed void. The Arabic Qaysariya (solid buildings for commercial facilities selling precious merchandise) is also included in this category. "Religious facilities" refer to mosques (Cami in Turkish, Masjid in Arabic), Madrasa (Medrese in Turkish, Madrasa in Arabic), mausoleums, or the Külliye, a combination of the aforementioned. Many mosques and Külliye have courtyards or outdoor yards and they are classified as uncovered voids. "Hamams and such" include the Hamam (in Turkish, implying public bath), Maqha (in Arabic, implying a coffee house), and toilets. Today, there are still Hamams that function as public bathing houses, but others have a different function and are being reused as commercial facilities, although they have retained their original form. "Other buildings" refer to buildings such as residences, city offices, and so forth.

The voids are of two types: public spaces such as streets that can be used by anyone at anytime, and mosques and Hans that are private spaces with limited functions. In this research, we regarded both types as "voids" because visually both are voids. We carried out our analysis using the above categories.

\section{Outline of the five cities and their bazaar areas}

As mentioned in the previous section, we chose five cities for our study: Bursa, Safranbolu, and Göynük in Turkey; and Aleppo and Qayrawan in the Arabic region. These five cities grew as trade hubs. The cities in Turkey were all transit centers on the east-west trade route in Anatolia; they flourished as caravan cities. They are surrounded by lush greenery, and have historical districts that take advantage of the sloping topography. 
Bursa is an historical city, being the first capital of the Ottoman Empire, and even today, it is a major city, bustling with trade activities. There are many historical commercial facilities still in use in the commercial area.

Safranbolu is a mid-size city where the old commercial area remains preserved. The old town spreads out into ravines while the new town is located atop a hill. An example of an historical commercial facility therein is the Arasta (a Turkish term meaning shops of the same trade built in a row), which has been restored for use. Together with other shops and workshops, it forms a commercial spread horizontally.

Göynük too is a city that spreads out into ravines. However, there are no distinguishable old and new towns like in Safranbolu and it is a small city that has developed primarily along an old caravan route.

In short, we are exemplifying Bursa as a city with a big commercial area, Safranbolu as a city that is not big but has a commercial area in which shops are spread out horizontally, and finally, Göynük as a city with a small commercial area mainly consisting of shops aligned along a caravan route. In each of these three cities, there is a regular market space inside a commercial area. In particular, Göynük is a small city with a wide commercial space that accommodates many people who gather from nearby villages.

To clarify the characteristics of the three Turkish cities, we examine two Arabic cities, Aleppo and Qayrawan. Both Aleppo and Qayrawan have clearly distinguishable new and old town areas, with a densely built commercial area in the center of the old town. In Aleppo, there are rows of small shops around the Umaiya Mosque and there are also many Hans. In the old town of Qayrawan, the central commercial area consists mostly of small shops and workshops. The main Han is located outside the castle wall and the Great Mosque is not adjacent to the commercial area. In the following paragraphs, we compare the spatial composition of subarea categories in the five cities.

\section{Bursa (Table 10.2)}

Bursa lies along the coast of the Marmara Sea. From 1326 to 1362, it was the capital of the Ottoman Empire and there remain a number of historical buildings that are standing primarily around mausoleums of the successive Sultans. The city is situated at the foot of Uludag (Mt. Olympus) and is blessed with an alpine ambience. The castle fort from the Byzantine days remains on the central hills, and in the lower elevations to the east, there is a wide, sprawling commercial area that includes the Great Mosque (Ulu Camii, in Turkish), plazas, Bedestens, Hans, and a number of other facilities. The construction of a modern road has divided the commercial area into north and south, making the old town smaller. The plaza that is situated to the east of the Great Mosque is bustling with people

as it serves as the entrance to the commercial area and is also a place of relaxation. A regular market is held along the streets that extend northward from the plaza. 
Table 10.2 The commercial area in Bursa

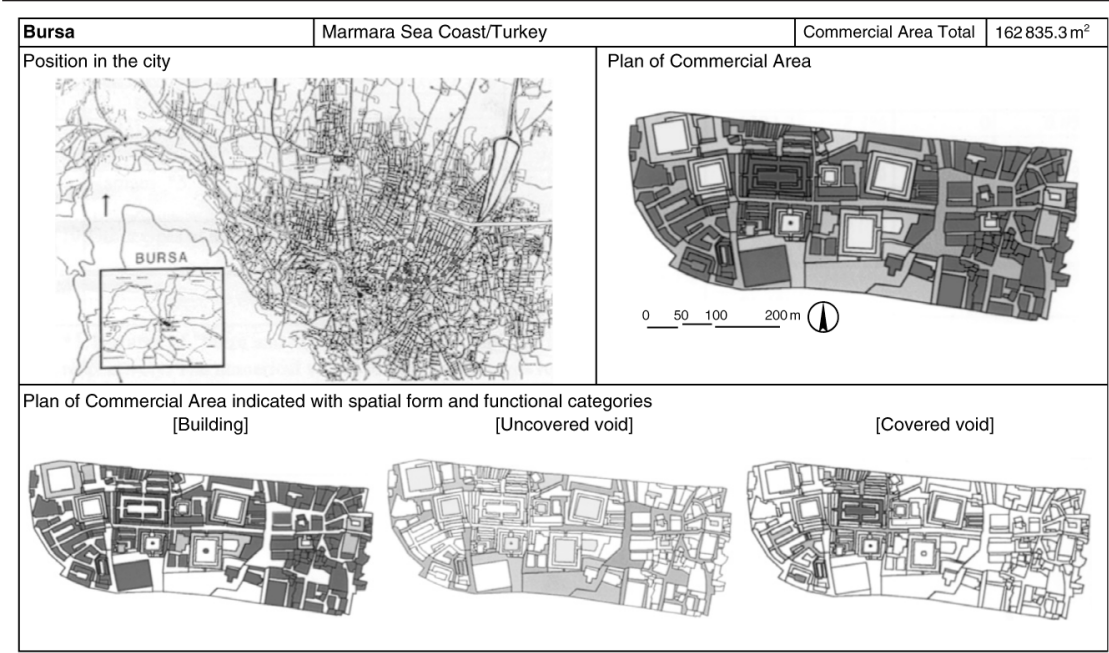

\begin{tabular}{|c|c|c|c|c|c|c|c|c|c|}
\hline & \multirow{3}{*}{$\begin{array}{l}\text { Functional } \\
\text { categories }\end{array}$} & & & \multicolumn{6}{|c|}{ Spatial form } \\
\hline & & \multicolumn{2}{|l|}{ Total } & \multicolumn{2}{|l|}{ Building } & \multicolumn{2}{|c|}{ Uncovered void } & \multicolumn{2}{|c|}{ Covered void } \\
\hline & & Area $\left(m^{2}\right)$ & $\%$ & Area $\left(m^{2}\right)$ & & Area $\left(m^{2}\right)$ & $\%$ & Area $\left(m^{2}\right)$ & $\%$ \\
\hline 1 & Street & 44041.3 & 27.0 & $\begin{array}{l}0.0 \\
0.0 \%\end{array}$ & 0.0 & $\begin{array}{r}35393.3 \\
80.4 \%\end{array}$ & 57.3 & $\begin{array}{l}8648 \\
19.6 \%\end{array}$ & 49.7 \\
\hline 2 & Plaza & 8977.8 & 5.5 & $\begin{array}{l}0.0 \\
0.0 \%\end{array}$ & 0.0 & $\begin{array}{l}8977.8 \\
100.0 \%\end{array}$ & 14.5 & $\begin{array}{l}0.0 \\
0.0 \%\end{array}$ & 0.0 \\
\hline 3 & $\begin{array}{l}\text { Plaza } \\
\text { and Street } \\
\text { with open-air } \\
\text { markets }^{1}\end{array}$ & 4582.9 & 2.8 & $\begin{array}{l}0.0 \\
0.0 \%\end{array}$ & 0.0 & $\begin{array}{l}4582.9 \\
100.0 \%\end{array}$ & 7.4 & $\begin{array}{l}0.0 \\
0.0 \%\end{array}$ & 0.0 \\
\hline 4 & Other voids & 3438 & 2.1 & $\begin{array}{l}0.0 \\
0.0 \%\end{array}$ & 0.0 & $\begin{array}{l}3438 \\
100.0 \%\end{array}$ & 5.6 & $\begin{array}{l}0.0 \\
0.0 \%\end{array}$ & 0.0 \\
\hline 5 & Shop & 57799.7 & 35.5 & $\begin{array}{c}56987.7 \\
98.6 \%\end{array}$ & 68.1 & $\begin{array}{l}0.0 \\
0.0 \%\end{array}$ & 0.0 & $\begin{array}{l}812 \\
1.4 \%\end{array}$ & 4.7 \\
\hline 6 & $\mathrm{Han}^{2}$ & 25862.9 & 15.9 & $\begin{array}{c}12186.5 \\
47.1 \%\end{array}$ & 14.6 & $\begin{array}{c}9289.7 \\
35.9 \%\end{array}$ & 15.0 & $\begin{array}{l}4386.7 \\
17.0 \%\end{array}$ & 25.2 \\
\hline 7 & Bedesten $^{3}$ & 6102.6 & 3.8 & $\begin{array}{c}3041.5 \\
49.8 \%\end{array}$ & 3.6 & $\begin{array}{l}0.0 \\
0.0 \%\end{array}$ & 0.0 & $\begin{array}{l}3061.1 \\
50.2 \%\end{array}$ & 17.6 \\
\hline 8 & $\begin{array}{l}\text { Religious } \\
\text { facility }^{4}\end{array}$ & 11124.5 & 6.8 & $\begin{array}{l}6076.3 \\
54.6 \%\end{array}$ & 7.3 & $\begin{array}{l}4671.9 \\
42.0 \%\end{array}$ & 7.6 & $\begin{array}{l}376.3 \\
3.4 \%\end{array}$ & 2.2 \\
\hline 9 & Hamam $^{5}$ & 2887.1 & 1.8 & $\begin{array}{l}2887.1 \\
100.0 \%\end{array}$ & 3.4 & $\begin{array}{l}0.0 \\
0.0 \%\end{array}$ & 0.0 & $\begin{array}{l}0.0 \\
0.0 \%\end{array}$ & 0.0 \\
\hline 10 & $\begin{array}{l}\text { Other types } \\
\text { of buildings }\end{array}$ & 2601.4 & 1.6 & $\begin{array}{l}2504.3 \\
\quad 96.3 \%\end{array}$ & 3.0 & $\begin{array}{l}0.0 \\
0.0 \%\end{array}$ & 0.0 & $\begin{array}{l}97.1 \\
3.7 \%\end{array}$ & 0.6 \\
\hline Total & 162835.3 & $\begin{array}{r}162835.3 \\
100.0^{\circ}\end{array}$ & 100.0 & $\begin{array}{r}83683.4 \\
51.4 \%\end{array}$ & 100.0 & $\begin{array}{r}61770.7 \\
37.9 \%\end{array}$ & 100.0 & $\begin{array}{r}17381.2 \\
10.7 \%\end{array}$ & 100.0 \\
\hline
\end{tabular}

Notes

1 The area of "Plaza and Street with open-air markets" are included in the area of "Street" or "Plaza" respectively. The numerical values are the percentages relative to the total dimensions.

2 Han (Turkish, Han, and Fondok in Arabic).

3 Commercial facility unique to Turkey. In Arab countries, Qaisariya is used as a research subject.

4 Mosque, Madrasa, Mausoleum.

5 Hamam (Turkish, Hammam in Arabic).

6 Residence, building of the government office, etc. 
The grand bazaar spreads northward from the Great Mosque, and the streets that center on the Bedesten are roofed. In the surroundings, there are rows of Hans that have their own courtyards. The town has a rich supply of water. Near the center, there is a hot spring site and there are many Hamams in the commercial area as well. Two of the Hamams have been restored and are being used as commercial facilities housing small shops. Since it is a big city, the percentage of buildings is high compared with Safranbolu and Göynük. However, this percentage is lower than for Arabic cities because the city has voids that are formed by Han courtyards, an outer garden of the Great Mosque, plazas and such.

\section{Safranbolu (Table 10.3)}

Safranbolu is the central city in the Safranbolu region in Karabük Prefecture along the western coast of the Black Sea. The old town, which became a registered World Heritage site in 1994, is called Çarşı. Apparent from its name, the commercial area spreads along the center of the old town and nearby, and there are traditional-style residences. As you go from the new town into the old town, you come to a plaza that serves as the entrance and there is a Hamam facing the plaza. At the back of the Hamam, there is a long road housing many wooden, one- or two-storey shops. The row-style shops make up about one-quarter of the entire commercial area.

Almost at the center is Cinci Han. Just like the Hamam at the entrance, it was built in the seventeenth century and it is currently being restored to be used as a hotel. At the back of the Han is a plaza where the Saturday market is held. Part of the plaza is covered space. In the plaza where the market is held, there is a workshop area that extends southward from the Han. Furthermore, there is an Arasta adjacent to the outer garden of the mosque located southwest of the Hamam. It is a commercial facility with rows of wooden, one-storey shops, and today, they are mostly souvenir shops for tourists. There are no roofs between the shops.

With the exception of the Arasta, the streets are not covered, but some of the streets are covered with grapevines. They form a comfortable space together with public fountains (çeşme, in Turkish) dotted throughout the city.

\section{Göynük (Table 10.4)}

Göynük is a small city that is situated in the center of the Göynük region in Bolu Prefecture along the western coast of the Black Sea. The commercial district is found in the city center around a caravan route. Religious facilities along a river and administrative facilities such as the City Office and Regional Office are other key elements of this city, forming its nucleus. The area is located in ravines adjacent to a hill in the middle and flanked by two rivers. Both sides of the main caravan route that runs parallel to a mountain ridge are lined with wooden, one- and two-storey shops. Çarşı Camii, the Market Mosque, is situated at the entrance of this main street. Group prayers are held at noon on Fridays in front of the mosque to pray for commercial prosperity. In addition, Monday markets are held at two 
Table 10.3 The commercial area in Safranbolu

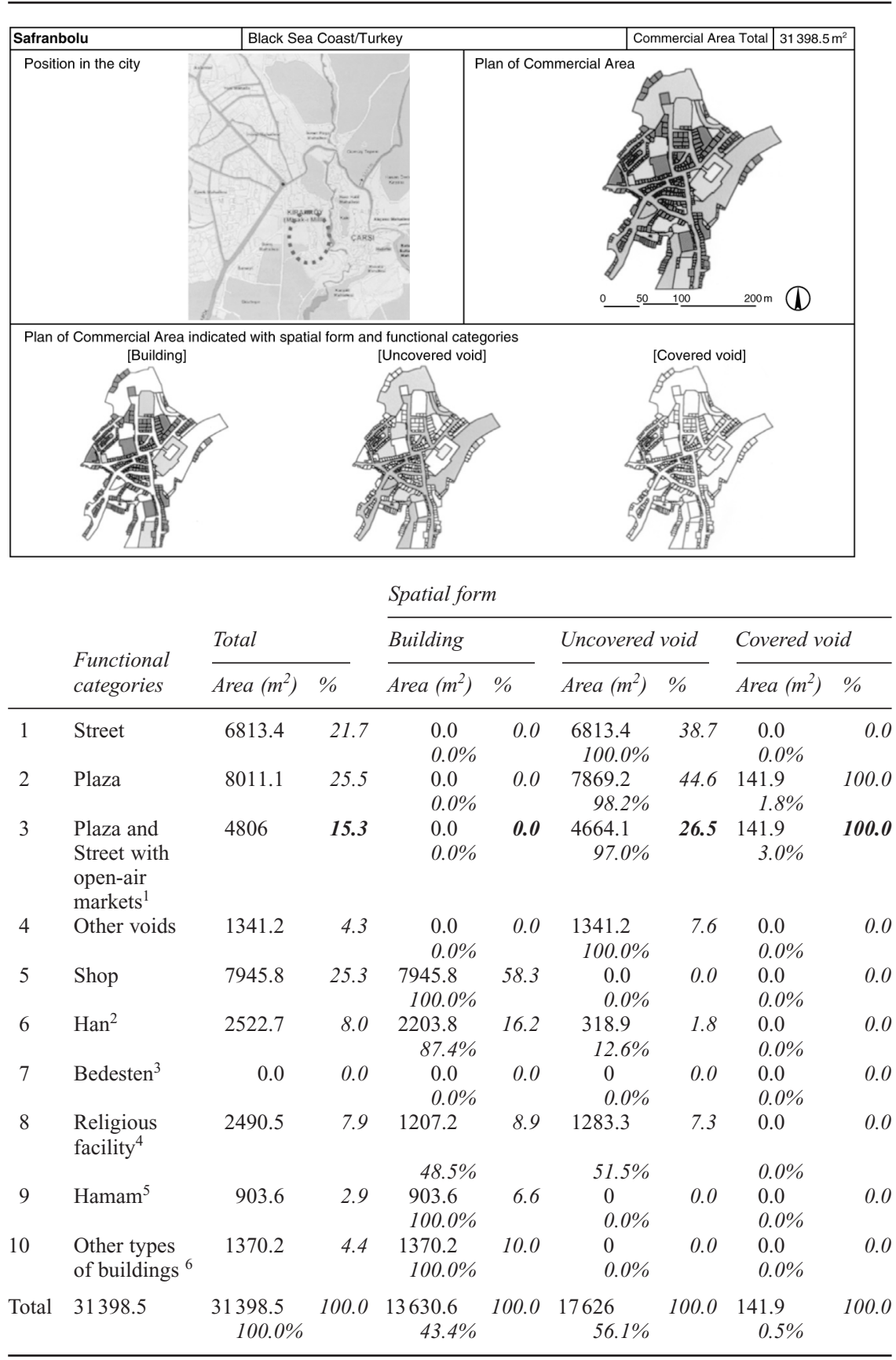

Notes

1 The area of "Plaza and Street with open-air markets" are included in the area of "Street" or "Plaza" respectively. The numerical values are the percentages relative to the total dimensions.

2 Han (Turkish, Han, and Fondok in Arabic).

3 Commercial facility unique to Turkey. In Arab countries, Qaisariya is used as a research subject.

4 Mosque, Madrasa, Mausoleum.

5 Hamam (Turkish, Hammam in Arabic).

6 Residence, building of the government office, etc. 
Table 10.4 The commercial area in Göynük

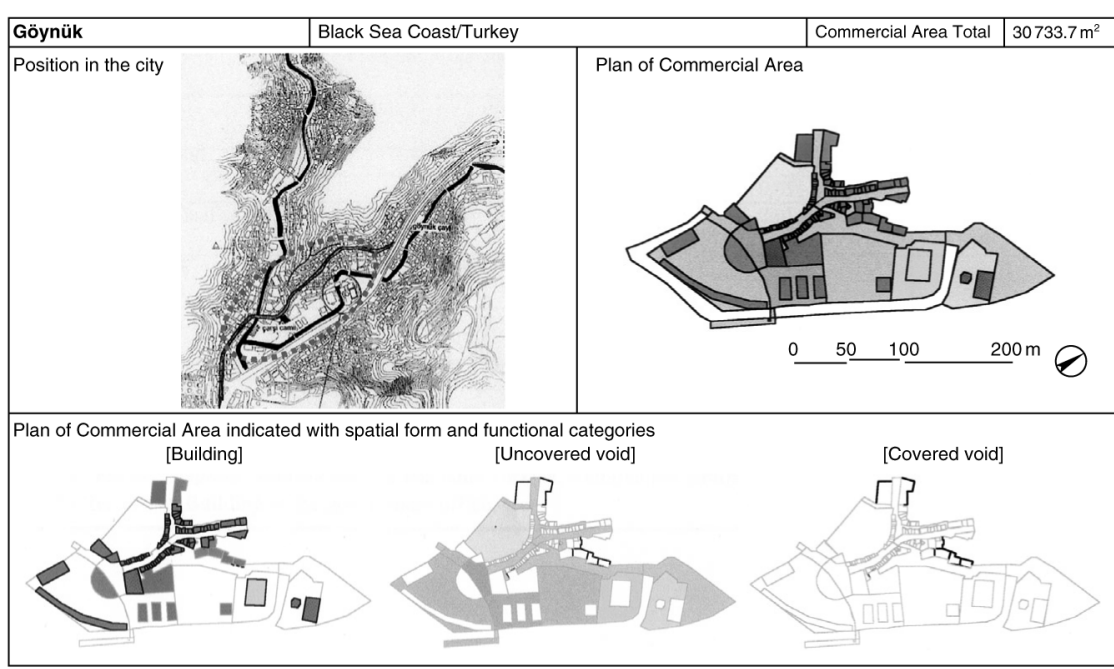

\begin{tabular}{|c|c|c|c|c|c|c|c|c|c|}
\hline & \multirow{3}{*}{$\begin{array}{l}\text { Functional } \\
\text { categories }\end{array}$} & & & \multicolumn{6}{|c|}{ Spatial form } \\
\hline & & \multicolumn{2}{|l|}{ Total } & \multicolumn{2}{|l|}{ Building } & \multicolumn{2}{|c|}{ Uncovered void } & \multicolumn{2}{|c|}{ Covered void } \\
\hline & & Area $\left(m^{2}\right)$ & $\%$ & Area $\left(m^{2}\right)$ & $\%$ & Area $\left(m^{2}\right)$ & $\%$ & Area $\left(m^{2}\right)$ & $\%$ \\
\hline 1 & Street & 6333.8 & 20.6 & $\begin{array}{l}0.0 \\
0.0 \%\end{array}$ & 0.0 & $\begin{array}{l}6333.8 \\
100.0 \%\end{array}$ & 27.9 & $\begin{array}{l}0.0 \\
0.0 \%\end{array}$ & 0.0 \\
\hline 2 & Plaza & 10122.2 & 32.9 & $\begin{array}{l}0.0 \\
0.0 \%\end{array}$ & 0.0 & $\begin{array}{l}10122.2 \\
\quad 100.0 \%\end{array}$ & 44.6 & $\begin{array}{l}0.0 \\
0.0 \%\end{array}$ & 0.0 \\
\hline 3 & $\begin{array}{l}\text { Plaza and } \\
\text { Street with } \\
\text { open-air } \\
\text { market }^{1}\end{array}$ & 8061.8 & 26.2 & $\begin{array}{l}0.0 \\
0.0 \%\end{array}$ & 0.0 & $\begin{array}{l}8061.8 \\
100.0 \%\end{array}$ & 35.6 & $\begin{array}{l}0.0 \\
0.0 \%\end{array}$ & 0.0 \\
\hline 4 & Other voids & 2938.2 & 9.6 & $\begin{array}{l}0.0 \\
0.0 \%\end{array}$ & 0.0 & $\begin{array}{l}2938.2 \\
100.0 \%\end{array}$ & 13.0 & $\begin{array}{l}0.0 \\
0.0 \%\end{array}$ & 0.0 \\
\hline 5 & Shop & 5500.6 & 17.9 & $\begin{array}{l}5500.6 \\
100.0 \%\end{array}$ & 68.2 & $\begin{array}{l}0.0 \\
0.0 \%\end{array}$ & 0.0 & $\begin{array}{l}0.0 \\
0.0 \%\end{array}$ & 0.0 \\
\hline 6 & $\operatorname{Han}^{2}$ & 0.0 & 0.0 & $\begin{array}{l}0.0 \\
0.0 \%\end{array}$ & 0.0 & $\begin{array}{l}0.0 \\
0.0 \%\end{array}$ & 0.0 & $\begin{array}{l}0.0 \\
0.0 \%\end{array}$ & 0.0 \\
\hline 7 & Bedesten $^{3}$ & 0.0 & 0.0 & $\begin{array}{l}0.0 \\
0.0 \%\end{array}$ & 0.0 & $\begin{array}{l}0.0 \\
0.0 \%\end{array}$ & 0.0 & $\begin{array}{l}0.0 \\
0.0 \%\end{array}$ & 0.0 \\
\hline 8 & $\begin{array}{l}\text { Religious } \\
\text { facility }^{4}\end{array}$ & 2505 & 8.2 & $\begin{array}{l}874.2 \\
34.9 \%\end{array}$ & 10.9 & $\begin{array}{l}1630.8 \\
\quad 65.1 \%\end{array}$ & 7.2 & $\begin{array}{l}0.0 \\
0.0 \%\end{array}$ & 0.0 \\
\hline 9 & Hamam $^{5}$ & 2252.4 & 7.3 & $\begin{array}{l}605.1 \\
26.9 \%\end{array}$ & 7.5 & $\begin{array}{l}1647.3 \\
73.1 \%\end{array}$ & 7.3 & $\begin{array}{l}0.0 \\
0.0 \%\end{array}$ & 0.0 \\
\hline 10 & $\begin{array}{l}\text { Other types } \\
\text { of buildings }\end{array}$ & 1081.5 & 3.5 & $\begin{array}{l}1081.5 \\
100.0 \%\end{array}$ & 13.4 & $\begin{array}{l}0.0 \\
0.0 \%\end{array}$ & 0.0 & $\begin{array}{l}0.0 \\
0.0 \%\end{array}$ & 0.0 \\
\hline Total & 30733.7 & $\begin{array}{l}30733.7 \\
\quad 100.0 \%\end{array}$ & 126.2 & $\begin{array}{l}8061.4 \\
26.2 \%\end{array}$ & 100.0 & $\begin{array}{r}22672.3 \\
73.8 \%\end{array}$ & 100.0 & $\begin{array}{l}0.0 \\
0.0 \%\end{array}$ & 0.0 \\
\hline
\end{tabular}

Notes

1 The area of "Plaza and Street with open-air markets" are included in the area of "Street" or "Plaza" respectively. The numerical values are the percentages relative to the total dimensions.

2 Han (Turkish, Han, and Fondok in Arabic).

3 Commercial facility unique to Turkey. In Arab countries, Qaisariya is used as a research subject.

4 Mosque, Madrasa, Mausoleum.

5 Hamam (Turkish, Hammam in Arabic).

6 Residence, building of the government office, etc. 
plazas adjacent to this plaza, attracting many visitors from nearby villages. At the plaza next to the City Office, food is sold; while at the plaza next to the Hamam, clothing and sundries are sold. Outdoor markets are not just limited to these plazas but extend along National route roads. Outdoor shops make up one-quarter or more of the commercial area. Plazas take up a large portion of the commercial area. If we look at the overall percentage of uncovered space, we notice that about three-quarters of the entire area is covered. The percentage of vaulted areas is extremely high, even compared with other cities, and spaciousness is very much apparent here. Both the Hamam and the mosque have outer gardens, giving an impression that the buildings exist within greenery. The large empty space to the west of the caravan route is a former site of the elementary school. Before it was an elementary school, it housed the Han. Over the last couple of years, there have been plans to reintroduce the image of the Han for a shopping center, but it is not yet known when construction will start. This empty space has boosted the percentage of voids. The City Office is a west-facing building along the southern edge of the plaza. The first and second levels are commercial shops, whereas the third level houses the City Office. The building is classified under the "shop" category because of its ground-level functions. The building is also classified under "Regional Office" and "residence" categories.

\section{Aleppo (Table 10.5)}

Aleppo is in the dry zone, situated inland from the eastern coast of the Mediterranean Sea. It is the second largest city in Syria. Aleppo boasts of a history of several thousand years. Since Aleppo is in a key trade area, it has been dominated by various empires such as the Hittite and Assyrian. The old town is surrounded by castle walls. Its structure is characterized by intertwining streets and shrines from Hellenistic and Byzantine days. After the seventh century, during the Arabic Islamic Age, the city began to change little by little, but retained its basic urban structure. Thus, even today, latticed street patterns, characteristic of Hellenistic cities, are seen in various areas of the old town. A small, steep hill soars to the east of the city and this was used as the castle fort. The city center used to house ancient shrines and an Agora, and during the Islamic Age, the Great Mosque and a commercial zone (souq in Arabic) were built. The commercial area that we chose for our study is in the city center. The study area has many shops surrounding the Great Mosque, while mosques, Han, Madrasa and other such facilities are intertwined in mosaic form. The study area has very few residences and it is an area for commercial functions. Seventy percent of the streets are either in arcades or under domes, creating a very closed space. Although the study area is a commercially oriented area, religious functions also play a key role and they make up nearly $20 \%$ of the entire area. There is no plaza, and the courtyards of mosques and Hans perform the functions of a plaza. However, unlike the western European public plaza, they are semipublic spaces with limited usage purposes. 
Table 10.5 The commercial area in Aleppo

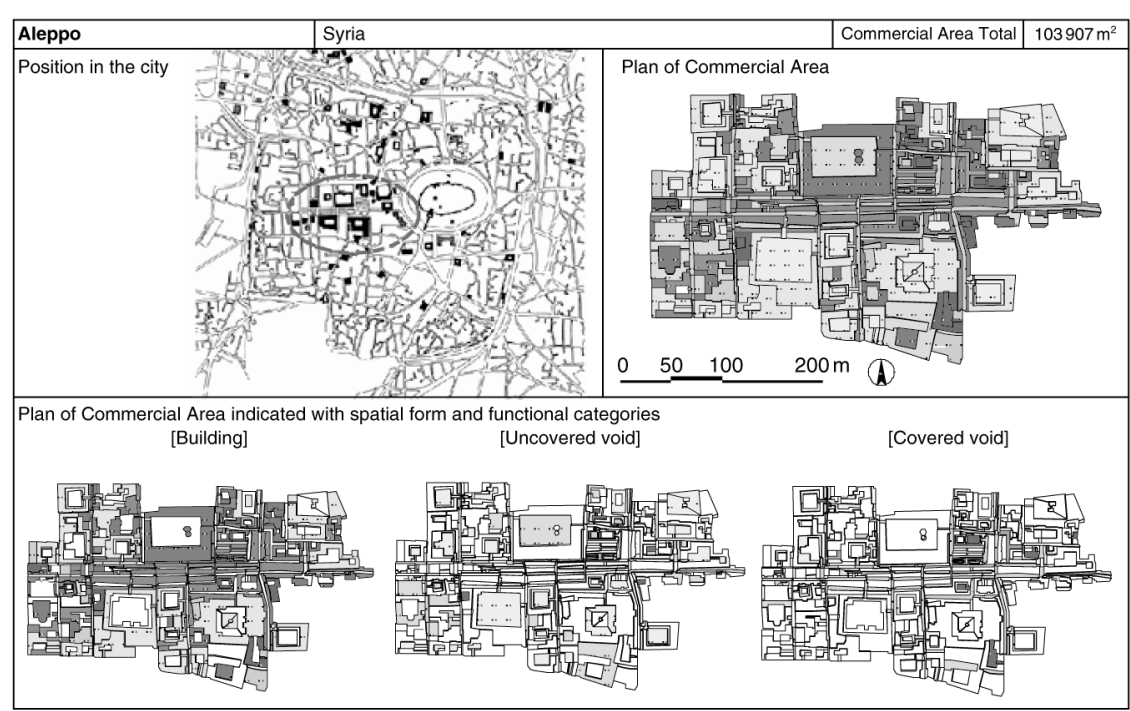

\begin{tabular}{|c|c|c|c|c|c|c|c|c|c|}
\hline & \multirow{3}{*}{$\begin{array}{l}\text { Functional } \\
\text { categories }\end{array}$} & & & \multicolumn{6}{|l|}{ Spatial form } \\
\hline & & \multicolumn{2}{|l|}{ Total } & \multicolumn{2}{|l|}{ Building } & \multicolumn{2}{|c|}{ Uncovered void } & \multicolumn{2}{|c|}{ Covered void } \\
\hline & & $\operatorname{Area}\left(\mathrm{m}^{2}\right)$ & $\%$ & $\operatorname{Area}\left(m^{2}\right)$ & $\%$ & $\operatorname{Area}\left(m^{2}\right)$ & $\%$ & Area $\left(m^{2}\right)$ & $\%$ \\
\hline 1 & Street & 10573.4 & 10.2 & $\begin{array}{l}0.0 \\
0.0 \%\end{array}$ & 0.0 & $\begin{array}{l}3093 \\
29.3 \%\end{array}$ & 11.1 & $\begin{array}{l}7480.4 \\
70.7 \%\end{array}$ & 51.9 \\
\hline 2 & Plaza & 0.0 & 0.0 & $\begin{array}{l}0.0 \\
0.0 \%\end{array}$ & 0.0 & $\begin{array}{l}0.0 \\
0.0 \%\end{array}$ & 0.0 & $\begin{array}{l}0.0 \\
0.0 \%\end{array}$ & 0.0 \\
\hline 3 & $\begin{array}{l}\text { Plaza and } \\
\text { Street } \\
\text { with } \\
\text { open-air } \\
\text { markets }\end{array}$ & 0.0 & 0.0 & $\begin{array}{l}0.0 \\
0.0 \%\end{array}$ & 0.0 & $\begin{array}{l}0.0 \\
0.0 \%\end{array}$ & 0.0 & $\begin{array}{l}0 \\
0.0 \%\end{array}$ & 0.0 \\
\hline 4 & Other voids & 0.0 & 0.0 & $\begin{array}{l}0.0 \\
0.0 \%\end{array}$ & 0.0 & $\begin{array}{l}0.0 \\
0.0 \%\end{array}$ & 0.0 & $\begin{array}{l}0.0 \\
0.0 \%\end{array}$ & 0.0 \\
\hline 5 & Shop & 18576.5 & 17.9 & $\begin{array}{c}18039.5 \\
97.1 \%\end{array}$ & 29.2 & $\begin{array}{l}0.0 \\
0.0 \%\end{array}$ & 0.0 & $\begin{array}{r}537 \\
2.9 \%\end{array}$ & 3.7 \\
\hline 6 & $\operatorname{Han}^{2}$ & 43490.6 & 41.8 & $\begin{array}{l}25855.1 \\
59.5 \%\end{array}$ & 41.9 & $\begin{array}{r}14008.5 \\
32.2 \%\end{array}$ & 50.4 & $\begin{array}{r}3627 \\
8.3 \%\end{array}$ & 25.1 \\
\hline 7 & Bedesten $^{3}$ & 4287.6 & 4.1 & $\begin{array}{l}2811.2 \\
\quad 65.6 \%\end{array}$ & 4.6 & $\begin{array}{l}444.2 \\
10.3 \%\end{array}$ & 1.6 & $\begin{array}{l}1032.2 \\
24.1 \%\end{array}$ & 7.2 \\
\hline 8 & $\begin{array}{l}\text { Religious } \\
\text { facility }^{4}\end{array}$ & 21067.6 & 20.3 & $\begin{array}{r}10283.6 \\
48.8 \%\end{array}$ & 16.7 & $\begin{array}{l}9068.4 \\
43.0 \%\end{array}$ & 32.6 & $\begin{array}{r}1715.6 \\
8.2 \%\end{array}$ & 11.9 \\
\hline 9 & Hamam $^{5}$ & 3207 & 3.1 & $\begin{array}{l}3014.5 \\
\quad 94.0 \%\end{array}$ & 4.9 & $\begin{array}{l}171.5 \\
5.3 \%\end{array}$ & 0.6 & $\begin{array}{l}21 \\
0.7 \%\end{array}$ & 0.1 \\
\hline 10 & $\begin{array}{l}\text { Other types } \\
\text { of buildings }{ }^{6}\end{array}$ & 2704.3 & 2.6 & $\begin{array}{l}1655.7 \\
\quad 61.2 \%\end{array}$ & 2.7 & $\begin{array}{l}1038.9 \\
38.4 \%\end{array}$ & 3.7 & $\begin{array}{l}9.7 \\
0.4 \%\end{array}$ & 0.1 \\
\hline Total & 103907 & $\begin{array}{l}103907 \\
100.0 \%\end{array}$ & 100.0 & $\begin{array}{r}61659.6 \\
59.3 \%\end{array}$ & 100.0 & $\begin{array}{r}27824.5 \\
26.8 \%\end{array}$ & 100.0 & $\begin{array}{r}14422.9 \\
13.9 \%\end{array}$ & 100.0 \\
\hline
\end{tabular}

Notes

1 The area of "Plaza and Street with open-air markets" are included in the area of "Street" or "Plaza" respectively. The numerical values are the percentages relative to the total dimensions.

2 Han (Turkish, Han, and Fondok in Arabic).

3 Commercial facility unique to Turkey. In Arab countries, Qaisariya is used as a research subject.

4 Mosque, Madrasa, Mausoleum.

5 Hamam (Turkish, Hammam in Arabic).

6 Residence, building of the government office, etc. 


\section{Qayrawan (Table 10.6)}

Qayrawan is an inland city near the desert and is situated in central Tunisia, northern Africa. In 670, during the Islamic Age, it was built as a military city (misr in Arabic), the center of the Arabic army offensive. It flourished around the ninth century and served as a trading hub that connected Spain and Morocco to the west with Egypt and Iraq to the east. The Great Mosque that was built in the ninth century was one of the most important mosques in North Africa and is situated in the northern part of the old town. Thus, it is away from the commercial area, the center of today's old town. The commercial area can be roughly divided into two zones. One is the intertwining arcade-type narrow street area that consists mainly of retailers. At nights and on holidays, the gate is locked. The second zone sprawls northwards of the first zone and consists of a group of shops that are primarily workshops, and manufacturing and processing shops. The streets are wide and therefore secure enough working space. In the commecial area, $80 \%$ or more of the streets are arcades. There are only two Hans (Fondok in Qayrawan), and there is no plaza. There is no Great Mosque but there are religious facilities such as Madrasa and Zawiya, making up $8.9 \%$ of the entire space. This percentage is slightly higher than that for the Turkish cities.

\section{Comparison of the five cities}

Having shown the outline of the five cities, we now comparatively examine differences and similarities between the five cities using the attribute values of the subarea categories defined in the preceding section.

\section{Buildings and voids}

The central commercial area in Bursa, one of the biggest cities in Turkey, is $160000 \mathrm{~m}^{2}$ and that of Aleppo is $100000 \mathrm{~m}^{2}$ or more. These are followed in size by Safranbolu and Göynük, each with approximately $30000 \mathrm{~m}^{2}$. The central commercial area in Qayrawan is even smaller at $23000 \mathrm{~m}^{2}$. We notice that the size of the central commercial area is closely interrelated to the size of a city.

First, let us observe the percentages of buildings and voids in the commercial area. The tabulated figures in Table 10.1 (percentages of the areas of functional categories) show that in both the Arabic cities of Aleppo and Qayrawan, the percentage of buildings is about $60 \%$, while that of voids is about $40 \%$. Although the size of their commercial areas is different, they have a similar level of building density. Turning to the three Turkish cities, we notice that in Bursa, facilities make up $51.4 \%$ of space. This is a high percentage for Turkish cities but low compared with Arabic cities. The percentages are lower for Safranbolu with $43.4 \%$ and Göynük with $26.2 \%$. Thus, we note that in Turkish cities, building density decreases and the percentage of voids increases with respect to city size.

Next, let us observe the percentage of covered voids in a commercial area. The covered void refers to an arcaded area or a space covered by eaves. In Bursa, the 
Table 10.6 The commercial area in Qayrawan

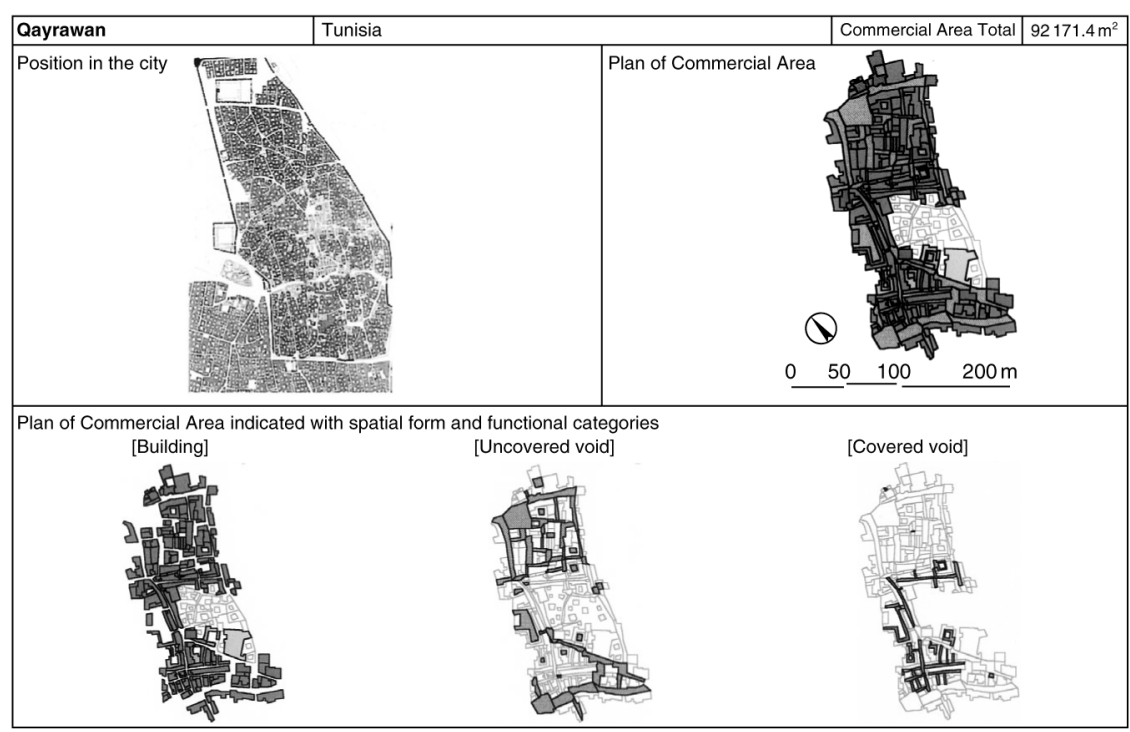

\begin{tabular}{|c|c|c|c|c|c|c|c|c|c|}
\hline & \multirow{3}{*}{$\begin{array}{l}\text { Functional } \\
\text { categories }\end{array}$} & \multirow{2}{*}{\multicolumn{2}{|c|}{ Total }} & \multicolumn{6}{|l|}{ Spatial form } \\
\hline & & & & \multicolumn{2}{|l|}{ Building } & \multicolumn{2}{|c|}{ Uncovered void } & \multicolumn{2}{|c|}{ Covered void } \\
\hline & & Area $\left(m^{2}\right)$ & $\%$ & Area $\left(m^{2}\right)$ & $\%$ & $\operatorname{Area}\left(\mathrm{m}^{2}\right)$ & $\%$ & $\operatorname{Area}\left(\mathrm{m}^{2}\right)$ & $\%$ \\
\hline 1 & Street & 7235.8 & 31.4 & $\begin{array}{l}0.0 \\
0.0 \%\end{array}$ & 0.0 & $\begin{array}{l}5953.6 \\
82.3 \%\end{array}$ & 87.2 & $\begin{array}{c}1282.2 \\
17.7 \%\end{array}$ & 66.1 \\
\hline 2 & Plaza & 0.0 & 0.0 & $\begin{array}{l}0.0 \\
0.0 \%\end{array}$ & 0.0 & $\begin{array}{l}0.0 \\
0.0 \%\end{array}$ & 0.0 & $\begin{array}{l}0.0 \\
0.0 \%\end{array}$ & 0.0 \\
\hline 3 & $\begin{array}{l}\text { Plaza and } \\
\text { Street with } \\
\text { open-air } \\
\text { markets }{ }^{1}\end{array}$ & 0.0 & 0.0 & $\begin{array}{l}0.0 \\
0.0 \%\end{array}$ & 0.0 & $\begin{array}{l}0.0 \\
0.0 \%\end{array}$ & 0.0 & $\begin{array}{l}0.0 \\
0.0 \%\end{array}$ & 0.0 \\
\hline 4 & Other voids & 451.5 & 1.9 & $\begin{array}{l}0.0 \\
0.0 \%\end{array}$ & 0.0 & $\begin{array}{l}451.5 \\
100.0 \%\end{array}$ & 6.6 & $\begin{array}{l}0.0 \\
0.0 \%\end{array}$ & 0.0 \\
\hline 5 & Shop & 11132.8 & 48.3 & $\begin{array}{l}10866 \\
97.6 \%\end{array}$ & 76.1 & $\begin{array}{l}0.0 \\
0.0 \%\end{array}$ & 0.0 & $\begin{array}{l}266.8 \\
2.4 \%\end{array}$ & 13.7 \\
\hline 6 & $\operatorname{Han}^{2}$ & 890.5 & 3.9 & $\begin{array}{l}522.4 \\
58.7 \%\end{array}$ & 3.7 & $\begin{array}{l}93.3 \\
10.5 \%\end{array}$ & 1.3 & $\begin{array}{l}274.8 \\
30.9 \%\end{array}$ & 14.2 \\
\hline 7 & Bedesten $^{3}$ & 0.0 & 0.0 & $\begin{array}{l}0.0 \\
0.0 \%\end{array}$ & 0.0 & $\begin{array}{l}0.0 \\
0.0 \%\end{array}$ & 0.0 & $\begin{array}{l}0.0 \\
0.0 \%\end{array}$ & 0.0 \\
\hline 8 & $\begin{array}{l}\text { Religious } \\
\text { facility }^{4}\end{array}$ & 2004.8 & 8.7 & $\begin{array}{l}1658 \\
82.7 \%\end{array}$ & 11.6 & $\begin{array}{l}230.6 \\
11.5 \%\end{array}$ & 3.4 & $\begin{array}{r}116.2 \\
5.8 \%\end{array}$ & 6.0 \\
\hline 9 & Hamam $^{5}$ & 690.7 & 3.0 & $\begin{array}{l}690.7 \\
100.0 \%\end{array}$ & 4.8 & $\begin{array}{l}0.0 \\
0.0 \%\end{array}$ & 0.0 & $\begin{array}{l}0.0 \\
0.0 \%\end{array}$ & 0.0 \\
\hline 10 & $\begin{array}{l}\text { Other types } \\
\text { of buildings }{ }^{6}\end{array}$ & 637 & 2.8 & $\begin{array}{l}535.9 \\
84.1 \%\end{array}$ & 3.8 & $\begin{array}{l}101.1 \\
15.9 \%\end{array}$ & 1.5 & $\begin{array}{l}0.0 \\
0.0 \%\end{array}$ & 0.0 \\
\hline Total & 23043.1 & $\begin{array}{l}23043.1 \\
\quad 100.0 \%\end{array}$ & 100.0 & $\begin{array}{r}14273 \\
61.9 \%\end{array}$ & 100.0 & $\begin{array}{l}6830.1 \\
29.6 \%\end{array}$ & 100.0 & $\begin{array}{r}1940 \\
8.4\end{array}$ & 100.0 \\
\hline
\end{tabular}

Notes

1 The area of "Plaza and Street with open-air markets" are included in the area of "Street" or "Plaza" respectively. The numerical values are the percentages relative to the total dimensions.

2 Han (Turkish, Han, and Fondok in Arabic).

3 Commercial facility unique to Turkey. In Arab countries, Qaisariya is used as a research subject.

4 Mosque, Madrasa, Mausoleum.

5 Hamam (Turkish, Hammam in Arabic).

6 Residence, Building of the government office, etc. 
percentage is about $10 \%$ of the total commercial area. This figure is almost the same as those of Aleppo and Qayrawan. The percentages in Safranbolu and Göynük are $0 \%$ as they have no arcaded commercial area. It is very likely that the commercial area inevitably grew bigger as building-density in cities intensified and the urban area expanded. This in turn prompted the construction of commercial facilities that incorporate facilities such as Hans and shops, resulting in the emergence of arcades and domes.

\section{Streets}

The percentage of streets in voids is $27 \%$ for Bursa, $21.7 \%$ for Safranbolu, and $20.6 \%$ for Göynük in Turkey. The percentage increases with the size of a city. The percentage is also interrelated to the presence of plazas, which will be discussed later. In large cities, buildings are constructed close to one another and streets serve as open space. However, in small cities, the building density is low and there are many plazas. Plazas also fulfil the functions of streets.

In Aleppo, the percentage of streets is extremely low at a meager $10.2 \%$. Thus, in the commercial area, buildings create an impression of being built close to one another. In Aleppo, Han courtyards act as an open space in place of streets and plazas. Although also an Arabic city, Qayrawan is different from Aleppo, and has a high percentage of streets, that is, $31.4 \%$. In particular, the percentage of streets bordering the commercial area is high. There, we find many workshops and manufacturing and processing shops that use streets as workspace or for loading and unloading. In Qayrawan, there are only two Hans in the commercial area in the center. Functionally, they are only being used as lodging houses and they are small in size as well. Large-sized Hans are clustered outside of castle walls and they are used as work sites, warehouses, and lodging houses. The percentage of Han courtyards in the commercial area is a low $0.3 \%$ in Qayrawan, whereas in Aleppo it is $13.2 \%$, posting a markedly higher percentage than for streets.

In addition, the percentage of arcaded streets (covered voids) is the highest in Aleppo with $70.7 \%$, followed by Bursa with $19.6 \%$, Qayrawan with $17.7 \%$, and Safranbolu and Göynük with $0 \%$, thus showing that streets are arcaded in large Turkish cities and in Arabic cities. In large cities, precious metals and expensive items are handled in the center of the commercial area, and so the buildings are sturdily built. In comparison, in both Göynük and Safranbolu, there are no arcaded streets. In large cities, arcaded commercial areas have gates to restrict the entry and exit of people at nighttime and during holidays, and the gates indicate a high security awareness. This security is also related to the presence of Bedestens in commercial areas that handle precious items. The number of solidly built Bedestens tends to be large in large cities.

\section{Plazas}

Because the Turkish cities tend to contain considerable open space regardless of the existence of city walls, and a large space exists between one building and 
another, there are many plazas even in the center of large cities. On the other hand, the two cities in the Arabic region are castle towns, which do not allow large space inside. Thus, there is no plaza in the center, but a space for markets and caravan troops. Such a space also exists outside the city gate.

Let us next look at the percentage of plazas in detail: Bursa 5.5\%, Safranbolu $10.2 \%$, and Göynük $14.1 \%$. These figures reveal that in the Turkish cities, plazas are situated in the city centers. In the Arabic region, both Aleppo and Qayrawan posted $0 \%$. There are very few plazas in the Arabic cities, but the courtyards of Great Mosques, Madrasas, and Hans have multipurpose functions and act as

plazas. However, the nature of plazas and courtyards is different. Unlike plazas that are open to anyone (public space), courtyards are mostly for the people who use the facilities and it is a semiprivate space.

Regarding the percentages of plazas (another type of void): in Göynük, it is $32.9 \%$, Safranbolu $25.5 \%$, and in Bursa $5.5 \%$. The percentage increases as the size of a city decreases, an opposite phenomenon to the percentage of streets. A small city like Göynük has a high percentage, because the city was not planned and streets were naturally generated; as a result, the boundary between a street and a plaza was not distinct but rather continuous, and this produced spaciousness.

\section{Plazas and streets with open-air markets}

As mentioned above, we pay special attention to plazas and streets with open-air markets. In Turkey, markets are held in the center of a city. Weekly markets are in the form of temporary commercial stalls or shops that lay out their products on a mat. Thus, even in a major city like Istanbul, there are large open spaces near mosques for markets. A similar tendency exists in the three Turkish cities studied. In Bursa, 2.8\% of the street and plaza land is market-space; this increases to $15.3 \%$ in Safranbolu, and $23.8 \%$ in Göynük. These figures show that the percentage of plazas and streets with open-air markets increases as a city becomes smaller and more local. Smaller cities have the character of caravan cities that connect the wide areas and also serve as centers that interconnect the surrounding agricultural villages.

\section{Other voids}

In Turkey, where a wooden-building culture is dominant, in many cases buildings are not close to each other, leaving a slight space between them. One other characteristic of Turkish cities is their sloping terrain, and in some areas, it is not possible to construct buildings. This causes gaps between buildings and the percentage of voids increases in small cities. In large cities, buildings are densely built and property boundaries are clear. However, in small cities, properties are large and property boundaries are often vague.

On the other hand, in the Arabic cities where a stone-building culture is the norm, the walls of buildings nearly touch one another, and so there are no gaps and the percentage of voids is zero. 


\begin{abstract}
Shops
In the three Turkish cities, the number of shops in the center increases with city size. Namely, in Bursa, the percentage is $35.5 \%$, Safranbolu $25.3 \%$, and Göynük $17.9 \%$. In Göynük, a small city, the commercial center is formed along a street. However, in larger cities, shops line many streets, resulting in a high percentage of shops.

On the other hand, in the Arabic region, the percentage is 17.9\% in Aleppo and $48.3 \%$ in Qayrawan. The percentage in Aleppo is lower than that in Safranbolu and Bursa, because in place of shops, there are many Hans that incorporate commercial functions. On the other hand, in Qayrawan, Hans are built outside the castle walls and commercial functions are an inherent part of the shops themselves, and consequently the percentage is high, close to $50 \%$.

Qayrawan and Aleppo are both Arabic cities, but in the former, there is an overwhelmingly large number of residences nestled behind shops. This is because, in Qayrawan, the commercial area has invaded residential districts, pushing residences aside. In comparison, in Göynük, which has rows of wooden shops, the shops are independently built with nothing directly behind them.
\end{abstract}

\title{
Hans
}

In Turkey, just as for the percentage of shops, the percentage of Hans increases with city size. Hans are necessary in large cities where more caravan troops stop to do business. In Aleppo, Hans naturally offer accommodation, and in addition, fulfil the key functions of production, processing, and sales. Thus, Hans have been incorporated into the center of commercial areas, resulting in their high percentage $(41.9 \%)$ of area usage. On the other hand, in Qayrawan, product consumption within the city is not great; its role as a trade-hub is more important. Thus, there are very few Hans within the castle walls. In many instances, Hans were built outside the castle walls for the convenience of caravan troops, to ease their loading/unloading. Materials transported to be made into commodities for consumption in the city are manufactured and processed in shops and workshops rather than in Hans.

\section{Bedestens}

Bedestens are commercial facilities unique to Turkey. Precious metals and precious items such as accessories are mostly handled here. Thus, they are mostly built of stone and are sturdy. Just like the arcades and gates that were discussed earlier, they imply a city conscious of security. There are few Bedestens in agricultural villages and small cities; thus, the presence of Bedestens serves as an index for gauging the developmental stage of an urban commercial area. Of the three cities studied, Bedestens are found only in Bursa. On the other hand, Arabic cities do not have Bedestens but have similar facilities called Qaysariya. Their use varies slightly depending on the region. 


\section{Religious facilities}

The percentages of religious facilities in the three Turkish cities are nearly the same, about $7-8 \%$. Overall, the figures are lower than for Arabic cities, because in Turkey, religious facilities such as Külliye are scattered throughout the city. In comparison, the percentage of religious facilities in Aleppo exceeds $20 \%$. In the Arabic region, a Great Mosque and Madrasas are in the central area, strengthening the religious atmosphere. Even in Qayrawan, where the Great Mosque is situated outside the central area near the castle walls, the percentage is $8.7 \%$, exceeding the percentages for each of the three Turkish cities. This implies dispersion of religious facilities in Turkey.

Let us now look at voids in religious facilities. In cities such as Göynük and Safranbolu where building density is low, the void percentage of plazas and courtyards relative to that of facilities exceeds $50 \%$. The percentage was particularly high for Göynük with $65.1 \%$. Bursa also captured a high percentage, about $45 \%$, showing a high void percentage relative to religious facilities. Religious facilities in Turkey are surrounded by an open space, with consideration for external design. In particular, in Göynük and Safranbolu, which developed in ravines, the key mosques that are situated in the center of the lower-lying land can be observed from anywhere and they play a key scenic role.

In comparison, the void percentages in religious facilities in Arabic cities are: Aleppo 43\%, and Qayrawan 11.5\%, showing lower figures than for Turkey. Arabic cities are constrained by city walls, and buildings inside the walls are densely built. Thus, there are few voids near facilities. Only courtyards that open out into the inside of buildings serve as voids, and external design is minimal. Only in Aleppo is the percentage slightly higher. There, mosques were built with large courtyards, typical of the mosque design in early Islamic days.

\section{Hamams}

The only city with a high percentage of Hamams is Göynük with $7.3 \%$, but in the other four cities in both Turkey and the Arabic region, the percentages are nearly the same at about $2-3 \%$. These figures show that facilities such as Hamam, Maqha (an Arabic term meaning coffee shop), and toilets are not interrelated to the size of a city, and the percentage is almost constant for all cities.

\section{Other buildings}

All five cities in both Turkey and the Arabic region contain several percent of "other buildings," and their number is not very different. A marked difference in the void percentage was observed between the Turkish cities and the Arabic cities, with $38.8 \%$ and $15.9 \%$ for Aleppo and Qayrawan, and $0 \%$ for the Turkish cities. The reason is because "other buildings" in the Turkish cities are either government office buildings or modern buildings with no voids, while in the Arabic region, there are residences with courtyards that serve as voids. 


\section{Conclusions}

In this last section, furthering the analyses in the preceding sections, we summarize the characteristics of the three Turkish cities, namely Bursa, Safranbolu, and Göynük, and compare them with the two Arabic cities, namely Aleppo and Qayrawan.

First, regarding the relationship of buildings and voids, the size of the commercial area is closely interrelated to the size of a city. The commercial area in Bursa is five times as large as that of the other two Turkish cities; and in addition, the percentage of buildings also exceeds $50 \%$. These figures show that Bursa is a large, high-density city. Safranbolu and Göynük are similar with respect to the size of commercial areas, but the percentage of buildings in Safranbolu is about $20 \%$ higher, indicating the accelerating construction of buildings there. In the Arabic cities, the percentage of buildings is about $60 \%$, which tells us that they have more densely built-up areas than in Turkey. The Arabic cities are restricted in size by city walls, and consequently they had no choice but to build densely within their confined areas. In comparison, it seems that the urban planning of Turkish cities did not consider city walls as a constraint, and they preferred to spread outward. Furthermore, Turkish buildings are designed to secure open space to consciously show off their appearance and provide a scenic view from the buildings.

The percentage of covered voids, such as arcades in the Turkish cities, is about $10 \%$, similar to the percentages in the Arabic cities. However, the percentage in the Turkish cities is affected by the size of the city. In Bursa, the percentage is about $11 \%$, whereas in Safranbolu and Göynük, the percentages are close to nil. These figures reveal that, in Turkey, changes in urban size result in major changes to the form of commercial areas, while in the Arabic cities, these same changes are small. We can thus say that these figures reveal a difference in urban planning policies between the Turkish cities and the Arabic cities.

Next, let us examine elements of voids in each city. Bursa has the highest percentage of streets among the three Turkish cities with $27 \%$, while Göynük has the highest percentage of plazas with about $33 \%$. Again, these figures are interrelated closely to the level of urban density. In Bursa, the percentage of streets is high because of its intricate network of streets that enables the smooth movement of humans and goods within the dense cluster of shops. On the other hand, in Göynük, the percentage of plazas is high. There are open spaces near buildings, creating a spacious, open design. Most of the plazas are used for market spaces, and we note that there are fewer permanently installed shops and facilities in comparison with Bursa. Göynük also marks a high percentage of other voids, about $10 \%$, thus implying that there are many spaces that are not used, or spaces that cannot be used, such as gaps between buildings resulting from sloping terrain, cliffs, etc. The percentages of streets and plazas in the Arabic cities are lower than those in the Turkish cities. The low percentage is particularly conspicuous for plazas, with $0 \%$ for both Aleppo and Qayrawan, indicating a big difference in urban planning there. A comparison of Aleppo and Qayrawan shows 
that both have high void percentages, of about $40 \%$. A breakdown of the figures shows that the percentage of Hans is high in Aleppo, while in Qayrawan, the percentage of streets is high. These figures reflect a difference in spaces used for processing/manufacturing work in commercial areas in the two cities, although there is little difference in the use of voids.

A look at the composition of buildings reveals a high percentage of shopsabout $36 \%$ for Bursa, again showing a high density. The percentage of Hans is also about $16 \%$, which tells us that it is a key trade hub where commodities are stocked. In comparison, Göynük has neither Hans nor Bedestens and even in Safranbolu, the percentage of Hans is $10 \%$ or less with no Bedestens. Both are on trade routes, but they are key transit hubs with little product consumption in the cities themselves. This could be the reason for their slow growth as commercial areas.

Concerning the percentage of religious facilities, interestingly, all three Turkish cities are in the $7-8 \%$ range. This percentage may be closely related to the urban formation of Turkish cities. Even in Bursa, urban formation began with the construction of a religious complex such as the mosque, called a Külliye, or a mausoleum, in favorable terrain such as atop a hill, or next to a river, and the residential space was developed around it. Thus, religious facilities were not concentrated in one region but had a strong tendency to be dispersed, leading to a constant percentage of religious facilities. On the other hand, in the Arabic cities, the percentage of religious facilities in the commercial area is higher than that in Turkey. This is because facilities such as Madrasa and mausoleums are built close to the Great Mosque. Another reason is the maintenance of facilities by Waqf (i.e. land or property charitably endowed in perpetuity for the benefit of a pious institution, and yielding an income). Even in Qayrawan where the Great Mosque is not found in the commercial area, the percentage is higher than that in Turkish cities.

From the above analysis, we can conclude as follows. The three cities of Bursa, Safranbolu, and Göynük, possess typical characteristics of Turkish cities. They are all cities in the greenery-filled wooden-building culture zone. Percentages of categorized areas also reveal clearly that, in comparison with the Arabic cities that have been densely and compactly built within city walls, the Turkish cities have much more open space such as spaces between buildings, front gardens, back gardens, and plazas, and consequently these cities reveal a spacious landscape. These characteristics tend to be clearer as a city becomes smaller and more rural.

Finally, we note that although we used mainly only the elementary functions of GIS, it unburdened our study, and enabled us to examine spatial relations from many aspects. In future, we will extend our analysis through the more advanced functions of GIS.

\section{Acknowledgments}

We would like to thank Dr Kubat Ayse Sema of the Istanbul Technical University and Okabe Atsuyuki for editing the chapter to make it more readable. We would also extend thanks to an anonymous referee for valuable comments. 


\title{
THE WATER SUPPLIES AND PUBLIC FOUNTAINS OF OTTOMAN ISTANBUL
}

\author{
Yamashita Kimiyo
}

\begin{abstract}
Introduction
In the mid-sixteenth century, at the zenith of Ottoman prosperity, a Spanish doctor who worked for Sinan Pasha (died 1553) was astonished at the great number of public fountains in the city of Istanbul (Carım 1964). The existence of so many public fountains demonstrated the status of that city. In Istanbul, which became the capital of the Ottoman Dynasty in the mid-fifteenth century, many large-scale urban facilities came to be built and, amidst the increase in population, water supply became an important theme. The construction of water supplies and public fountains proportional to water demand was deeply connected with the development of Istanbul.

The objective of this research is to clarify an aspect of the development of Istanbul, particularly the area inside the city wall ("old Istanbul"), by summarizing and analyzing the construction processes and the distribution state of water supplies and public fountains. The research subjects are the Halkalı Water Supplies and the Kurkçeşme Water Supply that were constructed in Istanbul from the midfifteenth century, after the conquest of Constantinople by the Ottomans, to the late eighteenth century, and the public fountains to which these water supplies distributed water. The references that we used for this research include the list of facilities to which water was supplied, compiled by the Ministry of Vaklf (IVB 1930), and the two maps of the water supply systems drawn by Çeçen (Çeçen 1991a: Pl. 7, 8, 1992 Pl. 8, 9). The articles by Çeçen include a particularly helpful reference collection, such as copies of the old maps of water supplies that were drawn during the Ottoman period, and give summarized remarks concerning features on the maps (Çeçen 1991, 1992, 1997, etc.). We used geographical information systems (GIS) to analyze the data about water supplies and public fountains obtained from these references and to study the process of how the city of Istanbul developed. Specifically, the map of Istanbul was digitized and GIS was used to measure the overall lengths of water supplies, calculate the number of public fountains and the distances between them. Calculating the lengths was particularly easy and they were calculated from various angles. Although digitalization was somewhat timeconsuming, it enabled us to easily categorize by age the numerous water supplies.
\end{abstract}


This study points out that there were many residential districts in the Kırkçeşme Water Supply distribution area. This is in contrast to the area that received water from the Halkalı Water Supplies, whose primary objective was to supply water to külliyes (a collection of buildings of an institution; usually composed of mosque, schools, hospital, soup kitchen, hostel, mental asylum, etc.).

\section{Construction of water supplies in the Ottoman period}

\section{Halkalı water and Kırkçeşme water}

To revive the city of Istanbul, which had declined toward the end of the Byzantine Empire, sultans and viziers (high officials) of the Ottoman dynasty donated külliyes under the Vakıf system. The Vakıf system was a donation system for contributing institutions and funds that are necessary for realizing public, charitable, and religious goals. During the reign of the Ottoman dynasty, the construction, maintenance, and control of the water supplies and various urban facilities that made up the külliye were carried out through this donation system.

During the Ottoman period, water from Halkalı and Kırkçeşme were carried from the outskirts to Istanbul, inside the city walls. The Halkalı water originates in the Halkalı area, northwest of Istanbul. Sixteen water supplies were used to transport the Halkalı water to the city, which we call collectively the Halkalı Aqueducts. Table 11.1 indicates the names, construction dates, and sponsors of the aqueducts. These were built individually over a period of about 300 years from 1453 to 1774 by various sultans and viziers. Mehmet II (reigned 1444-46,

Table 11.1 Halkalı Water Supplies

\begin{tabular}{llll}
\hline Names of aqueducts & Figure no. & Date & Sponsors \\
\hline Fatih & Fig. 11.1 & $1463-70$ & Mehmet II \\
Turunçlu & Fig. 11.1 & $1451-81$ & Mehmet II \\
Bayezit & Fig. 11.1 & $1481-1512$ & Bayezit II \\
Koca Mustafa Pasha & Fig. 11.1 & $1511-12$ & Koca Mustafa Pasha \\
Süleymaniye & Fig. 11.2 & $1550-57$ & Süleyman I \\
Mihrimah & Fig. 11.2 & 1560 & Mihrimah Sultan \\
Ebuusuud & Fig. 11.2 & $1545-74$ & Ebuusuud \\
Cerrah Pasha & Fig. 11.2 & $1598-1603$ & Cerrah Pasha \\
Sultan Ahmet & Fig. 11.3 & $1603-17$ & Ahmet III \\
Sarayçeşme & Fig. 11.3 & $1623-40$ & Murat IV (?) \\
Köprülü & Fig. 11.3 & $1656-61$ & Köprülü Mehmet Pasha \\
Laleli & Fig. 11.4 & $1453-74,1757-74$ & Mahmut Pasha, Mustafa III \\
Beylik & Fig. 11.4 & $1730-54$ & Mahmut I \\
Kasim Agha & None & $1623-44$ & Kasim Agha \\
Hekimoğlu & Fig. 11.4 & $1732-35$, & Hekimoğlu Ali Pasha \\
Nuruosmaniye & Fig. 11.4 & $1748-55$ & \\
\hline
\end{tabular}


1451-81), who conquered Constantinople and established Istanbul as the new capital of the Ottoman Empire, was the first to embark on construction of a water supply to transport Halkalı water to the city.

The Kırkçeşme water originates in the Kăğthane region, north of Istanbul. During the reign of Süleyman I, the zenith of the Ottoman prosperity, the Kırkçeşme Water Supply that transported Kırkçeşme water to the city was constructed by the royal chief architect, Sinan, in 1554-63. Unlike the Halkalı water supply system that consists of a number of independent aqueducts, this is a single route. The characteristic of the Kırkçeşme Water Supply is that it formed a large network in areas that the earlier Halkalı water did not reach.

\section{Construction of the Istanbul Water Supplies and the reason for the construction}

Here, we will study the construction processes of the 16 aqueducts of the Halkalı Water Supply and the Kırkçeşme Reticulation in the area inside the city wall by dividing them into four phases (1453-1512, 1512-1603, 1603-1703, 1703-74).

\section{Phase I: 1453-1512 (the reigns of Mehmet II and Bayezit II)}

Mehmet II, who initiated the construction of the first Halkalı Aqueducts, constructed the Fatih Aqueduct (the purple line in Figure 11.1) and the Turunçlu

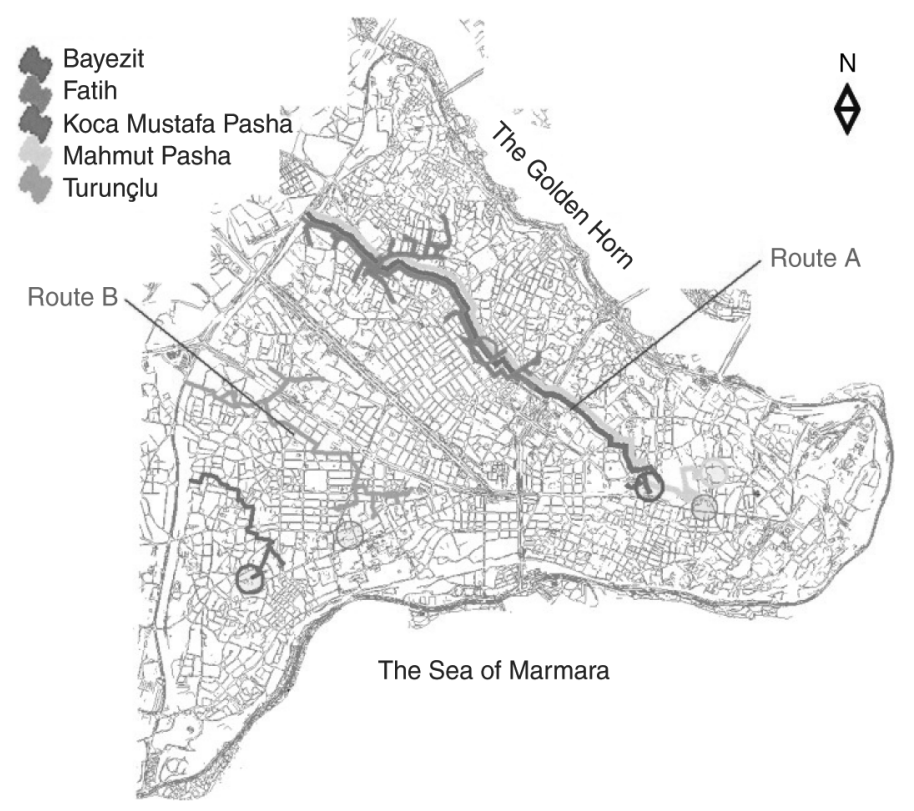

Figure 11.1 Water supplies from 1453 to 1512. 
Aqueduct (the orange line in Figure 11.1). The main objective of the Fatih Aqueduct was to supply water to the similarly named külliye built by Mehmet II between 1463 and 1470. Fatih külliye was the first large-scale külliye built during the Ottoman dynasty. It has a mosque in the center, and in surrounding areas, 16 medreses (law schools), a school for the study of the Koran, a library, a hospital, accommodation facilities and a soup kitchen for feeding the poor. According to the list of the facilities to which the Halkalı and Kırkçeşme water was supplied, and which was compiled by the Ministry of Vaklf (hereinafter, called the list of facilities supplied) (IVB 1930), the Fatih Aqueduct distributed water to 48 locations, including the facilities in the Fatih külliye. The Turunçlu Aqueduct, also constructed by Mehmet II, was built to supply water to the citrus fruit garden near the Çiçoz farm.

While serving as vizier (served 1453-74), Mahmut Pasha, a soldier representative from the reign of Mehmet II, built the Mahmut Pasha Aqueduct (the pinkish line in Figure 11.1) to supply water to the Mahmut Pasha külliye. According to the list of facilities supplied, the Mahmut Pasha Aqueduct distributed water to 29 locations. This aqueduct was later connected to the Laleli Aqueduct that was built under Sultan Mustafa III (reigned 1757-74) and the joint line came to be called the Laleli Aqueduct (the orange line in Figure 11.4).

The Bayezit Aqueduct (the green line in Figure 11.1) was built by Sultan Bayezit II (reigned 1481-1512). For the most part, this water supply ran along a route similar to that of the Fatih Aqueduct and supplied water to 63 locations, including the Bayezit külliye.

The Koca Mustafa Pasha Aqueduct (the blue line in Figure 11.1) was built by Koca Mustafa Pasha who served as vizier from 1511-12 during the reign of Bayezit II. It is not clear when the aqueduct was built, but it is surmised that it was built while the vizier was in office. According to the list of facilities supplied, this aqueduct distributed water to seven locations but mostly to the Koca Mustafa Pasha külliye.

Of the five water supplies that were built during Phase I (1453-1512), three were located in the northern part of the city (Figure 11.1). They are the Fatih, Mahmut Pasha, and Bayezit aqueducts that extended to the southeast from the northwest. These aqueducts entered the area inside the city wall from the southern side of Edirnekapt and then, for the most part, took the same route. In contrast, two other aqueducts were situated away from each other. The Turunçlu Aqueduct was constructed in the central part of the city and the Koca Mustafa Pasha Aqueduct on the southern part. In other words, the five aqueducts did not cover the entire area inside the city wall but were built in three areas: specifically, the northern, the center, and the southern part of the city, thus forming three parallel routes at almost equal distances (Figure 11.1). Later, a number of aqueducts came to be built along two of these parallel routes, forming the major water supply Routes A and B, which will be discussed later. These three parallel routes in Phase I show that the location of the key axes for development of Istanbul had been chosen during this period. 
Phase II: 1512-1603 (the reigns of Selim I, Süleyman I, Selim II, and Murat I)

Under the rule of Süleyman I (reigned 1520-66), the Ottoman Empire achieved its maximum expansion and reached the zenith of its prosperity. Upon ascending the throne in 1522, Süleyman I constructed the külliye and aqueduct that had been funded by his late father Selim I (the dark rose-colored line in Figure 11.2). Water was supplied to the külliye through an extension of the Fatih Aqueduct. In 1550-57, he built the Süleymaniye Aqueduct, the largest of the Halkalı Aqueducts (the pale rose-colored line in Figure 11.2) (Barkan 1972). For the most part, this aqueduct took the same route as the Fatih Aqueduct. According to the list of facilities supplied, it distributed water to 80 locations, primarily the külliye of Süleyman himself.

In addition to these aqueducts, Süleyman I also constructed a water supply to transport the Kırkçeşme water to the city. As shown in Figure 11.2, Kırkçeşme Reticulation (the sky blue line) had quite an extensive water supply network in Istanbul. This suggests that there was a rapid increase in demand for water in the capital of an empire that was enjoying its best days.

The Mihrimah Aqueduct (the purple line in Figure 11.2) was constructed by the daughter of Süleyman I, Mihrimah Sultan (?-1578). This aqueduct was constructed mainly to supply water to the külliye of Mihrimah herself in Edirnekapt. Various estimations have been made about the time needed to construct the Mihrimah Sultan's külliye but, generally speaking, it was built during the 1560 s

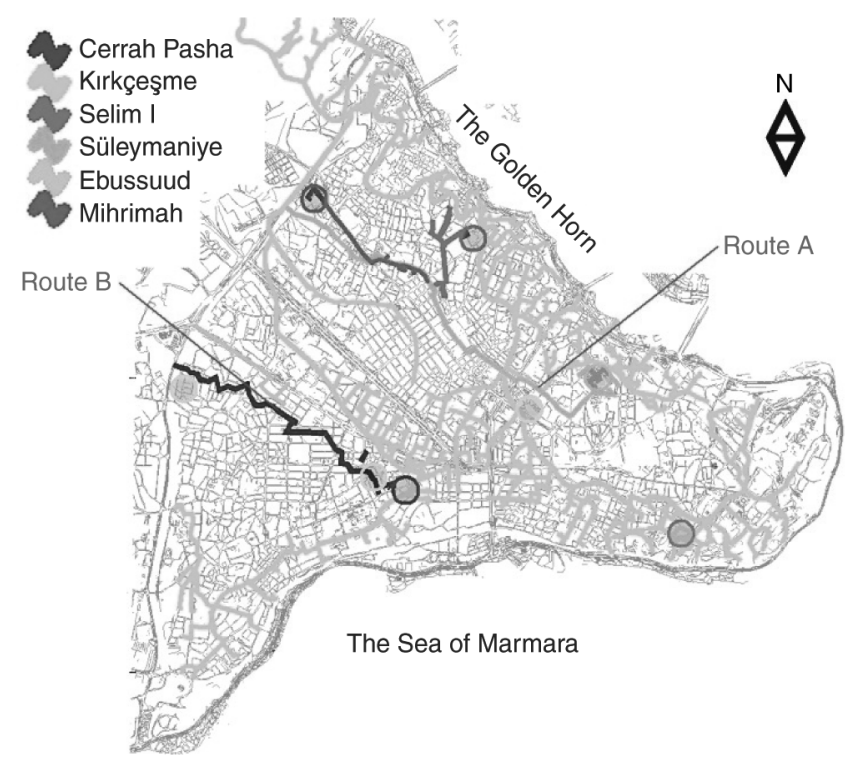

Figure 11.2 Water supplies from 1512 to 1603. 
(IA 1994). According to the list of facilities supplied, this aqueduct distributed water to 13 locations and can be described as being a relatively small aqueduct.

Ebuusuud, sponsor of the Ebuusuud Aqueduct (1490-1574), was an authoritative figure who served as Şeyh ül Islam for about thirty years from 1545 to 1574 . In the Ottoman dynasty, Şeyh ül Islam signifies the profession of Müfti in Istanbul. Müfti is a legal authority who is qualified to interpret and apply Islamic law and make comments on it. The Ebuusuud Aqueduct distributed water to 10 locations (the ochre line in Figure 11.2) and was linked to the Turunçlu Aqueduct that was constructed by Mehmet II. Most likely, it was built while Ebuusuud was in office, but the precise years of construction are not clear.

Cerrah Pasha who was the vizier under Mehmet III (1595-1603) constructed the Cerrah Pasha Aqueduct (the blue line, Figure 11.2). Since this vizier was ill, he was in office only for a short period of nine months in 1598-99. The construction year of this aqueduct is not clear but it must have been built between 1598 and 1603 under the rule of Mehmet III. According to the list of facilities supplied, this aqueduct distributed water to 10 locations.

The five aqueducts that were built during Phase II, 1512-1603, can be divided into the following three groups (Figure 11.2). The first group consists of the Süleymaniye, Mihrimah, and Selim I aqueducts that were constructed in the northern part of Istanbul. The Süleymaniye Aqueduct entered the city from the southern side of Edirnekap $r$ and travelled to the southeast from the northwest. Close to this line, the Mihrimah and Selim I aqueducts were built. This is the same route as the three aqueducts that were built during Phase I (1453-1512). The second group consists of the Ebuusuud and Cerrah Pasha aqueducts that were built in the center part, close to those built during Phase I. In these two groups, the routes of aqueducts are seen to form important axes. For this reason, the route in the northern part will be called Route A and that in the center part Route B (Figures 11.1 and 11.2) in this study. Third, the Kurkçeşme Reticulation that extended to the coastal areas along the Golden Horn Bay and the Sea of Marmara and to the central area of the city formed quite an intricate, extensive network (the sky blue line in Figure 11.2). Unlike the linear Halkalı Aqueducts, the main objective of which was to supply water to the külliye and its vicinities, the Kırkçeşme Reticulation was a network. We can say that with the completion of the Kırkçeşme Reticulation, water came to be distributed to almost all districts in Istanbul.

Süleyman I was responsible for the short-term construction of the Kırkçeşme Water Supply, a wide-area water supply network, during mid-sixteenth century. Tezkireti-Bünyan that chronicles the life of Sinan, architect of the Kırkçeşme Water Supply, records the following statement of Süleyman I concerning its construction.

My intention is that this water should reach every district of the city; let fountains be built where the life of the land is right. Where it is too high, let wells be dug that they be filled by conduits from the city's water supply. 
Let the elderly, frail widows and little children everywhere fill their pitchers and cups, let them pray for the continuation of my prosperity.

Mimar Sinan and Tezkiret-i Bünyan (Sözen 1989)

This statement suggests the sultan's concern over water shortage in Istanbul and his attempt to solve the issue for his citizens. It seems that water from the existing water supplies built in Phase I (Figure 11.1) was becoming insufficient to supply the demand. The drought that hit Istanbul in 1550 most likely reinforced the sultan's intentions (Kuban 1996). The sultan's statement also shows that Istanbul in the mid-sixteenth century had a population that was beyond the city's capacity and citizens were waiting for some kind of countermeasure by the government. However, according to a study by Çeçen, several individuals were opposed to the Sultan's plan to build a new large-scale water supply network. One of them, Vizier Rüstem Pasha, felt that the increase in population prompted by the construction of new water supplies might lead to a serious food shortage (Çeçen 1991a). Finally, the sultan's intentions were given priority and the Kırkçeşme Water Supply was built. It supplied water to the areas along the coasts of the Golden Horn Bay and the Sea of Marmara and to the center of the city. These areas must have suffered serious water shortage in the mid-sixteenth century and were therefore eagerly awaiting the construction of public fountains.

\section{Phase III: 1603-1703 (the reigns of Ahmet I, Mustafa I, Ottoman II,} Murat I, Ibrahim I, Mehmet IV, Süleyman II, Ahmet II, and Mustafa II)

During Phase III, 1603-1703, four aqueducts were constructed (Figure 11.3). Sultan Ahmet (reigned 1603-17) constructed the Sultan Ahmet Aqueduct (the green line in Figure 11.3) primarily to supply water to his namesake külliye. According to the list of facilities supplied, it distributed water to 20 locations, primarily the külliye.

There are many ambiguous factors concerning the constructor of the Sarayçeşme Aqueducts (the red line in Figure 11.3). However, as this aqueduct distributed water to the facilities donated by Sultan Murat IV (1623-40), Mahmut I (1730-54), and Fatma Sultan, it is most likely that Murat IV, who was responsible for the building of the oldest of the facilities, initiated its construction. It seems that, later, Mahmut I and Fatma Sultan took advantage of the aqueduct built by Murat IV to build an extension.

Although it is not definitely known, Kasım Agha who is thought to have constructed the Kasim Agha Aqueduct was the very same Kasim Agha who was the royal chief architect during 1623-44. Kasim Agha (died 1660) was apprenticed to Davud Agha, another royal chief architect. Most likely, this water supply was built during his service to the palace. Records show that the water supply transported water to a çeşme close to the Hospital of Haseki, but its exact location has not been determined even in past researches (Nirven 1946; Tanışık 1943; Ata 1922). 


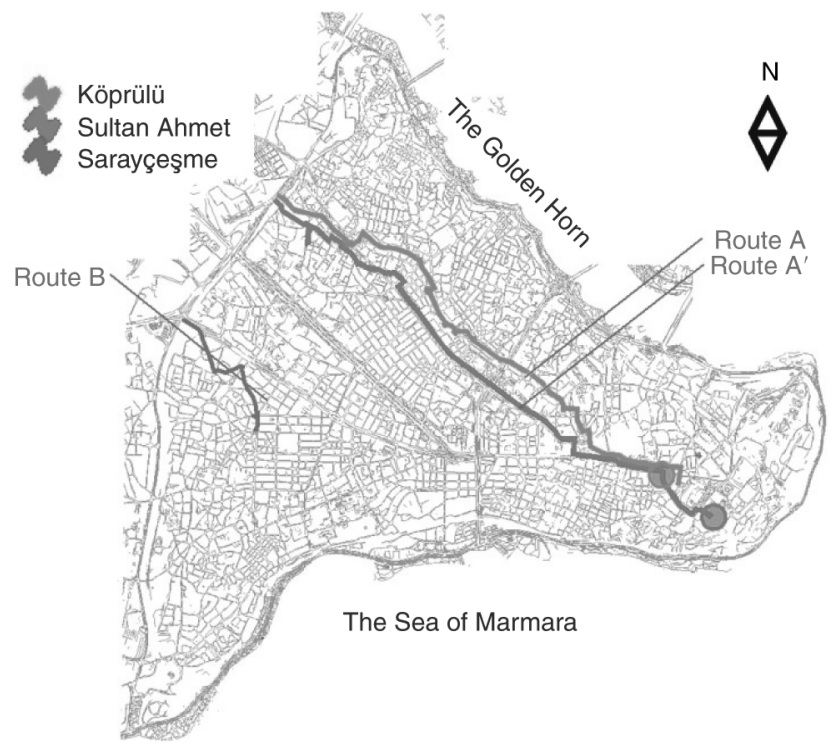

Figure 11.3 Water supplies from 1603 to 1703.

Köprülü Mehmet Pasha (died 1661) who served as the vizier from 1656 to 1661 constructed the Köprülü Mehmet Pasha Aqueduct (the yellowish green line in Figure 11.3). According to the list of facilities supplied, this aqueduct distributed water to six locations. Most likely, it was built while the vizier was in office.

Four aqueducts were constructed during Phase III, 1603-1703, and, just as in the past, they can be classified into aqueducts that ran from the northwest to the southeast in the northern part of Istanbul and aqueducts that ran in the central part (Figure 11.3). The Köprülü Mehmet Pasha Aqueduct took the Route A and supplied water to the Köprülü külliye. The Sultan Ahmet Aqueduct took a different route and ran parallel to the southern side of Route A. In this study, this route is called Route A'. In the central part, the Sarayçeşme and Kasım Agha aqueducts that ended at Haseki took Route B to the center of the city. These newly constructed aqueducts show that there was an increased demand for water and steady formation of an urban infrastructure on Routes $\mathrm{A}^{\prime}$ and $\mathrm{B}$.

\section{Phase IV: 1703-74 (the reigns of Ahmet III, Mahmut I,}

Ottoman III, and Mustafa III)

During Phase IV, two new aqueducts were constructed while two of the older aqueducts were repaired and extended (Figure 11.4). Sultan Mahmut I (reigned 1730-54) was responsible for the servicing of the Beylik and Nuruosmaniye aqueducts. The Beylik Aqueduct entered the city from the southern side of 
Edirnekap and through Route A transported water all the way to Topkapı Saray (the brown line in Figure 11.4). The characteristic of this aqueduct is that it consisted of a repair to an existing aqueduct and a new extension. However, it is not clear which parts were mended and which were the extension. According to the list of facilities supplied, the aqueduct distributed water to 35 locations. Next, construction for the Nuruosmaniye Aqueduct (the yellow line in Figure 11.4) began in 1748 together with that for the Nuruosmaniye külliye. They were completed in 1755 during the reign of Ottoman III (reigned 1754-57) after the death of Mahmut I. According to the list of facilities supplied, the Nuruosmaniye Aqueduct distributed water to 15 locations.

The Laleli Aqueduct (the orange line in Figure 11.4) constructed by Sultan Mustafa III (1757-74) incorporated parts of the Mahmut Pasha Aqueduct (the pinkish line in Figure 11.1) that was built during Phase I. Not much is known about the chronology of the joining of these two aqueducts.

Hekimoğlu Ali Pasha (born 1689, died 1758) who built the Hekimoğlu Ali Pasha Aqueduct was a key figure during the reign of Ahmet III, Mahmut I, and Ottoman III. He served as Beylerbey in 1719, Rumeli Beylerbey in 1722, Halep valisi (cabinet chief of Halep region), vizier in 1725, Beylerbey again in 1726, and for a total of about five years during 1732-35, 1742-43, and 1755-56 as grand vizier. This aqueduct distributed water to 68 locations, including his namesake külliye, and must have been constructed during his years as the vizier $(1732-35,1742-43,1755-56)$. The form of this aqueduct is similar to the

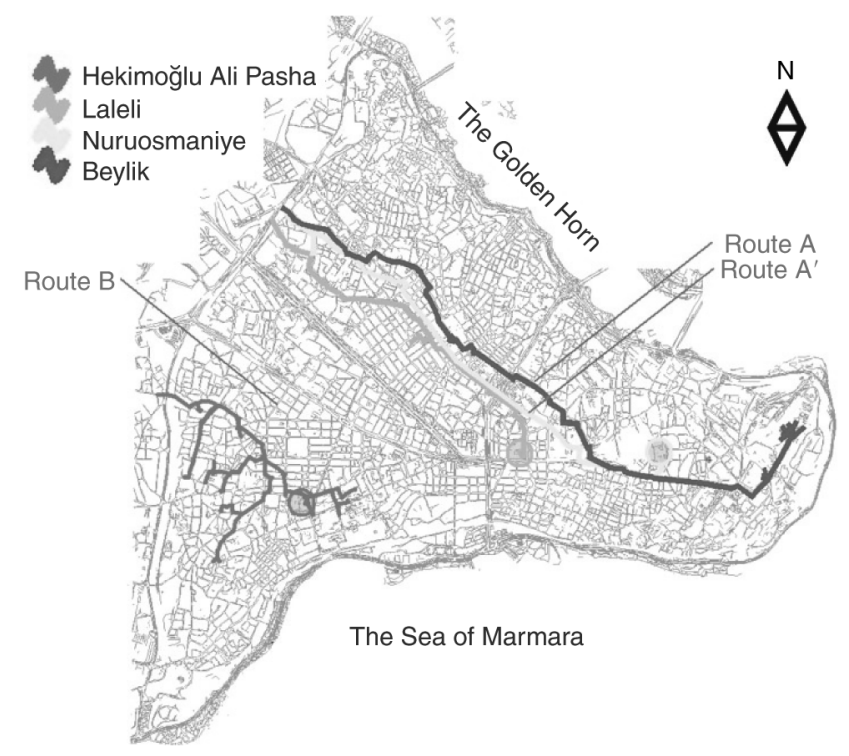

Figure 11.4 Water supplies from 1703 to 1774. 
Kırkçeşme Reticulation that was built by Süleyman I during Phase II. Rather than being linear, it was a network (the dark rose-colored line in Figure 11.4), most probably because it supplied water to undeveloped areas remaining between previously serviced areas.

During Phase IV, 1703-74, four aqueducts were built. Three were built in the northern part of the city and one in the southern part (Figure 11.4). Of the three aqueducts on the northern part, the Beylik Aqueduct took Route A. On the other hand, the Nuruosmaniye and Laleli aqueducts took the Route $\mathrm{A}^{\prime}$. Thus, during Phase IV, it can be said that Route $\mathrm{A}^{\prime}$ was preferred in the northern part. The construction of the Laleli külliye in Laleli district during Phase IV implies the further acceleration of the increased demand for water in the central part of the city that was already visible in Phase III.

Another characteristic of Phase IV is that existing aqueducts were repaired and then reused after being extended. The Beylik Aqueduct (the brown line in Figure 11.4) and Laleli Aqueduct (the orange line in Figure 11.4) are two such examples. About three hundred years had passed between Phase I and Phase IV, and naturally, the older aqueducts needed to be serviced. It seems that the decision to repair and reuse the existing aqueducts instead of constructing new ones demonstrates the levelling-off of growth inside the city wall and the beginning of the spread of urban infrastructure to a new town toward the Bosphorus and on the Asian side. The construction of the Taksim Water Supply in the new town underlines this kind of change.

So far, this study has attempted to describe the state of the city of Istanbul through the chronology of the construction of the water supplies. To sum up, the main water routes, specifically Routes $\mathrm{A}, \mathrm{A}^{\prime}$, and $\mathrm{B}$, served as important axes for the development of Istanbul, especially for the locations of the key külliyes, because all aqueducts on the routes served water to the key külliyes. The most important characteristic is that the routes are situated on hilltop locations. So far, many academics have pointed out that the urban silhouette was a very important factor for the architects of the large mosques that were part of the külliye; therefore they were on hilltops. In addition to this, one other reason for the concentration of külliyes in hilltop locations can be considered to be due to influences of hydraulic conditions related to water transport.

Figure 11.5 tabulates the overall lengths of the 16 Halkalı Aqueducts and a Kırkçeşme Reticulation inside the city wall by using GIS. The lengths of the Halkalı aqueducts are the same within $7000 \mathrm{~m}$ because they were constructed as more or less linear aqueducts for each külliye. As the old map of the Köprülü Aqueduct (Figure 11.6) [Map No.10] shows, they did not distribute water to the buildings to its right and left, but travelled in a straight line to the külliye, its final destination. Thus, those who built these water supplies had almost no intention of supplying water to the surrounding urban area other than the külliyes and their vicinities. On the other hand, the Kırkçeşme Reticulation did not supply water to a specific külliye but networked the area that had been untouched by Routes A, $\mathrm{A}^{\prime}$, and B. Its total length was $85410 \mathrm{~m}$. This difference in the overall lengths of 


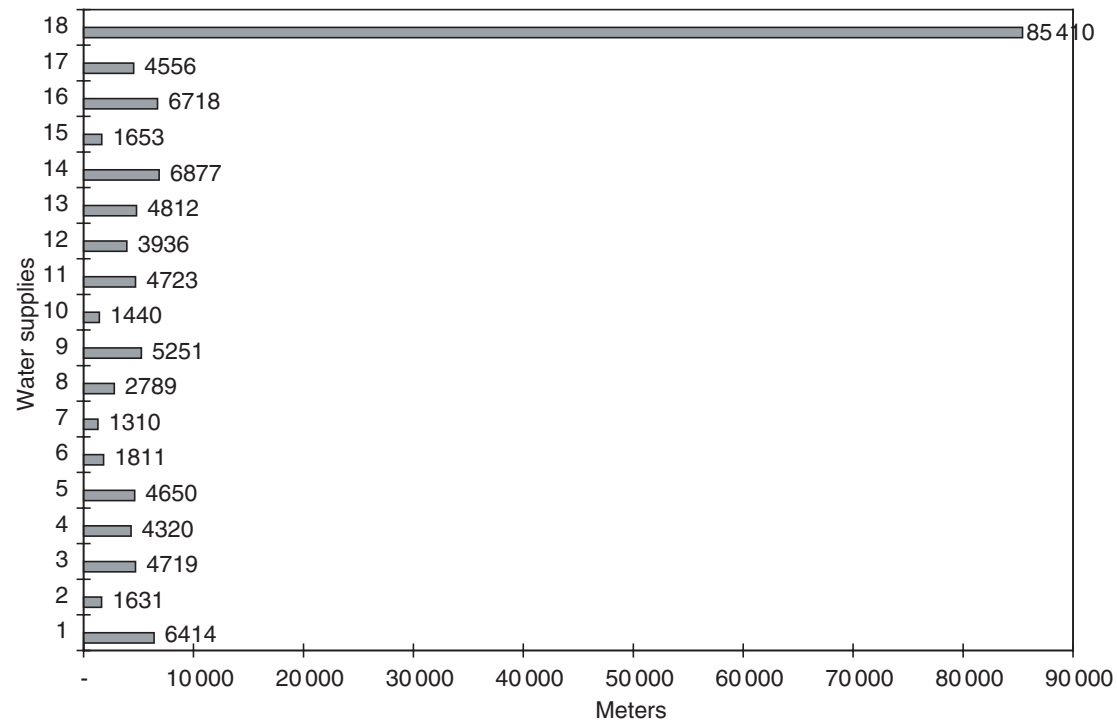

Figure 11.5 The lengths of the water supplies.

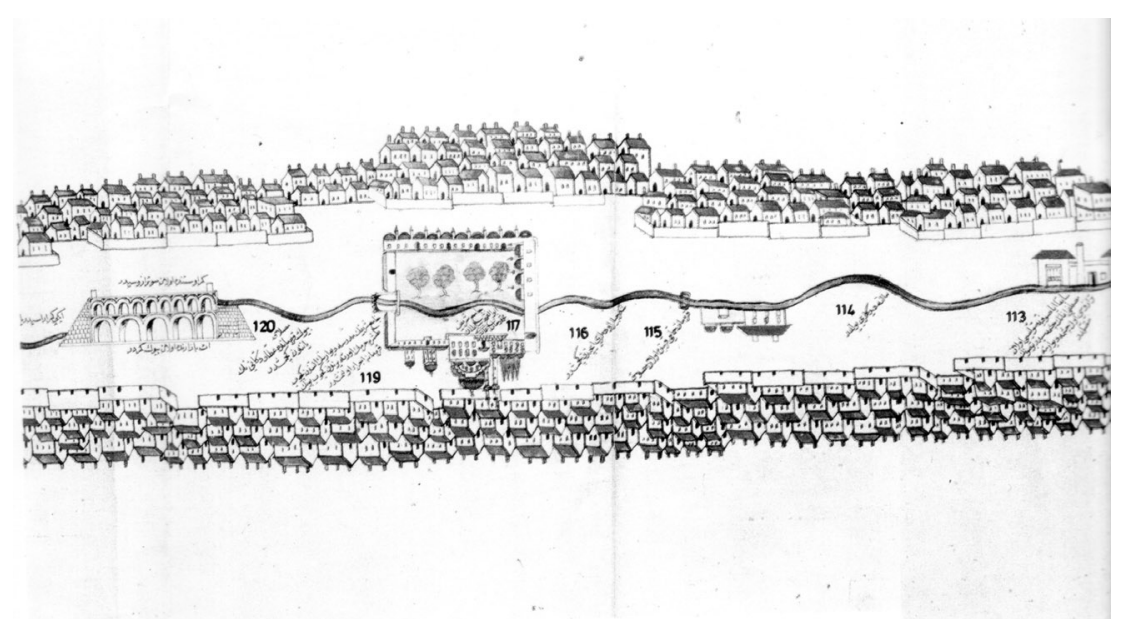

Figure 11.6 Old map of Köprülü Water Supply.

the two water supplies shows that the intent behind the construction of the Kırkçeşme Water Supply was completely different from that of the Halkalı Water Supplies, where the main purpose was to supply water to külliyes.

Next, we wish to examine the types of facilities supplied in order to probe the objective behind the design of the Kırkçeşme Water Supply. 


\section{Public fountains inside the city wall}

\section{Facilities to which the Halkalı and Kırkçeşme Water were distributed}

Water from the Halkalı and Kırkçeşme supplies became available in various urban facilities of Istanbul. Here, we wish to summarize the facilities receiving Halkalı and Kırkçeşme water to enable a comparison of the differences between these water supplies.

The list compiled by the Ministry of Vaklf in 1930 records the number of facilities that received water from the Halkalı Water Supplies and Kırkçeşme Water Supply (IVB 1930). A total of 435 facilities received water from the Halkal1 Water Supplies while 622 received water from the Kırkçeşme Water Supply. These numbers as recorded on the list were not always calculated in the same manner. Sometimes, a single facility was counted as one while at other times the total number of facilities supplied on the same precinct was counted as one. For Table 11.2 , the total number was revised by recounting so supply to every single facility was counted. According to the new calculation, 526 facilities received water from the Halkalı Water Supplies and 682 from the Kırkçeşme Water Supply.

As shown in Table 11.2, the types of buildings supplied varied greatly. There were 698 çeşmes (public fountains), 96 mosques, 54 medreses, and 53 mekteps (elementary schools). In many cases, çeşme, mosque, medrese, and mektep were located inside the külliye. The markedly large number of çeşmes implies that they were independent buildings, built away from the külliye.

Let us focus our attention on the number of çeşmes to which the Halkalı Water Supplies and Kırkçeşme Water Supply distributed water (Table 11.2). The results reveal a marked difference in the numbers recorded for the two supplies. The Halkalı Water Supplies distributed water to 263 çeşmes while the Kırkçeşme distributed water to 435 , a difference of 172 . There are slight differences in the records for other facilities, but they are not so marked as for the çeşme. Thus, we can conclude that the Kırkçeşme Water Supply supplied water to a particularly large number of çeşmes. Earlier, it was mentioned that the main objective of the Halkalı Water Supplies was to supply water to külliyes. In contrast, if we just look at the results of Table 11.2, we are presented with the possibility that the main purpose of Kirkçeşme Water Supply was to supply water to the çeşmes. Then, what type of an area requires çeşmes? Let us consider this by summarizing the characteristics of public fountains.

\section{Public fountains (çeşme, sebil)}

\section{Types of fountains and their characteristics}

As indicated in Table 11.2, there are two types of public fountains: çeşme and sebil (Egemen 1993). A çeşme (Figure 11.7) is a facility that provides water through a water duct (either with or without a tap) that has been installed 


\section{YAMASHITA KIMIYO}

Table 11.2 Total number of facilities to which the Halkalı Water Supplies and the Kırkçeşme Water Supply transported water

\begin{tabular}{|c|c|c|c|c|c|}
\hline Type of facilities & $\begin{array}{l}\text { Halkall } \\
\text { number }\end{array}$ & $\begin{array}{l}\text { Kırkçeşme } \\
\text { number }\end{array}$ & Type of facilities & $\begin{array}{l}\text { Halkall } \\
\text { number }\end{array}$ & $\begin{array}{l}\text { Kırkçeşme } \\
\text { number }\end{array}$ \\
\hline Abdest Musluklar & 1 & 0 & Kilise & 1 & 6 \\
\hline Ambar & 0 & 1 & Kışla & 2 & 1 \\
\hline Apteshaneler & 0 & 3 & Kütüphane & 4 & 2 \\
\hline Askeri Matbaa & 1 & 0 & Kuyu & 0 & 7 \\
\hline Askeri Saraçhane & 1 & 0 & Maliye & 1 & 0 \\
\hline Bab1 Fetva & 1 & 0 & Maliye Haznesi & 1 & 0 \\
\hline Baca & 0 & 19 & Medrese & 43 & 12 \\
\hline Basmahane & 0 & 1 & Mektep & 25 & 28 \\
\hline Bodrum & 0 & 1 & Mescit & 0 & 4 \\
\hline Cami & 39 & 57 & Meşrutahane & 1 & 1 \\
\hline Cami Mahfeli & 1 & 0 & Millet Bahçe & 1 & 0 \\
\hline Çatalçeşme & 1 & 0 & Muallimhane & 1 & 0 \\
\hline Cephanelik & 0 & 1 & Musluklar & 5 & 3 \\
\hline Çeşme & 263 & 435 & Nafia Nezareti & 1 & 0 \\
\hline Daire & 1 & 0 & Nisa Hastanesi & 0 & 1 \\
\hline Darülşşafaka & 1 & 0 & Nizamiye & 0 & 1 \\
\hline Dergah & 24 & 18 & Patrikhane suyu & 0 & 1 \\
\hline Elbise Ambarı & 1 & 0 & Postane & 0 & 1 \\
\hline Emin Bey & 3 & 0 & Şadırvan & 13 & 17 \\
\hline Evkaf Daire & 1 & 0 & Sebil & 37 & 17 \\
\hline Feshaneye cari & 0 & 2 & Şehremaneti & 1 & 0 \\
\hline Firın & 3 & 1 & Tabhane & 1 & 0 \\
\hline Gümrük & 0 & 1 & Tekke & 13 & 8 \\
\hline Hamam & 0 & 1 & Tomruk Dairesi & 1 & 0 \\
\hline Han & 1 & 1 & Tophane & 0 & 1 \\
\hline Hapishane & 1 & 0 & Topkaap1 Saray & 0 & 1 \\
\hline Hastahane & 1 & 0 & Tulumba & 1 & 8 \\
\hline Havuz & 6 & 3 & Türbe & 8 & 10 \\
\hline Hazne & 0 & 1 & Zaptiyekap1 & 1 & 0 \\
\hline İmaret & 10 & 3 & & 526 & 682 \\
\hline Karakol & 3 & 3 & Totals & 526 & 682 \\
\hline
\end{tabular}

on the external wall of the water tank. It was a drinking place for thirsty pedestrians and also where residents or the saka (water-carrier) could get water. A tap was installed inside the niche and below the niche was a basin and above the niche, an inscription. Many çeşmes were of simple design and were practical facilities.

A sebil (Figure 11.8), on the other hand, was a small, covered space. Through its latticed windows, the people inside distributed water in a metal bowl to pedestrians (Ünsal 1986, 1987). For the most part, they were located on street corners or on large streets and were easily visible to passers-by. A sebil consisted of a service room and an adjacent water tank. The person inside the service room obtained water from the çeşme built on the wall that separated the service 


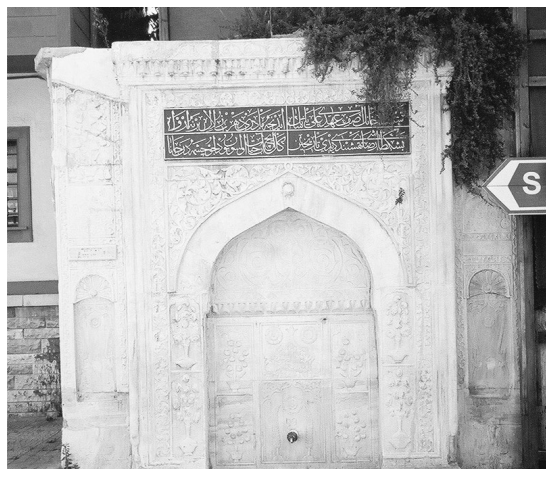

Figure 11.7 Example of a çeşme.

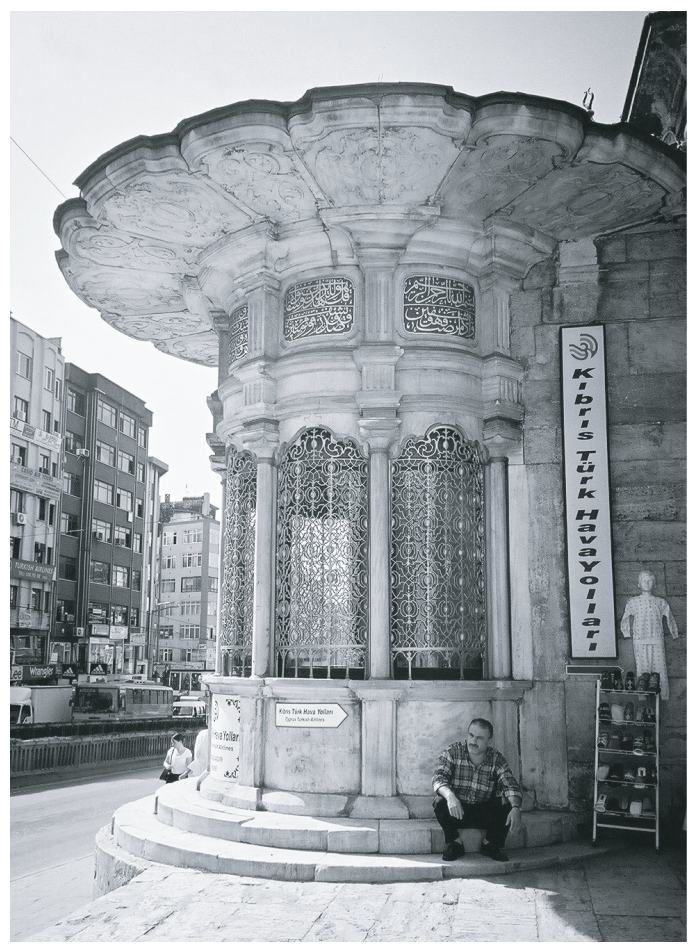

Figure 11.8 Example of a sebil.

room from the water tank and provided water to pedestrians through small windows. On the holy nights of the Islamic religion, fruit syrup or water directly from the spring was specially distributed. The multi-angled service room that protruded against the main road mainly consisted of a domed roof and a protruding 
building. This design ran contrary to the function-oriented çeşme. There was a counter board protruding from the back and from here water was handed out; above the counter board were a number of columns that were connected by an arch. Below the latticed windows that were built between the arches was an opening from where water was handed out. Judging from the size of this opening, it was possible to hand out only a bowl of water. Thus, it can be said that sebil was a facility that provided drinking water to thirsty pedestrians and not one where water for everyday use at home was provided.

As shown already in Table 11.2, the number of çeşmes was overwhelmingly large compared to that of sebils. We were able to determine the locations of 441 çeşmes and sebils that received water from either the Halkalı Water Supplies or the Kırkçeşme Water Supply and they are individually mapped out in Figure 11.9. This distribution map reveals that çeşmes were constructed over a wide area of Istanbul. Judgments about sebils, on the other hand, are not easy to make since only a few of them could be located, as shown in Figure 11.9. All we can say from the results is that it does not look as though they were constructed throughout the city of Istanbul. If we take into account the function and the number of sebils, it seems as though it was the çeşme, not the sebil that played a role as a facility to provide water for everyday use at home. Furthermore, if we take into account the functions of the çeşme, we are able to point out the possibility that areas with a wide distribution of çeşmes had many residential districts.

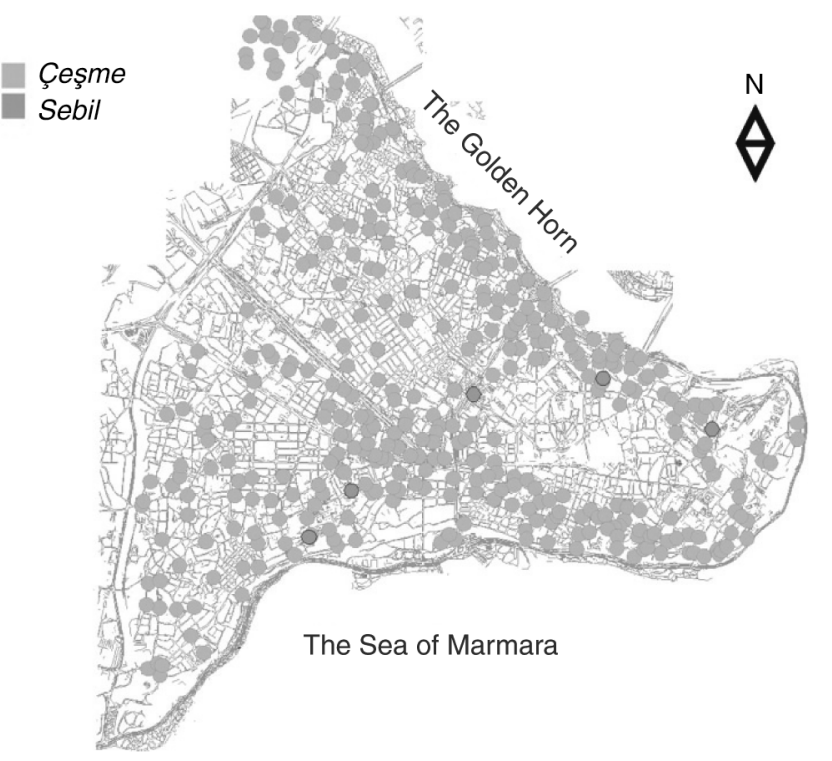

Figure 11.9 Distribution map of the fountains: types. 


\section{Location of çeşmes in Istanbul}

Let us then study the locations of çeşmes in order to read the characteristics of that particular area. We will focus on the distribution of public fountains in Figure 11.9. They can be considered in three groups: areas where there is a concentration of çeşmes, areas where there is a relatively small number of çeşmes, and areas devoid of çeşmes. The first includes the center part, the coastal area of the Golden Horn Bay, and the southeastern area along the coast of the Sea of Marmara. The area with a relatively small number of çeşmes is the part along the city wall, excluding the coast of the Golden Horn Bay. The Bayezit district and its vicinities can be put forward as an empty area.

First of all, let us study in greater detail the first (with many çeşme) area and the second area (with a relatively small number of çeşmes). The number of çeşmes signifies the amount of water for everyday use needed in proportion to the population density. Decisions on the locations of the çeşmes seemed to have been made by taking into account the distance between the çeşmes and will of the sponsors. Thus, I selected the çeşme-concentrated area and the area with a relatively small number of çeşmes (Figure 11.10) and calculated the shortest distances (by road) between one çeşme and another using GIS. Figures 11.11 and 11.12 show the measured distances between one çeşme and another in the southeastern part, along the coast of the Sea of Marmara (Figure 11.10 - Area (1)), and the coastal part of the Golden Horn Bay (Figure 11.10 - Area (2)). In both areas, the shortest distance (by road) between one çeşme and another was normally

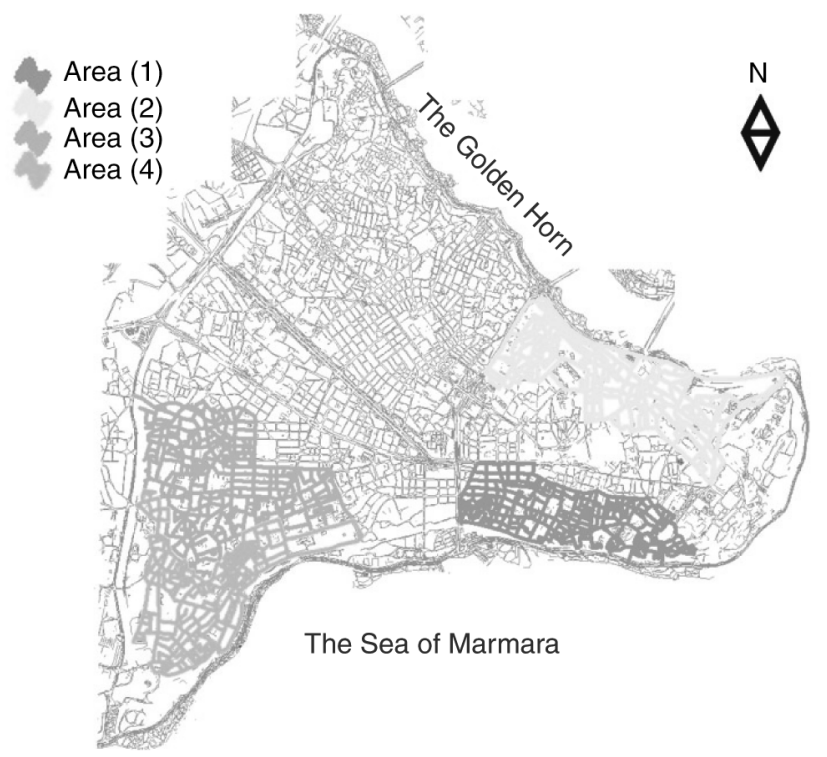

Figure 11.10 Areas where the shortest distance is calculated. 


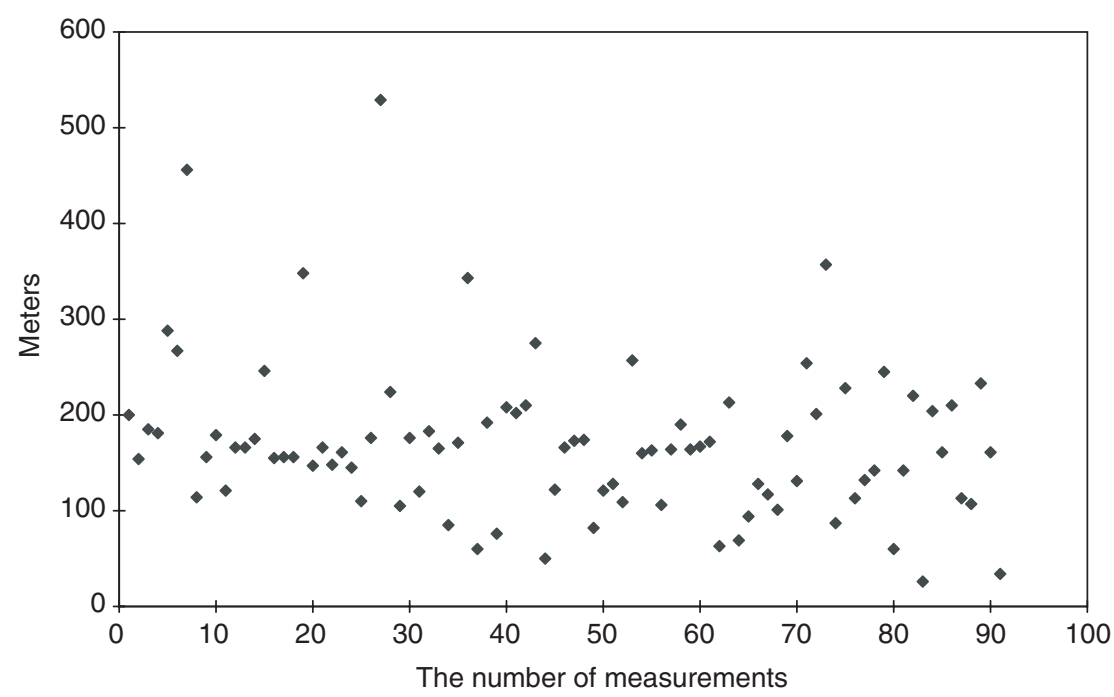

Figure 11.11 Area (1): the shortest distance between çeşmes (Kırkçeşme Water Supply).

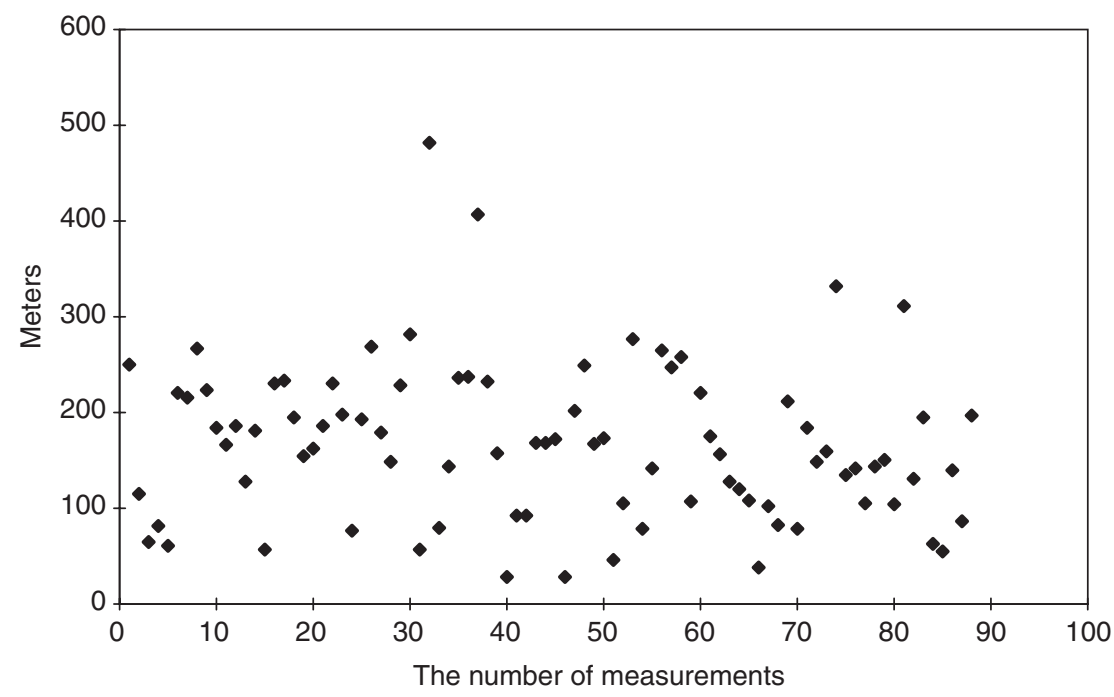

Figure 11.12 Area (2): the shortest distance between çeşmes (Kırkçeşme Water Supply).

$50-250 \mathrm{~m}$ and always staying within $300 \mathrm{~m}$. We can say that the sponsors built çeşmes where necessary by ensuring that there was one at least every $300 \mathrm{~m}$.

Second, two areas with a relatively small number of çeşmes were selected to calculate the distances between them. Figures 11.13 and 11.14 show the shortest 
THE WATER SUPPLIES AND FOUNTAINS OF ISTANBUL

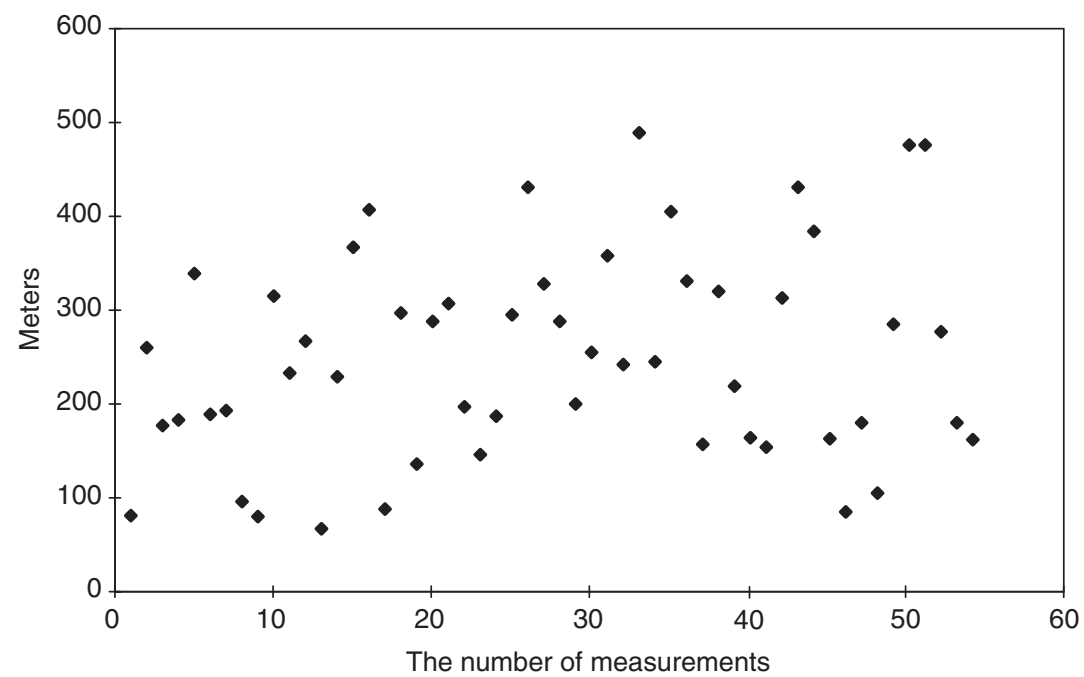

Figure 11.13 Area (3): the shortest distance between çeşmes (Hekimoğlu, Koca Mustafa Pasha, Sarayçeşme Water Supplies).

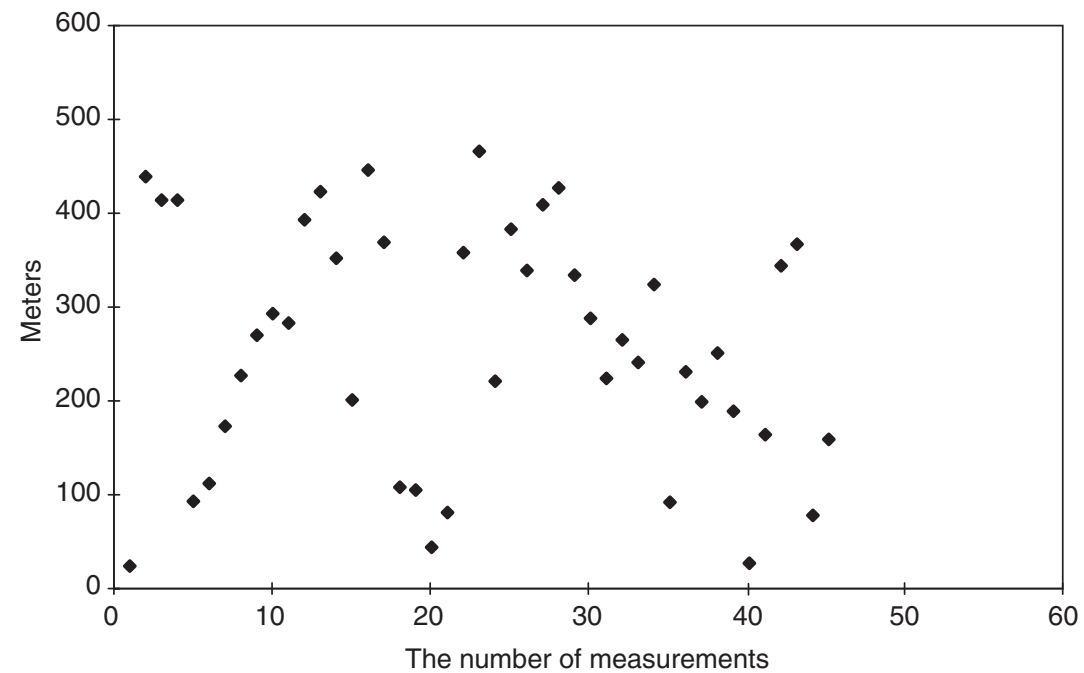

Figure 11.14 Area (4): the shortest distance between çeşmes (Kırkçeşme Water Supply).

measured distance (by road) between the çeşmes, calculated by using GIS. In the area shown on Figure 11.10 (Area 3), there are çeşmes that received water from the Hekimoğlu, Koca Mustafa Pasha, and Sarayçeşme aqueducts in the southwestern part. In the area shown on Figure 11.10 (Area 4), there are çeşmes 
that obtained water from the Kırkçeşme Reticulation in the southwestern part along the coast of the Sea of Marmara. The graphs (Figures 11.13 and 11.14) show that the çeşmes in Figure 11.10 (Areas 3 and 4) were dispersed at distances of about $100-400 \mathrm{~m}$ and the longest distance was within about $500 \mathrm{~m}$. The fact that the shortest distance between many çeşmes in Areas (3) and (4) is further than in Areas (1) and (2) implies a lower density of facilities; thus, less necessity for water in the concerned districts. From these results, we can say that Areas (1) and (2) had a denser population than Areas (3) and (4) and saw robust development during the Ottoman period (Figures 11.9 and Figure 11.10).

As aforementioned, çeşmes were constructed through a donation system $($ Vaklf $)$. The sponsors were various individuals, ranging from sultans and grand viziers to leading figures and relatively wealthy citizens in the town. Figure 11.15 shows the types of sponsors, differentiated by color, of the public fountains. According to Figure 11.15, the public fountains that were constructed by powerful figures such as sultans, royal family members (e.g. sultan's mother or daughters), high-level officials (e.g. grand viziers, Pashas) were not concentrated in a specified area but were distributed uniformly throughout the area inside the city wall. This distribution shows the intention of the powerful sponsors to develop the

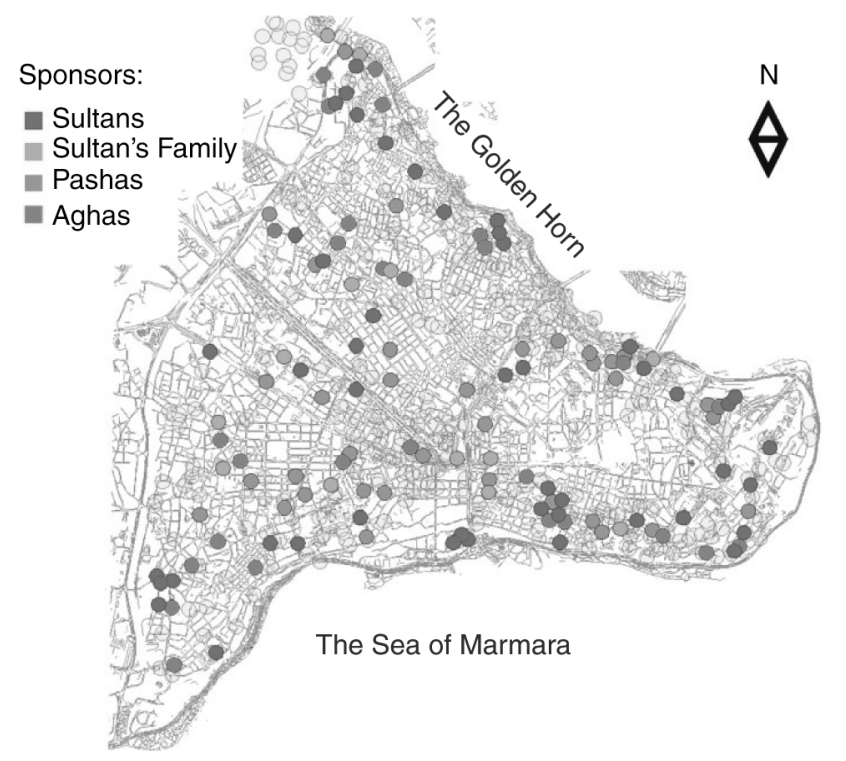

Figure 11.15 Distribution map of the fountains: sponsors.

Notes

1. Fatih, 2. Selim, 3. Turunçlu, 4. Bayezit, 5. Süleymaniye, 6. Mihrimah, 7. Ebussuud, 8. Cerrah Pasha, 9. Sultan Ahmet I, 10. Sarayçeşme, 11. Köprülü, 12. Laleli, 13. Mahmut Pasha, 14. Beylik, 15. Koca Mustafa Pasha, 16. Hekimoğlu, 17. Nuruosmaniye, 18. Kırkçeşme. 
whole city, not a specific district only. This proves the satisfactory functioning of donation activities during the Ottoman period.

Finally, let us consider the area empty of çeşmes, Bayezit district and its vicinities (Figure 11.9). In spite of the fact that the areas housed some külliyes built by sultans and grand viziers and many aqueducts travelled through the areas, the number of public fountains was small. The following two factors can be considered as the reason for this. First, the existence of külliyes signifies that there are many urban facilities, such as mosque and soup kitchens, educational facilities like mekteps and medreses, and commercial facilities like shops. Table 11.2 shows that water supplies were distributing water not only to public fountains but also to numerous urban facilities inside the külliye. In other words, it looks as though the water supplies were directly distributing water to many of the urban facilities in this area; hence, there was little need for çeşmes. Second, the small number of public fountains in that part probably has to do with the fact that there had been an Eski Saray (former palace). Details of the size and location of the former palace are not clear, so it was not possible to carry out a detailed deliberation.

\section{Conclusion}

This study analyzed the construction processes and distribution of the water supplies and public fountains that were constructed in Istanbul (inside the city wall) from the mid-fifteenth to the late eighteenth century to study how they contributed to the development of the city.

In Phase I, aqueducts that supplied water to külliyes were constructed in three parallel routes of almost equal distances. In Phase II, new aqueducts were constructed over two of the aforementioned three routes in an overlapping manner and thereby forming the main water routes A and B. An area mainly of religious, charitable, and educational facilities that formed a külliye came to be built along these main water supply routes.

In the areas without külliyes, there were heightened expectations for the construction of çeşmes in Phase II. Finally, between 1554 and 1563, the Kırkçeşme Water Supply was reticulated throughout the central area and the coastal areas of the Golden Horn Bay and the Sea of Marmara. In these areas, many çeşmes were built to provide water for everyday use at home to citizens.

During Phase III, Route A' was newly constructed as an addition to Route A, and ran parallel to it in a somewhat southernly direction. On Route B, more aqueducts were constructed. These facts indicate an increase in water demand to the central part of the city and therefore an increase in population. However, during Phase IV, existing water supplies were repaired and then reused, and their development tended to slow down.

In conclusion: (1) there were areas including many public facilities (e.g. religious, charitable, and educational facilities) along Routes A and B formed by the Halkalı Water Supplies, (2) there were areas including many residential districts in the center of the city and the coastal areas along the Golden Horn Bay and the Sea 
of Marmara where the Kırkçeşme Water Supply distributed water. According to the distribution state of the public fountains, however, the growth of the population was not uniform throughout all the residential districts. The center part, the coast of the Golden Horn Bay and the southeastern coast of the Sea of Marmara saw remarkable growth, but the area along the city wall saw less growth.

GIS, which we used for this study, proved to be an effective means to plot the large water supplies and several hundred public fountains to obtain a general picture. In particular, GIS made the analytical process easier as we were able to confirm on the computer screen the locations and characteristics from various angles in a short time without having to struggle through numerous large maps. However, this study was merely an elementary trial of applying GIS to urban history research and its use was confined to a simple distance-measuring function. In the future, we hope to use GIS to study relative position-relationships of the various facilities that can be analyzed with GIS and also probe the further potential of GIS-applied urban history research.

\section{Acknowledgments}

I received comments helpful to this research from Okabe Atsuyuki, Asami Yasushi, Jinnai Hidenobu, Terasaka Akinobu, Kitagawa Kensuke, Okada Yasuyoshi, and Hayashi Kayoko and anonymous referees. I wish to mention my appreciation to them all.

\section{Bibliography}

Arseven, C.E. (1983) Sanat Ansiklopedisi C.1, Istanbul: MEB.

Ata, G. (1922) Istanbul Evkaf Sulart Sihhiye Mecmuası No6, Istanbul.

Barkan, Ö.L. (1972) Süleymaniye Camii ve imareti inşaatı, Ankara: TTK.

Barkan, Ö.L. and Ayverdi, E.H. (1970) Istanbul vakıflart tahrir defteri: 953 (1546) tarihli, Istanbul: Baha Matbaas1.

Burhan, O. (1998) Bizans'tan Günümüze İstanbul Sular, Istanbul: Simurg.

Carım, F. (1964) Kanuni Devrinde İstanbul, Istanbul: Yeni Savaş Matbaası.

Çeçen, K. (1984) Istanbul'da Osmanlı Devrindeki Su Tesisleri, Istanbul: ITÜ.

Çeçen, K. (1986) Süleymaniye suyollarl, Istanbul: ITÜ.

Çeçen, K. (1991a) Halkalı Suları, Istanbul: ISKI.

Çeçen, K. (1991b) Istanbul'un vakıf sularından Üsküdar suları, Istanbul: ISKI.

Çeçen, K. (1992) Sinan's Water Supply System in Istanbul, Istanbul: ISKI.

Çeçen, K. (1997) Bayezid suyolu haritaları, Istanbul: ISKI.

Çeçen, K. (1998) In memoriam Prof. Dr. Kazım Çeçen, Istanbul: Renk Ajans.

Çeçen, K. and Kolay, C. (1997) Topkapı Sarayı'na su sağlayan isale hatları, Istanbul: ISKI.

Çeçen, K. and Kolay, C. (1999) Istanbul'un Osmanlı dönemi suyolları, Istanbul: ISKI.

Çelebi, E. (1971) Seyahatname, Vol. 14, trans. Danişmen, Istanbul.

Egemen, A. (1993) Istanbul'un Çeşme ve Sebilleri, Istanbul: Arıtan Yayınevi.

Eyice, S. (1979) Byzantinische Wasserversorgungsanlagen in Istanbul, Leichtweiss Institut für Wasserbau No. 64, T. U. Braunschweig. 
Kuban, D. (1996) Istanbul. An Urban History, Istanbul: Economic and Social History Foundation of Turkey.

İA (1994) Dünden Bugüne İstanbul Ansiklopedisi, Cilt 5, Istanbul: Türkiye Ekonomik ve Toplumsal Tarih Vakıfi.

IVB (1930) İstanbul Vakıflar Başmüdürlüğ̈ (ed.) The Version Written in Latin Alphabet in 13,5,1930.

Map No. 1: Millet Kütüphanesi, Fatih, Beylik Suyolu, No. 930, 992(H) /1584.

Map No. 2: Topkapı Sarayı Müzesi, Beylik Suyolu Hazine, No. E, 12431, 992(H) /1584.

Map No. 3: Topkapı Saray1 Müzesi, Beylik Suyolu III Ahmet Kütüphanesi, No. H. 1816, 1016(H) /1607.

Map No. 4: Topkapı Sarayı Müzesi, Beylik Suyolu III Ahmet Kütüphanesi, No. H. 1815, 1161(H) /1748.

Map No. 5: Türk İslam Eserleri Müzesi, Süleymaniye Suyolu, No. 3337, 18th c.

Map No. 6: Türk İslam Eserleri Müzesi, Bayezid Suyolu (İsale) No. 3338, 1815-17.

Map No. 7: Türk İslam Eserleri Müzesi, Bayezid Suyolu (Şebeke) No. 3339, 1815-17.

Map No. 8: Köprülü Kütüphanesi, Köprülü Suyolu, No. 2441/1, 1672.

Map No. 9: Köprülü Kütüphanesi, Köprülü Suyolu (İsale) No. 2441/2, 1275(H) /1859.

Map No. 10: Köprülü Kütüphanesi, Köprülü Suyolu (Şebeke) No. 2443/3, 1275(H) /1859.

Map No. 11: Nurosmaniye Ayvalı Dere Suyolu, Istanbul Vakıflar Başmüdürlüğü, 1748-55. (Çeçen 1991a).

Müller-Wiener, W. (1977) Bildlexikon zur Topographie, Istanbul: Tübingen.

Nirven, S.N. (1946) Istanbul Suları, Istanbul: Halk Matbaası.

Öziş, U. (1987) Mimar Sinanın suyolları, Izmir: DEÜ.

Pilehvarian, N.K. (2000) Osmanlı Başkenti İstanbulda Çeşmeler, Istanbul: YEM.

Sözen, M. (ed.) (1989) Mimar Sinan and Tezkiret-i Bünyan, Türkiye Istanbul: Emlak Bankası.

Tanışık, H. (1943) Istanbul Çeşmeleri, Cilt 1 Istanbul: Maarif Matbaası.

Ünsal, B. (1986) "Stil Yönünden Klasik Sonrası Türk Mimarlığında Sebil Anıtları," Türkiye Anıt Çevre Turizm Değerlerini Koruma Vakfi Yayını, Cilt1 Sayı1: 16-25.

Ünsal, B. (1987) "Türk Mimarlığında Klasik Sebil Anıtları," Türkiye Anıt Çevre Turizm Değerlerini Koruma Vakfi Yayını, Cilt2 Sayı: 9-22. 



\section{Part IV}

\section{NETWORK ANALYSIS WITH SPACE SYNTAX}





\title{
APPLICATION OF GIS TO NETWORK ANALYSIS \\ Characterization of traditional Turkish urban street networks
}

\author{
Asami Yasushi, Kubat Ayse Sema, and Istek Cihangir
}

\section{Introduction}

The geographical information system (GIS) is a powerful tool for analyzing networks, which are often characterized by their nodes (intersections) and edges (links between neighboring intersections), as well as the attributes attached to them. This representation of networks can be useful for analyzing modern street networks that have rather straight roads. On the other hand, traditional street networks possess certain features that are different from those in cities having a modern street network system. Typical of these features are an abundance of "organic" networks having a large number of dead-ends, curvy and narrow roads (on the human scale), and a lack of main streets. Some of these features may need more sophisticated measures to characterize them.

Several approaches can be used to analyze networks, one typical approach being to utilize graph theory. The focus of graph theory is mainly on the topological connections of nodes and edges, which can be useful for signifying the abundance of dead-end roads. Features related to traditional networks are not well characterized using this approach alone, and another approach is to analyze the street networks via image analysis. If all the roads are colored black, while other areas are left white, then the street network can be regarded as a black-and-white image. In this scenario, for example, the ratio of black pixels (color points) to all pixels is the road coverage ratio. To obtain a "skeleton" of the streets - that is, the centerlines of the streets - a thinning operation is often used in image analysis. The thinning operation gradually removes the network boundaries, so that the streets ultimately become connected by pixels, so that no further removal of the network boundaries is possible. The resultant image is the thinnest network possible, which is topologically the same as the original image. In this operation, we can count the number of "peeling" operations necessary for each edge, which 
yields the width of each edge. Using such an operation, we can measure the average width of streets.

Space syntax (Hillier and Hanson 1984; Hillier 1996) is also frequently used to analyze street networks. In the space syntax method, street networks are segmented into spatial units represented by axial lines, which are line segments representing a part of a road in which all the points in the unit are visible from each other. To represent a straight road, for example, a single line segment is adequate and therefore can be represented by a single axial line. On the other hand, a curvy road needs to be represented by several units and so is represented by several axial lines. This observation implies that the space syntax method distinguishes between straight roads and curvy roads; hence, indices based on this method may be useful for characterizing Islamic street networks.

Organic networks are a feature not only of Islamic cities; several cities that are outside the region of Turkish or Islamic influence, such as Venice and Sienna, also have such features. Therefore, we can ask, "what is the 'true' feature of traditional Turkish street networks?" Motivated by this problem, this work quantitatively investigated the indices or combination of indices that determine the traditional Turkish character revealed in street network patterns.

To do so, several cities in Turkey possessing a traditional Turkish character were selected for case studies. Moreover, some Turkish cities that do not possess any traditional character were also selected for comparison purposes. Other cities around the world have been studied by Asami et al. (1999a) using network techniques, and these are listed in the next section.

From a given set of indices obtained by several approaches, we determined an efficient discriminant function of the indices, which allowed us to differentiate traditional Turkish cities from other cities. A typical function used was a linear function of indices with proper coefficients. A discriminant function for traditional Turkish character will have the largest (positive) value for the most "traditional" city, as judged by the indices of the street networks, and would have the smallest (negative) value for the least "traditional" city. Ideally, the functional value would be greater than a certain threshold value for all traditional Turkish cities, and less than the threshold value for all non-Turkish traditional cities. Such a discriminant function can completely distinguish traditional Turkish cities from other types of cities. For simplicity, we will abbreviate "traditional Turkish" to "traditional" hereafter.

\section{Traditional cities and non-traditional cities}

To construct the discriminant functions, we needed to collect several sample cities of traditional and non-traditional character. For effective analysis, the street patterns of areas studied needed to have almost the same precision. Aru (1998) has provided a good collection of the street networks of some Turkish cities, and using this, we chose the following cities for our analysis ${ }^{1}$ : Adana, Adiyaman, Diyarbakir, Erzurum, Eskisehir, Izmir, Iznik, Kayseri, Konya, Kutahya, Manisa, Sivas, Tokat, and Urfa. 
The street networks of the above cities are depicted in Figure 12.1. Among these, Adana, Adiyaman, Diyarbakir, Erzurum, Kayseri, Konya, Kutahya, Sivas, Tokat, and Urfa are classified as traditional cities. Eskisehir, Izmir, and Iznik do not contain any traditional patterns, as they have been heavily influenced by transformations in city planning in the twentieth century and are therefore classified as "not traditional" cities. Manisa was not classified into either of these categories, and was left as "unclassified," for final classification using the resultant discriminant functions.

City data from non-Turkish cities were also collected for comparison, and we utilized the networks from Asami et al. (1999a) of the following cities: Amsterdam, Barcelona, Bombay, Edinburgh, London, Melbourne, New York, Osaka, Paris, Rome, Seoul, Sienna, Sydney, Taipei, and Venice.

These street networks of the above cities are depicted in Figure 12.2. All the cities in this category were classified as "non-traditional" cities.

All the street networks are to the same scale, and are framed using a $1.25-\mathrm{km}$ edge square window.

\section{Graph-theoretical and image-analysis based indices for characterization of network patterns}

Traditional cities tend to have some common features in their street networksmany dead-ends, large blocks, few intersections of four or more connected streets, narrow streets (on the human scale), curvy streets - and their total pattern is difficult to grasp. To express such features, the following indices were selected and measured, all of which are based on graph theory or image analysis. For a full exposition of the indices, see Asami et al. (2001).

\section{Graph-theoretical indices}

(I-1) Ratio of dead-end edges (ele): An entire network can be decomposed into nodes and edges. Nodes are intersections of streets or dead-end points. Edges are parts of streets connecting two neighboring nodes. The number of edges connecting to a node is called the order of a node. The intersection of two streets is a node of order four, and a dead-end is a node of order one. The ratio of dead-end edges is the ratio of the number of edges that are connected to nodes of order one, to the total number of edges.

(I-2) Ratio of dead-end nodes $(n 1 n)$ : Another simple measure of the abundance of dead-ends is the ratio of dead-end nodes. This is given by the ratio of the number of nodes of order one to the total number of nodes.

(I-3) Density of faces (blocks) in the region (face): In traditional cities, blocks tend to have some cul-de-sacs for access to houses. This may imply that "traditional" city blocks tend to be relatively larger than blocks in "nontraditional" cities. To measure such effects, the density of faces (blocks) in the region was measured.

(I-4) The average order of a node (avorder). 

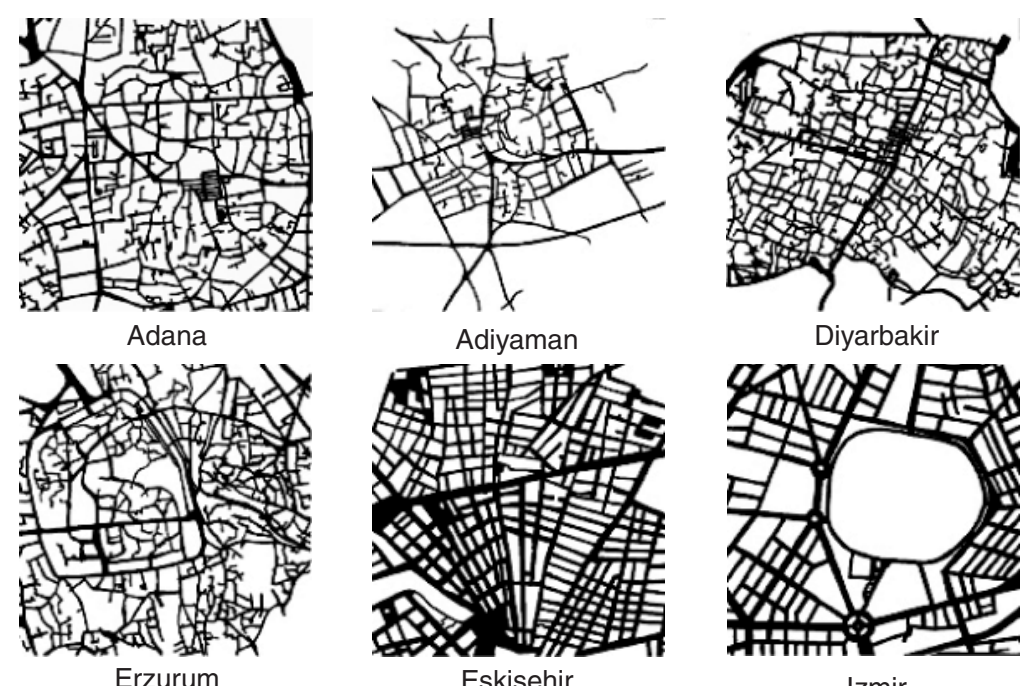

Diyarbakir
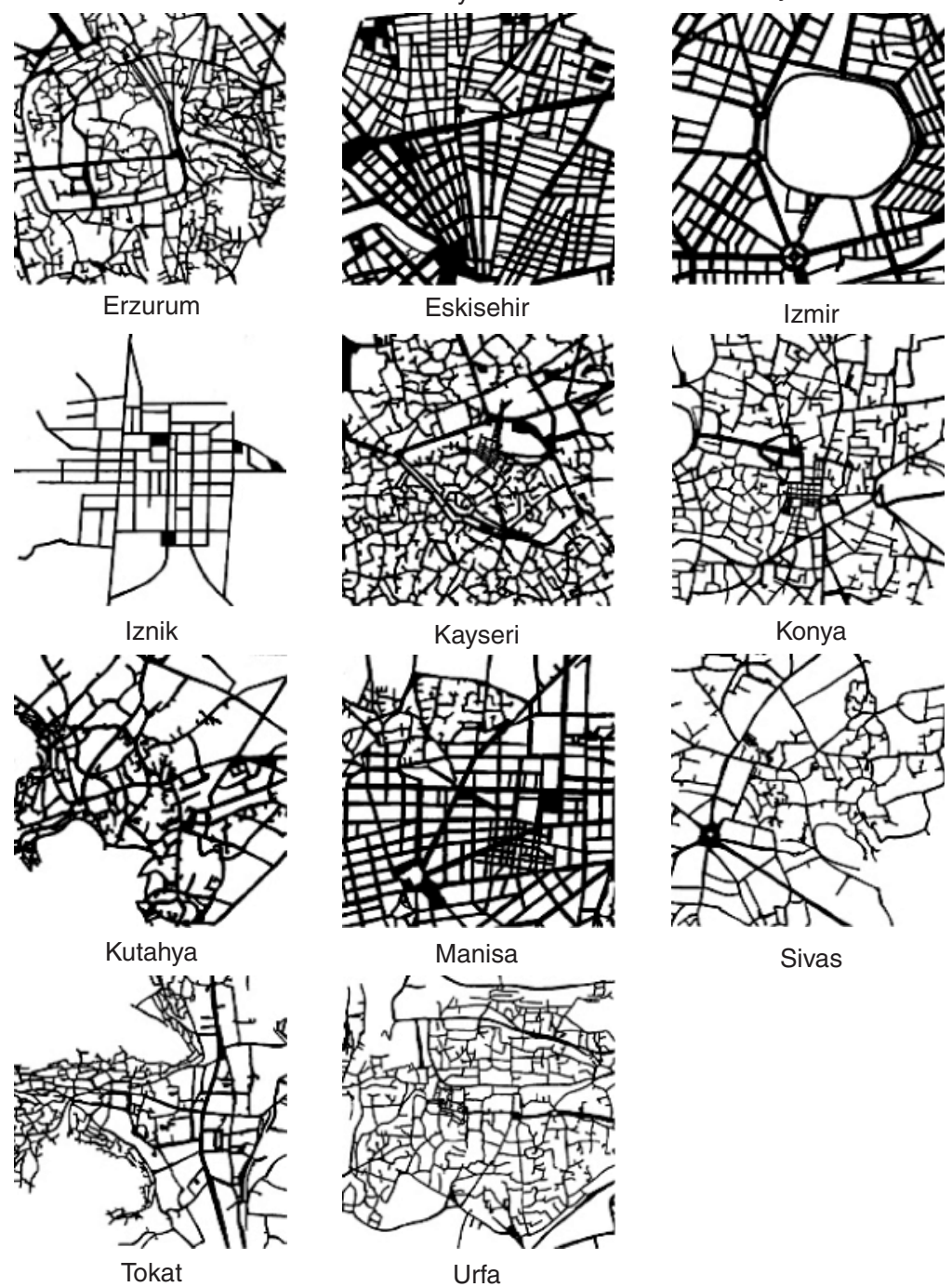

Figure 12.1 Street networks in Turkey. 


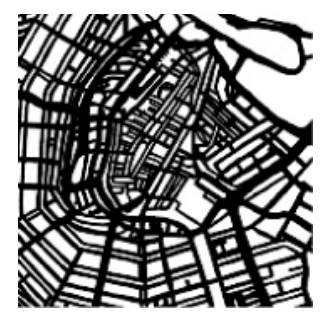

Amsterdam

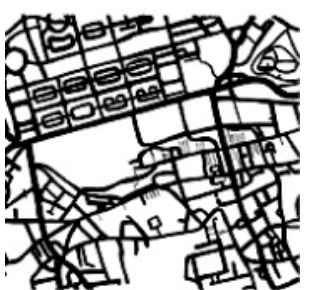

Edinburgh

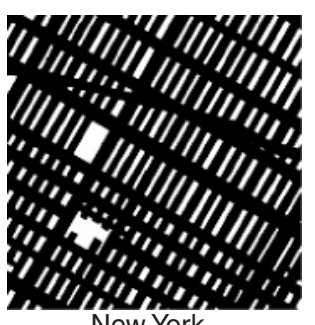

New York
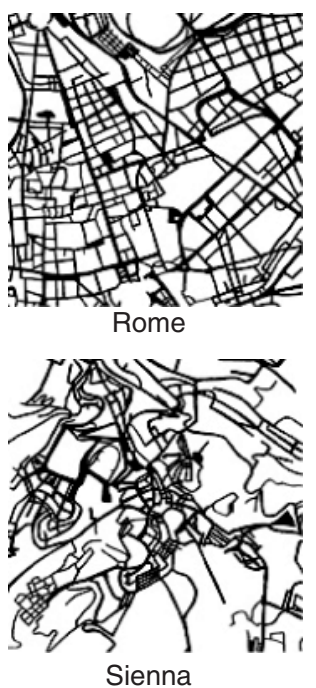

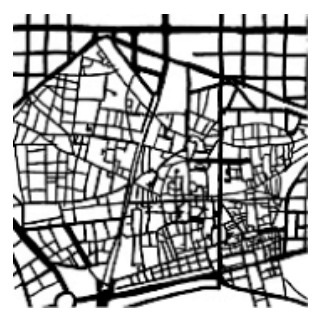

Barcelona

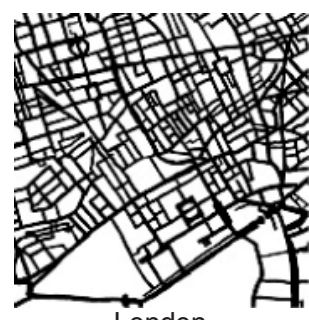

London
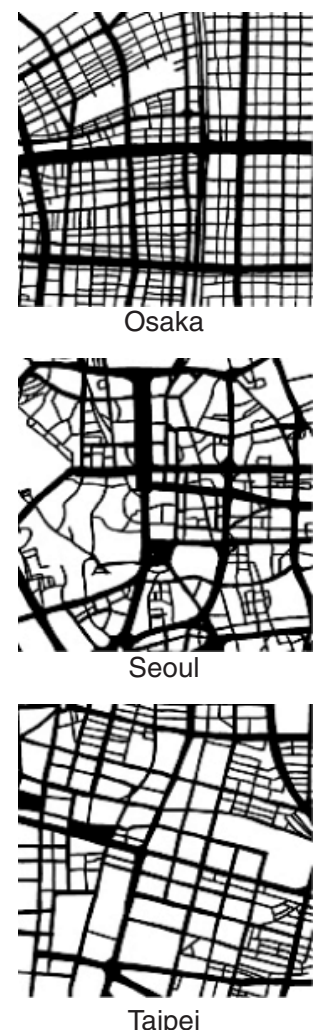

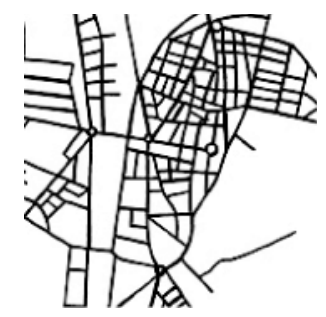

Bombay
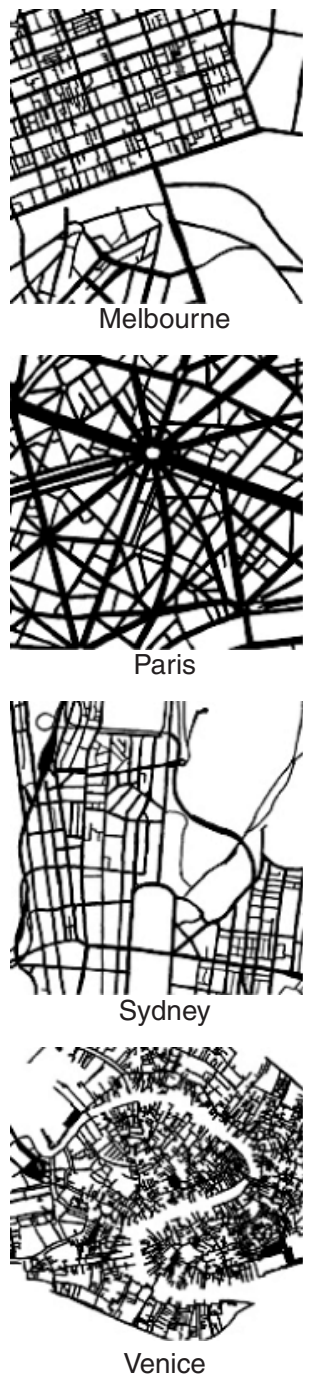

Figure 12.2 Street networks in the world. 


\section{Image-analysis related indices}

(II-1) The ratio of area covered by roads to the entire region (roadcov).

(II-2) The mean distance along an edge to the distance between nodes $(d d)$ : Streets tend to be curvy in "traditional" cities. If an edge is curvy, then the distance along the street tends to be greater than the distance between two straight neighboring nodes. This measure is called the mean distance along an edge to the distance between nodes.

(II-3) The average width of a road (avwidth): Streets tend to be narrow in "traditional" cities. To represent such a feature, the average width of a road was defined. This measure signified the average width of a road over the total length of the road.

\section{Space syntax-based indices for the characterization of network patterns}

This section describes a set of space syntax related indices. Space syntax is a method of capturing the fundamental features of spatial structures (Hillier and Hanson 1984; Hillier 1996). It is based on two basic tools, called convex and axial maps. As the basic framework of space syntax and notions therein are probably only familiar to researchers who have analyzed space using this concept, they are summarized here (Istek 1999).

The convex and axial maps are non-overlapping descriptions of space. Figure 12.3 illustrates the open space structure of a sample street network. On the base of Figure 12.3, the convex map breaks down the open space structure into two-dimensional extensions of space called convex spaces (Figure 12.4). By definition, the convex spaces identify the largest areas with the least number of segments that can be fully perceived at one time within the layout of an urban street network. The convex map reveals the "local constituents," since each

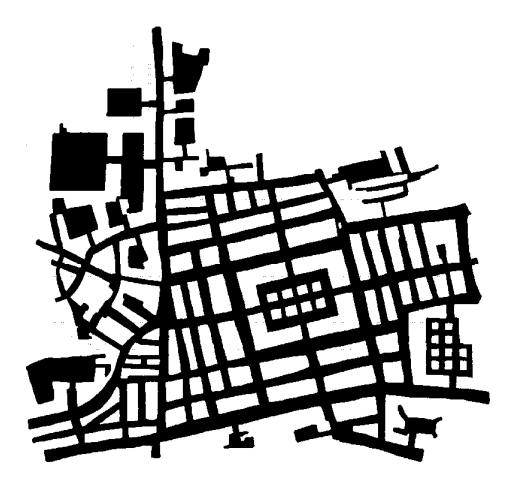

Figure 12.3 Black and white illustration of the open space structure of a sample street network. 


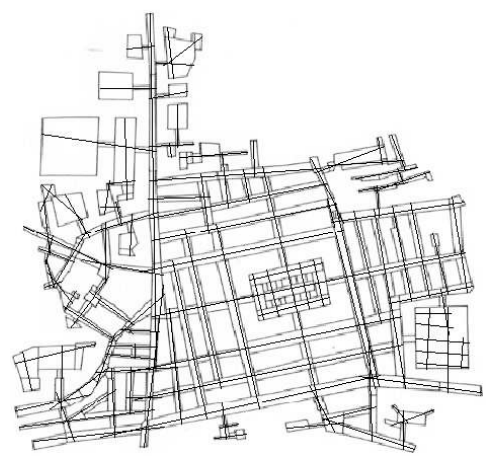

Figure 12.4 One- and two-dimensional space structures of a sample street network.

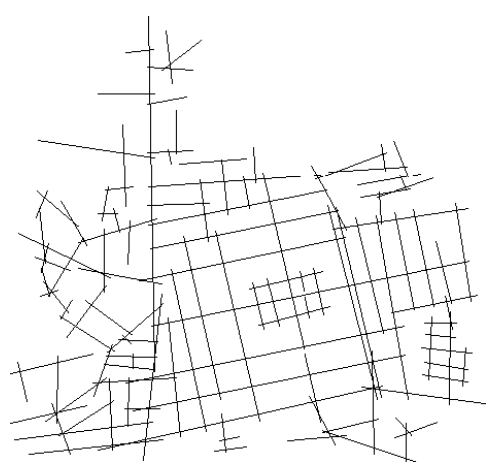

Figure 12.5 Axial map of a sample street network.

convex segment has a boundary of its own and is defined by every point that has direct accessibility to every other point in that segment. The axial map deals with the linear extension of the least and longest straight lines that cover all the available connections between the convex spaces (Figure 12.4). The axial map (Figure 12.5) tries to capture the overall sense of connection that is available to an observer moving about the street network, and therefore represents the "global constituents" of the layout.

Using these fundamental tools, the main aim of the syntactic analysis was to define quantitatively the extent to which each space was connected, either directly or indirectly, to all other spaces in the layout. In order to quantify this, the following configuration properties were computed. (For a full exposition of the indices, see Asami et al. 2001.)

(1) The mean depth (MD): The depth between two axial lines, $a$ and $b$, of a network system, $S$, is denoted by $D(a, b)$. This is equal to the minimum number of connections that must be used to reach $a$ from $b$. Thus, the depth is a non-metric 
distance measure, and it tells us about the properties of segregation or integration in the system.

The mean depth is a general indicator of the depth of a network system from any axial line. The main depth from an axial line, $a$, in a system, $S$, is defined by

$$
M D(a, S)=\frac{\sum_{b \in S, b \neq a} D(a, b)}{k-1}
$$

where $k$ is the number of axial lines in system, $S$.

(2) (Global) integration: The (global) integration identifies how well integrated or how segregated each axial line is in relation to all the other axial lines in a spatial configuration; it is therefore a "global" value. An axial line is integrated when all the other axial lines in the system are relatively near and there are few other intervening axial lines that must be traversed in order to reach one space from another. The integration of an axial line, $a$, in a system, $S$, is calculated by first counting the mean depth in terms of how many steps must be traversed to get to every other axial line in the whole system. This number is then used in the following expression to calculate the relative asymmetry value $(R A(a, S))$

$$
R A(a, S)=\frac{2[M D(a, S)-1]}{k-2}
$$

where $M D(a, S)$ is the mean depth value (see above), and $k$ the number of axial lines in the system. The quantity $0 \leq R A(a, S) \leq 1$ holds true for all $a$ and $S$.

Finally, the (global) integration value is calculated by dividing the $R A$ value by the "diamond value" (see Hillier and Hanson 1984: pp. 112-113) in order to obtain values that are comparable with any size of spatial systems. The integration value, INT, of a space $a$ in a system $S$ is

$$
\operatorname{INT}(a, S)=\frac{R A(a, S)}{R A D(k)}
$$

where $k$ is the number of axial lines in system $S$, and $R A D(k)$ is the diamond value calculated from

$$
R A D(k)=\frac{6.644 k \log _{10}(k+4)-3.17 k+2}{k^{2}-3 k+2} .
$$

(3) Local integration: As defined before, (global) integration identifies how well integrated or how segregated each axial line is in relation to all the other axial lines in an urban system. As this measure is a restricted version of the integration variable that computes the integration for all axial lines within three steps, 
it therefore gives a more local perspective than the global integration value. Higher values indicate more integrated axial lines in terms of their local areas within three steps. To describe a system as a whole, the mean value of the local integration of all the axial lines is used in our research.

(4) Correlation between integration and local integration: The correlation indicates the relationship between each part and the whole of the structure within the network system. Since the different radii of integration reflect different scales of the urban structure, it turns out that the important factor in understanding the relationship between each part and the whole of the network is an understanding of the relationship between the different integration radii (Hillier 1996: pp. 170-175). The precise measurement of this is the correlation coefficient between the global and local integration values of all the axial lines. The higher the correlation, the more the local areas in the system are well-structured local aggregations of the urban grid.

(5) Mean connectivity: This configuration variable defines the number of axial lines that are only one step away from every other axial line. It is calculated by counting the number of connections that each axial line has to its neighboring axial lines. The higher the connectivity value, the more an axial line is connected to neighboring axial lines. Connectivity is a local variable, since it only takes into account the relationship of an axial line to its immediately neighboring axial line. The lower the mean connectivity value, the higher the tendency towards cul-de-sacs in the street network system.

(6) Intelligibility: A spatial configuration's intelligibility is an important property in architecture and cities. The space syntax defines the intelligibility of a layout in terms of the relationship between the local and global connection properties. This definition suggests that a spatial system is intelligible, or understandable, when the information that is directly available (connectivity) to the user provides a good sense of position with regard to the layout as a whole (integration). Intelligibility is another spatial variable used to track down the notion of a cul-desac within a network system as a whole, since it addresses the way that people can learn about large patterns from their experience of small areas. If a network system mainly consists of cul-de-sacs, the spatial information of the whole network deduced from the way that local areas are connected to the whole will be minimal. Intelligibility is defined as the square of the correlation coefficient between the integration and connectivity values of all the axial lines in a system. The lower the intelligibility, the less one can infer location within a street network as a whole according to the directly available information.

(7) Axial ringiness (AR): The term "ringiness" refers to information on the formation of rings of axial lines in a network system. The measure of ringiness captures the number of circulation loops in the system, and thus, allows for "ringing," which is a measure of how much the global structure of the system is distributed among its axial lines. The axial ringiness of a network is defined as

$$
A R=\frac{I}{2 L-5}
$$


where $I$ is the number of islands (blocks), and $L$ the number of axial lines. The quantity $2 L-5$, is the maximum number of independent planar rings in a graph.

(8) Grid axiality (GA): This variable allows us to make a comparison of each axial system to an orthogonal (perfect) grid with the same number of islands (blocks). Therefore, using this comparison, the degree of axial deformation of the street networks can be stated unequivocally in a numerical form. The grid axiality is defined as

$$
G A=\frac{2 \sqrt{I}+2}{L},
$$

where $I$ is the number of islands, and $L$ is the number of axial lines. The result is a value between 0 and 1 , where values nearer to one indicate a strong approximation to a perfect orthogonal grid, and values nearer to zero indicate a greater degree of axial deformation.

(9) Mean axial length: This measure indicates the length of each axial line in pixels. Since an axial line is a global constituent and captures the overall sense of the visual and/or permeable connections that are available to a possible observer or passerby moving about the street networks, the length measure introduces a human-scale dimension to the system. To describe the system's average axial length as a whole, the mean axial length of all its spaces is used. The higher the mean axial length, the less the system is scaled to the human level.

In terms of terminology, the following indices are used in the present analysis, (abbreviations are indicated in parentheses).

\section{Space-syntax related indices}

(III-1) Thoroughfare/DE (thorough): This measure is related to the reciprocal of the graph-theoretical index, ele. The main difference is that thoroughfare, that is, the number of edges, counts the edges connecting to the boundary of the cut-off window, and DE is the number of dead-end edges. This index is calculated by using the thoroughfare value divided by the $D E$ value. "Traditional" cities are expected to exhibit small thorough values.

(III-2) Grid axiality (gridax) defined in equation (6) above.

(III-3) Axial ringiness (axring) defined in equation (5) above.

(III-4) Correlation coefficient of the global and local integration values (rofii3) defined in the section "Correlation between integration and local integration."

(III-5) Intelligibility (intellig) defined in the section on "Intelligibility."

(III-6) Mean connectivity (meanconn) defined in the section "Mean connectivity."

(III-7) Mean depth (meandpth) defined in equation (1).

(III-8) Mean axial length (meanaxlg) defined in the section "Mean axial length."

All these indices are summarized in Table 12.1. 


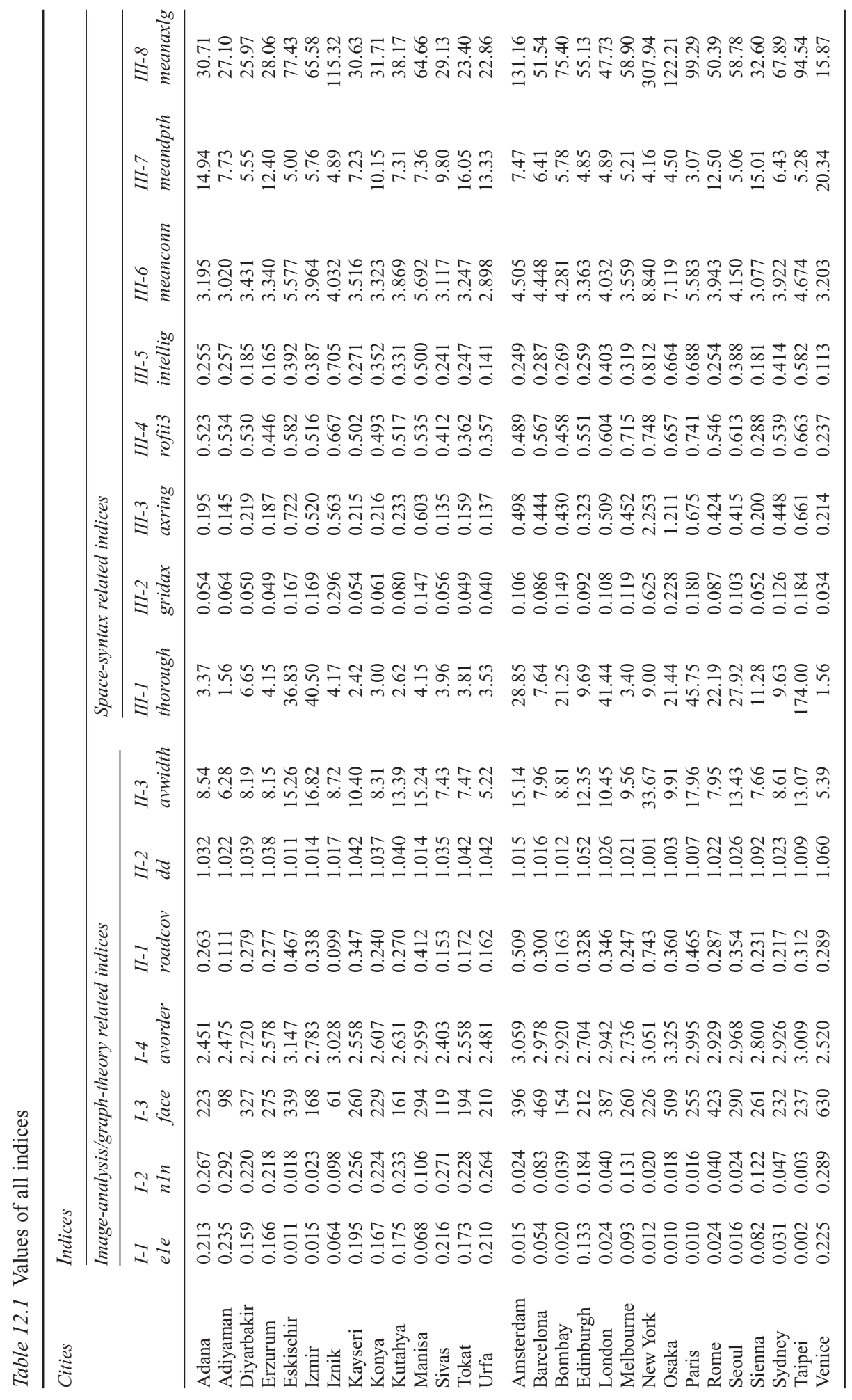




\section{Discriminant functions}

(1) Transformation of indices: Discriminant functions are typically linear (to be precise, affine, i.e. linear functions plus a constant term). This is valid when the variables approximately follow a normal distribution. Several indices used in our analysis do not follow a normal distribution. To remedy this situation, the distribution of the index values was transformed so that the transformed values did approximately follow a normal distribution. (See Asami et al. 2001 for this procedure.) The octothorp (\#) symbol located at the end of a variable name indicates that this variable was transformed using this procedure.

(2) Discriminant function: Discriminant analysis was conducted using the SPSS statistical software package, which typically provides us with a discriminant function of the form

$$
a+b_{1} X_{1}+b_{2} X_{2}+\cdots+b_{n} X_{n}
$$

where $a$ and $b_{i}$ are coefficients, and $X_{i}$ are variables signifying the space syntax or image analysis related indices of a specific city. If the discriminant function value is larger than a certain value, then the city is classified as "traditional," otherwise as "non-traditional."

(3) Correlation coefficient of indices: Using Pearson's coefficient of correlation (the usual coefficient of correlation), the following variables had very high coefficients (greater than 0.6 , or less than -0.6) using a "traditional" dummy variable (a variable which takes a value of 1 if the city is "traditional," and 0 otherwise): thorough\#: -0.651 , axring\#: -0.610 , ele\#: 0.673 , and n1n\#: 0.674 .

Using Spearman's rank correlation coefficient (a non-parametric coefficient of correlation, see Siegel (1956)), the following variables had very high coefficients (greater than 0.5 , or less than -0.5 ) using the "traditional" dummy variable: thorough\#: -0.538 , axring\#: -0.502 , meanaxlg\#: -0.516 , ele\#: $0.557, n 1 n \#$ : 0.557 , and avorder\#: -0.537 .

The values of these coefficients indicate that "traditional" networks are characterized by an abundance of dead-end edges, larger blocks, narrower (and hence human-scale) roads and an abundance of T-junctions.

(4) "Traditional" discriminant function using only space-syntax related variables: Discriminant analysis yielded the following result

$$
S S=-5.237+1.162 * \text { gridax } \#+1.928 * \text { axring } \#-1.331 * \text { intellig\#. }
$$

If the value of this function was less than -0.698 , then the city was classified as "traditional." Overall, 26 cities out of 28 (92.9\%) were classified correctly using this function. The sign of intellig\# was negative, which contrasts with the simple relationship between intellig\# and "traditional" cities, and this probably arises from a modification of the gridax\# and axring\# indices. This implies that largesized blocks (axring\#), and a large difference from an orthogonal grid pattern (gridax\#) mainly characterize traditional networks, in that order. 
(5) "Traditional" discriminant function using only non-space syntax related variables: Analysis yielded the following result

$$
I M=-4.472+2.254 * e 1 e \#-0.758 * d d \# .
$$

If the value of $I M$ was greater than 0.637 , then a city was classified as "traditional." Overall, 26 cities out of 28 (92.9\%) were classified correctly using this function. The sign of $d d \#$ was negative, which contrasts with the simple relationship between $d d \#$ and "traditional" cities, and this probably arises from a modification of the ele\# index. An abundance of dead-end edges characterizes a traditional network.

(6) "Traditional" discriminant function using all the variables: Discriminant analysis yielded the following result

$$
\begin{aligned}
A L= & -0.940+1.864 * \text { axring } \#-0.783 * \text { avwidth } \#-1.618 * n 1 n \# \\
& +0.852 * d d \# .
\end{aligned}
$$

If the value of $A L$ was less than -0.778 , then a city was classified as "traditional." The values of the avwidth\# and $d d \#$ indices were modified from the expected simple relationship with a "traditional" city. The existence of larger blocks and curvy roads characterize a traditional network, in that order.

(7) Conclusions from the discriminant analyses: The results can be summarized as follows:

(a) SS discriminated $92.9 \%$ of the cities using three variables, IM $92.9 \%$ using two variables, and $A L 100 \%$ using four variables. We can say that space syntax indices perform well in distinguishing "traditional" cities from other types of city. This may further indicate that space syntax can be quite a powerful tool in describing the fundamental character of street networks.

(b) For a first-order approximation of traditional character, the SS or $I M$ functions are adequate, but for a more detailed distinction, the $A L$ function should be used.

To assess traditional character, one can use either the $S S$ or $I M$ functions for ease of use. The variables used in the $S S$ function can be computed provided that one has the space syntax programs provided by the Space Syntax Laboratory at University College, London, otherwise some difficulties may arise. The ele\# index in the $I M$ function can be calculated easily, as one need only count the number of edges having dead ends and the total number of edges. The second variable, $d d \#$, is, however, harder to compute. One has to measure the length of all the edges. If a street network is already represented as GIS vector data, then this is easy to calculate. If GIS data has already been put into use, then we recommend using the $I M$ function. For in-depth analysis, the $A L$ function is superior.

Table 12.2 summarizes the results of the discriminant functions: $S S, I M$, and $A L$. As can be seen from the table, Manisa was classified as "non-traditional" 


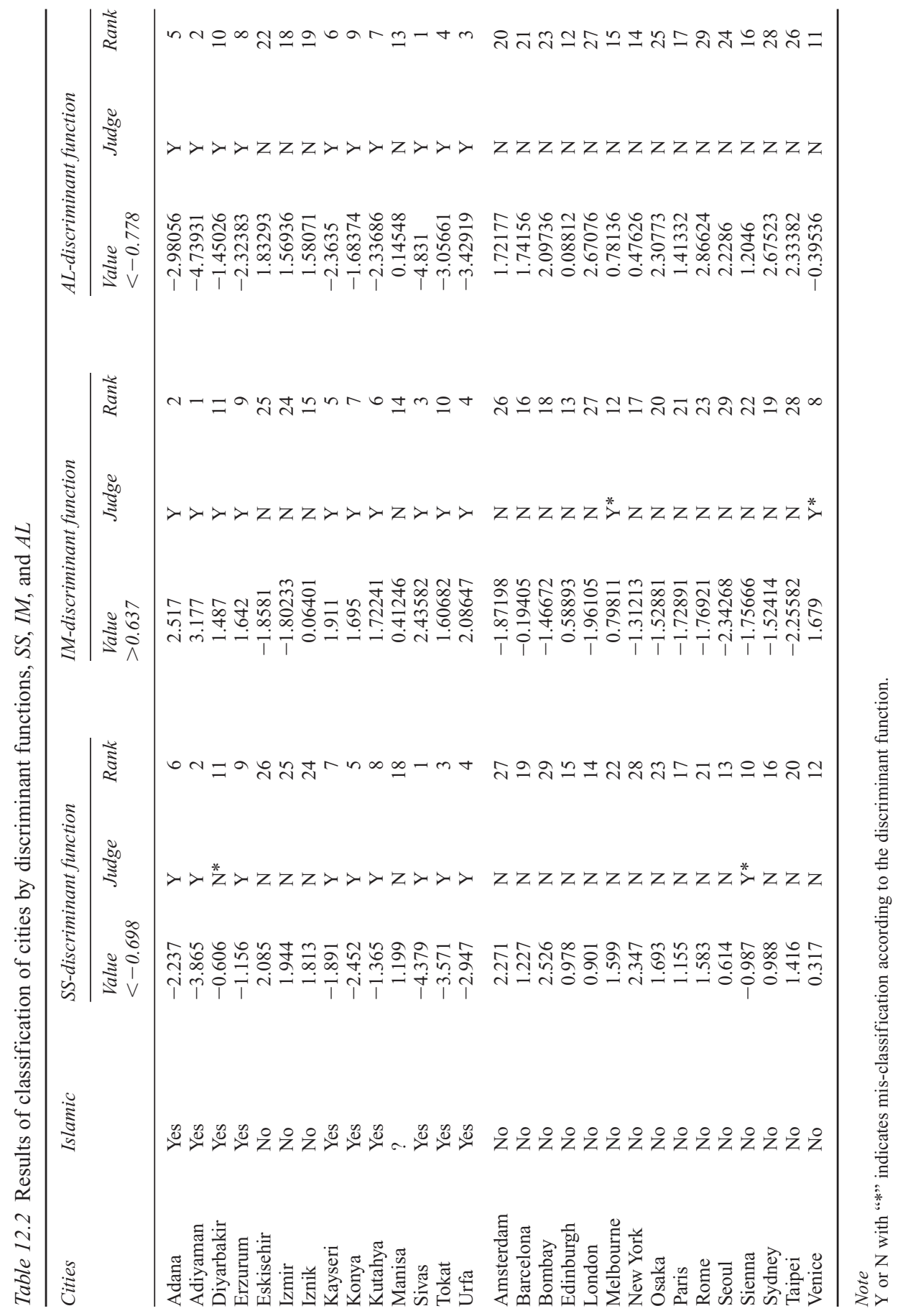


by all the discriminant functions. Cities that were misclassified by the $S S$ function were Diyarbakir and Sienna. Since the $S S$ discriminant function makes much use of large block and deformation from the orthogonal grid pattern, these cities were apt to be misclassified. The discriminant function $I M$ misclassified Melbourne and Venice, for it emphasized the abundance of dead-end edges.

The ranking of cities in terms of a traditional network was rather robust. Sivas was classed the most "traditional" by the $S S$ and $A L$ functions, and the third most "traditional" by the $I M$ function. Adiyaman was classed the most "traditional" by the $I M$ function, and the second most "traditional" Islamic city by the $S S$ and $A L$ functions. The robustness of the judgment from several discriminant functions suggests the reliability of the judgment as well as the potential transferability of the functions to other contexts. To test the transferability, the discriminant function $S S$ was applied to some areas in Istanbul, and is discussed in the following section.

\section{Application of the $S S$ discriminant function to some areas in Istanbul}

Several areas of Istanbul were selected for the application of the derived SS discriminant function. The study areas selected were Eyüp, Fener, Galata, Zeyrek, Ayvansaray, and Balat (see Figure 12.6). They have some inheritance of Islamic

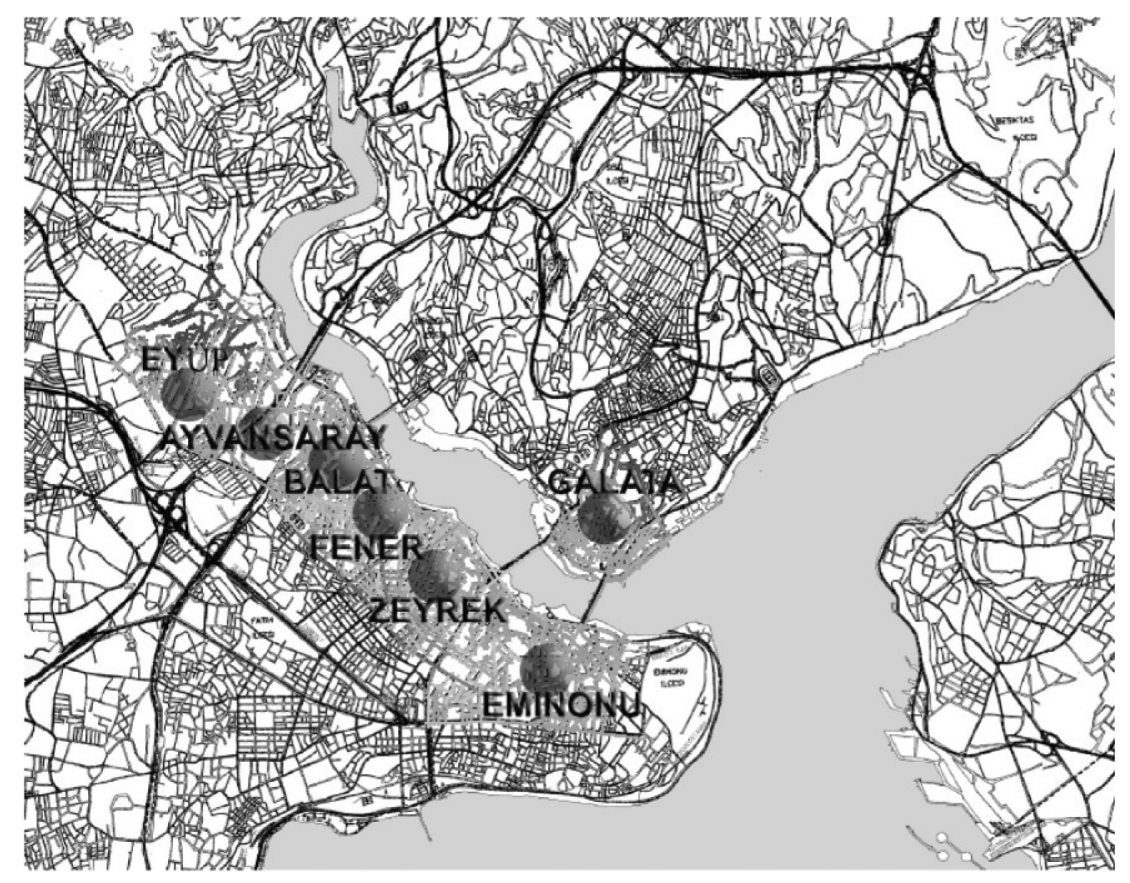

Figure 12.6 Study areas in Istanbul. 
culture, and parts of the street networks were found to possess some Islamic traditional patterns. They are all situated in the center of the city, and exhibit exceptional urban potential. The urban pattern of "mosaic peoples," reflecting their historical, traditional, cultural and religious characteristics, is still observable in these regions.

Surrounded by the Byzantine city walls dating from the fifth century AD, the Fener, Balat, Zeyrek, and Ayvansaray districts of Fatih constitute one of the oldest residential districts of the historical center. The focal point of the social and cultural lives of the Greeks, Armenians, Jews, and Muslims in the past, the Fener, Balat, Zeyrek and Ayvansaray districts are presently inhabited by a mostly Muslim population that emigrated there from rural areas. Outside the walls, the Muslim neighborhood, Eyüp, on the Golden Horn, was developed according to the fundamental goal of the conqueror to create a Muslim city in which the communities could live in accordance with the philosophy of Islam. Galata on the opposite side of Golden Horn, had been the non-Muslim center of the capital after the conquest. As the empire gradually submitted to the economic dominance of the Western powers, Galata naturally became the first place to accommodate European tradespeople, while Istanbul preserved its traditional, and predominantly Muslim, character.

The SS discriminant function derived in the previous section was applied to the selected areas, and the results are shown in Table 12.3. The table shows that the patterns of the selected samples were judged mostly as areas not reflecting any "traditional" character, with the exception of Galata. The dense pattern of Galata confirms the lines of topography and forms irregular urban blocks, thus reflecting an organic texture. In particular, Balat was judged to be the least traditional, as it does not reflect any organic pattern. However, its grid-like pattern was, in reality, still traditional.

This judgment of being far from the "traditional" character of Istanbul can be interpreted as an indication of the dominance of non-Islamic influences on the city. Its architectural and urban heritage reflects several cultures, and the pattern of a "mosaic of peoples, cultures and religions" is still observable in Istanbul. This colorful mosaic, related to religious and residential architecture, also affected the urban morphology. Its transformation from the Christian tradition to a sacred city of Islam produced unparalleled configurations in its urban forms. In

Table 12.3 Traditional character judged by the SS discriminant function

\begin{tabular}{llllll}
\hline Area & gridax & axring & intellig & DF & Islamic \\
\hline Eyup & 0.0568 & 0.1577 & 0.0890 & -0.042 & No \\
Fener & 0.0655 & 0.1887 & 0.1487 & -0.242 & No \\
Galata & 0.0852 & 0.2431 & 0.3144 & -0.890 & Yes \\
Zeyrek & 0.0688 & 0.2140 & 0.1564 & 0.391 & No \\
Ayvansaray & 0.0690 & 0.2123 & 0.1578 & 0.323 & No \\
Balat & 0.1436 & 0.2982 & 0.2429 & 1.854 & No \\
\hline
\end{tabular}

Note

$\mathrm{DF}=$ Value of the discriminant function. 
addition, large-scale, destructive natural disasters, such as fires and earthquakes, ruined the city, which was mostly redeveloped using Western-inspired planning principles. Moreover, the piecemeal planning after the fire disasters was conducted in parallel with the construction and regularization activities of the street patterns.

Even though irregular streets still exist in the areas, new roads and new squares have been opened, dead-ends have almost disappeared, a large section of the waterfront (the Haliç-Golden Horn) has been regularized, modern transportation has penetrated into even the most isolated and traditional neighborhoods, and much of the previously built fabric has been converted to concrete. By this reasoning, the city of Istanbul has absorbed and reflects the cultural heritage of eastern Orthodox Christianity followed by Islamic Ottoman civilization, and so cannot be accepted as an Islamic city at all. This is proven by the application of the $S S$ discriminant function on sample regions of Istanbul.

Istanbul has duality in its morphological structure. It reflects traditions of many cultures including Islamic. We should not expect the results of the analysis of this city to be reflected in the results of the other traditional Turkish cities. Istanbul has a Byzantine heritage, and reflects the mosaic of different communities. Accordingly, the city does not and cannot, reflect an Islamic character. If we put aside Galata, which was initially a Christian city, the other districts are influenced by the Armenian, Rum, Jewish, and Caramanian cultures, and also by Muslim traditions. The Turks came afterwards, and they of course, brought about some changes in the urban fabric. The different communities used to live together, and they are all influenced by each other in their culture and behavior. Only Eyüp was initially developed as an Islamic neighborhood, but this character later deteriorated following renovation projects. Zeyrek became more Islamic than the others after the fifteenth century following the conqueror's policy of converting the nation to reflect a Turkish style. The physical structure of the sample regions was affected by large-scale fires and earthquakes, and has been renovated several times during its history according to Western-inspired planning principles. These factors all caused the urban pattern of historical Istanbul to become far from Islamic.

Passages from several published documents explaining Istanbul's cultural and religious heritage confirm this interpretation:

Istanbul was the capital of a Muslim empire and a Muslim culture, nevertheless, Istanbul always had, in its composition, a Western element, not only in its cosmopolitan character, but also in its geography and underlying Romano-Byzantine heritage.

(Kuban 1996: p. 5)

The form of the main street, the general and unchanging structure of the basic elements of the city, the main forums, the sea shores, the walls, the harbours, the palace and the spatial distribution of vital functions, remained in place after the Turkish conquest.

(Kubat 1999: p. 34) 
Contemporary Istanbul has an evocative landscape where the weight of history is strong. Monuments of great cultural value enhance the magnificent site. The elements of the pre-Islamic past and the unique silhouette of a Muslim capital are surrounded by late Roman city walls, all of them are eloquent manifestations of a most varied cultural history.

(Kuban 1996: p. 5).

19th Century Istanbul was not a Muslim city according to the simplistic definition of the ideologically oriented historians. It was the 19th Century metropol with a Muslim past and a mixed society. Similarly, Istanbul today is a city inhabited by Muslims but it does not correspond to the definition of a Muslim city. Istanbul as a unique city has defined its own concepts of urban environment. Certainly many principles of life were regulated by religion but there were many others, historically, ethnically, topographically or geopolitically defined, and understandable only in these contexts.

(Kuban 1996: p. 207)

In recent times, the communication network of the city has improved, new roads and new squares have been opened, dead-ends have almost disappeared, a large section of the waterfront has been regularized, modern transportation has penetrated to even the most isolated neighborhoods, and much of the built fabric has been converted to concrete. However, many irregular streets still exist; the waterfront along the Golden Horn is crowded with factories, warehouses, and workshops.

(Çelik 1993: p. 162)

The city is still symbolic although Islamic traditions are applied in architecture and urban tissue of the city. Although the Byzantine and Roman cities were more symbolic and the Islamic cities were more instrumental, the morphology of the historical core of Istanbul didn't shift from symbolic character to instrumental. The main spine and the dominant axis of the old city were still in existence in the Ottoman period and it still is today. The city still maintained its symbolic character as the capital city of the two great civilizations: the Byzantine Empire and the Ottoman Empire. Time does not affect the architecture of cities as it affects the architecture of buildings. City form-morphology tends to change less rapidly than many human institutions. The main thoroughfares of modern Istanbul follow quite closely the course of the Roman roads built more than fifteen centuries ago.

(Kubat 1999: p. 40)

\section{Conclusions}

This chapter illustrates network analysis using GIS and other methods with a discriminant analysis technique to reveal the traditional character of the street 
network in cities. To do this, space syntax related and other indices (based on graph theory and image analysis) were utilized. Space syntax related indices were shown to differentiate effectively any traditional Turkish character. This result indicates that indices developed using the space syntax method are effective in characterizing any network pattern.

The functional forms derived in this chapter suggest that traditional street networks can be characterized mostly as being of a large block size, which showed a larger effect than difference from an orthogonal grid pattern or the dominance of dead-end edges. These features have been pointed out many times in the literature. The contribution of the present analysis lies not only in quantitatively confirming the well-said features but also in successfully ordering the elements of the basic features by applying analyses of discriminant functions.

One function, the $S S$ discriminant function, was applied to several areas in Istanbul. Since Istanbul has experienced a number of large conversions in its structure, it can be said that these areas are correctly judged to be non-traditional (except for one area, Galata).

Concerning the judgment about Galata, the authors are somewhat skeptical as to the validity of the discriminant function. Galata reflects an organic texture of roads that conform to the steep topography. Since the discriminant function does not take topography into account, it is hard to distinguish between the natural organic pattern and the organic pattern induced by topographical considerations. This may be a limitation of the current method. To remedy this defect, indices related to topographical information should be included in the construction of the discriminant function.

\section{Acknowledgments}

This chapter is based on Asami et al. (1999b, 2001). Comments by Arai Yuji, Fukami Naoko, Haneda Masashi, Kermeli Eugenia, Narli Nilufer, Oikawa Kiyoaki, Okabe Atsuyuki, Orbasli Aylin, Sazanami Hidehiko, and anonymous referees have been very helpful in refining this paper.

\section{Note}

1 Street networks of Turkish cities are taken from Aru (1998), except for Iznik (from Eyice (1987); see Kubat (1997)), and Eskisehir, Izmir and Manisa (from "Kijima collection" stored now in Asami's research unit).

\section{References}

Aru, K.A. (1998) Turk Kenti: Turk Kent Dokularinin Incelenmesine ve Bugunku Kosullar Icinde Degerlendirilmesine Iliskin Yontem Arastirmasi (Turkish Cities: Research on the Methodology and Contemporary Evaluations of Turkish Urban Patterns), Yapi Endustri Merkezi Yayinlari, Istanbul. 


\section{ASAMI YASUSHI ET AL.}

Asami, Y., Kamiya, H., and Shimazu, T. (1999a) "The perceptive similarity of urban road networks," Comprehensive Urban Studies, 69: 187-199.

Asami, Y., Kubat, A.S., and Istek, I.C. (1999b) "Characterization of the street networks in the Turkish-Islamic urban form," Proceedings of the International Symposium "Beyond the Border: A New Framework for Understanding the Dynamism of Muslim Societies", Islamic Area Studies, pp. 279-309, Kyoto International Conference Hall, Kyoto, Japan, October 8-10.

Asami, Y., Kubat, A.S., and Istek, I.C. (2001) "Characterization of the street networks in the traditional Turkish urban form," Environment and Planning B, 28(5): 777-795.

Çelik, Z. (1993) The Remaking of Istanbul, Berkeley and Los Angeles, California, USA: University of California Press.

Eyice, S. (1987) Iznik, Sanat Arastirmas Dergisi, Issue 1, No 1, p. 95, Istanbul, Turkey.

Hillier, B. (1996) Space is the Machine, Cambridge, Cambridge University Press.

Hillier, B. and Hanson, J. (1984) The Social Logic of Space, Cambridge: Cambridge University Press.

Istek, I.C. (1999) "Spatial Dynamics of market places," Discussion Paper No. 20, Center for Spatial Information Science, University of Tokyo, Tokyo.

Kuban, D. (1996) Istanbul an Urban History, Economic and Social History Foundation of Turkey, Turkey.

Kubat, A.S. (1997) "The morphological characteristics of Anatolian fortified towns," Environment and Planning B: Planning and Design, 24: 95-123.

Kubat, A.S. (1999) "The morphological history of istanbul," Urban Morphology Journal of the International Seminar on Urban Form, Vol. 3, No. 1, Henry Ling, UK, pp. 28-44.

Siegel, S. (1956) Nonparametric Statistics for the Behavioral Sciences, New York: McGraw-Hill. 


\title{
A THREE-DIMENSIONAL ANALYSIS OF THE STREET NETWORK IN ISTANBUL
} An extension of space syntax using GIS

\author{
Asami Yasushi, Kubat Ayse Sema, Kitagawa Kensuke, \\ and Iida Shinichi
}

\section{Introduction}

The analysis of street networks is often conducted by treating them as though the network lay on a flat, two-dimensional surface. In reality, street networks lie on a three-dimensional surface, that is, there are height variations. The historical part of Istanbul, for example, is famous for its rich topography, including its seven hills, and its urban form should be analyzed by taking into account its topography. This chapter illustrates the analysis of networks on a three-dimensional surface using the geographic information system (GIS), based on the work of Asami et al. (2002).

Space syntax, as originated by Hillier, has been a powerful tool for analyzing urban forms, and a number of empirical works have already been established (e.g. Asami et al. (2001, 2004), Brown (1999), Hanson (1989), Hillier (1999), Hillier et al. (1993), Kubat (1997, 1999, 2001), Penn et al. (1998), Peponis et al. $(1989,1997)$, and Read (1999)). A typical approach used in space syntax is to construct an axial map of a public space based on an actual city map (Asami et al. (2001, 2004), by drawing a set of axial lines which represent the minimum number of visible lines that cover all the space (Figure 13.1).

Since the axial lines drawn are based on a two-dimensional map, the axial lines fail to express any three-dimensional changes (i.e. height) within the space. In the conventional application of space syntax, a single axial line can express a straight road, while a curved road may need more axial lines to represent it, and thus, space syntax captures the curvature of roads.

A road may be curved because it was naturally generated that way, or because the topography does not allow a straight road owing to a change in height. This distinguishing aspect is very important for us in particular, when we want to apply 


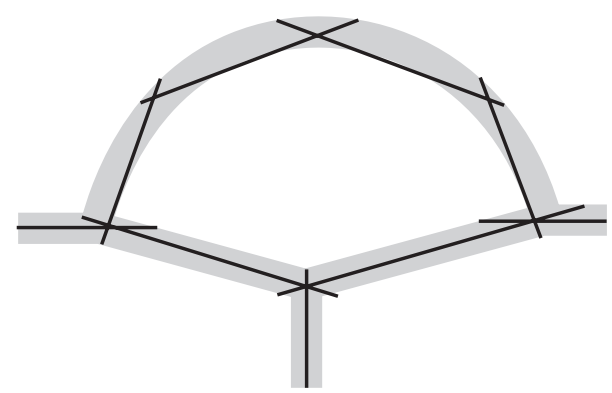

Figure 13.1 Axial map and axial lines.

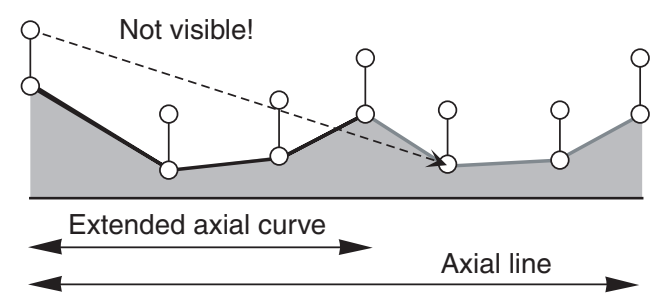

Figure 13.2 Axial line and extended axial curve.

space syntax to vernacular cities, such as traditional Islamic cities. Here, there is an urgent need for developing a new method that can capture the curvature of the ground surface, that is, the change in height, as suggested by Asami et al. (2001).

To develop such a method, we propose an extended version of axial lines called "extended axial curves" (Figure 13.2). To develop this idea, imagine that the space to be analyzed is a road network in a city. Standing on the road, the surface of the road is visible up to a certain point, beyond which it cannot be seen because the road curvature conceals the road, owing to the presence of buildings along the road, or because the road changes its surface height from sea level to some height high enough to conceal it any further on. By approximating this situation, an extended axial curve is defined as the representation of a space, such that all the points are visible by standing on any given location on the extended axial curve. To do this, it is essential to use GIS as a tool for analyzing networks on a surface.

The above concept was applied to the analysis of the road network in the historical part of Istanbul. The results show that an extended version of space syntactic indices captures well the local centeredness in Istanbul when it comes to the modern nature of local centers, such as the number of buildings and commercial activities along a road. However, other features of local centeredness that are well rooted in the historical and cultural background are not well captured by the method. This result is suggested by the low correlation coefficients between the experts' indication of local centers and those from the space syntactic indices. In 
Islamic cities, the straightness of roads is not a fundamental factor in forming cities. Nonetheless, symbolic buildings, such as mosques, stand out in traditional Islamic cities, and the construction of such facilities may have had the need to take topographic factors into account. This implies that a notion of visibility other than that along a public space should be developed to analyze such features in the urban form.

\section{Extended axial curves and extended axial lines}

An axial line in conventional space syntax is a representation of a given space that signifies a unit of space in which any two points in the space are mutually "visible." The definition of "axial line" is a little ambiguous, however, owing to the ambiguity of "visibility." Judged from common practice of axial lines, two points on a road in a space are defined as visible if two points projected to the axial line are mutually visible (see Figure 13.1).

Roads seldom lie on completely flat land, and the land surface has undulations, as do the roads that lie on it. Usually, axial lines are drawn based on a twodimensional map that does not take into account the change in height of any of the roads. However, as described in the introduction, the distinction between the road curvature from topography and the road curvature on flat land is a critical factor in analyzing vernacular cities, such as traditional Islamic cities. To remedy this situation, the notion of an axial line is extended here.

A natural extension of space syntax to a three-dimensional surface is to utilize the idea of visibility again. If the visibility of a point on a surface from another point on a surface is analyzed, then we can easily get into a difficult situation that says that a road consists of an infinite number (continuum) of axial "lines" that are composed of virtually all the points - for example, when the road forms a hill shape with a negative second derivative of the height with respect to the horizontal distance. To avoid such a case, a practical extension is to introduce an eye-level view (see Figure 13.2). That is, we judge a point on a surface as being visible if we can see it at an eye-level height above the surface. In our study, the eye-level height was set at $1.5 \mathrm{~m}$ above the road surface.

An extended version of the axial line is then defined by a portion of the surface of the road, the projection of which onto a flat plane (the surface of sea level as a practical example) is a line segment, so that any point on the portion is visible at eye-level from any other point on the portion as shown in Figure 13.2. Since this extended version of the axial line is typically a curve along the road surface, it will hereafter be called an "extended axial curve." As in the case of a conventional axial line, a point on the road is regarded as being visible if a point on the extended axial curve has a line segment between itself and the point on the road that is perpendicular to the extended axial curve, and if the point is visible from all points at eye-level on the extended axial curve.

Since it is very difficult to derive extended axial curves by minimizing the number of extended axial curves so that they cover the entire road network, 
a heuristic approach was adopted. First, the conventional axial lines were drawn based on the two-dimensional map, and then the projection of each axial line onto the road surface was checked with respect to its visibility on a three-dimensional surface. An axial line was partitioned into several extended axial curves so that visibility condition in the sense defined above was met. This procedure does not necessarily yield the exact minimum number of extended axial curves, but the resulting extended axial curves can be thought of as an approximation to the minimum number. The heuristic "extended axial curves" derived by this procedure are hereafter called simply "extended axial curves."

For each extended axial curve, a line segment was defined as that connecting a straight line between two end points of the extended axial curve. Since this line segment is straight by definition, it is hereafter denoted as an "extended axial line."

\section{Extended space syntactic indices}

Many frequently used axial indices are derived from looking at the relationship between a space and adjacent spaces, either in the global or local context. Global indices are derived by taking into account all the spaces that are in the area concerned, while local indices are derived by limiting the scope to a finite number of "steps," that is, the number of changes in direction in conventional axial analysis.

For conventional axial lines, the following indices were computed: connectivity, control, mean depth, integration, maximum depth, local mean depth, local spaces $(K)$, and the clustering coefficient $(G 1, G 2)$.

1 The connectivity index is the number of immediate neighbors of an axial line. This is equivalent to "the degree of vertex" in graph theory.

2 The control index can be thought of as a measure of the relative strength of an axial line in "pulling" the potential from its immediate neighbors. When an axial line has $n$ neighbors and the connectivity of each neighbor, $l_{i}(i=1,2, \ldots, n)$, is represented by $C\left(l_{i}\right)$, then the control value of the axial line is given by

$$
\text { Control }=\sum_{i=1}^{n} \frac{1}{C\left(l_{i}\right)} \text {. }
$$

3 The mean depth $(M D)$ is the mean distance of all the axial lines from a given axial line. The integration index is derived from the mean depth value, and it was introduced in an attempt to compare values between systems having different numbers of axial lines. Suppose that an axial line has mean depth $M D$, in a system with $k$ lines. The mean depth can be transformed so that it takes a value between 0 and 1 as

$R A=\frac{2(M D-1)}{k-2}$.

The relative asymmetry value $(R A)$ is then relativized by dividing by the $R A$ value of the "diamond-shaped" graph having the same number of vertices (axial lines). In the "diamond-shaped" graph, these vertices are ordered so that 


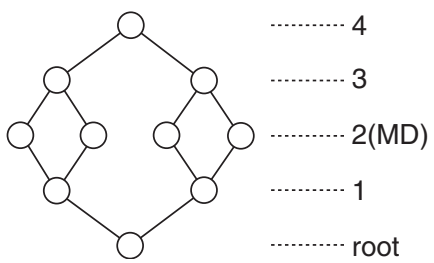

Figure 13.3 Diamond-shaped graph.

there are $m(>1)$ vertices whose distance from the root space is the mean depth of the system, with $m / 2$ vertices at a distance $M D-1$, and so on (Figure 13.3). The integration value is the reciprocal of this value, given by the formula

Integration $=\frac{D_{k}}{R A}$,

where

$D_{k}=\frac{2\left[k\left(\log _{2}((k+2) / 3)-1\right)+1\right]}{(k-1)(k-2)}$.

Discussions on this relativization method can be found in Hillier and Hanson (1984), and in Krüger (1989).

4 The maximum depth (MaxD) is the maximum distance of the axial lines found in the system.

5 The local mean depth $(M D i)$ is the mean distance of the axial lines within a number of steps, $i$, from the root space: (in this paper, $i=3,4, \ldots, 10$ ). The local spaces, $K i$, are the number of axial lines included in a local system. A local system within one step consists of only the root space itself, and a local system within two steps includes the root space and the axial lines that are adjacent to the root space.

6 The clustering coefficient ( $G i$, with $i=1,2)$ is based on the definition by Watts and Strogatz (1998), and measures the "cliquishness" (Watts 1999) of the neighborhood of the root space. It takes the form of the ratio of the actual number of connections (edges) to the number of connections of the complete graph having the same number of axial lines (vertices). $G 1$ includes the local system within two steps (i.e. the root space plus all the axial lines one step away), and G2 includes the local system within three steps (Turner et al. 2001).

\section{Local centers in Istanbul}

Local centers are generally represented by local integration values in space syntax literature (Asami et al. 2001; Kubat 1997, 2001). The effectiveness of the methods 
developed above can be tested by comparing the resulting space syntactic indices for conventional axial lines and extended axial lines to actual data derived from the study area of Istanbul. For example, local integration is supposed to represent the extent of local centeredness. Correlation coefficients between the local integration values and the actual volume of traffic on the road may reveal which approach produces a more appropriate notion of local centeredness.

To find the actual local centers in the historical part of Istanbul, three approaches were adopted: (a) local centers identified based on the number of taxi bays; (b) local centers identified based on the average number of stories of buildings along the extended axial lines; and (c) local centers identified based on the city planners' view points.

\section{Number of taxi bays}

There are several taxi bays in the historical part of Istanbul. Since the city is not fully equipped with railway facilities, hiring and sharing taxis are common modes of traffic. Taxi bays are regarded as centers of such traffic modes, and we can therefore expect that, to some extent, their locations indicate local centers in the city. In 1999, there were 53 taxi bays in use, compared to the total of 55 taxi bays that were planned by the Municipality of Metropolitan Istanbul for 1999 (Municipality of Metropolitan Istanbul, General Director of Transportation, Transportation Planning Department, 1999). A dummy variable, taxi, was constructed based on this information. The taxi variable was set to unity if the extended axial line included an existing taxi bay or a planned taxi bay, and zero otherwise. Since the number of existing taxi bays is small, the total number of existing and planned taxi bays was used.

\section{Average number of stories of buildings}

The limited number of survey points for taxi bays may prevent us from inferring any decisive conclusion on the effectiveness of the above methods. To overcome this limitation, we sought a proxy variable to indicate local centeredness. Fortunately, GIS spatial data for the study area were already available, and this allowed the number of stories of each building along each extended axial line to be computed.

To compute the average number of building stories, we first created a buffering zone for each extended axial line of radius $=41.5 \mathrm{~m}$, which was the value given by the total area of the region studied divided by the total length of the road network. Then, all the buildings were scanned, including those in the buffering zone, and the average number of stories of the buildings was calculated. This value was designated as the "building height."

Figure 13.4 shows the building height values along the extended axial lines. Areas possessing higher stories are marked in black. The districts, Eminonu, Aksaray, Beyazit, Fatih, etc., were shown to be local centers in the sense that there were higher-story buildings along the roads in those districts. 


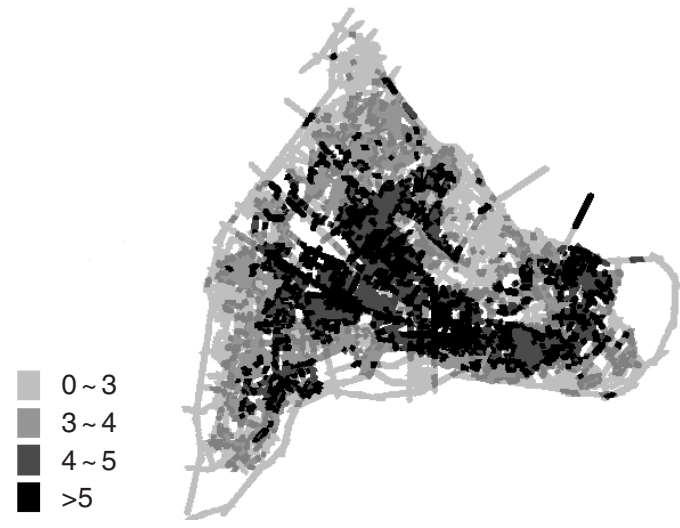

Figure 13.4 Average stories of buildings along extended axial lines. (Average stories are marked by gray tone.)

\section{Experts' notion of local centers in Istanbul}

Indices based on some physical phenomena are useful because they are objective, but they tend to be defective in the sense that they can only indicate a very limited aspect of local centeredness. In fact, the notion of a local center is very difficult to describe using a single physical index. To complement our analysis, we found it useful to identify local centers using the expert experience of Istanbul city planners also. This identification is of course subjective, but it can represent a more comprehensive notion of local centers.

Twenty academicians (or urban planners) majoring in city planning or architecture in the Faculty of Architecture at the Istanbul Technical University were asked to indicate on a map of Istanbul what they thought were local centers in the historical part of Istanbul. To do so, no definition of local centers was provided, for we did not want to confine the scope of "local centers" in this process. With this information, the whole area was classified into four zones: namely Zone0, Zone1, Zone2, and Zone3. The zone designated as Zone0, was the zone where no expert indicated that the area was a local center. Zone1 and Zone2 were zones where one and two academicians (or urban planners), respectively, indicated that the area was a local center. Zone 3 was the zone where three or more academicians (or urban planners) indicated that the area was a local center. Three dummy variables and one discrete variable were constructed based on this information. The variable, expertj, was defined as a dummy variable taking a value $=1$ if an extended axial line was included in an area where $j$ or more professors indicated it as a local center, or 0 otherwise for $j=1,2$, and 3. The variable, expert, took the value $k$, if the extended axial line was included in the zone, Zone $k$. Figure 13.5 displays the results of these variables. 


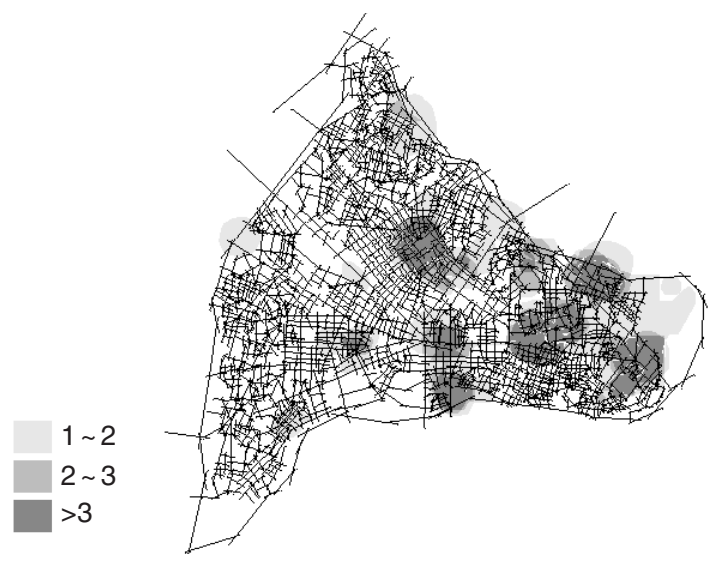

Figure 13.5 Experts' notion of local centers in Istanbul. (Zone $k$ is indicated by light gray for $k=1$, gray for $k=2$, and deep gray for $k>3$. Zone 0 is other areas than gray toned.)

\section{Commercial areas in Istanbul}

Local centers often consist of an aggregation of commercial facilities. For this reason, a dummy variable designated as "commercial," signifying whether or not an extended axial line was included in a commercial area, can express the degree of local centeredness to some extent. To perform this task, a land-use map (Yildiz Technical University, City \& Regional Planning Department 1996) was scanned, and the commercial areas were digitized. A dummy variable, commercial, was defined to be equal to 1 if an extended axial line was included in the commercial area, and 0 otherwise. Figure 13.6 shows the commercial areas highlighted in gray.

\section{The relationship between the space syntactic indices and indices representing the activities of local centers}

The space syntactic indices were calculated for the historical part of Istanbul (Figure 13.6). There were 1546 (conventional) axial lines. Taking into account the three-dimensional land surface change, these were partitioned into 7785 extended axial lines.

The correlation coefficients between the space syntactic indices (introduced in the Section "Extended space syntactic indices") and the indices representing activities of local centers (introduced in the Section "Local centers in Istanbul") were calculated. Table 13.1 shows the results for the conventional space syntactic analysis, which does not take into account any three-dimensional surface changes. 


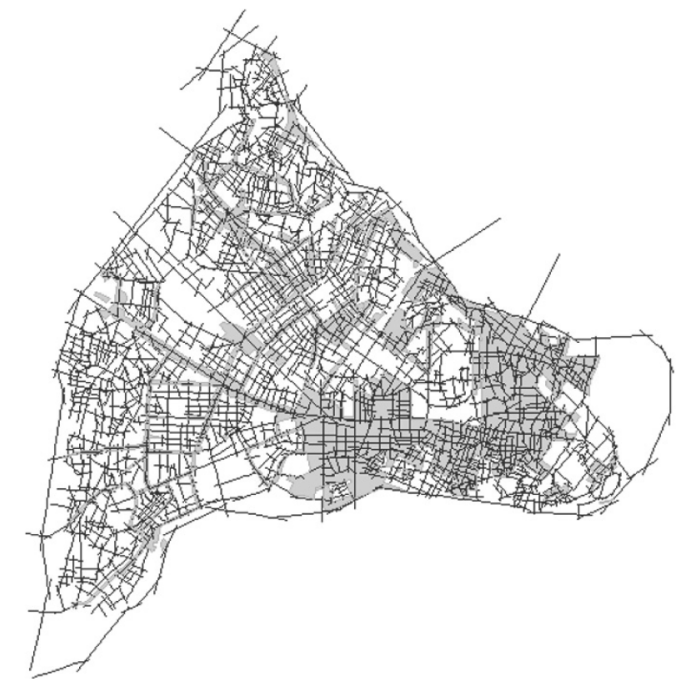

Figure 13.6 Land-use map of Istanbul. (Commercial areas in pink.)

Table 13.1 Correlation coefficients for (conventional) axial lines

\begin{tabular}{|c|c|c|c|c|c|c|c|}
\hline $2 D$ & $\begin{array}{l}\text { building } \\
\text { height }\end{array}$ & taxi & expert1 & expert 2 & expert3 & expert & commercial \\
\hline Connectivity & 0.216 & 0.239 & 0.147 & 0.154 & 0.155 & 0.173 & 0.262 \\
\hline Control & 0.043 & 0.185 & 0.107 & 0.112 & 0.117 & 0.127 & 0.123 \\
\hline G1 & -0.227 & -0.147 & -0.112 & -0.116 & -0.127 & -0.134 & -0.281 \\
\hline$G 2$ & -0.504 & -0.087 & -0.086 & -0.070 & -0.065 & -0.085 & -0.360 \\
\hline Integration & 0.382 & 0.198 & 0.063 & 0.113 & 0.113 & 0.107 & 0.329 \\
\hline$K 3$ & 0.354 & 0.291 & 0.145 & 0.169 & 0.161 & 0.179 & 0.353 \\
\hline$K 4$ & 0.396 & 0.281 & 0.122 & 0.154 & 0.142 & 0.158 & 0.351 \\
\hline K5 & 0.412 & 0.250 & 0.103 & 0.138 & 0.129 & 0.139 & 0.332 \\
\hline K6 & 0.408 & 0.222 & 0.077 & 0.121 & 0.116 & 0.118 & 0.316 \\
\hline$K 7$ & 0.389 & 0.198 & 0.053 & 0.106 & 0.105 & 0.098 & 0.308 \\
\hline$K 8$ & 0.365 & 0.178 & 0.029 & 0.091 & 0.095 & 0.078 & 0.308 \\
\hline K9 & 0.348 & 0.159 & 0.018 & 0.080 & 0.091 & 0.068 & 0.310 \\
\hline K10 & 0.339 & 0.144 & 0.014 & 0.073 & 0.087 & 0.063 & 0.311 \\
\hline$M D$ & -0.366 & -0.156 & -0.023 & -0.079 & -0.087 & -0.069 & -0.324 \\
\hline$M D 3$ & 0.339 & 0.104 & 0.017 & 0.071 & 0.041 & 0.048 & 0.272 \\
\hline MD4 & 0.340 & 0.085 & -0.020 & 0.017 & 0.001 & -0.002 & 0.191 \\
\hline MD5 & 0.245 & 0.017 & -0.064 & -0.021 & -0.006 & -0.037 & 0.074 \\
\hline MD6 & 0.099 & -0.040 & -0.112 & -0.052 & -0.020 & -0.074 & -0.024 \\
\hline MD7 & -0.110 & -0.114 & -0.124 & -0.088 & -0.054 & -0.104 & -0.116 \\
\hline MD8 & -0.302 & -0.175 & -0.113 & -0.111 & -0.083 & -0.118 & -0.197 \\
\hline MD9 & -0.386 & -0.207 & -0.072 & -0.109 & -0.094 & -0.103 & -0.252 \\
\hline MD10 & -0.405 & -0.214 & -0.047 & -0.103 & -0.100 & -0.092 & -0.291 \\
\hline $\operatorname{Max} D$ & -0.339 & -0.144 & 0.031 & -0.030 & -0.041 & -0.012 & -0.290 \\
\hline
\end{tabular}


The clustering coefficient, G2, within three steps has a high negative correlation coefficient with the building height and commercial indices. The clustering coefficients have a low value for networks close to a complete dual graph. In other words, the coefficients are small for networks with many intersections among axial lines. Local centers often are located at the core of the city, where many roads are gathered, which is similar to a tree graph. Thus, it is natural to have negative correlation coefficients with indices representing urban activities for local centers. A high (absolute) correlation coefficient value may indicate that the $G 2$ index based on a conventional space syntax approach can capture the features of local centeredness rendered by the building height and commercial indices. Moreover, the $G 2$ correlation coefficient using the conventional space syntax approach was found to show the highest absolute value, partly because the axial lines in the conventional space syntax approach tend to be longer than the extended axial lines using the extended approach. The network, therefore, extends to the largest area using the conventional approach, and each axial line has more intersections with other axial lines, and therefore, a tree graph-like feature is mostly emphasized using the conventional approach. It can be concluded that the conventional approach performs fairly well in indicating the features of local centers as represented by the building height and commercial indices.

The values of $K i$ (for $i=3$ to 10 ) represent the number of accessible axial lines within $i$ steps. Local centers should be accessible from many local spaces, and these indices are therefore expected to be positively correlated with the indices of urban activities. The maximum correlation was attained for the building height index with $K 5$, for the taxi, expertj's, and expert indices with $K 3$, and for the commercial index with $K 4$. This may suggest that local centers are influential within three to five steps from the center.

The local mean depth, $M D i$, indicates relative proximity to the center within an area of $i$ steps. This index had a positive correlation coefficient for a low number of steps, and a negative correlation coefficient for a high number of steps for all the activity-based indices. This means that the local center is very accessible to neighbors, but not farther afield.

Table 13.2 shows the correlation coefficients for the extended axial lines, which take into account the three-dimensional change in height.

The $G 2$ values still exhibit a high negative correlation coefficient with the building height and commercial indices, but show lower values than those using conventional space syntactics. The conventional method performs relatively well, even though it fails to take into account the three-dimensional aspects.

It is remarkable that the correlation coefficient between K10 and building height was very high (0.539 in Table 13.2) for the extended axial lines method. In fact, this value was the highest absolute correlation coefficient value among all the correlation coefficients calculated for this paper. Moreover, the value increased with respect to step value. The local spaces $(K i)$ values in limited steps are potentially the most powerful descriptor of local centeredness represented by building height. Similarly, the highest correlation coefficient with commercial 
THREE-DIMENSIONAL ANALYSIS OF STREET NETWORKS

Table 13.2 Correlation coefficients for extended axial lines

\begin{tabular}{lrrrrrrr}
\hline 3D & $\begin{array}{l}\text { building } \\
\text { height }\end{array}$ & \multicolumn{1}{l}{ taxi } & expert1 & expert2 & expert3 & expert & commercial \\
\hline Connectivity & 0.158 & 0.044 & 0.054 & 0.060 & 0.050 & 0.064 & 0.164 \\
Control & 0.020 & 0.024 & 0.021 & 0.019 & 0.012 & 0.021 & 0.063 \\
G1 & -0.124 & -0.048 & -0.044 & -0.049 & -0.034 & -0.050 & -0.125 \\
G2 & -0.351 & -0.035 & -0.075 & -0.084 & -0.067 & -0.087 & -0.218 \\
Integration & 0.473 & 0.056 & 0.177 & 0.225 & 0.182 & 0.224 & 0.285 \\
K3 & 0.265 & 0.052 & 0.071 & 0.082 & 0.071 & 0.086 & 0.227 \\
K4 & 0.347 & 0.049 & 0.088 & 0.096 & 0.083 & 0.103 & 0.271 \\
K5 & 0.405 & 0.054 & 0.095 & 0.110 & 0.092 & 0.114 & 0.301 \\
K6 & 0.449 & 0.057 & 0.094 & 0.123 & 0.100 & 0.122 & 0.325 \\
K7 & 0.483 & 0.061 & 0.097 & 0.137 & 0.108 & 0.131 & 0.343 \\
K8 & 0.507 & 0.062 & 0.097 & 0.149 & 0.115 & 0.137 & 0.355 \\
K9 & 0.525 & 0.065 & 0.097 & 0.158 & 0.123 & 0.143 & 0.362 \\
K10 & 0.539 & 0.066 & 0.097 & 0.165 & 0.129 & 0.148 & 0.368 \\
MD & -0.491 & -0.052 & -0.180 & -0.210 & -0.172 & -0.217 & -0.296 \\
MD3 & 0.276 & 0.013 & 0.048 & 0.066 & 0.058 & 0.065 & 0.157 \\
MD4 & 0.359 & 0.003 & 0.057 & 0.083 & 0.067 & 0.079 & 0.194 \\
MD5 & 0.399 & 0.018 & 0.058 & 0.099 & 0.076 & 0.088 & 0.212 \\
MD6 & 0.411 & 0.025 & 0.049 & 0.108 & 0.078 & 0.088 & 0.215 \\
MD7 & 0.403 & 0.026 & 0.049 & 0.114 & 0.079 & 0.091 & 0.205 \\
MD8 & 0.381 & 0.023 & 0.046 & 0.112 & 0.078 & 0.088 & 0.189 \\
MD9 & 0.356 & 0.024 & 0.044 & 0.108 & 0.08 & 0.086 & 0.170 \\
MD10 & 0.332 & 0.023 & 0.044 & 0.100 & 0.078 & 0.083 & 0.150 \\
MaxD & -0.446 & -0.045 & -0.288 & -0.280 & -0.225 & -0.310 & -0.285 \\
\hline & & & & & & &
\end{tabular}

was attained at step $K 10$ for the extended axial lines method. From these results, we can conclude that the local spaces $(K i)$ value with an appropriate number of steps explains well the feature of local centers as represented by the building height and commercial indices.

When the extended axial lines method was introduced, the correlation coefficient between the building height index and the $K i$ value was high. Since the average length of the extended axial lines was smaller than that of the conventional axial lines, the topological distance based on the extended axial lines tended to resemble metric distances. This observation suggests that introduction of metric distances within the analytical framework may improve the prediction power for local centers.

The taxi bay index failed to show any large correlation coefficients with any of the space syntactic indices. This is partly because taxi bays were not necessarily located in the most central areas, owing to the lack of space and to competition with other more intensive land users. Since the number of taxi bays was very limited, this may also be a cause of the low values seen.

The experts' notion of local centers (expert1, expert 2 , expert 3 , and expert) did not show any large correlation coefficients with the space syntactic indices. It is 
of interest to observe that the building heights and the existence of commercial activities were captured well by the space syntactic indices, while the experts' notion was not. Space syntactic indices are based on visibility relationships, which are a factor that a modern city planner tends to emphasize. In other words, the concept itself is suited to the analysis of modern cities. Istanbul is a very traditional city, having absorbed many influences from non-European cultures (Kubat 1999). In fact, the local centers suggested by the experts were, in many cases, local centers that had developed from earlier ages. These local centers are not based on any modern notion of city planning. This may suggest that some aspect other than visibility is the fundamental factor characterizing such local centers. In other words, the conventional space syntax approach is not an effective way in which to analyze traditional city forms inherited from other than the Byzantine or Roman city forms, or from a modern city form.

\section{Conclusions}

This chapter has extended the conventional space syntactic approach into three-dimensional space using GIS. For comparison purposes, several indices were measured to represent the actual urban activities in Istanbul. It was found that the average building height index and a commercial dummy variable showed high correlation coefficients with the space syntactic indices. This suggests that building height and the existence of commercial activities are captured well by the space syntactic method. In particular, the clustering coefficient, $G 2$, within three steps using the conventional space syntactic method explains well the feature of local centers, as represented by the building height and commercial variables. The best descriptor of local centers appears to be the local spaces $(K i)$ with an appropriate number of steps using the extended axial lines method. Using these connections, the extension of the space syntactic idea to a three-dimensional surface improves the traditional center identification ability. Moreover, our results suggest that the introduction of metric distances within the analytical framework may improve the analysis.

Space syntactic indices using any method, however, failed to capture the experts' notion of local centers. This may be because conventional space syntax depends heavily on visibility aspects, which are not an overwhelming factor in the formation of traditional Islamic cities. A notion other than visibility appears to be needed as a principal device for the spatial analysis of such cities.

\section{Acknowledgments}

The authors would like to thank Fukami Naoko, Jinnai Hidenobu, Kuroiwa Tomoko, Okabe Atsuyuki, Sadahiro Yukio, and Terasaka Akinobu for their valuable comments, and M. Simsek Deniz of the Metropolitan Municipality of Istanbul, as well as members of the City and Regional Planning Department of the Istanbul Technical University for helping us with data collection. The authors 
are also grateful to M. Aysan, F. Bolen, V. Dökmeci, N. Ergun, G. Erkut, E. Eyuboglu, C. Giritlioglu, E. Kerimoglu, T. Kilincaslan, K. Koramaz, M. Ocakci, O. Özcevik, A. Tezer, S. Turk, H. Turkoglu, H. Unutmaz, R. Yigiter, F. Yirmibesoglu, and M. A. Yüzer, who are members of the City and Regional Planning Department of the Istanbul Technical University, and M. Topaloglu, an urban planner, for providing valuable information on local centers.

\section{References}

Asami, Y., A.S. Kubat, and I.C. Istek (2001) "Characterization of the street networks in the traditional Turkish urban form," Environment and Planning B, 28(5): 777-795.

Asami, Y., A.S. Kubat, K. Kitagawa, and S. Iida (2002) "Introducing third dimension on space syntax: Application on the historical Istanbul,” Discussion Paper No. 44, Center for Spatial Information Science, University of Tokyo, Tokyo.

Asami, Y., A.S. Kubat, and I.C. Istek (2004) "Application of GIS to network analysis: characterization of the street networks in the Turkish-traditional urban form." In A. Okabe (ed.) Islamic Area Studies with GIS, London: Taylor and Francis.

Brown, M.G. (1999) "Design and value: spatial form and the economic failure of a mall," Journal of Real Estate Research, 17: 189-225.

Hanson, J. (1989) "Order and structure in urban design: the plans for the rebuilding of London after the Great Fire of 1666," Ekistics, 334/335: 22-42.

Hillier, B. (1999) "The hidden geometry of deformed grids: or, why space syntax works when it looks as if it shouldn't," Environment and Planning B, 26: 163-169.

Hillier, B. and J. Hanson (1984) Social Logic of Space, Cambridge: Cambridge University Press.

Hillier, B., A. Penn, J. Hanson, T. Grajewski, and J. Xu (1993) "Natural movement: or configuration and attraction in urban pedestrian movement," Environment and planning B, 20: 29-66.

Krüger, M.J.T. (1989) “On node and axial maps, distance measures and related topics," Paper for the European Conference on the Representation and Management of Urban Change, Cambridge, 28-29 September, Unit for Architectural Studies, London: University College London.

Kubat, A.S. (1997) "The morphological characteristics of Anatolian fortified towns," Environment and Planning B, 24: 95-123.

Kubat, A.S. (1999) "Morphological history of Istanbul, Urban Morphology," Journal of the International Seminar on Urban Form, Vol. 4, Design and Print Unit, Birmingham: University of Central England.

Kubat, A.S. (2001) "Istanbul: a configurational model for a metropolis," Third International Symposium on Space Syntax, 7-11 May, 2001, Institute of Technology, Georgia Tech., 62.1-62.7, Georgia, Atlanta, USA.

Municipality of Metropolitan Istanbul, General Director of Transportation, Transportation Planning Department (1999) Planning proposals for taxi bays and taxi parking lots for Istanbul's historical peninsula, published by Municipality of Metropolitan Istanbul, Istanbul, August 1999 [Tarihi Yarimada Taksi Duraklari ve Bekleme Yerleri Planlamasi, Istanbul Buyuk Sehir Belediye Baskanligi, Ulasim Daire Baskanligi, Ulasim Planlama Mudurlugu, Agustos 1999]. 
Penn, A., B. Hillier, D. Bannister, and J. Xu (1998) "Configurational modelling of urban movement networks," Environment and Planning B, 25: 59-84.

Peponis, J., E. Hadjinikolaou, C. Livieratos, and D.A. Fatouros (1989) "The spatial core of urban culture," Ekistics, 334/335: 43-55.

Peponis, J., C. Ross, and M. Rashid (1997) "The structure of urban space, movement and co-presence: the case of Atlanta," Geoforum, 28: 341-358.

Read, S. (1999) "Space syntax and the Dutch city," Environment and Planning B, 26: 251-264.

Turner, A., M. Doxa, D. O'Sullivan, and A. Penn (2001) "From isovists to visibility graphs: a methodology for the analysis of architectural space," Environment and Planning B, 28: 103-121.

Watts, D.J. (1999) Small Worlds: The Dynamics of Networks Between Order and Randomness, Princeton: Princeton University Press.

Watts, D.J. and S.H. Strogatz (1998) "Collective dynamics of 'small world' networks," Nature, 393: 440-442.

Yildiz Technical University, City \& Regional Planning Department (1996) Planning for sustainable heterogeneity of the historical Peninsula of Istanbul, published by Municipality of Metropolitan Istanbul, Istanbul. 


\title{
THE SPACE OCCUPIED BY MARKETPLACES AND THEIR SOCIETIES IN THE ISLAMIC WORLD- WITH PARTICULAR REFERENCE TO ISFAHAN AND ISTANBUL ${ }^{1}$
}

\author{
Istek Cihangir
}

\section{Introduction: the concept of an "Islamic city" and the marketplace}

Urban studies that have sought to explain the cities of the Islamic world have often been discussed within the framework of the "Islamic city" concept (Marcais, G. 1913, 1946; Marcais, W. 1928; Pauty 1951; von Grunebaum 1955; de Planhol 1959). According to this concept, Islam is an essentially "urban religion" conforming to urban life and regulating its societies, and is thus considered to be the prime definer of the city form. To explain urban morphologies and structuring principles, an Islamic city model-where the congregational (Friday) mosque forms the city's central core, with the market, the religious school, and the public bathhouse surrounding it - has been widely used (von Grunebaum 1955; de Planhol 1959).

Recently, discussions concerning the "Islamic city" concept have focused more on the link between Islam and the city. For example, Hakim's study of Tunis redefines the significance of this link, and the importance of Islam acting as a guideline for urban construction and life throughout the Islamic world, by discussing important urban and architectural elements (Hakim 1986). According to Hakim, the marketplace, as one of the most important elements in an Islamic city, is the spatial hierarchy of trades and products sold or distributed according to a "symbolic" framework of locations in relation to the Friday mosque. After analyzing the city of Fez, Bianca also agreed with Hakim on the particular importance of marketplaces in Muslim cities, and emphasized that the markets have always occupied a prominent position in the city center in relation to the Friday mosque and related social welfare buildings (Bianca 2000). Bianca points out that the Qur'an explicitly endorses a strong interaction between religious and 


\section{ISTEK CIHANGIR}

commercial activities, and that it has become one of the hallmarks of traditional Muslim cities.

On the other hand, since the 1980s, several other scholars studying cities from the Islamic cultural sphere have begun to criticize or revise the original concept of "Islamic city" by approaching it from different viewpoints. Kuban, for example, stresses that the structure of an Islamic city differs between Iran, Turkey, and the Maghreb among other places, and he denies that Turkish cities can only be understood within the framework of an "Islamic city" concept (Kuban 1980).

Abu-Lughod is another scholar who points out that the "Islamic city" concept is built on a sample from a specific region, chiefly the cities of North Africa (Abu-Lughod 1987). She strongly argues that it is a mistake to put too much emphasis on the role of Islam as a religion when making comparisons between cities from different cultural spheres. It is natural that diverse urban characteristics grew up within the same Islamic region, owing to differences in geography, history, and institutions, and that Islam is only one element that has given rise to such differences (Abu-Lughod 1989).

Wirth, who has also studied the links between Islam and cities from a geographical point of view, states that the two are separate, although it is undeniable that there are certain common features among cities in North Africa and Western Asia (Wirth 1982). Having examined several distinctive features of cities in the Islamic period, including labyrinthine networks, blind alleys, houses with inner courtyards, independent quarters, and marketplaces, he shows that of all these characteristics, the marketplace has the weakest connection with Islam as a religion. Thus, Wirth suggests that if these cities were all to be called "Islamic," further detailed comparative studies must explain whether these common features occurred as a result of Islam, and if so, to what extent.

It is this last point as raised by Wirth that brings us to the research interest of the present chapter. Since the early twentieth century, the expression "Islamic city" has been the favored form of reference to the cities of the Islamic world, mainly focusing on the Arab cities of North Africa and the Middle East. As this trend indicates, scholars have tended to link the cities of the Islamic world with Islam as a religion and a culture in an attempt to understand them as a whole, and in a unified and uniform way. A frequent argument has been to say that the particular phenomena of an area are the characteristics of "Islamic city" (Djait 1986). However, this view has also not been clearly specified so far, and there have not been enough studies that examine and compare these cities in their diversity, that is, their morphologies, cultures, regional and historical backgrounds, and especially so among the non-Arab cities within the Islamic cultural sphere, like those in Iran and Turkey. Furthermore, the space occupied by markets seems to have been poorly understood, and the actual way in which they work has been subjected to a great deal of abstraction and speculation at the expense of religious factors. In fact, the gap between their spatial aspects and their non-spatial implications (i.e. their societies) is what requires a more precise understanding with regard to the instrumental and symbolic components of their layouts, planning, 
and use. The main objective of this research is to find out whether it is possible to fill this gap by comparatively exploring the spatial configurations of two important classic cases: Isfahan and Istanbul, using a methodology adopted from space syntax (Hillier and Hanson 1984).

\section{Why and what is "space syntax"?}

Space syntax is both an analytical method and a descriptive model of space. Its representations particularly try to gain insights into the notions of "accessibility," "encounter," and "use" of urban public spaces. Recent research by Asami et al. (2001), testing various other quantitative methods of urban morphological analysis, has shown that the properties of space syntax are powerful in characterizing traditional urban street patterns. On the other hand, space syntax as a descriptive model of space, has always been emphasized at a level above the individual to inquire into the relationship between societies and space (Hillier and Hanson 1984; Hillier 1999; Peponis 2001). In this research, it is also this particular premise of space syntax that will be tested in Islamic Area Studies. The connection of space to societies and vice versa means that space syntax is one of the best available models for spatial analysis, which has been improved with the aid of geographical information systems (GIS). GIS is a general computer-aided tool for processing spatial data, that is, acquiring, managing, analyzing, and visualizing. As a model, space syntax departs from the idea that the way space is created (either by architects or planners, or by ordinary people) is fundamental to the way that people use it. In other words, it is based upon the way that space (and especially urban space and street networks) is ordered and structured as accessibility and encounter patterns.

The analytical framework of space syntax is based upon two basic representations, called convex and axial maps, which are used to model and capture the oneand two-dimensional structural properties of urban space systems. The convex map of a selected urban area (Figure 14.1a) shows the smallest set of the largest possible spaces, called the convex spaces, that can be fully perceived by a potential observer at a point, p, within them (Figure 14.1b). In order to construct the convex map, first, the ground plan is drawn or obtained in the usual map format. Then, its continuous open space structure is identified. Finally, the convex space representations are drawn. However, point "p" is not only part of the convex space indicated by the shaded area, but can also be seen as a part of a linearly extended space. The axial map represents this type of extension in space. Figure 14.1c shows the axial map of the same area, being the smallest set of the longest possible straight lines-of-sight that can connect all the available convex spaces.

As a direct implication of these representations, the spatial configurations can be seen at two different levels of operation at once. Whenever the observer at point "p" moves about the street networks, it is through the convex spaces that the local organization of the space where the person is in, is perceived. However at the same time, the global organization of the space is also perceived through the 
(a)

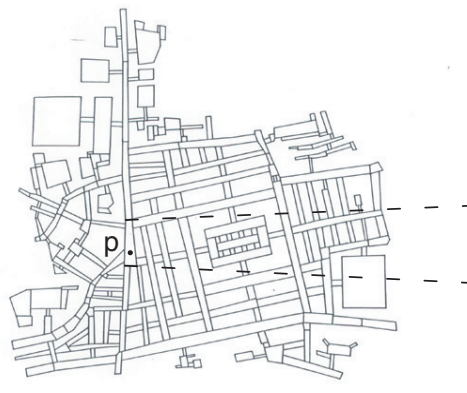

(c)

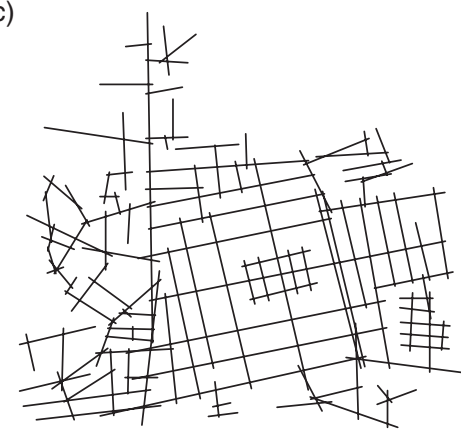

(b)

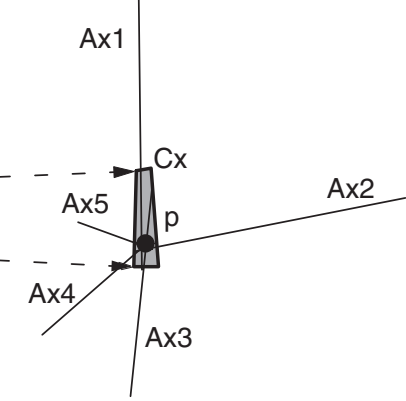

Figure 14.1 (a) Convex map; (b) the observer point "p" seen convexly and axially; (c) axial map.

axial lines of longest sight and accessibility (i.e. the way in which the space where the person is located is related to the rest of the city).

On the basis of the convex and axial maps, the main aim of the syntactic analysis is to define quantitatively the extent to which each space is connected either directly or indirectly to all the other spaces in the chosen urban area, and thus, to define how that area might perform.

\section{Analysis: a multi-contextual perspective}

The syntactic approach introduced in the previous section was carried out to investigate the markets at four distinct, but complementary levels: (i) markets within a global urban context, (ii) markets within a local urban context, (iii) markets within themselves, and (iv) markets and their space-use patterns.

At each level, the two basic representations - convex and axial maps-were applied to model the layouts, and also a series of quantitative analyses were carried out to discover the important spatial properties. (For more information on the mathematical definitions, please refer to Istek 1999.) 


\section{MARKETPLACES IN THE ISLAMIC WORLD}

\section{Markets within a global urban context}

The first level of the analysis concentrated on the markets within their large urban context to explore how they were related to each city's patterns of accessibility. Figure 14.2 shows the marketplaces and their axial map representations within the global urban context of Isfahan and Istanbul. The map of Isfahan includes the traditional site of the Seljuk and the Safavid cities to the northern banks of the Zayandeh River (ZR). The map of Istanbul covers the Byzantine and Ottoman city's main traditional sites along the Divan Yolu thoroughfare (DY), from the Square of Hagia Sophia (HS) to the Aqueduct of Valens (AV).
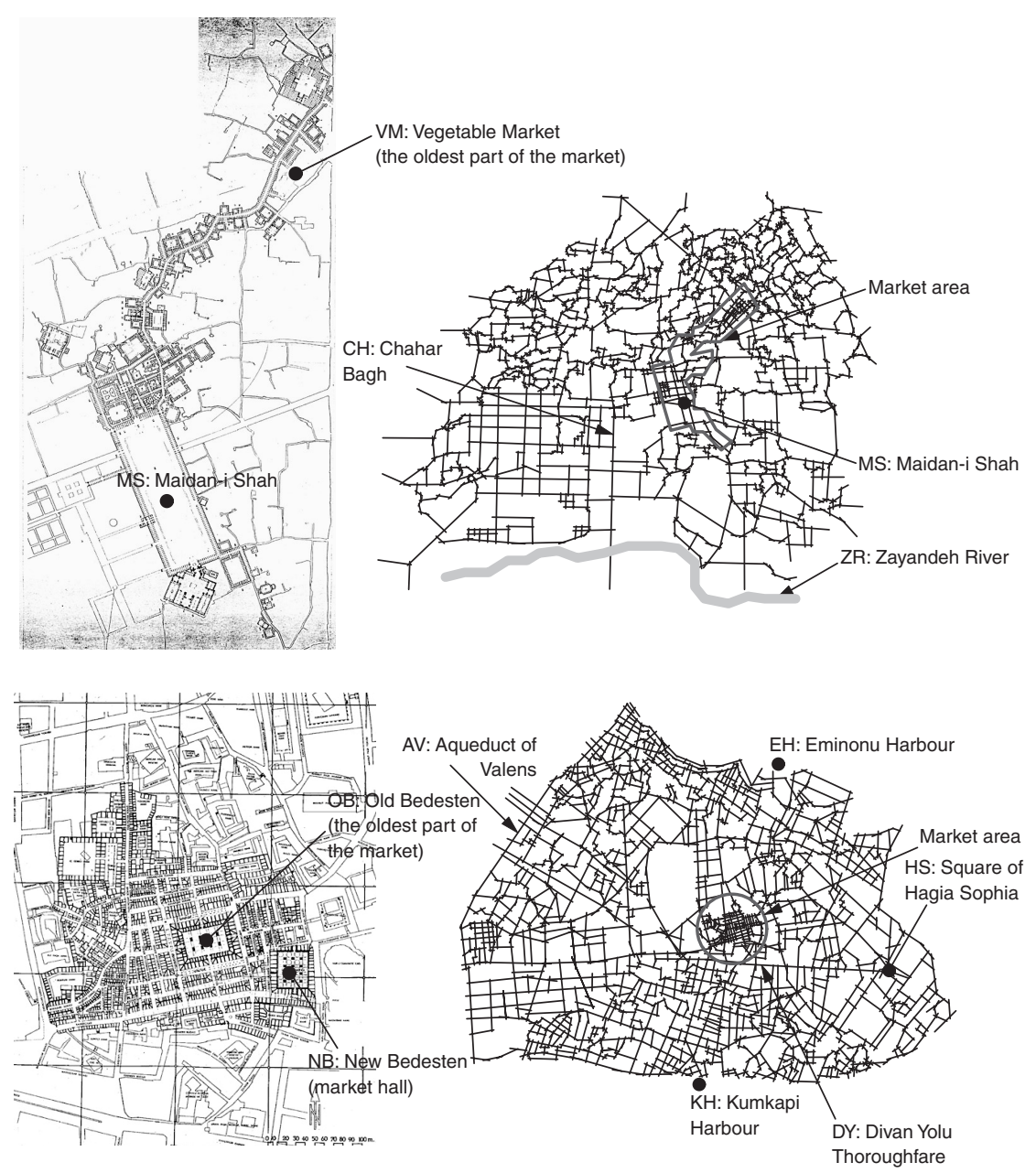

Figure 14.2 Marketplaces and their axial map representations within the global urban context of Isfahan and Istanbul. 


\section{ISTEK CIHANGIR}

The syntactic analysis of the axial maps provides two types of result: (i) numeric data in the form of line numbers with spatial parameters assigned to each line; and (ii) graphic data in the form of core maps, in which each line is toned in accordance with its value based on the numeric data. Although the latter data are rough approximations compared with the former, they allow us to have an immediate grasp of the spatial structure of the markets. Figure 14.3 shows graphic data of the distribution of global integration and segregation. From the viewpoints of accessibility and interface, the important results are from the computation that measures how far a space lies from every other space in an urban system. A space is called "integrated" when all the other spaces are relatively near, with a few intervening spaces that must be traversed in order to reach from one space to another.

(a)
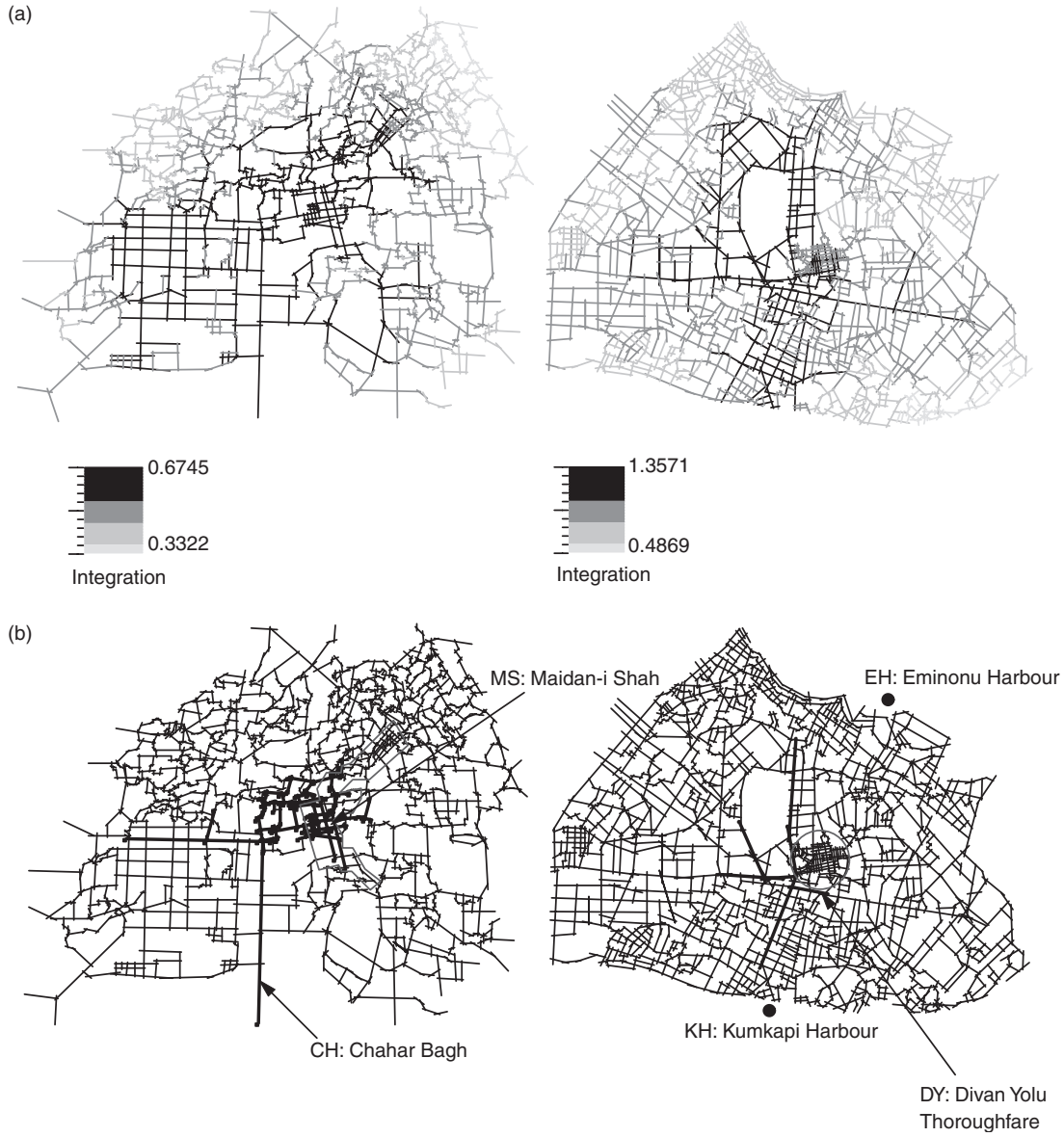

Figure 14.3 (a) Distribution of global integration and segregation; (b) locations of the markets and the GI-cores. 
A space is called "segregated" when all the other spaces are relatively far from it, and a large number of intervening spaces must be traversed in order to reach from one space to another. In Figure 14.3, the integration values of each street are represented by the tone spectrum from heavy black for the most integrated street through to light gray for the most segregated. The most integrated streets (in heavy black lines) are also called the "global integration core" (the GI-core).

One important outcome of this analysis is the strong correspondence between the locations of the markets and the GI-cores (Figure 14.3). For example in Isfahan, the GI-core selects the spaces strongly connecting the market's internal streets and its major public and market squares (MS) to the southern part of the city through a major axis (CB). In Istanbul, the GI-core is similarly concentrated in the area near the marketplace. Several streets in the GI-core provide access to the marketplace, especially from Istanbul's harbors ( $\mathrm{EH}$ and $\mathrm{KH}$ ), located on both sides of the peninsula. On the other hand, the quiet residential zones (in light gray lines) lying peripheral to the GI-core are selected as segregated areas.

The local integration offers a more local perspective than the global integration. This is computed in a similar manner as the global integration for all the spaces, but within their three axial lines only, and thus, the urban structure is literally read at different scales. The higher the local integration values, the more segregated the spaces in terms of their local areas, whereas smaller local integration values indicate more local integration. Figure 14.4 shows the distribution of the "local integration cores" (the LI-cores) in Isfahan and Istanbul, in heavy black lines. The locations of the markets are also captured in the LI-core values in several streets.

These two results both indicate that markets play a key role in creating the global and local structures within their cities. As the global and local integrations reflect different scales of the urban structure, an understanding of their interactions is the key to understanding the relationship between a part and the whole of a city (Hillier 1996). The scattergrams on the right plot each line in each city's axial map as a point located according to its degree of global integration on the horizontal axis, and its degree of local integration on the vertical axis. The heavy black points in the scattergrams are the streets, which make up the marketplaces. They form a reasonably linear scatter about their own regression line (R2) by crossing the main regression line $(\mathrm{R})$ at a steeper angle. The linearity implies a good relationship between the local and global integrations. The steepest slope across the regression line is from the most integrated lines within the city that are from the lines from the edge towards the center, and these are locally rather than globally integrated. Their local integration is more intense than their degree of global integration. The streets with strong local integration values, which define the slope of the black points (R2) for the local area, are invariably from these edge-to-center lines. We find this strong locality effect in both cities. It means that as one moves about the most globally integrated streets (such as CB in Isfahan, or DY in Istanbul), the markets make themselves available as well-structured local centers. 

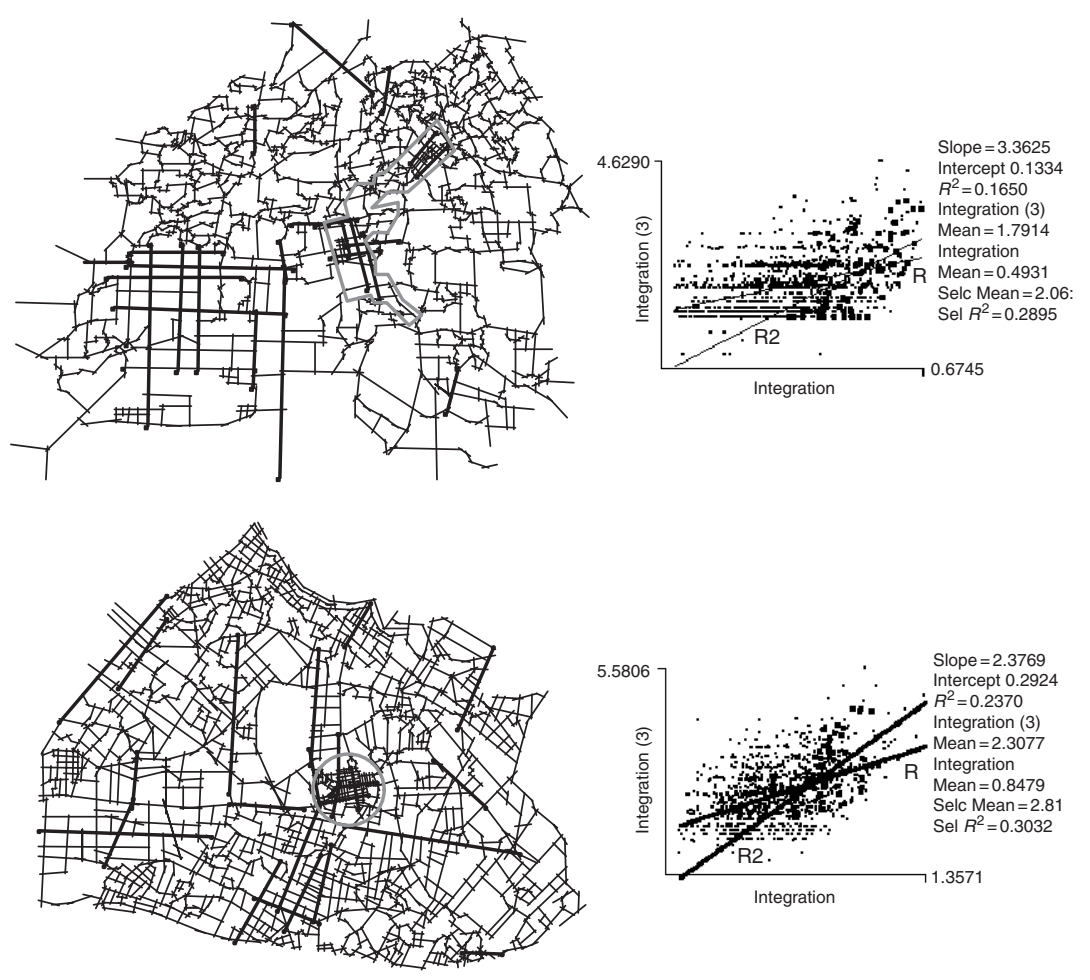

Figure 14.4 Distribution of the local integration cores in Isfahan and Istanbul.

\section{Markets within local urban context}

One outcome of the previous analysis was that both markets emerged as local centers within their global contexts. Exploring the cases within their more local urban contexts further emphasized this. Figure 14.5 shows the GI-core maps modeling the markets into their smaller surrounding areas.

In both cases, the GI-core is only distributed among the internal market streets, showing that the markets stand out clearly from their surroundings. In Isfahan, the GI-core primarily includes the main market street and several streets penetrating from the surrounding. However, it excludes the oldest part of the market (VM), and emerges into the MS district. In Istanbul, the GI-core is mainly concentrated in the market around the main market hall $(\mathrm{OB})$, and at least two of the major streets are selected.

As the extent of the analyzed areas is reduced, the markets begin to suggest certain morphological individualities with certain spatial properties. Comparisons between the numeric data from the two analytical levels (global and 


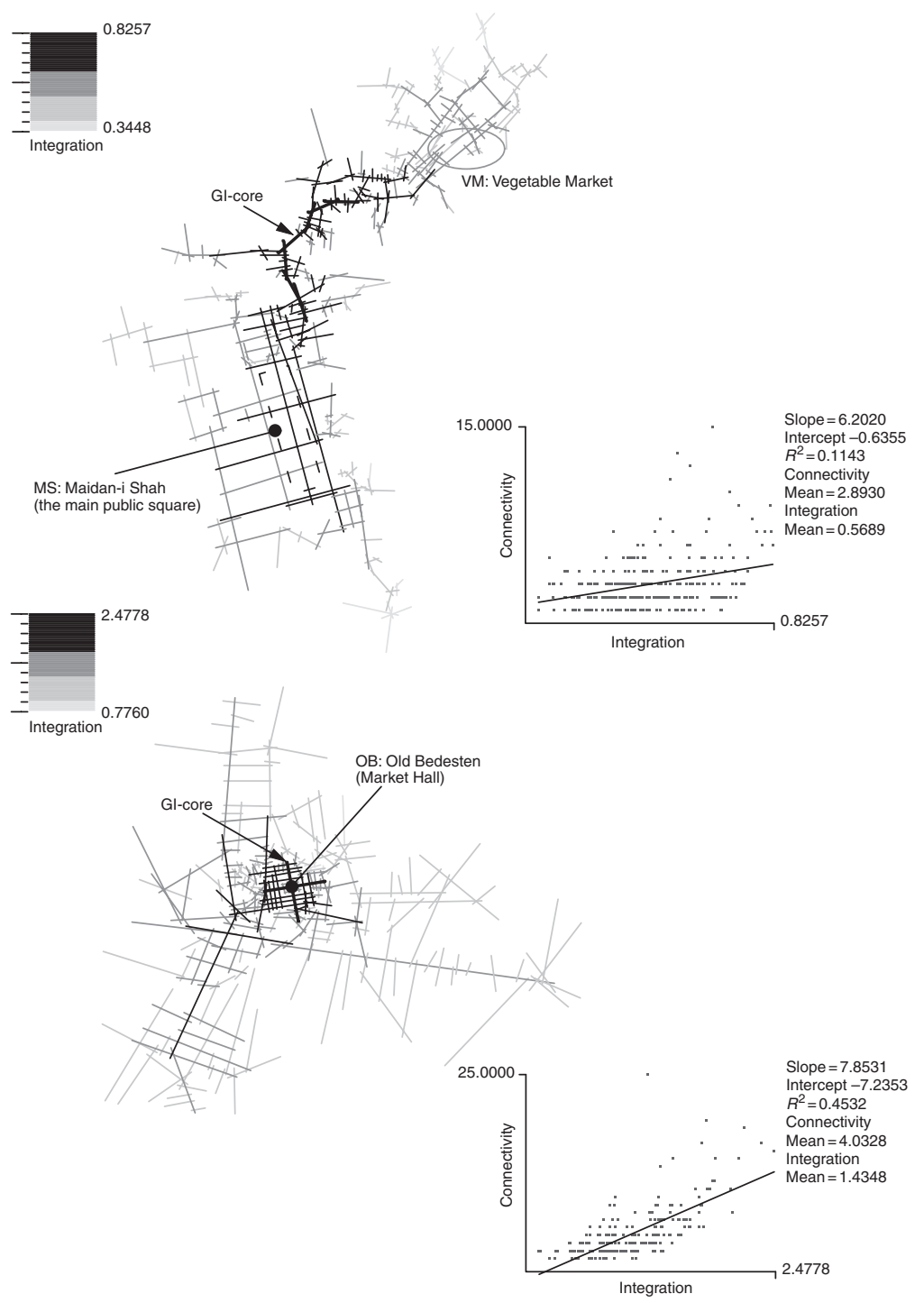

Figure 14.5 GI-core maps modeling the surrounding areas of the markets of Isfahan and Istanbul.

local contexts) are useful. One comparison used is intelligibility, defined as the square of correlation coefficient $\left(R^{2}\right)$ between the global integration and the connectivity values. Connectivity is the number of connections that each space makes to its neighboring spaces. The higher the connectivity value, the more a space is 


\section{ISTEK CIHANGIR}

connected to neighboring spaces from all the spaces in a system. The intelligibility, on the other hand, refers to the degree to which people can learn about large urban patterns from their experience of smaller parts. The lower the intelligibility, the less one can infer a location from within the street network as a whole, according to directly available information. For example, in the global urban context, the markets have a very weak intelligibility value (for Isfahan $R^{2}=0.107$, and for Istanbul $R^{2}=0.136$ ). In the local context, both improve (for Isfahan $R^{2}=0.114$, and for Istanbul $R^{2}=0.453$ ), however, the value for Isfahan is still lower than that for Istanbul.

The mean global integration value (mean-GI) describing each system as a whole is also informative for identifying key differences. This is the mean of all the global integration values. In the global urban context, the mean-GI for Isfahan $(0.493)$ is lower and more segregated than the Istanbul value (0.848). In the local urban context, the mean-GI value for Isfahan (0.569) improves slightly, however it is still more segregated than the Istanbul value (1.435).

\section{The actual markets}

This level of analysis was carried out using the following considerations: first, only the markets were considered, as they exist within their internal streets. Second, the markets were explored in two distinct modes: (i) in relation to all the spaces outside their boundaries, and (ii) in relation to only the spaces inside their boundaries. By doing so, it was hoped that the former might reveal any interface patterns between the inside and the outside, and therefore a relationship between the different categories of space-users (i.e. sellers as inhabitants, and buyers as visitors), whereas for the latter, similar patterns between the different categories of inhabitants inside each market would emerge. In other words, our hypothesis was that the reasons for the morphological differences between the markets might be the cause of the differences between the interface patterns of their users.

\section{Spatial relations with the outside}

In Isfahan, the GI-cores (heavy black lines) were mostly distributed among the spaces outside the marketplace, and in transitional spaces, such as gateways (see Figure 14.6a). The GI-cores did not form a continuous ring, but only linked the spaces to the main market route, and then stopped. They were also both globally and locally integrated, since there is a high correlation value of 0.903 between the global and local integration values.

Meanwhile, several short segments forming the main market street hold the highest control values (Figure 14.6b). The control value expresses not only the number of neighboring spaces a space has, but also the extent to which that space can control access to its immediately neighboring spaces. (Spaces with a control value greater than "1" have strong control, and those with values below "1" have weak control.) In Isfahan, the main market street has the highest control values, 


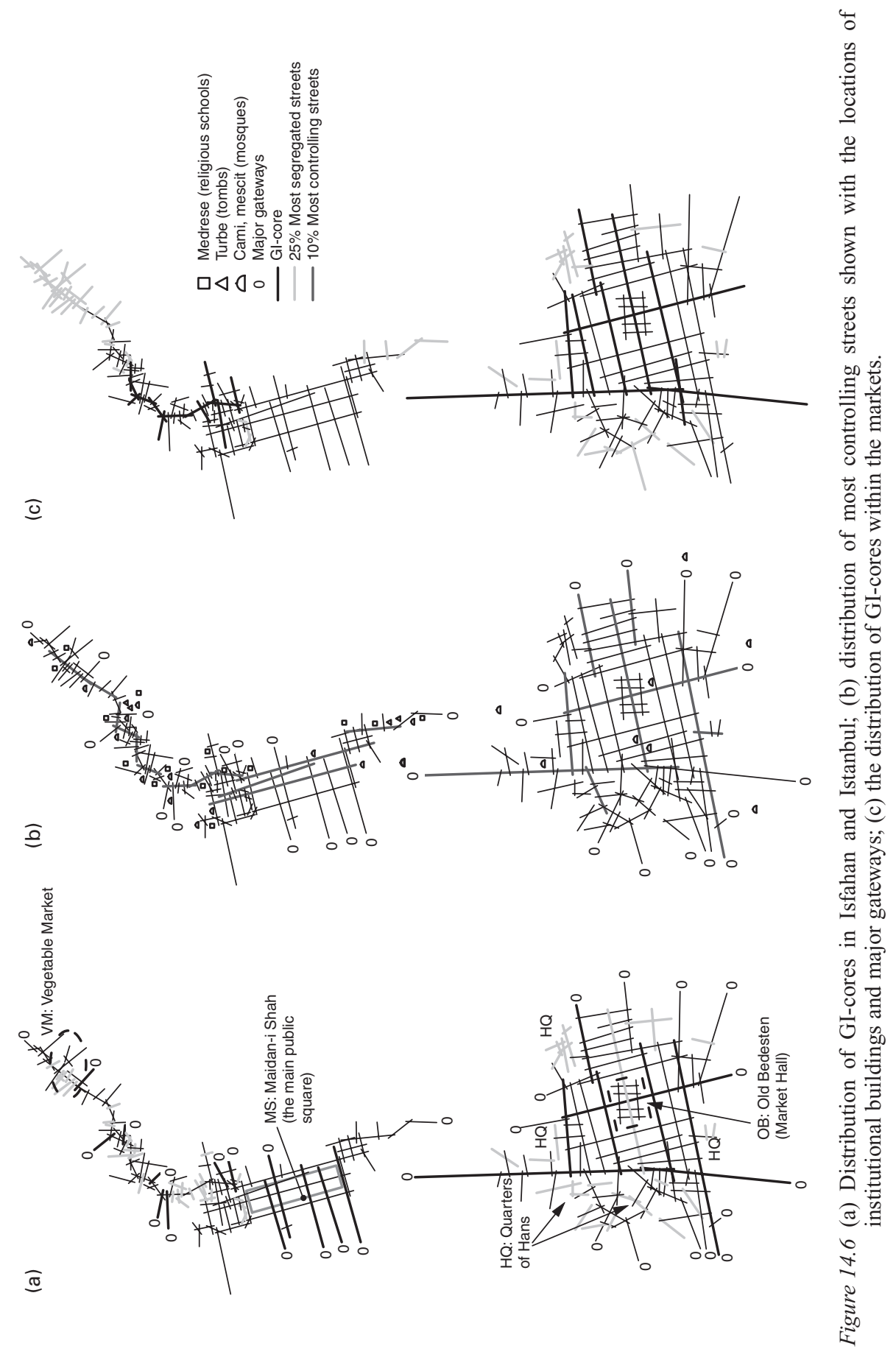


which control the shops and also the entrances of other institutional buildings (such as religious schools, tombs, and local mosques).

On the other hand, in Istanbul, the GI-cores take the shape of a concentric grid, and are mainly focused on the streets in and around OB, with several penetrating axes from the outside (Figure 14.6a). The segregated areas are not too far from the GI-cores, but usually are only one or two axial lines away. For comparison, the correlation between the global and local integration values shows a high $R^{2}$ value of 0.950 for Istanbul. The highest control values are also held mostly by those spaces located in and around OB (Figure 14.6b).

In addition, the markets present certain individualities that can best be illustrated by numeric data. The spatial structure of Isfahan shows a weaker value of intelligibility $\left(R^{2}=0.211\right)$ when compared to Istanbul $\left(R^{2}=0.656\right)$. However, considering the mean-GI values, both markets are quite integrated, and are even close to each other (mean-GI value $=1.724$ for Isfahan, and 1.781 for Istanbul).

\section{Spatial relations with the markets}

In this section, the markets are considered from within their boundaries only. The GI-cores in Isfahan are concentrated mainly in the middle of the major streets in the direction of MS (Figure 14.6c). The GI-cores however, do not connect both ends of this street, and therefore, VM stays globally segregated despite being locally integrated. Comparison with the previous analysis shows a weaker value of the intelligibility $\left(R^{2}=0.189\right)$, suggesting that the different local quarters selected by local integration are more effective than global integration.

In Istanbul, the GI-core structure has similarities with the previous analysis (Figure 14.6a). It shows a ring-like characteristic mainly concentrated around OB. In relation to the segregated areas, most of the highly integrated areas are not far apart, but at most, two axial lines away. On the other hand, the strong correlation between the globally and locally integrated spaces $\left(R^{2}=0.782\right)$ suggests that the spatial configuration has not much effect locally, over and above the global structure.

Comparison of the mean-GI values of Istanbul and Isfahan marketplaces shows that there is a large difference in mean-GI values between the two cities; Istanbul has a higher value of 1.615 , compared to 0.692 for Isfahan, which means that the Istanbul marketplace is more integrated and shallower as a whole.

\section{Markets and their space-use patterns}

The space-uses (i.e. spatial categories) and their relationship with configuration are explored here in order to understand certain tendencies in the way in which shops and other commercial buildings are arranged, and how their activities are carried out. In Figure 14.7, the convex maps illustrate the distribution of spaceuses, where each convex space is allocated according to the type of trade carried 


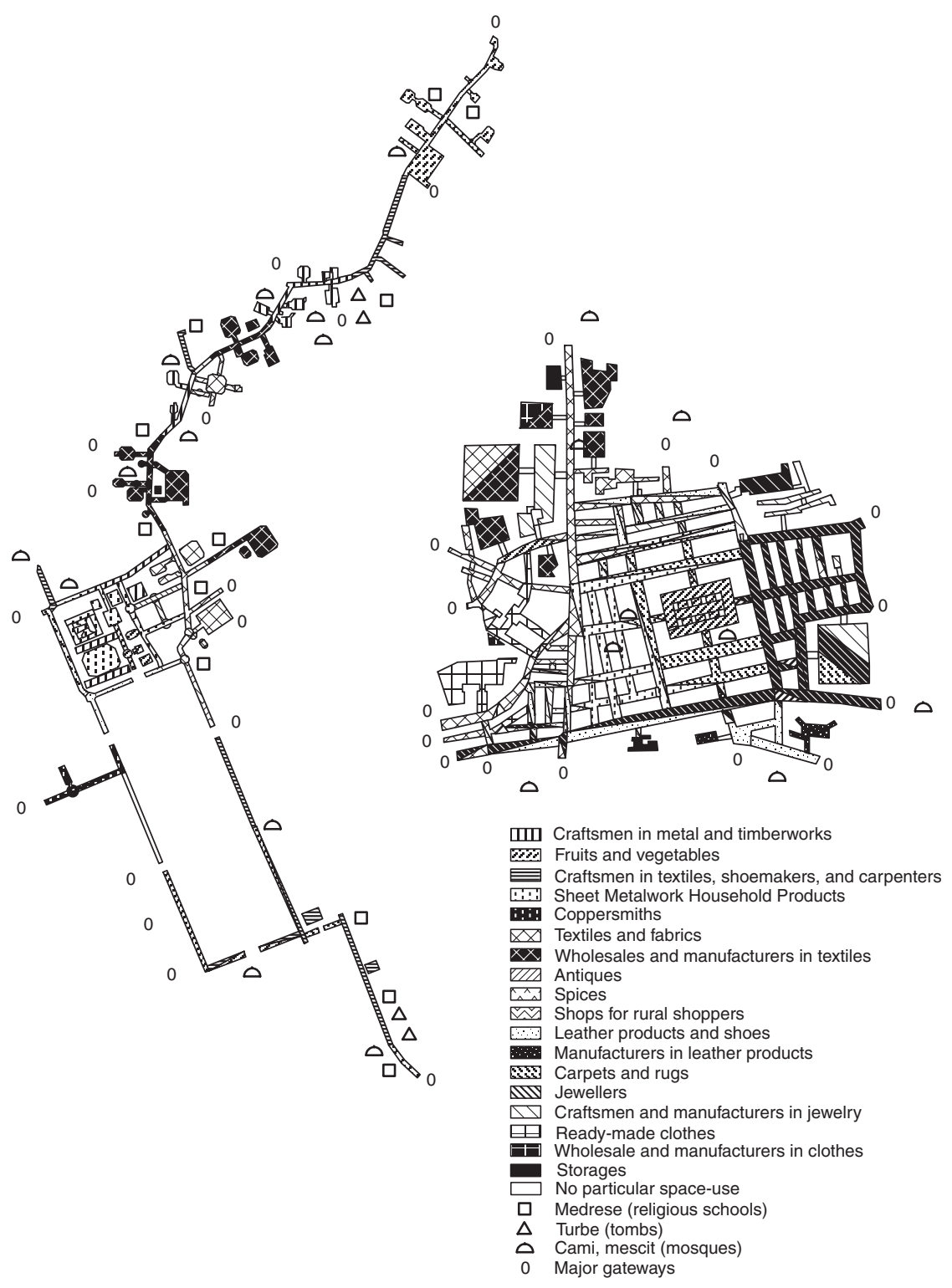

Figure 14.7 Convex maps showing space-use.

out by the shops opening into it. Blank convex spaces indicate that there are no trade activities in them.

Since most shops having similar trade activities share the same convex spaces, in Isfahan their spatial allocation is manifested with the exception of only five 


\section{ISTEK CIHANGIR}

convex spaces out of 297. These exceptional convex spaces (in several shaded tones) mean that there are several different trades carried out among the shops opening onto those convex spaces. On the other hand, in Istanbul, the exception has a much higher value than Isfahan (59 convex spaces out of 234). If we carefully examine the space-use of other buildings, there are many institutional and religious buildings that frequently have their entrances directly opening onto the main market streets, and thus punctuate the market in Isfahan (Figure 14.7). However, in Istanbul, there are only four small mosques within the market complex, and the other institutional and religious buildings are scattered outside.

Furthermore, the mean values of some syntactic properties provide a better picture of the spatial distribution among the major trade activities. For example, in Isfahan, the maximum percentage of space-use among the total of 192 convex spaces belong to shops dealing in trades such as, fruits and vegetables, textile wholesale, and supply-maintenance services. Similarly, in Istanbul, textile shops are also major space-users. Those shops dealing with jewelry, leather products, and ready-made clothes are next most numerous. On the other hand, some trades have certain consistencies in the way in which they are located in the markets. For example, dealers in spices have the highest mean-GI value of 1.655 in Isfahan. The next highest values belong to those dealers selling goods for rural shoppers, the coppersmiths, and the dealers in leather products and carpets. In Istanbul, the highest mean-GI value (1.226) belongs to the dealers in jewelry, followed by similar trades to those found in Isfahan, namely dealers in copper and silver household goods, tourist goods, leather products, and in carpets and rugs. The last three traders have also the highest mean-LI values. In addition, dealers in wholesale and manufacturing businesses occupy the locations with the lowest mean-GI values.

Finally, the locations of dealers in goods for rural shoppers in Isfahan and for tourist goods in Istanbul have the highest mean connectivity and mean control values. This means that these space-users have a good connection to, and the highest control over, their neighboring spaces.

\section{An interpretation}

The remainder of the chapter will discuss where all these findings are leading us. Despite the morphological and geographical differences between Isfahan and Istanbul, one of the important findings was the strong correlation between the locations of their markets and the cities' global integration cores. Since the GI-cores were selected by the distribution of highly integrated lines of sight and access, they are probably the most important superstructures in the urban configuration, and reliable predictors of how cities generate social encounters between different people, and what their patterns are. Particularly, the tendency found in

the way in which the GI-cores connect the markets to the other areas of their cities (i.e. city gates and harbor areas) provides access not only for products and services, but also for strangers into the transaction areas. Meanwhile, the markets 
provide access to private zones, and thus make the residents living relatively near the markets belong to the peripheries. This finding is contrary to that of some earlier studies (Bonine 1979; Hakim 1986) in which it was claimed that the residential areas are hierarchically separated from the markets-especially in Isfahan, where the market and residential areas are so tightly packed that even the study of one, as an independent entity, is nearly impossible. All these facts suggest that a strong natural interface will occur between strangers to the cities and the residents in the marketplace where products and services are offered. That will in turn reinforce an even stronger probabilistic interface involving an "exchange" relationship between the seller and these two groups of customers.

In the local urban context, the markets stand out to a greater degree. They are the local centers of their larger commercial districts, where the production and sale of goods has traditionally been carried out at one place. In view of their highly integrated locations, the market streets will attract a more natural movement of people, and thus, they control the overall commercial activity. From a shopkeeper's viewpoint, the agglomeration of shops at a highly integrated location can be seen as advantageous for production or for reducing marketing fees compared to the same activities carried out in scattered shops. In addition, individual shopkeepers, who own their means of production, can combine and act jointly as members of a larger form of solidarity based on the division of labor (Durkheim 1968).

The analyses within the boundaries of each market revealed the interface patterns between the different groups of space-users. Both markets are highly integrated from the outside. In particular, the compact GI-core found between the main gateways and the major streets suggests that the maximum movement in and out will take place at these spaces. Inside the boundaries, as the global and local integration parameters correlate with each other, the inhabitants (i.e. shopkeepers and craftsmen alike) will control the movement patterns of the visitors (i.e. the customers). However, there seem to be some differences in achieving this control.

\section{Isfahan}

In Isfahan, there is a stronger relationship between the social categories of shopkeepers and their spatial distributions than in Istanbul. That is somehow reflected in the division of labor within the market. The reinforcement of the local aggregate of shops allows for economic processes such as tax collection, goods distribution, and price control, and also allows for customer choice in purchases to be easily conducted (Bonine 1987; Kheirabadi 1993). However, it also leads to a constant interaction for the exchange of professional, political and religious ideas, thus keeping the unity of the shopkeepers in similar trades strong. For example, the evidence of several institutional buildings like mosques, religious schools, and tombs adjacent to each trade activity, their segregated locations in the market, and the strong control over their boundaries, all emphasize the local guild memberships of similar professions. The encounters between the same guild members are intensified through local contacts. Encounters between sellers and 


\section{ISTEK CIHANGIR}

buyers take place in the main street, which is the most integrated space in the market.

In addition, the strong spatial relationship between the mosques and the guilds in which the shops are incorporated, indicate the close ties between the religious and commercial life. This suggests that the socio-spatial agglomeration of the guild members is based not only on economic grounds, but also on religious and political grounds. Some earlier cultural studies on Iran also support the social findings detected by the spatial analysis. For example, according to Kheirabadi, in Iran the importance of the mosque to the local membership is so great that people of certain trades and professions often build their own mosques (Kheirabadi 1993). The mosques provide a sanctuary for members of the same guild, who frequently gather to pray together, and further reinforce their membership ties. Connected with the mosques, the religious schools are for the training of younger members, while the tombs usually belong to either the founders or the leaders. In our spatial analysis, segregated spaces were all of these spaces, where visitors or buyers would normally have little or no access, and which were found to be segregated. Yet, their quiet locations are achieved without totally isolating them from the noisy barter of the main market street.

According to Falamaki (as quoted in Kheirabadi 1993), the functioning of the economic, social, religious, and cultural centers within the single institution of the market is a phenomenon common to the Iranian cities. In many instances, the religious leaders come from the ranks of the market members. Thus, the market lends itself to the discussion of religious matters, which are tightly integrated with the politics and the economy. This also explains why non-Muslim shops remain beyond the walls of the marketplace (Singer and Baldridge 1936). Throughout Iran's Islamic history, the market members have tended to support the religious establishment financially and morally (Kheirabadi 1993). They also often become actively involved in the opposition to those centralized governments that, in the market's view, neglect traditional religious values. Good examples of market members' involvement in politics were seen during the constitutional movement of the early twentieth century and during the Iranian revolution of 1979.

In summary, the market in Isfahan is clearly the heart of the traditional city, and serves as its major thoroughfare. Containing the major public buildings, it functions as a complete integrated system. The market is the center of not only commerce, but also of social, cultural, religious, and political activities as represented by its institutional buildings. These are all tightly connected to the major market routes, and yet each has a separate and self-contained world with its own individual character. This factor particularly, distinguishes Isfahan from the so-called traditional Islamic city model with the Friday mosque at its center.

\section{Istanbul}

In comparison, the association between the social categories and their spatial distribution is sparser in Istanbul. Since several trades occupy many different 
locations in the market, the tendency toward a strong local identity among the shopkeepers is weak. However, these features did not prevail in the marketplace of the past, where each street was strictly devoted to a particular trade or craft, and was organized in a guild (Gulersoy 1990). However, the original layout and many trades have either disappeared, or been replaced with new ones during the course of time from the late nineteenth century when the (Ottoman Empire) state of Turkey was beginning to open up to the West. Today, it is only in a few streets that one can find the original concentration of single trades and crafts that have survived these structural changes, and the national importance of the market has diminished to a state where it now concerns mainly transactions involving gold and silverware.

Again, one cannot find any strong local connections between the shops and the other religious or institutional buildings in Istanbul. The solidarity among the shopkeepers is based on economic or occupational grounds more than religious or political allegiances. That, in turn, would allow all users, whether buyers or sellers, to interact with one another by using the same accessibility pattern, and this is more globally distributed and intelligible than in Isfahan, and thus creates a much wider network and an overall control across the market.

Some earlier studies, although they were not specifically concerned with space, support these social findings of the spatial analysis. For example, Mantran (1962) considers the Muslim brotherhood organizations as being the origin of the occupational guilds in Turkey. However, in the sixteenth century, when centralization by the Ottoman state (during which most of the urban markets were formed) was underway, these organizations became weakened and were transformed into occupational guilds with a rather strong and central administrative character. Since then, in an atmosphere of strong central administration, the guilds in Istanbul could no longer continue their religious and political activities. Thus, the former mentality was virtually lost, or replaced by an occupational mentality. In fact in Turkey today, there are no self-organized religious classes as found in Iran, and the religious figures are under the control of the secular state.

Baer (1970) stresses that there was also a close relationship between the central administration and the Turkish occupational guilds. In the seventeenth and eighteenth centuries, guilds functioned as points of contact between the rulers and the urban dwellers, and they were the means by which the state controlled and governed the multi-ethnic and multi-religious population.

According to Inalcik (1973), markets were shared domains between the Muslims and non-Muslims in traditional Turkish cities, where the ruling classes through endowments carried planned constructions. Inalcik also emphasizes the influence of the central power in social life and in urban economic activity. Markets were mainly places where economic processes such as the distribution of goods, tax collection, and price controls were conducted as part of the administration of the central state. According to Faroqhi (1979), market formations around the market hall called "Bedesten" built by the governing class were already indicative of the penetration of the central administration. 


\section{ISTEK CIHANGIR}

In summary, the market in Istanbul is at the heart of the commercial district in the traditional city. It is also the center for commerce and occupational groups. There are very few institutional buildings, particularly mosques, inside the market. Such facilities are mostly located outside the market, and are dispersed around the city. This factor in particular, distinguishes Istanbul from the traditional Islamic city model with the Friday mosque at its center.

\section{Consistencies between Isfahan and Istanbul}

Along with their differences, the two markets reflect some consistencies in the perceptions of traders. For example, those shops selling popular products (such as tea, coffee, spices, carpets, leather products, copper and silver household, or tourist goods, and products for rural shoppers) occupy the most accessible locations from the outside, to draw the maximum potential from the natural movement of people. Similar shops are also located in highly connected spaces, where they allow easy access to their neighboring trades. This leads us to the notion of "related selling," whereby the customer is persuaded to make another purchase from the next shop selling different goods. Shops concerned with relatively low-cost bulky items (such as those purchased by wholesalers and manufacturers) are located in the least accessible and segregated parts of the markets, whereas high-cost, small items (such as gold and jewelry) are located as close to the integrated spaces as possible.

Finally, some scholars of the Islamic urban form (Hakim 1986; Bianca 2000) have earlier suggested that there is a spatial hierarchy between trades and products sold or distributed according to a "symbolic" or "religious" framework of their location in relation to the Friday mosque. This research has not found any such relationship.

\section{Concluding remarks}

The religious influences in Islamic societies, such as those of Iran and Turkey, have prompted some scholars to consider their cities and urban forms as a pure reflection of Islam. However, it is virtually impossible to make such generalizations for an Islamic city, as there is no "one" Islamic city, and not all cities in the Islamic world are built purely on Islamic principles. What is more important in urban studies is to know how social behavior is ordered in society, as well as in space.

In this chapter, we have shown that the spaces occupied by urban markets and their configurations are predominantly influenced by social relations. Knowing the ways in which this occurs is even more crucial to understanding the differences between cross-cultural examples. The examination of the two classic cases of Isfahan and Istanbul has revealed that the morphologically distinct cities have certain instrumental and symbolic means that are to do with organizing movements and interfaces involving not only the religious, but also the cultural, economic, and political interactions among their people. However, they are also 
strongly related to their two different ways of social structuring of the market space between their inhabitants and customers: the controlled interfaces in Isfahan (as driven by the local rituals), or the probabilistic interfaces in Istanbul (as orchestrated by the overall politics).

Furthermore, the ways in which the different social entities, such as the communities, organizations, cultures, rituals, and politics that form the societies, use the space has an effect and is felt in real space-time relations, and in so doing create the "underlying structural principles" of the cultures through which we recognize cultural identities in spatial morphologies. More awareness of such principles is needed to reveal the whole set of simultaneously existing relations in all classic cities, as well as to evaluate their implications from design proposals for their future developments.

Finally, we consider space syntax as a GIS analytical model and a descriptive theory of space. Although the term "GIS" is not only used for spatial analysis, it can facilitate such analysis to a great extent, and may even provide insights that would otherwise be missed. It is possible, for example, that the representation of spatial data, such as movements, encounters, and space-use patterns that are mostly dealt with by space syntax research, and modeling results using GIS, could lead to an improved understanding both of the attributes being examined, and of the theories or procedures used to examine them. All of these areas suggest a number of possible research directions for future studies including more integrative methodologies with GIS and other computer-aided tools.

\section{Acknowledgments}

This research has been developed at the Center for Spatial Information Science, University of Tokyo, under a post-doctoral fellowship funded by the Japan Society for the Promotion of Science (JSPS), whose patronage is gratefully acknowledged.

The author also wishes to thank Prof. Dr Okabe Atsuyuki, Prof. Dr Asami Yasushi, Dr Orbasli Aylin, and the anonymous referees for their valuable comments.

\section{Note}

1 An earlier version of this chapter has been published as "Spatial Dynamics of Marketplaces" (Discussion Paper Series 20), Center for Spatial Information Science Published Papers, University of Tokyo, vol. 2, pp. 467-490.

\section{References}

Asami, Y., Istek, C., and Kubat, A.S. (2001) "Characterization of the street networks in the traditional Turkish urban form," Environment and Planning B: Planning and Design, 28(5): 777-793.

Abu-Lughod, J.L. (1989) "What is Islamic about a city?: some comparative reflections," Urbanism in Islam: the Proceedings of the International Conference on Urbanism in Islam, vol. 1, Tokyo. 


\section{ISTEK CIHANGIR}

Abu-Lughod, J.L. (1987) “The Islamic city: historic myth, Islamic essence, and contemporary relevance," IJMES 19.

Baer, G. (1970) "The administrative, economic and social functions of Turkish guilds," IJMES 1.

Bianca, S. (2000) Urban Form in the Arab World-Past and Present, Thames and Hudson. Bonine, M.E. (1987) "Islam and commerce: waqf and the bazaar of Yazd, Iran," Erdkunde 41.

Bonine, M.E. (1979) "The morphologies of Iranian cities," Annals of the Assoc. of American Geographers, 69(2): 208-224.

Djait, H. (1986) Al-Kufa: Naissance de la Ville Islamique, Paris.

Durkheim, E. (1968) The Division of Labour in Society (translated by G. Simpson), New York: Free Press.

Faroqhi, S. (1979) "Sixteenth century periodic markets in various Anatolian sancaks," JESHO, 22(1).

Gulersoy, C. (1990) Story of the Grand Bazaar, Istanbul: Istanbul Kitapligi.

Hakim, B.S. (1986) Arabic-Islamic Cities: Building and Planning Principles, London: Routledge \& Kegan Publishing.

Hillier, B. (1999) "Guest editorial: The need for domain theories," Environment and Planning B: Planning and Design, 26(2): 163-167.

Hillier, B. (1996) Space is the Machine, Cambridge: Cambridge University Press.

Hillier, B. and Hanson, J. (1984) The Social Logic of Space, Cambridge: Cambridge University Press.

Inalcik, H. (1973) The Ottoman Empire, Classical Age 1300-1600 (translated by N. Itzkowitch and C. Imber), London.

Istek, C. (1999) "Spatial dynamics of marketplaces" (Discussion Paper Series 20), Center for Spatial Information Science Published Papers, University of Tokyo, vol. 2, pp. 467-490.

Kheirabadi, M. (1993) Iranian Cities: Formation and Development, Austin, Texas: University of Texas Press.

Kuban, D. (1980) "Toward an understanding of architectural symbolism," in Toward an Architecture in the Spirit of Islam (ed. R. Holod), the Agha Khan Awards, Philadelphia.

Marcais, G. (1913) Les Arabes en Bernerie du XIe au XIVe Siecle, Paris.

Marcais, G. (1946) Berberie Musulmane et l'Orient au Moyen Age, Paris.

Marcais, W. (1928) “L'islamisme et la Vie Urbaine," L'academie des Inscriptions et BellesLettres, Comptes Rendus, Paris.

Pauty, E. (1951) "Villes Spontanees de la Villes Crees en Islam," AIEA9.

Peponis, J. (2001) "Introductory remarks: interacting questions and descriptions-How do they look from here?" Proceedings of Space Syntax 3rd International Symposium, Georgia Institute of Technology, Atlanta, May 7-11, pp. xiii-xxvi.

Planhol, X. de (1959) The World of Islam, Ithaca: Cornell University Press.

Singer, C. and Baldridge, C.L. (1936) Half the World is Isfahan, NY-London: Oxford University Press.

Wirth, E. (1982) "Villes Islamique, Villes Arabes, Villes Orientales?: Une problematique face au changement," in A. Bouhdiba and D. Chevallier (eds) La Ville Arabe, Tunis and Paris.

Von Grunebaum, G.E. (1955) Essays in the Nature and Growth of a Tradition, London: Routledge \& Kegan Publishing. 
Part V

\section{THREE-DIMENSIONAL SPATIAL ANALYSIS}





\title{
THREE-DIMENSIONAL VIEW ANALYSIS USING GIS
}

\section{The locational tendency of mosques in Bursa, Turkey}

\author{
Kitagawa Kensuke, Asami Yasushi, and Dostoglu Neslihan
}

\section{Introduction}

Three-dimensional analysis is sometimes very important in understanding the spatial factors in the history and process of urban development. For example, a hilltop may have a very important position from both a strategic and symbolic point of view. In particular, symbolic facilities are often located in relation to their visibility both from and to other places. In this context, an analysis of topographical elements from the view of regional studies can be important.

Geographical information systems (GIS) is equipped with the function of analyzing three-dimensional surfaces. This is sometimes a powerful tool for analyzing the formation of a city, especially in regard to monuments or to large facilities that can become landmarks. For such an analysis, the notion of a triangulated irregular network (TIN) is important.

A TIN is a representation of a surface that is composed of many connected irregular triangulated facets. It is often the case that several points on a land surface are surveyed, and their heights from sea level are known. Such a point is typically represented by $(x, y)$ coordinates and by the height, $z$. By connecting such points in three-dimensional space, we can construct a wire-frame model of the land surface. A TIN can be conceived as a surface in which the plane segments are attached to a frame. Strictly speaking, there are many ways to construct such a TIN, but the most accurate representation is the TIN with triangulated facets resembling, as near as possible, equilateral triangles. A formal definition of such a TIN has been made by Laurini and Thompson (1999). GIS can automatically construct a TIN from the $(x, y, z)$ coordinates.

This analytical tool may be useful for analyzing the development of cities from a three-dimensional point of view. In particular, places like the tops of hills, which can be seen from a wide area, can become politically and strategically important from their characteristic visibility, and they are often chosen as the location of symbolic and strategic facilities, such as religious, political, or military buildings. 
To illustrate the usefulness of the application of TINs, the following section outlines the analysis of the locational tendency of mosques in Bursa, Turkey.

\section{Development of Bursa}

Before describing the analysis proper, it is useful to survey the history of Bursa. Today, the city of Bursa, located to the south of Istanbul in the northwest part of Anatolia, is the fourth largest in Turkey. Historically, the city was established in 185 BC by the Bithynian king Prusias I who named it Prusias ad Olympum. Through time, the name of the city was first converted into Prusa and later into Bursa. The first development of the city occurred in the Hisar (castle) area on a geographical table surrounded by walls that were constructed by the Bithynians. In 74 BC, Bithynia, and thus Bursa, was invaded by the Romans. After the Roman Empire was divided into the Eastern and Western Empires in 395 AD, the Byzantine Era began in the region. Since Bursa was not located on the caravan or trade routes in this period, it remained a small city within castle walls until the Ottomans conquered the city in $1326 \mathrm{AD}$ (Yenal 1996). Bursa, which was included in the Ottoman territories by Sultan Orhan in 1326, became the capital of the Ottoman State, and expanded with the development of organic housing areas around the complexes (kulliye) in different regions outside the castle area, constructed by the five sultans who came to power in Bursa until Istanbul became the Ottoman capital in 1453. Sultan Orhan was the first leader to apply an urbanization model to Bursa, by constructing a complex (kulliye) consisting of a mosque, a Muslim theological school (medrese), a public kitchen (imaret), a public bath, and an inn (bedesten) located outside the city walls in $1339 \mathrm{AD}$ on the brushwood and swamp grounds of the wide Gokdere river bed, which extended from Cakirhamam to Setbasi during that period. The four sultans who came to power after Sultan Orhan in Bursa before the conquest of Istanbul had similar complexes built outside the city walls in different regions of Bursa. Each complex was given the name of the sultan who had built it, and functioned as a core of urban structure (Kuran 1996; Vogt-Goknil 1996; Aru 1998).

The importance of Bursa did not diminish after Edirne was declared as the center for military headquarters in $1365 \mathrm{AD}$ and Bursa became a center where the sultan's families resided and complexes were built (Orbay 1983; Dostoglu 2001), and even after Istanbul became the capital in $1453 \mathrm{AD}$. The Ottoman sultans continued to have inns built in Bursa to provide revenue for the monumental buildings they planned to construct in Istanbul, because Bursa had become one of the most important commercial and production centers in the world between $1450 \mathrm{AD}$ and $1600 \mathrm{AD}$. During this period, Bursa which had an important location on the Silk and Spice Roads, played an important role in the trade of cotton, wool, and especially silk, as well as spices. The importance of Bursa as a commercial center remained until the beginning of the seventeenth century, when it gradually decreased during the seventeenth and eighteenth centuries, as the public land organization in the Ottoman Empire dissolved, and the world trade system experienced changes. The nineteenth century was a period during which the Ottoman 
Empire aimed to regulate its political, social, and economic structure according to Western rules. The transformation in the socio-economic and political structure of the Ottoman Empire, especially in the second half of the nineteenth century, was reflected in the spatial structure of Bursa. Different types of buildings, required by the new socio-economic and political structure in the Ottoman Empire, were constructed, and new roads, bearing the influence of the axial planning tradition of the West, were laid out.

An analysis of the urban pattern in Bursa reveals that kulliyes, which are large urban complexes built by the sultans, may well have influenced the subsequent development of the city. In particular, the Ottoman sultans, who came to power in Bursa before Istanbul became the capital, competed in constructing larger mosques, which are still visually dominant in the city today. This casual observation suggests that the visibility of these kulliyes may well have influenced the formation of the city.

Usually, mosques were located in cities without being influenced by any strategic idea for forming cities. However, the era when Bursa was the capital was a period when the sultans' power extended to its widest reach (Itagaki and Goto 1993). Moreover, the building style of the mosques constructed in Bursa is particularly sophisticated. These factors may indicate some of the intentions behind the construction of these mosques (Jinnai and Tanimizu 1990). To test if there was any strategic choice of location of the mosques in Bursa, the TIN approach mentioned above has been applied and the results are discussed in the following section.

\section{Construction of three-dimensional spatial data}

To proceed with the analysis stage, the GIS spatial data for Bursa was preprocessed to facilitate three-dimensional analyses. The data were made available through the local-scale spatial analysis subgroup of Group 4 of the Islamic Area Studies Project. ${ }^{1}$ This preprocessing involves the construction of a surface model with a TIN, the construction of buildings with solid models, and the attachment of an old map onto the surface model using the drape operation of the GIS package.

The first step was the construction of the surface model with a TIN. In order to construct this model, standard points with data on height above sea level were collected. Such data can be found on topographical maps or in GIS data. In the case of Bursa, the standard points were distributed about every $20 \mathrm{~m}$, which is a sufficient density to reproduce a smooth enough surface model. With these data, the TIN was constructed using GIS, as shown in Figure 15.1. Since the standard points were not distributed evenly, some areas had a dense TIN, while others a sparser TIN. Generally, flat land does not need to have a dense pattern of standard points, while steep and varying land should have a dense pattern of standard points to ensure a good representation of the actual ground surface.

The second step was the construction of buildings represented by solid models. Three-dimensional objects are often represented by polyhedrons. A polyhedron is defined by a set of its vertices, edges, and facets. A solid model is a method of 


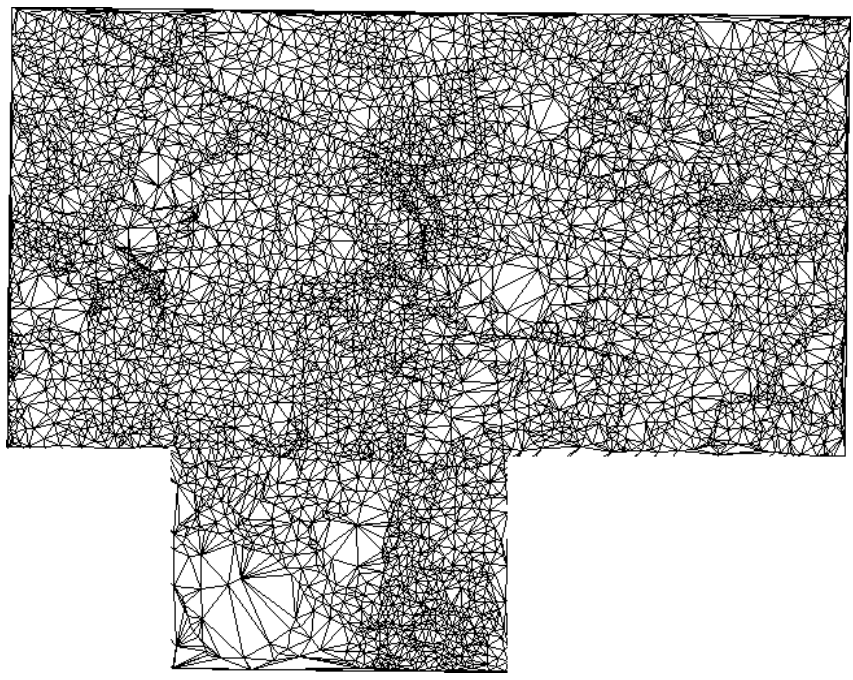

Figure 15.1 A model surface with a TIN.

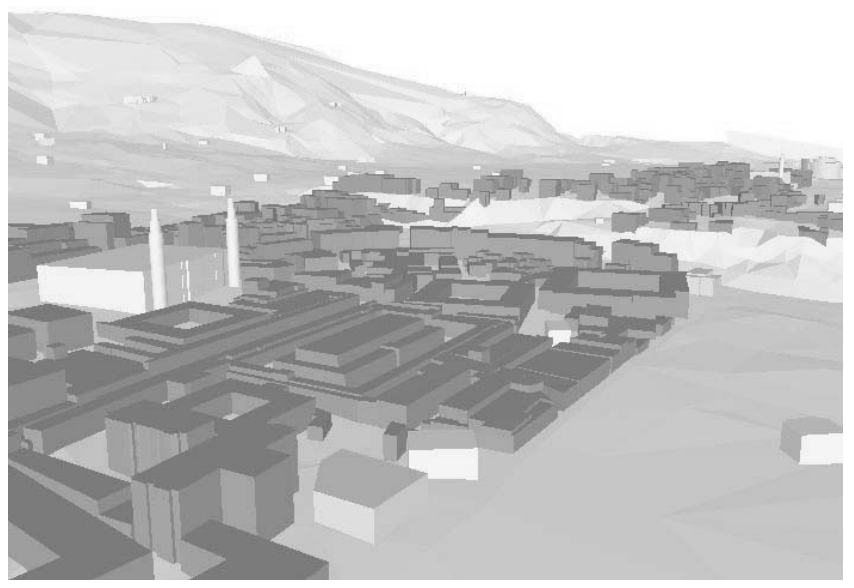

Figure 15.2 Representation of buildings as solid models.

representing a polyhedron so that its inner part is solid. Such spatial data can be constructed by computer-aided design (CAD) software, or by GIS software. In our analysis, the minarets (mosque towers) were very important, and hence, both the buildings and the minarets were constructed as solid models, as shown in Figure 15.2.

Finally, an old map was attached to the ground surface using the drape operation. With this operation, the map, which was originally a plane-like object, was 


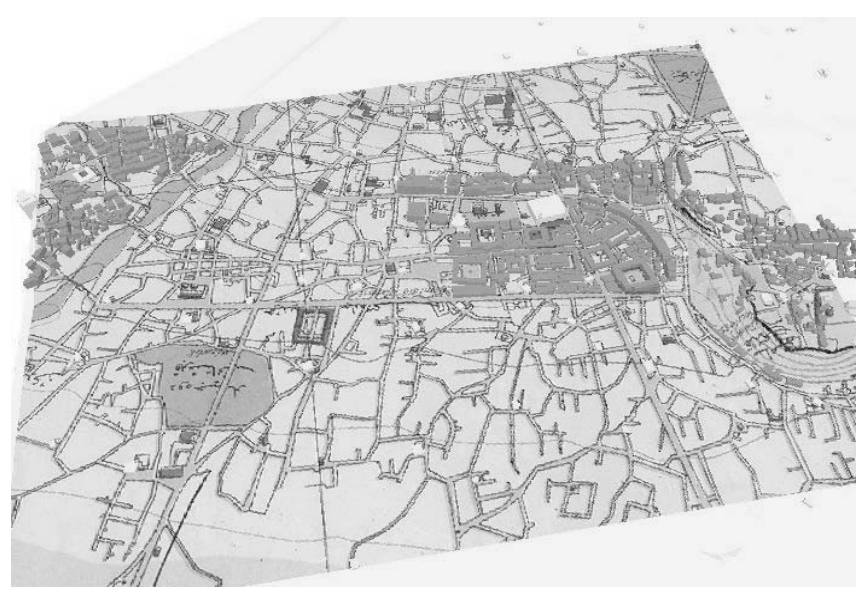

Figure 15.3 Attachment of an old map.

converted into a three-dimensional surface (see Figure 15.3). An old map may not always be very accurate, and some modifications may be necessary. One typical inaccuracy stems from the fact that an old map is not based on an aerial photo, and therefore, a spatial object can be deformed to some extent. In such cases, the old map should be modified using the GIS rubber-sheeting operation, based on an accurate contemporary map. The rubber-sheeting operation continuously transforms spatial objects, just like stretching a rubber sheet on which spatial objects are drawn. There are several methods that have been developed for this operation, and GIS is equipped with such a function (Laurini and Thompson 1999).

\section{Gradient of the slope of mosque locations}

To exemplify the application of a three-dimensional surface, the gradient of the slope of the mosque locations was analyzed. The gradient was calculated for each triangulated facet of the TIN. This was easily calculated using GIS. Figure 15.4 shows the distribution of the gradient of the land around the Green Mosque, which is one of the largest mosques in Bursa. The Green Mosque, which is one of the buildings in the Green Complex, was built during the reign of Celebi Sultan Mehmed from 1419 AD to $1424 \mathrm{AD}$. This Mosque, which is covered with beautiful green tiles in the interior, has two minarets and two large domes, one of which has a lantern.

To analyze whether there was a tendency to locate mosques on rather flat land, the distribution of the gradients of the land where mosques are located were compared with that of land in the city. To do this, triangulated facets were identified where the mosques were located, and their gradients were recorded. To obtain the gradient distribution for the city, the gradients of all the triangulated facets were weighted by their area, and summed. Figure 15.5 shows the result. 

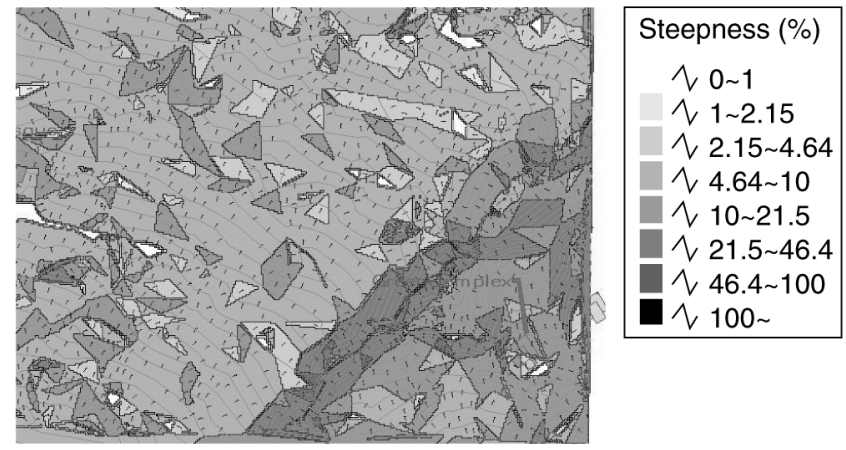

Figure 15.4 Geography surrounding the Green Mosque.
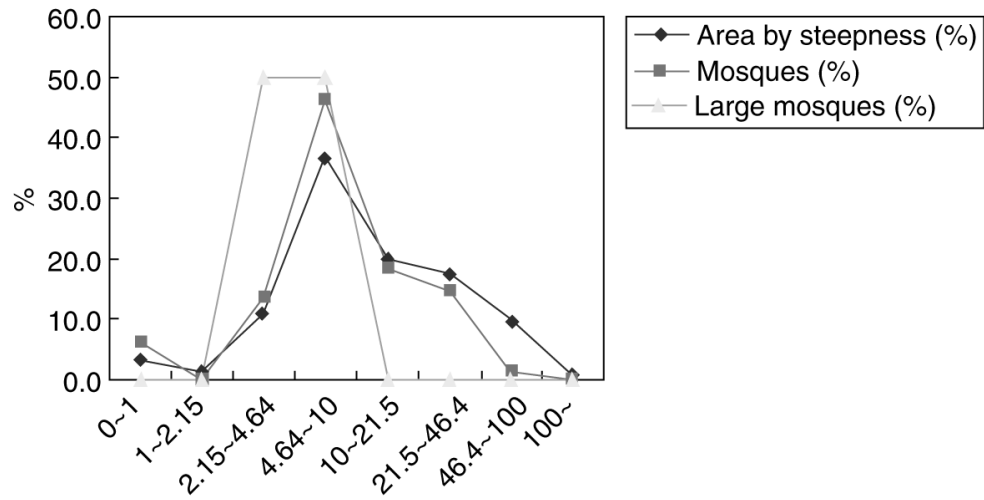

Figure 15.5 The distribution of the gradients of land and mosques.

If the mosques were independently located regardless of the gradient of land, then the distribution of mosques should also follow a similar distribution as the steepness of land. The line representing the mosques in Figure 15.5 indicates the distribution of the gradient of all the mosque locations in the area. The distribution of mosques and that of the land bear a close resemblance. This observation was statistically verified by a chi-square test. Based on this result, we can conclude that generally, mosques were not influenced by the gradient of the land when the site of their location was considered.

The line representing the large mosques in Figure 15.5 indicates the distribution of the four large mosques in Bursa, that is, the Muradiye, Sahadet, Ulu, and Green Mosques. Since the sample size of the large mosques was only four, 
the distributional difference was not statistically significant. It appears, however, that large mosques tend to be located on comparatively flat land. This is quite understandable, for a flat site is more suitable for the construction of large buildings.

\section{Visible areas}

To illustrate another analysis technique using TIN data, the visibility of mosques in an area was analyzed as follows.

Large mosques in Bursa, constructed by powerful sultans, may have been located on sites where their visibility was as large as possible. Since mosques are religious buildings constructed to commemorate the sultans, they should have been intended to exhibit the dignity of the sultans to the people at that time. To check this, visibility area analysis was conducted.

A visibility area is a region in which the object in question is visible on the land surface, provided that no other buildings are located in the area. Such an area can be calculated using GIS. It is noted that if point $\mathrm{X}$ is visible from point $\mathrm{Y}$, then point $Y$ should be visible from point $X$, too. This symmetric relation implies that the visibility area of a mosque is given by the area which is visible from the mosque.

To analyze this hypothesis, we focused on three visibility areas, namely, the visibility area of the minaret (tower), that of the dome, and that of the whole silhouette of the mosque. Naturally, a higher minaret has a larger visibility area than a lower one. The visibility area of the whole silhouette of the mosque is less than that of the minaret, or that of the dome. The analysis of the visibility area was conducted for the whole study area (whole area) where the city map was available, and for the area when it was urbanized in the fifteenth century (fifteenth century area).

Figure 15.6 indicates (by the grey color) the visibility area of the minaret of the Green Mosque for the whole area in question. To show that the visibility area of a location is large, the location has to be compared with other locations. To do so, 100 reference points were plotted on the study area at a constant interval (Figure 15.7). For each of the 100 reference points and the four locations where the large mosques actually exist, the visibility area was calculated using the condition that the mosque constructed was of equal size to the Green Mosque, that is, a mosque with a $35 \mathrm{~m}$ high minaret and a $26 \mathrm{~m}$ high dome. It was assumed that the whole silhouette of the mosque was visible from a point $2 \mathrm{~m}$ high at the location of the mosque. Figure 15.7 shows the comparison of the visibility areas of the whole silhouette for all 104 points. The area of each circle is proportional to the visibility area of the point.

As a result of these analyses, it was found that the visibility area of the Green Mosque is relatively high. In particular, the visibility area of the whole silhouette for the fifteenth century area is ranked the highest. That is, if we confine the city area to the urbanized area in $1451 \mathrm{AD}$, and calculate the visibility area, then the 


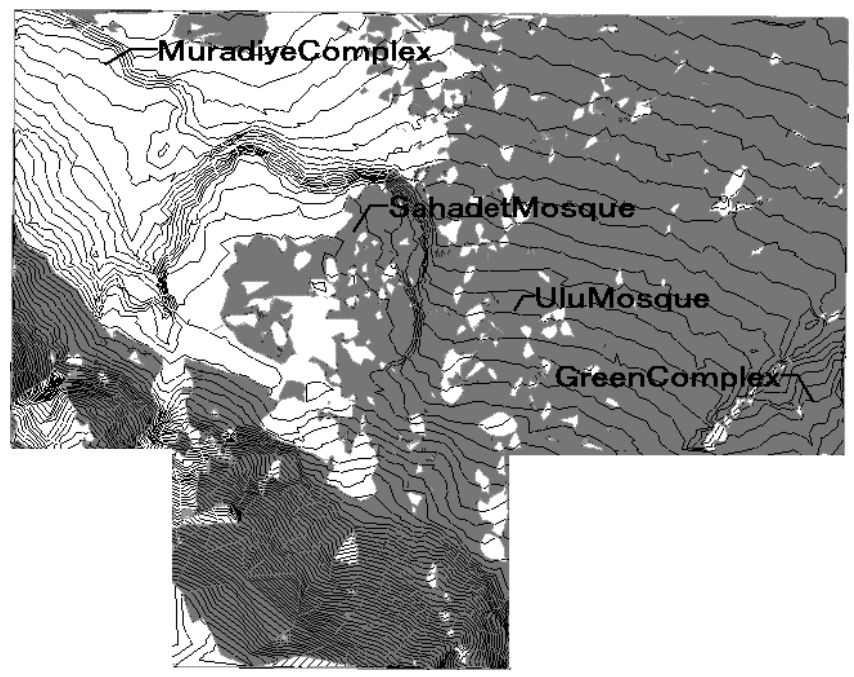

Figure 15.6 The visibility area of the minaret of the Green Mosque for the whole area.

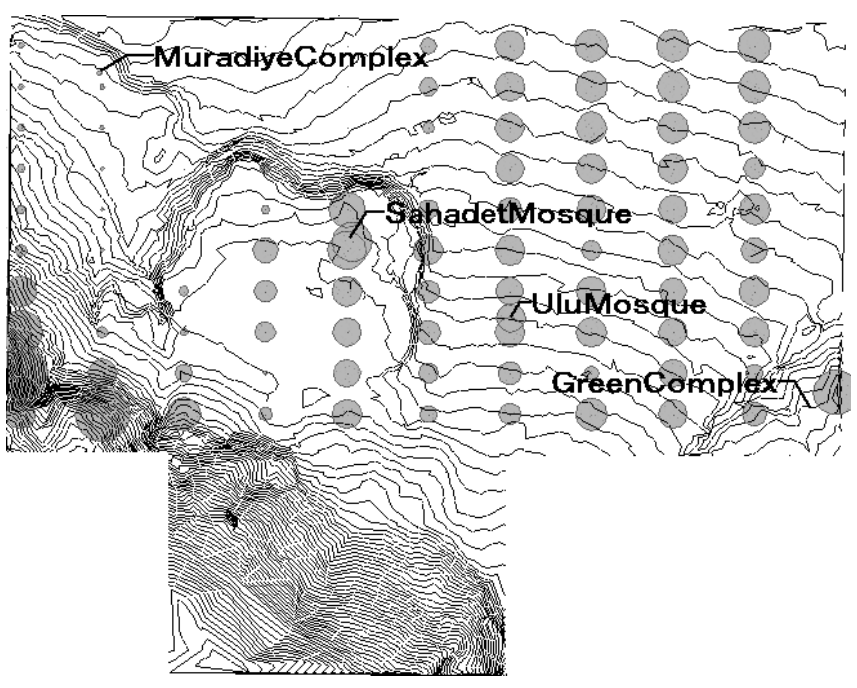

Figure 15.7 Visibility areas of the whole silhouette for the fifteenth-century area.

visibility area of the whole silhouette of the Green Mosque at the actual location is the largest among all the visibility areas of the 104 locations. Thus, it can be concluded that the Green Mosque was constructed where its visibility area of the whole silhouette was the largest possible. 


\section{Reconstruction of the townscape}

Part of the townscape can be reconstructed using the three-dimensional data. Among these, Figure 15.8 is of particular interest. This is a scene from the bazaar in the direction of the Green Mosque. The Green Mosque is visible from the bazaar.

Figure 15.9 indicates the view direction by a line. The road, which was constructed in the twentieth century, replaced a narrower road which existed there before the twentieth century. In Islamic cities, roads were seldom constructed in a straight line (Miura 1997), and we can infer that the road network may have been influenced by the visibility of the larger mosques.

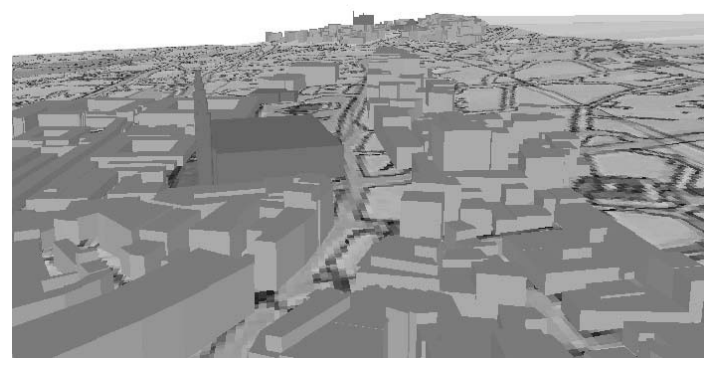

Figure 15.8 View from the bazaar in the direction of the Green Mosque.

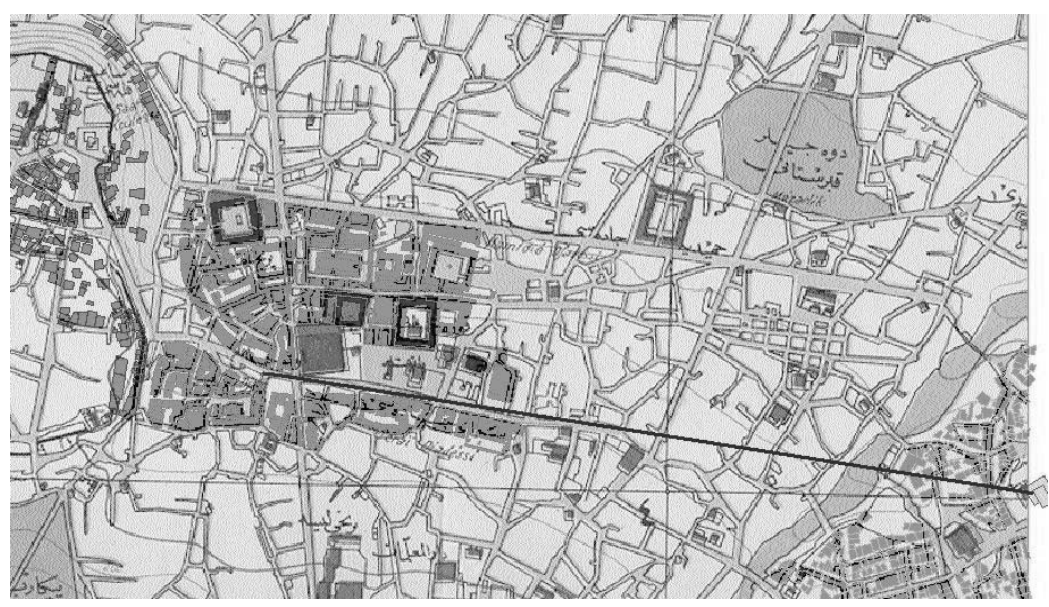

Figure 15.9 Visibility line along the road from the bazaar in the direction of the Green Mosque. 


\section{Conclusions}

The construction and analysis of three-dimensional data have been illustrated by the application of the analysis to the reasons for locating the large mosques at their sites in Bursa. Given standard points having a known height from the ground, the ground surface can be easily approximated by a TIN. In this chapter, the steepness, visibility area, and view were analyzed based on the constructed TIN.

It was demonstrated that the Green Mosque is located where the visibility area of its whole silhouette was the largest when it was constructed, and that part of the road network was constructed so that the Green Mosque is a visible landmark along the road. These results support the hypotheses that the sultan constructed a large mosque where its visibility would be high, and that the visibility of the large mosque was influential in forming the road network of the city.

The conformity of the hypotheses in this chapter should be checked with historical documents in order to reach a definite conclusion. However, spatial analyses such as that demonstrated can be a powerful tool in constructing potentially useful propositions and in testing them spatially.

\section{Acknowledgments}

We have benefited from the comments on an earlier version of this Chapter by Naoko Fukami, Istek Ismail Cihangir, and Hidenobu Jinnai. We are grateful to Kubat Ayse Sema for providing us with privileged use of the data, Atsuyuki Okabe, Yukio Sadahiro, and an anonymous referee.

\section{Notes}

1 In particular, we are grateful to Professor Dr Ayse Sema Kubat of Istanbul Technical University, who kindly provided us with privileged use of the data.

This thesis is based on Dostoglu, Kitagawa, and Asami (2004, forthcoming).

\section{References}

Aru, K.A. (1998) Turk Kenti, Istanbul: YEM Yayin.

Dostoglu, N. (2001) Bursa in the Ottoman Period, Antalya: AKMED.

Itagaki, Y. and A. Goto (eds) (1993) The Urbanism of Islam, Tokyo: Japan Center for Promotion of the Sciences.

Jinnai, H. and J. Tanimizu (eds) (1990) Turkey: Pilgrimage to Cities, Tokyo: Process Architecture.

Kuran, A. (1996) "A spatial study of three Ottoman capitals: Bursa, Edirne, and Istanbul," Muqarnas, XIII: 114-131.

Laurini, R. and D. Thompson (1999) Fundamentals of Spatial Information Systems, London: Academic Press.

Miura, T. (1997) The World of Islamic Cities, Tokyo: Yamakawa Publishing Co.

Orbay, I. (1983) Bursa, The Istanbul: Aga Khan Award For Architecture: 1983 Awards Ceremony Local Office.

Vogt-Goknil, U. (1966) Living Architecture: Ottoman, London: Oldbourne.

Yenal, E. (ed.) (1996) Bir Masaldi Bursa, Istanbul: YEM Yayin. 


\title{
AN ANALYSIS ON THE VISIBILITY OF MINARETS IN SANA'A OLD CITY OF YEMEN
}

\author{
Oikawa Kiyoaki
}

\section{Understanding Islamic cities from sight line}

It has long been known that there are seven towns, including Ghardia, in M'zab Valley at the northern tip of the Sahara Desert in Algeria. All seven towns sit atop hills and are surrounded by city walls. At the peak of each hill towers a native minaret, and courtyard houses coil around the minaret (see Figure 16.1). Climbing up a winding road, one reaches the mosque at the summit. Although the minaret is no more than about $10 \mathrm{~m}$ tall, it not only serves as a symbol of the city's scenery, but also controls the city's spatial structure. There is supposedly a spatial rule that no house may be more than $7.5 \mathrm{~m}$ high, so that the minaret is visible from all the houses. The sight lines connecting the residents' eyes and the minaret control the form of the urban space.

The towns of M'zab Valley teach us that "sight line" is one of the keys to gaining a better understanding of the spatial characteristics of Islamic cities.

There are two types of sight lines: obstructed and unobstructed. Obstructed sight lines are used to keep something out of the view of outsiders. Obstructed sight lines were an important factor in forming the maze-like streets and courtyard houses in the cities of M'zab Valley, as well as the Islamic cities in the Middle East, particularly Medina. As the winding maze-like streets obstruct view, they serve as an effective means of defense. The façade of courtyard houses is very simple and the window location, height, and shape are designed to prevent pedestrians from peeping in from the street. The windows on the street side are a bare minimum. In addition, the alley into the courtyard is often bent so passersby cannot directly look into the courtyard. Islamic society's prohibition of peeping into others' lives and, in particular, the custom of keeping women from the view of others, affect the design of the housing. Courtyard houses obstruct view from the outside and focus the sight lines into the courtyard.

Naturally, sight line is not the only deciding factor of the design of the maze-like streets and courtyard houses. Climate and other natural, as well as 


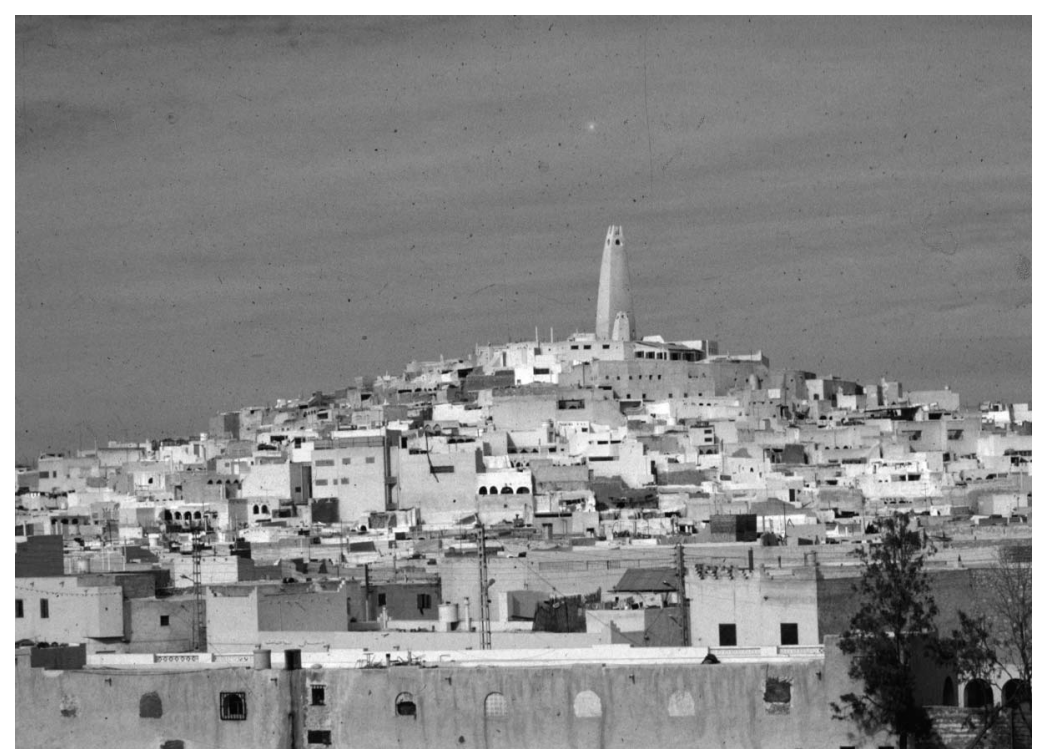

Figure 16.1 View of Ghardia in M'zab Valley.

social, conditions come into play. It is clear, however, that sight line directly affects the architectural and urban space compositions.

At the opposite end of the obstructed sight line is the unobstructed sight line. The minaret of a mosque is an example of an urban space component that is designed to be seen. While the foremost function of a minaret is to inform people that it is time for worship, it also has a visual function of symbolizing the existence of a worship facility. It is a device designed to be seen. Although the shape and size of a minaret differ greatly between regions, its distinguishing feature is its decorations with many small windows, sculptures, and tiles. Islamic city spaces are a mixture of obstructed and unobstructed sight lines.

\section{The visibility of minarets}

A minaret is a representative component that characterizes the landscape of an Islamic city. As an especially tall minaret can be seen from a distance, it serves as an urban landmark. While a minaret is obviously highly visible, very little calculation has been performed to determine exactly how visible a minaret is. No one, for example, has actually verified the visibility of the minarets in Ghardia, where it is claimed that the minarets can be seen from every household. More specifically, it has been difficult to calibrate visibility. Naturally, it would be possible to measure visibility by conducting an extensive on-site survey. Such a survey, however, would require excessive labor and time. Geographical information 
systems (GIS) is a technology that simplifies the calibration. By using spatial data, it would be possible to conduct simulations based on various scenarios, besides analyzing the current situation.

The aim of this chapter, therefore, is to reveal the characteristics of urban space compositions by placing the focus on the unobstructed sight lines in Islamic cities (i.e. the visibility of minarets) and analyzing the visibility with GIS from the viewpoint of urban landscape analysis. The old city of Sana'a, capital of Yemen Arab Republic, is used as a model for this analysis. The specific themes of this study are as follows:

1 Obtain an estimated value of the visibility of the minarets from the streets.

2 Clarify the locations where the minarets are highly visible, the locations where the minarets are often viewed, and the lengths of the sight lines.

3 Elucidate the effect of the characteristics of Sana'a's urban space compositions on the visible volume of the minaret.

4 Verify whether the minarets are well positioned for visibility.

\section{Overview of Sana'a Old City}

\section{Downtown}

First, let us take a general view of the city of Sana'a. The central highland area surrounding Sana'a is geographically at one of the highest elevations on the Arabian Peninsula. Sana'a is located near the center of the central highlands, at an elevation of approximately $2300 \mathrm{~m}$. Compared to the dry inland areas of the Arabian Peninsula, Sana'a is rich in greenery and has been called Arabia Felix, or Happy Arabia, since ancient times. Sana'a has prospered as a strategic trade center since the days of the Sabaean Kingdom of ancient Southern Arabia. It is a city that boasts a long history and culture (see Figure 16.2).

Surrounded by thick city walls, Sana'a Old City encompasses an area that is $1 \mathrm{~km}$ from south to north and $1.5 \mathrm{~km}$ from east to west or approximately $140 \mathrm{ha}$ (see Figure 16.3). Geographically, the eastern end of Old City is higher than the rest of the Old City, and located at the highest point is a fortress called Qasur al-Silah. In the western section of Old City, a wadi (river) named Wadi al-Silah runs from north to south and is used as a road.

In Old City, as in any other Islamic cities in Middle East Arabia, narrow alleys form a complex maze. Located at the center of Old City is central souq that is approximately 1.6 ha in size. Elements that are unique to Islamic cities, such as mosque, hammam, and samsarat (caravansary) can be found at various points in the city.

\section{Tower house}

A typical house in an Islamic city in Middle East Arabia is said to be a courtyard house. In Sana'a, on the contrary, visitors find tall tower houses that are as high 


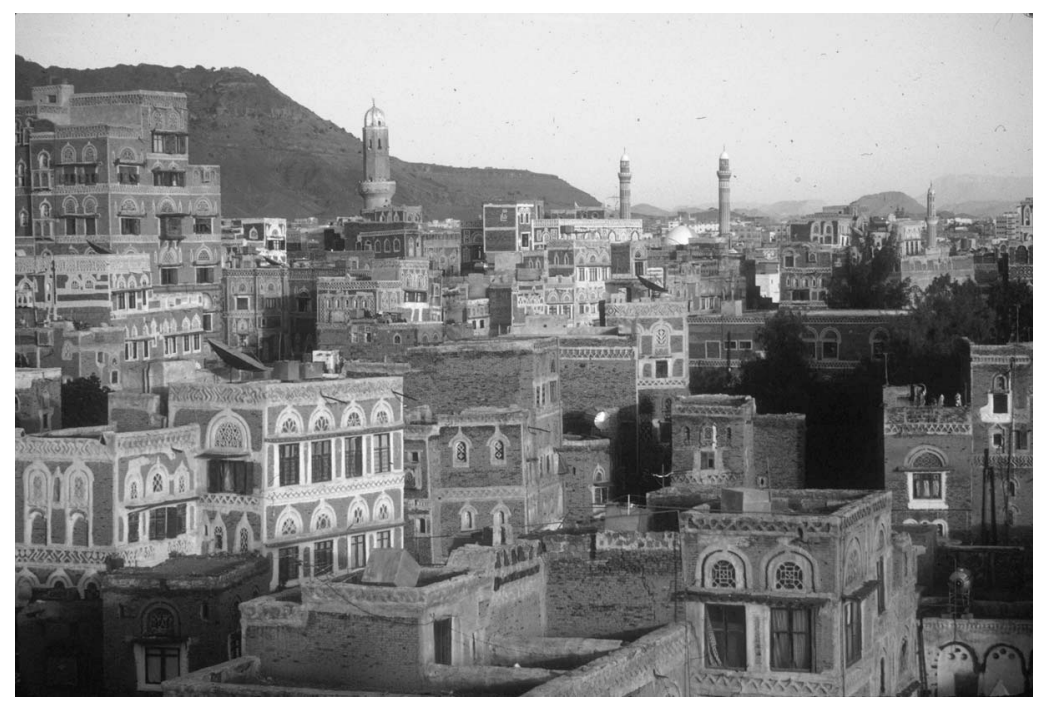

Figure 16.2 View of Sana'a Old City.

as seven stories (see Figure 16.4). Sana'a is referred to as "the oldest skyscrapercity in the world," and is designated as a World Heritage by UNESCO. Inside the city walls are some 7500 residential units.

The lower floors (first and second floors) of tower houses are used as entrance halls and warehouses and have very few windows. The upper floors (third floor and up) are used as residential floors. Each residential floor is separated into male and female spaces. Unlike the lower floors, which are closed, the upper floors feature decorated walls and windows that open to the picturesque scenery. On the top floor is mafraj, or an observation room where men relaxed. The large windows of mafraj provided a panoramic view of the many tower houses and minarets in the city.

While tower houses can also be seen in the mountain villages around Sana'a and Shibam, a city in the eastern part of Yemen, they are nevertheless rare residential constructions that are limited in dispersion.

\section{Greenery}

Besides tower houses, urban farmlands (greenery) are another distinctive feature of Sana'a Old City. These farmlands are called bustan and megsharnat (fruit orchard and vegetable farm, respectively) that have been donated to the mosque (see Figure 16.5; for the sake of convenience, they are simply referred to as bustan in this chapter). Each bustan is surrounded by a dense construction of tower houses and can be found at various points in Old City. Larger ones exceed 3 ha and their total area account for some $16 \%$ of Old City. 


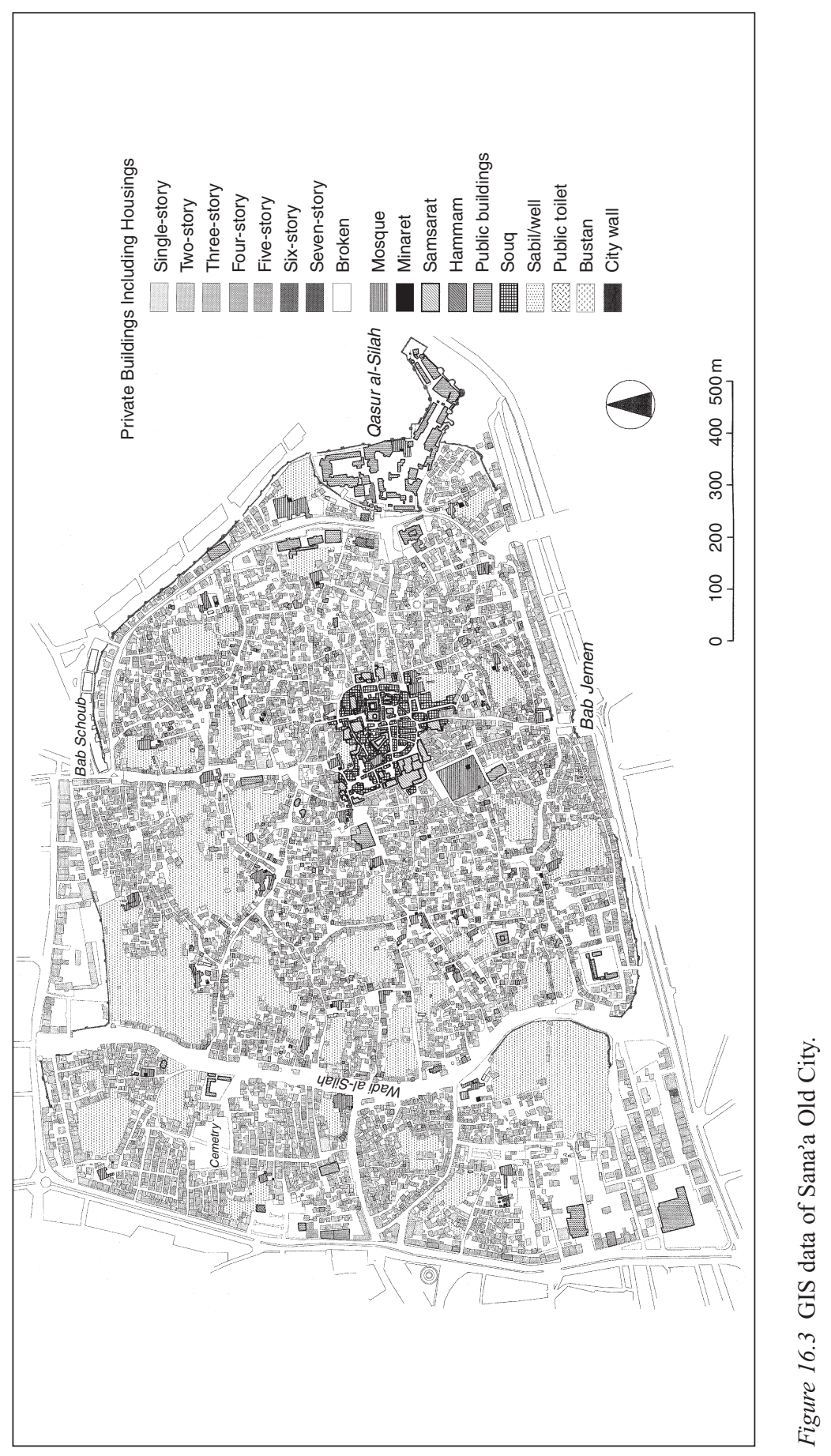




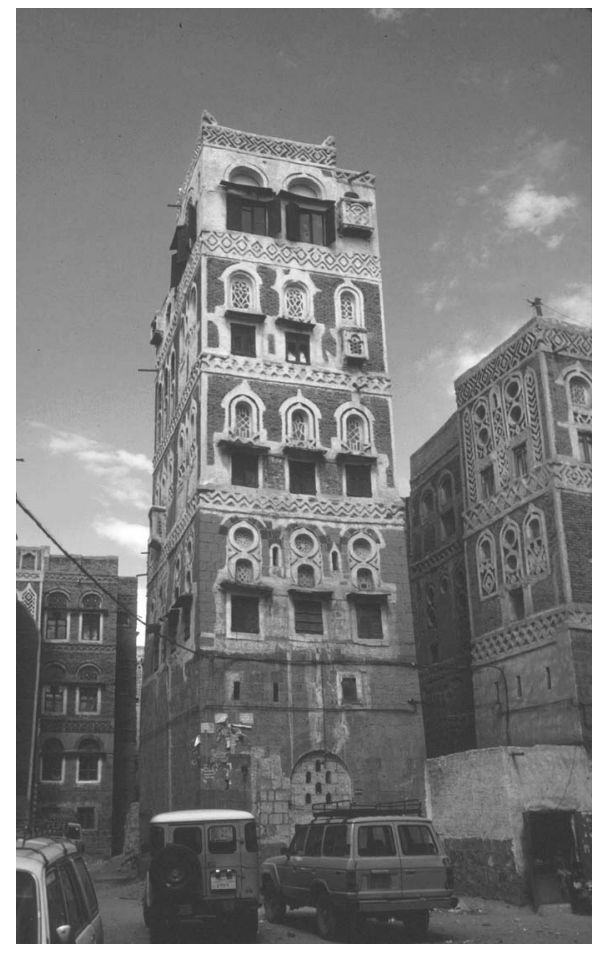

Figure 16.4 Tower house.

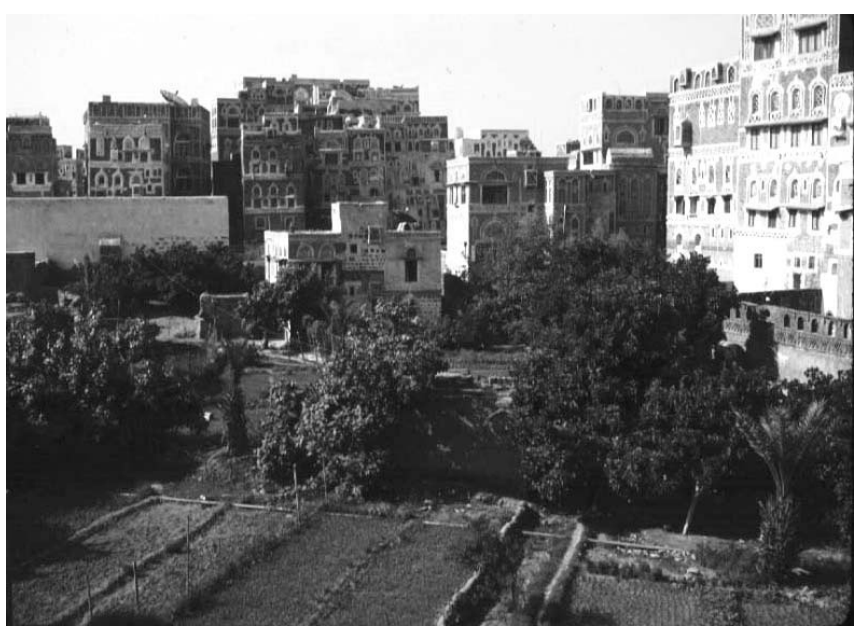

Figure 16.5 Bustan. 


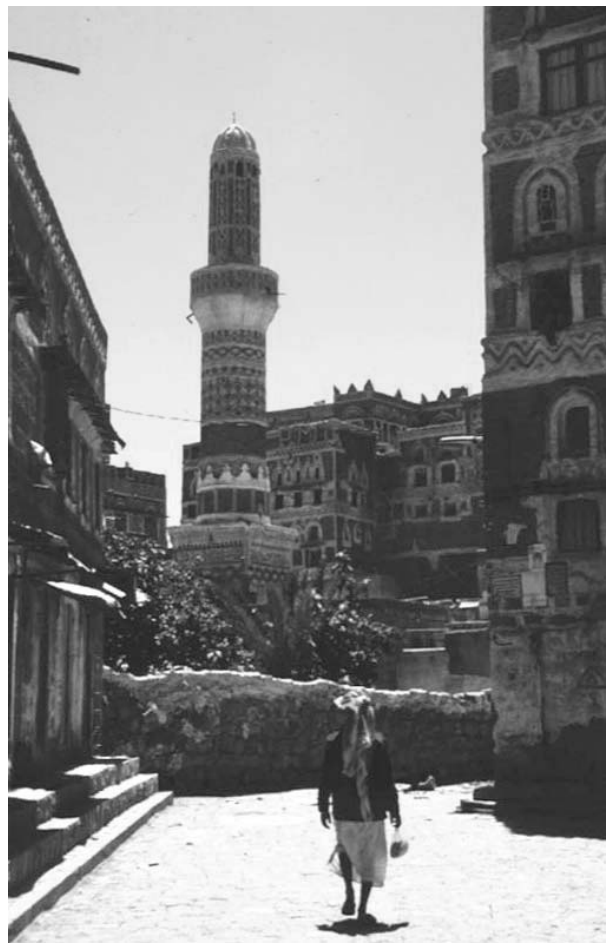

Figure 16.6 Minaret.

\section{Minarets}

In addition to the bristling tower houses and bustan, minarets are important elements that characterize Sana'a's urban landscape. Walking through the city, one can occasionally see the minarets from narrow streets (see Figure 16.6). The minarets serve as landmarks of the city.

\section{Creation of three-dimensional spatial data of Sana'a Old City}

\section{Residences and public buildings}

The author obtained a map of relatively high precision (scale of 1/1000) of Sana'a Old City. ${ }^{1}$ Based on this map, digitized location data and attribute data (e.g. usage, number of floors, and location of entrance) of buildings, bustan, and blocks were input to create a database (see Figure 16.3 before). Table 16.1 shows the land area by land use that was derived from this spatial data. Buildings occupy approximately $40 \%$ of the total land area, while bustan and other open spaces occupy the remaining $60 \%$. 
OIKAWA KIYOAKI

Table 16.1 Land use in Sana'a Old City

\begin{tabular}{lrrr}
\hline Land use & Area $(\mathrm{ha})$ & Ratio (\%) & Number \\
\hline Private buildings & & & \\
Single-story & 6.32 & 4.51 & 1087 \\
Two-story & 12.00 & 8.57 & 1806 \\
Three-story & 15.91 & 11.36 & 2399 \\
Four-story & 10.10 & 7.21 & 1692 \\
Five-story & 1.63 & 1.16 & 322 \\
Six-story & 0.07 & 0.05 & 17 \\
Seven-story & 0.03 & 0.02 & 2 \\
Broken & 0.75 & 0.54 & 146 \\
Subtotal & 46.82 & 33.43 & 7471 \\
Facilities & & & \\
Mosque & 2.72 & 1.94 & 43 \\
Samsarat & 0.70 & 0.50 & 20 \\
Public building & 1.45 & 1.03 & 22 \\
Hammam & 0.19 & 0.13 & 13 \\
Public toilet & 0.08 & 0.06 & 24 \\
Sabil (well) & 0.15 & 0.11 & 46 \\
Souq & 1.58 & 1.13 & 115 \\
Subtotal & 6.87 & 4.90 & 283 \\
Open spaces & & & \\
Bustan & 22.33 & 15.95 & 40 \\
Around buildings & 35.78 & 25.55 & - \\
Road-square & 28.25 & 20.17 & - \\
Subtotal & 86.36 & 61.67 & - \\
Total & 140.05 & 100.00 & \\
\hline
\end{tabular}

Unlike two-dimensional data, it is extremely difficult to obtain accurate data on the heights of buildings. Although insufficient to judge visibility, the only means currently available to determine the height is by the number of floors. For the purpose of the study, it is assumed that each floor of residence is $3 \mathrm{~m}$ in height and that the mosque, samsarat, hammam, and other public buildings are all $8 \mathrm{~m}$ in height. Furthermore, a building in souq is assumed to be $4 \mathrm{~m}$ high. Fences and trees are ignored.

Three-dimensional data is used by assuming that all the buildings are polygonal column in shape (see Figure 16.7). Furthermore, elevation differences are ignored, as there are few undulations in Old City, other than in Qasur al-Silah in the eastern area.

\section{Locations and heights of minarets}

Inside the city walls are 45 mosques that range from small to large. According to travel guidebooks and literature on Sana'a, there are 64 minarets in Old City. As mosques sometimes have more than two minarets each, the claim that there are 64 minarets for 45 mosques may not necessarily be exaggerated. Despite 


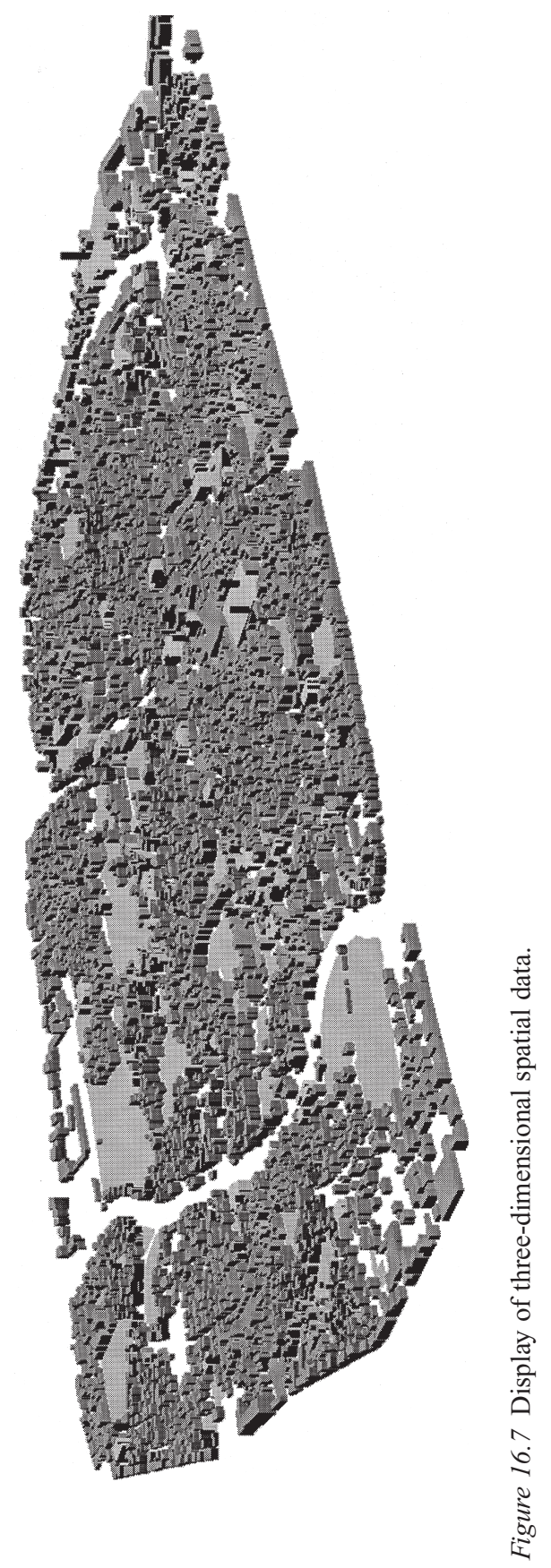


an extensive search through reference materials, the author could not verify that there are 64 minarets. The map may not reflect all the minarets. The 64 minarets may include those outside Old City. In any case, the author could actually confirm 31 minarets on the map. This, however, is a conservative figure. The map symbol for minaret is a circle, but so is that of a dome and sabil. About eight symbols on the map were difficult to decipher. The 31 confirmed minarets were clearly represented by the map symbol for minaret in the map legend (circle symbol and the characters "MIN"). Of these, two mosques have two minarets each.

Next, the author researched the height of the minarets. Drawings on principal mosques are provided in the literature (Serjeant and Lewcock 1983). The height of only seven minarets can be determined from this literature. The two minarets at the Great Mosque next to central souq are $37 \mathrm{~m}$ high. The other minarets are $46 \mathrm{~m}, 41 \mathrm{~m}, 25 \mathrm{~m}, 24 \mathrm{~m}$, and $15 \mathrm{~m}$ high. In subsequent analysis, we shall designate these seven minarets as "group A," and assume that their heights are as shown in the drawing of the literature. While the locations of the other 24 minarets are certain, their heights are not. These minarets are designated as "group B" (see Figure 16.8). This chapter therefore analyzes the visibility of these 31 minarets.

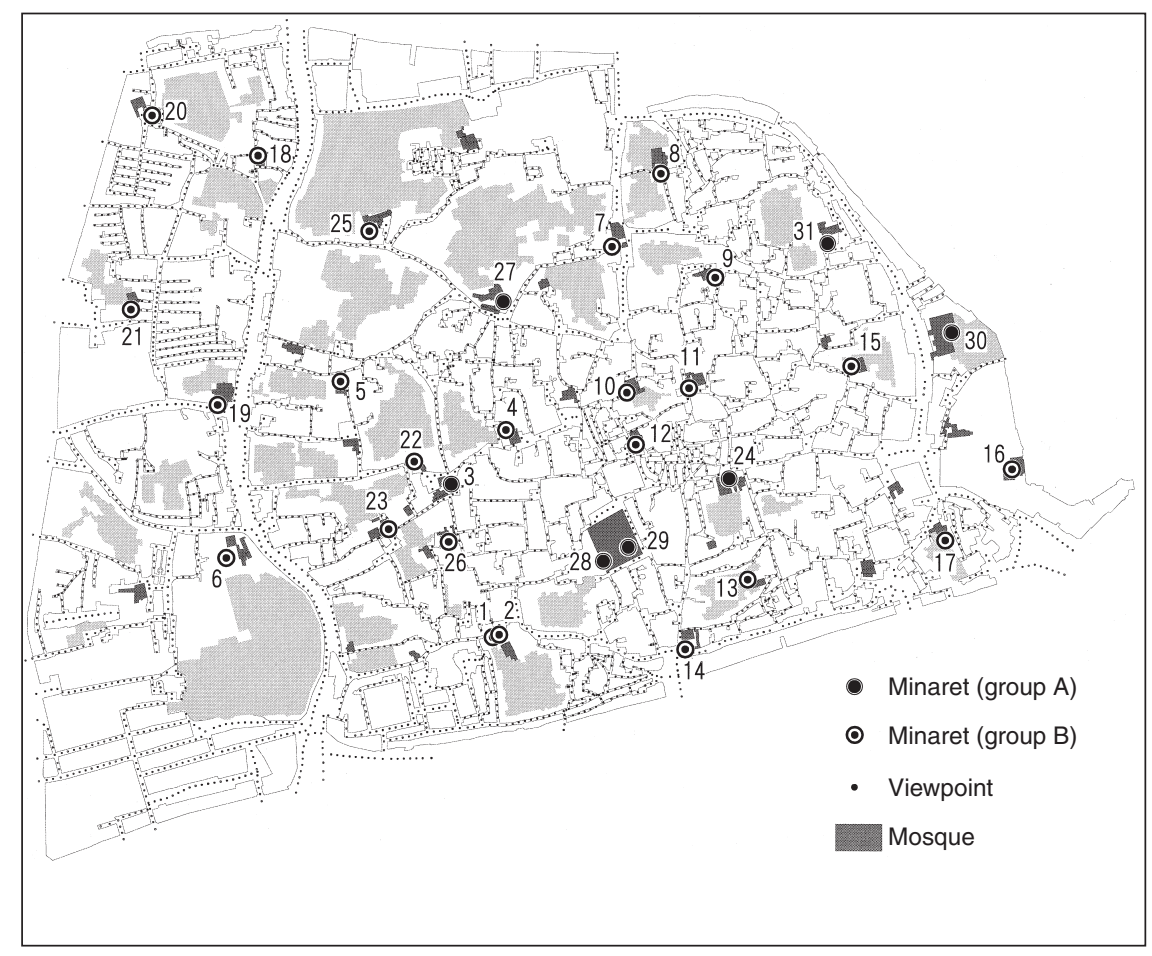

Figure 16.8 Locations of mosques, minarets, and viewpoints. 


\section{The method of counting visible quantity of minarets}

\section{Sight line from viewpoint to minaret}

In order to calculate the visible volume from the streets, it is necessary to define the method of measurement. First, each viewpoint is assumed to be in the center of the width of each street. The height of each viewpoint is assumed to be $1.6 \mathrm{~m}$ from the ground. The smaller the interval between viewpoints, the higher the precision. For this research, the author set the viewpoints $10 \mathrm{~m}$ apart, since the average building area per tower house is approximately $60 \mathrm{~m}^{2}$; assuming that the floor space is rectangular, the tower house would be approximately $8 \mathrm{~m}$ wide. The scope of viewpoints is almost within the city walls. Visibility of minarets from outside of Old City is excluded from the calculation. According to these premises, there are 3846 viewpoints (see Figure 16.8). As the viewpoints were adjusted to prevent concentrations near street intersections, the value is different from the figure derived simply by dividing the actual length of the streets, or $47525 \mathrm{~m}$, by $10 \mathrm{~m}$. As the center of wadi is used for automobile traffic and both sides for pedestrian traffic, the number of viewpoints is doubled for the length of wadi.

The judgment of visibility is very simple. An imaginary line is drawn between the viewpoint and the top of the minaret. If the imaginary line is not obstructed by any of the polygonal column buildings, the minaret is deemed to be visible.

\section{Measurement of visible volume}

The expression that minarets are "highly visible" from a street may mean either that many minarets are visible or that a minaret can be seen from many viewpoints. By calling the number of minarets that are visible from a given viewpoint as the "visible quantity," the former can be measured by the number of minarets that are visible from a given viewpoint (or "average visible quantity") and the latter can be measured as the percentage of visible viewpoints out of total viewpoints (this is called "visible rate"). The average visible quantity and visible rate can be generally referred to as "visible volume." "Visible point" refers to a viewpoint where the visible quantity is not zero or, in other words, where at least one minaret is visible.

\section{Estimation of minaret visible volume and characteristics of visibility}

\section{Estimation of average visible quantity and visible rate}

The author calculated how many minarets were visible from viewpoints on the streets according to the premises above. Since the heights of the minarets in group B are unknown, let us first determine the fluctuation in visible volume from height. Figure 16.9 shows the changes in the average visible quantity and visible rate 
OIKAWA KIYOAKI

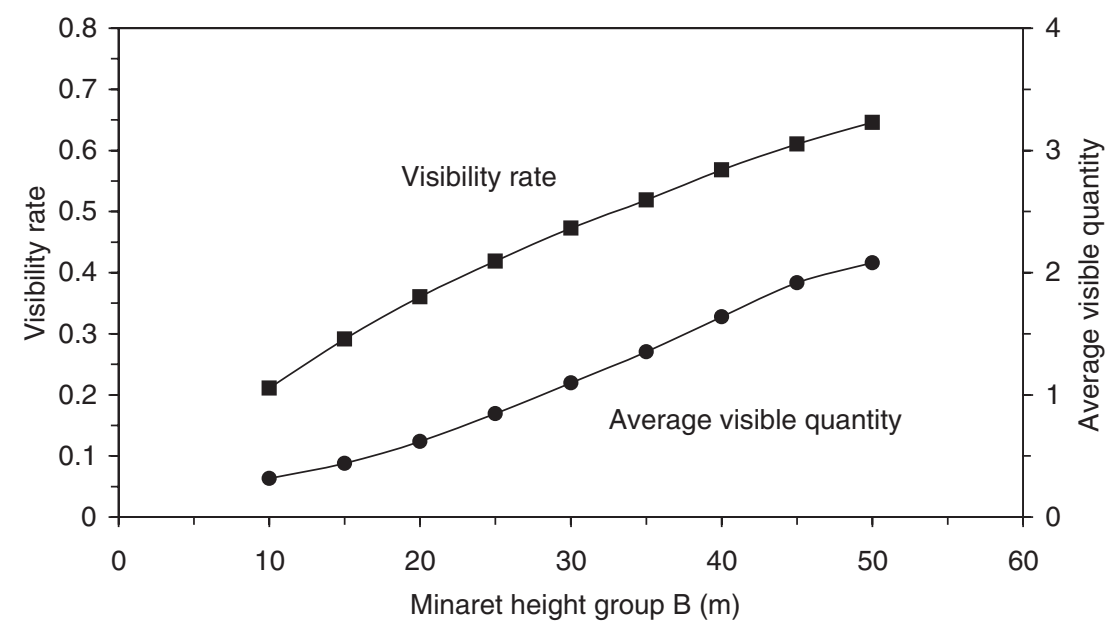

Figure 16.9 Correlation between minaret height and visible volume.

when all the minarets in group B are increased from 10 to $50 \mathrm{~m}$ in height. This figure illustrates that the taller the minarets, the more visible they become.

A visit to Old City or a look at a picture of Sana'a would reveal that the two minarets at the Great Mosque are two of the tallest minarets in the area. Very few minarets protrude far beyond the skyline formed by the tower houses. Only four minarets in group A are taller than $30 \mathrm{~m}$. Only a few minarets in group B exceed the skyline. The remaining minarets are estimated to be about the same height as the skyline formed by the tall tower houses. Therefore, if we were to assume that all the minarets in group B are of the same height, it would be appropriate to set the height at $15-25 \mathrm{~m}$. Figure 16.9 shows that the visible rate is 0.29 when the height is $15 \mathrm{~m}$, and it is 0.42 when the height is $25 \mathrm{~m}$. These figures can be used as estimates for the lower and upper visibility rates. To take a mid-level estimate, we assume that all the minarets in group B are $20 \mathrm{~m}$ high. The average visible quantity of minarets from a viewpoint on the street then is 0.62 and the visible rate is 0.36 . From this point, this report employs this mid-level estimate as the standard in advancing the analysis. ${ }^{2}$

\section{Locations where minarets are highly visible and minarets that are highly visible}

Figure 16.10 shows the visible quantity from viewpoints on the street when the minarets in group B are assumed to be $20 \mathrm{~m}$ tall. It is, in essence, a distribution chart of viewpoints where minarets are highly visible. It can be seen that minarets are highly visible from open spaces such as wide roads in the eastern area and near the city gate. In particular, many visible points are located on the road that 


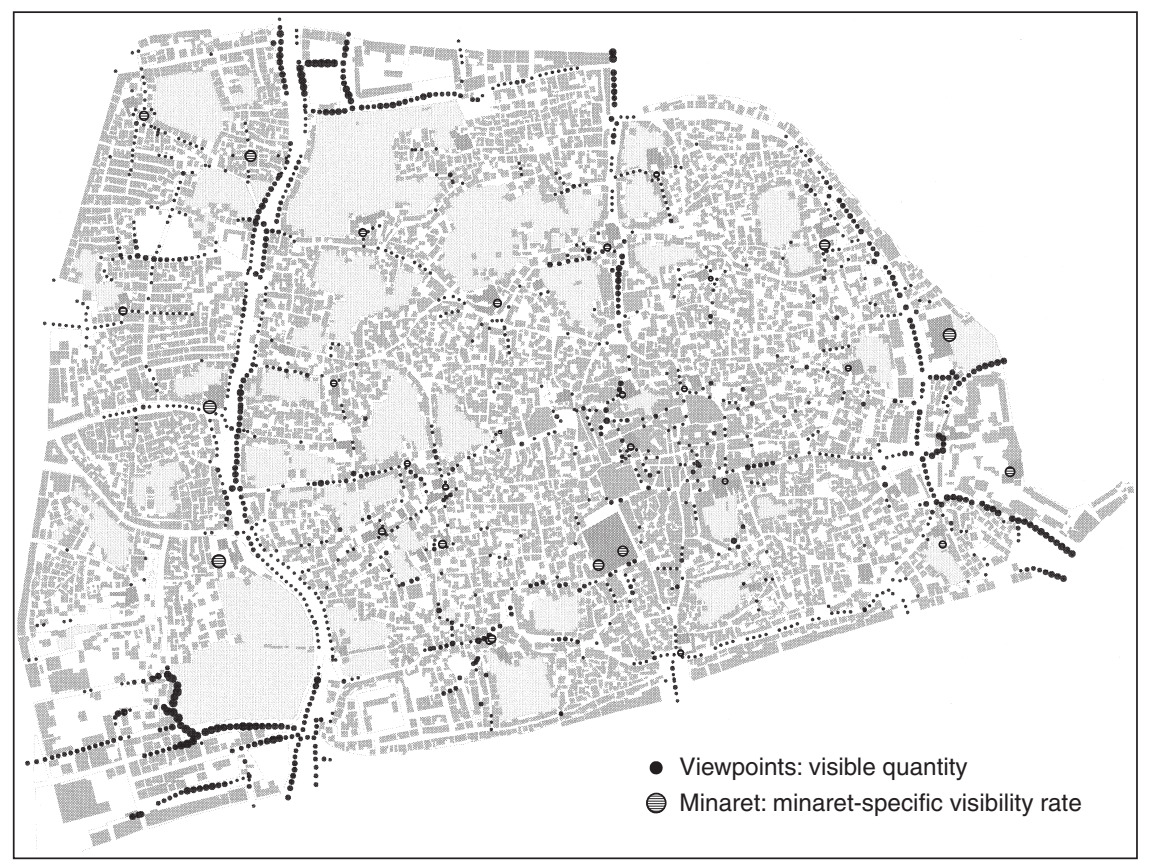

Figure 16.10 Visible quantities from viewpoints. • indicates the location of a viewpoint. The greater the number of visible quantity, the larger the circle appears.

runs along wadi. Even if the viewpoints along wadi (364 points) are excluded, the visible rate would be 0.32 . Various viewpoints in central souq also provide high visibility of minarets. Interestingly, a series of viewpoints on the road that leads to souq has large visible quantity. In other words, visitors to souq are able to view minarets as they walk the road toward souq. The emergence of visible viewpoints in intervals indicates that, for the pedestrian, the minarets come in and out of view. When a visitor walks the irregularly bent streets of Sana'a Old City, they are surprised by the sudden emergence of a minaret. This figure explains such a spatial experience.

Next, let us determine which minarets are highly visible. In Figure 16.10, the more a minaret is seen, the larger it is illustrated. Figure 16.11 shows the rank of minarets according to the minaret-specific visibility rate. Here, "minaret-specific visibility rate" refers to the percentage of viewpoints from which a particular minaret is visible, out of all the viewpoints. In other words, it indicates the visibility of a particular minaret. The minaret-specific visibility rate of the most viewed minaret is $5.4 \%$. The minaret-specific visibility rate of the two minarets of the Great Mosque, which are a symbol of Sana'a, is less than $4 \%$. It should be noted that the viewpoints are restricted to Old City. As visibility points of tall minarets must exist 


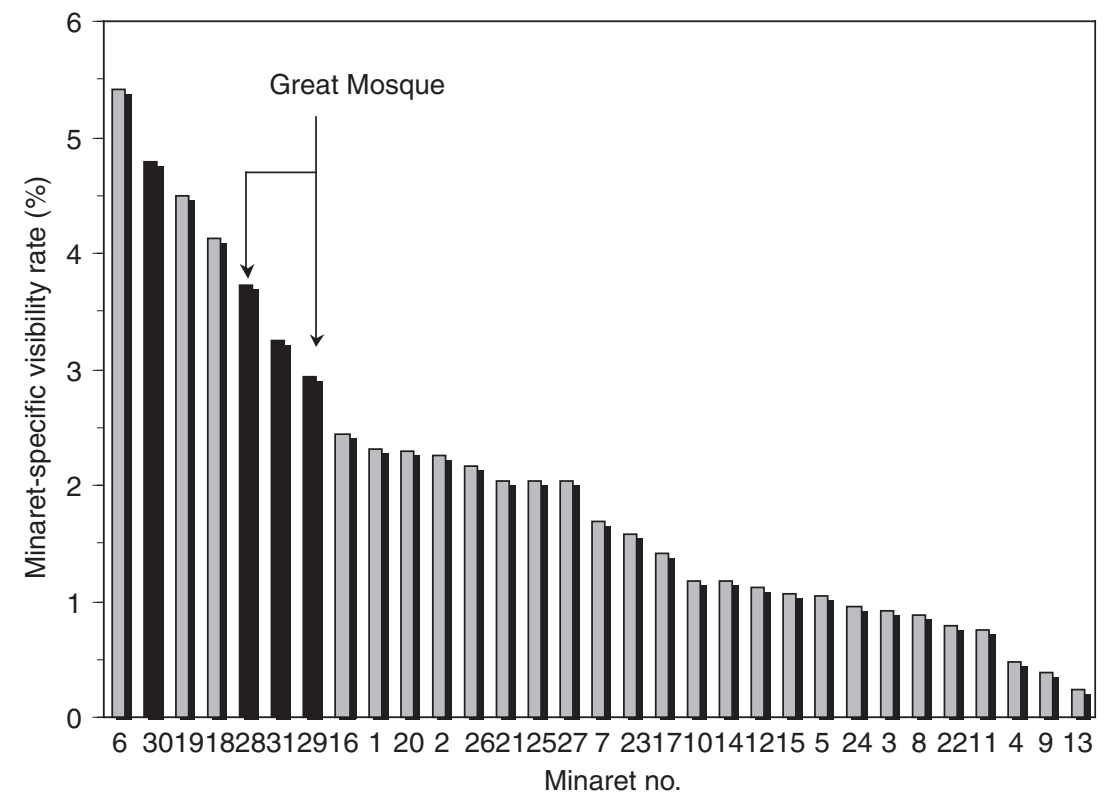

Figure 16.11 Minaret-specific visibile quantity. Minarets shown as black dots indicate those that are more than $30 \mathrm{~m}$ high.

outside of Old City, too, the minaret-specific visibility rate does not necessarily mean that the minaret is not very visible. The least visible minaret can only be seen from nine viewpoints. It can be seen that the four tall minarets are highly visible, but even the minarets in group B are highly visible from certain viewpoints.

The average minaret-specific visibility rate is $2.0 \%$, which translates into approximately 76 viewpoints. Since the viewpoints are spread approximately $10 \mathrm{~m}$ apart, a minaret can be seen from an average of approximately $760 \mathrm{~m}$ of street distance.

\section{Visible sight lines and their length}

The lines shown in Figure 16.12 are the sight lines between viewpoints and the minarets visible from those viewpoints. The figure shows which minarets are visible from which viewpoints. This figure reveals that while tall minarets can be seen from a distance, the closer minarets are more visible. Figure 16.13 verifies this fact. Here, the sight lines that connect all the viewpoints with all the minarets are divided into $50 \mathrm{~m}$ segments and the visible sight lines are shown as a percentage of all the sight lines. In essence, it shows the probability of visibility according to distance range. For example, the probability that a minaret located $100-150 \mathrm{~m}$ from a viewpoint is visible is 0.09 . Furthermore, the probability that a minaret located $50 \mathrm{~m}$ away is visible is 0.44 , which means that approximately half of such minarets are visible. 


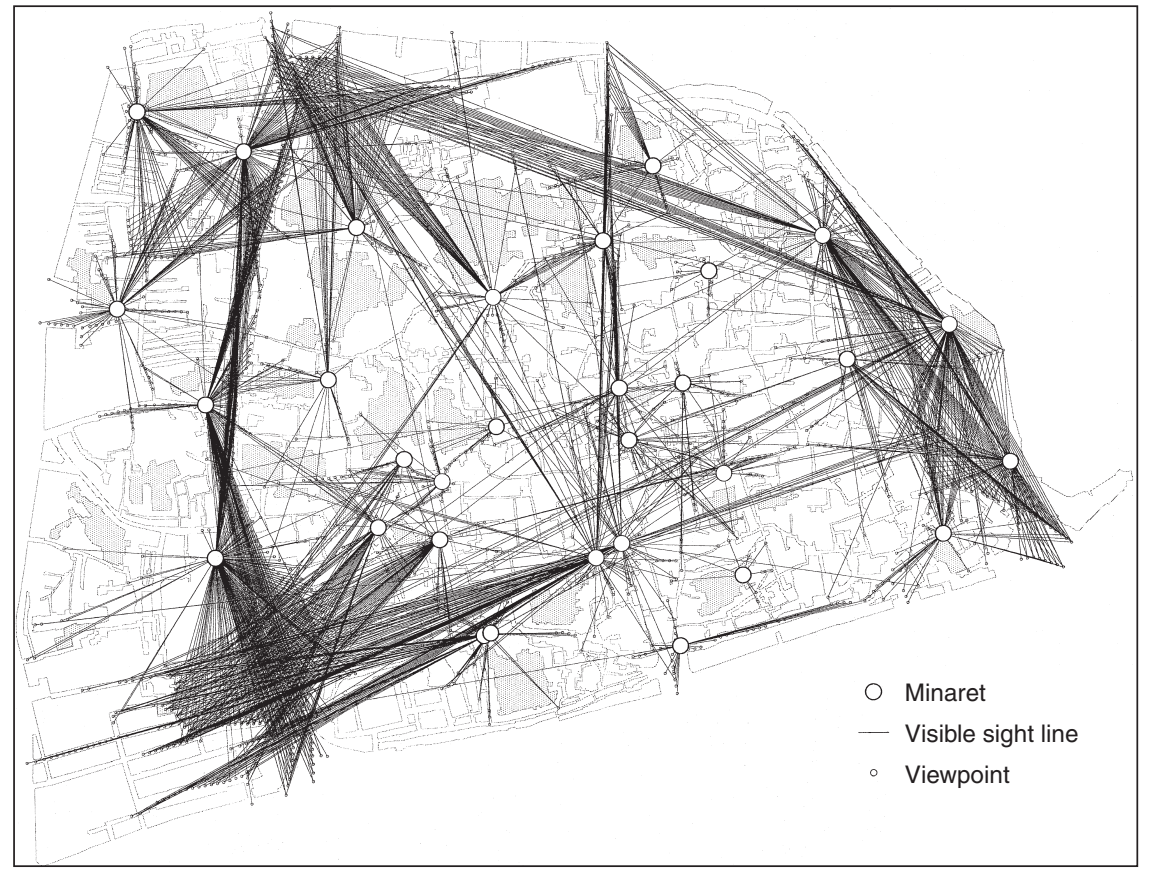

Figure 16.12 Visible sight lines connect a viewpoint to a visible minaret by a line.

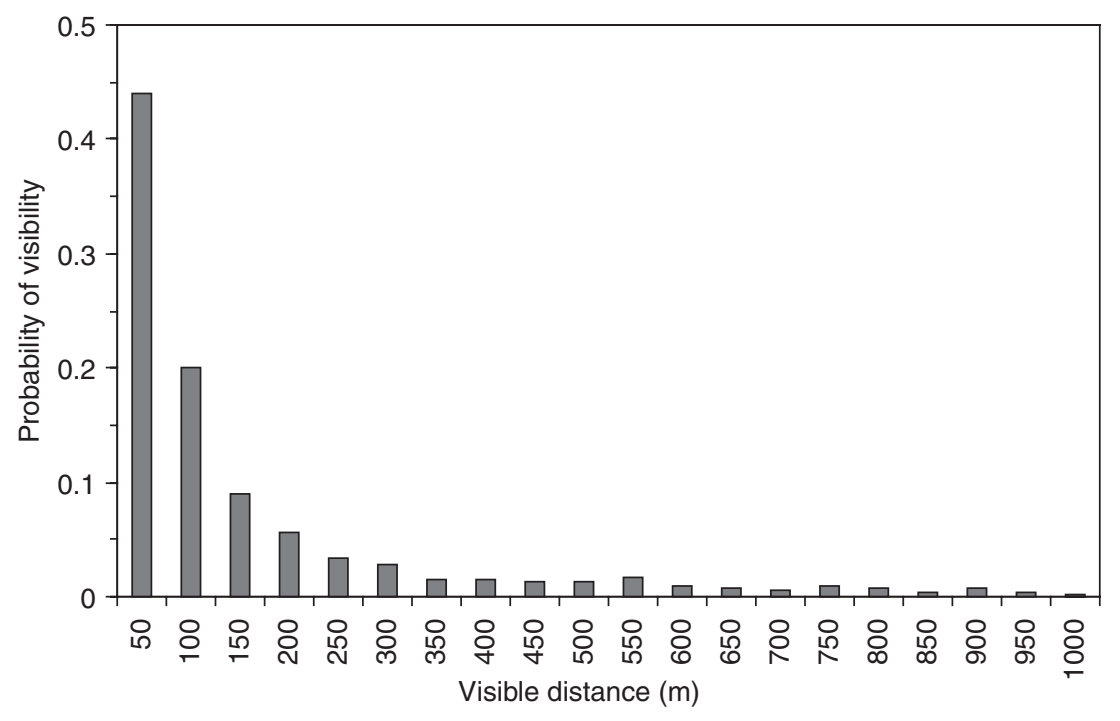

Figure 16.13 Probability distribution of visible distance. 


\section{Visibility factors}

\section{Five visibility factors}

Is the mid-level estimated visibility rate of 0.36 high? To answer this question, the figure must be compared with those of other cities. In this section, let us assume that the visible rate of minarets is high in Sana'a, and determine the factors that account for the high visibility. There are five factors that determine the visible volume of minarets. The first three concern minarets: their height, number density, and distribution pattern. The other two concern viewpoints: their height and the degree of openness of the surrounding area. As for this research, the height of viewpoint is fixed to $1.6 \mathrm{~m}$, let us study the remaining four factors by making assumptions.

\section{Height of minaret}

Needless to say, the taller the minaret, the more visible it is from the streets. In Islamic cities other than Sana'a, such as Istanbul, many minarets exceed $80 \mathrm{~m}$ in height. In Sana'a, where the tallest minaret is only about $50 \mathrm{~m}$, it is inconceivable that the height of minaret is a major factor contributing to visible rate.

\section{Number density of minarets}

Then what about the number of minarets? Since the number density of minarets is related to the number density of mosques, we must first determine whether the number density of mosques in Sana'a is high. The number density of mosques in Sana'a is 0.32 per ha. Shibam, like Sana'a, is composed of tower houses that are famous as "skyscrapers in desert." In Shibam, seven mosques are located in the 7.7 ha city. The number density of 0.91 per ha is much higher than that of Sana'a. Outside of Yemen, the old city of Damascus, for example, has 21 mosques in 131 ha of space (see Figure 16.14). ${ }^{3}$ Damascus also has sixteen churches and the density of religious facilities is comparable to that of Sana'a, but the density of mosques is lower than that of Sana'a. Although comparisons with more cities are necessary, it does not seem that the density of mosques is excessively high in Sana'a. Lack of data prevents a more detailed analysis of the number density of minarets, but judging from the density of mosques, it is inconceivable that the number density of the estimated 31 minarets would have a large impact on the level of visibility rate.

\section{Degree of openness of streets}

Street area and width

Minarets are highly visible if there is no tall building around the viewpoint and the street is wide and open. Sana'a is characterized by large proportions of land 


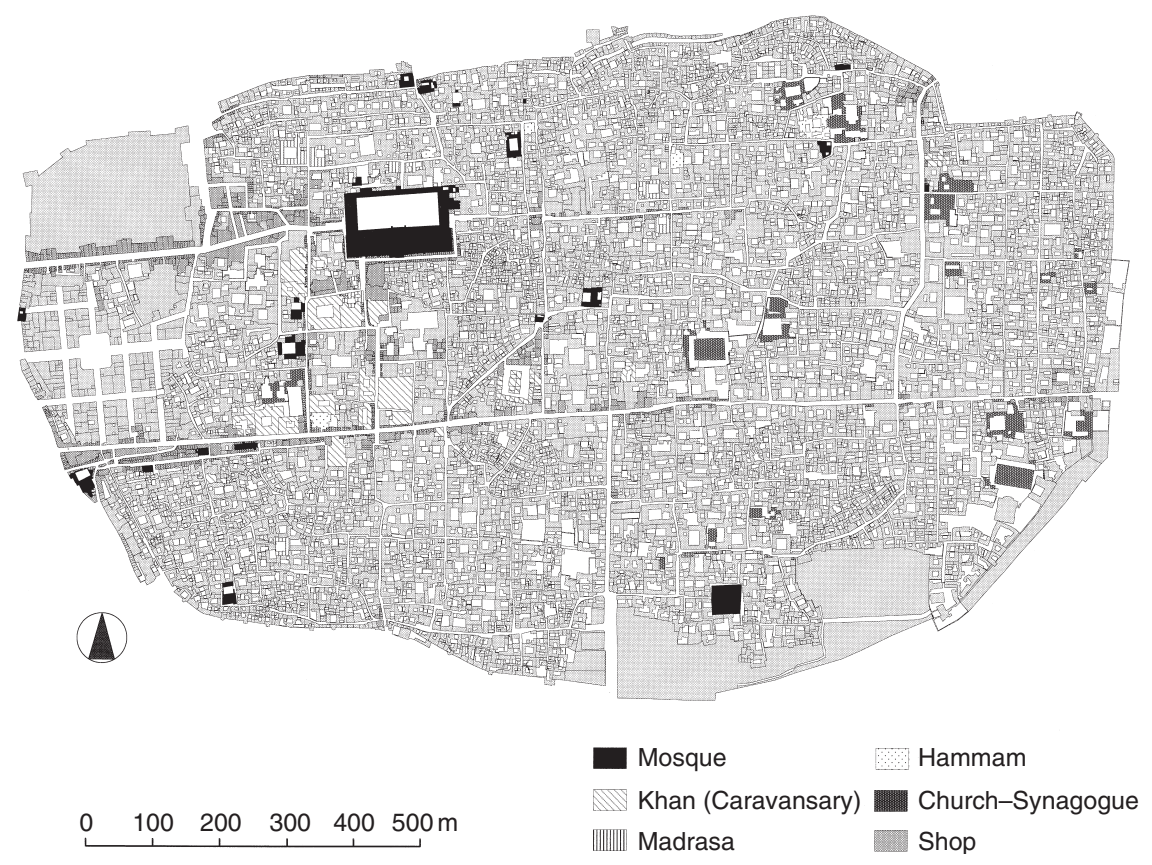

Figure 16.14 GIS data of Damascus Old City in Syria.

area that are allocated to streets and squares. For example, whereas the area of streets in Damascus accounts for $11.6 \%$ (15.31 ha) of the total old city area (131.45 ha), it is $20.2 \%$ ( $28.25 \mathrm{ha}$ ) in Sana'a (see Table 16.1 before). Of course, this figure includes the area of wadi. As the area of wadi is approximately $3.7 \mathrm{ha}$, or $2.6 \%$ of the area of the city, the area allocated for streets is large, even when wadi is excluded.

The total length of the streets in Damascus is $39.2 \mathrm{~km}$. Therefore, the average width of the streets in the city is approximately $4 \mathrm{~m}$. On the other hand, since the total length of the streets in Sana'a is $47.53 \mathrm{~km}$, the average width is approximately $6 \mathrm{~m}$. While Sana'a does have narrow streets, it also has wide streets and small squares around the buildings, which are believed to be the factors that improve the visibility of minarets.

\section{Bustan}

One of the major reasons that help the visibility of minarets is believed to be the existence of bustan. Therefore, to analyze the effect of bustan, let us assume that buildings line along the boundaries of bustan without any space in between and the current distribution of buildings remains the same. Assuming that every building is 
two stories ( $6 \mathrm{~m}$ in height), the average visible quantity would be 0.45 and visibility rate would be 0.30 . Furthermore, if we take into account the fact that an average household in Sana'a Old City is 2.7 stories high, and assume that all the buildings were 3 stories high ( $9 \mathrm{~m}$ in height), the average visible count would fall to 0.42 and visibility rate to 0.28 . In essence, it can be seen that bustan has a large impact on the volume of visibility. An analysis of visibility also reveals that in Old City where tower houses are densely constructed, bustan provide valuable open spaces.

\section{Shapes and distribution of buildings}

Upon an analysis of the distribution drawing, it can be seen that although buildings are built close to one another, there are also many open spaces around each building (see Figure 16.15). The area of such open spaces accounts for approximately one-fourth of the area of Old City (see Table 16.1), or more than the area of bustan. These open spaces provide the residences with lighting, ventilation, and privacy. As tall residential units block the sight lines to minarets, the issue is whether the urban space composition of "tower houses + surrounding open spaces" impairs the visibility of minarets.

Therefore, let us assume that Sana'a was filled with courtyard houses, as in Damascus, and not tower houses, and compare the visibility under this assumption with the actual visibility. The sum of the building area of residences and open spaces around buildings in Sana'a is $82.60 \mathrm{ha}$. Let us assume that this is the area for residential units and that courtyard houses were built there (see Figure 16.16). Assuming that all the floors of every house are of the same area and that broken buildings are single-story high, the total floor area of residences would be 127.98 ha. If all the houses were two-story courtyard houses, the building area would be one-half, or $63.99 \mathrm{ha}$, and the remaining $18.61 \mathrm{ha}(=82.60-63.99)$ would be courtyards. Here, the courtyards would account for $22.5 \%$ of the space

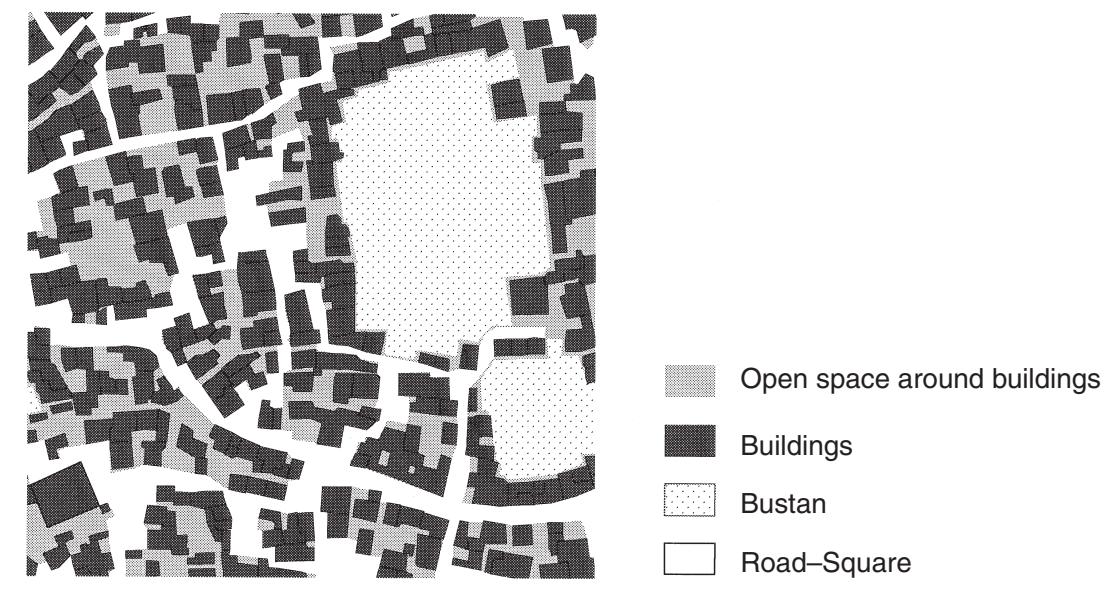

Figure 16.15 Open spaces around buildings. 


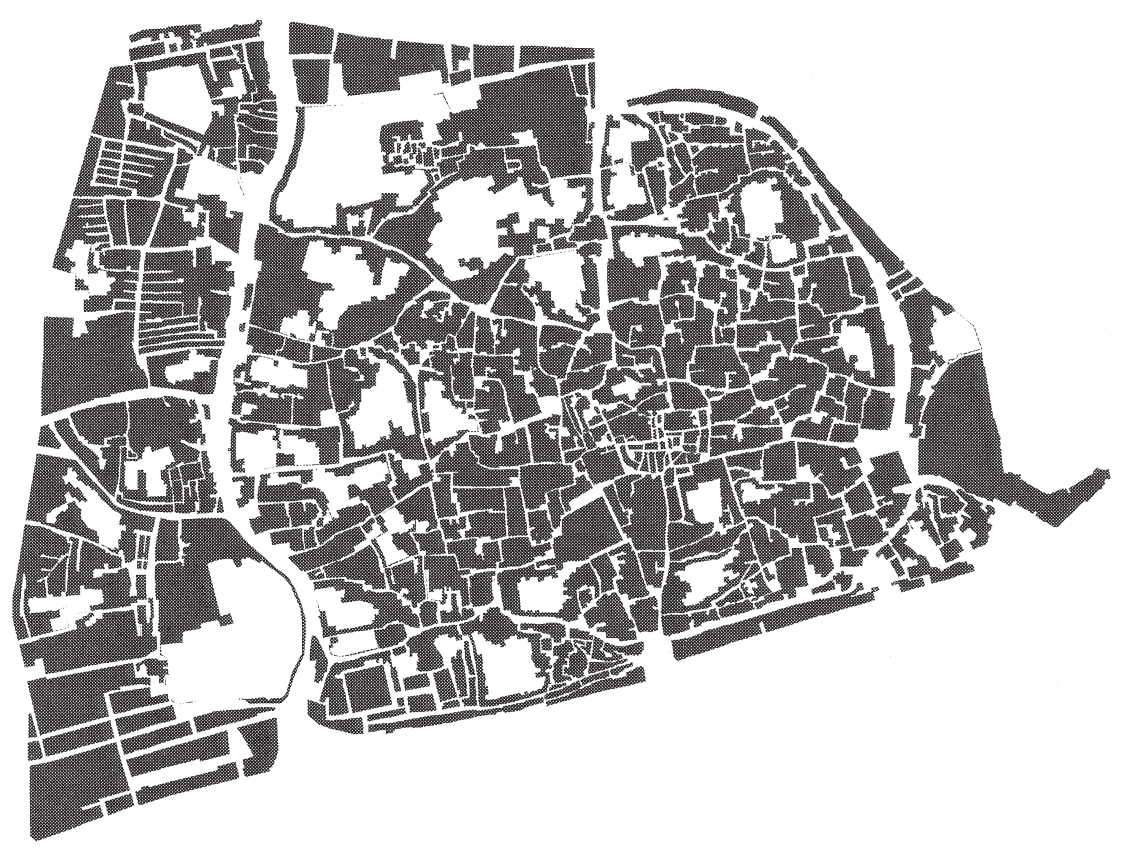

Figure 16.16 Residential lot with envisioned courtyard house.

(18.61/82.60). These are actually reasonable assumptions. In the old city of Damascus (see Figure 16.14), for example, the sum of the building area of all the buildings is $80.72 \mathrm{ha}$, and the sum of courtyards is 23.77 ha. Therefore, the percentage of courtyards in Damascus is $22.6 \%(23.77 / 104.99)$. In other words, the area for tower houses can be used directly as the area for courtyard houses.

If we assume that the bustan and streets remain the same, and $6 \mathrm{~m}$ high, twostory courtyard houses are densely constructed on the residential lots, as they are in Damascus, the average visibility quantity of minarets would be 0.51 and visible rate would be 0.33 . These results come as a surprise. While the volume of visibility is not much different from the actual volume of visibility, minarets are more visible now, although in Sana'a the number of residential units that are three stories or more account for some $60 \%$ of all residential units. The effectiveness of the open spaces around tower houses, the balance of different building heights, and the clever layout of residences and open spaces came as a surprise.

\section{Distribution pattern of minarets}

It became clear that minarets' volume of visibility is increased by the bustan, open spaces around residences, and the effective distribution of residences and open spaces. 
Next, let us study the distribution pattern of minarets, which is the most important factor that determines the visibility of minarets. In other words, let us see whether minarets are located where they are easily seen.

\section{Potential of minaret-specific visibility}

Before analyzing the distribution pattern, let us see where minarets are most visible. Let us divide the area, excluding streets, wadi, and bustan, into $10 \mathrm{~m}$ grids, and determine whether a point $20 \mathrm{~m}$ above the intersection of grids is visible from viewpoints. In essence, we want to see, when a $20 \mathrm{~m}$ minaret is erected on a residential lot, from how many viewpoints the minaret would be visible. Figure 16.17 shows the measurement results. The larger the circle, the more visible the point is or, in essence, the higher the potential of minaret-specific visibility.

From Figure 16.17, it can be seen that the area to the west of wadi and Qasur al-Silah, the fortress in the eastern area, are the most visible areas. Minarets in these areas are more visible than those in other areas. History books say that the city of Sana'a was built from the area where Qasur al-Silah is located, and expanded from east to west and, by the end of the sixteenth century, crossed wadi, which until then had been the western edge of the city. It is interesting to note that the potential of minaret-specific visibility is associated with the expansion of the city.

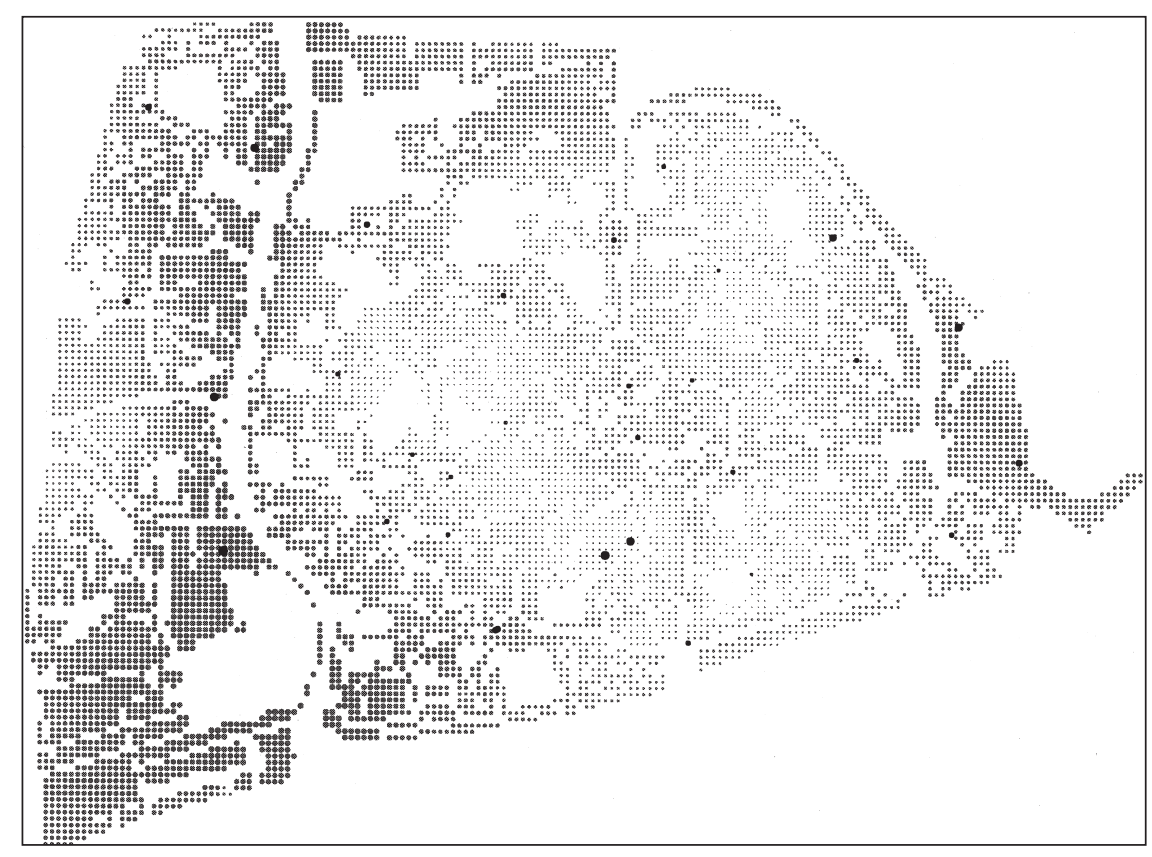

Figure 16.17 Minaret-specific visibility rate on grids. 
If minarets were built where they are most visible by design, then many should be distributed where the minaret-specific visibility is high. Figure 16.17 shows the current locations of minarets. According to this data, while some minarets are located where the potential is great, others are located where they are inconspicuous. It can be seen, for example, that the minaret of the Great Mosque is erected where it would be difficult to see if it were $20 \mathrm{~m}$ tall. In fact, if the eastern minaret of the Great Mosque were $20 \mathrm{~m}$ high, its minaret-specific visibility would drop from $3.7 \%$ to $0.04 \%$.

\section{Simulation}

To quantitatively determine whether the minarets are located in highly visible locations, the author randomly distributed 31 minarets of the same height throughout the city, excluding the streets and bustan, while leaving the buildings in their place (see Figure 16.18) and measured the volume of visibility. Figure 16.19 shows the results of 500 simulations compared to the actual values. The figure shows the percentage of viewpoints according to the number of minarets that are visible. As a result of the random distribution, the average visible quantity of minarets is 0.73 and visible rate is 0.34 . The average visible quantity is higher than the actual value of 0.62 , but the number of visible

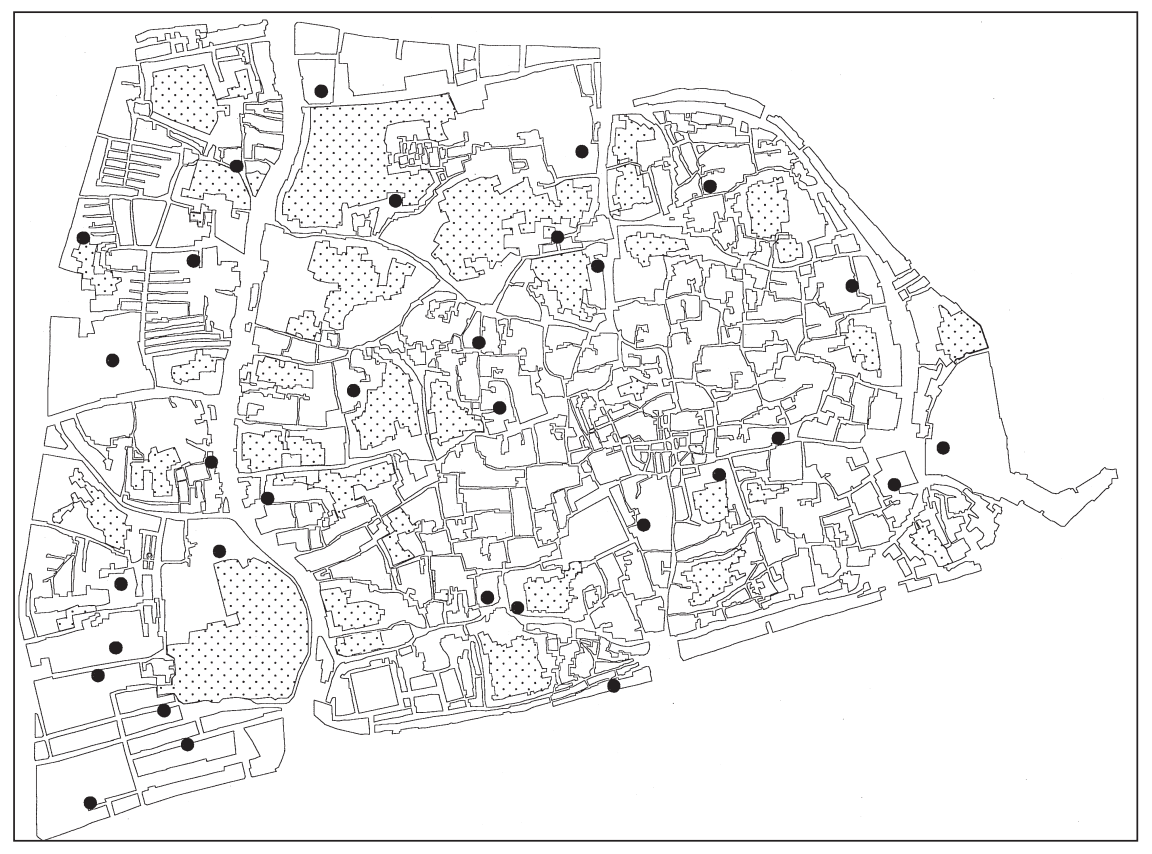

Figure 16.18 Sample random distribution of minarets. 


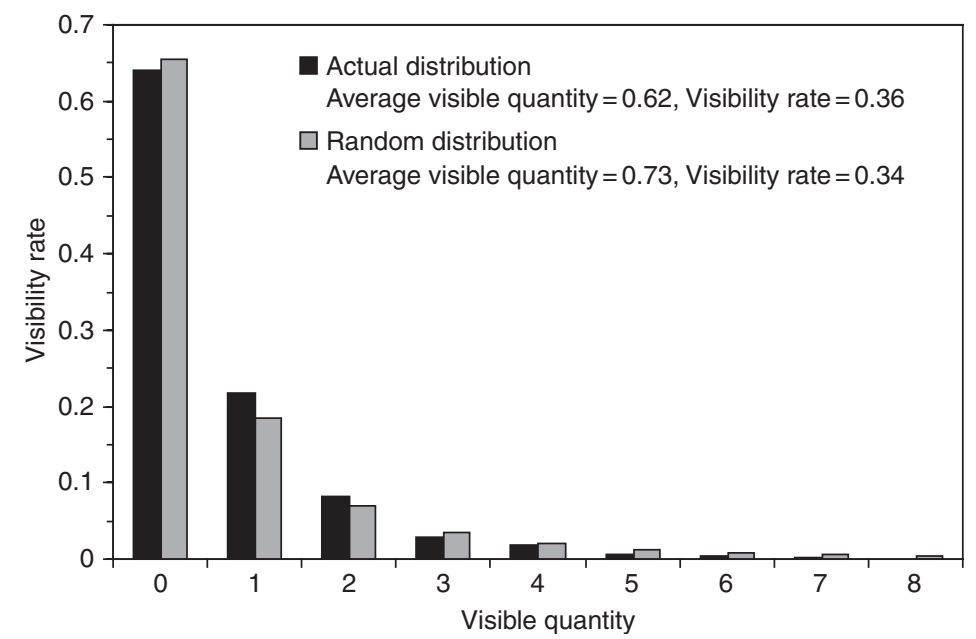

Figure 16.19 Frequency distribution of visible quantity.

viewpoints is slightly less than the actual value of 0.36 . In other words, there is negligible difference in the results between the random distribution of minarets and the actual distribution. It can be concluded that the present distribution of minarets is not necessarily designed for high visibility.

\section{Distribution pattern of mosques and minarets}

Let us now see whether the architect of the city randomly distributed the minarets. Nearest-neighbor measure $R$ is one of the indicators used to determine the distribution pattern of points.

Nearest-neighbor measure $R$ is defined as follows.

$$
R=\frac{r_{\mathrm{o}}}{r_{\mathrm{e}}}
$$

where $r_{\mathrm{o}}$ : average nearest neighborhood distance between distributed points; $r_{\mathrm{e}}$ : anticipated nearest neighborhood distance according to Poisson model.

Assuming that the number density of points is $\rho$, we have the equation $r_{\mathrm{e}}=1 / 2 \sqrt{\rho}$. A perfect random distribution is expressed as $R=1$. A distribution pattern where points are partially aggregated is expressed as $R<1$ (minimum value $=0$ ) and the more the points are spread out and distributed uniformly the greater the value of $R$ becomes (maximum value $\fallingdotseq 2.15$ ). If we measure the nearestneighbor measure $R$ of the 31 minarets, we would have 1.11. The value for the 45 mosques is also 1.11. Furthermore, the location points of mosques were designated as centers of gravity on the plane. In essence, mosques and minarets alike are distributed in a near random manner. As the nearest-neighbor measure 
$R$ is slightly greater than 1 , however, the distribution is slightly more uniform than random, or that the points are distributed at certain intervals. This is understandable, as each community probably had one mosque. The difference between the simulation and actual condition as shown in Figure 16.19 can probably be attributed to the distribution of minarets that is slightly close to a uniform pattern.

\section{Correlation between minaret locations and streets}

We have confirmed that the minarets were not necessarily built where they are most visible. Upon a visit to Sana'a, however, one receives the impression that minarets are highly visible. Is this merely a matter of quantity or is there some clever device? To find out, let us once again check the distribution of minarets and locations of visible viewpoints.

Referring to Figure 16.10, there are areas where visible viewpoints emerge continuously even on a narrow street. By analyzing the visible sight lines on Figure 16.12, it can be seen that the visible viewpoints of a minaret are distributed on a certain street. A more detailed study of the visible viewpoints of a minaret reveals that, interestingly, many minarets are located in the direction of the street. Figure 16.20 shows the visible viewpoints connected in a straight line when a minaret is located on the same line that connects the three consecutive visible

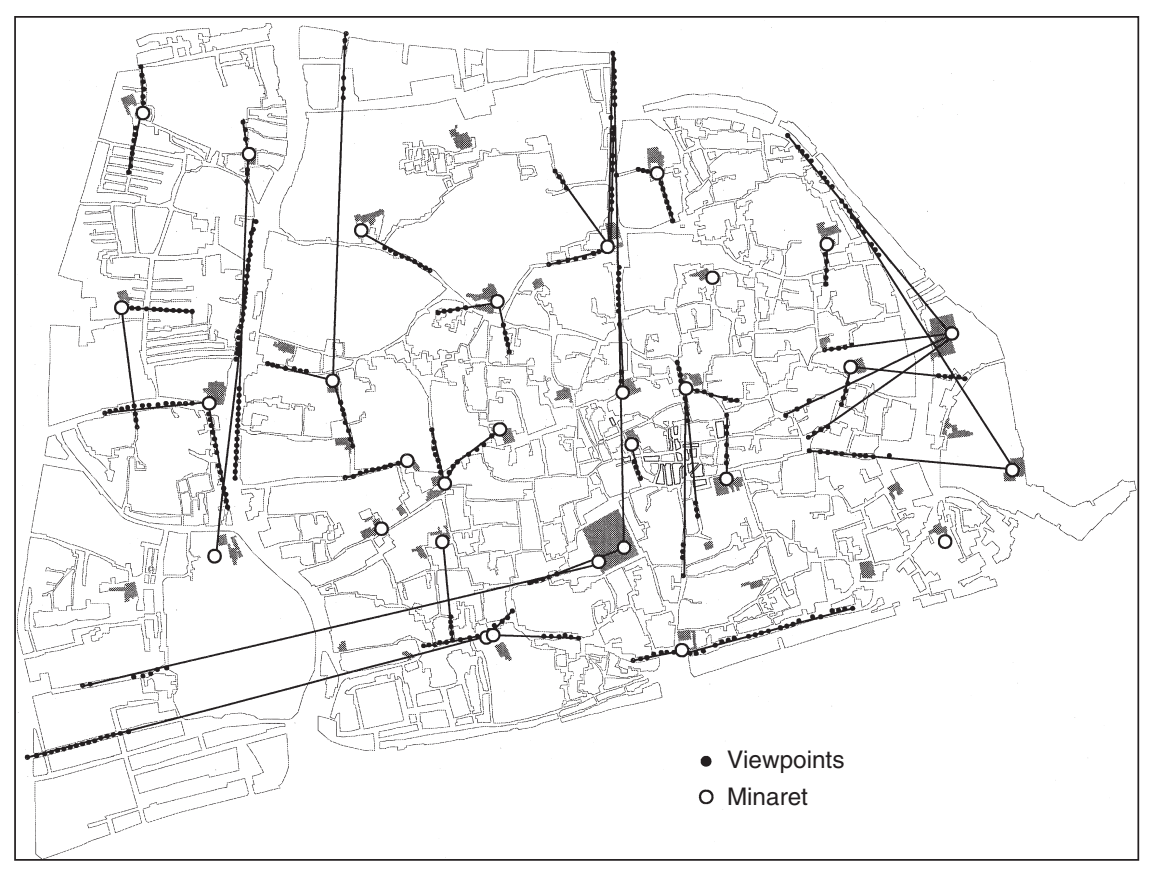

Figure 16.20 Minaret that serves as an eyestop. 
viewpoints or, in essence, when the minaret is an "eyestop." More noteworthy in this figure is the street from Bab Schoub to central souq. The eastern minaret of the Great Mosque is located on the street that runs north to central souq in the south. Along the same line, three mosques are located in relatively a straight line. These mosques seem to lead visitors from the gate to central souq.

As with many other Islamic cities in Middle East Arabia, the streets of Sana'a Old City form a complex maze. As the streets run in many different directions, a minaret may, purely by chance, be located at the end of a street. It would be inconceivable, however, to assume that all the straight lines in the illustration happened by chance. In particular, the minarets located on the line connecting Bab Schoub and the Great Mosque are too cleverly designed to be an accident. It is logical to assume that the minarets were positioned by design. So far, there is no means to confirm that the directions of the streets and positions of the minarets are based on a plan. It should be emphasized, however, that in many cases a minaret is located in the direction of the maze-like streets as an eyestop.

The expression that minarets are "highly visible" may mean that many minarets are visible, visible from many different viewpoints, and another meaning, that minarets are located in eye-catching areas.

\section{Conclusion}

Using Old City of the historical Islamic city Sana'a as a case study, the author has employed three-dimensional analysis using GIS to analyze the characteristics of urban spatial composition in terms of the visibility of minarets. The use of GIS has allowed the author to obtain various information from a single spatial data. Of these findings, the principal ones are summarized below.

1 Of the 31 minarets indicated on the map, we can estimate that at least one minaret is visible at $29-42 \%$ of the viewpoints on the streets. The mid-level estimate is $36 \%$. In essence, a minaret is visible at one-third of the viewpoints on the streets in Sana'a Old City. Each minaret is, on the average, visible from $2 \%$ of the viewpoints on the streets in Old City. In addition, the probability that a minaret within $50 \mathrm{~m}$ is visible is approximately 0.4 .

2 The high visibility of minarets in Sana'a Old City can be attributed to a number of factors. One is the large percentage of land area that is allocated to streets. The second is the availability of large open spaces such as bustan and the open spaces around tower houses. Furthermore, the existence of many houses higher than three stories does not impair the visibility of minarets. Minarets would be less visible if the city were filled with two-story courtyard houses of the same volume as the present tower houses. The balance of houses of different heights and the effective distribution of houses and open spaces are believed to be the causes of high visibility.

3 Whereas some minarets are located in highly visible areas, the distribution pattern of minarets is close to a random one. As a result of a simulation, it 
was found that overall, the minarets are not ideally positioned for visibility. Qualitatively speaking, however, a minaret is often cleverly positioned in the direction of the street as an eyestop so it is highly visible. The directions of streets and locations of minarets are believed to be based on a plan.

Unlike the minaret in M'zab Valley that controls the form of the city as introduced at the beginning of this chapter, the minarets in Sana'a probably do not play as important a role. The scenery analysis here is based on what outsiders observe, and not only on how the people who live in Sana'a perceive the visibility of minarets. To the people who have developed the city of Sana'a over its long history, however, the locations of mosques and minarets probably played an important role in building the streets and constructing the tower houses. As a result, these architects have succeeded in erecting minarets that are visible from one-third of the streets. Whether this figure is high cannot be determined without comparison with other Islamic cities. Even if there is an Islamic city where minarets are more visible, the city of Sana'a will still be a city with a unique scenery created by the series of tower houses, bustan, and the highly visible minarets.

\section{Acknowledgments}

The author would like to express his gratitude to Professor Okabe Atsuyuki and an anonymous referee for their invaluable comments in completing this chapter.

\section{Notes}

1 The map is "The map of Existing Condition in the Old City of Sana'a" prepared by The Executive Office for the Reservation of Old City of Sana'a, Y.A.R.

2 Let us assume that all 45 mosques have at least one minaret each (total of 47). We shall also assume that mosques that are judged not to have a minaret based on the map have a minaret at its side. Finally, we shall assume that all the minarets in group B are $20 \mathrm{~m}$ high and located at the side of a mosque. Here, the average visible quantity is 0.86 and the visible rate is 0.42 , which is comparable to the upper-level estimate. In essence, this is the upper limit even if we included the minarets whose existence could not be confirmed on the map. Should there be 64 minarets as commonly believed, there would be more mosques with minarets standing side by side. As minarets standing side by side can be seen from relatively the same range, while the average visible quantity would increase, the visible rate would not change much. Therefore, the high estimated value of 0.42 would not change.

3 The spatial data was prepared based on "Plan Cadastral" created by the French in the 1930 s.

\section{References}

Fujii, A., Oikawa, K., et al. (1998) "A study on high density dwellings of the traditional Islamic villages,” Annual Report of Housing Research Foundation, No. 24, pp. 107-116 (in Japanese).

Serjeant R.B. and Lewcock R. (1983) SAN'A'An Arabian Islamic City, World of Islam Festival Trust. 



\section{INDEX}

accessibility 223-4, 237

Afghanistan 103

Aleppo 141-2, 146-7, 152, 153, 154, $156-9,160-1$

AND 11

Andhra 75

Andijan 106, 109, 112-13, 115, 117;

Uprising (in 1898) 104, 109-11

Arasta 147, 149

Aravan 107, 115-16

Arcot 67

attribute data 30, 37-9

Aurangzeb 67

average: number of stories 212; order of a

node 189; width of a road 192

axial lines 188, 209

axial map 193, 223-4

axial ringiness 195

Balıkesir 122-4, 126-38

Baliqchi 107, 115-16

Barnard, Thomas 22, 68

Barnard Report 22, 25-7, 68, 70-3, 75, 78-81

Barthold, W. (Bartol'd, V.V.) 113

Başbakanlık Osmanlı Arşivi 122, 138

Basmachi movements 104, 115

bazaar 141

Bedesten 142, 146, 147, 149, 156, 158,161

Bedesten (Old) 225, 229, 231, 237

border issues 104

Brahmin 69-70, 73, 75, 78

Bursa 141, 146-9, 154, 156-9, 160-1, 244-5, 247-9, 252; bustan 256; open spaces 259, 270, 276; scenary 277 ; urban landscape 259; visibility of minarets 269
CAD 246

Caravanserai see Han

Çarş1 141, 149

Çeçen 162

census $(1897,1908,1917$, and 1920)

23-4, 70, 72, 106, 113-14

çeşme 173, 175; distribution of fountains

176; location of çeşme 177-80; saka

(water-transporter) 174; sebil 173, 175; sponsors 180

Chengalpattu (Chingleput) 22

Chennai 68

Chetti 75

Chingleput (Chengalpattu) 28, 73-4

chi-square test 248

choropleth map 17

çiftlik 130

classification 55

clustering coefficient 211

collector 22

commercial area 214

complex 244-5, 247

connectivity 210

construction of three-dimensional spatial data 245

control 210

convex map 192, 223-4, 232

convex spaces 192, 223, 232

correlation between integration and local integration 195

correlation coefficient 198, 214

courtyard house $253,255,270-1$

Damascus 268-71

dargah 73

data: acquisition 29, 32; correction 33, 37; creation 33; merging 33-4, 36-7

database 7 
INDEX

Davud Agha 168

density of faces 189

depth 193

deshmuk 70

development of Bursa 244

diamond-shaped graph 211

diamond value 194

digital: data xxiii; geographical data 3; map 3; table 3

digitization 33,35

digitizer 5

DiMSIS-Ex 124, 126, 130

discriminant function 188, 198

distance search operation 15

distribution pattern 272, 274, 276

division of labour 235

dot map 17

drape operation 246

due 81

edgematching 35-6

encounter 223, 235

English East India Company 21

ethnic composition 106-7

experts' notion of local centers 213

exploratory method 41

exploratory spatial analysis 88

extended axial curve 208, 209

eye-level view 209

eyestop 276-7

fakir 69

fee 81

Ferghana (city) see Margilan

Ferghana Incident (in 1989) 105

Fondok see Han

Friday Mosque 221, 236, 238

Galata 202

geographical data xxiii, 2

geographical phenomenon 1

geographic information systems (GIS) 2 ,

$141,142,162,171,182,187,207,223$, $239,243,245-7,249$

Ghardia 253-4

GIS see geographic information systems

Göynük 141, 146-7, 149, 151, 152, 154, $156-9,160-1$

gradient distribution 247

gradient of the slope of mosque

locations 247

grant 78

grantee 78 grantor 78

graph-theoretical indices 189

graph theory 187,189

Great Mosque 147, 149, 152, 154, 157, 159,161

Green Complex 247

Green Mosque 247-52

grid axiality 196

guilds $236-7$

Gulf War 41

guru 69

Halkalı Water 163-4; construction processes 164-70; lengths 171-2; Halkalı Water Supplies 162,

181

Hamam 142, 146, 149, 152, 159

hammam 255, 260

Han 141, 146, 147, 149, 152, 154, 156, $157,158,161$

Hindu 67,78

Hyderabad 67

image analysis 189; related indices 192

inam $69,78,81$

inclusion search operation 15

Indian Ocean 70

integration 194, 211, 226-7, 234-5, 238; value 194

intelligibility 195, 229, 237

interface 230, 235

intersection search operation 15

Iran 222, 236-7

irrigation canals (networks) 115, 117-19

Isfahan 225, 235-6, 239

Islamic city $221-2,238$

Islamic resurgence 103, 117-18

Istanbul 201, 208, 225, 235-9

Jagir $22-3,67-8$

Karakalpak(s) 108-10

karnam 28

Kashghari(s) 108-11

Kazakh(s) 111, 113

Kırkçeşme Water 163-4; construction process 166, 171; Public Fountains distributed by Kırkçeşme Reticulation 173

Kırkçeşme Water Supply (Kırkçeşme Reticulation) 162, 166, 171, 181

Kokand 106, 112-14, 117

Kokand khanate 106, 110-13 
külliye 146, 159, 161, 163, 181, 171-3, 244-5

land cover 56; change 41-4, 52-3

Land Register 128, 130, 137

land-title 75

land use 54, 60, 259

local 81; integration 194; mean depth 211

locational data 30

locational tendency of mosques 244

\section{Madras 68}

Madrasa 146, 152, 154, 157, 159, 161

mafraj 256

magan 85, 94-101

Maidan-i Shah 226, 229, 231

Maniyam 82

map digitizing 5

Margilan 106, 109, 111-12, 115, 117

marketplace $221-2,225,235-7$

math 69

maximum depth 211

mean axial length 196

mean connectivity 195

mean depth 193, 194, 210

mean distance along an edge to the distance between nodes 192

megsharnat 256

minaret $246-7,249$

mirasidar 25-6, 70, 73-8

Mirasi System 67

mobile GIS 6; notebook 6

Mokassah 68, 70, 81

morphology 221, 228, 230

mosque: Great Mosque 262, 264-5, 273 ,

276 ; height 260 ; location points 274 ; number density 268

Mudali 75

Mughal 67; empire 67

multispectral data 6

Muslim 67, 70-3, 75, 77-8, 81-2

Muttiriyan 72

M'zab Valley 253, 277

Naick 25, 72, 77

Namangan 106, 112-13, 115, 117

National Delimitation (in Central Asia in 1924) 103-4, 107, 112

nattar 70

Nawab 74, 78

nawab of Arcot 67

Nawab Mahfuz Khan 73, 78
Nawab Saudatulla Cawn 78

nearest neighborhood: distance 274; measure 274

neighborhood operation 11 network 187, 207

Nizam (Nizam-ul-mulk) 67

NOT 11

open-air markets 146,157

open space $270-1,274$

OR 11

Osh 106, 109, 111, 115, 117

Osh Incident (in 1990) 105

Ottoman Empire 122

Overlay 58; operation 11

pagoda 69

Palli 25, 73

panchromatic data 6

Paraia 70

pattadar 75,77

Permanent Settlement Record 23

Persian Gulf area 41-3, 49, 51-3

Pillai 69

Place, Lionel 22, 74-5

Place Report 22, 25, 27, 75-6

plaza $146,147,149,152,156-7,160$

Poisson model 274

poligar $25-6,28,68-70,72,78$

Ponneri 25, 27, 68-71, 73, 75-8, 81

population movements $105-7$

Public Fountain 173-6

Pulicat $69-70,77$

Qayrawan 141-2, 146-7, 154, 155, 156-9, 160-1

Qaysariya 146, 158

Qipchaq(s) 108-10, 117

qualitatively similar 46-7, 49-50; overall qualitative similarity 49,51 ; qualitative change $47,49,51-2$

Qyrghyz 106, 108, 109, 111, 115, 117

Qyrghyzstan 103, 119

raiyat 22

raiyatwari settlement $23,28,75$

raiyatwari system $21-2$

Raja (Rajah) 25, 72

random distribution 274

raster: data 30-2; format 30-2; map 4; -type digital map 4

ratio of area covered by roads 192

ratio of dead-end: edges 189; nodes 189 
INDEX

recipient 81

reconstruction of the townscape 251

Reddi 75

relational database 7

religious buildings and sites 119

remotely sensed data $41-2,52$;

Normalized Difference Vegetation Index

(NDVI) 43-5, 50; Pathfinder AVHRR

Land data set 42,52

resolution 5

road network 252

rubber-sheeting operation 247

Russian peasants 111,115

sabil 262

Safranbolu 141, 146-7, 149, 150, 154, 156-9, 160-1

Salapakkam Mullasaib 72

samsarat 255, 260

Sana'a Old City 255-60

Sart(s) 108, 110-14, 117

Saudi Arabia 52

scanner 3

scanning 4

segregation 226-7, 238

Settlement Registers 23, 75-6

Şeyh ül Islam 167

share 72, 81-2; distributing system 81

Shibam 256, 268

shrotrium $68-70,81$

sight line 253-5, 266, 270, 275

signature analysis 56

Skobelev see Margilan

social grammar 81

solid model 245-6

souq 141, 152, 255, 260, 262, 265, 276

space: structure $222,227,232$; syntax

xxvi, 188, 192, 207, 223, 239

space-syntax related indices 196

space-use 223, 232-4

spatial aspects 222

spatial autocorrelation 89-90

spatial data xxiii, 2, 255, 259; acquisition

29-30, 32, 39; clearinghouse 32

spatial search operation 11

stala majumdar 70

strategic choice of location of the mosques 245

street 142, 143, 154, 156, 160;

network 223

supervised classification 55

supra-local 72,81

syntactic analysis 224, 226 syntactic properties 228-30, 234

Syr Darya 103, 110

Tajik irredentism 112

Tajik(s) 106, 108, 109, 111-12, 117

Tajikistan 103, 112, 119

taluk 23

Tamil 67

Tamilnadu 68

taxi bay 212

Temettuat (Income) Register 122-3, 125-6, 138

tessellation 86-94, 96, 101; spatial 86,

$88,91,101$

thinning operation 187

thoroughfare/DE 196

three-dimensional: analysis 243; data 251,

260; space 243; surface 207, 243, 247

timar 129

time-series analysis 55,59

TIN 243-5, 247, 249, 252

topological data 10

tower house $255-6,270-1,276-7$

traditional 188

trend curve 44-51; annual trend curve

46, 47, 48, 50, 51; bottom 45-7; global

characteristic 46-7; local characteristic

46; local trend curve 45; peak 45-50; slope 45-6

Tsuruta Yoshiko 141-61

Turk(s) 108-10

Turkey 222, 237

Turk-Tatar(s) 111, 117

two-step approach xxiv

uniform pattern 275

unsupervised classification 55

urbanization 119

Uzbek(s) 106-8, 109-14, 117

Uzbekistan 103, 107, 115, 118-19

Vaklf 162, 163

VAO see Village Administration Officer variation in data: attribute-axis variation 45-6; horizontal axis variation 44; time-axis variation 44-6; vertical axis variation 45

vector: data 30-2; format 30-3; map 5; -type digital map 5

Vellala $25,70,72$

viewpoint 263-6, 268, 272-6

village: accountant 23 ; code 23 ; settlement 21 
INDEX

Village Administration Officer 23, 28 visibility: of minarets $254-5,269$; minaret-specific 272-3; minaretspecific visible rate 265-6; quantity 263-5, 270-1, 273; visible

rate $263-5,268,270-1,273$;

visible volume $255,263,268$;

volume of 271,273

visible 209; area 249

visualization 16 wadi $255,263,265,269,272$

Waqf 161

water resources 119

XOR 11

Yekabogam 77

zamindari 21, 23, 85-6, 94-9, 101; settlement 21 


